\title{
WHAT DO WE KNOW ABOUT THE WORLD?
}

Rhetorical and Argumentative Perspectives

Edited by Gabrijela Kišiček and Igor Ž. Žagar
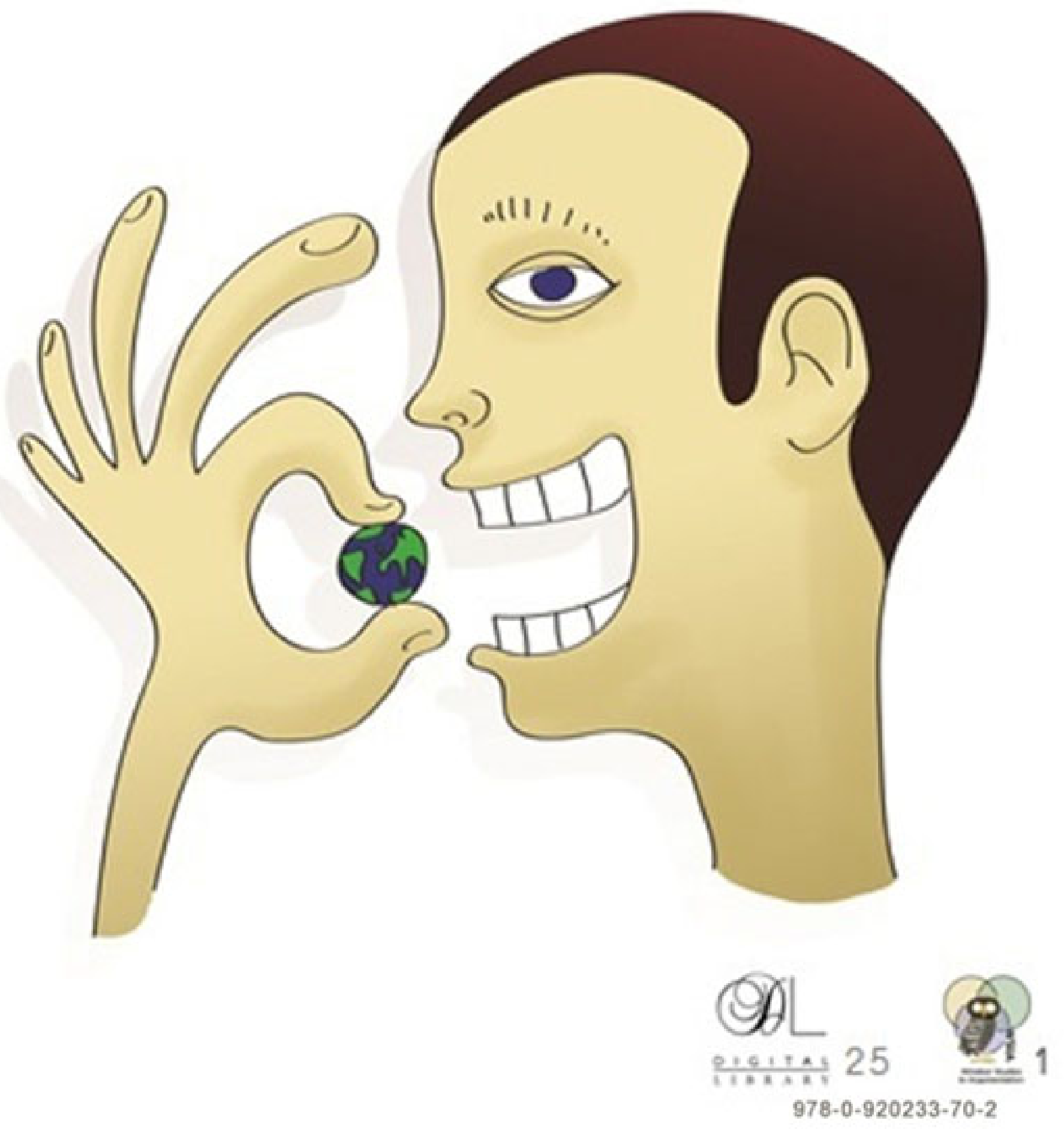
WHAT DO WE KNOW ABOUT THE WORLD?

RHETORICAL AND ARGUMENTATIVE PERSPECTIVES 


\section{WHAT DO WE KNOW ABOUT THE WORLD? RHETORICAL AND ARGUMENTATIVE PERSPECTIVES}

Edited by Gabrijela Kišiček (University of Zagreb) \& Igor Ž. Žagar JUniversity of Maribor \& University of Primorska)

Windsor Studies in Argumentation

Open Monograph Press

\section{Editors in Chief}

Leo Groarke (University of Windsor)

Christopher Tindale (University of Windsor)

\section{Board of Editors}

Mark Battersby (Capilano University)

Camille Cameron (University of Windsor)

Emmanuelle Danblon (Université libre de Bruxelles)

Ian Dove (University of Nevada Las Vegas)

Bart Garssen (University of Amsterdam)

Michael Gilbert (York University)

David Godden (Old Dominion University)

Jean Goodwin (Iowa State University)

Hans Hansen (University of Windsor)

Gabrijela Kišiček (University of Zagreb)

Marcin Koszowy (University of Białystok)

Marcin Lewiński (New University of Lisbon)

Catherine H. Palczewski (University of Northern Iowa)

Steven Patterson (Marygrove College)

Chris Reed (University of Dundee)

Andrea Rocci (University of Lugano)

Paul van den Hoven (Tilburg University)

Cristián Santibáñez Yáñez (Diego Portales University)

Igor Ž. Žagar (University of Maribor \& University of Primorska)

Frank Zenker (Lund University) 
Co-published in:

Digital Library Dissertationes series (volume

25): http://193.2.222.157/Sifranti/StaticPage.aspx?id=45.

\author{
Editorial Board: \\ Igor Ž. Žagar, Editor in Chief \\ Jonatan Vinkler \\ Janja Žmavc \\ Alenka Gril. \\ (C) Individual authors and WSIA 2013. \\ All rights reserved.
}


Gordana Varošanec-Škarić, University of Zagreb

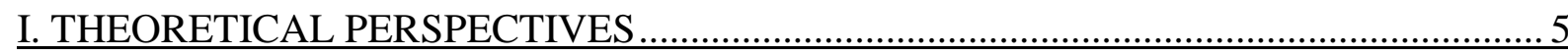

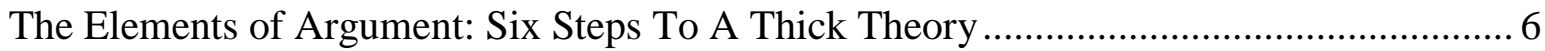

Leo Groarke, University of Windsor

Argumentation as poliphony: one speaker, several voices

Igor Ž. Žagar, Educational Research Institute \& University of Primorska

The linguistic-discursive creation of the speaker's ethos for the sake of persuasion: a key aspect of rhetoric and argumentation

Paul Danler, University of Innsbruck

The Sokal affair and beyond: on the strategic use of parody in the "science wars"

Ana Dimiškovska, Ss. Cyril and Methodius University of Skopje

The acts and strategies of defining

Fabrizio Macagno, Universidade Nova de Lisboa

Intolerance and the Zero Tolerance Fallacy

Sheldon Wein, Saint Mary’s University

II POLITICAL DISCOURSE

Political Discourse and Argumentation Profiles

Hans V. Hansen, University of Windsor

Rhetoric of the Crisis. Polish parliamentarian debates on the future of the EU 178 Agnieszka Kampka, Warsaw University of Life Sciences - SGGW

The Political Discourse on Croatia's EU Accession: a Rhetorical Analysis of the Presentation of the European Union among Supporters and Opponents of the EU. Gabrijela Kišiček, University of Zagreb

Rhetoric - Martial Art or the Art of Winning the Soul by Discourse?

Language of Politicians vs. Ethos, Pathos and Logos Joanna Szczepańska-Włoch, Jagiellonian University

The Analysis of Insulting Practices - Sticks and Stones in the Croatian Parliament 262 Alma Vančura, University of Osijek \& Diana Tomić, University of Zagreb 


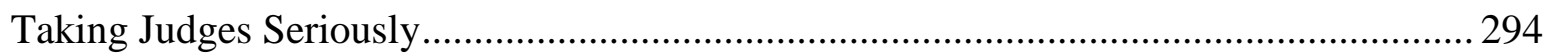

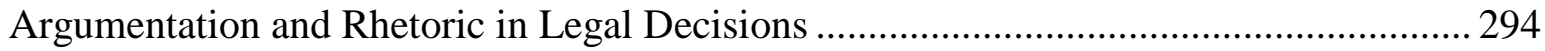

Maurizio Manzin, Research Centre on Legal Methodology (CERMEG), University of Trento

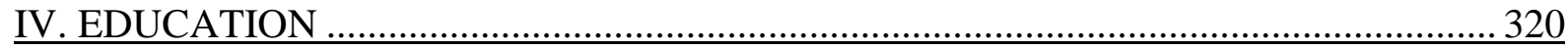

Debate as an Educational Tool: Is Polarization a Debate side effect? ............................. 321 Manuele De Conti, University of Padua

Teaching the writing of argumentative genre through imitatio: A solid basis for the

'beginner' writers

Fotini Egglezou, Athens

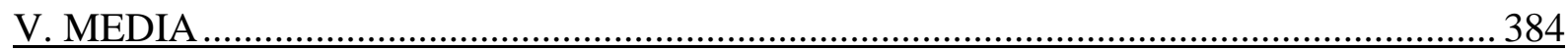

Challenges of Rhetoric in the Era of 'Bytes and Likes' ................................................. 385

Petra Aczél, Corvinus University of Budapest

The Cowboys, the Poets, the Professor... - Antonomasia in Croatian Sports Discourse... 408 Ana Grgić \& Davor Nikolić, University of Zagreb

Stakeholders in promotional genres. A rhetorical perspective on marketing communication

Sabrina Mazzali-Lurati \& Chiara Pollaroli, University of Lugano

The Representation and Reception of Paraphrase in Newspaper Headlines.....

Anita Runjić-Stoilova \& Josip Galić, University of Split 


\section{PREFACE}

What do we know about the world? Rhetorical and Argumentative Perspectives is a book trying to answer the title question by contributing to rhetorical and argumentative studies. It consists of papers presented at the "First International Conference on Rhetoric in Croatia: the Days of Ivo Škarić”. The Conference was organized with the intent of paying respect to the Croatian rhetorician and professor emeritus Ivo Škarić who was the first to introduce rhetoric at the Department of Phonetics at the Faculty of Humanities and Social Sciences, University of Zagreb.

As a phonetician, professor Škarić was interested in all aspects of speech and therefore revealed natural connections between phonetics and rhetoric. As a founder of the School of Rhetoric, he trained many of his students to become teachers of rhetoric and to get involved with rhetorical and argumentation analysis. This conference was a sign of gratitude from his students.

The conference was held at the island of Brač, professor Škarić's birthplace, between April $19^{\text {th }}$ and $22^{\text {nd }} 2012$, and it gathered 60 rhetoricians and argumentation scholars from 10 European countries as well as North America. The papers presented at the conference are distributed into six chapters of the book: Theoretical Perspectives discussing argumentation theory, relations between philosophy and rhetoric, and visual argumentation; Political Discourse presents papers interested in rhetorical strategies and argumentation analysis in various types of pubic discourse, i.e. parliamentary debates, persuasion in political speeches etc; The Media chapter presents papers containing rhetorical analyses of the media discourse, especially those interested in figures of speech and the New Media; the Legal Discourse discusses argumentation and rhetorical strategies in legal discourse; while Education presents a chapter involved in the importance of the rhetoric in education system, i.e. implementation of debate in education, writings of the argumentative genre, etc. The final chapter Other 
Approaches shows different approaches to rhetoric illustrating the multidisciplinarity of the conference.

The common feature of all the papers in the book is the attempt to understand the role of rhetoric and argumentation in various types of public discourse and to present interdisciplinary work connecting linguists, phoneticians, philosophers, law experts and communication scientists in the common ground of rhetoric and argumentation.

Gabrijela Kišiček 


\section{PROLOGUE}

\section{The Significance of Ivo Škarić for the Academic Development of Rhetoric/Public Speaking in Croatia}

Gordana Varošanec-Škarić, University of Zagreb

Professor Emeritus Ivo Škarić was born on 19 April 1933 here in Postira, on the island of Brač and he left us on 29 January 2009. Professor Škarić was an actual authority in the field of public speaking in Croatia. He authored seven books and about hundred and fifty scientific papers and he was also well-known to the Croatian public for his many newspaper articles and interviews on television.

He published three books on rhetoric, U potrazi za izgubljenim govorom (In Search of for Lost Speech, $1^{\text {st }}$ edition 1982), Temeljci suvremenog govorništva (Cornerstones of Contemporary Rhetoric, 2000, $2^{\text {nd }}$ edition 2003) and Argumentacija (Argumentation, 2011). The last one - Argumentacija - was published posthumously at the end of 2011. During the last years of his life, rethinking the meaning of science, and possible truth in rhetoric, he returned to the values of Nietzsche, Husserl, and Heidegger, shaping his understanding of argumentation, by respecting the past and incorporating it into present, consciously contemplating possible thematic fields of argumentation, including the one about decisions having future consequences.

He published many articles in the field of public speaking, for example Culture of Public Speaking Programme, Culture and Speaking, Culture of Speaking - Quality and Quantity, Measuring the Culture of Speaking, Culture of Speaking or by Speaking, Speech Universals, Euphony, Logic, Attentive Speech Listening, Identification Through Speech, 
Speaking Technique, Speech Volume, Time of Speaking, Speech Cognition, Speech - Cold Medium, Poetics in Speech, Conventional Speech, Rhetoric, Speech Preparation.

His passion for rhetoric culminated in his work with young enthusiasts resulting in his ultimate masterpiece - founding of The School of Rhetoric with the Department of Phonetics of the Croatian Philological Society and the Ministry of Science, Education and Sport of the Republic of Croatia. The School started amidst the Croatian War for Independence in 1992 in Mali Lošinj, and Professor Škarić supervised it for 17 years. His precious work continues to live on under the name: The School of Rhetoric "Ivo Škarić". His ideas are revived twice a year through young secondary school students who are developing critical thinking and are taught how to face future endeavours by acquiring speaking skills.

He believed that democracy is a spoken culture, and so for youth to be prepared for life they needed to be good speakers. He relied on logos, since the main goal of rhetorical education is rational speaking and young people should be taught to think argumentatively, focussing on thinking as a prerequisite for well-structured speaking.

We should always remember the legacy he left to his students - that critical discourse is passionate and ethical, and not cold (that is, a cunning and deceitful discourse), and that although it is in our nature to understand the world around us in terms of cause and effect, it does not imply that we should not fight for what is truly important, defendable and ethical, even when we are aware of the final consequences. 
I. THEORETICAL PERSPECTIVES 


\title{
The Elements of Argument: Six Steps To A Thick Theory
}

\author{
Leo Groarke, University of Windsor
}

\section{Summary}

In the last quarter-century, the emergence of argumentation theory has spurred the development of an extensive literature on the study of argument. It encompasses empirical and theoretical investigations that often have their roots in the different traditions that have studied argument since ancient times - most notably, logic, rhetoric, and dialectics. Against this background, I advocate a "thick" theory of argument that merges traditional theories, weaving together their sometimes discordant approaches to provide an overarching framework for the assessment of arguments in a broad range of contexts. In sketching such a theory, I propose six steps that can "thicken" traditional approaches to argument in the interests of a comprehensive theory.

Key words: the future of argumentation theory, thick theory of arguments, thin theory of arguments

\section{Introduction}

International scholarship over the last quarter-century has been characterized by an explosive growth of interest in argument as a topic of inquiry. An impressive range of disciplines and sub-disciplines have been involved. They include philosophy, rhetoric, dialectics (notably pragma-dialectics), informal (and formal) logic, linguistics, discourse analysis, computational modeling, artificial intelligence and cognitive psychology. The results are evident in burgeoning scholarship on competing theories of argument; in pedagogical research that explores different ways of teaching and testing reasoning and argument; in case studies of particular kinds of argument; in formal systems of reasoning and "assisted" reasoning; and in historical studies of the theories of argument that characterize different thinkers, times and places. 
I propose a view of these developments that understands them as steps toward a general ("umbrella") theory of argument that can be used to analyze, assess and explain arguments as they occur in a broad range of contexts. I describe the theory this implies as a "thick theory of argument." Its goals might be contrasted with the goals of many thin theories that have a narrower scope and focus. The latter may provide a detailed account of one kind of argument: say arguments by analogy or the sorites argument. In other cases, they attempt to explain some specific aspect of argument (e.g., the role that questions or quantifiers play in argument) or the arguments that occur within a specific kind of context (as instances of “negotiation dialogue," for example, or a specific variant of such dialogue like family mediation).

Like its physical counterpart, theoretical thickness and thinness is a matter of degree. A theory of ad hominem argument is thicker than an account of guilt by association arguments, which can be understood as a subspecies of ad hominem, but thinner than a comprehensive account of fallacies. A theory of argument schemes and their role in argument analysis is thicker than a theory of causal or deductive schemes, but thinner than a theory which features schemes as one of a series of conceptual tools (fallacies, dialogical considerations, etc.) proposed for argument analysis. My interest is the construction of a theory that is thick enough to be the basis of argument analysis and assessment in as broad a range of contexts as possible. I shall present a way of accomplishing such a theory which proceeds by broadening and enriching (by "thickening") traditional and contemporary accounts of argument.

In sketching a thick theory, I do not mean to diminish the significance of thinner theories. One misunderstands the thick/thin distinction if one understands it as a distinction between better and worse accounts of argument. If we imagine argumentation as one kind of communication, then we can think of a thick theory as a general account of such 
communication. While it attempts to provide a unifying account of all arguments that can explain their elements and how they work, it cannot encompass a detailed account of every aspect of every kind of argument. When analyzing an argument in law, parliamentary debate or physics, this may mean that one needs to supplement a thick theory with a thinner one that elaborates its general principles in this specific context. To the extent that it is possible, a fully complete account of argument analysis and evaluation would have to combine a thick theory with thin theories that provide a more detailed account of the kinds (and aspects) of argument it identifies.

In this essay, my interest is a thick theory. To that end, I propose six steps that culminate in such a theory. I think the time is ripe for such development, primarily because of the emergence of "argumentation theory," a contemporary amalgam of disciplines that aims to better understand argument as it naturally occurs in a great variety of contexts. I shall argue that the standard approaches to argument that characterize different branches of argumentation theory successfully illuminate key components of argument, but fall short when they are proposed as a general account of argument. I will try to thicken them by weaving together some of the disparate and contrary threads that they contain. In sketching six steps to a thick theory I aim to push the development of argumentation theory in this direction.

\section{Step One: Beginning with Logic}

One could root a thick theory in the approaches to argument that characterize logic, rhetoric or dialectics. I begin with classical logic's account of argument for autobiographical reasons - because my own interest in argument is rooted in philosophy and logic. Logic understands an argument as a set of propositions (a set of claims about what is true) which contains a proposition which is proposed as a conclusion and others which function as 
premises that offer evidence in support of it. A standard (if hackneyed) example is the Barbara syllogism: "All men are mortal. Socrates is a man. So Socrates is mortal." Traditionally, a good argument is understood as a "sound" argument which has true premises and a conclusion that necessarily (deductively) follows from them.

Aristotle offers an account of demonstration along these lines in his Prior Analytics, where he defines a syllogism, the basis of demonstration, as a "discourse (logos) in which, certain things being stated, something other than what is stated follows of necessity from their being so." (2000a, 1.2). Here each of the "certain things being stated" is a premise (protasis) of the argument, and the "something other than what is stated" which "follows of necessity" is its conclusion (sumperasma).

Logic's premise/conclusion account of argument is a common one that has been featured in thousands of introductions to logic and philosophy. One of its strengths is its normative dimension - its commitment to techniques that can be used to assess the arguments it considers. This side of formal logic is elaborated and used to analyze, construct, and assess particular instances of argument. In systems of formal logic they incorporate truth tables and trees as methods for testing valid inferences, and rules of inference (modus ponens, the "Rule of Necessitation", etc.) which allow the step by step construction of proofs which lead from given premises to conclusions that follow from them. The development of formal systems has given rise to sophisticated accounts of argument which play a practical role in computing and computational modeling.

"Informal" logic is an offshoot of classical logic that has focused on the informal arguments that characterize day to day contexts (in social and political controversy, personal exchange, public discourse, news coverage, advocacy and advertising, and so on). Because judgments of truth and falsity may be difficult to make in such contexts, it may assess premises in terms of their plausibility, probability, or "acceptability." The latter leaves open 
the possibility of truth understood as one kind of acceptability but introduces the possibility of others. In judging the mechanics of argument, one might compare formal logic's rules of inference to informal logic's attempt to identify and elaborate different kinds of argument schemes (argument by authority, causal generalizations, arguments by analogy, etc.) which infer particular kinds of conclusions from premises that answer "critical questions" in each case. An alternative method of judging arguments is fallacy theory, which diagnoses the problems with weak arguments by identifying common mistakes that they commit. Traditional lists of fallacies include problems with deductive reasoning (e.g., affirming the consequent), issues with premises (as in false dilemma and begging the question) and weak inferences (e.g., ad populum, ad baculum, and ad misercordiam).

In the present context, it is notable that informal logic is an attempt to create a thicker theory of argument than that which characterizes classical logic. In its attempt to encompass a broader range of argument, it proposes more broadly applicable accounts of premise acceptability and valid (and invalid) inference. In the process, it provides a general theory of argument that can be applied to everyday arguments that are not easily analyzed or assessed using formal logic's classical account of argument. This expands the scope of logic, but informal logic (at least as it was initially conceived) still has shortcomings when it is proposed as a thick theory. To better understand these limits and how they can be overcome we need to turn to key aspects of argument that are better recognized by the disciplines of rhetoric and dialectics.

\section{Step Two: Argument in its Rhetorical Context}

Following O'Keefe, 1977, many studies of argument have distinguished two meanings of the word "argument" that he labels "argument," and "argument ${ }_{2}$." Both meanings have their roots in ordinary English, where the observation that someone argued may mean that 
they offered premises in favour of some conclusion ( $\operatorname{argument}_{1}$ ) or, more simply, that they strongly disagreed with someone (argument 2 ). The latter notion underscores the interactions in which arguments in the logician's sense (instances of argument 1 ) are embedded. More generally, premise/conclusion arguments are embedded in uncertainty, which can arise from too much opinion (when arguers disagree) or too little (when arguers do not know what to think).

We can visually represent the relationship between arguments and their contexts of uncertainty as I have below. Above all else, this highlights the extent to which real arguments are not abstract entities, but tools with a concrete purpose: to resolve the uncertainty (and disagreement) that gives rise to them. In attempts to analyze and assess arguments as successful and unsuccessful, this means that we need to ask whether they successfully resolve the uncertainty they respond to. As this uncertainty resides in a group of people, a successful argument in practice is one which convincingly addresses them and eliminates their uncertainty.

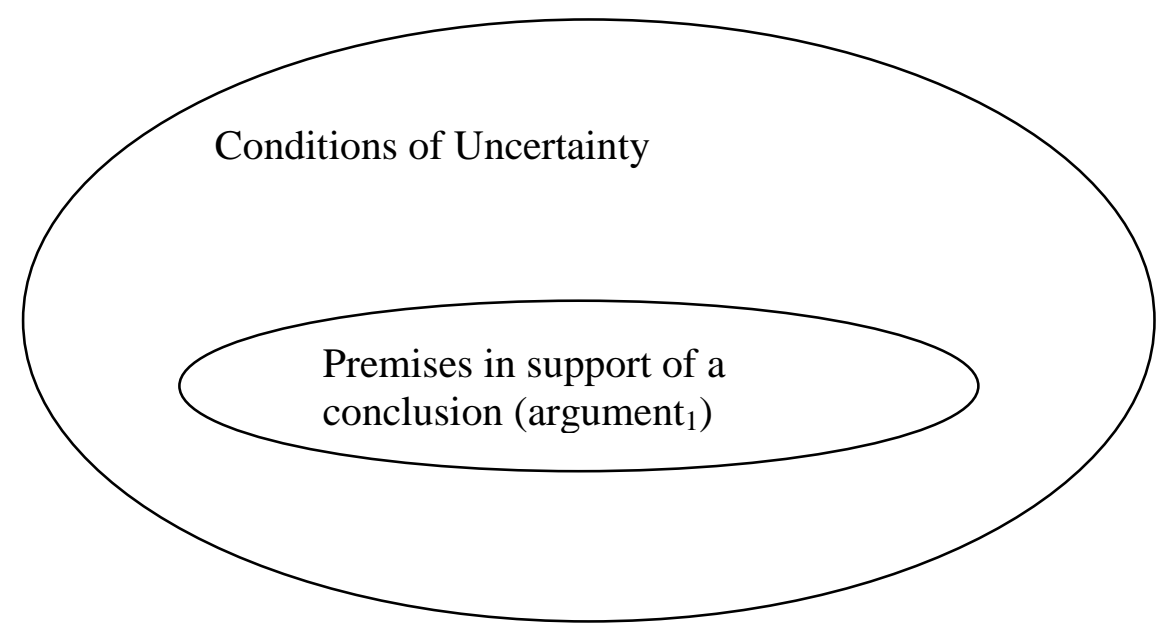

Historically, this aspect of argument has been better recognized by rhetoric than logic. It understands an argument as a vehicle of persuasion, and a strong argument as a successful 
attempt to persuade an intended audience of some point of view. Logic suggests that a good arguer constructs an argument by assembling premises they know (or think they know) to be true. Rhetoric proposes a fundamentally different approach, suggesting that an arguer begin by analyzing the audience to which their argument is directed, and by looking for premises that this audience finds acceptable. In real life circumstances, this has always been the strategy of adept arguers, who tailor their arguments to the audiences they address. Among other things, this implies that an arguer should use different premises when they address different audiences. If one wishes to argue that nationalism is an evil (or a boon), this suggests that one should use different arguments when one addresses Croatians, Mexican Americans, Indigenous people in Canada, Swedes, the United Nations, conservatives, libertarians, the so called "universal audience," and so on.

In the attempt to create a truly general theory of argument, these considerations make audience a key component of argumentation which is missing logic's account of argument. The easiest way to rectify this shortcoming is as Aristotle suggests in his Rhetoric: by understanding a successful argument as one that is logically impeccable and constructed in a manner that successfully addresses its audience's beliefs and convictions (their pathos). If one wishes to be a successful arguer, this means that it is not enough to employ premises one believes to be acceptable; one must go further and find premises that are acceptable to the audience one addresses. Creating a thick theory that recognizes this can dissipate some of the tension between logical and rhetorical conceptions of argument, accommodating key components of both in a "rhetorically enhanced" theory that recognizes audience as an element of successful argument. In the present context, I will treat this view of argument as a second step towards a thick theory that allows us to analyze and judge an argument from the point of view of logic (the acceptability of the premises, the strength of an inference, etc.) and/or the rhetorical requirement that it speak to the audience it addresses. 


\section{Step Three: Argument in its Dialectical Context}

Insofar as rhetoric highlights the role of audience in argument, it identifies one facet of an argument's context which must be recognized by a thick theory. One finds another in an argument's relationship to opposing points of view. Considered from this perspective, arguments are embedded in a context which typically includes an exchange between opposing points of view and the opposing arguments they produce. The construction of opposing arguments is an iterative process, making one argument a move in a broader dialectical exchange between arguers and their opponents (in some cases, arguers may be their own opponent, arguing 'with themselves,' defending opposing points of view). The dialectical view of argument this implies has an impressive lineage that is evident in Plato's dialogues, where interlocutors (usually Socrates and his antagonists) develop arguments and counterarguments for opposing points of view.

Like rhetoric, dialectics underscores the extent to which logic has traditionally treated arguments in a manner that removes them from the contexts in which they are embedded. In contrast, dialectics analyzes an argument by asking whether it is a reasonable move in an exchange between the proponents and opponents of the view that it defends. This approach suggests that a good argument must, among other things, successfully answer (and anticipate) opposing points of view. Johnson, 2000, endorses a dialectical approach when he maintains that arguments have a "dialectical tier" beyond the "illiative" core that logic recognizes; and that arguers have "dialectical obligations" requiring them to address competing arguments and points of view. A good argument for the conclusion that homosexual marriage is a right must, this suggests, include acceptable premises, a strong inference and an answer to the objections of those who think otherwise. 
Johnson concludes that the conception of argument that characterizes the history of logic — the giving of premises for a conclusion - is, without elaboration, only a "protoargument." In the building of a thick theory, the dialectical view suggests that a complete account of premise and conclusion arguments needs to be a "dialectically enhanced" version of logic's account of argument. The resulting theory must recognize dialectical considerations as a key component of argument analysis. Doing so adds a fourth element to our thick theory of argument: which must recognize premises, conclusions, audience and dialectical context as central ingredients of successful argument. I shall take this rhetorically and dialectically enhanced account of argument as our third step in the development of a thick theory.

\section{Step Four: Argument in its Dialogical Context}

Yet another approach to argument which emphasizes the context in which arguments occur is dialogue theory. It suggests that we understand an argument as an element in a "dialogue" which establishes parameters that dictate those moves that are acceptable and unacceptable in argument. In their classic account of pragma-dialectics, van Eemeren and Grootendorst, 1992, situate argumentation within a form of dialogue they call a "critical discussion." The theory of argument they develop distinguishes different stages of critical discussion (confrontation, opening, argumentation, closing) and elaborates rules that regulate the discussion at each stage. Good arguments are arguments that abide by the rules; poor arguments are arguments that fail to do so. In the process, fallacies are explained as violations of these rules.

In the building of a thick theory of argument pragma-dialectics tells us that arguments must be understood as elements of a form of dialogue which implies normative rules that delineate right and wrong ways to argue. From a pragma-dialectical point of view, we can 
diagram the general structure of premise/conclusion arguments as I have below. I will describe this structure by saying that the rules of critical discussion

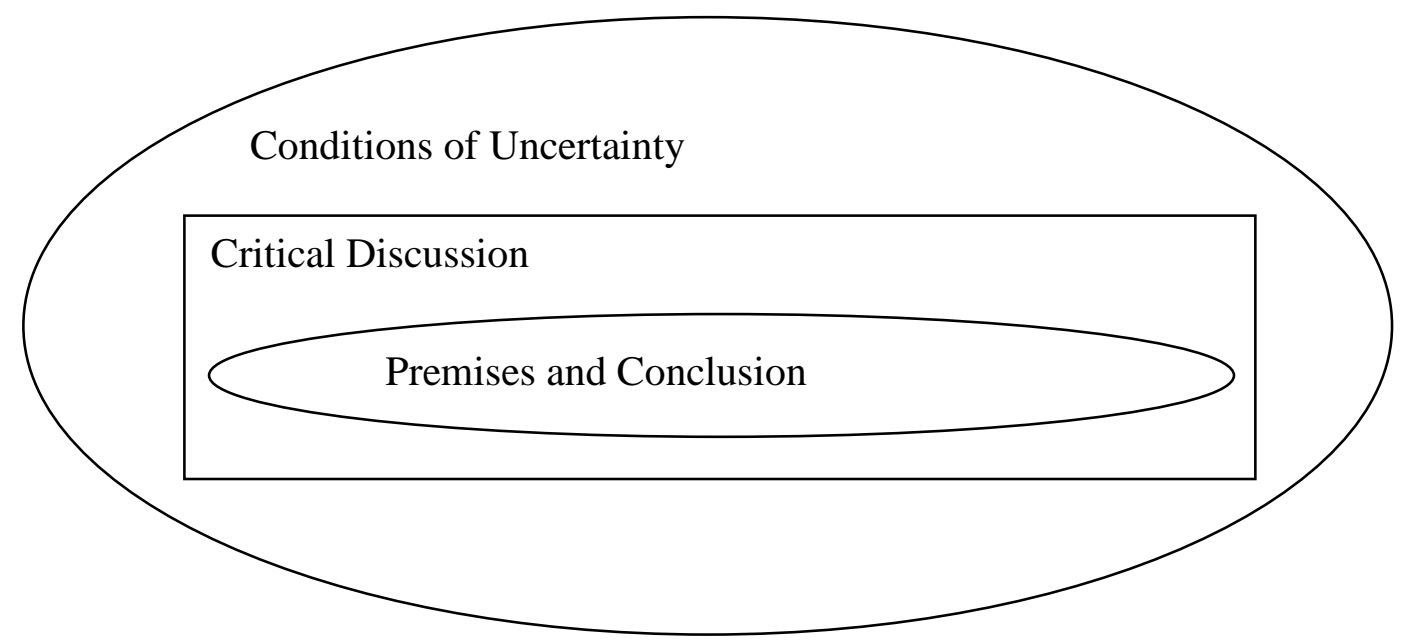

establish a dialogical frame of reference (or, more simply, "a frame") in which arguments occur (in passing it bears mention that Entman, 1993, and others use the word "frame" in a different way). Analyzing and evaluating arguments that occur within this frame must be done in accordance with the rules the frame implies.

In the evolution of argumentation theory, the pragma-dialectical account of critical discussions is a game-changing move because it recognizes dialogical frames as a previously neglected element of argument. The significance of this move is even more evident in subsequent discussions in argumentation theory, which identify other kinds of dialogue which are characterized by different frames - and the different goals, structures, and rules of engagement they incorporate. In his work, Walton has proposed seven different kinds of dialogue which have as their purpose: persuasion, inquiry, discovery, negotiation, information, deliberation and eristic exchange (see 2007). The distinction between these different kinds of dialogue has significant implications for the analysis of specific instances of argument, as 
each is characterized by a distinct frame which implies unique procedural rules and unique standards for success.

In an inquiry dialogue, arguments are exchanged to establish what is true. The dialogue is characterized by strict standards that determine what counts as evidence and counter-evidence for a particular conclusion. In contrast, a negotiation dialogue does not attempt to establish truth, but to bargain in a way that reconciles the competing interests of the parties who negotiate. In the case of collective bargaining, one species of negotiation dialogue, arguing is unacceptable it is "bargaining in bad faith" - by, for example, bargaining directly with the members of the union or the executive of the corporation rather than the team that represents them. This procedural rule has no obvious analogue in an inquiry dialogue. Neither do the standards for good argument. Threats have, for example, no legitimate role to play in inquiry dialogue (where they can be rejected as instances of the fallacy ad baculum), but play an essential place in collective bargaining, which is ultimately founded on the threat of a strike or a lock out.

Within argumentation, there are many instances in which dialogical frames are themselves matters of dispute and argument. Strategic arguers may move to ensure that the arguments they present occur within the frame in which they are most likely to be successful. The standards of evidence in tort law are, for example, looser than those that apply in criminal law. In view of this, the parents of O.J. Simpson's apparent victims sued him in civil court after he was found not guilty at his famous criminal trial. By moving the arguments to this new frame they were successful in securing substantial damages. In other situations, mediation would introduce yet another frame of reference.

In the development of a thick theory of argument, the role that frames play in determining standards of argument means that a theory which aims to provide a truly general account of argument must be dialogically (as well as dialectically and rhetorically) enhanced. 
I will therefore propose the recognition of dialogues and the frames that accompany them as a fourth step in our development of a thick theory.

\section{Step Five: Multi-Modal Argument}

Steps 2, 3 and 4 in our thick theory all extend logic's traditional account of argument so that it recognizes the role that context plays in instances of argument. The final two steps I want to propose as a route to a thick theory move in a different direction, broadening the scope of what logic (and most argumentation traditions) counts as argument. Step 5 is a broadening of the notion of argument beyond the assumption that arguments are conveyed verbally, as collections of sentences. In response to this assumption, many commentators have now argued that arguments can be expressed and communicated in non-verbal ways (see, e.g., Birdsell and Groarke, 2008; Blair, 1996; Dove, 2012; Groarke, 1996; Roque, 2008; Shelley, 1996; Slade, 2002; van den Hoven, 2011). Even textbooks have extended their accounts of argument to make room for non-verbal instances of argument (see Groarke and Tindale, 2013; and Lunsford et. al., 2010). While some sceptics remain (notably Fleming, 1996 and Johnson, 2005), the thick theory I propose - which aims for as broad a theory of argument as possible explicitly includes "multi-modal" arguments which have non-verbal elements.

The fundamental reason for accepting multi-modal arguments is the root notion that an argument is an attempt to support a conclusion by presenting evidence for it - something that can clearly be done in ways that extend beyond premises and conclusions understood as declarative sentences. To take only a few examples, I may try to convince you of some claim by presenting photographs, drawing a map, pointing to something, telling a story (fiction or non-fiction), showing a film, painting a picture, and so on and so forth. Our lives are replete with situations in which evidence for some point of view is presented in these and other ways 
that do not neatly correspond to the verbal paradigm that was always stressed in traditional accounts of argument.

In this essay, I will confine myself to one personal example. Consider a debate spurred by an unusual fruit I discovered during a kayak ride on the Detroit River. When my description ("nothing I recognize; a bumpy, yellow skin") initiated a debate and competing hypotheses on the identity of the fruit, I went back and took the photographs reproduced below. On the basis of these photographs, the fruit was quickly identified as beadfruit.

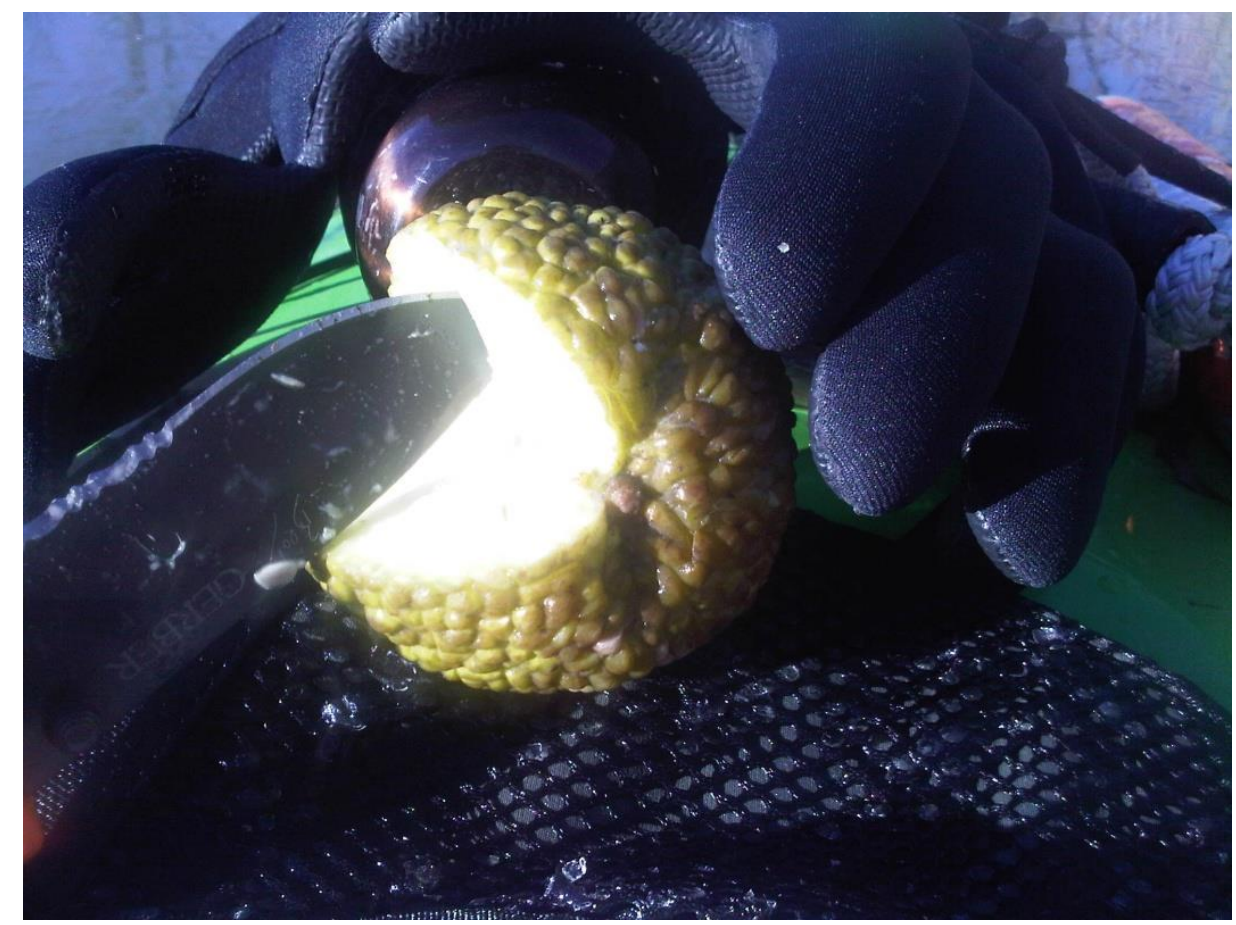




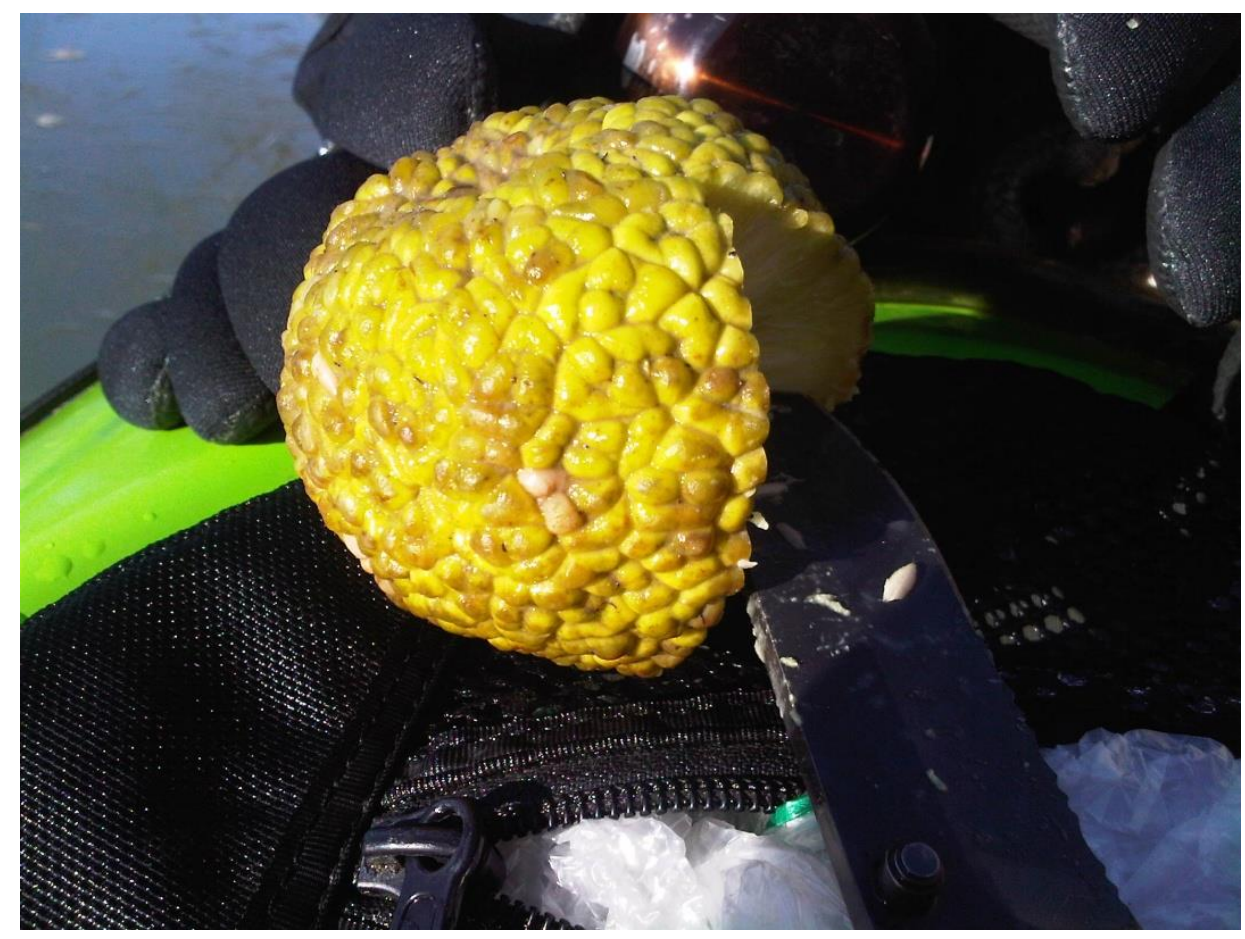

The argument that established this conclusion compared my photographs to similar photographs found in encyclopedia accounts of breadfruit. One might summarize the reasoning as: "The fruit is breadfruit, for these photographs are like standard photographs of breadfruit." But this is just a verbal paraphrase. The actual reasoning - what convinces one of the conclusion is the seeing of the sets of photographs in question. Using a variant of standard diagram techniques for argument analysis, we might map the structure of the argument as:

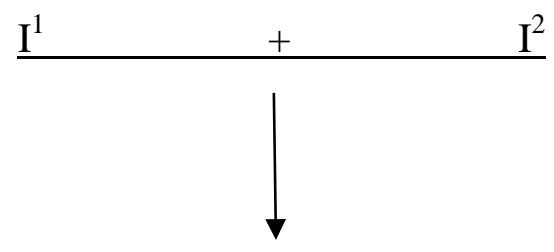

$\mathrm{C}$

where $\mathrm{C}$ is the conclusion that the fruit is a piece of breadfruit, $\mathrm{I}^{1}$ is the set of photographs $\mathrm{I}$ took, and $\mathrm{I}^{2}$ is the iconic photographs of breadfruit to which they were compared. 
One might compare many other instances of reasoning - identifying a criminal by looking at their "mug shot"; identifying an insect by comparing it to a preserved specimen; and so on. These are instances of "visual demonstration" - arguments which prove something by visually demonstrating that it is so (for a discussion, see Groarke and Tindale, 2013; Birdsell and Groarke, 2008). Other kinds of visual argument operate in different ways, by invoking visual symbols, metaphors, and so on. At a time when the development of digital communication is making it easier to transmit images, sounds, and even physical sensations, it is not surprising that arguments increasingly incorporate non-verbal elements that can be communicated in this way. Especially in such a context, recognizing multi-modal arguments is one way to broaden the scope of our general account of argument, taking us one step further in the development of a thick theory.

\section{Step Six: Argument and Emotion}

The last step I propose to take in developing a thick theory may be the most controversial. In some ways it is anticipated by Hample, who has criticized "the absence of emotions in argumentation theory," remarking that "our culture has inherited a persistent and bad idea, namely that rationality and emotionality are opposites. Arguing is identified with reason, which is held to be the opponent and discipline to passion." $(2005,126-127)$ The split between reason and emotion this refers to is especially common in logic and philosophy. It is tied to an influential view of argument that can be called "the cognitive account." This account sees argument as an attempt to judge truth and establish knowledge in a manner that eschews the emotions and the passions.

One might maintain the plausibility of the cognitive account in some contexts - e.g., mathematics and science. In other contexts which are highly charged with emotion, it may usefully explain what goes wrong in arguing. In judging who is right and who is wrong in 
contentious divorce proceedings, the cognitive account tells us that the ideal arguer proceeds by dispassionately marshalling evidence for and against particular conclusions. This implies an unemotional approach to argument that is not unduly influenced by loyalty, sympathy or antipathy toward one of the principals in question, or by hopes and desires about the outcome. In this and other contexts which naturally engage the emotions, the tendency to draw conclusions on the basis of emotional reactions rather than evidence may be prevalent and pronounced.

In such cases, the cognitive account usefully points out that emotion interferes with cogent reasoning. But we should not make too much of this. Concluding that emotions have no place in the realm of argument is like concluding that appeals to authority have no place in argument because they often go amiss. In a great many situations, emotions have a legitimate role to play in our decision to accept or reject particular conclusions: because these conclusions resonate with our ideals, our dislike of particular actions, our affection for our loved ones, and so on. Compassion for the victims of an earthquake or tsunami is appropriate, not inappropriate, when deciding whether one should contribute to a charity that aims to support them. Loving or fearing someone may give one strong reasons to conclude that they should be treated or viewed in certain ways. A prevalent lack of empathy is not a positive trait in thinking, but a defining feature of psychopathy, which is a mental disorder.

In the real world of argument, many arguments are explicitly designed to foster our emotions. Such arguments may rouse a team before a soccer game, generate public concern about an invasive species, or foster support for the Society for the Prevention of Cruelty to Animals. While specific examples of such arguments may go too far, it makes little sense to say that they are in principle illegitimate, or that excitement, fear, anger, disgust, hope, sympathy, and happiness should never play a role supporting some conclusions and mitigating against others. In a poll of scholars of American public address, Martin Luther 
King's "I have a dream" speech (American Rhetoric, 2012) has been ranked as the most significant political speech of the 20th century. Delivered to over two hundred thousand civil rights marchers at the Lincoln Memorial on August $28^{\text {th }} 1963$, it was a defining moment in the American Civil Rights Movement. The speech presents a powerful argument for civil rights which cannot be understood apart from King's success stirring the emotional convictions of his audience.

The influence of the cognitive account of argument on argumentation theory is seen in the history of fallacy theory, which has treated appeals to emotion as mistakes in argument. The standard list of fallacies thus includes appeal to pity (ad misercordiam), appeal to flattery, attacking the person (ad hominem), appeal to force (ad baculum) and, more generally, appeal to emotion. Recent work on argument has made it increasingly evident that this is too simple: that we cannot easily relegate all appeals to emotion to the realm of fallacies, and that many such appeals provide reasonable grounds for belief and action. To take one example, Wreen,1988a and 1988b, has argued that appeal to force (ad baculum) is an argument scheme that has rationally compelling instances. One cannot dismiss all instances of the scheme on the basis of the claim that it is predicated on an appeal to fear, for fear may be reasonable and may be a legitimate consideration in the drawing of conclusions. If you tell me that I should give you my wallet because you will shoot me with a gun in your hand if I don't, then I would be acting unreasonably if I did not accept this conclusion (telling someone with a gun that they are committing the fallacy ad baculum is not a recommended course of action). A number of other commentators have argued for a rethinking of the fallacies that treats $a d$ hominem and other fallacies associated with emotions as legitimate forms of argument (see, e.g., Govier, 1983; Groarke and Tindale, 1986; Hitchcock, 2006).

The role of emotion in argument is particularly salient if one's goal is a thick theory of argument, for such a theory must provide an overarching account of argument that is 
applicable in a broad range of contexts. Such a theory must, in particular, be able to provide an account of argument that can analyze and assess arguments in a variety of contexts which are inherently emotional: in political, moral, social and aesthetic debate; in interpersonal exchange; in mediation and conflict resolution; in bargaining; and so on. In the realm of evaluation, this means that a thick theory must be able to distinguish between legitimate and illegitimate (and more and less legitimate) emotional appeals. For though it is clear that emotion can play a legitimate role in such contexts, it is equally clear that arguers may treat them as opportunities to manipulate emotions and illegitimately establish their conclusions. Arguments in sales and advertising, with their very consciously designed appeals to our desires and hopes and fears (about sex, health, material possessions, etc.) are notorious for such appeals.

This is not the place for the development of a detailed account of how to analyze and assess emotion in arguments, but it behooves us to say something in this regard. To begin with, it may be said that there are important ancient precedents for recognizing the extent to which emotions influence argument (and vice-versa). In sharp contrast to the cognitive approach to argument, they view emotion's association with argument as an opportunity that adept arguers should explore, cultivate and exploit.

Such an attitude is an essential component of ancient sophism and ancient rhetoric, which are key instances of argumentation theory (for a recent attempt to rehabilitate the sophists as theorists, see Tindale, 2010). Gorgias, famous for his ability to argue anything, unabashedly champions the ability of argumentative discourse to provoke emotion, claiming that it accomplishes "miraculous works; for it can stop fear and assuage pain and produce joy and make mercy abound," producing "fearful shuddering and tearful pity and sorrowful longing" $(1999,9)$. Emphasizing the emotional power of words, he compares them to drugs, "For just as different drugs draw off different humors from the body, and some put an end to 
disease and others to life, so too of discourses: some give pain, others delight, others terrify, others rouse the hearers to courage, and yet others by a certain vile persuasion drug and trick the soul" $(1999,14)$.

Aristotle is impatient with Gorgias and the sophists, but the rhetorical tradition he initiates also recognizes emotion as a key component of argument, emphasizing the role that pathos plays in persuasive arguments. Literally, the word pathos means "feeling" or "affection", making the attempt to speak to an audience's pathe an attempt to appeal, not merely to what they believe, but to their feelings and their emotional attachments. In constructing arguments this means that we need to consider the emotional as well as the cognitive commitments of our audience.

In contemporary argumentation theory, the most direct call for a recognition of emotional argument is found in Gilbert, 1997; 2004. He expands the standard account of argument so that it includes an "emotional mode" which may employ emotion as a reason for a conclusion or an expression of emotion as a means of conveying an argument. On this account, a lover's outpouring of emotion may function as a good reason for accepting an entreaty to do what they desire. According to Gilbert, the strength of an emotional argument depends upon "such elements as degree of commitment, depth, and the extent of feeling, sincerity and the degree of resistance" (1997, 83-84; Carozza 2009 further develops this account). One way to incorporate this into a theory of argument is by broadening the notion of premise and conclusion acceptability one employs so that it incorporates some notion of emotional acceptability. Whichever way one goes, recognizing emotion as a legitimate component of argument thickens one's account of argument dramatically, taking us one step further in the development of a thick theory.

8. Conclusion: The Elements of Argument 
In this essay, I have tried to sketch the outlines of a thick theory of argument. We might summarize the theory I have suggested by saying that it recognizes seven elements of argument which need to be considered in a comprehensive theory of argument. We might describe these elements as: premises, conclusions, audience, dialectical exchange, dialogical frames, multi-modal discourse, and emotional content. While this list significantly thickens traditional accounts of argument, I do not offer it as definitive. Argumentation theory is, in a number of ways, engaged in working out a comprehensive list. In the final analysis, there may be other elements of argument that it should recognize. Hample, 1985, has, for example, suggested a notion of argument defined in terms of its cognitive dimensions (the mental processes by which argument occurs within individual arguers) that he calls argumento. This may point to another dimension of argument that needs to be considered. I leave a discussion of this and other possibilities for elsewhere, though it bears mention that the ultimate elements of argument must be elements that are not reducible to other elements.

This is not the place for an elaboration of what a recognition of the elements of argument imply for the analysis and evaluation of argument (much less specific arguments and specific instances of argument). It must nonetheless be said that the importance of the different elements of argument differs depending on the argument in question. If we think of one dimension of argument corresponding to each element, then it may be said that different arguments are situated at different places within these seven dimensions. As an object may be two rather than three dimensional, an argument may be two or three or four or seven dimensional. The assessment of some arguments will be heavily determined by dialogical frames, others not. Some, but not others, will be packed with emotional content. And so on.

In the context of argument evaluation it might be said that different kinds of argument evaluation address the different dimensions of argument. In judging an argument we may decide to judge the extent to which its premises are acceptable; the extent to which its 
conclusion follows from its premises; the extent to which it successfully addresses its audience; the extent to which it is dialectically or dialogically appropriate; the extent to which it is well expressed in multi-modal terms; and/or the extent to which it is emotionally

successful. It goes without saying that each of these assessments warrants an extended discussion of its own. For the moment it must suffice to say that the theories that this requires can be seen as further components of the thick theory I propose.

\section{References}

American Rhetoric. "Top 100 Speeches.”

http://www.americanrhetoric.com/newtop100speeches.htm.

Aristotle. Prior Analytics. Translated by A.J. Jenkinston. The Internet Classics Archive: (2000a) http://classics.mit.edu/Aristotle/prior.html.

Aristotle. Rhetoric. Translated by W. Rhys Roberts. The Internet Classics Archive: (2000b) http://classics.mit.edu/Aristotle/rhetoric.html.

Birdsell, D. and L. Groarke, eds. "2nd Special Issue on Visual Argumentation.” Argumentation and Advocacy: The Journal of the American Forensic Association 43 (2008): 3-4.

Birdsell, D. and L. Groarke. "Outlines of A Theory of Visual Argument." Argumentation and Advocacy. 43, no.3 (2008): 103-113.

Blair, J. Anthony. "The Possibility and Actuality of Visual Arguments." Argumentation and Advocacy. 33, no. 1 (1996).

Carozza, L. "The Emotional Mode of Argumentation: Descriptive, People-Centered, and Process-Oriented.” PhD Diss., Toronto: York University, 2009.

Dove, I. "Image, Evidence, Argument" in Topical Themes in Argumentation Theory, edited by van Eemeren, F.H., and B. Garssen. Amsterdam: Springer-Verlag, 2012. 
Eemeren, F. H. van and R. Grootendorst. Argumentation, Communication, and Fallacies: A Pragma-Dialectical Perspective. Hillsdale, NJ: Lawrence Erlbaum Associates, 1992. Entman, R.M. "Framing: Toward Clarification of a Fractured Paradigm.” Journal of Communication. 43, no. 4 (1993): 51-58.

Fleming, D. “Can Pictures Be Arguments.” Argumentation and Advocacy. 33 Summer (1996).

Gilbert, M. A. Coalescent Argumentation. Mahwah, NJ: Lawrence Erlbaum Associates, 1997.

Gilbert, M. A. “Emotion, Argumentation and Informal Logic.” Informal Logic. 24, no. 3 (2004): 245-264.

Gorgias. Encomium of Helen. Translated by Brian Donovan. Peitho's Web, Classical Rhetoric and Persuasion: http://www.classicpersuasion.org/pw/gorgias/helendonovan.htm, 1999.

Govier, T. “Ad Hominem: Revising the Textbooks.” Teaching Philosophy. 6, no. 1 (1983): $13-24$.

Groarke, L. and C. W. Tindale. "Critical Thinking: How To Teach Good Reasoning.” Teaching Philosophy. 9, np. 4 (1986): 301-318.

Groarke, L. “Logic, Art and Argument.” Informal Logic. 18 no.2 \& 3 (1996): 116-131.

Groarke, L. and C. W. Tindale. Good Reasoning Matters! Toronto: Oxford University Press, 2013. $5^{\text {th }}$ Edition.

Hample, D. "A Third Perspective on Argument." Philosophy and Rhetoric. 18 no. 1 (1985): $1-22$.

Hample, D. Arguing: Exchanging Reasons Face to Face Lawrence Erlbaum Associates, 2005.

Hitchcock, D. "Why there is no argumentum ad hominem fallacy." Unpublished (2006). http://www.humanities.mcmaster.ca/ hitchckd/adhominemissa.htm.

Johnson, R. H. Manifest Rationality: A Pragmatic Theory of Argument. Mahwah, NJ: Lawrence Erlbaum Associates, 2000.

Johnson, R. H. "Why "Visual Arguments" aren’t Arguments.” Edited by H. V. Hansen, C. 
Tindale, J. A. Blair and R. H. Johnson. Informal Logic at 25, Windsor: University of Windsor, 2005 (CD-ROM).

Lunsford, A. A., J.J. Ruszkiewicz, and K. Walters. Everything's an Argument, New York: Bedford's/St. Martin's, 2010.

O’Keefe, D. J. “Two Concepts of Argument." Journal of the American Forensic Association. 13 no. 2 (1977): 121-128.

Roque, G. "Political Rhetoric in Visual Images," in Dialogue and Rhetoric. Edited by E. Weigand. Amsterdam/Philadelphia: John Benjamins Publishing Company, 2008. Shelley, C. "Rhetorical and Demonstrative Modes of Visual Argument: Looking at Images of Human Evolution.” Argumentation and Advocacy. 33 no. 2 (1996): 53-68.

Slade, C. The Real Thing: Doing Philosophy with the Media, New York: Peter Lang, 2002.

Tindale, C. W. Reason's Dark Champions: Constructive Strategies of Sophistic Argument. Columbia: University of South Carolina Press, 2010.

Van den Hoven, P.J. “Iconicity in Visual and Verbal Argumentation,” in Seventh International Conference of the International Society for the Study of Argumentation: Proceedings, 831-834. Edited by F.H. van Eemeren, B. Garssen, D. Godden, and G. Mitchell. Amsterdam: Sic Sat, 2011.

Walton, D. N. Dialog Theory for Critical Argumentation, Amsterdam: John Benjamins Publishing Company, 2007.

Wreen, M. "Admit No Force But Argument." Informal Logic. 10 no. 1 (1988a): 89.96. Wreen, M. "May the Force Be With You." Argumentation. 2 no. 3 (1988b): 425-40. 


\title{
Argumentation as poliphony: one speaker, several voices
}

\author{
Igor Ž. Žagar, Educational Research Institute \& University of Primorska
}

\section{Summary}

For almost 40 years a French linguist Oswald Ducrot has been developing a new theory of argumentation, a theory of "argumentation in the language-system" (TAL), a theory that explores the argumentative potential of language as a system. TAL tries to show how certain argumentative features and argumentative orientation(s) are already written in the lexical and syntactical constructions; how, on certain levels, language seems to argue by and for itself; and how it can (and does) impose restrictions on our own (dialogical and interactive) argumentation.

This paper will show how Bakhtin's concepts of reported speech and dialogism were "borrowed" by Ducrot and elaborated into one of the key concepts of TAL, the concept of polyphony. The shaping and transformations of Ducrot's theory will be presented, why and how the concept of polyphony was (and had to be) introduced, how it was expanded and supplemented with the concept of topoi, as well as how these two concepts are used within TAL.

Key words: polyphony, topoi, argumentative orientation, argumentation in the language-system, Ducrot

For almost 40 years a French linguist Oswald Ducrot (1972, 1973, 1980, 1983 (with J. C. Anscombre), 1984, 1996, 2009) has been trying to develop his own theory of argumentation - a theory very different from the "mainstream" argumentation theories -, a theory of "argumentation in the language-system" (TAL from now on).

In this paper, I will try to shed some light on the shaping and the development of this theory, the transformation of its conceptual apparatus and its analytical scope, and try to point at some possible problems at the same time. My main point of interest will be the concept of polyphony, therefore I shall have neither time (n)or space to discuss all the problems and 
transformations Ducrot's theory is currently undergoing (e.g. theory of semantic blocks). Also, because of its general character, this overview will have to be more or less schematic.

In the second part of the eighties ${ }^{1}$, Ducrot used to distinguish four phases in the development of his theory of argumentation:

- the strong informativistic version

- the weak informativistic version

- the weak version of argumentation in language, and

- the strong version of argumentation in language.

The latter is (still) in a critical stage of formation and transformation.

\subsection{Informativeness and argumentativeness}

The basic supposition of the first, i.e. "strong informativistic" version - which Ducrot never really advocated, but used as a (presupposed) theory in opposition to which he constructed his own theory instead - is the postulate that every conclusion or, more accurately, every instance of putting forward an argument towards a conclusion, is based solely on "facts" conveyed (represented) by an utterance-argument. If it is possible to draw a C(onclusion) from an A(rgument), this is the case because the utterance A "factually" supports the utterance C: by quoting or presenting or referring to some "facts" that speak in favour of the utterance C. A different kind of support (if only subsidiary), for example a structural linguistic support (i.e. making use of special language particles, argumentative connectives or argumentative indicators), is not considered as a serious theoretical option.

\footnotetext{
${ }^{1}$ Lectures at Ecole des Hautes Etudes in Sciences Sociales, Paris, 1986 - 1989.
} 
Therefore, if the utterance

(1) Janez studied for only an hour or so

can be used as an argument or can serve as an argument supporting the conclusion

(2) He won't pass the exam

then - in accordance with the "strong informativistic" thesis - this can be done only on the basis of the "fact(s)" that Janez (in fact) studied for only an hour or so, and that an hour of studying is (usually, i.e. according to "average" experience) not enough to pass an exam. Within the framework of the "strong informativistic" version such a conclusion is not (co)supported by the argumentative orientation of the particle only, the orientation, which is the domain of language as a system ${ }^{2}$, and does not pertain to extra-linguistic "factuality." In example (1) we see the type of argumentation that is (supposed to be) entirely non-linguistic, or, it is linguistic only to the extent that it uses language as a conventional, standard means of communication, as a "medium," which does not affect the "message" that it conveys.

Of course, this spontaneous and common sense "theory" is immediately confronted with counter-examples. Let us assume (for the sake of the argument) that we are working on a seminar paper about frictions between Yugoslav nations in post-Titoist Yugoslavia, and that we are especially interested in the war in Bosnia; we ask our friends working in the social

\footnotetext{
${ }^{2}$ That some linguistic entity is argumentatively oriented means that its presence in the given discourse segment imposes or represents some restriction(s) affecting the continuation of the discourse. In other words, even if the particle only were followed by "twenty hours" and not "an hour or so," the utterance would still be represented as leading to a negative conclusion. This, of course, challenges the "factuality" of "the fact, that one hour of studying is (usually) not enough to pass the exam." Namely, how many hours are enough to pass the exam, especially if we take into account the restricting role of the particle "only"? More on this subject later in the text.
} 
sciences to refer us to somebody who might know something about our object of interest, and we get the following two answers:

(3) Janez did not read all the UN resolutions (Argument) > He may not be able to advise you (Conclusion)

and

(4) Marko read some of the UN resolutions (Argument) > He may be able to advise you (Conclusion).

Utterances (3) and (4) display an obvious discrepancy between informative and argumentative values. The "fact" that Janez did not read all the UN resolutions could on the "factual," informative level also mean that he read all the UN resolutions except maybe one. And the "fact" that Marko read some of the UN resolutions could on the "factual," informative level mean that he, perhaps, read only one or two. Janez could thus be an incomparably more suitable "informant" than Marko, but language simply doesn't allow argumentative strings (3') and (4').

(3') * Janez did not read all the UN resolutions (Argument) >

He may be able to advise you (Conclusion)

(4') * Marko read some of the UN resolutions (Argument) > He may not be able to advise you (Conclusion) 
In order to be able to remove asterisks from utterances (3') and (4') (i.e. make them discursively and argumentatively acceptable), we would have to bring in argumentatively oriented modifiers, for example but nevertheless in $\left(3^{\prime}\right)=($ But nevertheless, he might be able to advise you), or only in $\left(4^{\prime}\right)=$ (Marko read only some of the UN resolutions).

\subsection{To propose an argument, to demonstrate, to deduce}

We said that it was language (as a system) that didn't permit argumentative strings (3') and (4'). What precisely does this mean?

Above all it means that to propose an argument is not to demonstrate or infer something in a logical manner, and that argumentation in general (and TAL in particular) is not based on the rules of logical deduction. ${ }^{3}$ The mechanism to arrive at a conclusion in examples (3) and (4) is not the same as the one involved in (5).

(5) a. All Slovenians are nationalists

b. Janez is Slovenian

c. Janez is a nationalist

While example (5) represents a logically (deductively) supported conclusion, a syllogism, where the conclusion $c$ is a necessary consequence of the premises $a$ and $b$, the conclusions in examples (3) and (4) are in no way necessary consequences of the arguments that actually introduce them. Someone could use the utterance Janez did not read all the UN resolutions as an argument for a completely different conclusions, for example, Janez is a

\footnotetext{
${ }^{3}$ We are, of course, referring to the (so called) "classical," bivalent logic.
} 
very wise person, or Janez is an asshole, and these (conclusions) would, obviously, represent completely different argumentation frames from the one actually employed in argumentative string (3). However, these hypothetical conclusions would be no less grounded or justified. In contrast to (logical) demonstration or deduction, which is based on the laws of logic, argumentation in everyday life and conversation is based on (our) knowledge and judgment of the world, reality, and the concrete situation of the speaker and the addressee. And especially on the assessment of the position that an utterance has (or can have) in a concrete situation, and an assessment of (possible) conclusions an utterance-argument might lead to.

\subsection{Argumentative orientation}

An argumentative relation (i.e., a relation between an utterance-argument and an utterance-conclusion) is thus completely different from a logical (deductive) relation (between premises and conclusion). A claim that is clearly supported by the "fact" that some conclusions, discursively completely acceptable, logically make no sense at all.

Let us consider the following conversational fragment (which I borrowed from Moeschler (1985: 14)):

(6) A: Is dinner ready by now?

B: Yes, almost

In terms of (classical) logic, this dialogue makes no sense. Dinner can be either ready by now, or not ready yet. It can be almost ready, but this, logically taken, means that it is not ready yet. Therefore, Yes, almost, is in no way a logically acceptable answer to the question Is 
dinner ready by now? because it would represent a contradictory utterance, namely: Yes, dinner is not yet ready.

By contrast, this dialogue is discursively, pragmatically completely acceptable, and it owes this acceptability - paradoxically as it may seem - exactly to the (problematical) particle almost. The (utterance) Dinner is almost ready could be represented as an argument in favour of some implicit conclusion, such as, Hurry up! Such a conclusion is also supported by the (logically "purer") argument Dinner is ready (by now), the argument Dinner is ready (by now) being stronger (in view of the conclusion Hurry up!) than Dinner is almost ready but still with the same argumentative orientation. In other words, this means that on the argumentative scale of the "dinner's readiness" (if we constructed one)

/dinner's readiness/

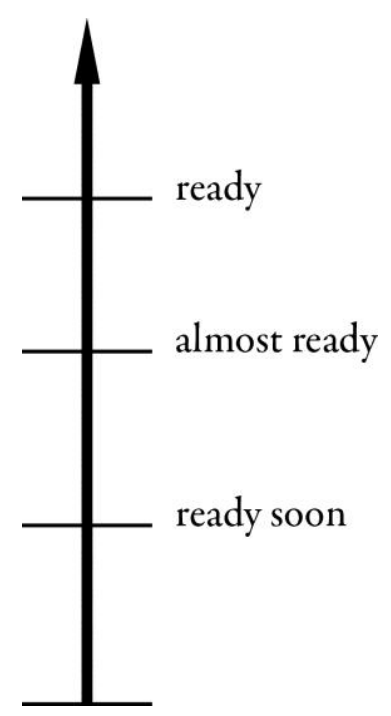

the argument Dinner is almost ready occurs as a weaker one, but it supports the same conclusion as does the strongest argument on the scale. An argumentative orientation must thus be, regardless of the context, inherent to the very particle almost, which means that every utterance-argument containing the particle almost represents a specific restriction affecting the continuation of the discourse (i.e. utterance-conclusion): the utterance-conclusion following it (i.e. following almost...) must argumentatively pursue and conform to the course 
mapped out, or delimited by the use of the particle almost, contained in the utteranceargument. In other words, from Dinner is almost ready it is impossible to conclude (in the direction of) There is still time, you don't have to hurry (unless we preface it by a concessive but, nevertheless...)

That explains, at least partially, why in the examples (3) and (4) we had to adopt the conclusions we had actually adopted. But let us step back for a moment, just to be able to see more clearly what really was the problem (for Ducrot).

\subsection{Posited and presupposed}

Examples (3) and (4), which we used to demonstrate the difference between informativeness and argumentativeness may seem rather illustrative, but they are certainly not the most appropriate ones because they use two (lexically and semantically) different morphemes: not ... all and some. The difference between informativeness and argumentativeness becomes much clearer when we have to deal with (lexically and semantically) synonymous morphemes, but with (very) different argumentative values. Ducrot's favourite example is the difference between the French adverbs peu and un peu (which could be translated into English as little and a little). Informatively/factually, there seems to be no difference between the two: both of them denote a "small quantity" of something. But argumentatively, if we use them in discourse, there is a rather big difference: little seems to be argumentatively oriented towards nothing, not at all, whereas a little seems to be argumentatively oriented towards a lot. How is that?

Let us take a look at the following two examples: 
(7) Janez worked little. > He may not pass the exam.

(8) Janez worked a little. > He may pass the exam.

Here we have two examples that on the "factual," informational level, deal with the same small quantities of something, but which argumentatively allow for very different conclusions. How can we explain that?

In his "weak informativistic" phase Ducrot tried to solve the problem by distinguishing between the posited and the presupposed in the utterance-argument. An utterance such as

(9) Prešeren ${ }^{4}$ was a great poet

could thus be analyzed into what is (explicitly) posited:

(p): Prešeren's poetry was extraordinary,

and into what is (implicitly) presupposed:

(pp): Prešeren was a poet.

In linguistics, it is often taken as a test for distinguishing what is posited from what is presupposed in a given utterance that the utterance's presupposition must not change if we

a) negate the utterance,

b) put it into an interrogative form, or

\footnotetext{
${ }^{4}$ Prešeren is a nationally glorified poet in Slovenia.
} 
c) embed it in a subordinate clause.

If we apply these three criteria to our example (9), we can see that, in this respect, our analysis was correct. Utterances

(9') Prešeren wasn't a great poet

(9") Was Prešeren a great poet?

(9"') Slovenians are convinced that Prešeren was a great poet,

in principle retain the same presupposition: Prešeren was a poet. We have to say 'in principle', because the range of the negation in $\left(9^{\prime}\right)$ could easily be the whole phrase great poet, and not only the adjective great, which means that the presupposition (Prešeren was a poet) would be negated too. That being the case, we could easily use (9') as an argument for a conclusion such as: He was an impostor, namely Prě̌eren wasn't a great poet (Argument), he was an impostor (Conclusion).

That is why Ducrot introduced a new, stronger and decisive criterion for distinguishing between what is posited and what is presupposed: an utterance-conclusion can only be drawn from what is (explicitly) posited, but not from what is (implicitly) presupposed. Only after applying this criterion can we be sure that our distinction between what is posited and what is presupposed in (9) was correct. From Prě̌eren was a great poet (Prešeren's poetry was extraordinary) we can easily conclude, We built him a monument, whereas the presupposition Prešeren was a poet doesn't allow for such a conclusion (at least not in Slovenia; which doesn't mean, of course, that there could not be a country where they build monuments for every poet they have). 
This criterion is crucial for explaining and understanding the different argumentative orientation of utterances (7) and (8). Utterance (7) could be analyzed into:

p: the quantity of Janez's work is small

pp: Janez worked

and the utterance (8) into:

p: Janez worked

pp: the quantity of Janez's work is small.

By doing that, we retain the informative component of both utterances (the quantity of Janez's work is small), and explain their different argumentative orientations (and conclusions that follow from them), but the problem of informativeness returns through the back door. How and why?

It should be understandable by now that little is argumentatively oriented in the same direction as nothing, not at all, and that a little is argumentatively oriented in the same direction as a lot. To the effect that both Janez worked a little and Janez worked a lot could be put forward as arguments toward a conclusion He may pass the exam. And, mutatis mutandis, we could say the same for Janez worked little and Janez didn't work at all, which could be put forward as arguments toward a conclusion He may not pass the exam. The difference is only in the force of the arguments, so that we can easily paraphrase and reinforce the argument Janez worked little by Janez worked little, even not at all, and the argument Janez worked a little by Janez worked a little, even a lot. 
But by doing that, we reestablish the discrepancy on the "factual", informative level: little is nevertheless something and not nothing, and a little is only a little and not a lot. It was that very problem that forced Ducrot into constructing his "weak version" of the theory of argumentation in language.

\subsection{Argumentative scales}

An important distinction that Ducrot introduces in this phase is the distinction between a sentence (phrase) and an utterance (énoncé) on the one hand, and meaning (signification) and sense (sens) on the other. Ducrot regards a sentence as a schematic, abstract construction, and thus as a matter of language (la langue) (in the Saussurean sense), and the utterance as its respective realization, i.e. a matter of speech (la parole). This means that every utterance of the same sentence is unique and always new. Therefore, there are no identical utterances even though sequences of uttered sounds and words may appear identical. Each utterance is the result of some concrete, individual act of uttering in a specific, constantly changing context that has to be reconstructed for each and every interpretation.

The conceptual pair meaning/sense is related to the pair sentence/utterance: meaning is the semantic value of a sentence, whereas sense is the semantic value of an utterance. However, Ducrot does not define (and this represents one of his innovations) the meaning (of a sentence) as part of its sense (as is commonly done in the formula: "sense $=$ meaning + context"), but rather as a set of instructions that should help us in disentangling the sense of utterances that are (or could be) possible realizations of the given sentence. The sentencemeaning thus guides our correct interpretation of an utterance, i.e. it guides our search for information, which must be, in order for our interpretation to be plausible, sought in the context. What does this mean? Let us go back to example (6): 
(6) A: Is dinner ready by now?

B: Yes, almost.

We have already said that the utterance Dinner is almost ready provides an argument in favour of some implicit conclusion that is oriented in the direction of lateness, e.g. Hurry up! The same conclusion is also supported by the argument Dinner is ready by now, but the latter is stronger (affirming that the dinner is ready, not just almost ready) than the former, yet both of them have identical argumentative orientations.

To be able to interpret an utterance of Dinner is almost ready, the construction of a sentence meaning would therefore have to consist of

a) informative (descriptive) instruction(s)

and

b) argumentative instruction(s).

Consequently, the utterances of the sentence Dinner is almost ready can be correctly interpreted only if we follow the instructions for its (sentence) meaning as stated below:

informative instruction:

some small quantity of time $\mu$ has to be defined or agreed upon; the utterance is true if dinner is not yet ready, and if the time difference between the utterance Dinner is almost ready and dinner's actual readiness equals $\mu$.

argumentative instruction: 
some conclusion $\mathrm{C}$ has to be found, which can also be supported by the utterance Dinner is ready by now, e.g. Hurry up!

Our examples with little (7) and a little (8) could thus be interpreted as follows:

(7) Janez worked little. > He may not succeed (in passing the exam).

informative instruction:

some quantity of work $\mu$ has to be defined or agreed upon, which can be regarded or can still be regarded as small. Utterance (7) is true if Janez has not exceeded this quantity (of work).

argumentative instruction:

some conclusion $\mathrm{C}$ has to be found, which would also be supported by the (stronger) utterance Janez did not work (at all), e.g. He may not succeed (in passing the exam).

Utterances (8) and (7) would thus share the informative, but not the argumentative instruction:

(8) Janez worked a little. > He may succeed (in passing the exam).

informative instruction:

some quantity of work $\mu$ has to be defined or agreed upon, which can be regarded or can still be regarded as small. Utterance (8) is true if Janez has not exceeded this quantity (of work). 
argumentative instruction:

some conclusion $\mathrm{C}$ has to be found, which could also be supported by the argument Janez worked a lot, e.g. He may succeed (in passing the exam).

With this conceptual innovation Ducrot still bases argumentation on the informative and the "factual," but at the same time he enables the regulation of the informative with what is completely argumentative in language. The expression "argumentation in the languagesystem" points precisely to this, i.e. to the "fact" that the argumentative orientation is inherent to the language as a system (language as an abstract structure, as defined by de Saussure), and that it is not (only) the result of the working of the context (on the contrary, it even creates/presupposes its own basic context). Despite this compromising solution two things immediately become obvious:

1. Descriptive, informative instructions are not really important for the course of argumentation itself, i.e. for the transition from an argument to a conclusion. In other words, the "factuality" or the truth of an utterance-argument (its congruence with the state of the so called "objective reality") is not decisive for the orientation of an argument, and it therefore becomes dominated by argumentative instructions.

2. The nature of an argument seems to be scalar or gradual. Several arguments support the same conclusion, but some of them (more) weakly than some others (almost ready, ready by now). That is why Ducrot (sometimes) calls almost and some other operators/connectives/indicators (e.g. already and yet) argumentative variables. They do belong to/act on the same argumentative scales, but they occupy/point to different positions on them. 
The dominance of argumentativeness over informativeness and the exposition of the gradual nature of arguments already provide all expedients for the transition into the latest, "strong version" of the theory of argumentation in language, in which the fundamental concepts are topoi and polyphony.

Topoi

The transition into the strong theory of argumentation in the language-system represents a radical break with former phases of the theory, not only terminologically, but above all conceptually. This break becomes evident from the two theoretical hypotheses characterizing this phase:

1. The transition from A(rgument) to C(onclusion) is based on topoi, which are general, common (within a given community), and scalar structures of the type

The more $\mathrm{P}$, the more $\mathrm{Q}$

or

The less P, the less Q

2. Argumentative values of utterances take complete dominance over their informative values, whereas exclusively informative utterances acquire a linguistically marginal status. 
In the "weak" phase of argumentation in the language-system, argumentation is still based on "facts," but it is controlled by argumentative instructions related to the meaning of the sentence. In the "strong" phase, however, the argumentative no longer simply controls the informative, but supersedes it: the informative becomes not only entirely subordinated to the argumentative, it is even derived from it. If argumentation (i.e. argumentative orientation) is (at least to some extent) inherent to language, then utterances merely describing reality or reporting about it are linguistically marginal: they use language only as the medium of transmission. Consequently, if argumentation is inherent to language, this medium can in no way be (argumentatively) neutral: argumentative variables (even accumulation or juxtaposition of variables if necessary) guide discourse in a quite specific direction, regardless of the representative or informative content conveyed in and by the discourse.

If we turn to Ducrot's conceptualization of topoi now, what does it mean that some topos is a) general, b) common and c) scalar?

It means that it is a) a general (and, at the same time, very abstract) scheme or matrix allowing a multitude of particular conclusions, which are not obligatory or binding in a way syllogism or logical deduction is. Topos (i.e. referring to a topos or applying it) can allow some conclusion, but it does not bind the speaker to that conclusion. Therefore, our addressee (and with this we have arrived at b)) can recognize the validity or appropriateness of the topos employed in our conclusion, without necessarily agreeing with it. He/she may find some other topos more appropriate to the situation, and may use it to support a different conclusion instead.

The assumption that topoi are common (within a specific community, ranging from small cultural or political sub-groups to the nation as a whole) only means that some community recognizes their validity, or validity and justifiability of the conclusions based on those topoi. It does not imply that every member of the community would necessarily use the 
same topoi in identical (or similar) situations. The application of some topos, or a conclusion stipulated by this topos, can always be refuted by applying some other topos to support a different conclusion.

If we try to apply such conceptualization of topoi to our examples (7) and (8)

(7) Janez worked little. > He may not succeed (in passing the exam)

(8) Janez worked a little. > He may succeed (in passing the exam)

we can see that the argumentative string (7) applies or refers to some topos ${ }^{5}$ such as

T1 The less we work, the smaller the likelihood of success,

and that (7) applies this topos weakly. Whereas the argumentative string in (8) applies (also weakly) some topos such as

T2 The more we work, the greater the likelihood of success.

Why do we say that argumentative strings (7) and (8) apply topoi T1 and T2 weakly? Or more precisely, how do we define "weakly" and its antipode "strongly"? That is where Ducrot's third concept, the concept of scalarity (c) comes in.

Ducrot initially defined "strongly" and "weakly" as more or less heuristic devices:

- to apply a topos strongly means that there are only few arguments that could be stronger than the one used;

\footnotetext{
${ }^{5}$ In other words, the argumentative string in question is constructed on a topos or, by the very transition from the argument to the conclusion (re)constructs a topos.
} 
- to apply a topos weakly means that there are only few arguments that could be weaker than the one used.

However, is it possible to define the values 'weak' and 'strong' in a conceptually more strict linguistic manner?

Let us assume, for the sake of the demonstration, that we operate with a two-part argument: let us label the first part of the argument A, and the second $\mathrm{B}$. We shall say that in this case the following two definitions apply:

1. Argument $\mathrm{A}$ is stronger than $\mathrm{B}$, if: "B, and even $\mathrm{A}$ " holds true.

2. Argument $\mathrm{A}$ is weaker than $\mathrm{B}$, if: "B, and at best/at worst $\mathrm{A}$ " holds true.

Now we should test these definitions on two examples:
A
$\mathrm{B}$

(10) This is a cold, or at worst a flu. > Don't worry!

A

B

(11) This is pneumonia, or at best a flu. > Take care!

Utterance (10) obviously applies some topos such as:

T3 The less we are ill, the less reason to worry

and utterance (11) 
T4 The more we are ill, the more reason to worry.

The A arguments are, in the light of our definition, stronger than the B arguments, which means that, if the given conclusion proceeds from B, it must also proceed (and with greater probability) from A. In other words, both utterances apply "their" topoi strongly. With regard to argumentative scales that could be constructed in accordance with our knowledge of the force of arguments in both cases 

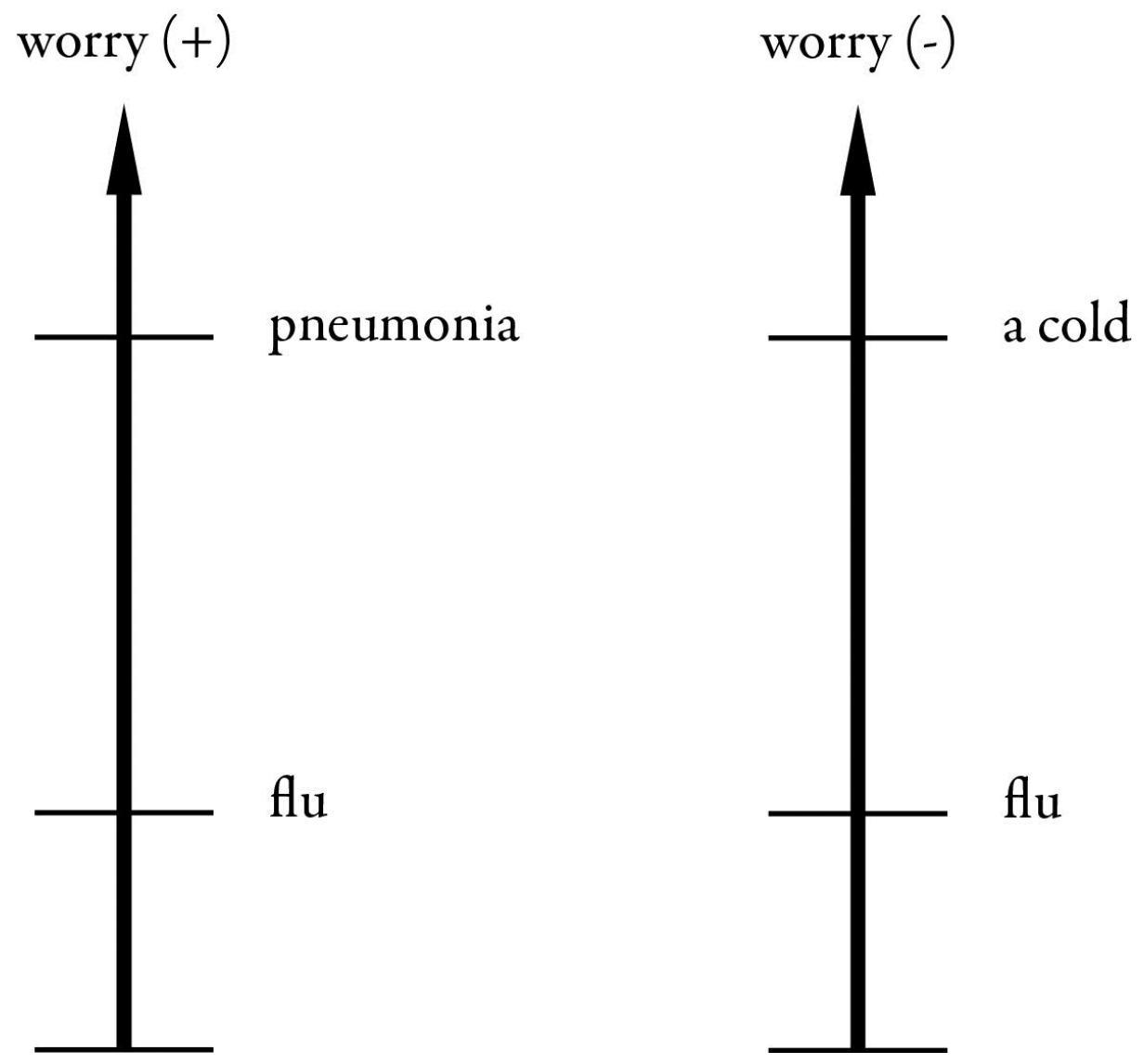

we can say that both utterances apply their topoi in the direction of argumentative scales; therefore, they strive toward the stronger application of topoi.

Let us now change the argumentative variables in (10) and (11). Instead of at best/at worst, we shall use even in $\left(10^{\prime}\right)$ and $\left(11^{\prime}\right)$, which results in:
A
B

$\left(10^{\prime}\right)$ This is a cold, even a flu. > Take care!

A B

(11') *This is pneumonia, even a flu. > Take care!

In accordance with our (i.e. Ducrot's) definitions of the weak and strong application of topoi, the introduction of the argumentative variable even changes (inverses) the force of the 
arguments (B is now represented as stronger than $\mathrm{A}$ ), and with this also the argumentative orientation itself! From the argument This is a cold, even a flu, we can no longer conclude Don't worry, but only Take care. Which entirely complies with the negative argumentative scale of worry (-) - as well as with our general knowledge of the world - where flu occupies a lower position than a cold, thus being closer to the cause of worry since the scale is negative.

That our claim about the decisive role (of the choice) of the argumentative variable is not exaggerated is demonstrated by the "transformation" of example (11). What happens to example (11) after we change the variable? To a "flu" (which occupies a lower position than pneumonia on the positive argumentative scale of worry $(+))$ the mere presence of even in the utterance, i.e. the argumentative orientation inherent to even, assigns the value of the stronger argument, thus leading to the conclusion Take care. Namely, the argumentative orientation inherent to even does not allow the argument following it to be weaker than the one preceding it; on the contrary, the argument introduced by even (i.e. the argument following the (argumentative) variable even), is represented as expected to enhance the force of the preceding argument. In Žagar (2010: 133-162), I described this mechanism triggered by (some) argumentative indicators (connectives, particles or operators) as creating certain argumentative expectation (and respective argumentative indicators as triggers of argumentative expectation).

Therefore, if we want to avoid the application of some topos T3' The less we are ill, the more reason to worry (which could be general, but hardly common), and thus recover the argumentative balance, we must introduce an additional argumentative variable in example (11'), for example:

(11") This is pneumonia, even only a flu. > Don't worry! 
or even (!)

(11'") This is pneumonia, maybe even only a flu. > Don't worry!

We could say that if only mitigates and modifies the argumentative orientation of even, then maybe (argumentatively) mitigates a potential logical disparity between coordinately related "propositional elements". Namely, if an illness is pneumonia, then it is not a flu, and vice versa; however, if we mitigate both assertions with maybe, we place them "between the brackets" and outside the logical system where they can be either true or false.

A few more words about conceptual bases of topoi. What really is a topos? How does it function? Topos functions as a warrant (in Toulmin's terms) authorizing the move from $\mathrm{A}$ (rgument) to $\mathrm{C}$ (onclusion) by indicating a link between two general properties, $\mathrm{P}$ and $\mathrm{Q}$, connected with A and C respectively. Let us take another one of Ducrot's favourite examples:

(12) It's warm (Argument). Let's go for a walk (Conclusion).

According to Ducrot, the topos that authorizes the move from A to C (in that particular case) could be reconstructed as

T5 The more it is warm, the more pleasant it is to go for a walk,

and relates two qualities, P ("the warmth"), connected to A, and Q ("the pleasantness of a walk"), connected to C.

These two qualities are gradual or scalar (i.e., could be represented as scales), which means that the more we go up one scale $(\mathrm{P})$, the more we go up the other $(\mathrm{Q})$ : the more it is 
warm, the more pleasant it is to go for a walk. But is that true? Isn't there a point where the warmth (an excessive warmth, for example) makes it unpleasant to go for a walk? Which means that from such a critical point the topos T5 couldn't be applied any more. Doesn't that make it non-valid? Not necessarily (topoi are general, not universal), it just means that from a certain point (yet) another topos (or even several topoi) may start to apply

T6 The more it is warm, the less pleasant it is to go for a walk.

or

T7 The less it is warm, the more pleasant it is to go for a walk.

Which, again, doesn't (necessarily) mean that T5 doesn't apply any more (at all), it just means that from a certain point it stops to be generally and commonly shared by a certain community, and another topos takes its place.

\subsection{Polyphony}

The other crucial concept for Ducrot's strong version of argumentation in language is polyphony, a concept he borrowed from Bakhtin, and generalised to the language-system as a whole.

As you already know, Bakhtin distinguishes between dialogism and polyphony. "Polyphony", he says, in his Marxism and the Philosophy of Language 6 (1973: 116), "is distinctly and fundamentally different from dialogue. In dialogue, the lines of the individual

\footnotetext{
${ }^{6}$ It is still disputed whether Marxism and Philosophy of Language was in fact writen by Bakhtin and only attributed to Voloshinov, or whether it was Voloshinov's original work.
} 
participants are grammatically disconnected: they are not integrated into one context." Dialogues, therefore, are produced by two or more speakers, while polyphony is a monological structure. He found examples of polyphonic structures (utterances) mostly in novels, and in his book on Dostoevsky (1984: 304) he gives this (now famous) definition of the polyphonic phenomenon:

\footnotetext{
"An author may utilize the speech of another in pursuit of his own aims and in such a way as to impose a new intention on the utterance, which nevertheless retains his own proper referential intention. Under these circumstances and in keeping with the author's purpose, such an utterance must be recognised as originating from another addresser. Thus, within a single utterance, there may occur two intentions, two voices".
}

So, for Bakhtin, a polyphonic construction belongs to a single speaker, but actually contains (mixed within it) "two utterances, two speech manners, two styles, two languages, two semantic and axiological belief systems" (1984: 304).

Bakhtin's study of polyphony was mostly confined to novels, while Ducrot generalised the phenomenon as far as language as a system. How does Ducrot define polyphony?

Ducrot thinks that what traditional linguistics refers to as a speaker is in fact a very complex (and confused) notion that covers a number of wholly different ideas. So he proposes that we distinguish between a producer, a speaker and an utterer of an utterance.

Who is the producer of an utterance? The producer of an utterance is the one whose activity results in the production of an utterance, i.e. the producer is the one who carries out 
(at least) the intellectual activity necessary for the production of the utterance. That may seem very obvious but there are cases where it becomes rather puzzling.

Think of yourself as a pupil, for example (once more, I borrowed this example from Ducrot): the school organizes a walk in the countryside and for you to be able to go on that trip you must have your parents' permission. Your teacher therefore gives you a form for your mother/father to sign. So you bring to your mother/father a form that says something like: "I allow my son/daughter to take part in the excursion", and at the bottom of the form there is a word "signature." What your mother/father has to do is to put her/his signature under the word "signature." Now, who is the producer of that form saying "I allow my son/daughter ..."? The one who signed it? The teacher who gave it to you? The secretary who typed it? The principal who dictated it to her? The Ministry of Education that sent it to all the principals? It is hard to say (isn't it?). It seems that producer is a very unclear notion. That is why we need the speaker and the utterer. The speaker would be the one who is responsible for the utterance, the one who is held responsible for the utterance itself or, at least, responsible for the act of uttering the utterance.

In the case of our pupil and his/her mother/father, there is no problem: the utterance contains a pronoun "I" that clearly points to the speaker (regardless of who actually produced it). But, what happens if the utterance contains no explicit devices such as pronouns? And even if they do, do we really have to hold the speaker responsible for everything that is said (and/or implied, conventionally or conversationally) in the utterance? Must everything that is said and/or heard in the utterance be taken as speaker's own point(s) of view?

That is where and why the utterers ${ }^{7}$ come in. According to Ducrot, there are several utterers or more correctly uttering positions within an utterance, which is another way of saying that several different viewpoints may be expressed through one utterance. Ducrot's

\footnotetext{
${ }^{7}$ The term Ducrot and his French folowers use is énonciateur(s). I think that utterer may be a better translation than enunciator; we enunciate something on rather formal, solemn occasions, while we utter this and that all the time in everyday conversation. And that is exactly how the term énonciateur is used in Ducrot's theory.
} 
position is even more radical; according to him every utterance could be analyzed in at least two uttering positions. For example, let us take the utterance

(13) This fence is not red.

The speaker of this utterance presents, roughly speaking, two utterers:

- the first one (U1) who affirms that the fence is red, and

- the second one (U2) opposing his/her affirmation.

The speaker, as the one who is responsible for the utterance, merges with U2.

But then, what makes it possible to proceed in this fashion? What gives us the right to distinguish between several uttering positions within a single utterance? In the case of (13), for example, the very fact that there are no fences that are non-red, non-yellow, and non-brown. Of course, a fence could be described as non-red, non-yellow, or non-brown, but such a description wouldn't give us any idea of the real colour of the fence. Therefore, if somebody is affirming that, $X$ is not... he must be objecting to somebody who is affirming the contrary, namely that, $X$ is ... (which, of course, does not mean that affirmations cannot be polyphonic: when one says, This fence is red,"one could well be affirming something that someone else has denied).

This may be too "ontological" an argument, so let me give you another example, this time from the philosophy of language. Some time ago (Žagar 1991a), I tried to analyse explicit performatives in terms of polyphonic analysis. Namely, I thought that performative utterances like:

(14) I promise. 
were extremely strange. You could of course object that such an isolated expression was taken out of the context, so let us examine the utterance (14) in one of its possible "contextualised" forms:

(14') I promise to come.

Unfortunately the utterance still seems very strange as well. I can hardly imagine someone saying (14') just like that, out of the blue. Again, you could object - and with good reason - that the utterance has been taken out of context, and that the locutor is probably responding to a question such as:

(15) Are you coming?

OK, now we have the minimal immediate context, but I still have a lot of trouble digesting dialogical linkages like:
(16) A: Are you coming?
B: I promise to come.

Perhaps in some Greek tragedy, but not in everyday conversation. There is something not quite right; either there is too much of something, or else something is missing. What is my point, then?

The most common answer to question (15) - if we remain in the affirmative register would undoubtedly be, either: 
(17) Yes

or

(14") I am coming,

but hardly (14'). If we answer by (14') there is, in its relation to the question, a dissymmetry, a surplus in our answer, a surplus which indicates that something may be missing in the conversation string. Let us compare the following two bits of conversation:
(16') A: Are you coming?
(16) A: Are you coming?
B: I am coming.
B: I promise to come.

What is the difference between the two? In the first version, B gives a straightforward answer to A's question, confirming his/her arrival. In the second version, B does not give a straightforward answer to A's question, but performs an act of promise, thus solemnly obliging him/herself to come. What does this (difference) mean?

If one observes more closely B's answer in the second version, one notices that B does not answer A's question at all. A did not ask him/her to promise to come, but only whether s/he was coming or not. It thus becomes obvious that in the second version, B is answering some other question, that B is reacting to some other (previous) intervention in the conversation, which is absent from the given fragment of conversation, but is interpretatively presupposed by the presence, by the very utterance (the very use) of the performative prefix.

The "basic structure" of the second version of the dialogue should have therefore been polylogical, and not only dialogical, something we could reconstruct as follows: 
(16") A: We are throwing a surprise party tomorrow evening. Are you coming?
B: Yes, I am.
C: That would be a surprise! You never come!
B: I promise to come.

However, one cannot, of course, present the viewpoints of different discursively reconstructed and implicit utterers in the way I have just done it: as fully-fledged utterances, as if somebody actually uttered them. They are just a reconstruction of the context. Consequently, it is not possible to assign to the viewpoints of different implicit utterers, which have been reconstructed within an utterance, a status that is equal to the status of the explicit utterance, which was taken as the starting point of the analysis, because they are nothing but products of the same analysis and therefore have only a theoretical status. The viewpoints of different utterers should only be presented in terms of attitudes, positions and orientations, so that one could end up by analysing example (16") as having a locutor (speaker) and (at least?) three utterers:

- U1 presents a fact $\mathrm{F}$ (the surprise party tomorrow evening), and words its presentation in the form of an invitation;

- U2 recognises the presentation of $U 1$ by accepting the invitation;

- U3 doubts the sincerity of U2 and therefore presents its consent (the consent of U2) as doubtful; - U2 opposes U3 and confirms its consent by a solemn turn of phrase.

One of Ducrot's most famous analyses is the pragmatic use of the French adverb toujours (Cadiot, Ducrot, Nguyen \& Vicher (1985)). Suppose we have an argumentative string like: 
(18) Allons au bistro. On y sera toujours au chaud.

Let's go to a bistro. At least we'll be warm there.'

According to Ducrot, we can distinguish at least five utterers within (18):

- U1 presents a fact $\mathrm{F}$, in our case a property $\mathrm{P}$ (warmth) of the object $\mathrm{O}$ (bistro) - "it is warm in the bistro" -, and presents that property as an advantage of the object $\mathrm{O}$;

- U2 uses that favourable property $\mathrm{P}$ as an argument for the conclusion $\mathrm{C}(\mathrm{C}=$ "Let's go to a bistro");

- U3 presents the property $\mathrm{P}$ as a merely weak advantage;

- U4 points out that weakness (of the property P) as a weakness that takes away every argumentative value from the fact $\mathrm{F}$ - which results in rejecting the viewpoint of $\mathrm{U} 2$;

- U5, on the other hand, thinks that property $\mathrm{P}$, though a weak advantage, is still a possible argument for the conclusion C ("It is a weak advantage, but it is nevertheless something"), thus rejecting the viewpoint of $\mathrm{U} 4$.

One particle, five utterers, and a crucial question: is there a limit to the number of utterers we can have within a single utterance or argumentative string? Ducrot's answer is: no, in principle there could be an unlimited number of utterers. My opinion is: we should be careful, and not multiply utterers beyond the point that the analysis (still) allows for. In the given example, I don't see any justification for distinguishing between U3 and U4. Such a distinction could only be made hypothetically, ideally; nevertheless, it is not supported by the given data. The use of the particle toujours (at least) only tells us that the argument is weak (thus supporting the viewpoint of U3), but there is no indication that the argument is considered so weak that it 
loses every argumentative value. In other words, if the polyphonic analysis is to be taken seriously (and as we saw, it can be a very useful tool for pragmatic analysis), we should stick to the given empirical data, not to the could-be "data".

With that in mind, let us have another look at example (12):

(12) It's warm (Argument). > But I'm tired (Conclusion),

a string used to answer, and reject, a suggestion for a walk.

According to Ducrot (1996/2009), there are at least four utterers in that argumentative string: U1 and U2 are related to, "It's warm" (argument), and U3 and U4 to, "I'm tired" (conclusion). U1 describes the weather by saying, "It's warm". "It's warm" is thus - don't forget that somebody suggested a walk - represented as an argument in favour of a walk, and U1 is supporting its argumentation by summoning a topos like:

T8 The warmer it is, the more pleasant it is to go for a walk.

Then another utterer, U2, comes in, and from U1's point of view concludes with the walk. U3, whose voice can be heard in the segment "I'm tired", by the very fact of introducing his/her (counter)argument by but, agrees with T8, namely that in warm weather it is pleasant to go for a walk. But s/he is building her/his (counter)argument on a different topos, a topos we could reconstruct like:

T9 Less one's physical state is good, less pleasant it is to go for a walk. 
So, in giving "I'm tired" as an argument for not going for a walk, the physical state is being represented as a property making a walk unpleasant. And finally, Ducrot concludes his analysis, there is a U4 who concludes from U3's point of view not to walk.

In Žagar (1997) I criticised such an analysis by saying: if U2 concludes something from U1's point of view, and U4 concludes something from U3's point of view, why do we need U2 and U4 at all? They could have well made their conclusions by themselves. But, as I have pointed out in relation to the example (16"), this is another attitude we have to avoid if we want to take the polyphonic analysis seriously (i.e. as a useful analytical tool): utterers aren't persons who can listen to each other and make their own conclusions - utterers are really just different uttering positions, different points of view, distinguishable within a single argumentative string. Utterers aren't real beings that talk to each other; they are just theoretical (and analytical) entities that help us reconstruct the course of argumentation. From that perspective, if we want to account for all the viewpoints within a single argumentative string, for all the (implicit) nuances, we do need $\mathrm{U} 2$ and $\mathrm{U} 4$ as well. 


\section{References}

Anscombre, J.C. \& O. Ducrot. L'Argumentation dans la langue. Brussels: Mardaga, 1983.

Bakhtin, M. M. Problems of Dostoevsky's Poetics. Edited and translated by Caryl Emerson. Minneapolis: University of Minnesota Press, 1984.

Ducrot, O. Dire et ne pas dire, Paris: Herman, 1972.

Ducrot, O. Le preuve et le dire, Paris: Mame, 1973.

Ducrot, O. “Structuralisme énonciation et sémantique.” Poétique 33 (1978).

Ducrot, O. Le dire et le dit, Paris: Minuit, 1984.

Ducrot, O. Les échelles argumentatives, Paris: Minuit, 1980.

Ducrot, O. "Note sur l'argumentation et l'acte d'argumenter." Cahiers de linguistique française 4 (1982).

Ducrot, O. “Opérateurs argumentatifs et visée argumentative." Cahiers de linguistique française 5 (1983).

Ducrot, O. Slovenian Lectures/Conférences slovènes. Translated by Sebastian McEvoy, edited by Igor Ž. Žagar, Ljubljana: ISH, Inštitut za humanistične študije, 1996.

Ducrot, O. Slovenian Lectures - Introduction into Argumentative Semantics. Translated by Sebastian McEvoy, edited by Igor Ž. Žagar, Ljubljana: ERI Digital Library, 2009. http://www.pei.si/Sifranti/StaticPage.aspx?id=70

Ducrot, O. et. al. Les mots du discourse, Paris: Minuit, 1980.

Eemeren, F.H. van, R. Grootendorst, \& T. Kruiger. The Study of Argumentation. New York: Irvington Publishers, Inc, 1984.

Moeschler, J. Argumentation et conversation. Element pour une analyse pragmatique du discours. Paris: Hatier-Crédif, 1985.

Toulmin, S. The Uses of Argument. Cambridge: Cambridge University Press, 1974.

Voloshinov, V. Marxism and the Philosophy of Language. Translated by Matejka, L. \& 
Titunik, I. R. Cambridge: Harvard University Press, 1973.

Žagar, I. Ž. “Argumentacija v jeziku proti argumentaciji z jezikom.” Anthropos 3/4 (1991a).

Žagar, I. Ž. "How to Do Things with Words - The Polyphonic Way." in Speech Acts: Fiction or Reality? 77-88. Ljubljana: Inštitut za družbene vede, 1991a.

Žagar, I. Ž. “O polifoniji, argumentativnem pričakovanju in njegovem sprevračanju.” Časopis za kritiko znanosti. (1992): 140/141.

Žagar, I. Ž. “Topoi: Argumentation's Black Box.” Understanding Argumentation - Work in Progress. Edited by F. H. van Eemeren, C. D. Williams \& I. Ž. Žagar, 145-164. Amsterdam: Sic Sat - Rozenberg, 2008.

Žagar, I. Ž. “Pa, a modifier of connectives: An argumentative analysis.” South Slavic Discourse Particles. Edited by M. N. Dedaić \& M. Mišković-Luković. Amsterdam/Philadelphia: John Benjamins, 2010. 


\title{
The linguistic-discursive creation of the speaker's ethos for the sake of persuasion: a key aspect of rhetoric and argumentation
}

\author{
Paul Danler, University of Innsbruck
}

\section{Summary}

The central topic of this brief study is the linguistic-discursive creation of ethos in rhetorical and argumentative texts. In order to understand why ethos plays a fundamental role in those text types it seems necessary to first discuss the very notions of rhetoric and argumentation. The main goal of rhetorical and/or argumentative texts is persuasion. For this reason it also has to be clarified how persuasion works in those text types. After that we will look at the topic of ethos from various points of view: ethos beside pathos and logos as one of the key elements of rhetoric; Aristotle's classification of the constituents of ethos into phronesis, eunoia, and arétè; ethos seen almost as a mask in the Jungian sense; the distinction between ethos as a discursive phenomenon and ethos as a prediscursive phenomenon; the role of topoi and doxa in the construction of ethos and finally the differentiation between rhetorical argumentation and linguistic argumentation, the latter of which being of particular interest for our applied analysis. In that final part we will eventually analyze a few exemplary morphosyntactic structures which in a way create the speaker's ethical portrait or, to put it differently, which discursively construct the speaker's ethos. The speeches we will draw upon were delivered by Mussolini between 1921 and 1941.

Key words: discursive strategy, persuasion, argumentation, rhetoric, ethos

\section{Introduction}

Persuasion $^{8}$ is the objective both of rhetoric and argumentation. The overall goal of persuasion is to make the listener or interlocutor change or give up his or her attitude in favour of the one represented by the sender (Breton 2008: 9; Danblon 2005: 13). The process of persuasion is multi-layered and occurs in a series of steps. The starting point and prerequisite for successful persuasion is the creation of a persuasive and/or convincing ethos on the part of the sender at the beginning of the rhetorical/argumentative commitment. In

\footnotetext{
${ }^{8}$ In this study we treat persuasion as a synonym of conviction without discussing any possible semantic differences between the two concepts.
} 
order to see the question of the creation of ethos in a more comprehensive context, we should like to first deal with the question concerning the possible differences between rhetoric and argumentation; second, with the phenomenon of persuasion; third, with the role of ethos in rhetorical and argumentative discourse; and fourth, with the multi-layered phenomenon of the linguistic-discursive creation of ethos in rhetoric and argumentation. After the theoretical introduction there will be an applied part to illustrate how the linguistic-discursive creation works in concrete political speeches. The four speeches which will serve as corpus for our analyses were given by Mussolini between 1921 and 1941. The first of them was delivered on April $3^{\text {rd }} 1921$ during the inaugural ceremony at the first encounter of the Fasci dell'Emilia e della Romagna (Mussolini 1921: 239, footnote). The second speech was given at the Teatro Sociale in Udine on September $20^{\text {th }} 1922$ on the occasion of the encounter of the Fasci Friulani di Combattimento (Mussolini 1922: 411, footnote). On September $18^{\text {th }} 1938$ Mussolini talked to the Triestines in the Piazza dell'Unità of their city Trieste (Mussolini 1938: 144, footnote). And with the last of the four speeches, which serve us as corpus here, Mussolini addressed the hierarchies of the Roman Fascists at the Teatro Adriano in Rome on February $23^{\text {rd }} 1941$ (Mussolini 1941: 49, footnote). The topics Mussolini dealt with in the quotations of these four speeches concern Fascist convictions, policies and ideological principles as we will see in part three.

Rhetoric and argumentation are occasionally used as synonyms, yet sometimes as quite distinct disciplines or approaches to discourse. We will have a quick glance at this ambiguity from a historical point of view. Concerning the issue of persuasion we will briefly retrace the etymological path of the term and then try to grasp the very nature of the phenomenon. The question of the nature of ethos on the one hand and the function of ethos in discourse on the other hand is our third topic. As is commonly known, the concepts of ethos, pathos and logos stem from one of Aristotle's magna opera Rhetoric (Aristoteles 2010) from 
the fourth century B.C. in which rhetoric is treated as $\tau \dot{\varepsilon} \chi v \eta$, téchne, which means art. This suggests that Aristotle already conceptualised the emergence of ethos in discourse as the result of an artful strategy. When talking about ethos nowadays it has to be verified whether it still and always stands for what Aristotle understood by it. If, however, we follow Aristotle's concept of ethos, which we will do, it will be interesting to find out how ethos comes about in discourse in general and in political speeches in particular and this is what we will analyse in the applied part of this brief study.

\subsection{Argumentation vs. rhetoric}

One of the more recent definitions of argumentation which has almost become a modern classic at least in the francophone world is the one by Anscombre/Ducrot $\left({ }^{3} 1997\right)$ according to which a speaker argues for or against something when he or she makes an utterance or various utterances which are meant to admit another one. ${ }^{9}$ The resulting chains or argumentative concatenations become an essential means for creating coherence (Ducrot, 1995: 85; Maingueneau 1991: 228) and coherence as well as cohesion as fundamental textual criteria are indispensable for successful argumentation. The overall pragmatic goal of argumentation, however, for which the textual criteria of coherence and cohesion are prerequisites, is making the addressee or listener adopt a conclusion which originally was not his or hers (Danblon 2002: 13). What is important is that the sender skilfully presents one, two or more premises which ideally make the addressee draw his or her own conclusions. In this case it is not the sender who directly suggests or tries to impose his or her own conclusions but he or she manages to make the addressee come to the conclusion which has been the sender's from the beginning. What is more, it is not only the specific premises that make for the respective conclusion. In one way or another it is the whole text which

\footnotetext{
9 “Un locuteur fait une argumentation lorsqu'il présente un énoncé E1 (ou un ensemble d'énoncés) comme destiné à en faire admettre un autre (ou un ensemble d'autres) E2. Notre thèse est qu'il y a dans la langue des contraintes régissant cette présentation." (Anscombre/Ducrot ${ }^{3}$ 1997: 8)
} 
contributes to the resulting conclusions (Vignaux 2004: 113) as it shapes concepts and attributes specific meanings to words, syntagmas and textual building blocks, the intrinsic semantic content of isolated words being minimal. However, usually the textual surface is not complete which means that either one or more of the premises or the conclusion are not explicated. Aristotle himself pointed out that common premises and shared knowledge should not be explicitly stated (Amossy $\left.{ }^{2} 2006: 164\right)$. What is left implicit, however, is far from being a textual blank without any function (Maingueneau 1991: 234). On the contrary, it is the addressee's task to activate his or her knowledge to make the seemingly fragmentary argumentation coherent and complete. Upon adding the missing links and thereby completing the argumentation structure, the addressee adopts a highly creative role (Eco 1983: $50 \mathrm{ff}$.). When doing that, he or she even becomes the co-author of the argumentation at stake (Maingueneau 2002: 40; Walton 2007: 186) which considerably contributes to the process of persuasion. As co-author the addressee is much more likely to fully identify with the indirectly suggested conclusion.

Argumentation is usually seen as opposed to demonstration (Boniolo/Vidali 2011: 7; Maingueneau 1991: 228). Demonstration, based on true premises, is part of formal logic whereas argumentation, based on probable and plausible premises, is the analogon in informal logic. What is relevant in discourse analysis, text linguistics and mainly in linguistic pragmatics is obviously argumentation rather than demonstration, where implicit premises, different kinds of implicatures, presuppositions and various kinds of inferential processes are at stake. The question which now arises is the one concerning the relationship between argumentation as informal logic and rhetoric. Ducrot understands by argumentation rhétorique (Ducrot 2004: 18) the verbal activity of making somebody believe something. Making somebody believe something seems to be the overall goal of rhetoric as well as of argumentation. Chaïm Perelman and Lucie Olbrechts-Tyteca, who have written history in 
argumentation theory with their Traité de l'argumentation, don't distinguish between rhetoric and argumentation as the subtitle of their work La Nouvelle Rhétorique (Perelman/OlbrechtsTyteca 1992) suggests. Interestingly enough though, this was also Aristotle's concept as in his work the terms rhetoric and argumentation, to which he still referred as rhetoric and dialectics, were interchangeable as well (Amossy ${ }^{2}$ 2006: 4; Meyer 2008: 12).

At any rate, even if certain differences between argumentation and rhetoric have occasionally been worked out, the concept of ethos has turned out to be equally important both for argumentation and rhetoric. It has for example been argued that in argumentation the language is at the centre of interest, whereas in rhetoric it is man himself. It has been claimed that argumentation tackles questions, whereas rhetoric tries to avoid them. Argumentation has been seen more closely related to reason, whereas rhetoric has even been treated as a discourse figure (Meyer 2008: 11 ff.; Breton/Gauthier 2000: 38). However, to conclude this short and panoramic overview we would like to recall Meyer's metaphorical and quite expressive definition of rhetoric according to which rhetoric is the negotiation of the distance between individuals concerning a question (Meyer 2008: 11). ${ }^{10}$ When taking this into account, it is perfectly coherent to consider argumentation as part of rhetoric as the overall goal of argumentation is also to reduce the distance between individuals concerning a question (Meyer 2008: 16). No matter whether rhetoric and argumentation are considered different, similar or the same domains, ethos is a key factor for both of them, and as a matter of fact it constitutes the starting point for argumentative and/or rhetorical strategies. However, before dealing with the very issue of ethos, its nature and its function, we will briefly touch upon the matter of persuasion as the main objective of argumentative and/or rhetorical strategies.

\subsection{The question of persuasion}

\footnotetext{
10 “La rhétorique est la négociation de la distance entre les individus à propos d'une question” (Meyer 2008: 11).
} 
Persuade derives from Latin PERSUADERE, PER indicating the accomplishment of something and SUADERE, SUASUS from Sanskrit SVADUS, to instigate someone to do something (cf. TLIO; Pianigiani). Persuasion as opposed to orders or proposals operates indirectly, as the addressee is not explicitly asked to do or to believe something (Maingueneau 1991: 228). It is the addressee himself or herself who draws the respective conclusions without mostly realizing that he or she has been prepared to do so by being familiarized with the premises leading him or her to draw that conclusion. However, it is not only the premises leading to a certain conclusion which constitute the persuasive part of a text. Every word as part of an utterance is argumentative as every utterance instigates the addressee to see, believe and act differently than before being addressed (Plantin 1996). The addressee integrates the new piece of information into his or her stock of information and then interrelates it with other pieces of pertinent information and thus eventually gains new insights. Hence, merely by being informed of no matter what, the addressee's cognitive state changes. Some new information is added, some old belief is cancelled, or some existing attitudes are modified and all of this brings about a change in the addressee's cognitive state. ${ }^{11}$ Perception is selective and the transmission of information is necessarily selective as well. For this simple reason every speech act is latently or potentially persuasive. It is only persuasive though, if the information is intentionally transmitted for the sake of bringing about a change in the addressee's attitude. Otherwise we'd rather speak of unconscious influence. In practice it is obviously difficult to clearly separate one from the other as this kind of unconscious influence can serve as an ideal mask for manipulation without the sending manipulator having to assume any responsibility for what he or she is saying and thereby suggesting. We have already described the objective of persuasion as such that the addressee should give up his or her own point of view in favour of the sender's. As to the nature of persuasion we have pointed out that not only

\footnotetext{
${ }^{11}$ In Relevance Theory these are the so-called positive cognitive effects (cf. Sperber/Wilson 1986)
} 
argumentative structures consisting of premises and conclusions are inherently persuasive but that any speech act potentially contributes to it. What is at the heart of persuasion according to Danblon (2006: 145) is the strategy of doing as if things were evident when they are not at all. Whenever something is presented as obvious, it turns out to be difficult to question, let alone refuse it. The creation of a credible and reliable ethos of the sender is indispensable to achieve persuasion based right on that premise within the framework of rhetoric and argumentation. In the following paragraph we would like to develop that idea a little further.

\subsection{The role of ethos in rhetoric and argumentation}

Aristotle distinguished between three modes of persuasion which are pathos, logos and ethos. Nowadays one tends to overlook that to his mind the three devices were equally important. Pathos refers to the emotional state of the audience which the speaker has to strive for in order to make the listeners receptive and sensitive to his or her concerns. Logos is the capacity of reasoning put into practice in argumentative discourse mainly in the form of enthymemes and examples. As far as ethos is concerned, it is often translated as the speaker's character (Danblon 2002: $69 \mathrm{ff} ; 2005: 34$ ff.). The speaker's character or personality has to be trustworthy and reliable otherwise the addressee won't follow his or her argumentation line. Groarke/Tindale ( $\left.{ }^{3} 2004: 359\right)$ point out the importance of ethos for practical reasons when saying that "ethotic considerations often play an important role in reasoning. They can arise in circumstances in which we do not have the time, the means or the ability to investigate a question in sufficient detail to decide the proper answer to it." In other words, the addressee follows the sender out of confidence. According to the principle of ethè in antique rhetoric the orator attributed a number of positive characteristics to himself in order to make his personality appear pleasant and trustworthy. As to the variety of desirable characteristics to be striven for, Aristotle himself made up a typology in which he distinguished between phronesis, 
practical wisdom, eunoia, benevolence (or goodwill, cf. Žmavc 2012: 183), and arétè, virtue (Maingueneau 1991: 183). ${ }^{12}$ However, according to Aristotle the discursive construction of ethos does not happen explicitly by the orator's speaking about himself or by the author's praising his own virtue but it is built up implicitly by the speaker's way of giving the speech (Maingueneau 1987: 31). The orator thereby elaborates a kind of mask which is socially acceptable and even desirable, a mask almost in the Jungian sense (Jung 1964: $311 \mathrm{ff.}$.). However, ethos has also had a different meaning ever since Greek antiquity. For the Greek philosopher Isocrates as well as later on for the Roman philosophers Quintilian and Cicero for example, ethos was not to be made up discursively, it was not supposed to be a linguistic mask, but it should reflect the orator's truly virtuous personality (Amossy 1999: 19). To do justice to the concepts of both, Aristotle and Isocrates, Amossy distinguishes between discursive ethos and prediscursive ethos, ethos discursif versus ethos prédiscursif or ethos préalable (Amossy ${ }^{2} 2006: 79$ ), the former referring to the constructed ethical picture arising from discourse, the latter referring to the speaker's true personality. Anyways, ethos is usually seen as a "multifaceted rhetorical concept" (Žmavc 2012: 181), especially when dealt with from a historical perspective. Žmavc (2012: 184-185) distinguishes between three ancient traditions of rhetorical ethos: In the first conception which stems from Plato and Isocrates ethos discloses the speaker's moral character, "which pre-exists discourse and should be reflected in the discourse." The second conception of rhetorical ethos derives from sophistic and textbook rhetoric. It is about practical examples and rules which are used and observed, respectively for the construction of speeches, often in connection with argumentative strategies which is typical of various sophists. The third conception of rhetorical ethos would be the merging of the "Greek rhetorical system" and the "Roman traditional oratory." However, maybe in order to simplify the rather complex conceptions of rhetorical ethos,

\footnotetext{
${ }^{12}$ Žmavc (2012: 183) points out, though that these notions are not Aristotle's but can be traced back even to Homer's Iliad.
} 
Žmavc (2012: 187) argues that generally speaking Greek rhetoric can be seen as a rhetoric of quarrel, whereas especially early Roman rhetoric used to be a rhetoric of consensus.

In any case, when we talk about the role of ethos in discourse nowadays, it still refers to the orator's personality which arises from his or her way of speaking (Maingueneau 2002: 79) and not from "extra-discursive" knowledge the audience has about the orator (Maingueneau 1999: 75). Orators have addressed audiences at all times and in all places. Consequently ethos cannot possibly be understood as one fixed set of traits which can be demonstrated and sold to any audience at any time in order to gain its confidence. The concept of ethos doesn't have anything to do with permanent and timeless values. On the contrary, it depends on ideology, religion, culture, current philosophical trends, the zeitgeist as well as the respective historical epoch. For this reason a very pragmatic and practical question has to be answered, namely which kind of ethos should be elaborated in the concrete speech. The orator's first main goal being to please the listeners in order to conquer them emotionally, which is indispensable for persuading them of his or her ideas in the course of argumentation, the central guideline for the elaboration of ethos can be seen in doxa, which again depends on all the variables listed above. For Aristotle the term doxa designated the opinion of all, of the majority or of competent and wise men (Amossy 2002a: 11). Seen in a somewhat simplified or even reduced way doxa can therefore be understood as common opinion (Maingueneau 1991: 233). The specific contents of the thus displayed common opinion are facts, truths, assumptions, and values (Maingueneau 1991: 232;

Perelman/Olbrechts-Tyteca ${ }^{5}$ 1992) which constitute the respective culture- and timedependent topoi. As opposed to Aristotle's and Perelman/Olbrecht-Tyteca's concept of topoi as empty schemes which allow the concatenation of utterances, topos is here to be understood as pragmatic topos which can be equated with commonplace (Amossy 2002a: 15 ff.; 2002b: $166 \mathrm{ff}$.). To cut a long story short, the pragmatic topoi as the backbone of doxa constitute the 
common basis of shared values for sender and addressee from which the sender can very well start his or her argumentation.

A final distinction between rhetorical argumentation and linguistic argumentation seems useful for our purpose. Ducrot generally understands by rhetorical argumentation the verbal activity which aims to make somebody believe something whereas linguistic argumentation refers to the different means of linguistically connecting propositions (Ducrot 2004: 18). The concrete linguistic issues which are of interest under the aspect of linguistic argumentation are for example the functions of the different syntactic structures such as question and negation, the function of adverbs of quantity, the role of interjections and, first and foremost, the function of the different syntactic connectors (Maingueneau 1991: $234 \mathrm{ff}$.). When going back to ethos now, we would like to recall that it comes about procedurally (Amossy ${ }^{2} 2006: 71$ ) as a result of linguistic-discursive construction and this is what we would like to have a closer look at next on the basis of various speeches delivered by Mussolini.

3. The linguistic-discursive creation of the speaker's ethos

In the following section, which is the applied part of the study, we will analyse six exemplary quotations from speeches given by Mussolini. Each of them will first be discussed under the aspect of the morphosyntactic criteria which in our opinion make for the construction of ethos. After that we will think about how that particular linguistic structure contributes to the improvement of ethos, provided ethos is understood as the result of a linguistic-discursive construction, which is obviously the case here.

In the first example we are shedding light on the function of morphosyntactic zerorealizations of arguments. It says 
(I) I popoli diventano grandi osando, rischiando, soffrendo, non mettendosi ai margini della strada in una attesa parassitaria e vile. (Mussolini 1941: 57)

Peoples become great through daring, risking, suffering, and not standing on the roadside in parasitic and vile expectancy

On the level of semantic valence it is obvious that the verbal functors osare, rischiare, soffrire, i.e. dare, risk and suffer take more than one argument as one always dares do something, risks something and suffers something or from something. However, when used generically, the materially realized verbs osare, rischiare, soffrire do not necessarily require another actant (Danler 2007). This means that the speaker doesn't have to explicitly state what peoples have to dare, risk and suffer to become great. If in that speech the speaker had explicitly said that he expected his people to dare kill others, to risk their lives for him and his policy and to suffer the deprivations of a war he himself was in favor of, he would have explicitly created a different image or ethos of himself. If he had done so, the speaker would probably have been reproached with selfishness, ruthlessness and irresponsibility. For this reason it was wise of him to use the verbs dare, risk and suffer generically without actantially specifying the second arguments.

In the second passage we see in a certain sense the opposite of the first example. In this case an argument wouldn't have to be morphosyntactically realized to fulfill the criterion of the well-formedness of the sentence and yet it is:

(II) Noi non facciamo della violenza una scuola, un sistema o, peggio ancora, una estetica. Noi siamo violenti tutte le volte che è necessario esserlo. Ma vi dico subito che 
bisogna conservare alla violenza necessaria del fascismo una linea, uno stile nettamente aristocratico o, se meglio vi piace, nettamente chirurgico. (Mussolini 1921: 241)

We (ourselves) don't make a school out of violence, a system or, even worse, some kind of aesthetics. We (ourselves) are violent any time it is necessary to be so. But let me tell you right now: it is indispensable to stick to a line, a clear, aristocratic style or, if you prefer, a clear, surgical line, for the violence necessary for fascism.

In Italian as in the other Romance languages which are pro-drop languages the first argument of the verb doesn't have to be realized if the referent can be gathered from the context which is the case in quotation number II. The unmarked and neutral realization would be non facciamo della violenza una scuola and siamo violenti tutte le volte che è necessario, we don't make ... we are violent, without realizing the first argument of fare/to make and essere/to be which in this case is the first person plural noi/we. By morphologically realizing it Mussolini skillfully starts his argumentation from a supposed preliminary agreement with the audience which he even points out by the marked realization of the first argument. It is as if he acted and spoke in the name of the audience. The preliminary agreement won't even be questioned as it is not the topic of the discussion and Mussolini will therefore get away with it. What is more, when saying we (ourselves) don't make a school out of violence, it is as if his spontaneous and natural reaction to violence were negative. The morphosyntactic negation entails a negative orientation. The resulting peace-loving image remains to a certain extent even though he afterwards says point-blank we (ourselves) are violent any time it is necessary to be so. Concerning the creation of ethos it is as if the speaker identified 
himself with the audience and as if he were speaking in their name. He portrays himself as a non-violent person in principle, full of sympathy and empathy.

In number III Mussolini uses a passive construction which allows him not to specify the agent:

(III) La disciplina deve essere accettata. Quando non è accettata, deve essere imposta. Noi respingiamo il dogma democratico che si debba procedere eternamente per sermoni, per prediche e predicozzi di natura più o meno liberale. (Mussolini 1922: 413)

Discipline has to be accepted. When it is not accepted, it has to be imposed. We reject the democratic dogma according to which one must eternally proceed by means of sermonizing, preaching and lectures of the more or less liberal kind.

The direct object of the corresponding active structure turns into the subject of the passive construction after the passive transformation whereas its subject turns into the agentive case which need not be specified syntactically any longer. By not having to explicitly state who would have to accept discipline and by whom it would otherwise be imposed, Mussolini appears much more harmless, responsible and maybe even paternal than if he said I will impose and enforce discipline and you'd better accept it. It is obviously only thanks to this morphosyntactic construction that the audience doesn't feel intimidated and threatened by the speaker. The speaker's ethos thus remains free of authoritarian or totalitarian claim despite the fact that certain democratic principles are even ridiculed.

In the excerpt number IV we see a passive construction with agent. Yet, as we have just pointed out, in the passive construction the realization of the agentive case is not required for 
the morphosyntactic well-formedness. From the functional sentence perspective this means that once it is realized, it has acquired special communicative weight, though. The reason for that is the fact that anything that goes beyond the realization of the minimal argumentative structure is syntactically superfluous but precisely because of that communicatively even more important.

(IV) Le privazioni, le sofferenze, i sacrifizî che dalla quasi unanimità degli italiani $e$ delle italiane vengono affrontati con coraggio e con dignità che può dirsi veramente esemplare, avranno il loro compenso [...]. (Mussolini 1941: 58)

The deprivation, the sufferings, the sacrifices, which are faced by almost all Italians with courage and dignity, which can be described as exemplary, will have their compensation $[\ldots]$.

The Italians who suffer the deprivations of war with courage and dignity are portrayed as heroes by Mussolini. This should prove his respect for them as well as his ethical integrity but it should also put pressure on the audience to follow him in his policy. Respect and moral integrity are the new facets of the speaker's ethos.

In quotation number $\mathrm{V}$ it is a diathetical change from causative to recessive or anti-causative that allows the speaker to appear less aggressive and dangerous than he probably is:

(V) Un milione e 850.000 elettori misero nell'urna la scheda con la falce ed il martello: 156 deputati alla Camera. Pareva imminente la catastrofe. [...] Io, tutto orgoglioso dei miei quattromila voti, e chi mi ha visto in quei giorni sa con quanta disinvoltura accettassi questo responso elettorale, dissi: la battaglia continua! (Mussolini 1921: 241) 
One million and 850,000 electors put the ballot paper with the sickle and the hammer into the ballot box: 156 delegates to the Chamber. The catastrophe seemed imminent. [...] I myself, all proud of my 4,000 votes, and whoever saw me in those days knows with how much composure I accepted that electoral verdict, and I said: the battle continues!

The verb continuare/continue can be used either as a causative verb as in Peter continues the argument or as a recessive or anti-causative verb as in The argument (between the two of them) continues. By resorting to the anti-causative version it is again possible to keep the agent secret. So The battle continues once more appears to be less aggressive and less dangerous than We continue to fight and thereby Mussolini is more likely to get the people's support than by showing his fanaticism and preference for fighting. Peacefulness and responsibility for the country should characterize the speaker's ethos.

Another particularity of the Italian language but also of other Romance languages is the SI-diathesis which implies a different way of looking at a given constellation of actants and circumstantials. When we say in English you know or one knows or even we know in order to depersonalize an action or a process, in Italian we would say si sa which is impersonal, si just being some kind of clitic tag. The other SI-diathesis is the passivizing one like in si fanno delle guerre/wars are waged, where le guerre/wars becomes the subject. Number VI illustrates the pragmatic consequence of the use the SI-diathesis:

(VI) [...] gli ebrei di cittadinanza italiana, i quali abbiano indiscutibili meriti militari o civili nei confronti dell'Italia e del regime, troveranno comprensione e giustizia; quanto agli altri, si seguirà nei loro confronti una politica di separazione. Alla fine il mondo 
dovrà forse stupirsi più della nostra generosità che del nostro rigore [...]; (Mussolini 1938: 146)

[...] the Jews of Italian citizenship, who have undeniable military or civil merits for Italy and the regime, will find comprehension and justice; as for the others, a policy of separation will be pursued. At the end, the world will perhaps be more surprised by our generosity than by our rigor $[\ldots]$;

Mussolini says that a policy of segregation will be pursued. Due to the morphosyntactic structure, it seems as if he didn't have anything to do with it. As if that wasn't hypocritical enough, he claims that the world will be surprised at his or their generosity. Again, Mussolini seems understanding, well-meaning and responsible and all that makes for the speaker's ethos which makes him appear a blameless, caring and sympathetic political leading figure.

\section{Concluding remark}

Due to skilfully used morphosyntactic constructions such as the zero-realization of arguments (I), the specification of syntactically unnecessary actants (II), the passive voice (III), the marked use of syntactically unnecessary circumstantials (IV), the recessive rather than the causative diathesis (V) as well as the use of the SI-diathesis (VI) allow the speaker to build up an extremely favourable ethos of himself. From these few quotations Mussolini emerges as disinterested and altruistic (I), non-violent, sympathetic and empathetic (II), politically farsighted (III), full of respect and integrity (IV), peaceful and responsible (V), understanding, well-meaning and caring (VI). According to the doxa of those times and under 
the circumstances of those days the portrait of the speaker which arose from his speeches, which is in other words the linguistic-discursively constructed ethos, was by all means positive. On the basis of this positive ethos as a first implicit premise the speaker has a promising starting point for his argumentation.

\section{References:}

Amossy, R. "La notion d'ethos de la rhétorique à l'analyse de discours." Images de soi dans le discours. La construction de l'ethos. Lausanne, 9-30. Paris: Delachaux et Niestlé, 1999.

Amossy, R. "Des topoï aux stéréotypes: le doxique entre logos et pathos.” Edited by E. Eggs, E. Topoï, discours, arguments, 11-25. Stuttgart: Steiner, 2002a.

Amossy, R. "Nouvelle rhétorique et linguistique du discours.” Edited by R. Koren, \& R. Amossy. Après Perelman: Quelles politiques pour les nouvelles rhétoriques? 153-171. Paris: L'Harmattan, 2002B.

Amossy, R. L'argumentation dans le discours. Paris: Armand Colin, 2006.

Anscombre, J.C. \& O. Ducrot. L'argumentation dans la langue. Liège: Mardaga, 1997. Aristoteles. Rhetorik. Stuttgart: Reclam, 2010.

Boniolo, G. \& P. Vidali. Strumenti per ragionare. Logica e teoria dell'argomentazione. Torino/Milano: Bruno Mondadori, 2011.

Breton, P. Convaincre sans manipuler. Paris: La Découverte, 2008.

Breton, P. \& G. Gauthier. Histoire des théories de l'argumentation. Paris: La Découverte, 2000.

Danblon, E. Rhétorique et rationalité. Bruxelles: Éditions de l'Université de Bruxelles, 2002.

Danblon, E. La fonction persuasive. Paris: Armand Colin, 2005. 
Danblon, E. “La construction de l'autorité en rhétorique.” Semen 21: Catégories pour l'analyse du discours politique, 141-153. Presses Universitaires de Franche-Comté, 2006.

Danler, P. Valenz und diskursive Strategien. Die politische Rede in der Romania zwischen 1938 und 1945. Tübingen: Gunter Narr, 2007.

Ducrot, O. “Topoï et formes topiques.” Edited by J. C. Anscombre. Théorie des topoï, 85-99. Paris: Kimé, 1995.

Ducrot, O. “Argumentation rhétorique et argumentation linguistique.” Edited by M. Doury, \& S. Moirand. L'Argumentation aujourd'hui, 17-34. Paris: Presses Sorbonne Nouvelle, 2004.

Eco, U. Lector in fabula: la cooperazione interpretativa nei testi narrativi. Milano: Bompiani, 1983.

Groarke, L. A. \& C. W. Tindale. Good Reasoning Matters. A Constructive Approach to Critical Thinking. Don Mills: Oxford University Press, 2004.

Jung, C. G. Zwei Schriften über analytische Psychologie. Zürich/Stuttgart: Rascher Verlag, 1964.

Maingueneau, D. Nouvelles tendances en analyse du discours. Paris: Hachette, 1987.

Maingueneau, D. L'analyse du discours. Paris: Hachette, 1991.

Maingueneau, D. “Ethos, scénographie, incorporation.” Edited by R. Amossy. Images de soi dans le discours. La construction de l'ethos, 75-100. Lausanne/Paris: Delachaux et Niestlé, 1999.

Maingueneau, D. Analyser les textes de communication. Paris: Nathan, 2002.

Meyer, M. Qu'est-ce que l'argumentation? Paris: Vrin, 2008. 
Mussolini, B. [1921]. “Discorso di Bologna.” Edited by E. Susmel \& D. Susmel. Dal trattato di Rapallo al primo discorso alla Camera. (13 novembre 1920 - 21 giugno 1921). Opera Omnia Di Benito Mussolini XVI, 139-246. Firenze: La Fenice, 1955.

Mussolini, B. [1922]. "L'azione e la dottrina fascista dinnanzi alle necessità storiche della nazione.” Edited by E. Susmel \& D. Susmel. Dalla conferenza di Cannes alla Marcia su Roma. (14 gennaio 1922 - 30 ottobre 1922). Opera Omnia Di Benito Mussolini XVIII, 411-421. Firenze: La Fenice, 1956.

Mussolini, B. [1938]. “Discorso di Trieste.” Edited by E. Susmel \& D. Susmel. Dal viaggio in Germania all'intervento dell'Italia nella seconda guerra mondiale. (1 ottobre 1937 10 giugno 1940). Opera Omnia Di Benito Mussolini XXIX, 144-147. Firenze: La Fenice, 1959.

Mussolini, B. [1941]. "Il discorso al Teatro Adriano di Roma.” Edited by E. Susmel \& D. Susmel Dall'intervento dell'Italia nella seconda guerra mondiale al discorso al Direttorio Nazionale del P.N.F. del 3 gennaio 1942. (11 giugno 1940 - 3 gennaio 1942). Opera Omnia Di Benito Mussolini XXX, 49-59. Firenze: La Fenice, 1960.

Pianigiani. "Dizionario etimologico online.” Accessed April 6", 2012 http://www.etimo.it/ Perelman, C. \& L. Olbrechts-Tyteca. Traité de l'argumentation. La nouvelle rhétorique. Bruxelles: Éditions de l’Université de Bruxelles, 1992.

Plantin, C. L'argumentation. Paris: Seuil, 1996.

Sperber, D. \& D.Wilson. "Relevance.” Communication and Cognition. Oxford: Blackwell, 1986.

TLIO. "Tesoro della lingua Italiana delle Origini.” April $6^{\text {th }}, 2012$. http://tlio.ovi.cnr.it/TLIO/ Walton, D. Dialectic, Persuasion, and Rhetoric. Cambridge: Cambridge University Press, 2007. 
Žmavc, J. "The Ethos of Classical rhetoric: From Epieikeia to Auctoritas.” Edited by F. H. van Eemeren \& B. Garssen. Topical Themes in Argumentation Theory, 181-191. Heidelberg/London/New York: Springer, 2012. 


\title{
The Sokal affair and beyond: on the strategic use of parody in the "science wars"13
}

\author{
Ana Dimiškovska, Ss. Cyril and Methodius University of Skopje
}

\section{Summary}

This paper analyses the argumentative aspects of the Sokal affair, a publishing hoax performed by Alan Sokal in 1996 when he successfully submitted a parodic, nonsensical paper masquerading as a highly scientific article to the academic journal Social Text. The analysis presented here of Sokal's hoax is carried out within the framework of a more comprehensive research project related to subversion in argumentative discourse and different strategies for tackling such subversion. The main point of this paper is to propose that the argumentative use of parody of Sokal's type can be seen as an instance of a strategy of "fighting fire with fire", the goal of which is to ridicule the intellectually abusive participants in rational communication and make them feel for themselves the negative and destructive effects of the subversion of intellectual standards. However, this paper will also show that the conditions for the successful application of this strategy are highly specific and that, under particular circumstances, such a strategy can easily turn against its own users.

Key words: Sokal affair, 'science wars', parody, subversion in argumentative discourse, argumentative strategies

Introduction: the origin of the Sokal affair

In 1996, Alan Sokal, a professor of physics at New York University, published an article in the special spring/summer issue of the journal Social Text (no. 46/47). This highly reputed academic journal of "postmodern cultural studies" devoted the special issue in question to the phenomenon of the "science wars". The expression "science wars" referred to intellectual exchanges taking place in American academic circles in the 1990s, focusing on

\footnotetext{
${ }^{13}$ The author would like to thank Žarko Trajanoski for first turning her attention to the Sokal affair, as well as the participants of the "Days of Ivo Škarić" conference held in Postira in Croatia (19-22 April, 2012) for their intellectually stimulating discussions and questions, and the editors of this volume and the reviewers of the first version of this article for their valuable comments and suggestions.
} 
questions about the nature of science, scientific methodology and scientific knowledge. The main "war camps" in this intellectual confrontation were represented on one side by adherents of scientific realism and on the other by their postmodernist critics.

In one of the opening paragraphs of Sokal's article, entitled "Transgressing the Boundaries: Towards a Transformative Hermeneutics of Quantum Gravity”, Sokal stated the following:

It has thus become increasingly apparent that physical "reality", no less than social "reality", is at bottom a social and linguistic construct; that scientific "knowledge", far from being objective, reflects and encodes the dominant ideologies and power relations of the culture that produced it; that the truth claims of science are inherently theory-laden and self-referential; and consequently, that the discourse of the scientific community, for all its undeniable value, cannot assert a privileged epistemological status with respect to counter-hegemonic narratives emanating from dissident or marginalized communities. (Sokal, 1996; reprinted in the annotated version in Sokal, 2010: 9)

By arguing in favour of the thesis that social and physical "reality", together with purported objective knowledge of that reality, is in fact a social and linguistic construct dependent on the power relations prevailing in the framework of the culture which produces that construct, Sokal apparently allied himself with postmodernist critics of the concept of scientific objectivity.

In an article for Lingua Franca of May-June 1996, however, Sokal revealed that the paper published in Social Text, 'Transgressing the Boundaries...', was actually a hoax-a parody whose purpose was "to test the prevailing intellectual standards" in "certain precincts 
of the American academic humanities" (Sokal, 1996a). Concerned by an apparent decline in standards of intellectual rigour in these areas of education and research, Sokal offered the following explanation of his motive in perpetrating the hoax:

(...) I decided to try a modest (though admittedly uncontrolled) experiment: Would a leading North American journal of cultural studies (...) publish an article liberally salted with nonsense if (a) it sounded good and (b) it flattered the editors' ideological preconceptions? (ibid.)

Sokal's hoax and its subsequent revelation caused a huge succès de scandale. The Sokal affair received extensive media coverage not only in the United States but also in Europe and Latin America, provoking lively debates in both academic and non-academic circles. Amongst many different issues raised in these debates, the following were particularly controversial: the (ir)relevance of postmodern critiques of science; the relation of the humanities and social sciences to the 'hard' sciences; academic ethics and the consequences of undermining the professional trust of the community of one's scientific peers; and the acceptable standards of intellectual rigour in scientific and academic contexts. Apparently these questions have still not lost their relevance even today. ${ }^{14}$

The complexity of the Sokal affair allows examination from many different perspectives and to study it with different theoretical goals in mind. In this paper an attempt is made to analyze several argumentative aspects of the debate pertaining to the Sokal affair. This will be done in the framework of a more comprehensive theoretical outlook related to the phenomenon of subversion in argumentative discourse and different strategies for dealing with such subversion. After an elaboration of the general theoretical platform, the emphasis

14 For follow-ups of the hoax, see Sokal and Bricmont, 1998; Sokal, 2010; and see: http://www.physics.nyu.edu/faculty/sokal/index.html. 
will be placed on the use of parody as a strategic device for countering a specific form of argumentative subversion, analysed through Sokal's example.

1. The argumentative aspects of the debate: subversion in argumentative discourse and antisubversive strategies ${ }^{15}$

The term "subversion in argumentative discourse" is proposed here as an umbrella term encompassing various forms of deviation from and violations of norms, standards and canons of rational communication and argumentation. The term thus comprises a wide and diversified range of phenomena, from employing intentional sophistic and eristic manoeuvres to merely neglecting to offer evidence and rational arguments in appropriate contexts.

In many cases the subversive quality of an argumentative act can be obfuscated by more or less developed argumentative manoeuvres intended to create an impression of logical and argumentative correctness. Although the terms "abuse" or "manipulation" could also be used to describe such phenomena, denoting them with the term "subversion" places the emphasis on the destructive effects they have on the very idea and practice of rational discussion and communication.

The possibility that one or more participants in rational communication may act in a subversive manner raises the question of what the other participants can do to prevent the negative effects of this kind of argumentative subversion. One possible answer would be to use what may be described as "anti-subversive strategies"-i.e. the employment of various devices to fight against the perceived disrespect of the canons of rationality and misuse of argumentative techniques.

\footnotetext{
${ }^{15}$ Sections 1 and 2 of the present paper are based on the author's presentation at the conference "Strategies in Argumentation" (Faculty of Philosophy of the University of Groningen, 14-15 February 2008), which was subsequently published as an article in Macedonian (see Dimiškovska, 2009). In that article, the Sokal affair was also mentioned as an example, but was not analysed at length.
} 
These devices are treated as "strategies" for two main reasons. First, the situations in which they are practiced possess an explicit or implicit agonistic flavour, because rational discussions are often perceived as different kinds of battles which can be won or lost depending on the verbal and argumentative skilfulness of the parties. This sense of "strategy" is clearly related to the confrontational aspect of argumentative activity. Second, the blocking of argumentative subversion imposes the need to choose an optimal, context-bound plan of action in order to be effective. This need originates from the character of argumentation as a goal-directed and rule-governed activity in which the desired end of justifying and refuting opinions must be reached by respecting the rules of use of reason and speech. Consequently, anti-subversive strategies must be adapted to the particular context, the specific profile of the opponent and the concrete type of breach of rules and principles of rational communication in the given situation.

Because of this need to adapt strategies to specific conditions, any attempt to study strategies for tackling argumentative subversion should include an attempt to capture the inherent diversity of their types and manner of application. This paper proposes a tentative typology of anti-subversive strategies intended to serve as an initial approximation to systematization, both in a descriptive and normative sense, of the vast field of their practical deployment. $^{16}$

\section{A typology of anti-subversive strategies}

The proposed typology comprises the following four kinds: the "appeal to norm" strategy; the "appeal to institutional authority" strategy; the strategy of "ignoring the sophist"; and the "fighting fire with fire" strategy. An attempt is made in this section to formulate

\footnotetext{
${ }^{16}$ Due to space limitations, a more detailed development of the concept of "subversion in argumentative discourse" and of the proposed typology of anti-subversive strategies cannot be presented in the framework of this article.
} 
criteria for identifying each of these anti-subversive strategies, the conditions of their successful use and the potential risks involved in their application.

\subsection{Appeal to norm}

The "appeal to norm" strategy consists in showing that the other party in the argumentative interaction is employing an argument that violates one or more norms of logical and argumentative discourse and is consequently fallacious. The goal of employing this strategy is to restore the argumentative correctness of the dialogue by forcing the other party to retract or modify the contested argument and all the propositions or arguments that depend on that argument.

Successful application of this "appeal to norm" strategy is dependent, however, on there being a consensus amongst the participants in the rational interaction as to the regulative status of the norm being invoked. In this sense, the formal logical validity of an argument is one of the strongest and most unquestionable criteria for its rational acceptance. For example, if the contested argument is shown to be logically invalid, withdrawing from it should follow immediately since the formal invalidity of an argument eliminates the necessity of accepting the conclusion even in cases when its premises are accepted.

It may be argued, however, that the norm of formal deductive validity is not the one and only norm to be taken into consideration when assessing the rational acceptability of argumentation. A number of supplementary criteria of argumentative correctness have been formulated in many contemporary approaches that address the dialogical aspects of rational communication and argumentation (Alexy, 1989; Barth and Krabbe, 1982; Grice, 1975/1989; Eemeren and Grootendorst, 1984; Eemeren and Grootendorst, 1995; Eemeren and Houtlosser, 2009; Rescher, 1977; Walton, 1992; Walton and Krabbe, 1995, etc.; cf. Eemeren and Grootendorst's rules for a critical discussion, Alexy's rules for general practical discourse, 
Grice's cooperative principle and conversational maxims, etc.). Despite many differences between these approaches, they all share a fundamental common feature, i.e., an attempt to elaborate wider complexes of norms and rules — besides strictly logical ones - that must be observed to bring the verbal interaction as close as possible to the ideal of rational and critical dialogue.

The models developed in the aforementioned approaches reveal their potential vulnerability, however, when they are adopted in a strategic manner to detect a possible violation of an argumentative norm by other participant(s) in the discussion. This vulnerability consists mainly in the fact that the normative force of these models is seriously affected by the still open problem of their justification. If the objection is raised that an opponent in a discussion is violating Alexy's rules of general practical discourse, for example, or Eemeren and Grootendorst's rules for critical discussion, the opponent could legitimately question the normative status of these rules. This is because such rules obviously do not have the same logical and argumentative power as, say, the norm of the formal validity of conditional arguments. As a matter of fact, because of the lack of a single comprehensive and canonical theory of argumentative discourse comparable to the theory of formal deductive logic, the justification for those rules usually takes the pragmatic form of a consensus among the participants of the discussion. ${ }^{17}$

There is therefore a need to elaborate different kinds of norms and criteria, besides the criterion of formal logical validity, with which to determine the rational acceptability of argumentation - especially in dialogically structured rational interactions. However, the justificatory force of these argumentative norms will still depend upon the particular system in which they are formulated and on the shared acceptance of their normative authority.

\footnotetext{
${ }^{17}$ For a discussion on the problems related to the concept of the conventional, intersubjective validity of pragmadialectical discussion rules, see Zenker, 2011.
} 


\subsection{Appeal to institutional authority}

While the "appeal to norm" strategy concerned violations of the rules for constructing arguments, the "appeal to institutional authority" strategy is applied in cases of violation or abuse of established procedural rules of discussion (although the possibility is not excluded that such cases may also include violations of the rules for the construction of arguments). For example, a kind of argumentative practice that misuses the established procedural rules of discussion is the practice of filibustering which occurs in the framework of parliamentary procedures. This consists in using the unlimited right of speech to delay or prevent the making of a decision on a legislative or other type of proposal.

The "appeal to institutional authority" strategy consists in invoking the institutionally given role and authority to block the argumentative subversion. It is obvious that this is applicable within institutionally structured and defined argumentative contexts such as the legal context of adjudication and the context of parliamentary debates. The goal of employing this strategy is to restore the procedural correctness of the argumentative exchange. Returning to the example of filibustering, there is also an institutional form of response to this kind of subversion: the "cloture" procedure (used in the US senate, for example) which imposes restrictions on the filibuster's unlimited right to speech and which is also initiated and applied in accordance with strict procedural rules.

In legal contexts, especially in litigation, the institutional authority to which one party can appeal in order to protect himself or herself from the subversive intentions of the other party is represented by the judge. Given the highly adversarial nature of paradigmatic legal litigation, in which each party is driven by his/her own interest, it is obvious that there is a need for some form of external guarantee — or even coercion — to ensure that the rules of rational argumentation are respected. Indeed, the procedural aspect of law includes numerous 
rules that regulate the argumentative and dialogical side of legal proceedings, including the invocation of the institutional authority of a judge in cases of perceived argumentative subversion or abuse. ${ }^{18}$

The successful application of this strategy clearly presupposes the existence of fair procedure and the functionality of the institution whose authority is being invoked. If the procedure in whose framework the argumentative exchange takes place is essentially unfair or biased, and/or if the institutional authority that should guarantee procedural correctness is dysfunctional or partial, then the appeal to institutional authority as an anti-subversive strategy will be ineffective if not directly counterproductive.

\subsection{Ignoring the sophist}

Unlike the previous two strategies, both of which are intended to restore argumentative and procedural correctness in cases when rational interaction deviates from its optimal course, the strategy of "ignoring the sophist" consists in strictly refraining from engagement in argumentative discussion with the other party. Its application is triggered in contexts in which it is estimated that the very possibility of rational discussion is undermined by the other party, whose profile and intellectual habits render futile any effort to comply with standards of rationality in argumentation. The goal of this strategy is obviously to disqualify the other party as a valid participant in rational discussion.

One particularly illuminative example of the application of this strategy can be found in Derrida's description of the way in which an audience of analytical philosophers in Oxford responded to the lecture he delivered on différance in 1967: "On that occasion the silence which followed was obviously eloquent. Eloquently saying: 'There is no arguing here and

\footnotetext{
${ }^{18}$ For example, the judge can prevent a party from asking the witness a suggestive question or allow the witness not to an answer a self-incriminating question, etc.
} 
there is no prospect of arguing with this man, or with this discourse.'." (cited from Badarevski, 2004: 264)

The application of this kind of strategy was recommended in Aristotle's writings as the ultimate resort in situations where rational communication has become impossible due to the intellectual habitus of the collocutor. In the eighth book of Topics, Aristotle thus suggests the following:

You ought not to discuss with everybody (...) for against some people argument is sure to deteriorate; for with a man who tries every means to seem to avoid defeat you are justified in using every means to obtain your conclusion, but this is not a seemly proceeding. (Topica, 164 b 9-10)

However, this strategy also suffers certain weak points and potential risks, mainly related to the possibility of its abuse. For example, a participant in rational interaction applying this strategy might significantly underestimate the capacity of the other party for reasoned discussion and argumentation. Moreover, one might (mis)use this strategy to compensate for one's inability to match the adversary in intellectual terms by calling him or her a "sophist" and meta-subversively evading rational discussion. This is why the "ignoring the sophist" strategy should be applied with caution and only in specific, adequately assessed circumstances.

\subsection{Fighting fire with fire}

The fourth strategy of "fighting fire with fire" is perhaps more complex than those previously elaborated as it represents an indirect way of attacking the argumentative subversion, i.e., by imitating it with critical and polemic intention. The use of parody, satire or 
irony in argumentative contexts could be treated as instances of adopting this particular strategy. ${ }^{19}$

The name suggested for this strategy derives from the French expression "contrefeux", denoting a fire deliberately set in front of another fire so as to create a vacuum and prevent its spreading. In the same sense as this metaphor, the goal of "fighting fire with fire" is to overcome adversaries in argumentative encounters by using their own means. More specifically, the main point of its application is to ridicule the other, intellectually abusive party and to make them feel for themselves the negative and destructive effects of the subversion of intellectual standards.

The successful application of this strategy presupposes that the targeted audience possesses sufficient knowledge of the phenomena which constitute the object of parody or satire and that the audience shares the same negative value attitude towards this object. These conditions are necessary to ensure that the parodic intention of the author is understood and that the argumentative impact is fully realised. Otherwise this strategy could either miss its target or have a self-defeating effect—increasing rather than decreasing the intellectual appeal and popularity of the parodied works.

The application of the "fighting fire with fire" strategy raises serious issues concerning communicational ethics. This is due to the lack of genuine commitment on the part of the person using this strategy to the opinions which they advance in the discursive interaction, potentially involving an element of deceptiveness in the communication process. In order to avoid the danger of producing "meta-level" subversion, this strategy should also be applied with great caution.

\section{The strategic aspects of Sokal's use of parody}

\footnotetext{
${ }^{19}$ The following analysis concerns only forms of critically intended parody, "parody-attack", which often turns into satire. See below, section 3 .
} 
The central idea of this paper, as mentioned in the introduction, is the proposal that Sokal's parody may be treated as a representative example of the application of a "fighting fire with fire" strategy. This idea will be elaborated using the following elements - triggers, goals, conditions of successful application and weak points of the strategy — as key parameters for the analysis, contextualised in the particular circumstances of the Sokal affair. At the same time, occasional comparisons with other strategies will make it possible to better perceive the specificities of its nature and application.

\subsection{Triggers for the activation of the strategy}

In the earlier section on theoretical analysis (2.4), it was suggested that the main trigger for the application of a "fighting fire with fire" strategy is the identification of some form of argumentative subversion followed by the impression that its direct, immediate blocking is either impossible or implausible.

In Sokal's case, as he says himself, it was his reading of Higher Superstition (1994) by Paul Gross and Norman Levitt that first led him to pursue the identification of subversive tendencies in the discourse in vogue in the field of humanities in the 1990s. According to Sokal, the focus of this influential book was "the analysis of a curious historical volte-face" concerning one of the fundamental tenets of the Enlightenment legacy-the belief that "rational thought and the fearless analysis of objective reality (both natural and social) are incisive tools for combating the mystifications promoted by the powerful - not to mention being desirable human ends in their own right” (Sokal, 2010: 116).

However, Sokal continues as follows: 
[O]ver the past two decades, a large number of "progressive" or "leftist" academic humanists and social scientists (...) have turned away from this Enlightenment legacy and - bolstered by French imports such as deconstruction as well as by home-grown doctrines like feminist standpoint epistemology - have embraced one or another version of epistemic relativism. Moreover, a small but growing subset of these scholars have turned their critiques on the natural sciences, questioning not only the political and economic organisation of scientific research but also the alleged "cultural prejudices inscribed in the very epistemology of scientific inquiry" (...). Gross and Levitt contend that these latter scholars, combining an inadequate philosophy of science with an utter ignorance of the science they purport to criticize, have made fools of themselves and subverted the standard of scholarship. (ibid.)

In Sokal's view, the subversive quality of the criticised aspects of the work of "some of the most prominent French and American intellectuals" (Sokal, 2010:153), whom he describes as "pontificating on science and its philosophy and making a complete bungle of both" (Sokal, 2010: xiii) included the following features: the advancing of "meaningless or absurd statements", "name-dropping", the display of "false erudition", "sloppy thinking and poor philosophy" (Sokal, 2010: 153).

Categorising the reasons for his resorting to parody as "pragmatic", Sokal gives the following explanation of his choice of strategy for attacking the targeted forms of discourse as well as their protagonists:

The targets of my critique have by now become a self-perpetuating academic subculture that typically ignores (or disdains) reasoned criticism from the outside. In such a situation, a more direct demonstration of the subculture's intellectual standards 
was required. But how can one show that the emperor has no clothes? Satire is by far the best weapon (...) (Sokal 1996a)

In terms of the proposed classification of anti-subversive strategies, the "reasoned criticism from the outside" would probably represent a kind of application of the "appeal to norm" strategy with the intention of demonstrating that the kind of discourse in question fails to comply with the rules and norms of rational argumentation. However, this approach would not work in this situation; such a step would clearly presuppose the existence of a normative consensus between the intellectual "war camps" involved concerning the standards that guarantee the argumentative legitimacy of their discursive practices. And yet the very lack of such a consensus is obviously the factor which initially created the gap between the two academic subcultures, the "scientific" and the "postmodernist". The "appeal to norm" strategy also seems more plausible on the micro-argumentative level, in which there is a violation of a single argumentative rule (or several of them) that can be clearly identified and isolated from the totality of the discourse. However, the form of subversion identified by Sokal in this case concerns rather the macro-argumentative level, for it stems from objections to the discourse as a whole, i.e. from the integral way of thinking and communicating in the framework of the criticised intellectual community. This is why the most plausible way to deal with it was to mimic the totality of the targeted discourse by producing its parodied form, i.e. applying the "fighting fire with fire" strategy.

As far as the other strategies are concerned, i.e., the "appeal to institutional authority" and the "ignoring the sophist" strategy, neither of these would be adequate in Sokal's situation. The application of the first one would be impossible because of the fact that the controversy in question is not placed in an institutional context, which implies that there is no institutional authority (judge, arbiter etc.) to be invoked in order to block the subversion according to pre-established procedural rules. The application of the second one would be 
implausible because of the fact that the ignoring of the opinions advanced by the intellectual adversaries would boil down to self-exclusion from the argumentative space and letting the subversion stay unexposed and unblocked. And that is precisely the opposite of Sokal's intention in that case. In sum, it can be concluded that his application of the "fighting fire with fire strategy" was dictated by the specific circumstances of the concrete argumentative situation and that, in those circumstances, it could be treated as a strategically adequate choice. $^{20}$

\subsection{The goal of the "fighting fire with fire" strategy}

Commenting on the analysis presented in Gross and Levitt's book, Sokal observes that "some of the writings they examine are so silly that they almost demand ridicule along with refutation" (Sokal, 2010: 136-137). In this sense, the writing of his parody fits in with the general goal of the use of the "fighting fire with fire" approach, which was defined above (in section 2.4) as ridiculing the other, intellectually abusive party by making them experience the negative and destructive effects of their own subverting of intellectual standards. Indeed, in his paper "Transgressing the boundaries: An afterword", published in Dissent, Sokal explicitly stated that in his parodic, nonsensical article he used the very same means of argumentative subversion which could be identified in the criticised texts:

Like the genre it is meant to satirize (...) my article is a mélange of truths, half-truths, quarter-truths, falsehoods, non sequiturs, and syntactically correct sentences that have no meaning whatsoever. (...) I also employed some other strategies that are wellestablished (albeit sometimes inadvertently) in the genre: appeals to authority in lieu of logic; speculative theories passed off as established science; strained and even

\footnotetext{
${ }^{20}$ The ethical implications of this choice will be discussed later, in section 3.4.
} 
absurd analogies; rhetoric that sounds good but whose meaning is ambiguous; and confusion between the technical and everyday senses of English words. (Sokal, 1996b; also in Sokal, 2010: 93-94)

Speaking of his intentions to turn the subversion of intellectual standards against its main perpetrators, Sokal remarks: “( $(.$.$) the blow that can't be brushed off is the one that's$ self-inflicted. I offered the Social Text editors an opportunity to demonstrate their intellectual rigor. Did they meet the test? I don't think so.” (Sokal, 1996a)

It is easy to see that the test to which the editors of Social Texts were subjected by Sokal's submission of the article reveals a kind of tactical ingenuity-a tactic that can be compared to the tactic of a fork or double-attack in chess, whereby the attacker stands to benefit from any possible response on the part of the adversary.

This phenomenon was nicely described by Michel Rio, one of the participants in the debate surrounding the Sokal affair. According to Rio, Sokal falsified the targeted form of discourse in order to test the criteria for recognizing its validity. Thus, if the adherents of this type of discourse (in this case the editors of Social Text) had identified the falsification-in which case they would not have published the text - they would have demonstrated the importance of the criteria of intellectual rigour, which were clearly not met in the falsified (parodic) form of discourse. If, on the other hand, they failed to recognise the falsification and went ahead and published the text, as actually happened, this would expose a fundamental flaw in their standards of academic and scientific rigour, implying that these standards are either inadequate or, worse, non-existent (Rio, 1997). In both cases, Sokal's point about the necessity of adequate, rigorous standards of acceptability of scientific and philosophical discourses and their implications would be made in a convincing way. ‘ 
In order to understand the goal of using the "fighting fire with fire" strategy in the argumentative situation created by the Sokal affair, it may be useful to explore Sokal's own opinion of the probative force and range of his "experiment". Thus, distancing himself from his "over-enthusiastic supporters" who "have claimed too much" in his text "What the Social Text affair proves and does not prove", Sokal writes:

From the mere publication of my parody I think that not much can be deduced. It doesn't prove that the whole field of cultural studies or cultural studies of science much less sociology of science - is nonsense. Nor does it prove that the intellectual standards in these fields are generally lax. (...) It proves only that the editors of one rather marginal journal were derelict in their intellectual duty (...) (Sokal, 2010: 152153; see also http://www.physics.nyu.edu/sokal/noretta.html).

According to Sokal, much more important than the conclusions which can be deduced from the fact of the publication of the parodic article are the conclusions that can be deduced from its content. Thus he points to the fact that "the most hilarious parts" of his "screamingly funny" article were not written by himself but were "direct quotes from the postmodern Masters" (ibid.).

The real targets of Sokal's critique are the "sloppy thinking" and "glib relativism" allegedly prevailing "in many parts of Science Studies (albeit not, by and large, among serious philosophers of science)" (Sokal, 2010: 155-156). Consequently, the main goal of applying the "fighting fire with fire" strategy in this case consisted not in ridiculing a handful of trendy intellectuals or intellectually lazy editors but in undermining the epistemological 
credibility of the criticised form of discourse by practically demonstrating (what Sokal perceives as) its absurdity ${ }^{21}$ and unsoundness.

\subsection{Conditions for the successful application of this strategy}

As mentioned above (section 2.4.), success in using parody as a form of the "fighting fire with fire" strategy is dependent on the fulfilment of certain conditions mainly related to the audience that is targeted by the parody. First, it is necessary that the audience possesses sufficient knowledge of the parodied genre; otherwise, it would not be able to identify the elements of content and style that imitate the original work that is the object of the parody. Second, the audience should correctly identify the author's critical intention; otherwise, it could interpret his/her work in a standard, "serious" manner and completely ignore the parodic element. Third, and perhaps most importantly, the audience should share the negative value attitude towards the criticised/parodied phenomena. If the audience is strongly attached to the parodied phenomena, the intended parody could serve to affirm and praise its targets rather than undermine them.

This is precisely the kind of situation which occurred with the reception of Sokal's article by the editors of Social Text. Because of their firm adherence to the discourse which was the object of the parody and their attaching of a positive intellectual and ethical value to it, the editors were not only unable to recognise the parody but did not change their opinion even after Sokal had revealed his intent (Robbins, 1996). Consequently, independently of the intention of the author of the parody, the arguments in the submitted article were interpreted

\footnotetext{
${ }^{21}$ Perhaps, as Leo Groarke suggested in an informal discussion during the "Days of Ivo Škarić" conference, Sokal's approach could be treated as an instance of reductio ad absurdum proof of the unsoundness of the criticised form of discourse. However, my choice to describe it with the metaphorical expression "fighting fire with fire" is motivated by the need to take into consideration not only the logical but also the rhetorical and ethical aspects of the controversy, which are not explicitly emphasized in standard reductio ad absurdum procedure.
} 
as standing on their own and as speaking in favour of rather than opposing the object of his criticism. $^{22}$

3.4. The weak points and controversial aspects of the argumentative use of parody

The above-described phenomenon leads to the fourth and final point to be made in relation to Sokal's parody as an instance of the "fighting fire with fire" strategy. This concerns the potential dangers of applying this strategy, i.e., the possibility of its being turned against those employing it and their original purpose, as well as the possibility of creating the effect of a higher-level subversion—a kind of "meta-subversion".

Below, in sections 3.4.1 - 3.4.5, I examine five potential weak points and controversial aspects of the argumentative use of parody.

\subsubsection{Popularisation of parodied phenomena}

As the example of Sokal's use of parody shows, besides the already mentioned risk of parody being taken seriously and thus undermining its critical effect, there is also a risk of popularising the parodied phenomena to such an extent that they attract new adherents. Thus, the intensive public debate related to the Sokal affair leaves the impression that there has been a corresponding increase in the number of members of both confronted intellectual camps. If so, this would mean that Sokal's parody has indirectly contributed to an enlargement of public support not only for his own cause but also for the criticised one. In this sense, it could be said that the "fighting fire with fire" strategy here has produced the opposite effect of the strategy of "ignoring the sophist". For in the latter case, not entering into any kind of argumentative

\footnotetext{
${ }^{22}$ On this point, compare the question raised by Johnson and del Rio in their paper "Interpretation and Evaluation of Satirical Arguments": "If a speaker or author makes a purposefully bad argument meant to illustrate the folly of someone or something, but that argument is interpreted by audiences in a serious way, then is the argument satirical or serious?" (Johnson and del Rio, 2011: 891)
} 
interaction with the adversary also prevents the spread of interest and possible public support for his/her stance.

3.4.2. Deepening the gap between the adherents and the critics of the object of parody By deeply dividing public opinion as to the legitimacy of the content as well as the method of Sokal's critique through parody, the Sokal affair also contributed to the mobilization of over-defensive attitudes on the part of the parodied authors and their allies, thereby 'heating up' the debate to an undesirable extent. This, in turn, has deepened the gap between the "natural sciences" and the "social sciences and humanities" camps, which was presumably not the original intent of the author of the parody. In this way the parody has served to further undermine the prospect of genuine interdisciplinary cooperation (cf. Robbins and Ross, 1996). ${ }^{23}$

The fierce confrontations which broke out within intellectual circles as a result of the Sokal affair created a situation, moreover, which could serve the interests of those political forces in society that feel threatened by the prospect of a strong, unified and critically oriented academy. Worried by this possibility, Ellen Schrecker, although basically siding with Sokal in his plea for strengthening the traditional academy by maintaining the highest standards of intellectual rigour, concludes her letter to Lingua Franca by expressing the following concern: "I am afraid that Sokal may not realize how potentially damaging his discursive booby trap may be. (...) I worry that Sokal's merry prank may well backfire and provide further ammunition for the forces that have damaged the academic community far more than a few trendy theorists" (Schrecker, 1996). Although the author of a parody cannot anticipate all

\footnotetext{
${ }^{23}$ The concern inspired by this situation is clearly formulated in the letter of Terry Reynolds to Lingua Franca (see http://www.physics.nyu.edu/sokal/mstsokal.html) in the framework of the discussion concerning the Sokal affair. Revolted by the form of the debate which "has taken the form of mutual accusation" of "scientists" and "cultural theorists", Reynolds writes: "I resent Sokal's piece because he used his command of a powerful and fascinating discourse to fortify the boundaries between disciplines, and I resent the editors of Social Text because they let him". (Reynolds, 1996)
} 
the effects the parody will have in the wider intellectual context, it is useful to bear in mind the possibility that this kind of argumentative use of parody may have a strong confrontational impact on the adherents and the critics of the forms of discourse being parodied.

\subsubsection{Deliberate deception and undermining the trust of the audience}

Besides the potential "backfiring" effects of the argumentative use of parody, it seems that the most controversial aspects of Sokal's use of parody are related to its ethical dimension, in the sense that his "unorthodox experiment" entailed his being deliberately deceptive and undermining the trust of the professional community of academics and intellectuals. One of the most serious objections raised in relation to Sokal's submission of the parodic article is that by doing so he violated the principles of sincerity and veracity - the fundamental principles of rational communication and inquiry. Consequently, he produced a kind of "meta-subversion" not so different from that which was the target of his critique.

Having anticipated this objection, Sokal gave his response in "A Physicist's Experiment with Cultural Studies". While acknowledging that he was not oblivious to the ethical controversies involved in his "experiment", Sokal insisted on the fact that his article was based on publicly available sources, using authentic, rigorously accurate citations, thus allowing readers to judge the validity and interest of these ideas independently of their provenance or of the intimate relation of the author towards them (Sokal 1996a). ${ }^{24}$ Thus it transpires that one of the many points of Sokal's paper is to show that the demand for authorial sincerity, in the sense of an author's believing in their own arguments, must be subordinated to the demand for logical and evidential support for the theses advanced. This is especially important to bear in mind in situations when the professed general theoretical

\footnotetext{
${ }^{24}$ The same basic point was made by Paul Boghossian and Thomas Nagel who, in their letter to Lingua Franca, remark that "[i]n the context of a purely philosophical/theoretical paper, it is not the business of an editorial board to judge the sincerity of its authors, but only the cogency of their arguments. In the case of Sokal's paper, that cogency was fully open to view." (Boghossian and Nagel, 1996)
} 
attitude of the author "flatters the ideological preconceptions" (ibid.) of the readers and could easily lead them astray into neglecting their intellectual duties by loosening the standards of argument evaluation, as was the case with the editors of Social Text.

\subsubsection{Using non-rational means for argumentative purposes}

A particularly important objection related to the deceptive aspect of Sokal's strategy concerns the legitimacy or lack of legitimacy of using parody and satire in the context of rational discourse. This objection boils down to the claim that nonsense, deception and the communicative phenomena dependent on them are contrary to the very nature of rational discourse and cannot be a part of it, let alone be used as a means of restoring the rational mood of argumentation. As Johnson and del Rio remark: "Satire and argument are a dangerous mix. What makes satire pleasurable is often how it differs from more rational argument. Satirical texts exaggerate and distort for comic effect resulting in sometimes little more than an ad hominem attack. Satire asks us to laugh first and think second." (Johnson and del Rio, 2011: 890) $)^{25}$

In the formulation of this kind of objection, deception and parody are apparently treated in a similar way as being assimilated within the category of non-rational communicative devices. However, it seems that the soundness of this categorisation could be questioned by recalling Grice's theory of conversational implicature (cf. Grice, 1975/1989). Following the basic tenets of this theory, it could be admitted that the mechanism of ironic and parodic discourse ${ }^{26}$ is indeed based on violation of one of the fundamental conversational maxims - that of quality, i.e., the 'rule' that says "Do not say what you believe to be false".

\footnotetext{
${ }^{25}$ On this point, an even more radical opinion is advanced by Lee D. Carlson: commenting on the negative aspects of the Sokal affair, Carlson advocates the excluding of parody and related phenomena from the area of rational discourse: "Deception, sarcasm, parodies, and ridicule have no place in rational discourse, even though they may sometimes have an amusing quality to them." (Carlson, 2008)

${ }^{26}$ The inclusion of parody in this perspective represents an extension of Grice's original position, which mentions irony, metaphor, meiosis and hyperbole as examples of flouting the maxim of quality. However, it seems that this extension is faithful at least to the spirit of Grice's theory, if not to its letter.
} 
Yet one of the main points of Grice's theory is the idea that violation of that maxim is not incompatible with respecting the general rational principle of conversational cooperation. Thus, if a participant in the communication adheres to the principle of cooperation but still openly and deliberately violates the maxim of quality, he or she, in fact, communicates an implicit message which, in the case of figures of style like irony and, mutatis mutandis, sarcasm and parody, is precisely the opposite from the explicit content of the utterance (or of a larger discursive unit). In fact the phenomena of what is called implicature or "pragmatic consequence" are based on the functioning of the above-described mechanism, the steps of which allow for a more or less precise rational reconstruction.

Bearing this in mind, I adhere to the view that parody is neither irrational nor deceptive in itself and that the general exclusion of its argumentative use would be too restrictive. The structure of a paradigmatic parody includes, indeed, a deviation from the principle of sincerity and truthfulness. However, the main intention of the author of a parody is that this deviation be recognised and identified as such by the audience. Indeed, the recognition of this intention is what makes the parody successful, because it gives the audience the indicators that its content should be interpreted in the "opposite" way, i.e. that the implicit message the author wants to communicate by parodying a piece of discourse contradicts the explicit meaning of his/her words when interpreted in a standard way.

Of course, the issue of the (ir)rational and deceptive character of parody and the legitimacy of its argumentative use is far more complicated than is possible to present here. In this particular context of analysis of the Sokal example, I will confine myself only to advancing the thesis that what prevents the assimilation of parody and deception in one and the same category is the essential difference in their conditions of success. Namely, a parody is successful when the intention of its author, i.e. the clue for interpreting his/her work in a critical—not in a standard — way, has been rightly recognised and understood by the audience. 
Conversely, a deception is successful when the real intention of its author stays hidden from the audience, i.e., when his/her discourse is not interpreted as it is really intended (which is, in fact, the essence of lying). This fundamental difference in conditions of success lends an initial plausibility to the use of parody in a broader context of rational discourse, although the plausibility of the final result of this use will depend on many other contextual aspects and the specific circumstances of the particular communicative and argumentative situation.

\subsubsection{Confusing "parody" and "hoax"}

Starting from this differentiation between paradigmatic parody and paradigmatic deception, based on the criterion of the transparency of the author's intention, one final question concerning the argumentative aspects of the Sokal affair may be raised: Can the words "hoax" and "parody" be used in a synonymous way (as they often are) in describing the nature of Sokal's original article?

If we stick to the standard meaning of "hoax" as a "deliberately fabricated falsehood made to masquerade as truth" ${ }^{27}$, the answer should be negative. Rather, it could be said that the manoeuvre performed by Sokal was not simply to create a parody but to use his parodic article in order to perform a successful hoax. But if we accept the thesis that deceptiveness, notwithstanding appearances, is not an inherent feature of parody, this kind of use of parody necessitates a subtle but essential deviation from the standard manner of its creation. This deviation would consist in concealing the real intention of the author, because if it stays transparent the parody would be identified as parody and the hoax would not be successful. Indeed, Sokal did make explicit moves in order to hide the parodic nature of his article, including the rewriting of passages which worried him by their potential "to betray the hoax" (Sokal, 2010: 36, \# 93).

\footnotetext{
${ }^{27}$ Retrieved at: http://en.wikipedia.org/wiki/Hoax. According to the source, the definition is Curtis D. MacDougall's.
} 
However, from the distinction between the fundamental nature of a hoax and that of a parody it follows that both cannot be successful simultaneously. In order for a hoax to be successful, the parody as such must fail. Thus Sokal in fact "sacrificed" parody by deliberately trying to ensure that it was not recognised by the editors of Social Text, thus performing a kind of "denaturation" of the parody and subordinating it to a deceptive goal. Of course, as Boghossian and Nagel remark: "Sokal sought to conceal his own disbelief in the nonsense he had so ingeniously cooked up; the experiment would not have worked otherwise." (Boghossian and Nagel, 1996) Still, in the context of analysing forms of argumentative subversion and strategies for tackling such subversion, this can be seen as a step into the grey area of meta-level subversion. From this point of view, what is controversial in Sokal's approach is not the fact that he used parody for an argumentative purpose but the way in which he did so. First he denatured his parody into a hoax (or an element of hoax) and then almost triumphantly announced that the parody had not been recognised as such by the editors of Social Text. Later, revealing the hoax, he still sought to benefit from the virtues of the parodic genre as if it had been used in its pure form in which cooperativeness with the audience is presupposed.

To this kind of objection to Sokal's manoeuver, an advocate of Sokal's approach may reply that the audience of Sokal's parody, like that of any other parody, is in effect, naturally differentiated between those who are sensitive to the parodic content and those who are not. Consequently, it is argued, there is nothing objectionable in the fact that some of the audience recognised Sokal's parody as such while another part did not (primarily the editors of Social Text). Blinded by their ideological preconceptions and the fervour of the "science wars", so the argument goes, the editors of Social Text simply excluded themselves from the first category of audience, missing the chance to identify the parody through their own fault, not Sokal's fault. 
In response to this line of argumentation, it may be observed that while in "normal" cases this differentiation of audience is a spontaneous effect of parody, it seems in Sokal's case that such differentiation was one of the main goals of its construction. That is to say, the parody was deliberately calibrated in such a way that the members of the targeted group would fall into the category of an audience "insensitive to the parody" — with all the unpleasant consequences that entails.

Perhaps, however, as was suggested in the previous analysis, some kind of similar meta-subversive manoeuvre is an inevitable element of the "fighting fire with fire" strategy. In order to attain its goal, this strategy often necessitates some kind of "transgressing the boundaries" of normal and unquestionably legitimate way of using argumentative techniques. But in assessing the implications of this transgression - probably different in nature and degree in each case of application of this strategy - it is useful to bear in mind that two (argumentative) wrongs do not always make a right.

\section{Conclusion}

An attempt has been made in this paper to analyse some argumentative aspects of the Sokal affair by focusing attention on the phenomenon of argumentative subversion and different strategies for tackling such subversion. It was suggested that the way in which Sokal employed parody for argumentative purposes may be treated as an instance of the application of the strategy of "fighting fire with fire"-a device for countering argumentative subversion when blocking such subversion directly and immediately is either impossible or ineffective. By means of parody, the intellectually abusive party is supposed to be ridiculed and forced to experience the negative and destructive effects of their own subversion of intellectual standards.

Sokal's use of parody as a means of combating argumentative subversion is an example of a rare strategic inventiveness that enabled him to make his general point in a 
persuasive way. However, his approach involved several controversial aspects which were revealed in numerous discussions related to the Sokal affair. These aspects concerned, on the one hand, the legitimacy of employing non-rational means to attain rational argumentative goals and, on the other hand, the backfiring effects of his strategy, i.e., the unintended effect of increasing the popularity of the parodied phenomena and deepening the already existing gap between the two intellectual "camps" in "the science wars", thereby dividing the academic community even further. A particularly serious objection addressed at Sokal concerned the deceptive, trust-undermining aspect of his submission of a nonsensical paper to a scholarly journal, thereby violating the principle of sincerity and veracity in academic work. In his replies, Sokal met at least some of these objections with plausible arguments. In future research, these arguments may serve as the starting point for elaborating more general forms of conditions and directions for the successful application of the "fighting fire with fire" strategy in combating argumentative subversion.

In this article I have suggested that, from a theoretical and conceptual point of view, the most controversial, albeit very subtle, manoeuvre performed by Sokal in applying his strategy was his (ab)use of the parodic genre in order to hoax his targeted audience. The very need to "reveal" the parody suggests that it was deliberately "concealed", implying that it was not employed in the natural, standard way that presupposes giving contextual clues to the audience for rightly recognising the critical intention of the author of the parody. The question as to whether there are good reasons to qualify this manoeuvre as a kind of "meta-subversive" act, as well as the implications which would arise from such a qualification, remain open for further exploration.

Analysis of the relevant aspects of the Sokal affair from an argumentative point of view has shown the complexity and the multi-dimensionality of the use of parody as a strategic device in argumentation. In order to succeed, this strategy demands highly specific 
conditions and careful application to ensure it achieves its goal and does not backfire on its users. By extending this kind of analysis to other practical examples of the argumentative use of parody we will hopefully be able to gain a deeper insight into its positive and negative argumentative effects and to take a step forward towards elaborating more general criteria for its appropriateness in different contexts of rational communication.

\section{References}

Alexy, R. A Theory of Legal Argumentation: The Theory of Rational Discourse as Theory of Legal Justification. Translated by R. Adler and N. MacCormick. Oxford: Clarendon Press, 1989.

Aristotle. Posterior Analytics. Translated by Hugh Tredennick. Cambridge, Massachusetts: Harvard University Press, 1961a.

Aristotle. Topica Translated by E. S. Forster. London: William Heinemann, 1961b.

Badarevski, B. “Analytic/continental and Derridaean.” Identities - Journal for Politics, Gender and Culture, 3, no.2 (2004): 247-267.

Barth, E. M. and E. C. W. Krabbe. From Axiom to Dialogue: A Philosophical Study of Logics and Argumentation. Berlin/New York: Walter de Gruyter, 1982.

Boghossian, P. and T. Nagel. Letter to Lingua Franca. 1996.

September 292012 http://www.physics.nyu.edu/faculty/sokal/mstsokal.html

Carlson, L. D. "Should this book have been written?" Review of Beyond the Hoax: Science, Philosophy and Culture. 2008. Accessed September 30, 2012. http://www.amazon.com/review/R1K5D396EAKNNE

Dimiškovska, A. “Субверзијата во аргументативниот дискурс и стратегии за справување со неа (Subversion in argumentative discourse and strategies for dealing with it)." Философија. 26 (2009): 93-111. 
Eemeren, F. H. van and R. Grootendorst. Speech Acts in Argumentative Discussions. Dordrecht: Foris, 1984.

Eemeren, F. H. van and P. Houtlosser. "Strategic maneuvering: Examining argumentation in context." Edited by F.H. van Eemeren. Examining argumentation in context: Fifteen studies on strategic maneuvering, 1-24. Amsterdam/Philadelphia: John Benjamins Publishing Company, 2009.

Eemeren, F. H. van and R. Grootendorst. "The pragma-dialectical approach to fallacies." Edited by H. V. Hansen and R. C. Pinto. 1995. Fallacies: Classical and Contemporary Readings. Accessed September 27, 2012. http://www.ditext.com/eemeren/pd.html

Grice, H. P. “Logic and conversation.” Edited by Cole, P. and J. L. Morgan, in Syntax and semantics, 3 (1975): 41-58. New York/London: Academic Press. Reprinted in H. P. Grice, Studies in the way of words, 22-40. Cambridge, Massachusetts/London, England: Harvard University Press, 1989.

Johnson, A. and E. del Rio. "Interpretation and evaluation of satirical arguments.” Edited by F. H. van Eemeren, B. J. Garssen, D. Godden and G. Mitchell. Proceedings of the 7th Conference of the International Society for the Study of Argumentation, 890-897. Amsterdam: Sic Sat, 2011. CD ROM.

Rescher, N. Dialectics: A Controversy-Oriented Approach to the Theory of Knowledge. Albany: State University of New York Press, 1977.

Reynolds, T. Letter to Lingua Franca. 1996. Accessed September 30, 2012. http://www.physics.nyu.edu/sokal/mstsokal.html

Rio, M. "Grâce au ciel, à Sokal et à ses pareils.” Le Monde. 1997. Accessed September 29, 2012. http://peccatte.karefil.com/SBPresse/LeMonde110297.html

Robbins, B. “Anatomy of a hoax.” Tikkun. 1996. Accessed September 272012. http://www.physics.nyu.edu/faculty/sokal/robbins_tikkun.html 
Robbins, B. and A. Ross. Editorial response to Alan Sokal's text. 1996. Accessed September 29, 2012. http://www.physics.nyu.edu/faculty/sokal/SocialText_reply_LF.pdf

Schrecker, E. Letter to Lingua Franca. 1996. Accessed September 30, 2012. http://www.physics.nyu.edu/sokal/mstsokal.html

Sokal, A. Beyond the Hoax: Science, Philosophy and Culture. Oxford: Oxford University Press, 2010.

Sokal, A. "Transgressing the boundaries: Towards a transformative hermeneutics of quantum gravity.” Social Text 46, 47 (1996a): 217-252. Accessed September 29, 2012. http://www.physics.nyu.edu/faculty/sokal/transgress_v2/transgress_v2_singlefile.html

Sokal, A. “A physicist experiments with cultural studies.” Lingua Franca, 1996b. Accessed September 29, 2012. http://www.physics.nyu.edu/faculty/sokal/lingua_franca_v4/lingua_franca_v4.html

Sokal, A. Transgressing the boundaries: An afterword. 1996c. Accessed Septemeber 29, 2012. http://www.physics.nyu.edu/sokal/afterword_v1a/afterword_v1a_singlefile.html

Sokal, A. What the Social Text affair does and does not prove. 1997. Accessed September 30, 2012. http://www.physics.nyu.edu/sokal/noretta.html

Sokal, A. and J. Bricmont. Intellectual Impostures: Postmodern Philosopher's Abuse of Science. London: Profile Books, 1998.

Walton, D. N. and E. C. W. Krabbe. Commitment in Dialogue: Basic Concepts of Interpersonal Reasoning. Albany: State University of New York, 1995.

Walton, D. N. "Types of dialogue, dialectical shifts and fallacies.” Edited by F. H. van Eemeren, F. H. van, R. Grootendorst, J. A. Blair and Ch. A.Willard. Argumentation Illuminated, 133-147. Amsterdam: SICSAT, 1992. Accessed September 26, 2012. http://www.dougwalton.ca/papers\%20in\%20pdf/92typesolog.pdf 
Zenker, F. "Why study the overlap between "ought" and "is" anyways? On empirically investigating the conventional validity of the pragma-dialectical discussion rules." Edited by F. H. van Eemeren, B. J. Garssen, D. Godden and G. Mitchell. Proceedings of the 7th Conference of the International Society for the Study of Argumentation, 2083-2091. Amsterdam: Sic Sat, 2011. CD ROM. 


\title{
The acts and strategies of defining
}

\author{
Fabrizio Macagno, Universidade Nova de Lisboa
}

\section{Summary}

Definitions are not simply descriptions of meaning. They are acts that have different purposes and conditions. They can be dialogical tools for altering and sometimes manipulating the hearers' commitments. They can be rhetorical instruments that can lead the interlocutor to a specific decision. The concept of persuasive definition captures the rhetorical dimension of the definitions of specific words, called "emotive". By modifying their meaning or the hierarchy of values that they are associated with, the speaker can redirect the interlocutor's attitudes towards a situation. From a pragmatic perspective, the meaning of a word can be described in different fashions, and be the content of different types of speech acts. Not only can the speaker remind the audience of a shared meaning, or stipulate or advance a new one; he can also perform definitional acts by omitting definitions, or taking them for granted. These silent acts are potentially mischievous, as they can be used to manipulate what the interlocutors are dialogically bound to, altering the burden of proof. The implicit redefinition represents the most powerful tactic for committing the interlocutor to a meaning that he has not agreed upon, nor that can he accept.

Key words: Definition; Emotive language; Persuasion strategies; Speech act;

Implicit definition

\section{Introduction}

Aristotle defined the notion of definition (horismos) as a discourse, or an expression (logos) signifying what a thing is, or rather, its essence (Topics, 101b 31; Chiba, 2010) by indicating its genus and its difference. However, he then pointed out that there can be other types of "discourses" (apart from the genus-difference one) that fall under the same branch of inquiry as definitions, as they are aimed at tackling questions of sameness and difference, and they can be referred to as "definitory". Such expressions describe the concept by setting out some 
of its accidents or properties that can uniquely (absolutely or in a given context) identify the definiendum.

In addition to their role as propositions that can establish a true or false (or rather an acceptable or unacceptable) equivalence between definiens and definiendum, the definitory expressions have a pragmatic and dialogical dimension. Definitions are moves in a dialogue, aimed at achieving specific dialogical purposes. We can use definitions to inform the interlocutor of what a word means, or to stipulate or impose a new meaning of a term. We can propose a definition and support it with arguments, or we can commit ourselves to use a word with a specific signification. We can also omit definitions, and use words with different, unaccepted or unacceptable meanings. When we define we perform an action. The semantic equivalence that we express is always directed to a pragmatic goal. Defining is always a form of action.

This pragmatic dimension is strictly related with a strategic, or rather argumentative one. Words can be extremely powerful instruments. Terms like "war" or "peace", "security" or "terrorism" can trigger evaluative conclusions, support implicit or explicit decisions, and arouse emotions (Stevenson, 1937). These words are implicit arguments and tacit rhetorical strategies. However, they have a potentially fallacious dimension, essentially connected with their definition, or rather their commonly accepted meaning. When wars become "acts of freedom" (Doyle and Sambanis, 2006: 1) and bombings pacific operations, when dictatorships are named "democracies" and torture is referred to as a civil offense, the boundaries of semantic vagueness and definitional freedom are somehow exceeded, and words are used not to describe reality, but to distort it. The distinction between a reasonable and acceptable use of a word and manipulation lies in the notion of definition and the conditions of defining or redefining. 
If the idea of an essential, immutable definition cannot be embraced (Sager, 2000: 217; Walton, 2005: 169-173), the alternative seems to be a relativistic approach (Schiappa, 2003). The impossibility of determining an immutable meaning leads to the impossibility of verifying any definitory discourse, and therefore to the equivalence between any definition. How is it possible to identify when words are used as weapons of deceit? Is it always possible to define any word, anyhow?

The purpose of this paper is to tackle the problem of the conditions of defining from a pragmatic perspective, starting not from the propositional aspect of the definitional logos, but from its role as a move in a discourse, as a speech act. If definitional statements cannot be verified, definitional acts can be assessed taking into consideration their conditions and their limits.

2. Definitions as argumentative instruments

The first crucial aspect of definitions is the argumentative role of the definiendum. Words have the power of affecting our emotions and influencing our decisions. Terms such as war or terrorism are usually judged negatively, and can be used to arouse negative emotions or elicit negative judgments concerning the state of affairs they are used to refer to. For this reason, the act of naming a fragment of reality can be considered as a form of condensed argument made of two reasoning dimensions: a classification of reality and a value judgment.

Stevenson first underlined this twofold aspect of the use of a word when he investigated the terms that he called "ethical" or emotive. He noted that some words, such as "peace" or "war", are not simply used to describe reality, namely to modify the cognitive reaction of the interlocutor. They have also the power of directing the interlocutors' attitudes and suggesting a course of action. For this reason, they evoke a different kind of reaction, 
emotive in nature. As Stevenson put it (Stevenson, 1937: 18-19), "Instead of merely describing people's interests, they change or intensify them. They recommend an interest in an object, rather than state that the interest already exists." These words have the tendency to encourage future actions (Stevenson 1937: 23; Stevenson, 1938a: 334-335; Stevenson, 1938b: 49-50), to lead the hearer towards a decision by affecting his system of interests (Stevenson, 1944: 210). Stevenson distinguished these two types of correlation between the use of a word (a stimulus) and its possible psychological effects on the addressee (the cognitive and the emotive reaction) by labeling them as "descriptive meaning" and "emotive meaning" (Stevenson, 1944: 54). Because of this twofold dimension, the redefinition of ethical words becomes an instrument of persuasion, a tool for redirecting preferences and emotions (Stevenson, 1944: 210):

Ethical definitions involve a wedding of descriptive and emotive meaning, and accordingly have a frequent use in redirecting and intensifying attitudes. To choose a definition is to plead a cause, so long as the word defined is strongly emotive.

The two crucial strategies for "redirecting and intensifying" attitudes are the persuasive definition and the quasi-definition. Quasi-definitions consist in the modification of the emotive meaning of a word without altering the descriptive one. The speaker can quasi-define a word by qualifying the definiendum (or rather describing its referent) without setting forth what actually the term means. The definitions provided by the famous Devil's dictionary mostly consist in this tactic. For instance, we can consider the following account of "peace" (Bierce, 2000: 179):

Peace: In international affairs, a period of cheating between two periods of fighting. 
Here, the speaker is not describing the meaning of "peace", but how a peaceful period of time should be considered. The outcome is that a concept usually evaluated positively is turned into one bound to the negative idea of deception.

The other tactic of redefinition of ethical words is called persuasive definition. The emotive meaning, namely the evaluative component associated with a concept, is left unaltered while the descriptive meaning, which determines its extension, is modified. In this fashion, imprisonment can become "true freedom" (Huxley, 1955: 122), and massacres "pacification" (Orwell, 1946). Persuasive definitions can change or distort the meaning while keeping the original evaluations that the use of a word evokes. A famous example is the following redefinition of "peace", or rather, "true peace" (Barack Obama, Nobel Peace Prize Acceptance Address Oslo, Norway December 10, 2009):

Peace is not merely the absence of visible conflict. Only a just peace based on the inherent rights and dignity of every individual can truly be lasting. Peace is unstable where citizens are denied the right to speak freely or worship as they please; choose their own leaders or assemble without fear. A just peace includes not only civil and political rights -- it must encompass economic security and opportunity. For true peace is not just freedom from fear, but freedom from want.

While retaining its original positive emotive meaning, "peace" is not referring anymore to absence of conflict, but also to specific war operations. However, how can these two dimensions be described? How is it possible to analyze these two different types of meaning? A possible answer can be found in examining them from a reasoning perspective. 


\section{Arguments in words}

The relationship between descriptive and emotive meaning and the role of definition in redirecting attitudes can be analyzed from an argumentative perspective. The concept of meaning can be accounted for as a form of reasoning that proceeds from a definition to a classification of an entity, or from values and properties to a value judgment. The emotive and the descriptive meaning can be seen as two different steps of reasoning, aimed at attributing to objects, individuals or state of affairs a name or an evaluation.

\subsection{Describing reality}

Descriptive meaning was investigated by Stevenson in terms of effects on the hearer. The cognitive effect, or rather the information that the interlocutor can obtain from the use of a word, can be explained in terms of reasoning, and in particular through the process of attributing a predicate to a subject. The most generic form of reasoning describing this mechanism is an abstract structure of argument combining the semantic relation of “classification" (Crothers, 1979; Hobbs, 1979: 68; Hobbs, 1985) with the logical rule of defeasible modus ponens (Walton, 1996: 54):

\begin{tabular}{|l|l|}
\hline MAJOR PREMISE: & $\begin{array}{l}\text { For all } x, \text { if } \mathrm{x} \text { has property } F, \text { then } x \text { can be classified as having } \\
\text { property } G .\end{array}$ \\
\hline MINOR PREMISE: & $a$ has property $F$. \\
\hline CONCLUSION: & $a$ has property $G$. \\
\hline
\end{tabular}

The generic semantic relation needs to be specified by taking into consideration some of the ancient maxims related to the topics of definition (Stump, 1989; Green-Pedersen, 1984). The passage from the predicate stated in the antecedent to the one attributed in the consequent 
needs to be grounded on a definitional semantic relation (Walton and Macagno, 2008), which concerns any issue of identity and difference between two predicates (Aristotle, Topics 102a, 5-9). This type of argument can be represented as follows (Walton and Macagno, 2010: 39):

\begin{tabular}{|l|l|}
\hline MAJOR PREMISE: & $\begin{array}{l}\text { For all } x, \text { if } x \text { fits definition } D, \text { and } \mathrm{D} \text { is the definition of } \mathrm{G}, \text { then } x \\
\text { can be classified as } G .\end{array}$ \\
\hline MINOR PREMISE: & $a$ fits definition $D$. \\
\hline CONCLUSION: & $a$ has property $G$. \\
\hline
\end{tabular}

As pointed out by Aristotle, the concept of definitional discourse includes different types of equivalences, of which the strongest and most famous is the definition by genus and difference. However, the same concept can be defined using other definitory statements. For instance, "peace" can be defined by its absolute or relative properties ("the state of well-being that is characterized by trust, compassion, and justice"), by parts ("the union of hot peace and cold peace"), or by its cause (“a pattern of cooperation and integration between major human groups"). There are also other types of definition that are not used to explain the meaning of the concept defined, but especially to communicate a judgment on it, such as the definition by metaphor ("peace is a gentle breeze").

Argument from classification and the different types of definitions that can be used for different purposes can provide an explanation from an argumentative perspective to the phenomenon of descriptive meaning. The other dimension of meaning, the emotive one, can be accounted for by considering another form of classification, not aimed at naming reality, but rather at evaluating it. This pattern of reasoning proceeds from a different type of classificatory principles: values.

\subsection{Argumentation from values}


According to Stevenson, emotive meaning is the propensity of a word to encourage actions. However, this type of "meaning" is connected with a specific form of reasoning that is based on propositions forming the grounds of our value judgments. This relationship emerges when it is attacked through the use of quasi-definitions. Using a quasi-definition, the speaker can undermine the implicit and automatic association between a concept and its evaluation. He needs to provide an argument rejecting the grounds of a shared value judgment; for this reason, he describes the referent appealing to values contrary to the ones commonly associated with such a concept. For instance, we can consider the following quasi-definition taken from Casanova's Fuga dai Piombi. The speaker, Mr. Soradaci, tries to convince his interlocutor (Casanova) that being a sneak is an honorable behavior (Casanova, 1911: 112) ${ }^{28}$ :

I have always despised the prejudice that attaches to the name "spy" a hateful meaning: this name sounds bad only to the ears of who hates the Government. A sneak is just a friend of the good of the State, the plague of the crooks, the faithful servant of his Prince.

This quasi-definition underscores a fundamental dimension of the "emotive" meaning of a word, its relationship with the shared values, which are attacked as "prejudices". This account given by the spy shows how the emotive meaning can be modified by describing the referent based on a different hierarchy of values. The value of trust is not denied, but simply placed in a hierarchy where the highest worth is given to the State.

The relationship between the use of a word, its meaning and the hierarchies of values (Perelman \& Olbrechts-Tyteca, 1951) can provide an explanation from a rhetorical perspective of the reason why words can lead to value judgments and decisions. Values can

\footnotetext{
28 "Ho sempre disprezzato il pregiudizio che conferisce un odioso significato al nome di spia: questo nome non suona male che alle orecchie di chi non ama il Governo: uno spione non è altro che un amico del bene dello stato, il flagello dei delinquenti, il fedel suddito del suo Principe".
} 
be thought of as the reasons for classifying something as desirable or not, and, therefore, for judging the action aimed at achieving it as worthy or not. By describing an entity or a state of affairs as valuable, namely indicating the values that can be used to assess it, the speaker can provide the interlocutor with a reason to act in a specific fashion. Values represent the criterion for establishing the desirability of a course of action, and the generic form of reasoning based on them can be represented as follows (Walton, Reed and Macagno, 2008: 321):

\begin{tabular}{|l|l|}
\hline PREMISE 1: & Value $V$ is positive (negative) as judged by agent $A$ (judgment value). \\
\hline PREMISE 2: & $\begin{array}{l}\text { The fact that value } V \text { is positive (negative) affects the interpretation and } \\
\text { therefore the evaluation of goal } G \text { of agent } A \text { (If value } V \text { is good (bad), } \\
\text { it supports (does not support) commitment to goal } G \text { ). }\end{array}$ \\
\hline CONCLUSION: & $V$ is a reason for retaining commitment to goal $G$. \\
\hline
\end{tabular}

For instance, the action of spying, or the quality of being a "sneak" can be classified as contemptible or hateful based on the classifying principle (value) that can be expressed as follows: "Who betrays the trust of another is a bad (contemptible...) person." On the contrary, Soradaci rejects such a principle and advances a different hierarchy of values: supporting the good of the State is the supreme good; therefore, whoever betrays another for the good of the State is a good person.

This type of reasoning is grounded on a judgment, which becomes a reason to carry out a specific action. Values represent the different ways and principles that are used to establish what is good or bad. In its turn, the moral judgment becomes a reason to act. The relationship between will, and desire, and action is underscored in Aristotle's Nicomachean Ethics. What is good, or appear as such, is maintained to be the goal of a decision to act (Nicomachean Ethics, 1113a15), as "everything aims at the good" (Topics, 116a 18). For 
instance, an "act of war" is usually regarded as negative, and naming an operation as such can become a reason for criticizing it. On the other hand, an "act of peace", or a humanitarian intervention leads to an opposite judgment, and suggests a different course of action. Similarly, in the case above, a "sneak" is not only despised, but cannot be trusted. Despite Soradaci's strenuous defence of the spies, Casanova cannot ignore his previous hierarchy of values, and for this reason he cannot trust him. On the contrary, he lies to him all the time.

The decision-making process can be thought of as a pattern of reasoning connecting an action, or rather a "declaration of intention" or commitment (von Wright, 1972: 41) with its grounds (Anscombe, 1998: 11). The grounds can be provided by the simple positivity or negativity of a course of action, or the presumption of continuity of a person's negative or positive behavior (Perelman \& Olbrechts-Tyteca, 1951). Depending on whether the speaker is assessing a specific course of action or considering a goal, the type of reasoning can have different forms. The first and simpler form of argument is the argument from consequences (Walton, Reed \& Macagno, 2008: 332)

\begin{tabular}{|l|l|}
\hline PREMISE 1: & If $A$ is brought about, good (bad) consequences will plausibly occur. \\
\hline PREMISE 2: & What leads to good (bad) consequences shall be (not) brought about. \\
\hline CONCLUSION: & Therefore $A$ should be brought about. \\
\hline
\end{tabular}

For instance, if a sneak usually betrays friends, trusting a sneak can probably lead to betrayal. Since betrayal is a negative outcome, a sneak should not be trusted. Similarly, the classification of an operation as humanitarian or an act of peace underscores its peaceful consequences, suggesting to the interlocutor to support it.

The other form of reasoning, called practical reasoning, is more complex, as it proceeds from a value to the means that can possibly bring it about (Walton, Reed \& Macagno, 2008: 323): 


\begin{tabular}{|l|l|}
\hline PREMISE 1: & I (an agent) have a goal G. \\
\hline PREMISE 2: & Carrying out this action A is a means to realize G. \\
\hline CONCLUSION: & Therefore, I ought to (practically speaking) carry out this action A. \\
\hline
\end{tabular}

This argument is frequently used to justify a potentially objectionable decision by highlighting a hierarchy of values. For instance, war is despicable, but when it is the only means to free people from a dictatorship it can be seen as positive. Similarly, lying is contemptible, but if it is the only way to avoid betrayal, it becomes a justified course of action.

\section{The acts of defining}

Redefinitions can be extremely powerful and sometimes dangerous instruments. By modifying the definition of a word, the speaker can alter the interlocutor's perception and evaluation of reality. He can distort reality and the appraisal thereof. However, definitions and redefinitions are extremely common moves, often necessary for clarifying new or obscure concepts or highlighting some of their dimensions. The crucial problem lies in the identification of a criterion for distinguishing deceitful definitional moves from the nonfallacious or simply persuasive ones. As noticed above, not only are there several definitions for the same definiendum, but there are also different ways of defining the same concept. In order to analyze the boundaries of definitions and redefinitions, it is necessary to shift from a propositional to a pragmatic level. Definitions can be fallacious or acceptable because they are acts, moves in a discourse. Definitions can have different purposes: they can be instruments for informing, imposing a meaning, or advancing a viewpoint. Accordingly, they are subject to different pragmatic conditions. 


\subsection{Definitions as reminders}

In his Nobel Peace Prize Acceptance Address, Obama needed to argue in favor of an extremely complex position: the president of a state engaged in different wars all over the world should be considered as the clearest champion of peace. In order to support this claim, at the beginning of his speech he underscores a fundamental principle that his audience should be acquainted with: wars can be justified. For this purpose, he reminds his audience of the concept and meaning of “just war” (Barack Obama, Nobel Peace Prize Acceptance Address Oslo, Norway December 10, 2009):

Definition as a piece of information or a reminder: "peace"

The concept of a "just war" emerged, suggesting that war is justified only when it meets certain preconditions: if it is waged as a last resort or in self-defense; if the force used is proportional, and if, whenever possible, civilians are spared from violence. [...]What I do know is that meeting these challenges will require the same vision, hard work, and persistence of those men and women who acted so boldly decades ago. And it will require us to think in new ways about the notions of just war and the imperatives of a just peace.

Obama is not advancing a new claim, but bringing to light a commitment that is or should be shared by his interlocutors. Definitions of basic cultural concepts need to be known by a community of speakers. By underscoring the ancient origin of "just war", Obama is making sure that its definition is part of the audience's common ground. In this fashion, he reinforces the hearer's commitment to such a concept, or rather he undermines the objectionability thereof. He reminds and informs the audience that the idea that wars (and in particular the ones waged or fought by the United States) can be justified cannot be considered as 
controversial. We can represent the structure of this act of defining as follows (Searle and Vanderveken, 2005: 129):

\begin{tabular}{|c|c|c|c|c|c|}
\hline Move & $\begin{array}{l}\text { Content } \\
\text { conditions }\end{array}$ & $\begin{array}{c}\text { Speaker's } \\
\text { commitments }\end{array}$ & $\begin{array}{c}\text { Hearer's } \\
\text { commitments }\end{array}$ & $\begin{array}{c}\text { Effects on the } \\
\text { speaker }\end{array}$ & $\begin{array}{c}\text { Effects on the } \\
\text { hearer }\end{array}$ \\
\hline $\begin{array}{l}\text { Informing } \\
(\text { Hearer; } \\
\text { Commitment to } p) \text {. }\end{array}$ & $\begin{array}{l}p \text { represents a state } \\
\text { of affairs / } \\
\text { judgment / } \\
\text { decision. }\end{array}$ & $\begin{array}{l}S \text { has grounds } \\
\text { supporting that } H \\
\text { is/should be } \\
\text { committed to / } \\
\text { knows } p \text {. }\end{array}$ & $\begin{array}{l}\text { - } H \text { is / should be } \\
\text { committed to } p \text {. } \\
\text { - } H \text { knows / } \\
\text { should know } p \text {. }\end{array}$ & $\begin{array}{l}S \text { is committed to } \\
H \text { 's Comm. to } p \text {. }\end{array}$ & $\begin{array}{l}\text { - Acknowledge } \\
\text { Comm. to } p \text { ). } \\
\text { - Reject (Comm. } \\
\text { to } p \text { ) based on } \\
\text { reasons. }\end{array}$ \\
\hline $\begin{array}{l}\text { Just war is a war } \\
\text { that is justified } \\
\text { when some } \\
\text { preconditions are } \\
\text { met. }\end{array}$ & $\begin{array}{l}\text { Meaning of "just } \\
\text { war." }\end{array}$ & $\begin{array}{l}\text { People are } \\
\text { presumed to know } \\
\text { what is generally } \\
\text { shared. } \\
\text { Authorities in the } \\
\text { past defined it. }\end{array}$ & & & $\begin{array}{l}\text { The interlocutors } \\
\text { cannot ignore the } \\
\text { definition. } \\
\text { The interlocutors } \\
\text { need to accept it or } \\
\text { show that it is not } \\
\text { shared. }\end{array}$ \\
\hline
\end{tabular}

Table 1: Defining for reminding - Dialectical profile

By reminding the audience of a definition, the speaker can take advantage of the presumption that the definition is, or should be, already part of the interlocutors' commitments. The burden of proof is shifted onto the hearers, who need to show that such a definition cannot be considered as part of the common ground.

\subsection{Definitions as standpoints}

Definitions can be used to advance a new meaning for a concept, or simply propose the existence of a new or more specific one. In this case, the speaker is not presuming that the meaning described is shared. On the contrary, he acknowledges that it is not part of the interlocutors' common ground, and for this reason he accepts the burden of proving it, or supporting it with arguments. A clear example can be found in the same Nobel Peace Prize Acceptance Address mentioned above. Obama splits the notion of peace into two concepts, a 
"true peace", amounting to a status characterized by the "inherent rights and dignity of every individual" and a "false" one, which corresponds only to the commonly shared definition of "absence of visible conflict". In order to support his standpoint, Obama underscores that only the first one can be lasting (Barack Obama, Nobel Peace Prize Acceptance Address Oslo, Norway December 10, 2009):

Definition as a standpoint: "peace"

For peace is not merely the absence of visible conflict. Only a just peace based upon the inherent rights and dignity of every individual can truly be lasting. [...]

This type of move can be described as a kind of a speech act of assertion, which commits the speaker to defending it if requested to do so (Houtlosser, 2001: 32). This condition can be shown in the following dialectical profile, pointing out its different components and requirements.

\begin{tabular}{|c|c|c|c|c|c|}
\hline Move & $\begin{array}{c}\text { Content } \\
\text { conditions }\end{array}$ & $\begin{array}{c}\text { Speaker's } \\
\text { commitments }\end{array}$ & $\begin{array}{c}\text { Hearer's } \\
\text { commitments }\end{array}$ & $\begin{array}{c}\text { Effects on the } \\
\text { speaker }\end{array}$ & $\begin{array}{c}\text { Effects on the } \\
\text { hearer }\end{array}$ \\
\hline $\begin{array}{l}\text { Advancing as a } \\
\text { standpoint }(p) \text {. }\end{array}$ & $\begin{array}{l}p \text { represents a } \\
\text { judgment / } \\
\text { proposal. }\end{array}$ & $\begin{array}{l}\text { - } S \text { believes that } \\
H \text { does not } \\
\text { (already, at face } \\
\text { value, } \\
\text { completely) } \\
\text { accept } p \text {. } \\
\text { - } S \text { believes that } \\
\text { he can justify } p \\
\text { for } H \text { with the } \\
\text { help of } \\
\text { arguments. }\end{array}$ & $\begin{array}{l}H \text { is not committed } \\
\text { to } p \text { (already, at } \\
\text { face value, } \\
\text { completely). }\end{array}$ & $\begin{array}{l}\text { - } S \text { is committed } \\
\text { to } p \text {. } \\
\text { - } S \text { is committed } \\
\text { to defend } p \text {. } \\
\text { - } S \text { is committed } \\
\text { to the fact } p \text { may } \\
\text { be not accepted. }\end{array}$ & $\begin{array}{l}\text { - Accept }(p) \text {. } \\
\text { - Question }(p) \text {. } \\
\text { - Reject }(p) \text {. } \\
\text { - Advance (non- } \\
p) \text {. }\end{array}$ \\
\hline $\begin{array}{l}\text { peace is not merely } \\
\text { the absence of } \\
\text { visible conflict. } \\
\text { [...] } \\
\text { true peace is based } \\
\text { upon the inherent } \\
\text { rights and dignity. }\end{array}$ & $\begin{array}{l}\text { Definition of } \\
\text { "peace". }\end{array}$ & $\begin{array}{l}\text { (Obama takes for } \\
\text { granted that the } \\
\text { shared definition } \\
\text { of peace is } \\
\text { "absence of visible } \\
\text { conflict.") }\end{array}$ & $\begin{array}{l}\text { ( } H \text { is committed to } \\
\text { the definition of } \\
\text { peace as "absence } \\
\text { of visible } \\
\text { conflict.") }\end{array}$ & $\begin{array}{l}\text { Obama supports } \\
\text { the definition with } \\
\text { an argument (it is } \\
\text { the only peace that } \\
\text { is truly lasting). }\end{array}$ & \\
\hline
\end{tabular}

Table 2: Definitions as standpoints - Dialectical profile 
In his discourse, Obama encourages his audience to replace the definition they are committed to with the new one. He provides reasons to believe that the ordinary account of peace is not sufficient, and proposes a different view whose positivity he highlights by marking it as the "true" one.

\subsection{Definitions as commitments}

As seen above, the definition-reminder represents a previous or presumptive commitment of the interlocutor, while a definition advanced as a standpoint presupposes that such an account of meaning is, or can be, not shared. Definitions can be also used to bind the speaker to a commitment, playing the role of a commissive, a type of promise that he makes to his interlocutor. A clear example can be found in Obama's Inaugural Address (In a Dark Valley: Barack Obama's Inaugural Address), where the U.S. President does not explain nor propose a new meaning, but commits himself to a specific use of a crucial term ${ }^{29}$ :

Definition as a commitment: "We-ness"

We -- and in this presidency, when I use that word, I will mean you and me, not the royal "we" to which American presidents have become far too attached -- we can, I think, hope to accomplish much, but only if we're honest with ourselves.

Obama uses the definition of the pronoun "we" to commit himself to using it with a specific, strategic meaning. He distinguishes two uses, corresponding to two classes of people: the pluralis maiestatis, used by his predecessors, and the ordinary meaning, which he commits himself to. The definition constitutes a promise of refusing the "royal we", and mirrors and

\footnotetext{
${ }^{29}$ Prelude to an Inaugural. (Retrieved from http://www.atimes.com/atimes/Front_Page/KA15Aa02.html on 26 August 2012).
} 
shows a political attitude where the people become an active part of the President's decisions and choices. The definition becomes a metaphor of his political behavior, to which he commits. This act of defining can be represented as follows:

\begin{tabular}{|l|l|l|l|l|l|}
\hline \multicolumn{1}{|c|}{ Move } & \multicolumn{1}{|c|}{$\begin{array}{c}\text { Content } \\
\text { conditions }\end{array}$} & $\begin{array}{c}\text { Speaker's } \\
\text { commitments }\end{array}$ & $\begin{array}{c}\text { Hearer's } \\
\text { commitments }\end{array}$ & $\begin{array}{l}\text { Effects on the } \\
\text { speaker }\end{array}$ & $\begin{array}{l}\text { Effects on the } \\
\text { hearer }\end{array}$ \\
\hline Committing to $(p)$. & $\begin{array}{l}p \text { represents a } \\
\text { future course of } \\
\text { action }(A) .\end{array}$ & $\begin{array}{l}-S \text { is not } \\
\text { committed to } p . \\
-S \text { normally } \\
\text { should not be } \\
\text { committed to } p .\end{array}$ & $\begin{array}{l}H \text { knows that S is } \\
\text { not committed to } \\
p .\end{array}$ & $\begin{array}{l}\text { - } S \text { is committed to } \\
p .\end{array}$ & $\begin{array}{l}H \text { knows that } S \\
\text { is committed to } p .\end{array}$ \\
\hline $\begin{array}{l}\text { when I use that } \\
\text { word "we"], I } \\
\text { will mean you and } \\
\text { me, not the royal } \\
\text { "we". }\end{array}$ & $\begin{array}{l}\text { Future use of the } \\
\text { pronoun "we". }\end{array}$ & $\begin{array}{l}\text { Usually presidents } \\
\text { use the pronoun } \\
\text { "we" as a pluralis } \\
\text { maiestatis. }\end{array}$ & $\begin{array}{l}\text { The audience } \\
\text { expects the } \\
\text { pronoun to be used } \\
\text { as a pluralis } \\
\text { maiestatis. }\end{array}$ & $\begin{array}{l}\text { Obama shall use } \\
\text { the pronoun } \\
\text { meaning "you and } \\
\text { me". }\end{array}$ & $\begin{array}{l}\text { The audience will } \\
\text { interpret the } \\
\text { pronoun as } \\
\text { meaning "you and } \\
\text { me". }\end{array}$ \\
\hline
\end{tabular}

Table 3: Defining for committing - Dialectical profile

The committing definition inserts the obligation to use a word with a certain meaning into the speaker's commitment store, not affecting the interlocutor's one. This type of definition is extremely strategic, as it imposes a language use commitment onto the speaker, but at the same time binds the interlocutor to a specific interpretation of the word. Without imposing the meaning of a term, the speaker imposes how it shall be interpreted in his discourse.

\subsection{Stipulative definitions}

Definitions can be used for imposing a new meaning. The speaker can stipulate (Robinson, 1950: 59; Leonard, 1967: 286; see also Viskil, 1995) what a word means, so that a commitment is inserted into the speaker's and the hearer's commitment stores. He is binding the interlocutor to a specific word use. In order to perform this act, the definer needs to have the authority to do so. For instance, this definitional move is characteristic of lawmakers, as they have the authority of deciding what the words in the laws mean. Stipulative definitions 
can be used to alter the meaning of a commonly shared word, so that the implications of the old use are associated with new referents (Schiappa, 1998: 31). For instance, the concept of "homeland security" was first introduced and defined in 2002 to refer to measures against terroristic attacks. However, in 2007 and 2010 it was redefined to ensure that the same exceptional measures were used also to prevent other types of threats. In order to deal with some emergencies, among which was the hurricane Katrina, proposals for a definitional change were advanced to include "man-made and natural hazards" (see Bellavita, 2008), until in 2011 a new definition was stipulated (Quadrennial Homeland Security Review Report, February 2010: 13) ${ }^{30}$ :

Imposing a redefinition "homeland security"

Homeland security is meant to connote a concerted, shared effort to ensure a homeland that is safe, secure, and resilient against terrorism and other hazards where American interests, aspirations, and way of life can thrive.

The implications of the old concept were kept (if something threatens homeland security, exceptional measures shall be taken), but the category of threats to homeland security was enlarged to include also cyber-terrorism. In this fashion, a prompt response to new types of dangers was guaranteed. We can represent the speech act of imposing a definition as follows:

\footnotetext{
${ }^{30}$ www.dhs.gov/xlibrary/assets/qhsr_report.pdf . (Retrieved on 27 August 2012).
} 


\begin{tabular}{|c|c|c|c|c|c|}
\hline Move & $\begin{array}{c}\text { Content } \\
\text { conditions }\end{array}$ & $\begin{array}{c}\text { Speaker's } \\
\text { commitments }\end{array}$ & $\begin{array}{c}\text { Hearer's } \\
\text { commitments }\end{array}$ & $\begin{array}{c}\text { Effects on the } \\
\text { speaker }\end{array}$ & $\begin{array}{c}\text { Effects on the } \\
\text { hearer }\end{array}$ \\
\hline $\begin{array}{l}\text { Imposing } \\
(\text { declaring })(p) .\end{array}$ & $\begin{array}{l}\text { - } p \text { represents a } \\
\text { state of affairs } \\
(S o A) \text {. } \\
\text { - The } S o A \\
\text { represented by } p \\
\text { is not an actual or } \\
\text { past one. } \\
\text { - The } S o A \text { can be } \\
\text { the case. }\end{array}$ & $\begin{array}{l}\text { - } S \text { knows that } H \\
\text { is not committed } \\
\text { to } p \text {. } \\
\text { - } S \text { holds the } \\
\text { authority to } \\
\text { impose a new } \\
\text { state of affairs. }\end{array}$ & $\begin{array}{l}H \text { is not committed } \\
\text { to } p \text {. }\end{array}$ & $\begin{array}{l}\text { - } S \text { is committed to } \\
p \text {. }\end{array}$ & $\begin{array}{l}\text { - } H \text { is committed } \\
\text { to } p \text {. }\end{array}$ \\
\hline $\begin{array}{l}\text { Homeland security } \\
\text { is a concerted } \\
\text { national effort to } \\
\text { prevent terrorist } \\
\text { attacks within the } \\
\text { United States, } \\
\text { reduce America's } \\
\text { vulnerability to } \\
\text { terrorism, and } \\
\text { minimize the } \\
\text { damage and } \\
\text { recover from } \\
\text { attacks that do } \\
\text { occur. }\end{array}$ & $\begin{array}{l}\text { Definition of } \\
\text { "homeland } \\
\text { security". }\end{array}$ & $\begin{array}{l}\text { - The Office of } \\
\text { Homeland } \\
\text { Security and the } \\
\text { President have } \\
\text { the authority to } \\
\text { define. } \\
\text { - The definition } \\
\text { of "homeland } \\
\text { security" is new. }\end{array}$ & $\begin{array}{l}\text { ( } H \text { is committed to } \\
\text { a previous } \\
\text { definition of } \\
\text { "homeland } \\
\text { security"). }\end{array}$ & $\begin{array}{l}\text { The Office of } \\
\text { Homeland Security } \\
\text { shall deal with } \\
\text { environmental } \\
\text { problems. }\end{array}$ & $\begin{array}{l}\text { The offices and } \\
\text { responsible for the } \\
\text { environmental } \\
\text { disasters shall refer } \\
\text { to the Office of } \\
\text { Homeland } \\
\text { Security. }\end{array}$ \\
\hline
\end{tabular}

Table 4: Stipulative definitions - Dialectical profile

The act of stipulating a new definition can be carried out in order to introduce ambiguities.

For instance, the concept of security triggers specific inferences because of its old military meaning. The redefinition creates a coexistence of meanings, so that the conclusions usually supported by the old one are also drawn when the newly defined word is used.

\section{The acts of non-defining}

Usually actions are associated with the "state or process of doing something". As seen above, verbal actions are performed in order to bring about specific conversational effects. However, the agent can cause intentionally some effects also by failing to perform a specific activity. For instance, the so called "code of silence" results in criminals being not prosecuted. In law, omissions are defined in terms of the duties to act, as breaches of an affirmative duty to 
perform the omitted actions (Glanville, 1983: 148-149; Fusco, 2008: 86). However, outside the codified domain of law the concept of omission can become more complex to define. Omission can be regarded as an act of a kind where the agent decides not to perform an action that was sufficient for the occurrence of a specific consequence at a later time (Aqvist, 1974; Chisholm, 1976; Walton, 1980: 317). In this sense, an omission is characterized by a deliberate decision to leave open the possibility of the occurrence of a specific state of affairs. For instance, the omission to report a crime does not prevent the authorities from being informed of prosecuting it. However, such a non-action leaves this possibility open by a deliberate choice.

Definitions can represent the propositional content of two different types of non-acts: the act of omitting a definition and the act of taking it for granted. While in the first case the speaker fails to provide a needed definition, in the second case he uses a word with a specific meaning, but omits the act of putting it forward. By deciding not to advance or to impose the definition he is using, he takes it for granted, performing a specific tacit act.

\subsection{Omitted definitions}

Definitions set out the conditions for the classification of a concept. The crucial importance of a definition emerges especially in the case in which it is lacking. The speaker may decide not to define a concept, so that he is not committed to any specific account of its meaning. For instance, with the amendment 1034 to the US Code, a new meaning of "armed conflict" was stipulated, in which the boundaries of this concept set out by the Geneva Conventions (Article 1 of Additional Protocol II - Geneva Convention 1949) were extended to include also operations against terrorists and the supporters thereof. However, this amendment mentions two concepts whose meaning cannot be the same as the ordinary one (emphasis added): 
Omitting definitions: "Belligerent and Hostilities"

(4) the President's authority pursuant to the Authorization for Use of Military Force (Public Law 107-40; 50 U.S.C. 1541 note) includes the authority to detain belligerents, including persons described in paragraph (3), until the termination of hostilities.

In this definition the words "belligerent" and "hostilities" are not defined, even though their meaning cannot correspond to the ordinary one after the extended definition of "armed conflict". In 2009 "hostilities" was first defined as "any conflict subject to the laws of war." (10 U.S.C. $§ 948$ a 9). However, in the aforementioned stipulative redefinition of "armed conflict" the idea of "hostilities" could not be governed by the laws of war, as armed conflicts against terrorists cannot fall within the definition that is shared all over the world. Similarly, "belligerents" cannot be simply limited to soldiers, as the new category of "war" encompasses also terrorism and non-ordinary conflicts. The legislators omitted to define such terms, and the result was that a classificatory freedom was introduced, which could allow the extension of security measures, such as interrogation and detention, also to suspected terrorists ${ }^{31}$.

As mentioned above, omissions are deliberate non-actions, where the agent decides not to provide what is requested or needed in order to achieve a specific effect. The definition that is deliberately not mentioned is known not to be shared, and the effects of such an omission are known by the (non-) speaker. One of the clearest cases of this relationship between omission and its effects is the lack of the definition of "torture" in the Russian and Armenian Criminal Codes. The Russian and Armenian governments were requested to define such a crucial term in order to curb the violence denounced by Amnesty International and other international Authorities (CAT/C/34/Add.15, 15 October 2001, art. 1 (4), p. 3;

\footnotetext{
${ }^{31}$ See for instance the proposal of introducing the "enemy belligerent act in Enemy Belligerent Interrogation, Detention, and Prosecution Act of 2010. (Retrieved from http://www.govtrack.us/congress/bills/111/s3081 on 24 August 2012)
} 
CAT/C/SR.246, 1996; EUR 54/02/00, April 2000, par. 2). Such governments knew the effects of the absence of a definition, which allowed them to avoid prosecuting crimes of torture by categorizing them as "violations of professional discipline., ${ }^{32}$ Moreover, they had any power to comply with the request of the United Nations. The structure of the act of omitting a definition can be understood from the cases mentioned above and represented as follows:

\begin{tabular}{|c|c|c|c|c|c|}
\hline Move & $\begin{array}{c}\text { Content } \\
\text { conditions }\end{array}$ & $\begin{array}{c}\text { Speaker's } \\
\text { commitments }\end{array}$ & $\begin{array}{c}\text { Hearer's } \\
\text { commitments }\end{array}$ & $\begin{array}{c}\text { Effects on the } \\
\text { speaker }\end{array}$ & $\begin{array}{c}\text { Effects on the } \\
\text { hearer }\end{array}$ \\
\hline $\begin{array}{l}\text { Omitting (a speech } \\
\text { act }-F p \text { ) }\end{array}$ & $\begin{array}{l}\text { - Fp represents a } \\
\text { dialogical move. } \\
\text { - Fp can be } \\
\text { performed by } S \text {. }\end{array}$ & $\begin{array}{l}\text { - } S \text { has the } \\
\text { commitment to } \\
\text { perform } F p \\
(C F p) \text {. } \\
\text { - } C F p \text { results } \\
\text { from an } \\
\text { institutional or } \\
\text { social obligation. } \\
\text { - } S \text { knows that } \\
\text { non- } F p \text { causes } \\
\text { effect } E \text {. } \\
\text { - } S \text { knows that } F p \\
\text { is necessary to } \\
\text { avoid } E \text {. }\end{array}$ & & $\begin{array}{l}\text { - } S \text { is not } \\
\text { committed to } F p \text {. } \\
\text { - } S \text { is not } \\
\text { committed to } \\
\text { refuse }(F p) \text {. } \\
\text { - } S \text { is not } \\
\text { committed to } E \text {. }\end{array}$ & $\begin{array}{l}\text { - H's dialogical } \\
\text { situation has been } \\
\text { altered }(E) \text {. }\end{array}$ \\
\hline $\begin{array}{l}\text { Omission of the } \\
\text { definition of } \\
\text { "torture". }\end{array}$ & $\begin{array}{l}\text { Russian } \\
\text { (Armenian) } \\
\text { governments had } \\
\text { the power to define } \\
\text { "torture". }\end{array}$ & $\begin{array}{l}\text { Russia and } \\
\text { Armenia were } \\
\text { requested to define } \\
\text { "torture" and } \\
\text { blamed for not } \\
\text { doing it. }\end{array}$ & & $\begin{array}{l}\text { Russia (Armenia) } \\
\text { are not committed } \\
\text { to a specific } \\
\text { meaning of } \\
\text { "torture". }\end{array}$ & $\begin{array}{l}\text { The category of } \\
\text { "torture" can be } \\
\text { applied arbitrarily. }\end{array}$ \\
\hline
\end{tabular}

Table 5: Omitted definitions - Dialectical profile

The omission of the definition of "torture" clearly differs from the non-definition of "hostility" and "belligerent". In the first case the speaker's commitment to the speech act of defining (or refusing to do it) results from an explicit act (request). In other cases, the commitment can derive from an institutional (legal) or a communicative rule, "avoid ambiguity." In both cases, the speaker is aware of the requirement (or expectation) and deliberately refuses to comply with it, knowing its effects. The omission of a definition leads to a specific effect: the

\footnotetext{
${ }^{32}$ Torture in Russia: "This man-made hell". AI Index: EUR 46/04/97. Amnesty International April 1997 (pp. $28-$ 29). (Retrieved from http://www.amnesty.org/en/library/info/EUR46/004/1997/en on 21 September 2011)
} 
possibility of implicitly redefining the definiendum, or rather using it with new unshared meanings. This latter move can be considered as a distinct act of a kind, the act of implicitly defining.

\subsection{Implicit definitions}

The omissions of definitions are strategic moves as they do not prevent vagueness or ambiguity; on the contrary, they can introduce them. The absence of a definition leaves open the possibility of defining or redefining a concept. More importantly, the lack of an explicit description of a word meaning allows the speaker to stipulate it implicitly. The speaker can take advantage of a controversial concept, not explicitly defined, and use it with a new, unshared definition. In this fashion he simply takes its definition for granted; and treats it as it were already part of the community's common knowledge.

One of the most famous cases is the implicit redefinition of "hostility" used by Obama to classify the American intervention in Libya. In order to avoid requesting the Congress' authorization to continue the hostilities (War Powers Resolution, sec. 5b, Public Law 93-148), the President needed to exclude the bombings in Libya from the boundaries of the concept of "hostilities." He took advantage of the absence of its definition in the War Powers Resolution Act (US Code 1541). The vagueness of the boundaries of "hostilities" allowed Obama to redefine it to exclude the American strikes in Libya. He did not advance or impose any new meaning. He simply used the term claiming that it could only refer to ground troop intervention, sustained fighting and exchanges of fire. He presupposed a tacit definition from which airstrikes were excluded, let alone when carried out by unmanned aircraft (Obama Administration letter to Congress justifying Libya engagement, June $15^{\text {th }}, 2011$, p. 25$)^{33}$ :

\footnotetext{
${ }^{33}$ Retrieved from http://s3.documentcloud.org/documents/204673/united-states-activities-in-libya-6-15-11.pdf on 25 August 2012.
} 
Implicit redefinition: "Hostilities"

The President is of the view that the current U.S. military operations in Libya are consistent with the War Powers Resolution and do not under that law require further congressional authorization, because U.S. military operations are distinct from the kind of "hostilities" contemplated by the Resolution's 60 day termination provision. [...] U.S. operations do not involve sustained fighting or active exchanges of fire with hostile forces, nor do they involve the presence of U.S. ground troops, U.S. casualties or a serious threat thereof, or any significant chance of escalation into a conflict characterized by those factors.

Here Obama is not performing any explicit act of defining, nor is he rejecting or attacking the shared one. He is just taking such definition for granted (Macagno 2012). He presupposes that "hostility" means only "active fighting by ground troops", contrary to any accepted definition of the term under the US laws or military dictionaries.

Through his implicit act, Obama imposes a new meaning without being committed to any stipulation or any definitional standpoint. His tacit act binds the speaker and the audience to a specific commitment, i.e., that "hostility" meant only "active fighting by ground troops". Searle and Vanderveken provided a generic rule from indirect speech acts that can be used to describe this kind of implicit speech act performed through the use of the presupposed definition for classifying the bombings in Libya (Searle and Vanderveken, 2005: 130). On their view, the assertion of a classification $\left(F_{l}\left(p_{1}\right)\right)$ commits the speaker to its sincerity conditions, namely that he believes the "hostility" has the proposed meaning. However, the assertion is possible only if another act is performed $(F(p))$, consisting in the stipulation of a new meaning of such a concept. The classification commits the speaker to the illocutionary point of an implicit act, imposing that "hostility only means active fighting by ground troops". We can represent the commitment structure of this implicit act as follows: 


\begin{tabular}{|c|c|c|c|c|c|}
\hline Move & $\begin{array}{c}\text { Content } \\
\text { conditions }\end{array}$ & $\begin{array}{c}\text { Speaker's } \\
\text { commitments }\end{array}$ & $\begin{array}{c}\text { Hearer's } \\
\text { commitments }\end{array}$ & $\begin{array}{c}\text { Effects on the } \\
\text { speaker }\end{array}$ & $\begin{array}{c}\text { Effects on the } \\
\text { hearer }\end{array}$ \\
\hline $\begin{array}{l}\text { Performing }(F p) \\
\text { implicitly by } \\
\text { performing } F_{l} p_{1} \text {. }\end{array}$ & $\begin{array}{l}\text { - } F p \text { represents a } \\
\text { dialogical move. } \\
\text { - } F p \text { can be } \\
\text { performed by } S \text {. } \\
\text { - The } \\
\text { performance of } \\
F p \text { is a condition } \\
\text { of the } \\
\text { performance of } \\
F_{1} p_{1} \text {. }\end{array}$ & $\begin{array}{l}\text { (depend on the } \\
\text { nature of } F_{l} p_{1} \text { ). }\end{array}$ & $\begin{array}{l}\text { (depend on the } \\
\text { nature of } F_{l} p_{l} \text { ). }\end{array}$ & $\begin{array}{l}\text { - } S \text { is committed } \\
\text { to } F_{l} p_{l} \text {. } \\
\text { - } S \text { is not } \\
\text { committed to the } \\
\text { performance of } \\
F p \text {. } \\
\text { - } S \text { is committed } \\
\text { to } p \text {. }\end{array}$ & $\begin{array}{l}\text { - Commitments } \\
\text { resulting from } \\
F_{l} p_{1} \text {. } \\
\text { - Commitments } \\
\text { resulting from } \\
F p \text {. }\end{array}$ \\
\hline $\begin{array}{l}\text { The war in Libya } \\
\text { is not hostility } \\
\left(F_{1} p_{1}\right) \text {, as it does } \\
\text { not involve } \\
\text { sustained fighting } \\
\text { by ground forces } \\
\left(F_{2} p_{2}\right) \text {. }\end{array}$ & $\begin{array}{l}\text { Obama is } \\
\text { committed to the } \\
\text { sincerity } \\
\text { conditions and } \\
\text { illocutionary point } \\
\text { of "Hostility } \\
\text { means active } \\
\text { fighting by ground } \\
\text { forces". }\end{array}$ & $\begin{array}{l}\text { - } S \text { believes that } \\
H \text { does not } \\
\text { (already, at face } \\
\text { value, } \\
\text { completely) } \\
\text { accept } p_{1} \text {. } \\
\text { - } S \text { believes that } \\
\text { he can justify } p_{1} \\
\text { for } H \text { with the } \\
\text { help of } p_{2} \text { and } p \text {. } \\
\text { - } S \text { believes that } \\
H \text { accepts } \\
\text { (knows) } p \text { and } p_{2} \text {. }\end{array}$ & $\begin{array}{l}\text { - } H \text { is not } \\
\text { committed to } p_{1} \\
\text { (already, at face } \\
\text { value, } \\
\text { completely). } \\
\text { - } H \text { is committed } \\
\text { to } p_{2} \text { and } p \text {. }\end{array}$ & $\begin{array}{l}\text { Obama needs to } \\
\text { support } p_{1} \text { if } \\
\text { requested. }\end{array}$ & $\begin{array}{l}H \text { needs to attack/ } \\
\text { challenge/question } \\
p_{1} \text { or accept it. }\end{array}$ \\
\hline
\end{tabular}

Table 6: Implicit definitions - Dialectical profile

Obama performs this move to commit himself and the interlocutors to the redefinition of "hostility". In this case, Obama could not have stipulated explicitly such a definition, as he has not the authority to do so, nor could he have advanced it, as the nature of his act of defending a standpoint requires the previous acceptance of the definition.

Obama's move is extremely powerful from a dialogical perspective. He is inserting into the interlocutors' commitment store a proposition that they could not possibly have shared (and we know this because Obama stipulated the new meaning). Moreover, contrary to the act of advancing a definition, he did not have the burden of proof here. The dialogical outcome of his move is to shift the burden of proof. The interlocutors become committed to a proposition they never accepted, and they carry the burden of rejecting this commitment. 
They need to prove that the definition is not part of their common ground. In this case, the Members of Congress had to prove that the definition was not the accepted one, which became extremely difficult, as there is not a legal definition of the concept in the act. Obama, instead of advancing arguments to support an extremely controversial point of view, played the defensive role, consisting in assessing the acceptability of the rebuttals. The implicit redefinition changes the dialogical roles of the participants to the discussion, shifting onto the other party the burden of disproving a controversial (and unacceptable, in this case) meaning.

\section{Conclusion}

Definitions are not simply descriptions of meaning. They are not only equivalences between a word and a phrase. They are rhetorical instruments that can lead the interlocutor to a specific decision. They are acts that have different purposes and conditions. They are dialogical tools for altering and manipulating the hearers' commitments. The concept of persuasive definition underscores the rhetorical dimension of the definitions of specific words, called "emotive". By modifying their meaning or the values that they are associated with, the speaker can redirect the interlocutor's attitudes towards a situation. A war can become an act of peace, and thus it can be justified and praised; a felony can be presented as an act of loyalty, and thus it can be positively regarded. The meaning of a word can be described in different fashions, and be the content of different types of speech acts. The speaker can use a definition to stipulate a new meaning, or remind the audience of the shared one. However, he can perform definitional acts also by omitting definitions, or taking them for granted. These silent acts are the most dangerous and potentially mischievous ones, as they can be used to manipulate what the interlocutors are dialogically bound to, altering the burden of proof. The implicit redefinition represents the most powerful tactic for committing the interlocutor to a meaning that he has 
not agreed upon, nor that he can accept. The speaker thereby eludes the burden of proving an otherwise unacceptable proposition and shifts the burden of disproving it onto the interlocutor.

\section{References}

Anscombe, G. E. M. “Practical Inference.” Edited by R. Hursthouse, G. Lawrence, and W. Quinn. Virtues and Reasons, 1-34. Oxford: Clarendon Press, 1998.

Aqvist, L. "A new approach to the logical theory of actions and causality." Edited by S. Stenlund. Logical Theory and Semantics, 73-91. Dordrecht: D. Reidel, 1974.

Aristotle. "Topics.” Edited by J. Barnes. The complete works of Aristotle, Vol. 1. Princeton: Princeton University Press, 1991.

Aristotle. "Nicomachean Ethics.” J. Barnes. The complete works of Aristotle, vol. II. Princeton: Princeton University Press, 1995.

Bellavita. "Changing Homeland Security: What is Homeland Security?" Homeland Security Affairs, 4 (2008).

Bierce, A. The unabridged Devil's dictionary, Athens: University of Georgia Press, 2000.

Casanova, G. Historia della mia fuga dalle prigioni della republica di Venezia dette "li Piombi,", Milano, Alfieri e Lacroix, 1911.

Chiba, K. “Aristotle on essence and defining-phrase in his Dialectics.” Edited by D. Charles. Definition in Greek Philosophy, 203-251. Oxford: Oxford University Press, 2010.

Chisholm, R. Person and Object: A Metaphysical Study, London: Routledge, 1976.

Crothers, E. Paragraph Structure Inference. Norwood: Ablex, 1979.

Doyle, M. and N. Sambanis. Making war and building peace: United Nations peace operations. Princeton: Princeton University Press, 2006. 
Fusco, F. "Commencement of the prescription period in case of damage due to omissions." Edited by H. Koziol and B. Stiengel. Essential cases on natural causation, 79-93. Wien: Springer, 2008.

Glanville, W. Textbook of criminal law, London: Steven \& Sons, 1983.

Green-Pedersen, N. The Tradition of the Topics in the Middle Ages, Munich: Philosophia Verlag, 1984.

Hobbs, J. Coherence and coreference. Cognitive science, 3 (1979): 67-90.

Hobbs, J. On the Coherence and Structure of Discourse. Report No. CSLI-85-37. Center for the Study of Language and Information: Stanford University, 1985.

Houtlosser, P. Points of view. Edited by F. H. van Eemeren F. H. Crucial concepts in argumentation theory, 27-50. Amsterdam: SicSat, 2001.

Huxley, A. Eyeless in Gaza, London: Chatto \& Windus, 1955.

Kempson, R. Presupposition and the delimitations of semantics, Cambridge: Cambridge University Press, 1975.

Leonard, H. Principles of Reasoning, New York: Dover Publications, 1967.

Lewis, D. Scorekeeping in a Language Game. Journal of Philosophical Logic, 8 (1979): $339-359$.

Macagno, F. "Reconstructing and assessing the conditions of meaningfulness. An argumentative approach to presupposition." Edited by H. Ribeiro. Inside Arguments: Logic and the Study of Argumentation, 247-268. Newcastle upon Tyne: Cambridge Scholars Publishing, 2012.

Orwell, G. Politics and the English Language. Horizon. April (1946).

Perelman, C. and L. Olbrechts-Tyteca. Act and Person in Argument. Ethics, 62, no.4 (1951): 251-269.

Robinson, R. Definition, Oxford: Clarendon Press, 1950. 
Sager, J. Essays on Definition, Amsterdam: John Benjamins Publishing Company, 2000.

Searle, J. and D. Vanderveken. "Speech acts and Illocutionary logic.” Edited by D.

Vanderveken. Logic, Thought and Action, 108-132. Dordrecht: Springer, 2005.

Stevenson, C. L. The Emotive Meaning of Ethical Terms. Mind, 46 (1937): 14-31.

Stevenson, C. L. Persuasive Definitions. Mind, 47 (1938a): 331-350.

Stevenson, C. L. Ethical Judgments and Avoidability. Mind, 47 (1938b): 45-57.

Stevenson, C. L. Ethics and Language, New Haven: Yale University Press, 1944.

Stump, E. Dialectic and its place in the development of medieval logic, Ithaca, N.Y.: Cornell University Press, 1989.

Viskil, E. Defending Definitions: A Pragma-Dialectical Approach. Edited by F. H. van Eemeren, R. Grootendorst, J. A. Blair and C. A. Willard. Perspectives and Approaches: Proceedings of the Third ISSA Conference on Argumentation, vol. 1, 428-438. Amsterdam: Sic Sat, 1995.

von Wright, G. “On so-called practical inference.” Acta Sociologica, 15 (1972): 39-53.

Walton, D. “Omissions and other negative actions.” Metamedicine, 1 (1980): 305-324.

Walton, D. Argumentation Schemes for Presumptive reasoning, Mahwah, N.J.: Lawrence Erlbaum Publishers, 1996.

Walton, D. "Deceptive Arguments Containing Persuasive Language and Persuasive Definitions.” Argumentation, 19 (2005): 159-186.

Walton, D. and F. Macagno. "Reasoning from Classifications and Definitions." Argumentation, 23 (2008): 81-107.

Walton, D. and F. Macagno. "Defeasible Classifications and Inferences from Definitions." Informal Logic, 30 (2010): 34-61.

Walton, D., Reed, C. and F. Macagno. Argumentation Schemes, New York: Cambridge University Press, 2008. 


\section{Intolerance and the Zero Tolerance Fallacy}

Sheldon Wein, Saint Mary’s University

Summary

When an activity is unwanted, administrators often adopt a zero tolerance policy towards that activity. The background assumption is that, by adopting a zero tolerance policy, one is doing everything that one can to reduce or eliminate the activity in question. Yet which policy best serves to reduce an unwanted behavior is always an empirical question. Thus, those who adopt a zero tolerance policy towards some behavior without first investigating and finding that they are in a set of circumstances where that policy is the most cost-effective way of reducing or eliminating the undesirable behavior are committing the zero tolerance fallacy.

Key words: argumentation theory, critical thinking, fallacy (or fallacies), rhetoric, zero tolerance

\section{Introduction}

This short paper has two goals. The first is to convince people that, when people advocate or adopt a zero tolerance policy, they are frequently committing a fallacy. The second is to stimulate people who suspect such a fallacy is being committed to accuse those they think are committing the fallacy of committing the zero tolerance fallacy. What I am suggesting, then, is that we add something to the rhetorician's arsenal: a newly named fallacy to hurl at opponents. I am aware of the downsides of suggesting this. As Quine observed, "[r]hetoric is the literary technology of persuasion, for good or ill" and it holds "the goal of persuasion above the goal of truth" (1987: 183). I must therefore make at least a prima facia case that, in this instance, more good than ill is likely to result from introducing the rhetorical device of the zero tolerance fallacy into our conversations about public policy. ${ }^{34}$

\footnotetext{
${ }^{34}$ I recognize that not all accounts of rhetoric (or all rhetoraticians) accept Quine's view that the discipline holds persuasion above truth. Though I note that Aristotle, the founder of the discipline, held this view.
} 
When an activity meets with widespread public disapproval and politicians or administrators feel the need to react, they often adopt the rhetoric of "zero tolerance". The implicit (and sometimes explicit) message is that, by adopting a zero tolerance policy towards an activity, one is doing all that one can — at least all that one can qua policy adoption - to reduce or eliminate the activity in question. Yet which policy or policies should be adopted to reduce or eliminate an unwanted behavior is always an empirical question, the answer to which will vary with the particular circumstances. And in many circumstances (indeed, in most circumstances), adopting a zero tolerance policy (whether alone or in concert with other policies and actions) is not the best way to combat unwanted behaviors. Thus, those who adopt a zero tolerance policy towards some behavior without first investigating and finding that they are in a set of circumstances where that policy is the most cost-effective way of reducing or eliminating the undesirable behavior are committing the zero tolerance fallacy. Or so I will argue.

I begin with a quick overview of the nature of fallacies, and I argue, in this case at least, for a fairly narrow conception of what sorts of arguments should even be considered as candidates to become named fallacies. I then say a few things about when we should name a fallacious argument. I then characterize the zero tolerance fallacy and argue that it is sufficiently common and sufficiently dangerous to warrant being included among those fallacies we name (and I argue for the name "zero tolerance fallacy"). I follow this with a few remarks concerning why people commit this fallacy (and in the course of doing so seek to justify the first word in my title_- “intolerance"). I then turn to various objections and problems. I close with a summary of the benefits that would accrue were the term "zero tolerance fallacy" to become widely adopted. 


\section{The Nature of Fallacies}

There is a long tradition among those who study rhetoric and critical thinking to find and name particular fallacies. Aristotle observed that "some reasonings are genuine while others seem to be so but are not," and he used the term "fallacies" for those instances of reasoning that appear to be acceptable but in fact are not. ${ }^{35}$ Aristotle, and especially his followers, went on to name several, thus turning fallacy identification and naming into something of an intellectual cottage industry. Galileo, who in general was not a friend of the Aristotelians, offered a more liberal account of what a fallacy is, holding that any unsound argument — any argument that fails to be both valid and have only true premises — was fallacious. Thus, he writes:

Either those who are to be persuaded are capable of understanding the reasons of Copernicus and others who follow him, or they are not; moreover, either these reasons are true and demonstrative, or they are fallacious. If those who are to be persuaded are incapable, then they will never be persuaded by the true or by the false reasons; those who are capable of understanding the strength of the demonstrations will likewise never be persuaded if these demonstrations are fallacious; so neither those who do nor those who do not understand will be persuaded by fallacious reasons. Therefore, given that absolutely no one can be dissuaded from the first idea by fallacious reasons, it follows as a necessary consequence that, if anyone is persuaded of the contrary of what he previously believed, the reasons are persuasive and true. But as a matter of fact there are many who are already persuaded by Copernican reasons. Therefore, it is true both that

\footnotetext{
${ }^{35}$ On Sophistical Refutations 164a22.
} 
these reasons are effective and that the opinion does not deserve the label of ridiculous but the label of worthy of being very carefully considered and pondered (1615: 70).

An even broader use of "fallacy" occurs in a report of an incident between the Greenpeace ship Sea Shepherd and a Costa Rican shark-fishing boat. The Sea Shepherd Society, responding to a claim that the Sea Shepherd had endangered the crew of the Costa Rican fishing boat, wrote, "the video evidence proves this to be a fallacy". Here "fallacy" simply seems to mean "false claim". 36

The contemporary literature on fallacies sides with Aristotle against Galileo, restricting fallacies to a subset of invalid arguments. ${ }^{37}$ (The Greenpeace use is-rightly in my view—just ignored by contemporary critical thinking theorists as a case of overblown rhetoric.) Thus Gregory Bassham, William Irwin, Henry Nardone, and James M. Wallace, in their popular textbook, write that some "arguments are sound and convincing but many are fallacious. An argument is fallacious when it contains one or more logical fallacies. A logical fallacy_ or fallacy, for short—is an argument that contains a mistake in reasoning" (Bassham et al, 2011: 119, emphasis in original). ${ }^{38}$ So a fallacy is a mistake in reasoning — not just the acceptance of a false premise - and a mistake that is unlikely to be noticed and hence is likely

\footnotetext{
${ }^{36}$ See http://www.seashepherd.org/news-and-media/2012/05/13/captain-paul-watson-arrested-in-frankfurtgermany-on-warrant-issued-by-costa-rica-1374 and http://www.bbc.co.uk/news/world-europe-18066901 (19. August 2012).

${ }^{37}$ Some logically valid arguments—-for example, petitio principii—are fallacious. For simplicity I will ignore such cases here. A valid argument is one where, if all the premises were true, the conclusion could not possibly be false.

${ }^{38}$ Galileo's position remains attractive. In a note to the above, the authors describe this as a "narrow definition" because it excludes arguments with false premises.
} 
to be convincing. Joseph Heath puts the same point as follows: "Strictly speaking, a fallacy is simply an argument that takes you from true premises to a false conclusion. What makes it a fallacy, though, as opposed to simply a mistake is that a fallacy sounds right when you first hear it. In fact, it often requires considerable subtlety to see why a fallacious inference is, in fact, invalid" (2009: 309). Unfortunately, Heath's way of putting it obscures the fact that even an argument with false premises may be fallacious. What he should have claimed - and from the context it is clear that this was his intention - is that a fallacious argument is one such that, were the premises true, it still could lead you to a false conclusion, and where, despite this fatal flaw, the argument seems to be a good one. ${ }^{39}$ So, we may say that an argument is fallacious when it is invalid but appears to be valid. And the better the fallacy (qua fallacy), the more difficult it is to see that the appearance of validity does not correspond to the invalidity of the argument.

Trudy Govier adds another feature, saying that a fallacy is "a common mistake in arguing. It is a mistake in the reasoning that underlies an argument. The mistake can be quite deceptive by seeming to many people to be just like correct reasoning" (105, emphasis added). So fallacious arguments that are common are called fallacies.

We now have three conditions for an argument being an instance of a fallacy: it must be invalid, it must appear to be valid, and it must occur frequently. But not every type of common, deceptive, invalid argument becomes a named fallacy. For that to occur, the type of argument has to be plausible enough to appear to not be fallacious; it has to be plausible enough that it can pass as an instance of some type of good argument. An argument that is so obviously bad that no sane person would accept it does not get to be called an instance of a fallacy. Second, the argument has to be one that is used sufficiently often that it is worthwhile naming it as a fallacy. This seems to be the standard used by the authors of most critical

\footnotetext{
${ }^{39}$ Heath rightly ignores cases such as begging the question that are both fallacious and logically valid.
} 
thinking textbooks. For example, in the very popular Oxford University Press textbook, The Power of Critical Thinking (Canadian Edition), by Lewis Vaughan and Chris MacDonald, we find this:

There are certain types of defective arguments that recur so frequently that they have names (given to them, in many cases, by ancient philosophers or medieval scholars) and are usually gathered into critical thinking texts so students can become aware of them. Such common, flawed arguments are known as fallacies, and they are therefore said to be fallacious. Fallacies are often beguiling; they can seem plausible. Time and again they are psychologically persuasive, though logically impotent. The primary motivation for studying fallacies, then, is to be able to detect them so you're not taken in by them (2008:170-171, emphasis in original).

A rarely used argument which seems to be genuine but which is not really so might count as a fallacious argument, but we would not call it a fallacy. This is because fallacies are commonly used fallacious arguments_-indeed, those common enough to warrant naming them as fallacies. This use is employed even when one is not writing on argumentation theory, or rhetoric, or in core areas of critical thinking. Thus, Chris MacDonald, in "Critical Thinking for Business Ethics", says that fallacies are "errors in reasoning [that] are so common that, over the years, they've been given names" (2012: 33). In sum, uncommon errors do not get to be named fallacies.

To be fully accurate, one should say that named fallacies are arguments that would be frequently used in the absence of a name for the fallacy. This is because, in naming a fallacy, the hope of argumentation theorists, rhetoricians, and critical thinking scholars is to reduce the 
frequency of that type of reasoning. (That is also my reason for suggesting that "the zero tolerance fallacy" be added to our collection of named fallacies.) But, if our standard were that something is properly a named fallacy only if its use is sufficiently frequent to warrant giving the fallacy a special name, and if doing that were to substantially reduce the frequency with which people commit the fallacy, then by our standard we would have to drop the fallacy from our list of named fallacies (because, subsequent to naming it, its use would become infrequent). Sadly there is no reason to fear that this worry is one worth holding. People have been naming fallacies since Aristotle's time and, so far as I know, there has never been a case where naming a fallacy has been so effective in changing people's patterns of argumentation as to actually make the fallacy extinct. The best that argumentation theorists can hope for in pointing out a certain form of reasoning as fallacious is a modest decline in the use of that type of reasoning. Consequently, I will not worry that, by filling our critical thinking and argumentation texts with warnings against using the zero tolerance fallacy, instances of that fallacy will become so rare that the fallacy is not one worth bringing to people's attention.

Despite the foregoing standard for something becoming a named fallacy, I will use an even narrower standard. I will hold that we should add an argument form to our list of recognized fallacies if, and only if, the argument is invalid, distinctive, plausible (in Aristotle's sense of one that could easily be mistaken for a good argument), frequently used (or would be frequently used), and, finally, if its use frequently has significant harmful consequences. By the last condition I am suggesting harm that goes beyond just that of having people participate in erroneous reasoning. We already have a lot of named fallacies, and there is little reason for adding to our list if the form of fallacious reasoning causes little or no social harm. But use of common fallacious reasoning - fallacious in that it meets the first three conditions discussed above - that does cause serious social harm warrants being given a name. We need to be able to briefly identify instances of reasoning which are not just 
substandard but which also lead to significant social harms when people are taken in by them. My claim is that arguments of the type I am suggesting we call zero tolerance fallacies do meet all five of these individually necessary and jointly sufficient conditions for warranting becoming a new named fallacy.

To review, my conditions for adding a new fallacy to our collection of named fallacies are:

- the argument type is invalid

- it is a distinctive type of argument

- $\quad$ arguments of this type are often plausible (or seem to be valid)

- the argument type is frequently used

- the argument type is one whose use causes significant harm.

The above constitutes a rigorous standard for adding a new named fallacy to our collection. I will now characterize the fallacy I think we should name, showing that it meets the first three conditions above. I will not, in this paper, defend the position that arguments that I think should be called instances of the zero tolerance fallacy meet the last two conditions. I take the facts here to be sufficiently obvious for the reader to discern this for herself.

\section{Characterizing the Zero Tolerance Fallacy}

A zero tolerance policy is one that automatically imposes a punishment for any violation of a given social rule. Once such a policy is in place, those charged with enforcing the policy are forbidden from using discretion as to whether observed violations of the policy are to be brought to the attention of those charged with punishing violators; and there is no provision for the punishment to be lessened or altered to fit particular circumstances. The only issue that may legitimately be entertained is whether the rule was violated. If it was, then the 
fixed punishment is to be imposed. Almost always when zero tolerance policies are adoptedthough this is not essential - the offences are strict liability offences. Indeed, from here on I will assume that the offences are strict liability ones. In addition, the penalty attached is usually thought to be severe relative to the offence that was committed.

Sometimes people adopt a zero tolerance policy for good reasons. They may judge that some activity or behavior has harmful consequences (or is itself harmful) and that the best or most cost-effective way to eliminate or minimize the behavior is to adopt a policy of zero tolerance towards that behavior. Reasonable people may well disagree about whether the behavior is such that steps ought to be taken to reduce its occurrence, or they may think that having zero tolerance for such behavior is draconian. (For example, someone might advocate a zero tolerance policy towards the possession of a drug. Others might think there should be no penalty attached to possession or consumption of that drug. Still others might think that people ought to be discouraged from possessing and consuming the drug in question but hold that a zero tolerance policy is simply too extreme a tool for dealing with the matter.) But we can hardly hold that if such behavior is to be eliminated or reduced as much as possible, then advocating the best or most cost-effective means of reducing that behavior necessarily involves the advocate in a fallacy. Nor am I interested in considering here those cases where people disagree about whether a particular behavior is one we want to discourage. Our interest is in whether having a zero tolerance policy is an appropriate means to a social end, not whether that end is one the society should seek to attain.

Rather, I am concerned with cases where a zero tolerance policy is adopted because, while it may seriously be believed that adopting such a policy is a good way to reduce the behavior in question, there is no evidence, or there is inadequate evidence, to support this belief (or those advocating the policy do not know of such evidence). In general, then, we can say that one commits the zero tolerance fallacy when one advocates or imposes a zero 
tolerance policy towards some activity while lacking evidence for supposing that having zero tolerance for that activity will best serve to reduce the activity in question. ${ }^{40}$

\section{Motivation for Committing the Fallacy}

The normal motivation for committing the zero tolerance fallacy is that officials think they need to appear to be doing something to address a supposed problem. If some behavior is unwanted and nothing is being done by those responsible for regulating behavior in that area, there is the concern that those responsible will be seen to be irresponsible. But adopting a zero tolerance policy against the unwanted behavior is an easy way to be seen to be doing something forceful to eliminate the problem. This is because the policy is simple and applies in an on-off way, with no need to weigh the details of particular cases. Furthermore, the stiff penalties attached to violations give the appearance that authorities are taking the matter seriously and doing something about it.

But a zero tolerance policy may turn out to be counter-productive. For instance, those charged with carrying out the policy— that is, with enforcing it — may simply not enforce it, or it may be the case that their enforcement of it will be much more lax than it would have been had some more reasonable policy been adopted. Suppose that, for some reason, parents come to fear that their children will be endangered if things that might be used as weapons are allowed at their children's school. (This is a perfectly natural and strong fear and one that

\footnotetext{
${ }^{40}$ Here I assume that evidence can, in principle, be obtained. Of course, I allow that the methods of providing such evidence — statistical analysis, precedent, arguments by analogy, et cetera — are likely to be quite varied. I am not sure what we should say about cases where evidence cannot be obtained, either because obtaining such evidence is impossible (as it might well be in some instances about the distant past) or because obtaining the evidence would violate serious ethical or legal protections of privacy needed to ensure that individuals can pursue lives free from undue interference.
} 
sometimes hinders clear reasoning.) Suppose further that the school board or the school principal responds to these concerns by adopting the zero tolerance policy of forbidding students from bringing to school items that might be used as weapons. If those charged with enforcing the policy see the penalty attached as being overly severe, they may well not enforce the policy. They may simply pretend not to observe relevant violations of the rule, and in the end this practice may result in even less deterrence than there would be if a nonzero tolerance rule was in place to discourage such behavior.

In the case imagined above, if expulsion from the school is the penalty attached to violation of the new rule and a child is discovered to have accidentally violated the policy, teachers or playground supervisors might just look the other way. Or they might enforce the rule differentially, based on some prejudice they have. Either way, their actions (or lack thereof) may serve to undermine the very purpose or aim for which the zero tolerance policy was originally adopted. Things become much more complicated if children seize the opportunity to report on other children as a way of settling playground quarrels.

\section{Problems}

I now turn to several problems that arise from the idea that we should have a new named fallacy, the zero tolerance fallacy. First, and most obviously, the fallacy in a zero tolerance argument is often hard to identify because the fallacious argument is implicit. Most arguments (at least as they are first presented) include implicit assumptions or hidden premises. Indeed, fallacious arguments are less likely to be explicit than fully developed arguments are, for the simple reason that, once an argument is made explicit, it is often easier to determine whether it is fallacious (and, typically at least, those who employ fallacious arguments either do not realize they are doing so or, when they are aware of this, they certainly do not want their audience to know it). The typical argument for a zero tolerance 
policy is an enthymeme - an argument with a missing or suppressed premise. And it is typically this premise that lacks adequate support.

We might break this problem down as follows:

1. Fallacies are arguments, and rarely is a full argument provided for adopting a zero tolerance policy.

2. Such arguments as are provided for adopting a zero tolerance policy are almost always enthymemes.

3. Enthymemes pose increased difficulties in interpretation.

4. There are cases where there are valid — indeed sound - arguments for zero tolerance policies. (And these have the same logical form as the fallacious arguments.)

5. Sometimes we want policies or rules that are (in some sense) overly strict, and these cases are sometimes difficult to distinguish from others.

But we should note the following considerations that collectively weaken the objection. (The numbers below respond to each of the numbered points above.)

1. This is a standard problem with social rules - rarely is a full justification offered. (This is so even in so-called hard cases of law where, typically, experts go to great lengths to justify their favored interpretation of a social policy or principle. ${ }^{41}$ )

2. The enthymeme is almost always filled in along the following lines: (i) we have this unwanted behavior; (ii) having zero tolerance for the behavior is the best way to reduce/eliminate the behavior; (iii) we have adopted (and put into place) a zero tolerance policy regarding the behavior; (iv) therefore we are doing the best we can to eliminate/reduce the behavior.

\footnotetext{
${ }^{41}$ Ronald Dworkin (1978: Chapter 4) distinguishes hard cases from clear ones operationally. A legal case is a hard case when reasonable people knowing all the relevant facts, including all the facts of institutional history, disagree on the proper disposition of the case.
} 
3. Premise (ii) (or something like it) is almost always the one in need of evidential support. And it is almost always the one that lacks such support.

4. Sometimes people have support for premise (ii) (or such support is easily available), and in those cases the fallacy has not been committed (or the charge that it has been can easily be countered). Simply pointing out the existence of such evidence to those who object to the zero tolerance policy is generally a social good.

5. In circumstances where we want simple absolutist rules, we also want flexibility in enforcing those rules - precisely those circumstances where we do not want zero tolerance policies.

It is, of course, an empirical matter how often there is a more effective approach available to us to rid ourselves of a social ill than the adoption of a zero tolerance policy. At present we often lack good empirical data regarding how frequently this occurs. ${ }^{42}$ Indeed, we do not even know roughly what percentage of times zero tolerance policies are more or less effective than other options in even a limited area. (The articles by Wilson and Kelling (1982) and by Marshall (1999) are good places to start in reviewing the available data.) But this fact should not be seen to be an undue hindrance to adopting the language I propose. For consider the circumstances under which one is likely to claim that someone else has committed the

\footnotetext{
${ }^{42}$ Marshall (1999) contains a good discussion. Lacking solid data forces us to rely on the wisdom collected by others. Perhaps most relevant here is Montaigne's observations about having zero tolerance for ending a marriage. He observes that, "We have thought to tie the knot of our marriages more firmly by taking away all means of dissolving them; but the knot of will and affection has become loosened and undone as much as that of constraint has tightened. And on the contrary, what kept marriages in Rome so long in honour and security was everyone's freedom to break them off at will. They loved their wives the better because they might lose them; and, with full liberty of divorce, five hundred years and more passed before anyone took advantage of it" (1580, Chapter XV: 320).
} 
zero tolerance fallacy (or to worry that one is committing it oneself). It is quite likely that someone will have either proposed or already have put in place a zero tolerance policy about some activity or behavior. The opponent of this policy may object for roughly two types of reasons. First, of course, she may think that the behavior in question does not need to be restricted, that there is nothing wrong with the behavior in itself and that it will not lead to negative consequences (or, at least, not consequences that are serious enough to warrant restricting someone's liberty). Second, she may agree that the behavior in question ought to be reduced and simply think either that having a zero tolerance policy is likely to be ineffective or that it is overly harsh (most likely because, in practice, it is almost certain to result in punishing too many of those who, for one reason or another, ought not to be punished).

If the objection is really of the first type, the challenge is easily responded to simply by pointing out that the objector disagrees with the end the policy seeks to reach, not with the means to that end. Advocates and opponents of the end in question can then get on with the matter of debating that issue. If the objection is of the second type, the defender of the policy has several options. She can offer data supporting the idea that, in this case, a zero tolerance policy is more likely to work than other policies. This need not include sophisticated statistical analysis, for such may not be available. Something as simple as "We have looked at [or have tried] other options and none of them seem to work as well as zero tolerance" is sometimes all one needs to defend against the charge that one has committed the zero tolerance fallacy. But if the defender cannot offer such data or a compelling reason for thinking that in this sort of case the data is unlikely to be available, she and her supporters will doubtless be prompted to look for such data. If, on the other hand, she does have such data, then she has not committed the fallacy. Finally, in those cases where someone has adopted a zero tolerance policy without having supporting data that such a policy is more 
effective than other alternatives but she is able to quickly find such data - so that the fallacy has been committed - then the finding and reporting of such data in response to the challenge that she committed the fallacy shows that, in this case, committing the fallacy itself did little harm. Furthermore, the charge that the fallacy had been committed will have had the virtue of bringing to light relevant data about what modifies behavior in this type of situation.

So, in general, it seems that making the claim that someone who has adopted or advocated a zero tolerance policy has committed a fallacy—viz., the zero tolerance fallacy—is likely to have positive results. Either the disagreement will be seen to be about ends rather than means, or if the end is agreed upon and the means are what is disputed, then both sides will turn to the issue of finding evidence to support their positions. And, we can hope, the side with the strongest evidential support is the one that will win that debate. Thus, we will be more likely to have zero tolerance policies confined to those situations where they are somewhat likely to accomplish what people hope they will.

\section{Good Zero Tolerance Arguments ${ }^{43}$}

I have been arguing that we need a new named fallacy, the zero tolerance fallacy. And I have been seeking to characterize that fallacy. But one might think that I should have proceeded in a different way. Given that there are cases where there is good reason to adopt zero tolerance policies and given that there can be good arguments for adopting such policies, it would, in those cases, seem that the logical way to proceed would be to characterize the structure of good or acceptable zero tolerance arguments, and then to characterize zero

\footnotetext{
${ }^{43}$ I am grateful to Leo Groake both for suggesting this approach and for pointing out the analogy that I consider here. His "Logic: Informal" entry in the Stanford Encyclopedia of Philosophy is a very useful place to start thinking about these matters. (See in particular the sections titled "Fallacy Theory" and "An Example: Ad Hominem," as well as the literature Groake cites there.)
} 
tolerance fallacies as cases that simply fail in some respect to live up to the standard of a good zero tolerance argument. An analogy is with ad hominem arguments. For years, indeed centuries, logicians have treated these simply as fallacies. But since there are obviously perfectly good ad hominem arguments, some have recently suggested that we should seek to establish what makes good ad hominem arguments good while identifying those ad hominem arguments which fail to live up to this (as yet not fully developed) standard as instances of the ad hominem fallacy. This approach strikes me as potentially quite fruitful. My reason for not using it here is that it will almost certainly involve more than can be accomplished in a single short paper. On this very point, the analogy with ad hominem arguments is again helpful: while we have many accounts of ad hominem fallacies, we are still working towards a full account of what makes a successful ad hominem argument a good one. (For an interesting attempt along these lines, see Dahlman et al, 2011.) I would be extremely pleased if, in addition to making the idea of a zero tolerance fallacy a popular one, my work were to stimulate critical thinking theorists to work on the development of standards for successful zero tolerance arguments. That is a worthy goal, for then we could characterize arguments which commit the zero tolerance fallacy as simply those arguments which attempt to defend zero tolerance policies but which fail to live up to the proper standards (whatever those might be) for being a good zero tolerance argument. However, it is important to note that we should not tolerate bad zero tolerance arguments while we wait for argumentation theorists to provide us with an account of what constitutes a good argument for zero tolerance policies.

\section{Conclusion}

I am aware that "to label the view of your philosophical opponent a 'fallacy' is, much more often than not, a cheap rhetorical trick" (Joyce, 2006: 152). Nonetheless, I hope I have demonstrated that having something called "the zero tolerance fallacy" as part of our social 
and political rhetoric would be, on balance, a good thing. In those cases where zero tolerance policies are inappropriate, having a named fallacy would serve as a useful rhetorical device to make this fact known in a simple and accessible manner. And in cases where one might allege that the zero tolerance fallacy has been committed, defenders of the policy could easily respond, and their responses would serve to move the discussion to just those areas that are most likely to be productive of improved critical thinking about what social rules or policies we should endorse. In the end, were we lucky, all of this might help reduce the unwarranted use of zero tolerance policies and nudge the level of intolerance slightly closer to zero. ${ }^{44}$

\footnotetext{
${ }^{44}$ I am grateful for comments I received after presenting some of these ideas at the Days of Ivo Škarić conference in Postira, Brač, Croatia (2012 April $20^{\text {th }}$ ) and from a generous anonymous referee. I especially want to thank Thea E. Smith for her help and Gabrijela Kišiček for doing such a splendid job of organizing the conference.
} 
References

Bassham, G., Irwin Wm., Nardone H., and J. M. Wallace. Critical Thinking, New York: McGraw Hill, 2011.

BBC News Europe. “Sea Shepherd founder Paul Watson faces extradition.” Accessed August 19, 2012). http://www.bbc.co.uk/news/world-europe-18066901

Dahlman, C., Reidhav D., and L. Wahlberg."Fallacies in Ad Hominem Arguments" Cogency. 3, No. 2 (2011): 105-124.

Dworkin, R. Taking Rights Seriously, London: Duckworth, 1978.

Galileo, G. [1615]. “Galileo's Considerations on the Copernican Opinion.” Galileo's Considerations on the Copernican System, from The Galileo Affair, Edited by Maurice Finocchiaro. Berkeley: University of California Press, 1989.

Govier, T. A Practical Study of Argument, Second Edition, Toronto: Wadsworth Publishing Company, 1998.

Groarke, L.“Informal Logic.” The Stanford Encyclopedia of Philosophy, Edited by Edward N. Zalta. 2012.

Heath, J. Filthy Lucre, Toronto: Harper Collins, 2009.

Joyce, J. The Evolution of Morality. Cambridge, MA: MIT Press, 2006.

MacDonald, C.“Critical Thinking for Business Ethics,” forthcoming in Aspects of Business Ethics: Foundations, Contents, and Canadian Perspectives. Edited by Peter Kissick. Emond Montgomery Press, 2012.

Marshall, J. “Zero tolerance policing.” South Australia Office of Crime, 9 March 1999.

Montaigne, M. de [1580]. The Complete Essays of Montaigne, Translated by Donald M. Frame. Garden City, NY: Anchor Books, Doubleday and Company, 1960.

Quine, W.V.O. Quiddities: An Intermittently Philosophical Dictionary, Cambridge, MA: The Belknap Press of Harvard University Press, 1987. 
Sea Shepherd. "Captain Paul Watson Arrested in Frankfurt, Germany on Warrant Issued by Costa Rica.” Accessed August 19, 2012. http://www.seashepherd.org/news-andmedia/2012/05/13/captain-paul-watson-arrested-in-frankfurt-germany-on-warrantissued-by-costa-rica-1374

Vaughan, L., and C. MacDonald. The Power of Critical Thinking (Canadian Edition), Toronto: Oxford University Press, 2008.

Wilson, J.Q., and G.L. Kelling."Broken Windows: The police and neighborhood safety.” The Atlantic Monthly, March 1982. 
II POLITICAL DISCOURSE 


\section{Political Discourse and Argumentation Profiles}

Hans V. Hansen, University of Windsor

\section{Summary}

A way in which argumentation workers can be of value to society and have their field of study and expertise recognized is proposed: it is to make profiles of the argumentation behaviour of political parties during election campaigns. The profiles are to be made in terms of concepts unique to the study of argumentation: argumentation schemes and dialectical roles, for example. The argumentation profiles will be of value to members of the voting public, as well as the political parties. Moreover, undertaking such empirical research affords an opportunity for argumentation workers to test the efficiency and adequacy of their concepts.

Key words: argumentation worker, argumentation agent, argumentation profile, dialectical role, dialogical role, dialogical position.

\section{Introduction}

Can we argumentation workers ${ }^{1}$ be of any use to society? Yes, we teach many students to write, analyse and evaluate argumentation, and this undoubtedly makes them better at dealing with arguments and ideas, and maybe even makes them better citizens. Still, our contribution overlaps with, and tends to be fused and confused with, the work done by our colleagues who teach history, civics, economics, grammar, politics, philosophy, psychology, and sociology, etc. There is nothing wrong with that: education is about the integration of knowledge and harmonizing of skills. But that the original work of the argumentation worker gets put in the mix with that of so many other fields, all of which have a better known history and higher recognition value, makes it hard for the public, and education programmers and

\footnotetext{
1 'Argumentation worker' is my term for those who work with arguments and argumentation (qua arguments and argumentation). Calling ourselves 'scholars' or 'theorists' may be saying too much; 'analysts' too little.
} 
administrators, to appreciate the fact that argumentation work constitutes a unique and important field of research and teaching. We need to show both the academic and the nonacademic worlds that we have an original and valuable contribution to make. I expect there will be a number of different ways we can make our presence felt and appreciated. This paper outlines the suggestion that we promote ourselves through the development of what may (tentatively) be called argumentation profiles.

\section{Argumentation profiles}

An argumentation profile is a description or characterization of argumentation behaviour over time as exhibited by an argumentation agent — an individual or a group, party, or collective that makes and takes responsibility for arguments.

How can argumentation profiles be of social value? Argumentation-behaviour is important for democracy: we want to elect people who will not only argue well, but also argue openly, fairly, and productively. Past argumentation-behaviour encapsulated in an argumentation profile may be considered a predictor of future argumentation-behaviour.

Argumentation profiles may also be a window through which we can come to understand an argument agent's true political attitudes. Richard Weaver, in his 1952 work, The Ethics of Rhetoric (p. 55) wrote that "[a] reasoner reveals his philosophical position by the source of arguments which appears most often in his major premise because the major premise tells us how he is thinking about the world" and that "a man's method of argument is a truer index in his beliefs than is an explicit profession of principles" (p. 58). In other words, 
we can learn something about a person's political beliefs and deep-seated attitudes by looking at the record of his or her argumentation. ${ }^{2}$

Weaver maintained that the eighteenth century political theorist, Edmund Burke, whom we recall as a conservative, mostly used the argument from circumstance in his speeches and writings, a kind of argument more appropriate to expediency and liberal politics than to conservatism. In contrast he associates the argument from genus with Abraham Lincoln, a kind of argument usually associated with conservatism and the status quo; yet Lincoln is cherished as a pragmatic and liberal politician.

So, what we may take from Weaver is that the arguments agents make tells us something important, perhaps revealing and surprising about that agent. Below Weaver's insight is extended by taking political parties as subjects, not just individuals, and by expanding the number of indexes (beyond major premises) that can contribute to characterizations of argument agents - to profiles. The focus is on the profiles that can be made of agents engaged in political argumentation, but profiles could also be made of argumentation agents in other fields like science, law, ${ }^{3}$ and religion.

Some people have identified a male way of conducting argumentation, and found it objectionable. A generalization about the way men argue is implicitly a fragment of an argumentation profile of men. That there are such generalizations is an indication that there is a rough, or intuitive, idea of argumentation profiles already at large. The present proposal aims to give shape and character to such profiles.

\footnotetext{
${ }^{2}$ Weaver mentions four kinds of arguments: (i) the argument from genus or definition, (ii) similitude arguments, (iii) the argument from consequences, and (iv) the argument from circumstance.

${ }^{3}$ See, e.g., Cassel (2012).
} 
A notable aspect of argumentation profiles is that they do not characterize argument agents on the basis of isolated argument behaviour - a particularly ingenious analogy, or an atrocious fallacy, for examples - but on their argumentation behaviour over a period of time. Thus, the import of profiles is that they will indicate how agents have been disposed to engage in argumentation in the past, and how they may be inclined to argue in the future.

\section{Concepts put to work}

An argumentation profile of an argument agent should be based on an analysis of the agent's argumentation-behaviour over a period of time and executed in terms of concepts unique to the study of argumentation. Thus, when making profiles of argumentation behaviour in political contexts it is not the usual issue-oriented categories we need such as views on the economy, education, energy, the environment, and health care. The concepts needed for argumentation profiles will be quite different. They do not have to do with policies or platforms, or party philosophies. Which concepts in particular will be useful for making profiles is something we will have to find out through experimentation, but it is reasonable to begin by testing some of the concepts argumentation workers already have to hand.

Doug Walton and I have finished one pilot study of the argumentation in political campaigns, and we are now engaged in a second one. ${ }^{4}$ Our work is similar to that of William Benoit who has studied the argumentation in the nomination acceptance speeches by presidential candidates in the United States from 1960 to 1996 . In one study three basic functions in the speeches were recognized, which were distinguished as acclaiming, attacking and defending.

\footnotetext{
${ }^{4}$ We studied the Ontario provincial election held in September-October 2011 (see Hansen and Walton, 2012b), and we are now gathering data on the provincial election held in Alberta, March-April, 2012.
} 
Themes that portray the sponsoring candidate or party in a favorable light are acclaims. Themes that portray the opposing candidate or party in an unfavorable light are attacks. Themes that explicitly respond to a prior attack on the candidate or party are defenses. (Benoit 1999, 254)

Benoit's leading research question was, "What is the relative frequency of use of the functions of acclaiming, attacking and defending?” (P. 253) He found that the Democratic Party nominees engaged in acclaiming slightly more than the Republican party nominee did (77\% to $68 \%$ ) but that the roles were reversed when it came to attacking ( $30 \%$ to $23 \%$ ) as well as defending (16\% to 3\%). Clearly, Benoit's interests and approach are consonant with our programme of creating argumentation profiles by studying the argumentation behaviour of argument agents. Our approach differs from his, however, in that we focus on arguments as the basic of unit of interest.

In our first study, Walton and I sketched profiles on the basis of which kinds of arguments and dialectical roles were utilized most frequently by the agents. In our second study we are modifying and enlarging our inventory of argument kinds and roles, and adding some other categories whose utility we want to test. We are experimenting to find out which factors and categories can contribute to the making of useful argumentation profiles. The following list of concepts is being considered:

1. Argument kinds: The primary classification tool we have is a list of kinds of arguments, also called argument schemes. The schemes are, roughly, definitions of different kinds of arguments. A comprehensive list of the kinds of arguments that occur in political argumentation will help shape a picture of an agent's inclinations in argumentation. In our first study we used the basic inventory of schemes identified in Walton's Fundamentals of Critical Argumentation (2006), and we will use the same list again, modified in light of what 
we learned in that study. The kinds of arguments we identified, in descending order of frequency, were these:

Negative Consequences, Practical Reasoning, Positive Consequences, Argument from Sign, Fairness, Direct ad hominem, Inconsistent Commitments, Popular Opinion, Analogy, Commitment, Position to Know, Ad Hominem Circumstantial, Misplaced Priorities, Authority, Classification, Explanation, Values, Argument from Alternatives, Cause to Effect, Correlation to Cause, Sympathy.

In constructing argumentation profiles, one looks to see which kinds of arguments are preferred by the argument agent.

2. Pragma-dialectical argumentation schemes: It is also possible to classify arguments broadly on the basis of the kind of conduit they provide from premises to conclusions. Pragma-dialectical theory offers a three-fold classification in this category: symptomatic argumentation, instrumental argumentation, and similarity argumentation (van Eemeren and Grootendorst 1992: $94 \mathrm{ff}$.). Even though there are only three 'schemes' here they have the advantage that they are mutually exclusive and jointly exhaustive, or at least appear to be so. (The same cannot be said for the informal logic schemes: with them it is possible that an argument could instance two schemes, and then a decision has to be made about which scheme is the better fit to the argument.) Nevertheless, because there are only three schemes in this typology, we can only expect very general information to come from this classification. But, as before, one is curious to see if an argument agent prefers one kind of scheme to the others.

3. Aristotle's pisteis: Aristotle's three artificial means of persuasion might also give us some insight into the argumentation proclivities of agents (See Rhet. 1356a). We will attempt to classify arguments on the basis of whether it is logos (appeal to evidence), ethos (character) or pathos (emotion) that is brought to bear. 
These first three categories of classification (kinds, schemes, pisteis) have to do with the internal nature of the arguments themselves - they are ways of classifying either the kind of reasons brought to bear, or the way that the reasons are related to the conclusion. It is also possible to study the external (relational) properties of arguments in an ongoing political discussion, in particular to consider the roles, or functions, of the arguments in the ongoing discussions.

4. Dialectical roles: Argument agents have purposes they want to achieve by the use of their arguments and thus the arguments are instrumental to their ends. Hence, given a context like that of a provincial or national election, arguments may be seen as being used for certain purposes by the agents in the argument exchanges. These purposes can be classified and accordingly arguments used may be seen as playing a role. There is no determinate list of ends arguers have in using arguments, and so no determinate catalogue of roles has been established. Walton and I felt free to invent a short list of four dialectical roles which we noticed recurring in the data of political campaign arguments. These were the policy-positive role (used to defend a statement or policy), the policy-critical role (used to criticize a statement or policy), the person-critical role (used to criticize an opponent rather than his/her position), and the defensive role (used to deflect criticisms). After reading Benoit (op. cit.) we added a fifth by dividing his category of acclaiming into positive and negative roles, allowing us to add a person-positive role.

Studying an argument agent's choice of roles will tell us something not only of his/her/ its resources, but also about the possibilities it sees for advancing its cause. The analysis of dialectical roles must, however, be tempered by the following two dialogical considerations.

5. Dialogical roles: Is an argument being used to initiate discussion of an issue, or is it a response-argument, made as a reply or alternative to an argument or policy already before the 
public? My hunch is that response arguments are more likely to be cast in a negative role than arguments that introduce a new topic or policy. But it is not impossible that a response argument has a positive role or that an initiating argument has a negative one. This is a factor to take into consideration when constructing argumentation profiles.

6. Dialogical position: Whether an argument agent is the incumbent party or a challenger establishes his/her/its dialogical position, is something which may well affect the choice of dialectical roles an agent gives to arguments. My inkling is that an incumbent party is more likely to have occasion to use the defensive role, clarifying misinterpretations, and defending policies. Challengers we would expect to be on the attack, being critical of both policies and incumbents. Of course, both sides will likely make arguments in all the roles, but certain roles may predominate for an agent during the course of a campaign. In sum, in constructing the argumentation profiles, both the dialogical positions of the agents, and the dialogical roles of their arguments, must be taken into consideration.

The above concepts present themselves as being of interest to argumentation workers who attempt to make argumentation profiles. To illustrate the kind of analysis we have in mind, consider the following example taken from the Alberta provincial election this spring.

In this example, the party in power, the Government, is being criticized for proposing a new law that would impose "penalties on drivers with a blood-alcohol concentration above $.05 "$. In response the Solicitor General made this argument,

This [law] targets people who habitually drink and drive, ... When similar legislation has been enacted elsewhere, it has had the effect of reducing the amount of alcoholrelated injuries and fatalities on the road. (Calgary Herald, 2012.)

This is an interesting example because it is both clear and complicated. It is indicative of the kinds of challenges our research will face. It is clear because it immediately told us that 
because of the presence of the word 'similar,' this is an Analogical Argument; however, both the minor premise and the conclusion are unstated, and so we reconstruct the argument as follows (placing the elements added in reconstruction inside square brackets):

In other jurisdictions, imposing penalties on drivers whose blood alcohol concentration exceeds .05 per cent has had the effect of reducing the number of alcohol-related injuries and fatalities on the road;

[Our jurisdiction, Alberta, is relevantly similar to the other jurisdictions];

[So, imposing penalties on drivers whose blood alcohol concentration exceeds .05 per cent, will have the effect of reducing the number of alcohol-related injuries and fatalities on Alberta roads.]

The sample also presents a complication since although it is an Argument by Analogy, it is also a case of Practical Reasoning: an end is specified as desirable (" reducing the number of alcohol-related injuries and fatalities on Alberta roads") and a means is proposed ("imposing penalties on drivers whose blood alcohol concentration exceeds .05 per cent"). We are then left with a case in which one argument is an instance of at least two schemes. If we want to have a one-to-one match of arguments with argument kinds, however, we will have to make a decision. In this case, I am inclined to treat this as being an Analogical Argument for the reason that in the context of political election campaigns a great many of the interchanges concern practical affairs, and therefore what will be of interest from the point of view of the empirical study of argumentation is the various ways that politicians encapsulate their practical reasonings about how to deal with the matters of concern. Let us then consider our example to be of the kind, Analogical Argument.

As an analogical argument our example is an instance of the Pragma-Dialectical similarity scheme. (If one considers it as belonging to the argument kind Practical Reasoning, 
then it will be an instance of the causal argumentation scheme.) The argument is best classified as an instance of the logos means of persuasion since there is no appeal to either character or emotion in view. The dialectical role of the argument is to defend a policy; the dialogical role is that of response, and the dialogical position is that of the incumbent.

\section{Illustration}

Elaine Cassel has 'profiled' the argumentation behaviour of members of the United States Supreme Court during the recent hearings about Obama-care. She found, through looking at their argumentation behaviour, that some of the judges showed empathy and compassion for poor people, some were of even temperament, some showed an authoritarian approach to legislation, some kept their politics out of their argumentation and stuck to legal arguments, some remained aloof from the fray. Cassel claims to have learned something about the judges by studying their argumentation (see Cassel 2012).

Suppose we obtained the following result for three parties in a given election:

\begin{tabular}{|l|l|l|l|}
\hline Priority rankings & \multicolumn{1}{|c|}{ Party A } & \multicolumn{1}{|c|}{ Party B } & \multicolumn{1}{c|}{ Party C } \\
\hline ARGUMENT KINDS & Practical reasoning, & Negative consequences; & Fairness; \\
& positive consequences; & direct ad hominem; & Analogy; \\
& fairness & misplaced priorities & Sympathy \\
\hline PD SCHEMES & instrumental & Symptomatic & similarity \\
\hline PISTEIS & Ethos & Logos & pathos \\
\hline DIALECTICAL ROLE & policy $+;$ person $+;$ & person $-;$ policy $+;$ & policy + ; person $-;$ \\
& defensive & policy - & person + \\
\hline
\end{tabular}




\begin{tabular}{|l|l|l|l|}
\hline DIALOGICAL ROLE & response; initiator & initiator; response & initiator; response \\
\hline DIALOGICAL & Incumbent & Challenger & challenger \\
POSITION & & & \\
\hline
\end{tabular}

What might we say about these results? We might venture these thumbnail sketches:

Party A: Problem-solution oriented but balanced with considerations of fairness; depends on credibility of agent; stresses the advantages of own policies and leadership; corrects misinterpretations and deflects criticism.

Party B: Depicts incumbent party as having bad policies, and attacks character of its members; wants to establish alternative goals; sees policies of government as indication of corruption; appeals to statistics and public opinion; puts priority on criticizing opponents over promoting own policies; initiates lines of discussion (criticism) more so than responding to the ideas of others, indicating an attempt to control the discussion.

Party $C$ : Primarily concerned with social justice; makes case by drawing comparisons to other more vivid injustices; appeals to sympathy of electorate; initiates lines of argument stressing value of its own policies and is somewhat critical of incumbent and other opponent; tries to change agenda to discuss its own issues; depicts itself as having a high moral character.

Notice that these argumentation profiles are descriptive, not evaluative. Some argumentation workers would go further and, from a distant point of view, evaluate the arguments and argumentation of each of the agents, and thus create an evaluative argumentation profile of agents. Christian Kock, for example, urges that the argumentation of politicians should be evaluated from the point of view of whether it meets the needs of the voting public in its quest to make an informed decision at the ballot box (Kock 2011, 14). 
However, until the methodology of making argumentation profiles is better developed it may be advisable not to take a position on the quality of individual agents' argumentative behaviour because that can be interpreted as partisanship and sink our scientific aspirations. Instead we should lay out our findings in vivid and accessible detail, letting the public make of it what it will. My anticipation is that, properly packaged, we can catch its eye.

\section{Summary}

I began by suggesting that one way in which argumentation scholars could distinguish their work from that of their colleagues, and show their usefulness to society, was to construct argumentation profiles of politicians' behaviour during election campaigns. I have suggested some of the concepts that could be the building blocks of such profiles. Why are such profiles of value?

A. Value to voters. Voters may want to take profiles into consideration when making their decisions at the ballot box: not only do we want to support politicians who advocate policies we approve of, we also want to elect people who will conduct themselves in an intellectually capable and responsibly manner if they are elected. Profiles can be an indicator of future argumentation behaviour.

B. Value to political parties. Political parties will be interested in their own profile as well as those of their opponents. This is especially so if the public takes the view that they want their politicians to behave in an intellectually responsible manner, they will want to know how they can improve their own profile and how they can take advantage of their opponents' weaknesses as revealed in their profiles.

C. Value to argumentation workers. Profiles of parties (or individual politicians) can be tailored for consumption in the public media, e.g., newspapers, radio, television, blogs, etc., 
either during a campaign or shortly afterwards, as long as public interest endures. This is a way to bring the work of argumentation workers to the attention of the public. Walton and I

have done this. ${ }^{5}$ To this end one will find using the broader more intuitive categories like the dialectical roles, most suitable. In general, the greater public doesn't care to distinguish three kinds of ad hominem arguments.

\section{Externalities}

Argumentation profiles can contribute directly to the quality of political life by providing information that is vital to political parties who are argument agents, and to citizens who must evaluate those parties. There are, in addition, a number of spin-offs, or externalities, of doing argumentation profiles that can be felt within the academy.

D. Inter-disciplinary cooperation. Argumentation workers need the cooperation of at least three other fields in order to make argumentation profiles sound and valuable. (1) These profiles will profit from being supplemented with communication factors which take into account other components: tone of voice, posture, choice of language, etc; hence, coordination with communication workers with complementary interests will make the argumentation profiles more valuable. (2) Our analyses can be enriched by the participation of social psychologists, people who study personality, group behaviour, and social cognition. (3) Creating profiles of political behaviour invites participation and cooperation with colleagues in political studies. We should engage the cooperation of workers from these other disciplines, but keep the argumentation profile as the central, unifying component.

E. Concept testing. What argumentation theorists themselves should find valuable about this kind of study is that it allows them to test their concepts. This is especially so for the list of

\footnotetext{
${ }^{5}$ See Hansen and Walton (2012a).
} 
informal-logic argument schemes and the dialectical roles. Whereas text books look for arguments they can use to illustrate schemes, we look for a list of schemes that will be adequate to the identification and classification of all the arguments in a given field of discourse. What is optimal here? We need a balance between what is useful and manageable. This means that the list of argument kinds (schemes) should be comprehensive enough to allow classification of all the arguments found in the discourse, but it should not be so finegrained that it will introduce minute distinctions that have little or no consequence for the making of argumentation profiles.

F. Student participation. Student participation in gathering, classifying and analysing the arguments used in the creation of the profiles is important for at least two reasons. The one has to do with the user-efficiency of the concepts and methods of informal logic. If these cannot be used by university students at the upper undergraduate level, or the beginning graduate level, then we have lost sight of an important goal of informal logic viz., to provide tools of analysis and evaluation useful to the public in general. In gathering the information needed for making the profiles, we can observe how well our students do with the materials we provide for them to work with, and make adjustments as needed The other reason to have student involvement in the making of the profiles is to stimulate interest in election campaigns among young people. Only 38 per cent of the 18-24 age group voted in the 2011 federal election in Canada. (Edmonton Journal, 2012)

This completes my case for seeking the involvement of fellow argumentation workers in the study of political campaigns, and the value of making argumentation profiles.

\section{References:}

Aristotle. Rhetoric. (Many editions). 
Benoit, William L. "Acclaiming, attacking and defending in presidential nomination accepting addresses, 1960 - 1996”. Quarterly Journal of Speech 85, (1999): 247-67.

Calgary Herald. "Drunk driving laws divisive; Opposition strongest in Calgary." (March 30, 2012).

Cassel, E. "Profiling the Supremes: Politics \& Personalities on Display in Arguments Over ObamaCare.” Counterpunch. Accessed April 12, 2012. http://www.counterpunch.org/

Edmonton Journal. "Party leaders try to rally the student vote." April 10, 2012.

Eemeren, Frans H van, and Rob Grootendorst. Argumentation, Communication and Fallacies. Hillsdale: Erlbaum, 1992.

Hansen, Hans V. and Douglas N. Walton. "Four key ways politicians use arguments." Windsor Star, February 6, 2012a. http://www.windsorstar.com/news/Four+ways+politicians+arguments/6106681/story.ht ml\#ixzz1rjUkqAXK

Hansen, Hans V., and Douglas N. Walton. Argument kinds and argument roles in the Ontario provincial election, 2011. [under review] 2012b.

Kock, Christian. De svarer ikke. Copenhagen: Gyldendal, 2011.

Walton, Douglas N. Fundamentals of Critical Argumentation. Cambridge: Cambridge University Press, 2006.

Weaver, Richard M. [1985]. The Ethics of Rhetoric. Davis, Calif.: Hermagoras Press, 1952. 


\title{
Rhetoric of the Crisis. Polish parliamentarian debates on the future of the EU
}

\author{
Agnieszka Kampka, Warsaw University of Life Sciences - SGGW
}

\section{Summary}

The analysis of the Polish parliamentary debates on the Euro zone crisis indicates in what ways politicians use metaphors to construct the situational definitions. The paper shows the common area of the three notions of the rhetorical situation, definition of the situation and the persuasive definition. It serves to answer the question, what factors influence the way of presenting the given aspects of reality in the public speeches. The examples of the metaphors used in the debates are recalled in the context of the functions that similes may play in the political discourse.

Key words: metaphor, rhetorical situation, crisis, parliamentary debates

Democracy assumes that people may disagree both as to the ends and the means of action. Tough social situations, such as an economic crisis and increasing discord in metastate institutions make differences and conflicting views more evident and visible. There are different ideas in the society as to the ways of solving problems. In addition, the differences are also present in the definitions of the problems. Therefore a debate is a key issue in a democracy. Differences of opinion result often from a different understanding of reality, since we consider its fragments in different contexts and have disparate criteria of evaluating the actions we took.

However, if democracy assumes a drive for agreement, for finding a satisfactory solution for all - it is necessary to present one's point of view in a clear fashion as well as a proposed course of action. It is mandatory to define a situation as a starting point, as well as detail the conditions and give a name to that which is going on or is about to happen. In order to prove that signing of a fiscal pact is a good solution can be done only after we have 
demonstrated that the situation requires signing of such a pact. Political action largely depends on the ability to provide meaning to significant people, events or processes.

The following analysis of the parliamentary debates is an attempt to answer a question in what way a specific rhetorical device - a metaphor - is used by politicians when they define the situation. The objective of the analysis contains the selected debates concerning the economic crisis and the Future of the European Union, which were held in the Polish Seym in the years 2008-2011. The research question concerns first of all the functionality of the metaphor in the political discourse, as well as its usefulness in the main task a politician faces i.e. imposing on others their own interpretation of events, and the understanding of facts and processes. ${ }^{45}$ The economic crisis forces politicians to make quick decisions in a situation of many unknowns. Political leaders today - as Giandomenico Majone (1992) rightly said - can only utilize arguments in favor of competing hypotheses rather than hard data. Therefore, an important question to pose in the analysis of political rhetoric concerns the tools used for constructing a definition of the situation. How can politicians justify their choice of one of the future hypothetical scenarios? How do they argue that the interpretation of reality which they propose is correct, and thus their decisions also are appropriate? One of the tools used for this is a metaphor. Analysis of metaphors used in political discourse have repeatedly shown that they can serve for constructing political myths, can be a part of argumentative strategies (Charteris-Black 2005), and the expression of an adopted model of the world (Lakoff 2004). The question is whether they may also serve as an indicator of ritualization of political debate? Dispute can be described as a "ritual chaos" (Czyzewski et al. 1997). It is a type of discussion, where despite sharp expressions, all roles and arguments are known and remain unchanged. It is thus difficult to speak of a real debate, rather than a ceremonial skirmish.

\footnotetext{
${ }^{45}$ The quotations appearing in the text were taken from the stenographic records found in the webpage of the Polish Seym, www.sejm.gov.pl
} 
What is the situation definition? What are its components and what impact does it have on the rhetoric strategy of the speaker? - these are the questions that define the structure of the first part of the investigation. The second part is concentrated on the features of the metaphors that make them effective in the political discourse. Eventually there are examples of concrete metaphors used by Polish politicians while describing the Euro zone crisis.

1. How is the situation defined?

The competition of various definitions of situations is the crux of political action in the democratic system. Parties and politicians convince citizens that their interpretation of events is accurate and if the diagnosis is right then the remedy they propose is also correct. Defining the situation is the first step in a successful persuasion exercise. We are not concerned solely with the recognition of the factual circumstances of the speech. What is more important is the significance that the speaker or the audience attributes to the circumstances.

Rhetoric analysis of the public discourse or the public debate always requires very good knowledge of the context. As we read in Theaetetus: "Whatever each city judges to be just and fine, these things in fact are just and fine for it, so long as it holds these opinions" (Plato, Theaetetus $167 \mathrm{c} 4-5)$. That sentence indicates the significance of the situation definition in political rhetoric. "There is nothing more elusive than an obvious fact" Sherlock Holmes used to say and it has to be admitted that it is absolutely true in reference to political life. Explaining what it is that we see, and what is the name of the things going on, thus imposing one's own definition of the situation on other participants of the public life, is one of the key activities of politicians. When we think of the term of situation definition and refer it to a concrete rhetorical situation a number of necessary elements have to be considered. In rhetoric and social sciences there are three concepts which seem to be mutually 
complementing each other. These are: rhetorical situation, definition of situation and persuasive definition.

What shall we consider a rhetorical situation? In the most concise approach we mean the context in which a given utterance is presented and received. "Not the rhetor and not persuasive intent, but the situation is the source and ground of rhetorical activity" Lloyd Bitzer explains (1999: 220). It is the situation that defines the way of speaking. Who the speaker is, what social role he/she plays, the nature of the audience and the time and place those are the factors construing the rhetorical situation. Thus when we speak of rhetorical situation, we mean specific historic circumstances. In the analyzed debates that context was out of necessity created by the economic crisis, that hit the Euro zone, decisions that the leaders of the EU states took, aiming at the reduction of the effects of the crisis and the necessity to define what actions the Polish government should have taken (or already has taken) considering the circumstances. Of no lesser importance there was the arrangement of the Polish political scene, as well as the interests and needs of the political parties. Also the level of support they received from the voters as well as the timeframe for the elections. The analyzed debates took place in different timeframes: in the middle of the Seym's term, several months before its completion but still before the official beginning of the election campaign as well as in the beginning of the new term. It seems natural that the debates become more heated the closer the date of the elections. Similarly the first sessions of the new parliament are rich in lively discussions, since our envoys (or new political groups) are eager to present themselves as active and significant political forces. The debates which were analyzed were not particularly exciting. There were several factors responsible for it. First, direct effects of the crisis were not yet particularly felt by the Poles. True, there was already present a general awareness of the crisis, but particularly dramatic situations were absent and thus did not provide the material for emotionally loaded narratives or moving examples. Secondly, Poles 
are generally in favor of the EU, supporting further deepening of the integration process. Some later studies showed that the opinion was divided as far as the commitment of Poland in the aid to the crisis stricken countries (CBOS 2012), but the debates took place at the time, when the information on the fiscal pact just began to appear in the public debate. That is the time when the public opinion on the subject started to coalesce. That obviously created an opportunity for the politicians - a skillful definition of the situation would allow that interpretation to appear in the media and then in the public opinion. And - it is a third important factor - the Union issues do not seem to be the main bone of content in the Polish political scene. The concepts of Poland's role in the EU do not constitute the basis for differentiation of the political parties. As it is well known, political rhetoric is the most spectacular only when it is strongly related to the identity of the given party (Kampka 2009).

Rhetorical situation it is actually all that is contained in the mutual relations between the speaker, the audience, the topic of the speech and the circumstances of its delivery. The rhetoric is "essentially-related-to-situation", as Bitzer explains. Rhetorical situation is also closely connected with interaction ritual (Goffman 1967). The speech is the response to the situation; rhetoric "changes reality through the mediation of thought and action" (Bitzer 1999: 219).

The analyzed debates present undoubtedly the cases of exigence - the economic crisis requires fast decision making, the MPs demand from the government full information on the actions taken and the effect of it is the debate called: current information. The place in which the concrete opinions are expressed influences what is being spoken as well as the way it is spoken. The plenary sessions of the Seym, radio and TV transmission of the debates, the attention of the media - all those elements influence the rhetoric choices of the speakers. Some of the most influential factors are related to the social roles performed by the broadcasters. Political rhetoric is highly ritualized, and, as a result - the verbal behaviors are 
quite predictable. If the head of the government speaks, most certainly he will concentrate on proving that the decisions of the cabinet are justified, while the representative of the opposition will focus on arguing that they are not.

The next important notion we discuss is the definition of the situation, a term used by a sociologist, William Thomas. It is a sort of mutual agreement that all participants of the interaction have adopted. That sociological definition of the situation is close to the suggestions of Kenneth Burke, for whom the function of rhetoric is exactly an appropriate naming or defining of what the given situation is (Burke 1969: 206). The speaker (sender) uses rhetoric in order to select, from the surrounding plethora of objects, principles, and events the ones whose properties correspond to meanings he/she would like to focus on. The objective of fitting properties and meanings together is to make the listener accept the understanding of the situation presented by the speaker. We can see it in this simple example. We have an apple vendor, who advertises them to the customers. On a hot day he speaks of their juicy nature and how they can quench the thirst. A young mother is being persuaded that the apples contain lots of vitamins and that they are very healthy. To an elderly gentleman the vendor praises their softness and to the housewife he recommends his apples as the best kind for the apple pie. Apples have also many other features - they are round, red or yellow, have a soft or tough skin, they are sweet or sour - but rhetoric is the matter of choice. Situation definition turns out to be a negotiation of mutually accepted meanings important for the both parties in the communication situation. The matter is similar in the case of the economic crisis. It does not matter then if the prime minister has a good rapport with his ministers and plays ball with them, but what matters is his ability to make decisions quickly and accurately. Action is possible only when we have interpreted the situation and have defined what it really is so that we will be able to behave accordingly. Meeting a group of people in the street we make an instant decision as to the fact that those are tourists who lost their way and ask for 
help in finding their way to the city center, or a gang of sports fans willing to express their anger for their team's defeat. Definition of the situation turns out to be one of the basic human activities in social contacts.

From the vantage point of the political rhetoric it is particularly important to consider the consequences of the adopted definition. Independently of the fact of whether the situation definition is true, the effects of its adoption are always true. If we interpret the behavior of a young man approaching us in the street as a threat, we will start running regardless of the fact that he wanted only to ask us what time it was.

Let us check how it works in a political situation. On April 10, 2010 Poland experienced a trauma of a great magnitude - the presidential plane crashed in Smolensk in Russia. Almost a hundred of the most important persons in the country perished, including the president and his wife, generals, MPs, high level state officials and representatives of many institutions and organizations. The interpretation of this event still splits the Polish society and the political scene. In the public discourse two totally different narratives are present. The first assumes that the catastrophe was an ordinary airplane crash, the causes of which are being investigated by a special commission. According to the other definition of the situation that tragedy had been planned and it was an assault against President Kaczynski. The consequences of adopting one of the versions result in definite type of behavior. People, who are convinced that it was an assault see the present president and prime minister as traitors, who want to push the truth under the carpet. In effect they organize protests and demonstrations demanding full exposure of the truth.

And thus in the case of the interactive definition of the situation words create the circumstances. The situation is the effect of the words used. What was uttered produces concrete deeds which change reality. And though it might seem that the two terms rhetoric situation and the situation definition exclude each other, in the language of politics they are 
complementary. A speaking politician expresses specific words on the one hand because he must utter them (he is a prime minister or the leader of the opposition etc.) but on the other hand he utters them because he wants to achieve something, to influence the audience.

The third important concept we want to discuss is the persuasive definition. It is a type of a definition, which provides a presentation of the case that is the most advantageous to the sender (Walton 2007: 275). Charles Stevenson was the one who developed that notion by paying attention to the specific emotional and descriptive dimensions of words. In the persuasive definition we focus on the emotional effect that the given word produces. Hence precious are the metaphors here, which have the ability to invoke emotional associations. Naturally we may ponder the effectiveness of identifying the persuasive definitions, since strong arguments can be mustered in favor of the view that all definitions are persuasive. They are always biased, after all, since they depend on the choice of which species properties we will define as distinctive. Both Cicero (1942: II, 109) and Quintilian (2005: VII, 3, 15-18) stated that since the use of the definition serves a definite purpose, in consequence it is always partial to a degree, and since its objective, first of all, is to convince the listeners, it must contain some emotional and narrative elements. It is the common sense that provides the liminal condition here. It is worth remembering that Cicero wrote about three means of persuasion; that what matters is 1 . That we prove that what we defend is true, 2 . That we convince those that are listening to us, 3 . That we direct their emotions in a way that supports our cause, "the proof of our allegations, the winning of our hearers' favor, and the rousing of their feelings to whatever impulse our cause may require" (Cicero 1942: II, 1152). And the use of emotions is a key factor in identifying a given definition as a persuasive one.

Persuasive definitions used in the language of politics bring with them extremely important legal or financial consequences. The change of the definition in the law results in the change of the qualification of the deed, as it is shown in the case of analysis of the term of 
rape (Zarefski 2006) or wetland (Schiappa 2003). Therefore persuasive definitions should not be treated as unimportant language tricks, since they are one of the most powerful instruments of politics (Walton 2007:281). In addition those definitions span bridges between facts and values. In the case of the persuasive definition words happen to be the effects of the speaker's intention, their objective is therefore the change of the situation through the transformation of the receivers' attitudes.

Summing up then, in the rhetorical situation words are the effects of circumstances, it is the situation that influences the rhetorical choices of the speaker. In the interactive definition of the situation to the contrary - it is words, i.e. the naming of the reality, that is the cause of the new situation created. It is worth remembering that the way of perceiving the reality and its interpretation does not happen out of nowhere. There are also present situational conditionings. They depend on the identity of individuals and social roles performed by them as well as on the time and place, they also depend on the receivers. A person lurking by the window with a sack on his back may be interpreted as Santa Claus, if he is seen in December by a four-year-old through his room's window, or as a thief if in another season he is seen by a janitor in a storage area. It is evident that in spite of the apparent contradiction both terms, the rhetorical situation and the definition of the situation, have something in common. Similarly we can find a common element in the persuasive definition. While it is formulated it must take under consideration the circumstances, which might facilitate or hinder the acceptance of that definition by the receivers.

And thus, in order to analyze the definition of the situation, which politicians construe in their pronouncements, it is necessary to consider all three discussed terms in their scope of meanings, since the phenomenon we are discussing is located exactly in the field common to all those areas. 
2. What is a metaphor in politics

Actors participating in the public debate use metaphors in order to illustrate ideas and views. It is possible to speak of the double role of the metaphors depending on to whom they are addressed. Metaphors, on the one hand, are a sort of identification signs, pointers that allow for an instant recognition of the sender and at the same time construct the sense of the group's community (Charteris-Black 2005: 205). Similar to the graffiti on the walls which point out who rules the district, metaphors used by a given political milieu provide clear signals of the unity of their attitudes to the members. On the other hand the metaphor addressed to the external world serves as a visible and convincing presentation of a given topic. Naturally most often the same metaphor performs both functions simultaneously. The debate on the exposé by Prime Minister Kazimierz Marcinkiewicz can serve as an example here. He assumed power in 2005 on behalf of the Law and Justice party (PiS), which proclaimed the need of fundamental renewal of the Polish public life. He used a metaphor of the state as a gambling table, where politics, businessmen, special services functionaries and gangsters play bridge. The metaphor turned out to be catchy and other politicians and journalists used it often. For the supporters of the party it was a clear cut brief of the program - it is necessary to overthrow the table and return to the concept of the common good, when political activity is a service and not a dirty play aiming at promoting private interests at the expense of the citizens and damaging to the state. This simple image was supposed to convince those hesitant ones to accept the definition of the situation, i.e. the diagnosis of the condition of the state according to PiS. Metaphor is a convenient tool in political polemics, since it is difficult to deny or to undermine it. In the example above the opposition had embarked on such an attempt - it used the same metaphor to convince the voters that although the players change the table still stands and the proclaimed renewal of the state is just a 
pretense. The above example clearly indicates how important a role the metaphor plays as an aid in defining the situation.

Rhetoric analyses may be seen as a test in what way we persuade others by means of symbols, as well as how symbols influence people (Schiappa 2003: 3). Metaphor is a specific carrier of symbolic meaning, therefore in the studied political utterances it is treated as an element of the argument and not the embellishment (ornatus). Therefore the analysis of the metaphors used by politicians must respond to the same questions we answer when we try to define the situation. Thus it concerns all the issues covered in the theory of stasis (Lausberg 2002: 67-87). We are talking about the issues concerning the identity of the participants of a given debate. It also concerns the limitations presented by the given rhetoric genre.

It is worth pointing out that in the case of economic crisis and the future of the EU the classic questions of status coniecturalis, definitivus, qualitatis (i.e.: is it there? what is it? what is it like?) bring in many potential answers. Moreover in contemporary politics we often deal with the phenomenon defined by the ancients in reference to the court trial. We mean a status finitionis, which is an attempt to find a name for what has happened (Cicero 1993: De inv. I, 8, 10). The correspondence between a thing and a word is an important issue in the public discourse. Contemporary law provides sanctions for unsubstantiated use of certain terms. Therefore sometimes the use of a metaphor may be an attempt to avoid penal responsibility. Calling the prime minister a pitiful clown is quite a different matter than presenting a picturesque image of a circus, in which an ignorant clown usurped the place of a director, even if the only possible interpretation of that image is the recognition that the state is the circus.

A metaphor is a complex phenomenon. We may view it both as a linguistic phenomenon, as well as a cognitive one (the thriving practice of cognitive analysis of the metaphors is a proof). We may study its emotional dimension but also its socio-cultural 
ramifications. We may analyze in what way a metaphor corresponds to a given fragment of reality or follow the merging of separate fields, by means of which it is possible to explain something what is new through a reference to something already known, or we may have a revealing look at something already well known but presented in a different than usual light due to the metaphor. A metaphor is a main supportive frame of the communique since it is able to structure ideas. It is also a very useful tool in constructing persuasive definitions, since it exposes or conceals selected contents (Charteris-Black 2005; Cameron and Maslen 2010, Musolff and Zinken 2009). In this connection it is worth remembering that in the case of political rhetoric quite often we deal with a situation in which a new, initially effective metaphor loses quickly its persuasive thrust and by overuse becomes sterile and thus of negligible cognitive and visual value, as such cases were analyzed convincingly by Michael Biling and Katie MacMillan (2005).

In the debates I have chosen I was interested in the metaphors playing important roles in arguments of both sides of the conflict regardless of the degree of the metaphor 's complexity. Additionally the devices used by the politicians I treat as intentional actions rather than as an expression of subconsciously coded cultural patterns or ideological schemata. Naturally it is necessary to consider the fact that such factors as political orientation, biography or upbringing influence stylistic and cognitive choices made by politicians. It is also worth considering that in political rhetoric it is usually more important who listens than who speaks. Biblical analogies in the mouth of the conservative politician may be closer to the imagination and value system of his potential voters than himself. Therefore the cognitive approach attempting to answer the question what a given metaphor changes in the way of thinking is useful first of all in the studies of communication effects. Hence, in the cases referred to below it matters more to find the connection between the image used and its place in the adopted argumentative tactics (Plantin 2009). 


\section{How to define crisis?}

In analyzed debates the participants were representatives of the parliamentarian clubs of the most important Polish parties. The coalition government is made up of the two parties; Citizens' Platform (PO) and the Polish Peasant Party (PSL). The first one is the center liberal party universally associated (although not necessarily reflecting the actual facts) with young, entrepreneurial citizens, rather than with wealthier urban inhabitants. PSL is a traditional agrarian party. Law and Justice (PiS) the largest opposition party, a conservative rightist party, in conventional wisdom (again not necessarily squared with the truth) representing the interests of the losers in the Polish transformation, inhabitants of the poorer regions of the country. Democratic Left Alliance (SLD) or the Palikot Movement (RP) did not play any significant role in the analyzed debates, since they are pro-EU parties, supporting the European policy of the government. The main line of contest runs between PO and PiS. Both parties, sharing the same roots in the Solidarity movement and formerly planning to form a coalition, at present are locked in a dire conflict, both in the policy program areas as well as at the personal level (Jarosław Kaczyński, the leader of PiS, is a twin brother of the late President, and he is accusing the government of the incompetent carrying out of the investigation of the Smolensk plane crash). PiS, although generally supportive of the EU, perceives Poland's role in the EU differently than PO does.

From the parliamentarian enunciations metaphors referring directly to the crisis or the EU have been selected. In the analyzed material metaphorical descriptions of the EU of an unequivocally positive kind appeared only twice. The prime Minister spoke of "a great, beautiful European adventure", while Robert Biedroń, one of the opposition MPs (in the proUnion Palikot Movement), explained that "the European Union is a mutual dream not of 500 million Euro but it is a dream of 500 million Europeans". 
As far as depicting the crisis is concerned, metaphors presenting the economic crisis as a natural catastrophe appear more frequently in the government's rhetoric. The opposition, however, focuses on the presentation of the Euro zone crisis as a faulty edifice. It has, quite naturally, a very simple justification. Presenting the crisis as a turmoil, a flood, a storm or a quake the government explains that the events which the European countries are battling now are as equally unexpected and unexplainable as the climatic phenomena. The role of the authorities is to counteract the negative effects of those conditions. It is worth remembering, that the metaphor style concerning the wide range of natural disasters or diseases is an important element of the political rhetoric, particularly in the cases of strong ideological contests - there is often talk of the flood, fire, fever or pestilence. To a large extent it was used by President Truman at the time of the Cold War (Ivie 1999). The objective is always to build up the tension and the exploitation of emotions. The threat perspective produces reactions different than the usual ones, among them greater than usual license for quick decision making by the rulers. It is then easy to give up regular democratic procedures of debate, justifying it with the necessity of an immediate response. Such mechanism could be observed after 09.11, mainly in the USA. The opposition metaphors suggest, on the other hand, that there is somebody responsible for the crisis, it is possible to point out an incompetent architect, hence the images of "a poorly constructed edifice, of the European home erected on quicksand". This last image, evoking the evangelical parable in the mouth of the rightist envoy assumes an additional meaning, since the audience (and particularly supporters of the party) are used to the opinion that the EU is an institution whose activities are far from the conservative or Christian values, and often openly hostile to them.

The metaphor of the EU as a home is used also by the government side, which is explaining that implementation the opposition's vision would put Poland in a cul-de-sac, or will remain in the anteroom and in the draft. The metaphor of the common home, household, 
marriage is universally used in the discourse on the EU (Musolff 2006). The metaphor of the EU as a home according to Paul Chilton and Mikhai Ilyin (1993) has been started by Michail Gorbachov with the statement made in the mid-80s about the common European home in the context of mutual responsibility of the states for Europe.

Let us have a look at the metaphors used in the debates. Different metaphors imply different ways of dealing with things, Norman Fairclough comments (1989: 120). If the problem rests in the faulty foundations of the building, it needs general renovation. If the problem rests with an incoming tornado, escape might be the only rational action. Naturally in the analyzed cases those two solutions did not materialize since, as I said, the metaphors did not serve as ways of looking for solutions but as the method of identifying the culprits. Simultaneously that example indicates another important feature of the metaphors - their customary character. Almost each metaphoric image may be used in many different ways. Let's return to the image of the state as a building. We may pay attention to the foundation of values, on which the state is posited or stress the open door for immigrants (Fairclough 1989:120). The choice of a given aspect depends on the situation and the sender's intention. One of the more frequent images is the one of a boat/ship. All parties accepting the Union politics of the government use this metaphor although they use it in many different ways. EU may be a "navy ship", which cruises in the stormy sea and it should be aware of other ships in the ocean - such as America or Asia. Poland may be "a ship" which is sailing "steadily" in "the rough seas". Those are pretty standard descriptions of the economic crisis, rough seas is a classic image presenting a difficult situation, uncertain, very challenging particularly as the speed and accuracy of decision making is concerned.

Finally it can be said of the EU that we are "all in one boat. In this boat we will either make it or we will all drown, and there is still a group of candidates waiting in the wharf, many countries, not only Croatia, but also the Western Balkans". This picture serves the 
purpose of justifying the sense of solidarity, which all Union countries displayed, and which finds its expression in the financial assistance obligations. Those examples prove the universality and the repetitiveness of political images in general. In research on the metaphors in German politics and media debates in the years 1989-1990 the words of similar meaning ranges have been compared, i.e. to boat and ship. Used in metaphorical expressions they evidently service different aspects of events. The ship appears in references to complex economic projects, the reference is made to the ship sailing in rough seas. While the boat is used in two contexts. Firstly, as an illustration of the expression - "to be in one boat", which means the mutuality of interests, and the other one - that metaphor appears in the reference to the newcomers - the country is like a boat; we have limited space and there may not be room for all (Zinken 2006).

In Polish debates the image of a ship appeared in one more context: Poland may be a ship but so could any other country, since the most important thing is that in "the captain's bridge there stands" a leader of the political party supported by the citizens. The topos of a ship has been developed through centuries in the European culture - at its early beginning there is the Biblical Noah's Ark, thanks to it humanity survived the deluge, as well as the New Testament's Peter's boat, whose rumple is firmly held by the succession of the popes. In the Renaissance literature there were frequent juxtapositions of the serene farmer's life versus the dangerous and risk-laden life of a sailor, crossing the rough seas. In the Polish literature the motif of a motherland as a mighty ship had been extremely popular with the call for all hands on deck cooperating for keeping its due course, while during the partitions and the loss of independence the image transforms into a vision of a sinking vessel. In one of the discussed debates Prime Minister Tusk used that metaphor as a means of political fight. "The leader of the opposition woke up and shows courage in TV spots (...) You know what, president Kaczynski, I 've seen many brave men in spots and ads (...) but the leader of the 
political formation is required to stand fast on the captain's bridge when citizens handed him the right and a chance of exercising power". As it appears the position on the bridge has to be seen as a counter to the fake courage that can be demonstrated in the political ad. Juxtaposing something true and fake is a permanent rhetorical device used by politicians.

The next example of contradicting reality and appearance can be found in the metaphor of a remedy. The economic crisis and turmoil in the EU are treated as a disease that has to be cured. The opposition speaks of harmful effects of the drugs used so far, i.e. the rescue measures adopted by the European leaders. The Prime Minister treats the opposition's ideas with disdain: "You want to look for prescriptions, you want to help, so go and look for them there where they can be found in order to use the remedy to fight the disease, and not simply because somebody had an idea. We cannot afford to use fake instruments". The career of the word true in the political discourse is still another matter well presented particularly by the language of the propaganda researchers (Klemperer 1992, Głowiński 1991).

We often deal with the image of a feast, sitting at the same table. Contrary to the appearances it is a complex metaphor. The government speaks of the danger of transformation of the Union into an exclusive club for the wealthiest, and explains that it is not evident to every member state, that all countries should sit at the same table - some believe that the functional criterion must be the membership in the Euro zone. In this approach sitting at the table does not necessarily mean a feast but rather the possibility of participating in the negotiation. An elaborate image presented by one of the envoys of the opposition, it refers to the perception of the EU as the source of luxury and welfare.

The MP explained that to lend money to the International Monetary Fund from the budget reserve was like "paying insurance fee for a house in which we do not live, in order to relieve wealthier neighbors, because we will participate in the decision making on the menu of their dinner and maybe we will deliver some produce from our garden and will have the 
honor to clean the table after that". In those sentences there is contained the attitude towards the EU characteristic of many milleaux. On the one hand the Union seems to be something desirable and good (after all those are the wealthy neighbors), but on the other hand as something unjust, harmful and hungry for costs and funding. In spite of the irony in this imagery there rings an echo of the subordinate position of our country.

The only way to deny a metaphor is to find a new interpretation of the same image. It is attempted by a later speech of the parliamentarian of the ruling coalition who, referring to the above mentioned sentences, said: "MP Żyżyński helped himself with the following metaphor: why should we insure the house from fire if we do not live in it? But it happens. If the houses are located next to each other, it may be proven that buying insurance on the house next to us might be prudent, because being adjacent when it goes on fire my house may burn down, too". It is clearly visible how subtly the initial metaphor is transformed in order to serve the new objectives. First there was a talk of a dinner not a fire. If contributing to the meal of the wealthier neighbors seems absurd then paying for the fire insurance, which might also threaten us, does not seem to be so senseless any longer. The well known principle operates here - the perspective of our own benefits changes the sense of the whole situation. One of the oppositionist parliamentarians opposing the definition of the situation proposed by the government explained that "It is not one table and one menu", while another MP criticizing the government's activities during the Polish presidency maintained that Poland proved itself only as a hostess arranging for "meals, meetings and hotels".

The imagery which connects the Union politics with feasting seems to be well established in the imagination of the Poles. The roots of those metaphors can be found in a symbolism of power, which is of very ancient provenience. Since the times of organized social groups the privilege of those in power was their access to food. Wealth and power, since times immemorial, regardless of the period and cultural model, were always 
demonstrated, inter alia, by festive meals, what still finds its echo in ceremonial dinners or suppers held by the heads of state to honor the invited guests. Thus power in the everyday imagery is related to the access to economic privilege. It is demonstrated in the colloquial idiom, that a person aspiring to the high office "elbows oneself to the feeding place".

There is still vivid - originating in the Polish People Republic period - a commonplace notion of the wealthy West, although polling research shows that migrations significantly modified the image of the European - from quite an attractive creature he/she becomes slowly "a human being like myself."

Another element of the EU image is its financing source potential. It is characteristic that the public opinion polls systematically indicate that those who perceive their material situation as a good one are more satisfied with the EU membership. The use of the Union's financial aid is seen as one of the greatest benefits of the integration. A majority of the Poles are in favor of the EU, and place a lot of trust in it and its institutions $-74 \%$ of the Poles declare trust in the EU, although they have relatively scant knowledge of its institution at the same time (CBOS 2009). Maybe a following principle is in operation here - I trust the one who brings benefits to me and if everything goes well, I do not need to go into the details of the operation. The Euro zone crisis and the fiscal pact draft indicate the fallacy of that approach. We must still remember that the addressees of the public speeches are the people for whom the Union is still a certain abstract being.

The opposition, according to its basic argumentative strategy, proclaiming that the government's activities led/ are leading to the partial loss of sovereignty, is using the metaphor of a client or sidekick. Poland - as the audience should read that image - gives up its role as an active player, an important actor in the international scene, and the aspirations of the rulers are limited to the winning of favors from the powerful patron. 
Polish politicians also use typical imagery concerning movement. The economy is a living organism which can "get winded", or it may "slow down", and venture capital can "get rampant". Also the metaphor depicting the EU as a vehicle is connected with movement. The vehicle must be "prevented from skidding", therefore Poland should act as a "driver of change" and not as "a brakeman". The brakeman - he is a popular character in the Polish political discourse, most frequently the president is accused of being one when he vetoes the bills.

It is worth pondering on the source domains of the heretofore mentioned metaphors. Generally they are closer to the everyday (or even closer - the physical) experience than more abstract target domains. Both the Union and the crisis are the abstract notions. Hence the metaphors used by politicians serve cognitive purposes to a large degree; they help to establish a certain structure, as it happens to be in the analyzed case - the rather ill-defined crisis. The metaphors of the building, of a natural disaster or a feast are naturally much closer to the everyday experience of the audiences. The only exception is the metaphor of the boat/ship - navigation is not a commonplace in Poland, but the familiar nature of this activity is the result of the linguistic idiom. As I have mentioned already, the topos of the motherland as a boat/ship is one of those most often used in Polish literature, which is the basis of school education, therefore those images are immediately recognized as such. For the same reason the analyzed metaphors are the conventional ones, the use of which is well grounded in the language (Kovecses 2011:194). Their conventional nature to a certain degree limits the rhetoric choices of the speakers. The language community often imposes the way in which the given matter is discussed (the case of the boat/ship metaphor is a good example). Undoubtedly the choice of the metaphor is related to a large degree with the ideological embedding of the given political party. Brock et al. indicate, using American politics as a reference, how the ideological profile of the person influences the rhetorical choice strategy (Brock 2005, 85n). In reference to the Polish conditions it makes sense to recall three 
examples. Conservatives use an idealistic perspective, making reference to the individual's character or the acting person. The elements of such a strategy we can find both in the opposition politicians' enunciations (PiS) as well as in the ruling coalition. Liberals in their arguments often refer to situational factors; action is determined by the circumstances. Such arguments appear in the speeches of PO envoys. And finally the radicals point to the structural conditions. In the analyzed debates it is assumed that the source of the crisis rests in the systemic weakness of the EU and the capitalist economy.

\section{Unused potential?}

Summing up, metaphors used in the analyzed debates belong to the standard imagery repeatedly appearing in the political discourse. None of them have become so influential that it would dominate the debate. Nevertheless they constitute a part of the argumentative tactics and serve the purpose of intensifying the message. They are not constitutive, however, of the argument itself, and do not explain something that is totally unknown. They perform an illustrative function instead - in the cases of more elaborate images. Most of the analyzed examples cannot be defined as rhetorical figures in the full sense of the word, although undoubtedly they are metaphorical expressions. It is still in accordance with Cicero's explanations, who by connecting the particular value of metaphors with their sensualism, i.e. making references to specific senses (first of all the sight), explained that sometimes it suffices to use a word to activate a given sense (Cicero 1942: III, 161). Due to that the message is much clearer. Quintilian explains that the use of metaphors is particularly applicable when the metaphorical word is better, more expressive or more decent than the accurate one (Quintilianus 2005: VIII, 6, 5-6). In the analyzed debates the MPs most often used the simile due to its expressiveness. It is worth remembering though, the qualification that the value of the metaphor (as well as all other figures) depends on its functionality. 
Let us ponder the criteria of the metaphor's effectiveness, since it is the metaphor which imposes the interpretation on others that is the most desirable for the politicians. Such a metaphor should meet some conditions, nevertheless. It is good if it can appear in the beginning of the pronouncement and should not be too complex. Too many details make the picture less clear. It should also provide a fresh look on things, or a new solution, but at the same time refer to the everyday experiences of the audience. The New Testament presentations of God's Kingdom may serve as examples here. When Christ speaks of the vineyard, sheep or the olive tree in the parables, he uses images extremely close to and well known in the experience of his listeners. And at the same time those metaphors serve to give the human mind real and acceptable shape for the transcendental concepts.

In the analyzed debates, it seems, politicians do not use the full persuasive potential of the metaphors. They use them somehow unawares (to the extent that in the parliamentary debates we deal with a non-reflexive use of any construct...). None of the recalled examples was a spring for a further debate. In particular, the economic crisis did not spur the politicians to the creative use of the language. However, it is beyond doubt that metaphors used by politicians function as instruments in constructing the situation definitions, which are connected with the whole argumentative strategy of the party. As it is evident, metaphors may perform many functions in political discourse. First of all they serve the purpose of simplifying the abstract and complex issues in order to make them comprehensible for the public. Metaphors help in formulating an expression worth quoting (sound-bite). They produce humorous effects. Their generalizing and equivocal nature is very useful (Semino 2008: 84). In the analyzed debates the cognitive role seems to be the primary one. Images were used to facilitate comprehension of difficult decisions, and also provide the vision of the alternative to the indefinite future. 
The metaphor is used to build the definition of the situation; it helps policy-makers to justify an undertaken action. Selection of a particular image association that politicians want to impose on the public depends on a variety of factors that make up the rhetorical situation: The time of occurrence, roles played by the politician, current image, collective identity of the party's members and supporters. One of the most important is undoubtedly the position of the party on the political scene. The main differences in the choice of metaphors are not associated with the ideological axis (e.g. left-right as Lakoff [2002] described), but rather the axis of the government and the opposition.

Strength of the metaphor is based on surprise, ability to show a new perspective. In the debates which have been analyzed not only were the metaphors conventional, but it was also easy to predict who and at what point uses them. So what is their true task? It seems that the key role of metaphor is one of a rhetorical prop in the ceremonial dispute.

\section{References}

Billig M. and K. MacMillan. "Metaphor, idiom and ideology: the search for 'no smoking guns' across time.” Discourse Society 16, (2005): 459-480.

Bitzer L. F. “The Rhetorical Situation.” Edited by J.L. Lucaites, C. M. Condit and S. Caudill. Contemporary Rhetorical Theory. A Reader, 217-225. New York-London: The Guilford Press. 1999.

Brock B., L., Huglen, M., L., Klumpp J., S. and S. Howell. Making Sense of Political Ideology. The Power of Language in Democracy, Lanham-Oxford: Rowman\&Littlefield Publishers, Inc, 2005.

Burke, K. A Rhetoric of Motives, Berkeley: University of California Press, 1969.

Cameron L. and R. Maslen, eds. Metaphor Analysis, Research Practice in Applied Linguistics, Social Sciences and the Humanities. London-Oakville: Equinox Publishing Ltd, 2010. 
Rogudka, B., ed. Postrzeganie instytucji unijnych. Komunikat z badań. Warszawa: CBOS [Public Opinion Research Centre], 2009.

Rogudka, B., ed. Polacy o pakcie fiskalnym i pogłębianiu integracji w Unii Europejskiej. Komunikat z badań. Warszawa: CBOS [Public Opinion Research Centre], 2012.

Chilton, P. and M. Ilyin. "Metaphor in political discourse. The case of the 'Common European House."” Discourse and Society 4, no.1 (1993): 7-31.

Cicero De oratore. Translated by E.W. Sutton, B. C. L. M.A., London: William Heineman Ltd., Cambridge: Harvard University Press, 1942.

Cicero, Marcus Tullius De inventione; De optimo genere oratorum; Topica. Translated by H. M. Hubbell. Cambridge, Mass.; London: Harvard University Press, 1993.

Charteris-Black, J. Politicians and Rhetoric. The Persuasive Power of Metaphor, New York: Palgrave Macmillan, 2005.

Czyżewski, M., Kowalski, S. And A. Piotrowski eds. Rytualny chaos. Studium dyskursu politycznego, Kraków: Wydawnictwo Aureus, 1997.

Fairclough, N. Language and Power, London-New York: Longman, 1989.

Głowiński, M. Nowomowa po polsku. Warszawa: Wydawnictwo PEN, 1991.

Goffman, E. Interaction Ritual: Essays in Face to Face Behavior, New York: Anchor Books, 1967.

Ivie, R. L. "Fire, flood, and red fever: Motivating metaphors of global emergency in the Truman doctrine speech.” Presidential Studies Quarterly, 29, no.3 (1999): 570-591.

Kampka. A. Perswazja w języku polityki. Warszawa: Wydawnictwo Naukowe Scholar, 2009.

Klemperer, V. LTI. Lingua Tertii Imperii. Notatnik filologa. Translated by M. Stroińska. Toronto: Polski Fundusz Wydawniczy w Kanadzie, 1992.

Kövecses, Z. Język, umyst, kultura. Praktyczne wprowadzenie Translated by A. KowalczePawlik, M. Buchta, Kraków: Universitas, 2011. 
Lakoff, G. Moral Politics: How Liberals and Conservatives Think. Chicago: University of Chicago Press, 2002.

Lakoff, G. Nie myśl o słoniu! Jak język kształtuje politykę. Obowiązowa lektura dla myślacych postępowo. Translated by A. Nita, J. Wasilewski, Warszawa: Oficyna Wydawnicza Łośgraf, 2011.

Lausberg, H. Retoryka literacka: podstawy wiedzy o literaturze. Translated by Albert Gorzkowski. Bydgoszcz: Homini, 2002.

Majone, G. Evidence, Argument, and Persuasion in the Policy Process, Yale: Yale University Press, 1992.

Musolff, A. "Metaphor Scenarios in Public Discourse.” Metaphor and Symbol, (2006): 21(1), $23-38$.

Musolff, A. and J. Zinken eds. Metaphor and Discourse, New York: Palgrave Macmillan, 2009.

Plantin, Ch. "A Place for Figures of Speech in Argumentation Theory." Argumentation 23, (2009): 325-337.

Platon. Parmenides; Teajtet. Translated by W. Witwicki. Kęty: Antyk, 2002.

Quintilianus, Marcus Fabius Kształcenie mówcy. Translated by M. Brożek. Wrocław: Zakład Narodowy im. Ossolińskich. Wydawnictwo; Warszawa: De Agostini Polska, 2005.

Schiappa E. Defining Reality: Definitions and the Politics of Meaning. Carbondale and Edwardsville: Southern Illinois University, 2003.

Semino, E. Metaphor in Discourse. Cambridge, New York: Cambridge University Press, 2008.

Sopory, P., and J. P. Dillard. "The Persuasive Effects of Metaphor A Meta-Analysis.” Human Communication Research, 28, no.3 (2002): 382-419. 
Walton D. Media Argumentation. Dialectic, Persuasion, and Rhetoric. Cambridge: Cambridge University Press, 2007.

Zarefsky, D. "Strategic Maneuvering through Persuasive Definitions: Implications for Dialectic and Rhetoric.” Argumentation 20, (2006): 399-416.

Zinken, J. "Discourse metaphors: The link between figurative language and habitual analogies." Cognitive Linguistics. 18, no. 3 (2006): 445-466. 


\section{The Political Discourse on Croatia's EU Accession: a Rhetorical Analysis of the Presentation of the European Union among Supporters and Opponents of the EU}

Gabrijela Kišiček, University of Zagreb

\section{Summary}

This article describes salient argumentation strategies used in speeches of members of the political majority in support of Croatian EU membership as well as and those who opposed it. The analysis includes the usage of ideologically marked words, expressive terms with emotional value, and figures of speech, particularly metaphor. Corpora for this research were political speeches broadcast on television and radio collected over a period of 3 months, including the most important political figures of the previous and the present government as well as representatives of "Europhobes," such as leaders of right wing political parties and civil organizations. The main goal of the analysis is to determine what kinds of arguments are frequently used, which fallacies are most frequent, and what are the differences and similarities in rhetorical means and argumentative strategies between two opposed sides? Analysis showed very weak argumentation and frequent use of appeals to emotions, especially appeal to fear, for both supporters and opponents to EU.

Key words: argumentation, fallacies, political discourse, Europhobes, Europhiles

\section{Introduction}

Croatia, which was formerly part of the Republic of Yugoslavia, gained independence in 1991. In 2003 it applied for membership in the European Union and in early 2004 the European Commission recommended Croatia be granted candidate country status. By mid-2004 the European Council granted Croatia's application for candidate status. Membership negotiations officially started in October 2005. They were concluded on June 30th 2011 and followig the signing of treaty on December 11th 2011, Croatia officially became the 28th member of the European Union. 
The negotiation process between Croatia and the EU has been the longest in EU history, and was complicated for various political reasons, amongst them the extradition of Croatian citizens (in particular, certain individuals who had been Generals in the Croatian army during the war 1991-1995) to the International Criminal Tribunal in The Hague. The EU required the Croatian government to cooperate with the court as a necessary condition for a continuation of the negotiation process. On one occasion, the EU postponed the commencement of negotiations because the Croatian government's effort to capture a fugitive Croatian general was deemed insufficient. Another reason for the lengthy duration of the negotiations was the Croatia-Slovenia border dispute which resulted in Slovenia blocking Croatia's EU accession for 10 months. Political issues such as the above have had a deep impact on the perception of the EU among Croatian citizens. Ultimately, a referendum was held on January $22^{\text {nd }} 2012$ which resulted in $66 \%$ of the voters being in favor of Croatia joining the European Union.

This paper analyzes political speeches of both supporters and opponents of Croatian membership in the EU. The majority of Croatian political parties supported EU membership. The opponents were radical right wing parties and right extremists so far not elected to parliament, as well as other representatives of civil organizations. Political analysts widely agreed that the public debate about an EU membership was insufficient and that the period between the finalization of the negotiation process and the referendum was too short for an exchange of opinions between EU opponents and supporters. Moreover, opponents complained about a lack of media coverage with respect to their own efforts to raise arguments against Croatia joining the EU. Although outnumbered in parliament, Europhobes organized meetings and gatherings in public places which received media coverage and thus provided data for this research. 
2. Materials and methods

For the purpose of this research, we used political speeches broadcast on three national Croatian television channels (HRT, RTL, Nova TV), as well as political statements and interviews in two daily newspapers (Jutarnji list, Večernji list) over a period of 3 months (June and December 2011, and January 2012). Data were selected on the basis of political relevance and media presence (i.e., the speeches of the most important political figures in Croatia including the president Ivo Josipović, the former and the current prime minister, Jadranka Kosor and Zoran Milanović, respectively, as well as the former and the current minister of foreign affairs, Gordan Jandroković and Vesna Pusić (all four of whom can be regarded as EU supporters). Opponents of EU included leaders of right wing parties Daniel Srb and Ruža Tomašić, as well as activists, and representatives of civil organizations, for instance Roko Šikić, Željko Sačić, Marko Francisković etc.).

The analysis conducted in this paper was based, on the one hand, on Critical Discourse Analysis (CDA) which encourages the critical study of discourse within its discursivehistorical context of production (van Dijk, 2001) and, on the other, on rhetorical analysis which aims at extending CDA beyond lexico-grammatical analysis by introducing an argumentation component.

The study of political discourse in the terms of language analysis was conducted for the first time after World War II when linguists tried to understand and explain the roles and importance of language and communication in totalitarian regimes and their propaganda. They demonstrated how political discourse is determined by society in what may be termed "a social practice" (see Wodak and Meyer, 2012: 17). 
Our method is similar to that used for analyzing the discourse of proponents and opponents of the Iraq war (Sahlane, 2012) which also combined CDA and rhetorical argumentation analysis.

Critical discourse analysis included the examination of vocabulary, especially the usage of ideologically marked words (e.g. Euroslavia), the usage of expressive words with emotional value (e.g. national consciousness, independence), and figures of speech, especially metaphors (such as tunnel of darkness or the light at the end of the tunnel). The rhetorical analysis was primarily oriented to rhetorical argumentation and aimed at tracing differences and similarities in the means of persuasion used by opponents and supporters of Croatia's EU membership.

Tindale (2004: 20) explains rhetorical argumentation:

"Rhetorical argumentation draws features from the rhetorical tradition and mixes them with newer innovations. For the core of what the tradition provides, another Aristotelian triad is useful: that organization of the rhetorical that distinguishes ethos, pathos and logos. The processes of rhetorical argumentation meld together these three bringing into relief and inextricably wedding to one another in the argumentative situation, the arguer, audience and "argument". To understand the argumentation is to understand the interactions of these components; to evaluate argumentation is to do the same."

Based on previous research on a similar topic (Sahlane, 2012), we assumed that appeals to emotion, especially the appeal to fear (argumentum ad metum) and pity (ad misericordiam) — would be frequent. Johnson (2000) has emphasized that in order to be effective, the rhetoric used in mass media needs to take human emotions, in particular fear and pity, into account. $\mathrm{O}^{`}$ Keefe (1996) mentions these in relation to persuasion short cuts. 
Appeals to fear and pity work as persuasive arguments using the dual process model of persuasion. "According to this model there are two routes of persuasion, a central and peripheral route. The central route requires an elaboration of the rational argumentation in the mass of evidence in a case. But appeals to fear and pity offer a short cut to a mass audience by suggesting a peripheral route." (cited after Walton, 2007: 128)

Put generally, we assumed that ethos and pathos will be dominant modes of persuasion. Here, pathos is broadly defined in the Aristotelian tradition as a means of "creating a certain disposition in the audience" (1991: 301) and, while common in forensic oratory, it is "also at home in deliberative oratory" (Carey, 1996: 405). According to Aristotelian scholarship, as a means of persuasion ethos is more common in deliberative oratory, since a credible and trustworthy character of a politician is important in persuading an audience, and thus in creating a public opinion.

The combination of CDA, rhetorical argumentation analysis and persuasion techniques_ - or so we assumed_yields a more complete picture of that part of Croatian political discourse that deals with the question of EU membership.

\section{Results and discussion}

3.1. Critical Discourse Analysis (lexico-grammatical analysis and figures of speech)

Critical Discourse Analysis distinguishes among the experiential, the relational and the expressive value of words. For the purpose of this research, the most interesting and important were the expressive values of words because, as Fairclough (1989: 119) puts it: "they are always the central concern for those interested in persuasive language." Since 
differences between Europhobes and Europhiles are, at least in part, ideological, the expressive value is important insofar as "differences between discourse types in the expressive values of words are again ideologically significant” (1989: 119).

Our analysis supports the claim that the choice of words in the speeches of both Europhobes and Europhiles is ideologically motivated in a way that is consistent with the differences characteristic of right wing and left wing parties. According to the Lexicon of Basic Political Terms (Prpić: 1994) the dominant feature of left-wing parties is liberalism. Prpić (1994) defines liberalism as a political philosophy which takes freedom to be the main criterion for the evaluation of social institutions. Key terms of liberalism are freedom, individualism, equality, social justice, and democracy. On the other hand, a dominant feature of the right is conservatism, for which terms such as legality, sovereignty, and nationalism are key. Since Europhobes are represented by right wing parties and conservative civil organizations, the expressive value of words is manifested through terms such as national identity, national consciousness, national treason, independence, national interests etc. The main characteristic of Europhobes' value of words is aggressiveness, and an anticipation of "bad" consequences manifested through strong words like death, tears, grave, slavery, humiliation, danger etc. Europhiles likewise anticipate the future, but expect stability, better life, investments, better education and a higher standard of living.

The main difference between Europhobes and Europhiles, as traced through the choice of words and the choice of metaphors, is that Europhiles are turning towards the future, while Europhobes are expressing their attitudes (implicitly and explicitly) by turning to the past (in particular to Croatia's history). For Europhiles, a new age is coming, and Croatia is given a new opportunity; for Europhobes, Croatia is about to enter Euroslavia (i.e., is to be enslaved by the EU) and is thus looking for a new master. Such differences are at times even more explicit. Europhiles say: vote for the future; Europhobes emphasize: we have to turn to history 
to learn how to preserve our national identity. Interestingly, Europhiles use terms such as

family, children and grandchildren more often, which again evidences their orientation to the future, while Europhobes remember the casualties of the past war, and the generals in prison.

Table 1 List of expressive words

\begin{tabular}{|c|c|}
\hline Europhobes & Europhiles \\
\hline $\begin{array}{l}\text { By entering Euroslavia Croatia will lose } \\
\text { independence (D. Srb, HSP) }\end{array}$ & $\begin{array}{l}\text { Signing the most important document in } \\
\text { Croatian history (I. Josipović, president) }\end{array}$ \\
\hline $\begin{array}{l}\text { We need to wake up our national } \\
\text { consciousness (D. Srb, HSP) }\end{array}$ & $\begin{array}{l}\text { This [i.e. not becoming a EU member], of } \\
\text { course, would be catastrophic for Croatia } \\
\text { (V. Pusić, minister of foreign affairs) }\end{array}$ \\
\hline $\begin{array}{l}\text { The referendum is an act of national } \\
\text { treason }\end{array}$ & $\begin{array}{l}\text { This is a historic day for Croatia (I. } \\
\text { Josipović, president) }\end{array}$ \\
\hline $\begin{array}{l}\text { The Common Agricultural Policy is } \\
\text { nothing but a scam which is going to } \\
\text { chase the Croatian milkman to grave }\end{array}$ & $\begin{array}{l}\text { Croatia has a historic chance }(\mathrm{Z} . \\
\text { Milanović, prime minister) }\end{array}$ \\
\hline Exploitation will result in Croatian tears & $\begin{array}{l}\text { A new age is dawning for Croatia (I. } \\
\text { Josipović, president) }\end{array}$ \\
\hline The EU is union of enslaved countries & $\begin{array}{l}\text { We are witnesses of a historic event (J. } \\
\text { Kosor, HDZ, former prime minister) }\end{array}$ \\
\hline $\begin{array}{l}\text { Absurd and humiliating results of poll } \\
\text { which demonstrate that the people of } \\
\text { Croatia have no idea what the EU means } \\
\text { (P. Macut, HSP) }\end{array}$ & $\begin{array}{l}\text { It was a great honor to work for Croatia } \\
\text { for the past two years and to reach this } \\
\text { historic success (J. Kosor, HDZ, former } \\
\text { prime minister) }\end{array}$ \\
\hline
\end{tabular}




\begin{tabular}{|c|c|}
\hline $\begin{array}{l}\text { Croatia is going to get a new master (I. } \\
\text { Vekić, former minister of internal affairs) }\end{array}$ & $\begin{array}{l}\text { By becoming a member Croatia is } \\
\text { returning to its cultural and historic roots } \\
\text { (I. Josipović, president) }\end{array}$ \\
\hline $\begin{array}{l}\text { They say that we are filthy Balkans who } \\
\text { oppose the shine of the EU } \\
\text { (representative of civil organization) }\end{array}$ & $\begin{array}{l}\text { It would be irresponsible to miss this } \\
\text { opportunity for our children and } \\
\text { grandchildren (I. Josipović, president) }\end{array}$ \\
\hline $\begin{array}{l}\text { Simple people are going to bear all the } \\
\text { weight of the economic crisis (L. Iličić } \\
\text { representative of civil organization } \\
\text { HRAST) }\end{array}$ & $\begin{array}{l}\text { We are going to be the central part of } \\
\text { Europe (N. Vidošević, president of HGK) }\end{array}$ \\
\hline $\begin{array}{l}\text { The referendum about joining the EU is a } \\
\text { humiliation of democracy (L. Iličić, } \\
\text { representative of civil organization } \\
\text { HRAST) }\end{array}$ & $\begin{array}{l}\text { The EU is a community of values and that } \\
\text { is what Croatia shares with it and what } \\
\text { Croatia believes in (H. Marušić, assistant } \\
\text { of forgein affairs minister) }\end{array}$ \\
\hline $\begin{array}{l}\text { EU funds are nothing but fraud (R. Šikić, } \\
\text { representative of civil organization "I } \\
\text { love Croatia") }\end{array}$ & $\begin{array}{l}\text { We have to believe in ourselves, have } \\
\text { confidence and decide for the EU } \\
\text { because it is the most elite club in the } \\
\text { world (A. Plenković, state secretary for } \\
\text { European integrations) }\end{array}$ \\
\hline $\begin{array}{l}\text { In the EU, we will become a bunch of } \\
\text { people without identity (M. } \\
\text { Francisković), representative of civil } \\
\text { organization "Be brave") }\end{array}$ & $\begin{array}{l}\text { Vote for the future of your country. You } \\
\text { may not like me, but you have to like } \\
\text { your life. People, it is our life that is in } \\
\text { question (V. Pusić, foreign affairs } \\
\text { minister) }\end{array}$ \\
\hline
\end{tabular}




\begin{tabular}{|c|c|}
\hline $\begin{array}{l}\text { Entering the EU brings danger and a lack } \\
\text { of perspective (M. Bošnjak, } \\
\text { representative of civil organization "EU - } \\
\text { No, thank you") }\end{array}$ & $\begin{array}{l}\text { The EU means stability, investments, } \\
\text { higher standards in defending human } \\
\text { rights and a better life for our families (V. } \\
\text { Pusić, foreign affairs minister) }\end{array}$ \\
\hline $\begin{array}{l}\text { The EU is not fulfilling its promises (R. } \\
\text { Šikić, representative of civil organization } \\
\text { "I love Croatia") }\end{array}$ & $\begin{array}{l}\text { Croatia is becoming an important part of } \\
\text { the most influential Union in international } \\
\text { politics (A. Plenković, state secretary for } \\
\text { European integrations) }\end{array}$ \\
\hline $\begin{array}{l}\text { We must fight the ideology of } \\
\text { consumerism (B. Lukšić, representative } \\
\text { of civil organization "Truth about EU”) }\end{array}$ & $\begin{array}{l}\text { We have reached a historic dream of the } \\
\text { Croatian people (G. Jandroković, former } \\
\text { foreign affairs minister) }\end{array}$ \\
\hline $\begin{array}{l}\text { They are selling national interests to } \\
\text { imperialists such as the USA (M. } \\
\text { Francisković, representative of civil } \\
\text { organization "Be brave") }\end{array}$ & $\begin{array}{l}\text { Croatia is fulfilling its goal by becoming } \\
\text { a member of EU, and that is happiness } \\
\text { and good life (Z. Milanović, prime } \\
\text { minister) }\end{array}$ \\
\hline
\end{tabular}

Differences between supporters and opponents of the EU are reflected in the figures of speech, especially metaphor. Figurative language in political discourse has been of great interest for many scholars, regardless of the differences in their approaches. For instance, Norrick (2001: 78) uses a semantic approach, and attempts to demonstrate how an analysis of figures of speech in specific discourse contexts can contribute to our understanding of figurative language. Proponents of Conceptual Metaphor Theory such as Grady et al. (1999) hold that the metaphorical meaning occurs in conceptual predication (some A is conceptualized in terms of B) when source and target domains are different. Although much of the research on hyperbole, tautology and paradox has been undertaken within semantic theory, metaphor has 
often been of central interest in CDA. CDA considers metaphor as the most important figure of speech because of its connection to ideology. Fairclough (1989: 119) concludes that "any aspect of experience can be represented in terms of any number of metaphors, and it is the relationship between alternative metaphors that is of particular interest (...) for different metaphors have different ideological attachments."

Analysis of metaphors used in political speeches shows differences between Europhobes and Europhiles being reflected in the source of a metaphor. For Europhobes, the source of a metaphor is often the Book of Genesis, Christianity and history in general. The European Union is compared with the Tower of Babel which, according to the Book of Genesis, had been built by Noah's descendants (who spoke a single language) "with its top in the heavens." This, in turn, angered God and, as a punishment, he confused their languages. Further, supporters of the EU are considered to be non-baptized beasts, human sacrifices on altars are made, etc. The conservative point of view is manifested through an unwillingness to be multicultural, to accept differences (we are going to depend on some maharajas), and the European Union is seen as a dungeon and a tunnel of darkness. Europhiles are oriented to the future and to liberal, progressive attitudes which are reflected in metaphors grounded in growth, progress, and change (Croatia is opening its doors, Croatia is a fertile ground). The EU is seen as the light at the end of the tunnel, and the most elite club in the world. For Europhobes, Croatian citizens will be slaves (again, returning to the past) and for Europhiles they will be creators of the European destiny (something new, challenging).

Table 2 Metaphors in speeches of Europhobes and Europhiles

\begin{tabular}{|l|l|}
\hline Europhobes & Europhiles \\
\hline If Croatia decides to become a member of & The path toward the European Union was \\
the EU in this referendum, then this will & covered with thorns (J. Kosor, HDZ, \\
\hline
\end{tabular}




\begin{tabular}{|c|c|}
\hline $\begin{array}{l}\text { be the victory of non baptized beasts and } \\
\text { viscious thieves (I. Vekić, former minister } \\
\text { internal affairs) }\end{array}$ & former prime minister) \\
\hline $\begin{array}{l}\text { Croatia is entering the tunnel of darkness } \\
\text { (D. Srb, HSP) }\end{array}$ & $\begin{array}{l}\text { By becoming a member, Croatia is } \\
\text { returning to its cultural and historic roots } \\
\text { (I. Josipović, president) }\end{array}$ \\
\hline $\begin{array}{l}\text { Croatians will be slaves in the EU (R. } \\
\text { Tomašić, HSP - AS) }\end{array}$ & $\begin{array}{l}\text { We can finally see the light at the end of } \\
\text { the tunnel (J. Kosor, HDZ, former prime } \\
\text { minister) }\end{array}$ \\
\hline $\begin{array}{l}\text { Croatia cannot and must not sacrifice its } \\
\text { best people on the altar of the } E U(\mathrm{H} \text {. } \\
\text { Hitrec, representative of civil } \\
\text { organization HRAST) }\end{array}$ & $\begin{array}{l}\text { Croatian citizens will be creators of } \\
\text { Europe's destiny (V. Pusić, foreign affair } \\
\text { minister) }\end{array}$ \\
\hline $\begin{array}{l}\text { Croatia needs to understand that games } \\
\text { are played in Bruxelles (M. Tuđman, } \\
\text { HIP) }\end{array}$ & $\begin{array}{l}\text { The claim that the EU is a third } \\
\text { Yugoslavia is an example of political } \\
\text { blindness (V. Pusić, foreign affair } \\
\text { minister) }\end{array}$ \\
\hline $\begin{array}{l}\text { The EU is the Tower of Babel (M. } \\
\text { Francisković, representative of civil } \\
\text { organization "Be brave") }\end{array}$ & $\begin{array}{l}\text { Croatia is not giving up its independence, } \\
\text { Croatia is investing its independence in } \\
\text { Europe (I. Josipović, president) }\end{array}$ \\
\hline $\begin{array}{l}\text { The EU is the dungeon for Croatian } \\
\text { people (M. Francisković, representative } \\
\text { of civil organization "Be brave") }\end{array}$ & $\begin{array}{l}\text { Croatia is opening the doors of Europe } \\
\text { for all other countries in the region ( } \mathrm{J} \text {. } \\
\text { Kosor, HDZ, former prime minister) }\end{array}$ \\
\hline $\begin{array}{l}\text { They want to surrender our Croatia into } \\
\text { the hands of big masters (R. Šikić, }\end{array}$ & $\begin{array}{l}\text { By entering the EU, Croatia is coming } \\
\text { back home (J. Kosor, HDZ, former prime }\end{array}$ \\
\hline
\end{tabular}




\begin{tabular}{|c|c|}
\hline $\begin{array}{l}\text { representative of civil organization "I } \\
\text { love Croatia") }\end{array}$ & minister) \\
\hline $\begin{array}{l}\text { We are going to depend on some } \\
\text { maharajas (R. Šikić, representative of } \\
\text { civil organization "I love Croatia") }\end{array}$ & $\begin{array}{l}\text { Giving up on the EU is giving up on } \\
\text { ourselves (I. Antičević-Marinović, SDP) }\end{array}$ \\
\hline $\begin{array}{l}\text { We will come to the situation that, } \\
\text { through financial occupation, we will be } \\
\text { left bare foot on the soil of our own } \\
\text { country (M. Francisković, representative } \\
\text { of civil organization "Be brave") }\end{array}$ & $\begin{array}{l}\text { We started the negotiation process when } \\
\text { the EU was experiencing its first tsunami, } \\
\text { when France and the Netherlands said } \\
\text { NO to further expansion (A. Plenković, } \\
\text { state secretary for European integrations) }\end{array}$ \\
\hline $\begin{array}{l}\text { We have to turn to history to learn how to } \\
\text { preserve our identity (M. Francisković, } \\
\text { representative of civil organization "Be } \\
\text { brave") }\end{array}$ & $\begin{array}{l}\text { Croatia is a fertile ground which is not } \\
\text { used enough ( N. Vidošević president of } \\
\text { HGK) }\end{array}$ \\
\hline $\begin{array}{l}\text { People who are not identifying } \\
\text { themselves with the EU are victims of } \\
\text { intellectual violence (N. Raspudić, } \\
\text { political commentator) }\end{array}$ & $\begin{array}{l}\text { Today we are in front of the door, but } \\
\text { tomorrow we will be inside, voting (H. } \\
\text { Marušić, assistant of foreign affair } \\
\text { minister) }\end{array}$ \\
\hline $\begin{array}{l}\text { Europhiles are blind with healthy eyes in } \\
\text { their head (A. Milardović, professor of } \\
\text { political sciences) }\end{array}$ & $\begin{array}{l}\text { We have to believe in ourselves, have } \\
\text { confidence and decide for the EU, } \\
\text { because it is the most elite club in the } \\
\text { world (A. Plenković, state secretary for } \\
\text { European integration) }\end{array}$ \\
\hline
\end{tabular}


Critical Discourse Analysis (CDA) has demonstrated that ideological differences between Europhobes and Europhiles are manifested in their respective expressions, and that both sides use expressive and ideologically marked terms to persuade, or to sustain a belief already held by, their audience. As Fairclough (1989: 152) emphasizes: "Just as even a single sentence has traditionally been seen to imply a whole language, so a single discourse implies a whole society."

\subsection{Rhetorical argumentation analysis}

Rhetorical analysis introduces the argument component into the speeches of Europhobes and Europhiles. Our main goal was to examine the nature of arguments, to evaluate them as weak or strong, good or fallacious arguments. Despite some differences in the preferred argument types between opponents and supporters, the similarities are obvious.

As was pointed out above, emotional appeals were dominant, especially the appeal to fear (loss of sovereignty if Croatia becomes a member of EU or economical collapse if it doesn't). More traditional logical and epistemological analyses regularly presuppose a strict, and ultimately a normative, separation of reason and emotion. Standardly, appeals to fear or pity are considered means of audience exploitation and manipulation, and are therefore considered fallacious. However, contemporary scholarship especially in the rhetorical tradition of argument analysis suggests a more nuanced understanding, and indeed provides some justification for the use of emotions in argumentation, especially in political discourse and the mass media.

For Walton (1992: 68) for instance, once one departs from the paradigm equating good arguments with deductively valid forms of inference, one finds numerous legitimate contexts for emotional appeals in argumentation such that appeals to emotion may be more generally recognized as legitimate arguments under the right conditions. McClurg (1992) 
argues that such appeals are not always fallacious, especially not in democratic societies where political action rightly depends on persuasion, and persuasion in turn depends on rhetoric. Based on Walton (2007: 131), the appeal to fear is currently recognized within social sciences as a distinct argument scheme, used by those in the business of changing public opinion and attitudes through mass media. Although some empirical investigations in the social sciences have claimed to demonstrate the effectiveness of this type or argumentation scheme, Trip and Devenport (1988) submit that such arguments are ultimately negative insofar as they sustain inaction, and thus the status quo, while positive arguments work better to persuade an audience to take action. Arguments that appeal to fear are typically used in issues of health and safety. However, legitimate or not, argumentation cannot be based dominantly or solely on appeal to fear. A complete absence of rational reasoning makes the argumentation weak and represents a short-cut solution to a complex question.

Table 3 Appeal to fear in argumentation

\begin{tabular}{|l|l|}
\hline Europhobes & Europhiles \\
without consulting its people, the & Western Balkan. Our standard [of living] \\
demonstrations in Greece and on Wall & will decrease. We will suffer. (J. Radoš, \\
Street are going to be a "piece of cake" & HNS) \\
compared to Croatia (I. Vekić, former & \\
minister internal affairs) & \\
\hline $\begin{array}{l}\text { We have had bad experiences in joining } \\
\text { big unions. Disintegration of such unions }\end{array}$ & I don`t want to be cruel, but if we do not \\
always ends in bloodshed and Croatia is & any pensions. (V. Pusić, HNS) \\
always a part of it. It has happened with &
\end{tabular}




\begin{tabular}{|l|l|}
\hline $\begin{array}{l}\text { Yugoslavia, Austro-Hungarian empire } \\
\text { (D. Srb, HSP) }\end{array}$ & \\
\hline The EU is going to exploit our natural & Without the EU our credit rating is going \\
going to be worthier than oil in a few & to fall, and there will be no economic \\
years-and we are going to be left with & \\
nothing (M. Francisković, representative for us. (V. Pusić, HNS) \\
of civil organization "Be brave")
\end{tabular}

Arguments presented in the speeches of both supporters and opponents to the EU were weak, fallacious and regularly overlooked other alternatives (The EU is the only possible solution according to supporters of the EU; otherwise we are going to suffer, be poor, without pensions and prospect. If we become an EU member, we are going to lose our independence, language and identity, according to EU opponets.) It is not implausible that appeals to fear may have caused a negative attitude toward the EU referendum in general; less than $50 \%$ of Croatian citizens voted in the referendum. Appeals to fear then were a dominant argumentation strategy for both Europhobes and Europhiles, which in turn caused the disapproval of many human rights activists. Željko Puhovski, one of the founders and presidents of the Croatian Helsinki Committee concluded at the end of the referendum: "This 
is a good result for the EU. It is a shame that it was not reached in democratic way.'(Večernji list, January 23 2012)

3.2.1. Preferred types of argument in the speeches of Europhiles

Argumentation in the speeches of Europhobes and Europhiles showed some differences in the choice of arguments. Supporters of the EU (such as the Prime Minister, government members and the president) frequently used the argument from expert opinion which is a species of the argument from authority. Rieke \& Sillars (2000: 123) explain that "even persons of high credibility frequently use the credibility of others to argue a claim. In argument from authority you argue that a claim is justified because it is held by a credible person." Willard (1990) claims that public decision-makers are inescapably dependent on authoritative testimony from experts. "The public decision-maker's dependence on authority is most apparent when we consider that most decisions are inferences drawn from facts or, more accurately, drawn from testimony interpreting facts" (1990: 12).

Authorities who were frequently cited, paraphrased or just referred to included:

1. Paul Vandoren, Head of the Delegation of the European Commission to the Republic of Croatia who is referred to when explaining job opportunities in EU in the speeches of the minister of foreign affairs Vesna Pusić.

2. Stefan Fuele, Commissioner responsible for enlargement and European neighborhood policy who announced the end of the negotiation process; he was referred to in the speech of J. Kosor when arguing for new economic opportunities Croatia is going to get when becoming a member of European Union. 
3. Jose Manuel Barosso, President of the European Commission whose words "this is a victory moment for all Croatian citizens" after Croatia signed the ascension treaty were cited in the speech of president Josipović who promised a higher standard of living.

4. Berndt Posselt, a German representative in the European Parliament who was paraphrased in Jadranka Kosor's speech as saying that Croatia had the most difficult requirements to become a member and by fulfilling them she becomes the most valuable member of EU.

Statements of European representatives were used to support the position of the Europhiles on how important it is for Croatia to become a member, how successful the negotiation process was (implying that Croatia satisfied many of the EU's criteria, and therefore improved on its extant laws, judicial system, human rights etc.) and how important and welcome Croatia is in the European Union.

As Walton (2006: 87) writes: "The appeal to expert opinion is based on the assumption that the source is alleged to be in a position to know about a subject because he or she has expert knowledge of that subject. Appeal to expert opinion should, in most typical cases, at any rate, be seen as a plausible but defeasible form of argumentation."

Similarly, Wagemans (2011: 331) writes about the assessment of argumentation from expert opinion which is characterized as "argumentation that renders an opinion (more) acceptable by claiming that the opinion is asserted by an expert."

In analyzed speeches, the argument from expert opinion is easily defeasible because of the biases of EU representatives. Their knowledge and expertise on EU affairs are not in question, because the cited authorities are highly positioned representatives with experience in politics. The question, rather, is exactly how biased those authorities are. They are certainly not neutral and objective, since they were involved in the negotiation process, and impartiality 
may be viewed as necessary characteristics of authority. From an epistemological perspective, arguments from expert opinion are a weak part of the Europhile's argumentation since, as Walton emphasized: "Using the appeal to expert opinion as an argument should not be seen as a substitute for getting factual evidence by scientific methods of data collection" (2006: 88).

Epistemologically stronger arguments by Europhiles were found in speeches citing facts, statistics and examples which they frequently used to point out the benefits of EU membership. Their claims that a better life, a higher living standard and more job opportunities would follow from joining the EU were sometimes supported by facts. For instance, the minister of foreign affairs Vesna Pusić, in an interview for the television show "EU 28" (which specifically addressed questions on Croatian EU ascension), explained what the EU means for Croatian citizens:

"[...] more money in EU development funds than ever before in the Croatian budget and development projects are what makes for new employment and a stronger economy. We will get 3.5 billion Euros in the first two years of membership, 373 million Euros for Agriculture. Every Croatian citizen will be free to move and work in all the countries of the EU, students will be able to study abroad. Custom duties and limitations on goods and capital movement will be eliminated."

Although, the possibility of funding becoming available for Croatia is a good argument from consequences, what it lacks is warrant. For instance, the alleged connection between custom duties and a higher standard of living is not explained in the above example. In the same interview, V. Pusić talks about a better judiciary system: 
"When becoming a member of the EU, the courts are not going to be something that give you stomach aches, courts are going to help you, be at your service."

Further on, she claims:

"The biggest benefit is stability of the state and institutions. In the EU people will not have to fear for their heritage, for their property, for their lives. The EU provides a guarantee for long term stability, and living in a community which is stable is the biggest benefit of all."

Her speech is, strictly speaking, an example of circular reasoning; traditionally know as petitio principii (i.e., the claim to be supported is presupposed). It this case stability in Croatia is supported with stability of the EU (which is a slightly different claim, and could be supported independently).

Another characteristic of Europhile argumentation is the frequent use of arguments based on popular opinion (ad populum). Although classical logical analyses regularly consider an argumentum ad populum to be fallacious, Freeman (2005) writes that such arguments are often assumed to be reasonable, or to have at least some standing, especially in democratic political system and political argumentation. Herbst (1993) conducted research on how opinion polling shapes politics and states that many arguments in both the political and the private sphere are based on premises that express what public opinion is supposed to be. Walton (2006) concludes it is important that arguments are evaluated in each particular case. If so, then the arguments based on popular opinion in the speeches of the Europhiles are in most cases fallacious. For instance, the former Prime Minister J. Kosor's statement: "It is important to learn how to function inside EU and live by the rules which are good for 500 million Europeans," implies: 'if it is good for 500 million people, it will be good for us' 
which may be considered to be fallacious. It is plausible that, because of Croatian historical, political, economical or geographical characteristics, perception or acceptance of some political rules is going to be debatable.

The claim that Croatia achieved a good agreement with the EU during the negotiation process has also been supported by the number of people who worked on that project. J. Kosor's argument that "More than 3000 people in Croatia worked on the EU project for more than 6 years, closed 35 chapters, met a requirement for more than 400 criteria" is again fallacious, in the sense that the number of people and amount of time is not a guarantee of quality (though it may defeasibly indicate such quality).

\subsubsection{Preferred types of argument in the speeches of Europhobes}

Europhobes, which were mostly represented by activists and representatives of civil organizations, participated in political talk shows and organized protests, arguing that Croatia should say NO on the referendum for EU ascension. The main characteristic of their speeches was the frequent use of argumentum ad hominem which can be considered as the main difference in the argumentation between opponents and supporters of the EU. In contrast, Europhiles almost never attacked their opponent's character.

Copi and Cohen (1990: 97) explain ad hominem as follows:

"It is very common in rough-and-tumble argument to disparage the character of the opponents, to deny their intelligence or reasonableness, to question their integrity and so on. But the personal character of an individual is logically irrelevant to the truth or falsehood of what that person says, or the correctness or incorrectness of that person's argument." 
Contemporary research in argumentation theory, however, recognizes that there is a "good" argumentum ad hominem:

"A good ad hominem bases a claim on premises that show that someone is in some way unreliable. The version of ad hominem we call an 'argument against authority' argues that a person is not a reliable authority and should not, therefore, be taken seriously. (...) It is important to distinguish ad hominem attacks that discredit a person's position because of their character from attacks on the person alone. The latter is often called an abusive ad hominem because it does little more than hurl abuse." (Groarke and Tindale, 2013: 320)

Therefore, argumentum ad hominem is not always fallacious; it might be considered as a legitimate argument which is "relevant to the conclusion of the argument when the person in question is supposed to be an expert" (Mizrahi, 2010: 438). However, in our case study the arguments used by opponents to the EU are instances of the abusive ad hominem, and so logically irrelevant for a critical discussion. They are instances of what Woods calls "slanging." "Slanging is a rhetorical device, as old as the hills. Its objective is to expose, embarrass, ridicule, mock, calumniate or humiliate one's opponent, typically with the intent of rattling him dialectically" (Woods, 2007: 109).

Our analysis of speakers protesting against the EU evidences the usage of a number of abusive ad hominem arguments.

Table 4 Use of abusive ad hominem arguments

\begin{tabular}{|l|l|}
\hline Example of ad hominem argument & Speaker \\
\hline Who is leading us to Europe? Sons of & Dražen Keleminec (representative of the \\
\hline
\end{tabular}




\begin{tabular}{|c|c|}
\hline $\begin{array}{l}\text { those who were once for Yugoslavia, for } \\
\text { Tito, for communism, who were against } \\
\text { Croatia. The father of Ivo Josipović was a } \\
\text { well known communist, Radimir Čačić is } \\
\text { a communist child, Zoran Milanović's } \\
\text { grandfather was a partisan. }\end{array}$ & radical right wing party A-HSP) \\
\hline $\begin{array}{l}\text { Who represented Croatia in the EU } \\
\text { Parliament in signing the treaty....Bebić, } \\
\text { Pusić, Pupovac and the rest of the traitors } \\
\text { of our country }\end{array}$ & $\begin{array}{l}\text { Dražen Keleminec (representative of } \\
\text { radical right wing party A-HSP) }\end{array}$ \\
\hline $\begin{array}{l}\text { Everyone who believes in the EU is } \\
\text { crazy. They were brain-washed. }\end{array}$ & $\begin{array}{l}\text { Ivan Pernar (representative of a civil } \\
\text { organization "Coalition for changes") }\end{array}$ \\
\hline $\begin{array}{l}\text { When minister Linić said that our wallets } \\
\text { will be full in the EU - believe me, he } \\
\text { was thinking of his own wallet, not yours } \\
\text { or mine. }\end{array}$ & $\begin{array}{l}\text { Ivan Pernar (representative of a civil } \\
\text { organization "Coalition for changes") }\end{array}$ \\
\hline $\begin{array}{l}\text { Members of our government are traitors } \\
\text { who spit on our history, who turned their } \\
\text { backs on our generals, villains who rule } \\
\text { in our country }\end{array}$ & $\begin{array}{l}\text { Željko Sačić (representative of the } \\
\text { council "No to EU) }\end{array}$ \\
\hline $\begin{array}{l}\text { Those who support the EU are naive and } \\
\text { have the logic of a small child. }\end{array}$ & $\begin{array}{l}\text { Marko Francisković (representative of a } \\
\text { civil organization "Be brave") }\end{array}$ \\
\hline $\begin{array}{l}\text { They are cheaters and their campaign is } \\
\text { nothing but fraud. }\end{array}$ & $\begin{array}{l}\text { Roko Šikić (representative of civil } \\
\text { organization "I love Croatia") }\end{array}$ \\
\hline All of them who are supporting the EU & Natko Kovačević (representative of civil \\
\hline
\end{tabular}




\begin{tabular}{|l|l|}
\hline will be judged and processed by the & organization "Justice") \\
Croatian people because they are traitors. & \\
\hline Our miserable, worthless politicians & Željko Sačić (representative of the \\
\hline $\begin{array}{l}\text { Jadranka Kosor and Ivo Josipović talk } \\
\text { about a historic event. They are historic } \\
\text { traitors. }\end{array}$ & Josip Miljak (HČSP) \\
\hline $\begin{array}{l}\text { Communists that are now our } \\
\text { government scare us with the Balkan. } \\
\text { They married Serbian women, they sleep }\end{array}$ & \\
with them and scare us with Balkan?! & Josip Miljak (HČSP) \\
\hline $\begin{array}{l}\text { Our politicians are not people, they are } \\
\text { rats. }\end{array}$ & Ivan Pernar (representative of civil \\
\end{tabular}

Examples such as the above show that the abusive argumentum ad hominem occurs with some frequency in the speeches of Europhobes. Discrediting politicians who support the EU appears to be the main argumentative strategy. However, they are rarely attacking their opponent's expertise and political competence (this holds especially for the newly elected government). As mentioned above, supporting and opposing the EU has ideological grounds in the Croatian political discourse. The source of this dispute is the 1990s war between Serbia (more precisely, the Yugoslav communist army) and Croatia. Thus, history and a person's ethnic origin are the main bases for abusive versions of the argumentum ad hominem.

Apart from an appeal to fear and the abusive argumentum ad hominem, the other most common form of argumentation used by Europhobes is based on an appeal to pity. Aggressive presentation and appeal to pity often go hand in hand. Walton (1997: 135) writes: 
"[T]he problem is that in many cases appeals to pity are weak and poorly substantiated as logical inferences, yet pressed forward in an aggressive and emotionally powerful presentation that is designed to overwhelm the critical judgment of the respondent".

As mentioned earlier, in their speeches Europhobes often refer to the war in Croatia in the 1990s, to Croatian generals who are charged at the The Hague court, and to injustice during their prosecution, to the city of Vukovar and to the thousands of Croatian citizens who lost their lives during the war. The Europhobes hold that in this context, the European Union is to blame for war ("The EU was on the Chetnik's side during the war" - N. Kovačević, representative of civil organization "Justice"), the EU is responsible for bringing the generals to The Hague, where the Croatian government abandoned them and, in the opinion of the Europhobes, gave independence to the "godless creation called EU which wants to turn us into the slaves" (Europhobes protest on the Zagreb's main square, January $12^{\text {th }} 2012$ reported on all Croatian national televisions).

In general, Europhobes offered very weak argumentation. Sometimes it was even absurd, including many contradictions, and appeals to emotions. A good example of such absurd claims, weak argumentation and an aggressive presentation is provided by Davor Pavuna, a Croatian scientist and Europhobe. In the political discussion presented on Croatian television, he claimed that Croatia has no chance for prosperity in the EU because it has a population of only 5 million people (his opponent gave him an example of small countries which are successful and big countries which are not, concluding that the size of the population is not significant for the prosperity of a country). Further on, when asked about alternatives to the EU, he responded: "The alternative to the EU is Croatization of the planet" which, according to him, is possible insofar as Croats currently live in 40 different countries 
all over the world. So, on the one hand, there are not enough Croatians to succeed in the EU, while a "Croatization of the planet" is claimed to be possible. Because of the obvious contradictions and the absurdity of the idea of a "Croatization of the planet," this speaker was not taken seriously, and his argumentation soon came to be seen as rationally unacceptable.

A similar answer to the frequently asked question "What is the alternative to the EU" was provided by Gordan Masnjak, a representative of the civil organization "No to EU" who addressed a Croatian audience with the answer "the alternative are all of you!"

Often represented by speakers with an aggressive presentation, the Europhobes' absurd claims and weak argumentation did not enjoy a strong credibility in the Croatian public sphere. The weakest point of their argumentation, and thus one of the reasons why the Europhiles appeal to fear was more effective, consisted in not being able to answer the question on the alternative to the EU. Answers such as "the alternative are the Croatian people; the alternative is a Croatization of planet; the alternative is Croatia becoming like Switzerland" were neither persuasive nor convincing. The risk of an economic collapse and a poor credit rating (as consequences of remaining outside of the EU) was regarded as the more plausible consequence of non-EU membership than the loss of identity and independence.

\section{Conclusion}

Political discourse analysis in Croatia regarding the question of EU ascension included Critical Discourse Analysis (CDA) which focused on the usage of expressive and ideologically marked words and figures of speech, as well as a Rhetorical Analysis which aimed at discovering the means of persuasion and preferred argumentation strategies in the speeches of the supporters and opponents of EU.

The argumentation analysis proceeded descriptively, and aimed at identifying the strength and validity of the arguments in the speeches of Europhobes and Europhiles. 
Europhobes claimed that Croatian citizens should vote NO on the referendum, while Europhiles claimed that they have to say YES. Argumentation for the claims of both sides was based on appeal to emotions, especially the appeal to fear (rather than more rational forms of reasoning). Europhobes stated that becoming a member of the EU meant a loss of independence and sovereignty; this emotional effect appears to have been intensified by mentioning the war which Croatia has led to gain its independence after the disintegration of Yugoslavia. Using the comparison between Yugoslavia and the EU, they predicted another war for Croatia - which plausibly amounted to the strongest appeal to fear available in this context. Europhiles on the other hand compared Croatia with other Balkan countries, and predicted poverty and isolation as consequences of not becoming an EU member. Appeals to fear were accompanied by expressive and ideologically marked words such as Euroslavia, slavery and humiliation on the one hand, and a historic chance and a new age on the other.

The main difference between the argumentation of Europhobes and Europhiles was the use of the abusive argumentum and hominem, often found in the speeches of Europhobes but rarely used by Europhiles. The strategy of attacking an opponent's credibility, thus his or her ethos, was dominant but was deemed fallacious in this study. After all, such attacks were normally not directed at the opponent's competence, and were normally not corroborated with facts or supported by examples. Rather, such attacks were aimed at offending them on a national basis, by referring to their ethnic or political origin (e.g., coming from a Serbian or communist family); in other cases these attacks were straightforward assault such as calling them liars, rats, traitors etc.

Europhiles used the argument from authority to support their claims on job opportunities, funding possibilities, the political importance of Croatia etc. Arguments from authority were in this study deemed to be not very strong, considering the subjectivity and 
bias of the cited politicians; however, they were frequently corroborated by facts and examples.

Persuasion through reference to the ethos of the speaker may be expected in political discourse where a trustworthy character is important. We believe that this had a significant influence on the result of the referendum (which resulted in a $64 \%$ vote pro EU membership). Representatives of Europhiles included members of the former government, the president (who was the most popular Croatian politician) and members of the new government (which won the elections one month before the referendum). Europhobes enjoyed a rather poor credibility because they were not unified, nor organized, but scattered across several small parties or organizations, and were often represented by extremists known to the public for their unpopular, intolerant nationalistic attitudes.

In conclusion, this analysis supports the claim that the Croatian political discourse on the issue of EU ascension paid insufficient attention to $\log o s$, i.e., rational reasoning, as a way of supporting claims and persuading audiences in the public sphere.

\section{References}

Aristotle. On Rhetoric: A Theory of Civic Discourse. Translated by G. Kennedy. Oxford: Oxford University Press, 1991.

Carey, Ch. "Rhetorical Means of Persuasion.” Edited by Rorty Okrenberg, A. Essays on Aristotle's Rhetoric, 399-416. Berkley: University of California Press,1996.

Copi, I. and C. Cohen. Introduction to Logic $\left(5^{\text {th }}\right.$ ed). New York: Macmallian Publishing Company, 1990.

Dijk van, T. "Critical discourse studies: a sociocognitive approach.” Edited by R. Wodak and M. Meyer. Methods of Critical Discourse Analysis, 62-87. Los Angeles: SAGE, 2012. 
Dijk van, T. “Critical Discourse Analysis.” Edited by D. Schiffrin, D. Tannen and H. Hamilton. The Handbook of Discourse Analysis, 352-372. Malden: Blackwell Publishing, 2001.

Fairclough, N. Language and Power. London: Longman, 1989.

Freeman, J. Acceptable Premises: An Epistemic Approach to an Informal Logic Problem. New York: Cambridge University Press, 2005.

Grady, J.E., Oakley, T and S. Coulson. "Blending and Metaphor." Edited by G. Steen, and R. Gibbs. Metaphor in Cognitive Linguistics, 101-124. Amsterdam: John Benjamins, 1999. Groarke, L. and C. Tindale. Good Reasoning Matters! A Constructive Approach to Critical Thinking. $5^{\text {th }}$ Ed. Ontario: Oxford University Press, 2013.

Herbst, S. Numbered Voices: How Opinion Polling Has Shaped American Politics. Chicago: University of Chicago Press, 1993.

Johnson, R. Manifest Rationality: A Pragmatic Theory of Argument. Mahwah: N.J. Lawrence Erlbaum Associates, 2000.

McClurg, A. J. “The Rhetoric of Gun Control.” American University Law Review, 42, (1992): 53-113.

Mizrahi, M. "Take My Advice_- I Am Not Following It: Ad Hominem Arguments as Legitimate Rebuttals to Appeals to Authority.” Informal Logic, 30, no.4 (2010): 435 456.

Norrick, N. "Discourse and Semantics." Edited by D. Schiffrin, D. Tannen amd H. Hamilton. The Handbook of Discourse Analysis, 76-100. Malden: Blackwell Publishing, 2001.

O`Keefe, D. Persuasion: Theory and Research. Thousand Oaks, CA: Sage, 1996.

Prpić, I. Leksikon temeljnih pojmova politike. Sarajevo: Otvoreno društvo BiH, 1994.

Reike, R., Sillars, M. Argumentation and Critical Decision Making. ( $5^{\text {th }}$ Ed), New York: Longman, 2000. 
Sahlane, A. "Argumentation and Fallacy in the Justification of the 2003 War on Iraq." Argumentation. March, 2012.

Tindale, C. Rhetorical Argumentation: Principles of Theory and Practice. London; SAGE Publications, 2004.

Trip, G. and A. Devenport. "Fear Advertising - It Doesn`t Work.” Health Promotion. 27 (1988): 17-19.

Wagemans, J. "The Assessment of Argumentation from Expert Opinion.” Argumentation, 25 (2011): 329-339.

Walton, D. The Place of Emotion in Argument. University Park: Pennsylvania State University Press, 1994.

Walton, D. Appeal to Pity: Argumentum ad Misericordiam. Albany: State University of New York Press, 1997.

Walton, D. Fundamentals of Critical Argumentation. New York: Cambridge University Press, 2006.

Walton, D. Media Argumentation: Dialectics, Persuasion and Rhetoric.New York: Cambridge University Press, 2007.

Weiss, G. and R. Wodak. Critical discourse analysis - Theory and Interdisciplinarity. Basingstoke: Palgrave, 2003.

Willard, C. Authority. Informal Logic. 12, no. 1 (1990): 11-22.

Wilson, J. "Political Discourse.” Edited by D. Schiffrin, D. Tannen and H. Hamilton. The Handbook of Discourse Analysis, 398-415. Oxford: Blackwell Publishers, 2001.

Wodak, R. and M. Meyer. "Critical discourse analysis: history, agenda, theory and methodology." Edited by R. Wodak, and M. Meyer. Methods of Critical Discourse Analysis, 1-34. Los Angeles: SAGE, 2012.

Woods, J. Lightening up on the Ad Hominem. Informal Logic. 27, no. 1 (2007): 109-134. 


\section{Rhetoric - Martial Art or the Art of Winning the Soul by Discourse?}

\section{Language of Politicians vs. Ethos, Pathos and Logos}

Joanna Szczepańska-Włoch, Jagiellonian University

Martial art.

The art of winning the soul by discourse (Plato).

A collection of stones piled with the aim of laying a mosaic. The style of the mosaic depends on the intentions of the craftsman, the time he lives in; thus everyone leaves his individual mark (Lichański).

The application of reason to imagination "for the better moving of the will" (Bacon).

\section{Summary}

“All men (...) up to a certain point, endeavour to criticise or uphold an argument, to defend themselves or to accuse" (Aristotle, 1959: 3). Hence politicians cannot do otherwise and "rhetoric as a technique of argument (...) rather than of ornamentation", one of the oldest surviving disciplines (Dixon, 1971: 14), whose insights and rules still possess the capacity to adjust to the ideological and social change (Cockcroft and Cockcroft, 2005: 3 ), is to forward the achievement of the goals politicians work towards. In this study an attempt is made to depict the persuasive dialogue in the functional language, i.e. the language of politicians in the Polish political arena. Prior to that, structuring the content of the article, a theoretical background and methodology are proposed based on The Art of Rhetoric by Aristotle (1959). Three kinds of proofs, means of persuasion or structural principles by virtue of which the goal is attained, i.e. ethos, pathos and logos, are addressed. In the part to follow we will analyse several models of arguments which prevail in the political speeches as well as various means of rendering ethos and pathos.

Key words: language of politicians, inventio, ethos, pathos, logos

1. Introduction

Classical rhetoricians defined rhetoric as ars bene dicendi, the art of speaking well, the art or skill conveying bene aesthetic beauty and ethical value in dicendi oral and written texts 
(Wilczek, 2009: 8). Plato perceived it as the art of leading ("alluring" or "beguiling" - Asmus, 1986: 156) the soul by means of words - seeing in it its deceptive nature, while Gorgias called it "a means of fascination, peculiar psychagogia, spiritual seduction with a magical effect" (Kucz, 2009: 18), holding “the power to effect 'most divine' deeds" (Asmus, 1986: 156). Aristotle (1959: 15) referred to rhetoric as the "the faculty of discovering the possible means of persuasion in reference to any subject whatever". He argued that rhetoric served "the function of no other of the arts, each of which was able to instruct and persuade in its own special subject". Rhetoric was not so much to persuade as to find "the existing means of persuasion" (Aristotle, 1959: 13). This belief also "removes rhetoric from the realm of the haphazard and the fanciful" (Dixon, 1971: 14), the charge which was often filed by the Aristotle's opponents.

Aristotle (1959: 3) in his definition of rhetoric compares rhetoric to dialectic, saying it is its "counterpart (...) for both have to do with matters that are in a manner within the cognizance of all men and not confined to any special science". He explicates that "all men (...) up to a certain point, endeavour to criticise or uphold an argument, to defend themselves or to accuse". However, it needs to be emphasised that some do it accidently, while others do so habitually. We can infer that some do not possess any knowledge of the art of rhetoric, while others grasped the insights and use it to their advantage. The above-mentioned definition applies to the language of politicians, who sometimes appear to criticise or support an argument, or attempt to refute it, or defend it or accuse their opponents of some error in reasoning. It cannot, however, escape our attention that in the contemporary language of politics, public relations play a prominent role. Thus the arcane art of how to address the public is becoming or has already become an indispensable and required skill for every politician wishing to achieve success, even if doing so amounts to blurring his/her real positions. "Rhetoric as a technique of argument (...) rather than of ornamentation" (Dixon, 
1971: 14) is to forward its achievement. Even if it constitutes one of the oldest surviving disciplines, its insights and rules still possess the capacity to adjust to the ideological and social change (Cockcroft and Cockcroft, 2005: 3).

2. Data presentation

The persuasive dialogue in functional language, i.e. the language of politicians, constitutes the central focus of this article. The Art of Rhetoric by Aristotle (1959), in turn, serves as the theoretical background structuring the content of the article. Three kinds of proofs (ethos, pathos and logos) are discussed, followed by the elaboration of various models of argumentation.

The ultimate success of the persuasive dialogue is subject to the language chosen to fit in with the subject of the interaction, the social context and the audience. Not only the persuader but also the persuadee needs to be involved, for the dialogic interaction entails reciprocal participation and involvement. In the material examined we will concentrate on the pragmatic and linguistic techniques the persuader uses so as to influence the audience. The material comprises two presidential debates held on 27th and 30th June 2010, between two candidates: Jarosław Kaczyński, representing Prawo i Sprawiedliwość (Law and Justice), and Bronisław Komorowski, the candidate of Platforma Obywatelska (Civic Platform). The data for the analysis come from the website of Gazeta Wyborcza: http://wyborcza.pl/. All the extracts have been translated by the author of the article.

3. Stages of shaping the composition 
Cicero (1948: I. 142, quoted in Dixon, 1971: 24) presents a process of rhetorical composition, in which the orator "must first hit upon what to say; then manage and marshal his discoveries, not merely in orderly fashion, but with a discriminating eye for the exact weight of each argument; next go on to array them in the adornments of style; after that keep them guarded in his memory; and in the end deliver them with effect and charm". The abovementioned explication can be transferred into skills which consist of "five phases/stages" (Lichański, 2007: 87; Wilczek, 2009: 9-10): invention (inventio), arrangement or disposition (dispositio), style (elocutio), memory (memoria) and delivery (actio). Our attention, though, will be attached only to the first stage of the classical composition, namely inventio.

\subsection{Inventio}

Invention, being the skill of finding and collecting material, includes: proof, topics, and commonplaces (Dixon, 1971: 24; Lichański, 2007: 96). Proof, according to Aristotle (1959: 15), can be inartificial or artificial, the latter denotes the invention of the speaker, the former the evidence of the law court (Dixon, 1971: 24). In turn, the artificial proof is subdivided into ethos, pathos and logos.

These three kinds of proofs, means of persuasion or structural principles by virtue of which the goal is attained denote: ethos "the moral character of the speaker" (persuasion through personality and stance), pathos "putting the hearer into a certain frame of mind" (persuasion through the arousal of emotion), and logos "the speech itself, in so far as it proves or seems to prove" (persuasion through reasoning) (Aristotle, 1959: 17).

\subsubsection{Ethos}


Aristotle (1959) in defining ethos as depending upon "moral character" stresses that it is the "moral character" of the orator that represents the most influential means of proof when persuading the audience. He explains that to persuade by means of perceived "moral character" the orator needs to deliver a speech in such a manner that the audience will find him/her worthy of confidence. Following Robert and Susan Cockcroft (2005) ethos will be divided into personality and stance.

Personality is rendered as the power to win trust and confidence in the audience, impress them with individuality. Trust, as Garver (1994: 132-138) and Cockcroft and Cockcroft (2005: 16) stress, comprises "moral strength (arête), benevolence (eunoia)", "constructive competence or the ability to offer shrewd, practical but principled advice (phronesis)". As to the individuality, it translates into differentiating such traits of character that would best suit the audience and the topic. What also affects the persuadee is the level of the individual engagement of the persuader, the higher the level appears to be, the more compelling the persuasion.

Stance equals the persuader's viewpoint, vantage point, the issue which rests upon the source of the process of interaction, for the success of the exchange cannot be guaranteed in its absence. Stance is inherently interactive, and evinces group values, yet, it is entirely contingent upon the persuader.

The assessment and confidence of the audience placed in the persuader will be substantially dependent on the persuader's stance, along with the personality and image. The persuader, on the other hand, must be attentive, observe, adjust to the needs of the audience, establish empathy with the audience. Lynette Hunter (1984, quoted in Cockcroft and Cockcroft, 2005: 31) asserts that what matters is not the topic someone relies on, but the manner with which they do so. The persuader can assume either a firm, rigid and authoritative stance; an indecisive and flexible one; or suppress it before disclosing it later. The stance may 
take the form of a structured and ordered process of interaction or a disorganised and uncontrollable one. Nevertheless, as Quintilian (1920) upholds, no fixed rules are to be found that can facilitate persuasion. Still, pragmatism, adaptability and flexibility in one's stance are requisite in order that success is guaranteed. Human capability of choosing the rhetorical language facilitating persuasion cannot be excluded as well.

Hunter (1984, quoted in Cockcroft and Cockcroft, 2005: 32) also discriminates between positive and negative rhetoric, the former explicates the persuader's stance as the interaction progresses, depicting shifts in stance; the latter conceals the values and the standpoint. The part the audience plays is equally significant. The audience must discern the stance, spot the strategy and evaluate its principles. For, as Hunter (ibid.) maintains, there is nothing worse than naiveté of the audience since it results in the audience surrendering to the imposed stance.

\subsubsection{Ethos - Patterns of behaviour adopted by the persuader}

Coming back to the persuader's stance, we shall propose a few patterns of behaviour s/he can exhibit. To begin with, the persuader can prioritise a stance such that the audience perceives the benefits for themselves (positive face, Involvement Strategy (Scollon and Scollon 1995)), seeks approval, the positive self-image (Brown and Levinson 1987; Kasper 1994; Scollon and Scollon 1995; Fairclough 1989/2001; Fairclough 1992/2008). The other pattern relies on the opposite assumption, i.e. the persuader being in the privileged or empowered position threatens the audience with the exclusion of the benefits, hence plays on the emotions, pathos, of the audience (negative face - the want of self-determination, the claim to territories, personal preserves, rights to non-distraction). Tactics described above reflect the concept of saving or threatening face rooted in Brown and Levinson's theory ${ }^{46}$.

\footnotetext{
${ }^{46}$ For details on the aspect of face with reference to the language of politicians, see Szczepańska-Włoch (2010).
} 
As a subsequent tactic worth drawing our attention to, the persuader may adopt lies on the belief that "being yourself" does not entail success. Customarily, the persuader needs to implement intuition and calculation in displaying his/her stance, determine how much of self, image and personality to propose so that it will not discourage a prospective listener. Too personal or too impersonal a stance can be equally counter-effective (Hunter 1984).

Likewise, humour can serve as a tactic deployed by the persuader. It conveys either a release of tension, acts as a reflection of a non-serious stance, or an embodiment of the persuader's personality, being the consequence of his/her conviction. Lastly, it can also function as a gun that cons the audience into falsehood, ergo yields dubious benefits.

Changing sides by the persuader and his/her willingness to admit it openly constitutes a strategy which, if managed skilfully, can bring a desirable effect. Nonetheless, it appears to be risky and requires a considerable skill. For the inconsistency of stance can exert an adverse impact and lead to the feeling of distrust on the part of the audience (ibid.).

Stance and personality are realised by basic features of language that, as Cockcroft and Cockcroft (2005: 38) suggest, "lay the foundations of meaning and human contact". The dialectic of persuasion is to be grounded in three functions propounded by Halliday (1973), i.e. ideational (ideas about the real world), interpersonal (social relationships), and textual (realisation of language choices). All the functions enumerated must be fulfilled so that the persuasive character of ethos is communicated. The first one - ideational, say, can be realised by making use of the language depicting the persuadees's experience; the second one interpersonal - by the use of modal verbs (expressing possibility, uncertainty, criticism, expectation, etc.), and personal pronouns (showing distance); the textual function - by virtue of textual cohesion and coherence: verb tense, syntax, word order and variation of sentence type. 
To illustrate the above points and to see how politicians realise ethos, two extracts from the presidential debate held on 27th June 2010 are presented. In the first extract Jarosław Kaczyński (a leader of Prawo i Sprawiedliwość) responds to the question on the equality of opportunities between regions in Poland:

(1) We have two conceptions in Poland. One, in short, is called the conception of motor force and it is the conception of concentrating resources in those regions of the country in which we can already encounter a substantial level of prosperity, in addition, it has been estimated that the above-mentioned level of prosperity will later spread over other regions of our homeland. And there is the conception of the balanced development, of which I am a loyal supporter and which I developed when I was the Prime Minister. It is the conception of a special support for those regions of Poland, which suffer - through no fault of theirs in general, most often through no fault of theirs - a certain backwardness. It was articulated by an algorithm of the implementation of the European funds, very beneficial for the least favoured voivodeships [a voivodeship - a Polish administrative district equivalent to a province-ftn. JSW], in particular those in the east, as well as special programmes, which we managed to win for those voivodeships in Brussels. In short, we are of the opinion that a 'good' development of Poland is equivalent to a balanced development, and it is essentially in the interest of all of us. For the reason that nowhere in the world the development via those so-called motor forces - it has its scholarly name I will not allude to - brought desirable effects, islands of prosperity and the ocean of stagnation were established, or such spheres where the reverse process took place, where they were getting poorer. In short, it would be better if we do not try to implement that conception, I refer to it because the 
present government has proposed such sorts of plans under such scholarly terms. Those are the plans which are not compatible with what is going on in Poland, since it is not that those metropolises are developing so rapidly in Poland, and, I repeat, that conception has not been checked anywhere in the world. Here our standpoint is firm, my standpoint is univocal, as the President of the Republic of Poland, I will do everything to make Poland develop in a balanced manner.

After a brief introduction of two concepts of the economic reform of Poland, Jarosław Kaczyński openly presents his firm standpoint in saying "I am a loyal supporter", via the use of the first person singular pronoun "I" he emphasises his view. Only twice does he use "I", in the exordium and peroratio stages of the speech, to open and close his composition, with the aim of demonstrating his rigid stance (interpersonal function). By contrast, in the course of his speech Kaczyński repeats the first person plural pronoun "we" four times, thus he identifies with his party and reflects their values, or wishes to "get closer" to the audience and warm (improve) his image (Fairclough 1989/2001). Kaczyński also repeats the phrase: "through no fault of theirs in general, most often through no fault of theirs", to claim common ground with the audience (ideational function), or rather prospective voters, i.e. the inhabitants of the disadvantaged regions, the reason being to win their votes. By referring to the "so-called motor force" and "scholarly term", he depreciates the government's policy, moreover, with a derogatory tone. Further, he claims common ground with the people, distances himself from the world of science, often perceived as foreign to the average citizen of the country ${ }^{47}$. Subsequently, he refutes the opponent's idea by displaying its uselessness. He concludes his speech by confirming his stance.

\footnotetext{
${ }^{47}$ It needs to be emphasised that politicians appear to juggle that strategy; depending on the aim they strive to achieve they either distance themselves from the world of science or show their affiliation with it.
} 
In the second excerpt Bronisław Komorowski (a candidate of Platforma Obywatelska for the presidential seat), being interviewed about the problem of legalization of homosexual relationships, declares:

(2) So, there is a question whether a new law should be established. For in accordance with the Polish law, in effect at present, there is a possibility for inheriting, there is a possibility for medical care for all the people living in such relationships, which are not marriages, except for a few cases concerning, among others, adoption rights I cannot imagine that in Poland such a bill can ever be brought forward to the president's office, since it is something different to create possibilities for living together and taking care of each other, and inheriting, and it is something different to go in the direction of mechanisms, or regulations, which concern a sphere, or a traditional model of family. I suppose that it is rather a fancy question, because I don't expect that such a legislative initiative is probable in the nearest future, it is rather being talked about in quite narrow circles. One should be decent towards everyone, we should not be too inquisitive about the private lives of others, but we can also solve problems of people living in such relationships decently, in accordance with the law currently in effect. If it turned out that something is missing, that some mechanisms require polishing up, that, for example, there is no easy access to medical care, when somebody goes to hospital, so such a bill should be enforced in the name of political decency. But we shouldn't mix it with a problem of marriage, adoption or other situations of that type, which are confined to the marriage of people of different sex. 
The question posed by the interviewer appears to be somewhat controversial, especially for a politician representing a right-wing and centre-right-wing party. Nevertheless, even if Komorowski evades answering the question, he does not conceal his standpoint. Later, we can decipher that he is in favour of a traditional family model, though, it is expressed covertly (ideational function). He makes use of hedges of casual conversation, such as "I suppose", modal verbs: "can", negative form of "can" - "cannot", "should", a conditional structure to avoid answering (textual function). He does so in the face of an oncoming election and in order not to discourage a part of his electorate. Komorowski's lexical choice, the use of colloquial or humorous words, e.g. "fancy" (in Polish wydumany denoting something "unlikely, improbable, fake" (Słownik Języka Polskiego), or "trivial, made-up, far-fetched" (Słownik Synonimów)) or a not very complex syntax, as well as an impersonal style also serve to create his positive image (interpersonal function). The aforementioned factors contribute to the adaptability and flexibility of the candidate, factors which guarantee success in the political discourse, which in turn is persuasive in its nature.

To recapitulate, Quintilian maintains that "no man can be a good orator unless he is a good man" (Non posse oratorem esse nisi virum bonum - Quintilian, 1907: 416 [12,1,1], quoted in Kucz, 2009: 31). Plato (1973: 83), on the other hand, holds that the persuader is an "expert in rhetorical subtlety", equipped with the knowledge of speech cohesion and coherence (structure of the speech) enabling to offer proof, but without any insight into and consideration of truthfulness or real knowledge of the subject. Which perception appears to be closer to the contemporary definition of the persuader-politician? With the power of PR prevailing in the public eye, shaping the ethos of every celebrity in such a manner that by means of distinctiveness s/he becomes persuasive, losing the real meaning on the way, the answer is: the latter. Today, Aristotelian ethos is substituted for a highly powerful "image" 
exerting a considerable effect on the persuasive language, the success of which is often founded on the image (dress, speech), and political charisma (voice, language, or appearance).

\subsubsection{Pathos}

Pathos is equivalent to persuasion through an emotion that is roused (Aristotle, 1959: 17), thus the orator by virtue of "a certain frame of mind" entices the audience. The persuader will intentionally use an emotional appeal, which many a time constitutes a source of distrust of rhetoric, owing to "its association with insincerity, irrationality and rabble-rousing" (Cockcroft and Cockcroft, 2005: 55). It seems that there is no other way but to employ emotions to manipulate the audience. After all, as Damasio (1999, quoted in Cockcroft and Cockcroft, 2005: 55) holds "humans cannot think properly unless, as a prior condition, they feel". Downes (2000, in Cockcroft and Cockcroft, 2005: 55) adds that what we feel mirrors what we think by means of semiotic systems, i.e. verbal and non-verbal signs. Nonetheless, it should be propounded that emotions can obscure the view, preventing people from gaining a broader and a true perspective on the issues raised, and when out of control can threaten and discourage the audience.

Cockcroft and Cockcroft (2005: 57) propose two kinds of emotions: universal and contingent. The former reflects emotions common to humanity (e.g. joy, anger, fear), the latter emotions as socially conditioned manifestation (e.g. pride, contempt, indignation, guilt). Both are culture-specific, context-dependent, historically-bound and central to persuasive rhetoric. Both are present in literary and functional persuasion, though universal emotion is often associated with literary persuasion or formal discourse (Nash, 1989).

The use of pathos by the orator will in a substantial manner depend on the agreement between the persuader, the topic and the audience in a socially structured context. Notwithstanding, it is within the ability of the speaker or writer that s/he adjusts the language 
to match the topic raised and to appeal to the audience. Therefore it is language that plays a vital role in the persuasive discourse. It is also via language that the standpoint, the prejudices the persuader holds are unveiled. Ergo at this point we return to the interdependence of thought, feeling, and language (and its social context $)^{48}$.

Following Cicero and Quintilian (1920), vivid and graphic language appears to be a persuasive factor, enabling the actualisation of emotions. The above-mentioned authors use energeia and fantasia to influence the hearer, energeia renders clarity, fantasia imagination. A subsequent factor carrying a highly persuasive aim, somewhat different than the above one, is the use of abstract concepts, such as honour, patriotism, or justice. The orator making use of the cited concepts may move the audience substantially by alluding to the topics they regard highly. Such a strategy resorts to the individual strongly-held beliefs and values, which assure the audience of the truthfulness of the persuader and arouse greater confidence in him. Again, we revert to the pragmatic concept of face, in the aforesaid example we can perceive positive face realised by claiming common ground, the approval of each other, shared wants and shared knowledge, and reciprocity of obligations (Brown and Levinson 1987: 62).

Finally, it should be borne in mind that playing on pathos can either facilitate the understanding of a logical argument, helping to acknowledge it, or obscure the logical judgement of an argument advanced by the persuader. The persuader wishing to be effective in the art of persuasion must acquire all skills indispensable in influencing the audience, should monitor the response, converge with beliefs and convictions of the audience, reverse his own standpoint, if required. It becomes clear that the persuader must acquire

\footnotetext{
${ }^{48}$ At this point I wish to draw our attention to the significance of language and its social context in the process of discourse analysis. I advocate a view that language does not exist in isolation. Fairclough (1989/2001, 1992/2008) in his framework for the textual analysis of discourse or critical discourse analysis explicates that no analysis is reliable without careful examination of three dimensions: textual, discursive and social. Van Dijk (1998), in turn, stresses that language users in a communicative act rely on social acts, participate in a form of dialogue, which cannot be isolated from social and cultural context. Finally, Bourdieu (2008) highlights that language does not exist for its own sake, language is determined by the relation it bears with the speakers who bring it into use and who possess language competence, therefore to interact the whole social structure is required.
} 
psycholinguistic knowledge, i.e. the complexities of the human character, so as to rate the responses of the audience and shape them effectively. All the ploys stated above are realised by means of language, which occupies a paramount role. Pathos is actualised with the help of argument and repetition, together with stylistic structures, such as antithesis, metaphors and rhythmic patterns, syntactic structures, i.e. fronting, word order, interrogatives, and lexis, i.e. vivid and descriptive adjectives (Nash, 1989; Cockcroft and Cockcroft, 2005).

The following passage is taken from the presidential debate held on 27th June 2010, Bronisław Komorowski responds to the question on the separation of state and church, as well as financing in vitro fertilization:

(3) Ladies and gentleman, not only do I understand a problem of paternity, but also, simply, raised five children. Five times did I experience happiness of being a parent, a father, and I am the last person who would wish to deprive young marriages or couples of hope, chances, and there are twenty per cent of couples in Poland, who cannot have children. (...). But we cannot deprive others of that hope. The issues concerning a system of faith, or an ethical one - here everyone needs to take decisions in his own conscience whether to employ such method, regarding it as effective, or not. Personally, I was, am and will be a supporter of the conciliar principle in effect between the church and the state, namely mutual respect, respect for the autonomy of the church by the state and the state by the church (...). But the compromise is of high importance, the compromise which was arrived at while working on the anti-abortion law, which allows specific exceptions connected also to human life, but it is utterly the law protecting life. I was, am and will always be an advocate of life, I have experienced happiness five times, life of my own 
children, welcoming lives of my own children, I will not deny anybody the right to happiness.

Bearing in mind the theoretical background on pathos explicated above, we can enumerate a number of ploys to which Bronisław Komorowski resorts, the first being the use of abstract concepts, e.g. happiness, hope, faith, conscience, ethics, religion. By evoking abstract categorization, Komorowski appeals to the emotions of the audience reflecting their values, aspirations and experience, the concept of positive face is also brought into play. He is aware of the fact that by alluding to the concepts the audience prizes greatly, he will win their votes. Moreover, he places himself in the position of an expert owing to the experience he has gained, making himself worthy of being trusted. Komorowski is sure of his opinion and voices it firmly. Nevertheless, finding some space for a compromise he, conversely, displays openness and flexibility. In the field of the stylistic and syntactic structures we can also spot some examples, i.e. rhythmic patterns, emphatic structures and repetition.

\subsubsection{Logos}

Logos denotes "reasoned discourse", argument from reason. According to Aristotle (1959: 17), logos relates to "the speech itself, in so far as it proves or seems to prove". Persuasion "by speech itself" can be achieved only if "the true" or "apparently true" can be extracted from the ways of persuasion within the particular subject. Paul A. Rahe (2008: 23) adds that logos "makes it possible (...) to perceive and make clear to others through reasoned discourse the difference between what is advantageous and what is harmful, between what is just and what is unjust, and between what is good and what is evil", which undeniably differentiates us from animals. 
Logos is composed of an issue lying at the heart of a debate which needs to be identified, arguments which will support the issue addressed, the structure of thought which underpins the arguments, coherence and logical value.

Prior to examining which classes of arguments the speakers or writers employ in the persuasive process of the genre under investigation, we shall elaborate on their types. Aristotle (1959: 265) distinguishes three classes of arguments which need to be applied by the orators, firstly, the topic of the possible and impossible, secondly, that a thing will happen or has happened, thirdly, the topic of magnitude. The possible explicates that of two contrary things one is possible, so is the other one; analogically, if of two similar things, one is possible, so is the other one (an argument a fortiori). The possible, therefore, constitutes the source of arguments for the impossible being the opposite of what has been said about the possible. As to a thing that will happen or has happened, Aristotle (1959: 173-273) maintains that if a foundation is laid to believe or if a certain premise has been made that something has happened or will happen, then something will most probably have happened. Finally, topos of magnitude, Aristotle (ibid.) holds that all men use extenuation and amplification (exaggeration of both great and small things) in deliberating, praising or blaming, accusing or defending, for "the particular has more authority than the general". Not only can the topics of argument stimulate the persuader's mind, but also structure the persuasive discourse, enabling the speaker/writer to make use of all available means, which consequently serve the speaker in preparing his/her compositions. Nevertheless, topics, if applied too scrupulously, can deprive a composition of its originality and inventiveness.

Cockcroft and Cockcroft (2005: 83-107), in turn, provide us with ten models of argument, as they call them, substituting topoi with models, meaning "adaptable, flexible concepts", offering "systematic and organising methods of 'thinking through' a topic, and of selecting and organising the most effective arguments". The models of argument which will be 
discussed are as follows: definition, cause and effect, similarity, oppositional, degree, testimony, genus/species, part/whole, associational, and root meaning.

The definition model of argument implies that the speaker or writer makes use of the general category so as to move to the unique feature of a point discussed. Thus, in a persuasive discourse every definition might incite a counter-definition. The cause and effect model embodies an integral part of a persuasive process, both in literary and functional discourse, although it takes a different form in each of them. In the language of politicians, which is our central focus, it is effect-centred, since the said ploy seems to be more convincing. Nonetheless, it is not devoid of predicaments (e.g. oversimplification, disproportion etc.) Cockcroft and Cockcroft (ibid.) identify three processes of cause and effect, the first being a simple cause producing a simple effect, the second a complex cause producing a simple effect, the last one a complex cause producing a complex effect. We need to accentuate that the cause and effect model is grounded in the dialectical process.

Comparison and parallelism emerge to be the key issues of the similarity model of argument. The oppositional model, on the other hand, depicts contradictory motifs. We can enumerate a few sub-varieties of the model: contraries, contradictions, privatives and relatives. Similarly to the cause and effect model, the aforementioned model of argument is present in a dialectical process, involving two-way interaction, not infrequent in the language of politicians, in which one thread of thinking is adopted ruling out at the same time the other one. Such an argument lies at the basis of provocation. The degree model of argument constitutes the third common topos referred to in political rhetoric by Aristotle, together with the similarity and oppositional models. It rests upon constant dynamics, desirability of a goal, instrumental means of achieving it (ibid.). The subsequent type, i.e. the testimony model, is founded on the credibility of a witness, as a consequence it is considered as one of the weakest topics. The testimony model is to be encountered in television broadcasts, notably 
political interviews, for its declarative function, in which the political figures display their loyalty and support for a particular standpoint or a political party or offers certain instruction, hence it often acts as an ideological weapon. The genus/species type of argument carries an interactional function, in which the speakers after initiating a discussion, making a statement, refute each other's arguments, moving from genus to species, or further to sub-species. The part/whole model appears to correspond to the previous model of argument. What differentiates it from the former is that the genus/species can exist separately, while parts and wholes are co-dependent. In the associational model the hearer is manipulated by false logical and ethical assumptions. The above argument can be sub-divided into subject/adjunct (a quality, condition of a subject being its basis), lifestyle/status (an argument, the basis of which being lifestyle/status), place/function (place/function taking the role of a premise), or time/activity (an argument reflecting people's expectations and social rituals) association models of argument (ibid.). Lastly, the root meaning category of argument typifies one of the most manipulative models of argument, the persuader changes the received meaning of a word used and searches for the hidden or alternative meaning.

\subsubsection{Models of argument versus language of politicians}

After having examined two presidential debates held on 27th and 30th June 2010, we can come to a number of conclusions. Firstly, there are several models of argument which prevail in the political speeches - namely, cause and effect, degree, genus and species, associational and oppositional (of dialectical nature); the rationale being its persuasive and emotive functions, as well as vivid distinctiveness in the values and standpoint the politicians have adopted. Secondly, the remaining models are either too sophisticated and would require greater expertise or are not beneficial enough to be used in the political discourse. Lastly, the 
choice of arguments is highly dependent on loyalty and ideology of a politician, the party s/he adheres to determines a line of attack he pursues.

Let us now provide a few examples of the above-mentioned models:

1/ definition model of argument, in which a generalisation is narrowed down into a precise meaning:

(4) Jarosław Kaczyński: (...) privatization, as I have already said, conveys an introduction of entirely different rules of the game. A private hospital will have a possibility to sign an agreement with the National Fund, though it will not be required, and there is every likelihood that such a situation will take place that people belonging to a low income group will simply not have an easy access to treatment, at least in their towns/cities.

2/ cause and effect model of argument, Bronisław Komorowski by means of a conditional sentence explicates that the effect of a fall of a standard of living will be emigration to Great Britain - a simple effect produced by a simple cause; in the second example granted that liberal ideology is challenged, Poland will become a more prosperous country - seemingly ${ }^{49}$ a simple effect of a simple cause:

(5) Bronisław Komorowski: If the standard of living is improved, nobody will go to Great Britain.

(6) Jarosław Kaczyński: (...) only when we reject liberal ideology (...) only then will we bring about development of Poland.

\footnotetext{
${ }^{49}$ I deliberately use the word "seemingly" for the argument is simple only in wording.
} 
3/ similarity model of argument - the following example rests upon parallelism of the process, the speaker's understanding of a problem is linked to his memory-based schemata, that is the speaker's experience:

(7) Bronisław Komorowski: Ladies and gentleman, not only do I understand a problem of paternity, but I also, simply, raised five children.

4/ oppositional model of argument - the example below is grounded in a dialectical process, involving two-way interaction between two participants. Jarosław Kaczyński responds to the question on equal opportunities between Poland A and B. He firmly states that such a division is present in Poland; at the same time he provides solutions to the problem. In turn, Bronisław Komorowski denies that the division exists (the argument Bronisław Komorowski employed might have been borrowed from Barak Obama’s 2004 Democratic Convention Keynote speech in which he said that "There are no red states. There are no blue states. There is only the United States of America”, the speech that earned Barak Obama widespread and welldeserved recognition with respect to successful rhetoric):

(8) Bronisław Komorowski: There is one Poland, there is neither Poland A nor B, nor C nor D. There is no north, south, west or east Poland. There is one Poland and we need to take care of it, and the government does it.

5/ degree model of argument - both examples are founded on the qualitative aspect of argument saying that one thing is better/cheaper, etc. than another one:

(9) Bronisław Komorowski: It is important for the professional army, such is always better $(\ldots)$

(10) Bronisław Komorowski: For sure Poland is much stronger than in 1997 (...) 
6/ testimony model of argument - considered one of the weakest of topoi, however, in the political discourse it may be used as an ideological weapon. In the example to follow, the interviewee instructs the audience how to act, he also accentuates his stance by the use of anaphora:

(11) Jarosław Kaczyński: It is an old teaching of Giedroyć, it is an old teaching of Józef Piłsudski, we should make use of it and we should all go this way.

7/ genus/species model of argument - the following dialectical model of argument is based on the pattern: genus to species, species to sub-species, etc. By way of illustration, Bronisław Komorowski makes an assumption, in turn Jarosław Kaczyński counters this assumption with a subsequent example, the procedure further continues. In the example to follow we can also spot aitiologia (a rhetorical figure (trope), in which the same speaker asks and later answers a question posed), a ploy popular in political rhetoric:

(12) Bronisław Komorowski: Facts are on our side: is there half a billion for the University of Rzeszów? Yes, there is. Is there an improvement of an algorithm calculating money for health sector? Yes, there is. You took it away, we will give it and that's the difference. There is no point in alluding to theories, of one kind or another, facts are unrelenting (undeniable) Mr Chairman, and that's all, full stop. Jarosław Kaczyński: I also have some time, so I will say: half a billion is much less than, for example, twelve billion for Gęsicka's plans. Well, Mr Speaker, you won’t escape from it.

Bronisław Komorowski: Well, Mr Chairman, you can promise twelve billion, but you didn't give a penny, but we will give half a billion. Jarosław Kaczyński: It came from the European funds. 
8/ part/whole model of argument - in which the part represents the whole, in the example below, the speaker enumerates consequences of an economic crisis pertaining to supply estimates and public expenditure, which represent parts of a larger whole:

(13) Bronisław Komorowski: The Italians cut clerks' salaries, pensions (...)

9/ associational model of argument - it provokes the user to make false logical assumptions, as may be the case of the example to follow:

(14) Jarosław Kaczyński: (...) contrary to what the Minister of Foreign Affairs of that government claims, so I presume so does Mr Speaker (...)

10/ root meaning model of argument - characteristic of manipulation, the interviewee deliberately searches for an alternative meaning of a word to manipulate. In the context mentioned the speaker uses the word: "report" sarcastically, for it was uttered by the brother of his opponent after he won the election in 2005, in the form: I report that the task has been completed (originally the statement was not used to display complete dependence, which this word may denote, but to express contentment resulting from victory). Bronisław Komorowski, however, attempts to distort the meaning by referring to it literally since he wishes to show that he is an independent politician:

(15) Bronisław Komorowski: (...) I will not file a report to the Prime Minister (...)

\section{Conclusion}

In every discourse where persuasion is the primary goal we observe the co-existence of the structural principles: ethos, pathos and logos. The type of interaction, personality, stance, as well as emotional appeal may determine the choice of arguments. Conversely, the choice of arguments may reflect the influence arguments exert on emotions and standpoint adopted by 
the persuader. The process is simultaneous. Quintilian (quoted in Dixon, 1971: 25)

maintained that every aspect of speech enhances character: the tone reveals the orator's good will towards the audience, the ordering of arguments reflects his/her intelligence and sense of values, while the feelings expressed embody the goodness of his/her heart. Ergo the orator should be able to comprehend psychology, know the values of the audience and respond to them effectively and truthfully.

Tactics employed by the speaker include postulating the irrelevance of the opponent's argument, by showing its ambiguity, inconsistency or preposterousness. In effective persuasion the issue, the arguments and their relevance must stand in line since an attentive hearer will perceive any incoherence and lack of cohesion upon which they are grounded. Correspondingly, the more the persuader understands his audience, the more s/he will be compelling.

According to classical rhetoric, all the arguments are or can be polar opposites, "either/or", hence they can limit a free mind. The composition, structurally controlled, systematised and classified, may cramp a free development of ideas. Aristotelian rhetoric offers a form of argument, not a compromise, agony being its aim (Dixon, 197; BudzyńskaDaca, 2008). The language of politics appears to draw interest from that rhetoric, in which it has inexorably settled, for the aim of the political discourse is tantamount to that of rhetoric, even if it has, in the opinion of its opponents, become morally suspect, "the art of the purple passage and the debating trick, language masquerading as thought" (Dixon, 1971: 1-2, 70), language used so as to "influence, persuade, perhaps to exhort and instruct", language used to manipulate, language requiring consummate skills.

In sum, on one hand, we can defend a position adopted by Cap (2005, 2006, quoted in Skowrońska, 2010), who upholds that "skilful use of language is not only an asset, but a must in legitimization" of politics, "broadly defined as the ultimate goal sought by politicians". On 
the other one, following Chilton (2004: 23), we can accept the assumption that every political speaker needs to "imbue their utterances with evidence, authority and truth". According to Aristotle, word has to be bound with being, as a remedy for abuse and manipulation within human cognition (Stefańczyk, 2000, quoted in Kucz, 2009: 22). The question arises: does anybody attach any importance to actions in the era of power of mass media? Do actions speak louder than words? Highly debatable. A word is the weapon in Plato's rhetoric, something you use to fight with the opponent's view, or rather with him/her in person, something you apply to defend, refute or maintain the stance adopted, something fulfilling a conative function, finally, something lying on the brink of manipulation. Ergo does rhetoric render martial art or the art of winning the soul by discourse? Both, depending on the perspective we adopt or, more probable, on the goal a politician wishes to achieve.

\section{References:}

Andrews, R. Rebirth of Rhetoric, London and New York: Routledge, 1992.

Aristotle. The Art of Rhetoric, London: William Heinemann Ltd, 1959.

Arystoteles. Retoryka. Retoryka dla Aleksandra. Poetyka, Warszawa: Wydawnictwo Naukowe PWN, 2008.

Arystoteles. Polityka, Warszawa: Wydawnictwo Naukowe PWN, 2010.

Asmus, E. "Psychagogia" in Plato's Phaedrus. Illinois Classical Studies. 11, no. 1 \& 2 (1986): 153-157.

Barłowska, M., Budzyńska-Daca, A. and P. Wilczek. Retoryka, Warszawa: Wydawnictwo Naukowe PWN, 2008.

Barłowska, M. “Amplifikacja retoryczna.” Edited by M. Barłowska et al. Retoryka, 98-115. Warszawa: Wydawnictwo Naukowe PWN, 2008.

Black, E. Rhetorical Criticism, New York: The Macmillan Company, 1965. 
Bourdieu, P. "Language and Symbolic Power.” Edited by A. Jaworski and N. Coupland. The Discourse Reader, 480-190. London and New York: Routledge, 2008.

Brown, P. and S. C. Levinson. Politeness, Cambridge: Cambridge University Press, 1987.

Buckler, W. E. and A. B. Sklare. Essentials of Rhetoric, New York: The Macmillan Company, 1966.

Budzyńska-Daca, A. "Sztuka argumentacji." Edited by M. Barłowska et al. Retoryka, 57-76. Warszawa: Wydawnictwo Naukowe PWN, 2008.

Burke, K. “Tradycyjne zasady retoryki.” Edited by M. Skwara. Retoryka, 35-38. Gdańsk: Słowo/Obraz Terytoria, 2008.

Cap, P. “Axiological Proximization.” Edited by I. Plisiecka-Witczak. Pragmatics of Semantically-Restricted Domains. Vol. II, 3-20. Newcastle upon Tyne: Cambridge Scholars Publishing, 2010.

Chapman, R. Linguistics and Literature, London: Edward Arnold, 1973.

Chilton, P. Analysing Political Discourse, London and New York: Routledge, 2004.

Chilton, P. "Politics and Language.” Edited by J. L. Mey. Concise Encyclopedia of Pragmatics, 688-695. Oxford: Elsevier Science Ltd, 1998.

Cockcroft, R. and S. Cockcroft. Persuading People, New York: Palgrave Macmillan, 2005.

Dijk, T. van., ed. Discourse as Structure and Process, Vol. I. London, Thousand Oaks and New Delhi: Sage Publications, 1998.

Dijk, T. van., ed. Discourse as Social Interaction, Vol. II. London, Thousand Oaks and New Delhi: Sage Publications, 1998.

Dijk, T. van., ed. Dyskurs jako struktura i proces, Warszawa: Wydawnictwo Naukowe PWN, 2001.

Dixon, P. Rhetoric, London: Methuen and Co Ltd, 1971.

Dobrzyńska, T. Tekst - styl-poetyka, Kraków: Universitas, 2003. 
Douglass, R. B. “Arystotelesowska koncepcja komunikacji retorycznej.” Edited by M.

Skwara. Retoryka, 86-96. Gdańsk: Słowo/Obraz Terytoria, 2008.

Fairclough, N. [1989]. Language and Power, London: Longman, 2001.

Fairclough, N. [1992]. Discourse and Social Change, Cambridge: Polity, 2008.

Fairclough, N. and R. Wodak. “Critical Discourse Analysis.” Edited by T. van Dijk.

Discourse as Social Interaction. Vol. II, 258-284. London, Thousand Oaks and New Delhi: Sage Publications, 1998.

Fish, S. Interpretacja, retoryka, polityka, Kraków: Universitas. 2002.

Garver, E. Aristotle's Rhetoric: An Art of Character, Chicago: University of Chicago Press, 1994.

Gazeta Edu. Accessed June 30, 2010. http://slowniki.gazeta.pl/pl

Gazeta Wyborcza. Accessed June 30, 2010. http://wyborcza.pl/

Gordon, G. N. Persuasion, New York: Hastings House Publishers, 1971.

Joseph, J. E. Language and Politics, Edinburgh: Edinburgh University Press, 2006.

Kasper, G. "Politeness.” Edited by R. E. Asher et al. Encyclopedia of Language and Linguistics, 3206-3212. Edinburgh: Pergamon and University of Aberdeen Press, 1994.

Kucz, A. "Retoryka i oratorstwo w starożytności.” Edited by M. Barłowska et al. Retoryka, 17-34. Warszawa: Wydawnictwo Naukowe PWN, 2008.

Lakoff, G. and M. Johnson. Metaphors We Live by, Chicago and London: The University of Chicago Press, 2003.

Lemmermann, H. Komunikacja werbalna. Szkoła retoryki, Wrocław: Wydawnictwo Astrum, 1999.

Lichański, J. Co to jest retoryka?, Kraków: Polska Akademia Nauk, 1996.

Lichański, J. Z. Retoryka. Od renesansu do współczesności-tradycja i innowacja, Warszawa: Wydawnictwo DiG, 2000. 
Lichański, J. Z. Retoryka. Historia - Teoria - Praktyka, Warszawa: Wydawnictwo DiG, 2007.

Nash, W. Rhetoric: The Wit of Persuasion, Oxford: Blackwell, 1989.

Musolff, A. Metaphor and Political Discourse, New York: Palgrave Macmillan, 2004.

Ożóg, K. Język w stużbie polityki, Rzeszów: Wydawnictwo Uniwersytetu Rzeszowskiego, 2004.

Quintilian. Institution Oratoria. Translated by H. E. Butler, 4 vols. London: Heinemann, $1920-2$

Rahe, P. A. Against Throne and Altar: Machiavelli and Political Theory under the English Republic, Cambridge, New York: Cambridge University Press, 2008.

Schopenhauer, A. Erystyka, Kraków: Verso, 2007.

Skwara, M. Retoryka, Gdańsk: Słowo/Obraz Terytoria, 2008.

Sowińska, A. “Going Nukelear: On Manipulation in Bush’s and Ahmadinejad's

Legitimisation of Nuclear Power." Edited by I. Plisiecka-Witczak. Pragmatics of Semantically-Restricted Domains. Vol. II, 21-50. Newcastle upon Tyne: Cambridge Scholars Publishing, 2010.

Szczepańska-Włoch, J. “Aspects of Conduct in Polish and British TV News Interviews with Politicians.” Edited by I. Plisiecka-Witczak. Pragmatics of Semantically-Restricted Domains. Vol. II, 127-145. Newcastle upon Tyne: Cambridge Scholars Publishing, 2010

Sztachelska, J., Maciejewski, J. and E. Dąbrowicz. Teatr wymowy, Białystok: Wydawnictwo Uniwersytetu w Białymstoku, 2004.

Wiedzy PWN. Accessed April 10, 2012. http://sjp.pwn.pl/slownik

Wierzbicka, E., Wolański, A. and D. Zdunkiewicz-Jedynak. Podstawy stylistyki i retoryki, Warszawa: Wydawnictwo Naukowe PWN, 2008. 
Załęska, M. “Retoryka a językoznawstwo.” Edited by M. Barłowska. Retoryka, 173-191.

Warszawa: Wydawnictwo Naukowe PWN, 2008.

Zdunkiewicz-Jedynak, D. Wyktady ze stylistyki, Warszawa: Wydawnictwo Naukowe PWN, 2008. 


\title{
The Analysis of Insulting Practices - Sticks and Stones in the Croatian Parliament
}

\author{
Alma Vančura, University of Osijek \& Diana Tomić, University of Zagreb
}

"It's interesting how people cling to insults or what they think is an insult. " (House M.D.,

S07/E15)

\section{Summary}

The aim of this paper is to study the forms and functions of insults in the Croatian Parliament and compare them with recorded instances of insults found in the British and the Swedish parliaments. The corpus for analysis includes transcripts of two sessions of the 6th Parliamentary assembly and 5 randomly selected sessions from each of the previous assemblies. The corpus includes Aktualno prijepodne (i.e. Question time) as well. Levels of analysis are: forms of (un)parliamentary polarization, mitigation strategies and identification of convergence (between a group of like-minded politicians) and divergence (between opposing groups) by usage of insults and derogatory terms. Reactions to the insults were analyzed as part of the identification process, as it was noted that the Members of Parliament (MPs) were often offended by the insult and wanted to comment on it, even when the insult was not personally addressed to them.

The results show, as expected, that the MPs of the Croatian Parliament are polarized. The offensive expressions are based on pathos in first Assemblies, while later change to ethos-oriented logos, mainly trying to discredit the MPs' credibility, with occurrences of ad hominem arguments. The preferred mitigation strategies are attribution transfer, followed by formulation of insults as questions rather than statements. Unification of politicians is purely along the party-line and is shown through forms of address, the procedures to respond to offensive phrases, labeling and stereotypes.

Key words: insults, insulting practices, Croatian parliament, mitigating strategies, logos, pathos and ethos 


\section{Introduction}

This paper provides an insight into the insulting practices found in the Croatian Parliament compared with the recorded instances of British and Swedish parliaments (Illie, 2001, 2004, 2010a, 2010b). It also offers some explanation to the underlying workings of the insult initiator and insult target.

In everyday life individuals sometimes tend to express their opinions of politicians in the form of insults. When speaking privately, people can say more or less whatever they want without any consequences, but what happens when one is using offensive, derogatory or disparaging terms publicly? More oppressive societies have insult laws (Walden, 2002: 207) which "regulate freedom of expression and enforce laws that punish the criticism of the government officials and institutions". In their basis, these laws are very rigid, oppressive and prevent freedom of speech and opinion. On the other side, democratic societies take pride in the possibility of an individual publicly saying whatever s/he chooses. Nonetheless, even such societies have something to regulate offensive public discourse, and that is criminal defamation law (Walden, 2002) which protects a person when his/her reputation is threatened by falsely asserting a fact. Therefore, when speaking publicly, especially when one's conversation is being broadcast or documented, individuals need to think in advance of how and to whom they are going to address their insult, as there are consequences to their speech acts. However, what happens when an insult is done in the parliament by the Member of Parliament (MP)? Do the same rules apply? Is it normal to expect and assume that, beside the proscribed rules of conduct in the Parliament, working in such an environment and at such a distinguished position will immediately bring a higher moral code and values of conduct of its elected officials? 


\subsection{Rationale}

Studying insults, especially those done by the MPs can give an insight into "social and cultural systems of moral values" (Ilie, 2004: 45), ideology behind the insult, party affiliation, balance of power between the opposing sides/parties, power (not only power granted by "institutional status" (Ilie, 2001: 236), but power seen as " "interactional skill and process'“ (2001 :236), i.e. the power obtained through interaction with other MPs, and finally, language style of an individual MP. Diachronic analysis of unparliamentary discursive practices during different parliament sessions can reveal the possible change of institutionalized language as well as indicate the degree of development of a national parliamentary discourse and, implicitly, of democracy itself. Cross-cultural studies (Ilie, 2001, 2004, 2010a, 2010b), like this one, show forms and functions of insults in different cultures, the direction of parliamentary discourse in connection with the political/social climate, and can serve as a possible guideline of conduct for the future elected government officials.

\subsection{Research questions}

How do MPs gain desired discursive power and, implicitly, more influence with the wider audience? Do insults play an important role in attention-getting? What is perceived as an insult by MPs and what triggers a response? Do the MPs respond to the insults? Are insults party -line, wing-line or individually oriented? How do insulting practices change over time, if they do? Which types of parliamentary insulting strategies are preferred and dispreferred in Croatian debates in comparison to British and Swedish ones? Does the change in insulting practice show development of parliamentary discourse, its participants and, implicitly, of democracy itself? These were some of the questions that this research has raised. 


\subsection{Historical overview}

The Croatian Parliament (Hrvatski Sabor), 22 years since its foundation, is significantly younger when compared with the other parliaments in similar studies. The modern British Parliament, one of the oldest continuous representative assemblies in the world, was formed in 1707 but has its traditions set way back into the 13 th century ${ }^{50}$ and the Swedish one (Riksdag), established in 1917, has roots found in $1453^{51}$. The modern Croatian Parliament was formed in 1990 and although its origins can be traced back into the 13th century, geopolitical changes in Croatia from that period onwards make this historical continuity irrelevant for this research. Although the representative body can be treated as a fairly new phenomenon in Croatia, the same cannot be said for the profession of politician. Specifically, a number of representatives in the Croatian Parliament had significant political functions in the political institutions of Yugoslavia and consequently more experience in public speaking than other MPs in the newly formed Croatian Parliament in the nineties. However, communism and democracy do not share the same political discourse practice. Therefore, possible in/experience of politicians in political discourse and its correlation with success of getting across ideas/views will be left for some future studies.

After the Croatian War of Independence and the formation of the modern Croatian Parliament in 1990, the predominant numbers of seats were mostly won by the moderate right-wing party HDZ (Croatian Democratic Union). According to Čular (2001) the Croatian party system consists of 7 larger parties: HDZ (Croatian Democratic Union), SDP (Social Democratic Party), HNS (Croatian Peoples Party), HSLS (Croatian Social Liberal Party), HSS (Croatian Peasant Party), IDS (Istrian Democratic Assembly) and HSP (Croatian Party

\footnotetext{
${ }^{50} \mathrm{http}: / / \mathrm{www}$.parliament.uk/about/living-heritage/evolutionofparliament/originsofparliament/

${ }^{51} \mathrm{http}: / /$ www.sweden.gov.se/sb/d/4140
} 
of the Right). Although the number of parties has changed over time, the two most influential parties from that time onwards are the already mentioned HDZ and SDP (Social Democratic Party), which is a moderate left-wing party. Although both parties place themselves around the centre, Croatian people perceive them as more predominantly left and right (Banković Mandić, 2007).

\section{Theoretical background}

2.1. Insults and culture

Different cultures use abusive language in a variety of ways and in different areas of life. Brown and Levinson (1987) claimed that politeness is a universal concept, but also that some cultures may be characterized as negative politeness cultures and others as positive politeness cultures. Although Spencer-Oatey (2002 qtd. in Hickey and Stewart 2005) disputes this approach saying it is susceptible to ethnocentrism, everyone who is familiar with the situation in Croatia can confirm that Croatian society is quite ethnocentric, especially because of the Croatian War of Independence that made Croatians quite sensitive to their own national identity. Even though tradition makes up an important part of Croatian everyday life, polite forms of address have changed as they have been much more rigid in the past than they are nowadays (Marot, 2005). This could be the result of a merger between previously strictly separated forms of written and spoken politeness, or "multifunctionality“52 (Silić, 2006:36) of language in different contexts of public communication, which is shaped by different functional styles (Silić, 2006). The same dichotomy has been noted in Italian political language (Galli de' Paratesi, 2009; Held, 2005). As in Italy, written politeness in Croatia is still much more formal and rigid than the more spoken-oriented style, characterized by more

\footnotetext{
${ }^{52}$ Originally in Croatian, translated by Vančura
} 
simplified syntactic patterns, less complex vocabulary and direct language, all "with the aim of realizing spontaneity“ (Galli de' Paratesi, 2009: 138). As a result, the public "has learned not to be surprised any more at expressions that were once confined to dialect and lower registers, typical of extremely familiar and highly informal situations ${ }^{\text {“53 }}$ (Galli de’ Paratesi, 2009: 140). With this gradual erosion of respect for institutional conduct, it is only natural to expect the common usage of verbal transgressions in the Croatian Parliament, as they represent one of the basic expressions of a linguistic substandard.

\subsection{Insults as unparliamentary language}

The unparliamentary language was defined and described extensively in the work of Ilie (2001, 2004), who says that those are "subversive transgressions of the institutional boundaries of parliamentary language use and practices“ (2001: 259). One is immediately aware that the context of argumentation (Tindale, 2007), beside being multi-layered, varied and complex, is extremely important for the analysis of these transgressions. Richards (1938 qtd. in Perelman and Olbrechts-Tyteca 2008:124) stresses that "it is always the context that gives a word its meaning, and it is only through the context that we can discover what the word does". Irvine (1993: 110) specifies that "insult is a communicative effect constructed in interaction", which presupposes a context of some kind. On the other hand, whether or not something is going to be perceived as an insult and bring about any kind of response relies heavily on the affective characteristics of the insult target. This is what J. L. Austin (1975) calls illocutionary force of an utterance, where in order to properly understand the message the listener needs to understand the intention of the speaker and what he meant, how the words spoken were used, or how the utterance was to be taken or ought to have been taken.

\footnotetext{
${ }^{53}$ Originally in Italian, translated by Vančura
} 
As Ilie (2001: 237-238) says "words are not insulting in themselves, but rather that it is their underlying conceptualisations which are perceived as offensive“. These underlying conceptualizations mostly derive from a linguistic base, but we believe that insult categorization also strongly relies on an extralinguistic base, i.e. paralinguistic cues. Thus, it is both the emotional characteristic of the insult target/s, as well as the emotionality of the insult initiator that are indispensable for understanding an utterance. "The more emotional an utterance is, the more significant the role of the intonation, while at the same time the importance of lexical (linguistic) material diminishes" ${ }^{\text {“54 }}$ (Vuletić, 1980: 35). Finally, we can conclude that insults are defined through both linguistic and paralinguistic cues.

When used in Parliament, insults represent deviations from the norm in a highly normative context where MPs' conduct is controlled by the speaker and the proscribed rules, i.e. Standing Orders of the Croatian Parliament, Code of Conduct, and Code of Ethics for Civil Servants ${ }^{55}$. Parliament sessions provide a highly competitive context and political discourse "involves cooperation as well as conflict" (Chilton, 2004: 198). These parlamentary divergences quite often turn into debates which can be defined as "institutionalised deliberation ritual that starts with a basic assumption on the part of the debators concerning the desirability of deliberating and taking action in order to bring about certain agreed upon changes in society“ (Ilie, 2001:242). Debates that are held in the parliament are commonly known to be adversarial, and MPs try to show their power by attacking and counter-attacking each other, so it is of no surprise that they will use unparliamentary language. Face threatening acts include requesting, advising, refusing or criticizing and reflect "social-power structures“ (Held, 2005: 294) and quite often evolve into insults or are perceived as insults. Insults serve to undermine MPs' credibility or a party's institutional trustworthiness and consequentially, serve to enhance the ethos of the insult initiator and shatter the opposing

\footnotetext{
${ }^{54}$ Originally in Croatian, translated by Vančura

${ }^{55} \mathrm{http}: / / \mathrm{www}$. sabor.hr/Default.aspx?sec=714
} 
party's reliability. Ethos is seen in the Aristotelian tradition (Habinek, 2005), where proofs, in this case insults, are based on some feature of the insult target character.

\section{Methodology}

\subsection{Corpus}

The examined corpus consists of transcripts of two sessions of the 6th Parliamentary term and 5 randomly selected sessions from each of the previous Parliamentary terms as well as Question time (Aktualno prijepodne), randomly chosen from the 1992-2011 period. The sessions were: fourth session in the Second Term (November 1992), $22^{\text {nd }}$ session from the Third Term (November 1997), 36 ${ }^{\text {th }}$ session from the Fourth Term (September, 2003), $17^{\text {th }}$ Session form the Fifth Term (November, 2005), $23^{\text {rd }}$ and $24^{\text {th }}$ session from the Sixth Term (April, October 2011). One session, i.e. debates about different proceedings, lasts on average 12-14 hours, so altogether about 70 hours of material have been analyzed.

\subsection{Criteria}

The criteria that was used for insult selection was either content-based or response-type based because, as previously discussed, context and illocutionary force of an utterance play an important role in defining what can be perceived as an insult. If the insult was response-based, it was observed whether it was by an addressee, party-member or the speaker or whether paralinguistic cues were used. No response to an insult was signaled by the MP going back to the content. 


\subsection{Procedure}

The corpus was analyzed in the following way. First, the recorded sessions were watched and then the part of MPs' speech or debate evaluated as an insult was transcribed. The analysis of data was based on Ilie's (2004) framework of interface between rhetoric, discourse analysis and cognitive linguistics. Firstly, a discourse theory perspective with foundations in Lakoff and Johnson's (1980 qtd. in Ilie 2004) cognitive schemata theory was applied. It explains that the human process of understanding is done through image-schematic structures which are "rooted in preconceptual embodiment patterns" (2004: 49) and which thus reveal "inferential processes and implied meanings that are derived in the course of institutional confrontation“" (2004: 49). Secondly, parliamentary transgressions were analyzed based on the classical Aristotelian rhetorical framework (Habinek, 2005) where the insults, insult initiator/s and insult target/s are observed through types of categories the orator uses in his discourse (in our case insulting strategy) for his insult to come through. Logos oriented insults focus on the rational use of language and the reasoning stems from the language itself. Ethos oriented insults appeal to the insult initiator or insult target character or moral qualities, and pathos oriented are those that are based on emotion, feelings of the audience "that can change the ways that people affect their judgments“(Jaffe, 2010: 338).

Levels of analysis included, on the one hand direct insulting strategies mostly done through fallacies like ad hominem, antiphrasis, guilt by association types of arguments and which serve to establish either in-group identity or polarization. On the other hand, indirect insulting strategies were analyzed, which were achieved through rhetorical (rhetorical questions, sarcasm, irony) or pragmatic (juxtaposition of opposite notions, insults formed as questions, attribution transfer strategy) devices. All the aforementioned levels of analysis were then placed according to Ilie's (2004) division into layers of (un)parliamentary polarization 4.1., (un)parliamentary mitigation strategies 4.2., and interplay between in-group 
identity and inter-group dissent 4.3., expanded by diachronic aspect of parliamentary discourse.

Furthermore, we have compared insults in the Croatian Parliament with the recorded instances of British and Swedish Parliaments (Ilie, 2004, 2009, 2010a) to see whether they vary in forms and functions and to identify culture-specific correlations between them.

Finally, to get a deeper insight of the possible temporal change of parliamentary discourse in Croatia, we have observed different sessions through a period of time in order to get a diachronic perspective that would show the possible development in the deliberative genre (Habinek 2005, Ilie, 2004).

4. Results and Discussion

Results show that Croatian MPs use different insulting strategies to establish the trustworthiness of their party and their own credibility i.e. their "(rhetorical ethos), primarily by displaying consistency between their statements and their actions"(Ilie, 2009:72) as opposed to other MPs, representing other parties.

In spite of political and organizational differences between Swedish, British and Croatian Parliaments, we can say that they display some common features, such as tendency of MPs to exchange rude remarks in heated debates which are then kept under control by the Speaker. The possibility of comparison lies in the fact that "rudeness seems to be a universally occurring phenomenon"(Ilie, 2004: 51) and that basic rhetoric patterns and insulting strategies are shared by the MPs of the previously mentioned institutions.

4.1. Direct insulting strategies: (un)parliamentary polarization

Croatian MPs show similar strategies in debates to British MPs in the sense that they both show a "confrontation-seeking tendency" (Ilie, 2004: 54) and are not that keen on trying to 
minimize disagreement as is the case with the Swedish MPs. The political polarization is based on party membership, which can be supported by the fact that no instance of an MP insulting another MP that belongs to his/her party has been documented. However, polarization in terms of political orientation is quite common and depends solely on the coalition formed during a particular term. Direct insults, even in the forms of address are quite frequent and the etiquette sometimes presents a good opportunity for a direct insult, as the following examples will show ${ }^{56}$ :

(1) B, A. (SDP): Moje pitanje će biti upućeno predsjednici Vlade RH, predsjednici HDZ-a, bivšoj potpredsjednici Vlade i ministrici branitelja, bivšoj potpredsjednici Hrvatskog sabora, bivšoj predsjednici HDZ-a Grada Zagreba i bivšoj najbližoj suradnici i prijateljici gospodina Ive Sanadera gospođi Jadranki Kosor. A ono glasi: znate li koliko radnika u Hrvatskoj radi, a ne prima plaću? (6 saziv/23 sjednica, Aktualno prijepodne, 6. travnja 2011.)

A. B. (SocDem) I will address my question to Croatian Prime Minister, the president of CDU, former Deputy Prime Minister and Minister for Veteran Affairs, former Deputy Speaker, former President of HDZ's Zagreb Branch, and former closest associate and friend of Mr. I. Sanader: Mrs. Jadranka Kosor. And the question is: do you know how many workers in Croatia do not receive a salary? (Term 6/ session 23, Question time, 6 April, 2011)

This example precisely shows how insults are context-based, as it seems like there is no harm in an MP enumerating all of the ex-Prime Minister's (PM) titles. The context in which these forms of address were perceived and interpreted as insulting was instigated by the Prime Minister's reaction during the Question time in which she often warned other MPs who spoke

\footnotetext{
${ }^{56}$ The examples show MPs' initials followed by his/her political party. We believe that party allegiances are important for better understanding of the examples. Italicized is the part of the example that best represents the category under discussion.
} 
before A. B. to use the proper forms to address her, for instance when they forgot to say Prime Minister before her name. This example shows how irony and playful tone can disguise the MP's hostile and scornful attitude, but also how paralinguistic cues can be essential for insult recognition, since the whole form of address is purely ironic. It also displays guilt by association type of ad hominem (Tindale, 2007), with the attempt to discredit the PM by closely associating her in the penultimate and the last form of address to the ex-prime minister, who was at the time awaiting trial for a corruption scandal. The insult assumes that any 'guilt' that characterizes the former PM can be transferred to the insult target (PM at the time) as well.

(2) J, Ž. (SDP): Moje pitanje je namijenjeno osobno odabranoj nasljednici Ive Sanadera na mjesto predsjednice Vlade, gospođi Kosor. Gospođo Kosor možete li nam reći kako se u Hrvatskoj može preživjeti sa 2 tisuće kuna plaće ili mirovine? (6/23, Aktualno prijepodne, 6.travanj 2011)

(3) K, J. (Premijerka): Gospodine predsjedniče, budući da ovo nije pitanje nego samo nastojanje da se uvrijedi, ja, naravno, to je poznato javnosti koja poznaje Ustav Republike Hrvatske i hrvatske zakone da ja nisam nasljednica jer ovo nije monarhija, pa onda ja ne mogu biti nasljednica. (...) Ja ću vam na ovo pitanje koje to nije odgovoriti, objasnite vi meni gospodine Jovanoviću kako se može ljetovati za 7 kuna i je li se pri tom platio ili se nije pri tom platio PDV? (6/23, Aktualno prijepodne 6.travnja 2011.)

Ž. J. (SocDem): My question is for the personally selected successor of Ivo Sanader in the place of Prime Minister, Mrs. Kosor. Mrs. Kosor can you tell us: 
how can you survive with a two thousand kuna salary or pension in Croatia? (6/23, Question time, 6 April, 2011)

J.K. (Prime Minister): Mr. Speaker, since this is not a question as it is an attempt to insult, I, of course, it is known to the public who knows the Constitution of the Republic of Croatia and Croatian laws, that I am not the successor, because this is not a monarchy, and then I cannot be the successor. (...) I will give an answer to this question, although it is actually not a question at all, please explain, Mr. Jovanović, how can one spend their holidays paying for it 7 kuna and in doing so, has one paid or has one not paid VAT? (6/23, Question time, 6 April, 2011)

In the example (2) we can again see the same ironical form and guilt by association type of ad hominem in the form of address as in the example (1). Prime Minister Kosor's answer to the question, which she clearly perceives as an insult, is an example of circumstantial ad hominem attack, also known as the tu quoque (you too) (Krabbe and Walton, 1993; Walton, 1998; Tindale, 2007) type of argument, which Croatian MPs use quite often. It represents a case where the critic replies to a previous ad hominem attack by saying that the insult initiator is the same as the insult target and therefore cannot be accountable for delivering the criticism in the first place. It can also, according to Krabbe and Walton (1993: 82), serve as "a sign of a shift to a quarrel', which is what the Prime Minister (3) tried to achieve, as she promptly reacted to an accusation with a counter-accusation. At the same time, in her counter attack, instead of you she is using the indefinite pronoun one, which is marked for non-specificity. This strategy is called defocalization (Haverkate, 1992: 516) which is "a distancing technique applied by the speaker in order to minimize his/her own role or that of the hearer in the state 
of affairs described" and is often found in the Croatian parliament when MPs try to mitigate assertive force of their accusations or insults.

Like their British colleagues, Croatian MPs demonstrate constant parliamentary transgressions directed towards opposite political parties i.e. political rather than rhetorical polarization (Ilie, 2004: 56). This type of polarization is based solely on party membership, and not on the ideology. The relationship between political camps shifts according to the coalition formed and according to the power-shift.

\subsubsection{Diachronic aspect of (un)parliamentary polarization}

As for the types of polarization, Croatian unparliamentary language has undergone a significant diachronic change. In the Second Term (1992-1995), insulting acts were primarily pathos-oriented, just like the British ones (Ilie, 2004), which in the Croatian case can be explained with the political and social situation (Croatian sovereignty, homeland security, neighboring country at war, war and post-war situation in Croatia, refugees etc.) at the time. Chilton (2004) claims that political discourse has specific connections to the emotional centers of the brain and that "some politically relevant feelings, such as territorial belonging and identity ('home'), love of family, fear of intruders and unknown people (...) might have an innate basis and be stimulated automatically in the political use of language“" (2004: 204), which was especially perceptible in the terms following the Croatian independence. The dominant party at the time was CDU, right-wing party, with the predominant number of seats won (85, as compared to the second largest, 14 won by CSLP) and most of the insults at the time were pathos-oriented, group-identity oriented, with colorful metaphors, ad personam attacks and rhetorical questions, meaning you are either with us (Croats) or against us, i.e. pro-Serbian, which is a typical example of non sequitur. A lot of insults were generally addressed towards decisions done by the government, and only isolated instances were 
personally drawn. Most of the MPs used pathos to construct their insult by appealing to the general public, emphasizing what the wider audience was thinking and/or wanting to hear. The example that follows shows the usage of ad hominem arguments and rhetorical questions for a pathos-oriented strategy:

(4) Đ, Š. (HDZ): I dalje, predlažem da se ukine smiješni zakon o oprostu četnicima! To je smiješni zakon! Gospodo, cijela se Europa smije Hrvatskoj da je oprostila nekakovim snagama koje vrše genocid, etnocid, memoricid nad hrvatskim narodom jednako katoličke i muslimanske vjeroispovijesti, a da ovaj Sabor nije imao hrabrosti, a ja bih rekao ni pameti, da kaže s kim je to Hrvatska u ratu. Ja se pitam tko vodi pregovore sa državom koja nije pristala niti na primirje?! Pa, što smo mi, jesmo li mi dječji vrtić ili smo Hrvatski parlament? (...) I, nemojte se ljutiti na mene vi, moji stranački kolege, jer Hrvatska demokratska zajednica je stvorena da oslobodi hrvatski narod, a ne da se cjenka sa cincarima! (2/4, 4. studeni 1992.)

Đ, Š. (CDU): I propose to abolish the ridiculous Amnesty Act for Chetniks! This law is ridiculous! Gentlemen, the whole of Europe is laughing at Croatia for forgiving so called forces which perform genocide, ethnocide, memorycide against the Croatian people, equally those of Catholic and Muslim faith, and that this Parliament has not had the courage, and I would say neither the brains, to say who is it that Croatia is in war with. I wonder who is negotiating with the state that has agreed not even to a treaty?! Well, what are we, are we a nursery school or Croatian Parliament? (...) And, do not get mad at me, you, my party colleagues, because I believe that Croatian Democratic Union was created to liberate Croatian people, not to bargain with cheapskates! (2/4, November 4, 1992) 
Almost 20 year later, MPs in the Sixth Term (2008 - 2011) made a radical shift and started using strategies closer to their Swedish colleagues, having much more "ethos-oriented logos “ (Ilie, 2004:56), especially since the debates in the $24^{\text {th }}$ session preceded election time. These insults are based on the argumentation that lies on the common presumption "that the quality of an act reveals the quality of the person responsible for it" (Perelman and Olbrechts Tyteca, 2008:70). Insults directed towards the target's ethos try to discredit the MP's personal qualities, gaining the attention of a multiple audience (Ilie, 2010b) and stirring an emotional reaction out of the political adversary (Ilie, 2004). These insults try to show that as a public person, an MP represents a particular party and ideology, and is also responsible for implementing its policies in a particular constituency and for promoting and acting in accordance with particular moral values and social norms. "At the same time, an MP is also a citizen and a private person. On account of these multiple roles, all of which can be made public to a certain extent, the institutional targets of insults are often more vulnerable, and consequently much easier to harm“ (Ilie, 2001: 348).

The following example covers exactly these two roles of one MP, his multiple roles, taken as possible grounds for insulting his incompetence in entrepreneurial and managerial skills as an ex and future Minister.

(5) S, Đ. (HDZ): O čemu se radi, gospodine ministre Popijač vas ću pitati. Naime, radi se o jednom bivšem ministru iz hvala Bogu bivše koalicijske vlasti od 2000. do 2003. koji se obilato koristio svojim ministarskim mandatom i sklapao poslove u vrijednosti od 132 milijuna. No nije pitanje vezano uz to, pitanje je vezano nedavno on na radiju, televiziji grmi, grmi, grmi, borit ćemo se, mi kad dođemo mi ćemo radnicima, plaće se ne isplaćuju, a što se dešava? Upravo njegovih 17 tvrtki za koje je on interesno vezan, ne papirnato nego su one njegove, prenesao je, ne isplaćuju plaću svojim radnicima. Ovdje je 1000 radnika u igri koji ne primaju 
plaću, a on licemjerno laže ljudima u oči i kaže da će se boriti protiv toga. Borit će se za nešto drugo, to je istina. Gospodine ministre, lijepo vas molim, što ćete učiniti i sa ostalim radnicima koje ovakvi tajkuni izrabljuju na razini robova ih drže, ne isplaćuju im plaću? (6/23, Aktualno prijepodne, 6. travnja 2011.)

S, Đ. (CDU): I will ask you, Minister Popijač, what is it all about. The question is about a former Minister who was part of, thank God, the former Coalition Government from 2000 to 2003, who had liberally used his ministerial mandate and mantled jobs valued at 132 million kunas. My question does not address that issue, but is related to his recent media appearance, where he shouts and storms, we will fight, when we come (to power) the workers will be paid. Wages are not paid, and what is happening? His 17 companies for which he is bound by interest, not only on paper, do not pay wages to their workers. We are talking about 1000 workers who do not receive a salary, while he is being a hypocrite and blatantly lying to their faces and saying he will fight against it. He will fight for something else, that is for sure. Minister, I kindly ask you, what will you do with other workers who are being exploited in a slave-like manner, and who are not being paid? (6/23, Question time, April 6, 2011)

Here, we have several strategies being intertwined to use this ethos- oriented logos. The MP is using antonomasia, in order to avoid revealing the proper name of the insult target, but anyone who was even remotely familiar with the situation knew who s/he was referring to. Another strategy the MP chose to use was praeteritio, by actually first incriminating the insult target and then asserting that this is not part of the question and that it is not relevant. We can say that it makes a subversive ad personam attack. Also, we see some rhetorical questions 
that are again answered by the MP herself. Finally, juxtaposition of opposite notions, such as corruption, lying vs. morals, is constantly emphasized throughout the question.

\section{2.(Un)parliamentary mitigation strategies in the Croatian parliament}

Every MP knows that there are rules of conduct that should be obeyed in the Parliament. In order to avoid institutional sanctions Croatian MPs often resort to mitigation strategies. Fraser (1980 qtd. in Haverkate 1992: 505) says that mitigation serves to disguise the intention of the speaker for the purpose of reducing "unwelcome effects of his/her performing a certain kind of speech act". The most common mitigation strategies are very similar to those found in both British and Swedish parliaments (Ilie, 2004) such as a) attribution transfer strategy, b) juxtaposition of opposite notions and c) the formulation of insults as questions rather than as statements.

\subsubsection{Attribution transfer strategy}

Ilie (2004: 59) defines it as usage of "indirect attribution strategies in order to avoid taking direct responsibility for using derogatory qualifiers to characterise someone“. Basically, what the MPs do is they transfer the negative qualifier to the target's acts or statements rather than directly insulting the person. The following examples show how Croatian MPs transfer the insult to some abstract notion (procedure) instead of directly insulting another MP or his/her party:

(6) N, D. (HSLS): (...) Ukoliko zakonom propisani postupak procjene utjecaja na okoliš nije zadovoljavajući, (...) potrebno ga je dopuniti, a ne propisivati paralelan postupak koji će kao i postojeći prvenstveno služiti za pranje novca (...). ( 4/36, 3. rujna 2003.) 
N, D. (SocLib): (...) If legally prescribed procedure on the environmental impact assessment is not satisfactory, (...), it is necessary to supplement it, and not to prescribe a parallel procedure that will, as the existing one, primarily serve for money laundering (...). (4/36, September 3, 2003)

It is obvious that it is not the procedure, but the people behind it (and implicitly, the ruling party) that the MP is trying to disqualify. Another instance of attribution transfer strategy, commonly used by the Croatian MPs, is non-specific reference to the insult target (also see example (5)). Unlike the former example, where the insult initiator is trying to mitigate his/her insult through insulting the target's acts or statements or some abstract notion, in the following example the initiator avoids directly mentioning the insult target's name, and instead uses a description of his actions. It is more than clear who the MP is referring to, but nowhere in the whole process does s/he name the person in question and therefore s/he can distance her/himself from the direct derogatory attribution:

(7) B, D. (HSLS): Dame i gospodo, ako ste osoba protiv koje je podnijeto desetak kaznenih prijava, ako sami u svojim intervjuima dajete izjave koje ukazuju da ste i sami počinili, osim tih prijava kaznena djela, što je vama učiniti? Otići na jahtu, predsjednika države, to je inovacija. Ili na topovnjaču. Ispovjediti se bez pokore, dobiti razrješenje. I ne samo to, nego još i sklopiti posao i još sklopiti posao u drugoj zemlji, a hrvatska politika šuti, političke stranke šute, mediji o tome govore, ali Ministarstvo pravosuđa se ne očituje o toj strani s etičkog i političkog gledišta (...). (4/36, 4. rujna 2003.)

B, D. (SocLib): Ladies and gentlemen, if you are a person against whom a dozen criminal charges have been filed, if you alone in your interviews give statements indicating that you have committed those crimes, apart for those criminal charges, 
what would you do? Go to the President's yacht, well, that's a new one. Or on the gunboat. Confess without repentance, get absolution. Not only that, but still be able to make a deal and do business in another country, and all the while, Croatian politics is silent, the political parties are silent, the media talk about it, but the Ministry of Justice does not give any statements about this from either an ethical or political standpoint (...). (4/36, September 4, 2003)

4.2.2. The formulation of insults as questions rather than as statements

Another recurring mitigation strategy of Croatian MPs is to use questions rather than statements. They serve to introduce "ready-made assumptions and prejudicial ideas" (Ilie, 2004:59). Quite often they are in the form of repetitious Wh-questions, which are often rhetorical because the answer is obvious, insulting or incriminating.

(8) K, M. (HSLS): Hoće li temeljem ovoga zakona kazneno odgovarati primjerice Brodogradilište Viktor Lenac i donedavni predsjednik uprave gospodin Vrhovnik zbog obmanjivanja Vlade o poslovnim rezultatima te tvrtke? Pa je onda obmanuta Vlada toj tvrtki izdala 60 milijuna ili 60-tak milijuna dolara državnih jamstava. Hoće li odgovarati Riječka banka? Hoće li primjerice odgovarati Hrvatski fond za privatizaciju koji je evidentno zlouporabom ovlasti recimo gospodinu Štroku omogućio vlasništvo nad Otokom života? Ili će pak ovaj zakon pogoditi neke sitnije ribe i ribice koje ne plivaju u onom pravcu koji se vladajućima sviđa (4/36, 4. rujna 2003) 
K, M. (SocLib): Will, for example, shipyard Viktor Lenac and its, till recent CEO Mr. Vrhovnik, be held criminally liable due to misleading the Government about the business results of the company? And then that misled government issued 60 million, or 60-odd million dollars of government loan guarantees to that company. Will Riječka banka be held accountable? Will, for instance, Croatian Privatisation Fund, also be accountable, which by abuse of authority enabled Mr. Štrok to become a proprietor of Island of Life? Or will this legislation catch some smaller fish and fishes that do not swim in the direction suitable to the ruling party? (4/36, September 4, 2003)

This is an example of an insult in the form of multiple, multi-layered wh-questions. We can argue that they are fallacious, as they contain more questions piled together in an apparently single question (Ilie, 2004), which could be read as an attempt to show the corruption and lack of good judgment of the ruling party. Moreover, they function more as rhetorical questions than the real ones, as the MP provides a scornful answer to them at the end. Questions in the example contain repetition (Perelman and Olbrechts-Tyteca, 2008), precisely anaphora (will be held accountable), which serves to accentuate a point and increase the "feeling of presence“" (2008: 175) of arguments. Repetition is one of the surest and easiest ways to make arguments more pronounced and less surprising, and this is exactly what the MP tried to achieve.

(9) K, D. (IDS): Da li ste tome pritvoreniku iz Salzburga, da ne kažem kriminalcu, kako ga predstavljaju mediji, ijednom rekli gospodine Sanaderu, prijatelju, druže, kamaradu, gospodine, ekscelencijo, pretjerali ste, dosta toga. Nije valjda da niste mogli naslutiti kamo ide njegova samovolja. (...) ali ministri znali su u $90 \%$ slučajeva što se zapravo zbiva u Vladi, kod čovjeka koji je, tako mediji govore, 
90\% radio mimo zakona, a svega 10\% valjda u skladu sa zakonom. (6/24, 28. rujna 2011.)

K, D. (IstrianDem): Have you ever said to this detainee from Salzburg, I will not use the word criminal, as the media call him, Mr. Sanader, friend, comrade, compadre, Sir, Your Excellency, you have gone too far, it's enough. Is it possible that you could not have guessed where his autocracy was leading. (...) but the ministers knew in $90 \%$ of the cases what was actually going on in the government, with the man who was, as the media claim, $90 \%$ of the time working on the other side of the law, and only 10\%, I suppose, in accordance with the law. (6/24, September 28, 2011)

This example shows ad hominem attacks and irony in the form of rhetorical question, but it also displays a brilliant usage of the deictic device called hedge (Lakoff, 1972). The MP first uses an ad hominem attack to say that the former Prime Minister is a criminal, but then uses the mitigating effect of the hedge, in this case the media, to avoid making the impression that he is personally responsible for the assessment, and thus modifies the force of the insult so that he cannot be accountable for something someone else said. This example also displays the usage of etiquette and forms of address as an opportunity to insult (see also example (1)). The rhetorical figure of irony stems from ridicule that is, according to Perelman and Olbrechts-Tyteca (2008: 207), “often achieved through clever deductions drawn from what one is trying to criticize“. Here, the MP is criticizing and trying to insult the leading party members by accusing them of knowing what was going on at the time. 
4.2.3. Juxtaposition of opposite notions: Democracy, morality vs. communism, corruption, lying

Croatian MPs use juxtapositions of opposite notions as a possible mitigation strategy. This is usually done by using the rhetorical figure of antithesis which has two contrasting ideas intentionally juxtaposed. Demetrius (Dean Anderson Jr., 2000: 21) says that "the use of antithesis makes the speaker both gravis and ornatus“, i.e. important, serious, and his speech elegant and ornate.

Diachronically, during the 90 's ( $2^{\text {nd }}$ and $3^{\text {rd }}$ Term), the notion that was used as a way of mitigating an insulting strategy was democracy vs. communism/old habits. In the terms that followed, these notions were mainly used by the right-wing parties when they wanted to accuse the Left of preferring the previous system more. Later on, morality vs. corruption came up in face-threatening acts. It is of no surprise, since MPs' vulnerability can easily be enhanced by attacking the MPs' ethos through his/her wrongdoings, i.e. lying, cheating and corruption. These notions at first seem different from respect vs. contempt used by British and Swedish MPs (Ilie, 2004), but implicitly they are the same, since it is known that people who are corrupt and lie deserve contempt, as opposed to those who are honorable, fair and deserve respect. The following example shows the constant juxtaposition of these notions:

(10) C, Z. ( HDZ): Kako ćete postaviti tu moralnu dvojbu i prozivati ljude koji nisu htjeli stati [na vašu stranu] na temelju tih vaših nemoralnih postupaka u politici jer jedno govorite drugo radite, a s druge strane optužite Hrvatsku demokratsku zajednicu da bi trebala biti u takvim situacijama moralna i prepustiti vama političku vlast (...). Pa prema tome, budimo realni, vi koji stvarate jednu areolu tobožnje demokratičnosti. Tko bi u tom slučaju trebao dobiti mjesto predsjednika skupštine ili gradonačelnika? (3/22 5. studenoga 1997.) 
C, Z. (CDU): How do you plan to set up this moral dilemma and single out people who would not choose [your side] on the basis of these immoral actions in politics, because you say one thing and do another, and on the other hand, you accuse Croatian Democratic Union and say that in such situations it should behave morally and give you the political power (...). Therefore, let's be realistic, you who try to create a halo of the so-called democracy. In that case, who should be made a president of the assembly or a mayor? $(3 / 22$, November 5,1997$)$

According to Aristotle (qtd. in Demetrius 1902: 267) "the merit of an antithetical style is that it brings contraries into emphatic juxtaposition“. These notions are paired in order to create, in this case, an ethical dilemma between two moral imperatives out of which only one is preferable. The opposition serves to emphasise and further accentuate the difference between these two notions. The example carries an underlying message that a party that is immoral does not deserve to be in power. MPs use corruption, cheating, lying, and immoral actions to discredit and insult the opposing MPs or their parties.

\subsection{In-group identity and inter-group dissent}

Croatian group identification depends solely on the party or coalition formed and is not based on the similarities or differences in the interpretation of socio-political events. It also purely depends on the individual's political identity and how much does s/he feel like a part of the group. The goal of these insults is to weaken the authority of the adversaries, whether be it an individual MP or his/her party, as "individuals influence our impression of the group 
to which they belong, and, conversely, what we think of the group predisposes us to a particular impression of those who form it“ (Perelman and Olbrechts-Tyteca, 2008: 322).

Insults to show in-group identity are often expressed by using irony (see also examples (1), $(2),(7),(9))$. It is a rhetorical figure where "one seeks to convey the opposite of what one actually says“ (Dumarsais qtd. in Perelman and Olbrechts-Tyteca, 2008: 207) and the application of the same device is antiphrasis, which is a deliberate ironic use of inadequate illustration by reference to qualifications. These qualifications are assigned to a person and represent a generally accepted statement illustrated by someone's behaviour (Perelman and Olbrechts-Tyteca, 2008). The following example shows how an MP is displaying her/his ingroup membership by using a deliberately inadequate illustration to ironically insult the other group (ruling party):

(11) H, M. (SDP): Samo je vama uspjelo poći za rukom da broj za nezaposlenost raste i ljeti. To zaista treba znati i to je zaista odlična realizacija programa gospodarskog oporavka. I tako danas imamo 300 tisuća nezaposlenih upravo zahvaljujući vašoj sposobnosti. Vjerujemo da će građani tu vašu sposobnost nagraditi na sljedećim izborima (6/24, 28. rujna 2011.)

H. M. (SocDem): Only you have succeeded in having unemployment rates increasing even during the summer. It is really not easy to pull it off and that's a really great realization of the economic recovery program. And so today we have 300 thousand unemployed thanks to your competence. We believe that the citizens will reward this competence in the next election (6/24, September 28, 2011) 


\section{Conclusion}

The line between criticisms, accusations, and disparaging, derogatory terms perceived as insults is very fuzzy and sometimes difficult to establish. Insults are achieved via both linguistic and extralingusitic cues and are contextually defined. Most of the time, insults made by the Croatian MPs serve to interact with other interlocutors and reaffirm the party position represented by a particular MP, at the same time undermining the insult target and consequentially the party represented by this particular MP. They also serve as attentiongetters, in which case the insult is "usually directed for the benefit of an on-looking audience and with the intent to strengthen the silencer's own position“ (Tindale, 2007:90). The audience that the insult initiator has in mind is often wider than the one in the session hall and we could define it as "a third party consisting of the spectators" (Eemeren and Grootendorst, 2004: 178) i.e. reporters, journalists, and constituency members (Ilie, 2010b).

There are various cues for insult recognition, usually ad hominem/ad personam attacks, notions such as corruption, lies, morale, irony and sarcasm, forms of address, rhetorical questions, together with the expressive force of the insult instigator and the conception of what an insult is by the MP her/himself. Many of the insults are done in the form of rectifying the incorrect statement, when MPs have a right to correct a statement previously discussed. Responses to insults are individual, sometimes it is the addressee that responds and sometimes someone else (Speaker, other MP of the same party). MPs often use the response to an insult to make an insult themselves or shift the topic of discussion.

MPs position themselves only along the party lines. This shows that the possible common ideology behind the same-wing parties does not play any significant role in the Croatian Parliament. The frequency of insult initiators is purely individual and there are certain MPs who use unparliamentary language more often than others, which basically serves to promote their own image in a highly competitive environment. There is no gender-dependent 
difference between insult initiator/s or target/s, which can be linked to Kišiček's (2008) research, which showed that there were no significant differences between female and male rhetoric in politics.

Preferred insulting strategies are pathos and ethos-oriented insults to show political polarization, juxtaposition of opposite notions such as democracy vs. communism, morality vs. corruption/lies; insults as (rhetorical) questions, attribution transfer strategy, defocalization, irony and sarcasm.

Over time, insulting practices in the Croatian Parliament have changed from pathosoriented logos to ethos-oriented logos. Notions used for mitigation strategies have also changed from more abstract (democracy) to more specific (corruption, bribe, lies) ones. The usage of unparliamentary language was prompted by the introduction of spoken and lower registers into a highly institutionalized place, which opened up new possibilities for linguistic expression.

Croatian MPs show similar insulting and mitigation strategies as both British and Swedish colleagues. Still, we must conclude that, when compared in closer detail, they behave more like the British MPs, i.e. they display a "confrontation-seeking tendency" (Ilie, 2004:54), polarization which is more political than rhetorical, balance between terms of respect and contempt, irony and direct insults. Diachronically, in the $2^{\text {nd }}$ and $3^{\text {rd }}$ Terms Croatian MPs behave more like the British MPs using pathos-oriented insults and in later terms more like their Swedish counterparts, using ethos-oriented insults (Ilie, 2004), by attacking the other MPs' personal values and acts and discrediting their credibility.

On many occasions, there have been instances of very harsh and rude insults by the Croatian MPs that have been discussed even in the news (e.g. that women are known to be good in bed, but not in places where intelligence is necessary), but they were not part of our randomly selected corpus. Still, it is inevitable to conclude that the insults are becoming more 
and more direct and used with less constraints than before. Whether the common usage of insults promotes democracy and shows development of parliamentary discourse remains open. We believe that is important to be verbally polite "in order to maintain harmonious, efficient interaction“"(Held, 2005: 303) which, we think, is a sign of democracy, more than insults will ever be.

Acknowledgements

The authors would like to thank the Croatian Parliament, especially the Information and Documentation Department headed by Ms. Daniela Sraga Ph.D. who patiently responded to all our requests.

\section{References}

Austin, J. L. How to Do Things with Words, Oxford: Oxford University Press, 1975.

Banković-Mandić, I. “The 'Left'and the 'Right' Identities.” Edited by J. Granić. Language and Identities, 27-37. Zagreb/Split: HDPL, 2007.

Brown, P. and S. Levinson. Politeness: Some Universals in Language Usage, Cambridge: Cambridge University Press, 1987.

Chilton, P. Analysing Political Discourse, Theory and Practice, London/New York: Routledge, 2004.

Čular, G. "Vrste stranačke kompetencije i razvoj stranačkog sustava.” Edited by M. Kasapović. Hrvatska politika 1990-2000: izbori, stranke i parlament u Hrvatskoj, 123147. Zagreb: Fakultet političkih znanosti Sveučilišta u Zagrebu, 2001.

Dean Anderson, Jr., R. Glossary of Greek Rhetorical Terms, Leuven: Peeters, 2000. 
Demetrius Demetrius On Style. The Greek text of Demetrius De Elocutione. Edited By Rhys

Roberts, W (after Paris manuscript.) Cambridge: Cambridge University Press. 1902.

Eemeren, F. H. van and R. Grootendorst. A Systematic Theory of Argumentation, Cambridge:

Cambridge University Press, 2004.

Galli de' Paratesi, N. "Eufemismo e disfemismo nel linguaggio politico e nell'italiano di oggi."

Synergies Italie. No. special, (2009): 137-144.

Government Offices of Sweden. Accessed August 25, 2012. http://www.sweden.gov.se

Habinek, T. Ancient Rhetoric and Oratory, Oxford: Blackwell Publishing Ltd, 2005.

Haverkate, H. “Deictic Categories as Mitigating Devices.” International Pragmatics

Asssociation. 2, no.4 (1992): 505-522.

Haverkate, H. “Diectic Categories as Mitigating Devices.” Pramatics. 2, no. 4 (1992): 505522.

Held, G. "Politeness in Italy." Edited by L. Hickey and M. Stewart. Politeness in Europe, 292-305. Clevedon /Buffalo/Toronto: Multilingual Matters Ltd., 2005.

Hickey, L. and M. Stewart. "Introduction.” Edited by L. Hickeyand M. Stewart. Politeness in Europe, 1-12. Clevedon /Buffalo/Toronto: Multilingual Matters Ltd., 2005.

Hrvatski Sabor. Accessed August 30, 2012. http://www. sabor.hr

Hrvatski Sabor. Accessed August 27, 2012). http://www.sabor.hr/Default.aspx?art=39167

Ilie, C. "Unparliamentary Language: Insults as Cognitive Forms of Ideological Confrontation."

Edited by R. Dirven, F. Roslyn F. and C. Ilie. Language and Ideology Volume ii:

Descriptive Cognitive Approaches, 235-262. Amsterdam/Philadelphia: John Benjamins Publishing Company, 2001.

Ilie, C. "Insulting as (un)parliamentary practice in the British and Swedish parliaments: A rhetorical approach.” Edited by P. Bayley, P. Cross-Cultural Perspectives on 
Parliamentary Discourse, 45-86. Amsterdam/Philadelphia: John Benjamins Publishing Company, 2004.

Ilie, C. "Argumentative functions of parentheticals in parliamentary debates." Edited by G. Álvarez-Benito, G. Fernández-Díaz, and I. Mª Íñigo-Mora. Discourse and Politics 6179. Newcastle upon Tyne: Cambridge Scholars Publishing, 2009.

Ilie, C. "Strategic uses of parliamentary forms of address: The case of the U.K. Parliament and the Swedish Riksdag." Journal of Pragmatics. 42, (2010a): 885-911.

Ilie, C. "Identity co-construction in parliamentary discourse practices." Edited by C. Ilie. European Parliaments Under Scrutiny: Discourse Strategies and Interaction Practices, 57-78. Amsterdam/Philadelphia: John Benjamins Publishing Company, 2010b.

Irvine, J. T. "Insult and responsibility: verbal abuse in a Wolof village." Edited by J. H. Hill. And J. T. Irvine. Responsibility and Evidence in Oral Discourse, 105-134. Cambridge: Cambridge University Press, 1993.

Kišiček, G. "The Comparison of Female and Male Rhetoric in Politics.” Speech, 25, no.2 (2008): 189-201.

Krabbe E. and D. Walton. "It's All Very Well for You to Talk! Situationally Disqualifying Ad Hominem Attacks.” Informal Logic. 15, no. 2 (1993): 79-91.

Jaffe, C. Public Speaking: Concepts and Skills for a Diverse Society. Sixth Edition. Boston: Wadsworth Publishing Company, 2010.

Lakoff, G. "Hedges: A study in meaning criteria and the logic of fuzzy concepts." Edited by P. M. Peranteau, J. N. Levi and G. C. Phares. Papers from the Eighth Regional Meeting, Chicago Linguistic Society, 183-228. Chicago: Chicago Linguistic Society, 1972.

Marot, D. "Uljudnost u verbalnoj i neverbalnoj komunikaciji." Fluminensia. 17, no. 1 (2005): 53-70.

Parliament UK. Accessed May 10, 2012. http://www.parliament.uk 
Perelman, C. and L. Olbrechts-Tyteca. The New Rhetoric, A Treatise on Argumentation. Notre Dame: University of Notre Dame, 2008.

Roberts, R. W. Demetrius on Style. Cambridge: Cambridge University Press, 1902

Silić, J. Funkcionalni stilovi hrvatskoga jezika, Zagreb: Disput, 2006.

Tindale, Christopher W. Fallacies and Argument Appraisal, Cambridge: Cambridge University Press, 2007.

Vuletić, B. Gramatika govora, Zagreb: Graficki zavod Hrvatske, 1980.

Walden, R. "Insult Laws." The Right to Tell: The Role of Mass Media in Economic Development, 207-224. Washington D.C.: The World Bank, 2002.

Walton, D. Ad hominem Arguments, Tuscaloosa/London: University of Alabama Press, 1998. 
III. LEGAL DISCOURSE 
Taking Judges Seriously

\section{Argumentation and Rhetoric in Legal Decisions}

Maurizio Manzin, Research Centre on Legal Methodology (CERMEG), University of Trento Summary

Logical evidence in legal reasoning is one of the most important criteria for evaluating the soundness and legal congruence of Courts' decisions. In Italy such a principle has been fixed in art. 360.1.5 CPC (the Italian Civil Procedure Code), art. 606.1.e CPP (the Italian Criminal Procedure Code) and by a number of judgments by the Supreme Court. Logical proof in Courts" opinions is usually related to the paradigm of "legal syllogism": a practical syllogism whose major premise is given by the statute law and whose minor one is given by the facts under judgment. In this article I argue that the premises of legal syllogisms are not precisely given, but rather built, thanks to an linked process of (rhetorical) argumentation. Such process can be divided into gradual steps, each of them logically reliable: my aim is to outline a preliminary description of these phases as capable of being conceptualized and improved upon by the judge and to furnish a reliable scheme for Supreme Court judges, allowing them to check the logical consistency of lower Courts' opinions. My aim is to provide lawyers and prosecutors with some recommendations which may help them to achieve effective argumentation.

Key words: legal argumentation, legal language, legal reasoning, legal syllogism, rhetoric

Logic and the law in the main Italian legal sources

What does logic have to do with legal decisions? Answering this question implies describing the nature of legal reasoning, because we need to establish whether the reliability of the decisions in trials depends upon some formal schemes of deduction or if it concerns other modalities of evidence.

A rapid overview of some sources of Italian legal system will provide some previous guidelines for dealing with the question. In particular, one must refer to the Italian codes of Civil (CPC) and Criminal (CPP) procedure. Art. 360.1.5 CPC assumes that a judgment is invalid if the reasoning relating to a crucial and controversial fact is "lacking", "insufficient" or "contradictory". Beside that and in a very similar way, art. 606.1.e CPP specifies that a 
judgment is invalid if the argument is "lacking or clearly illogical" "57. Briefly, according to Italian codified law, decisions must be considered invalid when the argument is "insufficient", "contradictory" or "clearly illogical" and consequently judges are asked to know what logical consistency clearly is and whether it is sufficient or not. Consistency which does not appear to be perfectly coherent logically (such as, for instance, in Tarski, 1994), since the Legislator mentions the contradiction as one kind of bad argument alongside others (i. e. insufficiency and clear illogicality), not treating it as the only possible one. So we must conclude that for serious judges - and namely the ones in the Italian Supreme Court (s.c. Corte di Cassazione) - the problems are the following:

1. to determine when a legal argument is contradictory;

2. to determine when it is clearly illogical (but not necessarily contradictory);

3. to determine when it is insufficient;

4. to determine when there is no argument at all (lacking).

All these commitments imply precise viewpoints on logic and argumentative sufficiency on the judges' part. A very difficult task, it must be conceded, for which no codified rules are provided and leaving perhaps too much space for free will and responsibility. Are Italian judges (especially those in higher Courts) prepared to do that?

The modern formalistic heritage

The fact is that Italian legal culture has been influenced for a very long time by a formalistic model of reasoning, dating back to the ideas of thinkers like Charles-Louis de Montesquieu (La Brède 1689 - Paris 1755) and Cesare Beccaria (Milan, 1738 - 1794): authors who adopted a basic presupposition about the paradigm of certainty in knowledge. They thought that no interpretation should be admitted in legal decisions, because such a practice by

\footnotetext{
${ }^{57}$ It is important to notice that in Italian Civil and Criminal procedure, the judge must always declare the grounds of decision in his/her judgment and not only the purview (so-called "obligatory nature of the motivation").
} 
judges would lead to unpredictability and arbitrariness, whereas citizens have the right to know exactly what to do or not to do and what consequences they risk in doing or not doing something (Beccaria, 1982; Montesquieu, 1994). According to such a conviction, the right thing would be to have clear and durable written norms, similar to the axioms of the formal sciences and established by an effective authority (the souverain: a king or a parliament). With norms like these, the judge's task would consist exclusively in recognizing when a fact is relevant as a species of the normative genus: a truly logical operation of "deduction" from a general and unambiguous list of obligatory behaviours and sanctions. This is the so-called "legal syllogism" which I am going to describe in more detail in this article. But for the moment let us pause a moment, and ask what idea of "logic" is in step with such a model of reasoning (for an overview on logic in history: Blanché \& Dubucs, 1996; Varzi et al., 2004).

We usually say that something is "logical" either when it is strongly linked to one or more premises, or when it is part of an ordered scheme. In the former sense we admit for instance that having determined that all black birds are (named) ravens, if we find a black bird it must logically be (named as) a raven; in the latter sense we can, for instance, say that just because yesterday was Monday today must logically be Tuesday, having previously established (or accepted) a scheme of consequence about the series of the (names of the) days. In other words, "logic" means that a certain conclusion - (the name) raven or (the name) Tuesday - is obligatory because some premises have been established or at least accepted by participants in the discourse.

The formula of such an argument can be expressed in the most general terms as if $P$ then $Q$. It implies (at least) that:

1. one or more premises $(\mathrm{P})$ do exist in the discourse before the argument;

2. this or these premises are clearly understood as $\mathrm{P}$ and not as other than $\mathrm{P}$ by participants in the discourse; 
3. this or these premises are accepted by participants in the discourse;

4. one and only one connection can be found between $\mathrm{P}$ and $\mathrm{Q}$, avoiding arguments like if $P$ then $Q$ or other then $Q$.

From the modern point of view (the one of Montesquieu and Beccaria) argument if $P$ then $Q$ can be guaranteed by the immutability of the premises $(\mathrm{P}=\mathrm{P})$ according to the basic principle of identity. We must imagine a closed circle of reasoning in which all possible Qs (such as raven or Tuesday) are ab initio part of the genre $\mathrm{P}$ (such as black birds or week). The closure of this circle depends on the impossibility of disputing the existence of the premises (pt. 1 in the list above), their univocal comprehension (pt. 2), their acceptance (pt. 3), the existence of one and only one possible connection with Q (pt. 4). Obviously, this is a very hard set of conditions to achieve in contexts which are neither formal nor monological (and the trial is just one of these, being linguistically unformalised and dialogical in structure), although authors like Montesquieu and Beccaria maintained that legal science must deal with the sciences par excellence, such as mathematics or physics.

\section{A classical meaning of logic}

But is this the only possible way to say that something is "logical"? If we look at classical thought we can find a different point of view, according to which "logic" means "belonging to $\log { }^{\prime 58}$ : an original activity (not created by men's thinking but rather anticipating it) allowing men's speeches to name the things with a variety of words (difference), obtaining however a unity of sense (identity). A "divine" power for Heraclitus and later Plato; the revelation of the Being for Aristotle, who wrote: "Being is said in many ways" (Metaph. $\Gamma$ 2, 1003a 32-33). So "logic" in a classical perspective does not mean compulsory in one and only one way, because

\footnotetext{
${ }^{58}$ In this context the opposite terms "classical" and "modern" are used not in a chronological sense but in a conceptual one. In fact, there have been in ancient and medieval times some positions conceptually modern (as for instance those of Anaxagoras, Zeno, most of Neoplatonic authors etc.) and, vice versa, in the modern age some others conceptually classical (as, in the very beginning of it, Petrarch) (Manzin, 1994, 2008).
} 
there are many ways at men's disposal: many methods are provided for seeking the unity of sense among the multiplicity of situations. The classical account is essentially dynamic, whereas the modern one is static (more similar to the Ephesian philosophies: on this recently, Puppo, 2012). Perelman would have probably said that while classical thought tends to argumentation, the modern and Cartesian one prefers demonstration (Manzin, 2004, 2012a). These two tours d'esprit about logic are supported by two different metaphysics or conceptions of Being: for Plato and Aristotle, Being is "discontinuous", while for Cartesius or Hume it is "continuous"

(i.e. coherent in every part of itself, either from an analytical or empirical point of view: see Manzin, 2008, 2009). In order to avoid the thaumazein, every single thing must be linked to the other, with no vacuum in the middle. The goal of modern logic, and particularly of formal logic, is "to study such links not in order to explain their nature, but rather and above all to make a concise catalogue of few and simple rules with them" (Lolli: 1991, 13); the advantage of this choice is evident, it is a practical one: knowing in advance the conclusions on the exclusive ground of knowing the causal relations.

Thanks to Boole and Frege, modern logic will finally conduct reasoning to artificial languages and to "mathematization" (Agazzi \& Vassallo, 1998: 33-45).

. The legal syllogism

When we speak about logic in legal decisions are we assuming that legal reasoning is also a matter of discourses? In that case, it depends simply on what sort of logic we are talking about. For modern logic, the more certain a decision must be, the more it must avoid discursive forms, because the judge, as Montesquieu argued, must play the unique role of loudspeaker of the written norms. He/she is "la bouche de la loi" (the mouth of the law), but possibly not the brain. He/she must repeat rather than speak, for speech is a slippery slope 
where thaumazein can occur at any moment. We can never forget that the modern ideology of legal positivism is founded upon a double (axiomatic) presupposition: the completeness and univocity of the legal system itself. On the contrary, discourses in the real world are never complete or univocal (Endicott, 2003; Luzzati, 1990; Paganini, 2008; Puppo, 2011, 2012). Although such a presupposition is no longer professed by most legal positivists, a large proportion of lawyers and judges are still convinced that legal reasoning is basically a "subsumption", that is, a logical deduction from a normative major premise and a factual (descriptive) minor one. There are, indeed, different discourses from the legal point of view: depending on the speaking subject (the Legislator, the judge, the positive law scholar, the prosecutor, the lawyer etc.), on the context (before, during or outside the trial), on the issue (norms, principles, judicial proceedings etc.).

I am now going to consider the judge's discourse in detail, in so far as it is directed at arriving at a legal decision. My aim is to show that the so-called "legal syllogism", masquerading as a formal scheme of reasoning independent from interpretation, is conversely, by its own nature argumentative. To do so, I will start by considering the formula of the syllogism as follows (Alexy, 1978; Rotolo, 2001; Bernal, 2013):

$$
\begin{array}{ll}
\text { Major Premise: } & \text { (1) } \forall \mathrm{x}(\mathrm{Px} \rightarrow \mathrm{MQx}) \\
\text { Minor Premise: } & \text { (2) } \mathrm{Pa} \\
\text { Conclusion: } & \text { (3) } \mathrm{MQ} a
\end{array}
$$

To be a legal syllogism (which is a kind of "practical syllogism") such a logical operation must have the following structure:

1. (Normative) Major Premise: a general rule connecting a sanction to a course of conduct. Premise (1) states that, for every $x$, if $x$ is $\mathrm{P}$ (and $\mathrm{P}$ is for instance the set of 
features of the type of offence), then the sanction Q (such as, for instance, detention) must be applied to $x$. In a general and informal way: people having committed P must be submitted to measure $Q$.

2. (Factual) Minor Premise: a concrete event which has happened to someone. Premise (2) states that a specific legal case $a$ is $\mathrm{P}$ since it has the same features as $x$. In a general and informal way: $B$ has committed $P$.

3. Conclusion or "subsumption": a necessary inference. Since, according to minor premise (2), $a$ is $\mathrm{P}$, the rule expressed in major premise (1) applies to $a$ : then $\mathrm{Q}$ must be valid for $a$. In a general and informal way: $B$ must be subject to the measure $Q$.

According to the founders of modern legal positivism the judge charged with deciding the case (we are referring particularly to trials in Civil Law systems) already has the elements for finding both the normative major premise (the codified law in the hierarchy of legal sources) and the minor one (the rules of evidence). His/her task is hence "to subsume the latter under the former" in order to logically obtain the conclusion. A totally "automatic" task, as stressed by Montesquieu and Beccaria.

5. Some problems relating to the syllogistic model

This logical scheme of inference isn't wrong in itself, but it counts only as a final operation in which all elements have been previously determined. Indeed, if we look at the judicial context in the real world, we can easily realize that the judge at the beginning of his/her reasoning has no clear elements to work with. The normative major premise (1), for instance, 
"exists" only as a set of potential meanings related to some statements written in (what has been recognised as) the books of law.

So the judge has first of all to choose one or more normative statements from the books and, in the second case, also a combination between them (it is not unusual in fact that more than one statement could satisfy the judge's search for a normative qualification of the reported behaviour of $\mathrm{S}$ and, consequently, that more than one combination could be possible within different statements); secondly he/she must interpret the legal statements according to grammar, syntax and lexis: an operation allowing the judge to detect a significance for legal statements relating to the concrete situation of the circularity between the judge himself/herself, the case and the system of normative sources, which is possible only within the framework of the pragmatic referents. Only after such a complex procedure as this can the (serious) judge establish a (still provisional) major premise for his/her final decision.

Of course during the phases of the interpretative process, many criteria can be proposed to justify the choice of the legal statement(s), their possible combination and even the pragmatic referents: the trial is a place of dialogue and controversy, and different actors are there precisely for providing a number of criteria to identify the normative genre which the disputed behaviour of S should be traced back to. That is why I say that the major premise of the socalled "legal syllogism" is not given, but must be found following a typical argumentative process. For this reason, this phase of legal reasoning cannot be defined as formal under any respect, nor can the reasoning itself be taken as being "automatic" (i. e. without choice ). Believing that the major premise of the syllogism was immediately available to the judge, modern legal formalists have focused their attention on the minor one that, arising from events which had occurred in the past had to be discovered by the judge through the rules of evidence (Taruffo, 2009). Such an operation - the description of a "fact" - is seemingly similar to an empirical proof: an observer (the judge) must verify the description of what actually (or at 
least more probably) happened and answer the question: did B commit or not commit $P$ ?, just as a scientist has to explain the modalities of a specific event (e.g. is the hole in the ozone layer responsible for global warming, or not?). This account tends to look at the trial as a sort of "neutral" laboratory, where the more scientific the approach to the judgment, the more the decision itself will be guaranteed (Manzin, 2004).

The fact is that the rules of evidence are quite different from empirical procedures, though they sometimes make use of scientific tools. First of all, they are rules in the sense that they prescribe what, when and how such tools can be legitimately used (whereas from this point of view, scientists are much more, although not totally, free); secondly, the legitimation of evidence does not necessarily depend on its efficacy (while the effectiveness of technical instruments is essential in empirical proof); thirdly, the most widely-used "instrument" for obtaining evidence - the witness - would normally be unacceptable from a strictly scientific viewpoint: what medical journal, for example, would publish an article about a crucial scientific discovery resting only upon the testimony of a few witnesses?

Scientific contexts and legal ones

Upon reflection, I am quite convinced that there is a fundamental difference between scientific contexts (either formal or empirical) and legal ones.

A scientific context is:

i. monological

ii. linguistically artificial

iii. moving from hypothesis and axioms stipulated in advance.

On the contrary, a legal context is:

i'. dialogical (as the trial's structure clearly shows)

ii'. $\quad$ linguistically vague 
iii'. moving from various possible starting points (topoi).

At any point in the debate, legal actors can advance a particular point of view about normative interpretation, factual description, or logical connection. Each of them can choose from an open set of opinions the one(s) that is (are) thought to be effective for building a reasonable and persuasive discourse: a truly argumentative task performed by lawyers, the prosecutor (in a criminal trial), mediators, and even expert witnesses and witnesses, all giving the judge a variety of interpretations, descriptions and inferences as possible premises (1) and (2), and conclusions (3), for his/her reasoning.

Moreover, it should be noted that the legal conclusion reached by the judge has the power to oblige someone to do or to suffer something. The judge must decide and his/her decision must be applied (subjective and objective obligation) by reason of his/her normative authority, and not only as a result of the logical consistency or the empirical evidence of his/her reasoning - a fundamental difference from authority in science, which is based mainly upon coherence and verifiability.

In conclusion, since legal argumentation is not a matter of science, we could conclude that it simply has to do with the legitimate power of the judge ("auctoritas non veritas facit legem": Scarpelli, 1984). But this cannot be sustained, because a mere expression of power, even if authorized by the law, cannot properly be an argumentation; on the contrary, from an argumentative point of view, it is a fallacy (see for instance argumentum ad baculum or ad metum). This is also the reason why a number of constitutional principles and rules preserve the reasonableness of legal judgments (as set by before quoted arts. 360 CPC and 606 CPP). The will of the judge certainly plays a central role in legal decisions, but the domain involving an exercise of will cannot be the only one in which either general or individual rules are given: reasonable elements are required in addition to assure a just judgment. 
The next question is: how to obtain a reasonable argument in legal context, which is not a merely scientific one? A typically methodological question indeed.

\section{Rhetoric and the law}

A logic suitable for a context that is dialogical, controversial, linguistically vague and governed-by-commonplaces - such as the legal one - must face a number of problematic issues, which are unfamiliar to the procedures of formal logic (Eemeren et al., 1996).

First of all, in a polemical dialogue monitored by an impartial "third party" (the judge or the jury), actors struggle to draw the decision-maker's attention. Consequently, they need some strategies for giving their discourses an attractive appeal. Especially in the initial phase of argumentation, actors should provide aesthetic and emotional means through their attitude (actio) and speech (elocutio) in order to strike the audience: a logic of pathos in which both body and language are involved to prepare further reasoning and to invite listeners to appreciate the actor's own argument (protrepticon) (on the role of pathos in language and argumentation: Plantin, 2011).

Such concern for material and linguistic tactics for eliciting pathos should not be limited to the very first steps of argumentation ${ }^{59}$, for we should not forget that a legal context remains dialogical and controversial from the beginning to the end; so actors must be on their guard at every moment, if they want to avoid audience inattention or emotional vacuums (Manzin, 2010).

The aesthetic aspect of argumentation, being a peculiar connotation of rhetoric, came to be considered dominant especially during the modern age, when formal procedures of reasoning increasingly acquired a condition of exclusivity in Western thought. But from a broader (and

\footnotetext{
${ }^{59}$ As maintained for instance by F. Cavalla, according to whom the sole purpose of aesthetic in rhetorical argumentation is the captatio during the starting phase (Cavalla, 2007).
} 
classical) point of view, material and linguistic strategies for emotional persuasion are only one part of the rhetorical argumentation, even if an important one. In fact, in the classical and holistic account, the means of knowledge are not limited to a purely abstract dimension (reason in the Cartesian meaning of the word), because they deal with the totality of human being: logos (language-thinking), pathos (body and emotions) and ethos (will).

Other features of rhetorical argumentation are those given by the capabilities of making a discourse easy to understand (by using linguistic means such as metaphors, examples, figures, evocative words or phrases etc.) and rationally approvable (by using commonplaces [topoi] widely shared and/or based on experts' opinion [memoria], arranged in a certain order [dispositio], assisted by empirical evidences [causae] etc.). This phase of argumentation is especially devoted to the creation of effective grounds for legal reasoning: the actors want to suggest to the judge a way of building normative and factual premises, along with a logic connection between them.

The last part of rhetorical work is dedicated to the confutation of the opponent's argument (confutatio). This engagement is typically dialectical: the actor must show the audience that all (or at least some) of the adversary's premises are based on unacceptable (or at least less acceptable) grounds or that even if they may be acceptable, they are badly connected (and consequently the conclusion is unacceptable). Such conduct could seem extremely conflicting and socially dangerous to some scholars of legal sociology, but it is not, because counterargumentation should be regarded from every perspective as a sort of "public acknowledgement" of the adversary's full dignity to stand in front of his/her rival as a peer. What else, in fact, is the counter-arguer going to do, if not treat his/her opponent as real and effective, critically analyzing his/her discourse, if only for the purpose of showing how wrong it is?

A logical method for legal reasoning 
The dialectical level of legal argumentation is performed in the trial not only by the debating parties but also by the judge, in order to check their premises and conclusions. When balancing the two "legal syllogisms" advanced by the parties, the judge is definitely charged with choosing among a variety of logic elements (standpoints, values, interpretations, descriptions etc.) which cannot remain - partially or totally - together.

It is at such a stage that the (serious) judge looks at the arguments at stake and contemplates how to build his/her own reasoning. A complex operation which can be accomplished in accordance with either, or even partially both, of the parties' proposals, in a way that I am going to consider shortly. At this point in his/her decisional process, the judge's choice depends on a series of logical moves that I will try to summarize as follows (supposing the judge asking him/herself a progressive set of questions):

1. plausibility check: to what extent are the standpoints of the parties really authoritative?

To establish its standpoint each party has adopted one or more starting points validated by common or expert beliefs, based on shared values, arranged in a certain order of importance, assisted by a certain degree of evidence etc. It is clear that points like these aim at being more than simple opinions (doxai): they aspire to be the most plausible ones (endoxa) (Cavalla, 1992). So the task of the judge will be to check if in fact they are so (are they really shared? by whom? still today? in the way specified by the arguer? etc.).

2. coherence check: are the starting points in each party's discourse logically connected with one another? Is the conclusion of the discourse consistent with its starting points? 
It might be the case that the standpoint is predicated upon solid opinions (endoxa), but that these opinions are linked together in a wrong or questionable way, so that the conclusion is not correct or at least not the only one possible.

3. dialectical check: which discourse, compared to the other, is more consistent? As I have noted previously, this argumentative stage is the most complex of all. The judge, having previously ascertained the consistency of each party's argument (plausibility and coherence checks), must now compare their force. It is clear that every discourse has been constructed upon constant reciprocal confrontation; every opinion has been submitted to the opponent's objections. The simultaneous presence of opposing arguments obliges the judge to ask him/herself a number of questions: how many points in the opposing discourses (S1 vs S2) are authoritative and how authoritative are they? Which of them is more pertinent to the case under discussion? Are the conclusions in S1 and S2 clearly connected to their own starting points? Are they coherent with all the starting points or only with some of them? Are there any common points in S1 and S2? Would it be possible to connect the points in each party's argument in a different way? Would it be possible to connect points arising out of the different discourses, S1 and S2? As noted before, at the concluding steps of his/her reasoning the judge might choose $\mathrm{S} 1, \mathrm{~S} 2$ or even something else: a "legal syllogism" partially different from the ones put forward by the parties (e.g. accepting the normative qualification advanced by the prosecutor but not the measure of punishment, having also accepted some lawyer's arguments on the seriousness of the crime).

4. building premises for the "legal syllogism" $"$ : what standpoint is reasonably acceptable?

\footnotetext{
${ }^{60}$ In a previous article (in Italian) I described step \#4 as an "enthymematic inference" and step \#5 as "[conclusion of] legal syllogism" (Manzin, 2012c: 74-75). I want to clarify now that since the inference constitutes the final move in legal argumentation, it necessarily implies both the establishment of the premises
} 
At the end of the dialectical check the judge has the precise elements required for the justification of (1) and (2). In other words, he/she can build the premises for the unique "legal syllogism" authorized by the law, premises that must be clearly indicated in the written reasoning of the decision, in order to easily allow a further check by higher Courts, practical jurists and scholars of jurisprudence. We can properly say that from now onwards the judge is no longer a critical listener to the parties' discourses and an evaluator of their soundness: he/she is becoming now a sort of "third speaking person" having his/her own discourse (S3), even if it is built with elements dialectically taken from S1 and S2. S3 is neither S1 nor S2; compared to them, its content is the following: (the syllogism proposed by) S1 is right; or (the syllogism proposed by) $S 2$ is right; or, in an intermediary way, something (but not all) is right either in (the syllogism proposed by) $S 1$ or $S 2$.

5. enthymematic inference: given (1) and (2), then...?

The last move of legal argumentation links together the premises which have been built by the judge in the above mentioned ways: according to one of the parties' proposals or in a particular combination of both. In any case, because it starts from an evaluation (or rather a set of evaluations) of the standpoints expressed in S1 and S2, the judge's inference cannot ever be defined as a mere "copy" of the one or of the other. In addition, $\mathrm{S} 3$ is performative in nature and such a condition integrates (not replaces!) its logical position. Content of (3) concludes the "legal syllogism" and makes the judgment argumentatively forceful, providing a kind of deduction (enthymema) to the legal reasoning.

Here it is a diagram summarising S3:

and the drawing of the conclusion, scheduled respectively under \#4 and \#5. For this reason I prefer to distinguish here the former step of building (1) and (2) from the conclusive one of inferring (3). 


\begin{tabular}{|l|l|l|}
\hline Normative (de iure) & Descriptive (de facto) & Practical/Legal \\
\hline$\forall x(\mathrm{P} x \rightarrow \mathrm{MQ} x)$ & $\mathrm{P} a$ & $\mathrm{MQ} a$ \\
\hline The judge - after checks & The judge - after checks & The judge \\
\#1, 2, 3 and $4-$ chooses & $\# 1,2,3$ and $4-$ chooses & enthymematically infers $a$ \\
the normative proposals in & the descriptive proposals & practical conclusion from \\
S1 or S2, or partially both & in S1 or S2, or partially & premises built in \#4 \\
& both & \\
\hline
\end{tabular}

9. What is legal truth?

The conclusion (3) of the legal reasoning - at the same time argumentative (rhetorical) and performative - has a status usually defined as "legal truth". I have tried so far to explain how legal evidence is not only a matter of "subsumption" among supposedly given data (legal norms and facts): the task of the judge is much more complicated, implying interpretation and evaluation of arguments. We can say that "a proposition of law is true" (Patterson, 1996) only after determining, by an argumentative analysis of the parties' discourses opposed in the controversy, a set of meanings related to the normative and factual statements.

The rhetorical (not formal) nature of legal reasoning would seem to have little to do with the concept of truth, whose fundamental connotation should be the one of undeniability. Thus a proposition of law like (3) should be more exactly described as probable or plausible and not true in the proper sense. Regarding such a question (which of course can be discussed here only very briefly) I believe that two main issues are at stake: (a) what does probable mean and (b) what a factual (or historical or material) truth is. 
(a) The first issue dates back to the "great division" between demonstration and argumentation as addressed especially by Chaïm Perelman, according to whom a proposition ascertained by formal or empirical science is undeniable, whereas argumentation gains only disputable conclusions (Perelman \& Olbrechts-Tyteca, 1958; contra Manzin, 2012a). As I have said before, the field of science is characterized by linguistic and contextual conditions which are different from the ones in a trial: the former allow conclusions to be inferred that are true because they are coherent with the formal or empirical premises of the demonstration (which have been conventionally established before the logical operation of deduction or induction and never put in doubt during the operation itself). Legal argumentation, on the contrary, works with language that is vague and constantly under question. For this reason Perelman argued that argumentative conclusions were probable and not certain, maintaining that a demonstration, proceeding from undisputed premises, finishes with an indisputable conclusion, while an argumentation, proceeding from disputable premises, ends with a disputable conclusion. Basically, Perelman believed that the conclusion of a syllogism had the same status as its premises: true, probable, wrong, etc. But let us consider the conclusions of a syllogism such as all men are mortal, Socrates is a man, then Socrates is mortal. Is it a demonstration or an argumentation? According to Perelman and many others, it depends on the nature of the premises. In medical sciences, for instance, the mortality of all human beings is established from the outset and no longer in dispute, so the syllogism would be right. But in human sciences the mortality of a man/woman can be related to the memory of his/her behavior, depending on the agreement about it; in this case the syllogism could be wrong if, for instance, Socrates was thought to be immortal as a philosopher since his thinking is still alive.

In conclusion: certainty on one side (that of formal and empirical science), plausibility on the other (that of the humanities) - "the two cultures" of modern Western thought (Snow, 
1959). But is it really so? From the logical point of view, the syllogism in my example is always valid if the conclusion is coherent to its premises. By this I mean, if you have accepted a certain definition of "mortality", "Socrates", "man" etc., and as far as such definitions are not disputed, then the conclusion itself, if correctly inferred (in this case by modus ponens), cannot be refuted because it simply has no incontrovertible alternatives. In other terms, it is true. Truth is therefore a matter of the impossibility of contradiction, regardless of the nature of the premises (either formalised or unformalised), and a proposition of law is true insofar as no reasonable argument can deny the selected topoi and the logical connection between them (Manzin, 2011, 2012c).

(b) The second issue has metaphysical implications, dealing with the question of "Being and time". According to an underlying Cartesianism, scholars of legal sciences and practical jurists often distinguish a so-called factual (or historical or material) truth from the legal one obtained at the end of the trial. Some of them skeptically maintain that the former is inaccessible; some others consider the latter as a sort of gradual approach to "what really happened" ${ }^{\prime 61}$. This kind of legal pessimism/optimism, broadly diffused among lawyers, judges and simple citizens, implicitly or explicitly presumes that a factual truth does exist "somewhere" in unchangeable conditions (like $\mathrm{A}=\mathrm{A}$ ) and that the purpose of the trial is to (try to) describe A using the means given by law and human knowledge. No doubt that the purpose of the judgment is to furnish normative descriptions of "something" like A, but such "something", since it happened in the past, never properly exists within the space-time context of the judgment. In other words, A remains always and only hypothetical, because no further perspective points are provided in a space-and-time-free condition to verify the correspondence $\mathrm{A}=\mathrm{A}$. Then, when we talk of "true" or "false", such a definition should be correctly related to the description of the event under judgment, not to the event itself, which

\footnotetext{
${ }^{61}$ For a critical comparison between realistic and anti-realistic accounts on legal truth, see Patterson (1996).
} 
is inconceivable outside our knowledge of it in a different space-time. Indeed, what "truth" could a fact in itself have? The one deriving from a sort of self-evidence? - If so, our reasoning should suffer a fallacious regressus ad infinitum. Is it then a sort of transcendental status? - We could affirm that only by accepting some prescriptive assertions: a matter of will, in such case, not of reason. Finally, is it the result of an empirical proof? - Contemporary physics recognises very well that empirical observations always modify the object of the experiment.

In conclusion: there is no "factual" or "historical" or "material" truth which we can talk about at the end of the trial (and, I would guess, everywhere) but the truth of rhetorical arguments built around some normative and factual hypothesis, in a way and to the extent that such arguments were coherent and, thus, undeniable.

Why legal truths are truths

The above-mentioned "legal pessimists/optimists" could presume at this point of my article that argumentative (rhetorical) truth is actually a very weak one, depending on the consistency of standpoints whose places and connections can be put in doubt at any time. I might agree with them, but my question is: what, then, is a strong(er) truth? If it were demonstrable, as in Perelman's opinion, it should be a truth granted by the coherence between formal or empirical premises and the conclusion. From this point of view, the only difference between demonstration and argumentation should be the one regarding the nature of scientific monologue, which is conventional and linguistically artificial, compared to the nature of argumentative dialogue, which is unconventional and linguistically vague, but no other difference could be found. Both demonstrative and rhetorical truths are truth because and to the extent that they are undeniable (i.e. a logical alternative does not exist). If you have accepted their premises and if the inference is correct, you can never deny their conclusion 
without being contradicted. When ruled by coherence, rhetorical argumentation is definitely not a "weaker" kind of reasoning than scientific demonstration, but only a type which is especially suited to unformalised and controversial contexts.

Of course, in scientific demonstration (monological) truth remains undisputed as long as convention is maintained, while in rhetorical argumentation (dialogical) it must be defended every time it is attacked by the interlocutors. But such a difference has nothing to do with the strength of the truth- it has to do, if anything, with its duration. In abstract and very general contexts (such as for instance, in mathematics) premises and methods usually last a long time before meeting criticism; in concrete and particular ones (such as for instance, in public contexts like law or politics) it is not unusual to encounter objections at every step. So what follows? Do we really think (as Montesquieu and Beccaria did) that the absolute reduction of concrete to abstract - of practice to theory - would be the best way of reasoning in law? I believe that history itself has already reached a judgment about that.

\section{Some conclusions}

Having offered (although very briefly) a short account of argumentative logic and legal $\operatorname{truth}^{62}$, I shall try now to answer the questions I posed at the beginning of my article. My essential aim was to point out how logic could help the (serious) judge decide on the case, knowing that his/her commitment to logical consistency is also provided for under statute law (see in Italy arts. 360.1.5 CPC and 606.1.e CPP).

I would like to emphasize once again that if logic can help legal decisions (avoiding the reduction of trial to a mere act of legitimate power) it can do so only by building and connecting the argumentative premises in iure et in facto, not by formalizing the legal

\footnotetext{
${ }^{62}$ For an accurate survey of theories on legal argumentation, see Feteris (1999).
} 
reasoning into a "subsumption". Hence logic in law implies, from the judge's perspective, a process of selection from the parties' discourses and a final multiple checks in the sense clarified by the diagram at the end of Section 8 .

Points in opposite arguments S1 or S2 will be discarded when incoherent in themselves or between each other, either because referents framing the interpretation are changed or for connections are wrongly made. Let us consider the following diagram:

\begin{tabular}{|l|l|l|l|l|}
\hline S1 or S2 & Premise (1) & Premise (2) & Conclusion (3) & Qualification \\
\hline Referent R & means a & means $\mathrm{b}$ & $\mathrm{S}$ & possible \\
\hline Referent R' & means c & means $\mathrm{d}$ & $\neq \mathrm{S}$ & possible \\
\hline Ronnection & $\forall x(\mathrm{P} x \rightarrow \mathrm{MQ} x)$ & $\mathrm{P} a$ & $\mathrm{MQ} a$ & correct \\
\hline Connection & $\forall x(\mathrm{P} x \rightarrow \mathrm{MQ} x)$ & $\mathrm{P} d$ & $\mathrm{MQ} a$ & incorrect \\
\hline
\end{tabular}

Conclusions of arguments could be $=\mathrm{S}$ or $\neq \mathrm{S}$, depending on the proposed interpretative framing (referent R or R'); it could happen, however, that premises in the same argument were intended at a certain point of the reasoning as "a" (under referent R) and at another point as "c" (under referent R'), leading to an incorrect conclusion. In fact, once having accepted premises (1) and (2) in some sense ("a" and "b" or "c" and "d"), the inference is compulsory: $=\mathrm{S}$ in the former case, $\neq \mathrm{S}$ in the latter. For the same reason, if premise (1) is constructed under referent R (and means "a"), you cannot connect it to a premise (2) meaning "d" (referent $\left.\mathrm{R}^{\prime} \neq \mathrm{R}\right)$ : in such case too conclusion MQ $a$ would be logically incorrect - and lawfully invalid.

As can be seen, most of this procedure is governed by the rule of non-contradiction, expressly mentioned in art. 360.1.5 CPC (“contradictory argument" as a motivation for the invalidity of a judgment). But its complexity also makes it clear that legal reasoning might be "clearly illogical" (as stated in art. 606.1. e CPP) not only when simply "contradictory": for 
example, we could have a conclusion inferred from incomplete premises (i.e. where some places are lacking). See the following,

$$
\begin{aligned}
& \text { if }(b, c, d) \text { then (1); if (1) and (2), then (3) } \\
& \text { now (b,c) then (1); if (1) and (2), then (3); now (3) = incorrect }
\end{aligned}
$$

In this case, the argument is not "lacking" in the strict sense of the word (as maintained by both the cited arts. in CPC and CPP) but, more exactly, "insufficient" (as in 360.1.5 CPC). In conclusion, I hope that these few guidelines on legal argumentation - inspired by, but not limited to, the statements set out in the Italian codes of Civil and Criminal procedure - could help (serious) judges in their justification in cases ${ }^{63}$. At the same time, I assume that a clear cognition of rhetoric in legal reasoning could enable (serious) lawyers to argue in a more effective way in trials, that is to say, in a way that is more persuasive for the audience and more logically suitable for the judge.

\section{References}

Aarnio, A. The rational as reasonable. A treatise on legal justification, Dordrecht: Reidel, 1987.

Aarnio, A. "Argumentation theory - and beyond. Some remarks on the rationality of legal argumentation." Rechtstheorie, 14, (1983): 385-400.

Aarnio, A., Alexy, R., Peczenik, A., Rabinowicz, W. and J. Wolenski. (1998). On coherence theory of law, Lund: Juristfoerlaget, 1998.

Agazzi, E. \& Vassallo, N., eds. George Boole. Filosofia, Logica, Matematica, Milano: Franco Angeli, 1998.

\footnotetext{
${ }^{63}$ My scheme of argumentation is especially focused on the jurisdiction of "legitimacy" (higher Courts), but it could obviously be applied in jurisdiction "on the merits" too (lower Courts), in order to avoid dismissal.
} 
Alexy, R. Theorie der juristischen Argumentation. Die Theorie des rationalen Diskurses als Theorie der juristischen Begründung, Frankfurt a.M.: Suhrkamp, 1978.

Beccaria, C. [1764] Dei delitti e delle pene, Milano: Mursia, 1982.

Bernal, C. "Legal Argumentation and the Normativity of Legal Norms." Edited by C. Dahlman and E. T. Feteris. Legal Argumentation Theories: Cross-Disciplinary Perspectives, 103-112. Dordrecht, Heidelberg, New York, London: Springer, 2013.

Berto, F. and L. V. Tarca. Logica da zero a Gödel, Milano: Bruno Mondadori, 2006.

Blanché, R. and J. Dubucs. La logique et son histoire, Paris: Colin, 1996.

Cavalla, F. “Topica giuridica.” Enciclopedia del diritto, 44: 720-739. Milano: Giuffrè, 1992.

Cavalla, F. Retorica processo verità. Principi di filosofia forense, Milano: Franco Angeli, 2007.

Eemeren, van F.H., Grootendorst, R., Benthem, J. and F.Veltman, eds. Logic and Argumentation, Amsterdam: North Holland, 1996.

Eemeren, van F.H. In Reasonableness, Amsterdam: Rozenberg / Sic Sat, 2012.

Endicott, T. Vagueness in Law, Oxford: Oxford University Press, 2000.

Feteris, E. T. Fundamentals of legal argumentation. A survey of theories on the justification of judicial decisions, Dordrecht: Kluwer, 1999.

Feteris, E. T. Strategic manoeuvring with linguistic arguments in legal decisions. Edited by E. T. Feteris and H. J. Plug. Argumentation and the application of legal rules, 55-73 Amsterdam: Sic Sat, 2009.

Hage, J. C. Law and Coherence. Ratio Juris, 17, (2004): 87-105.

Hage, J. C., Leenes, R., and A. R. Lodder. "Hard cases: a procedural approach.” Artificial Intelligence and Law, 2, no. 2 (1993): 113-167.

Lolli, G. Introduzione alla logica formale, Bologna: Il Mulino, 1991. 
Luzzati, C. La vaghezza delle norme: un'analisi del linguaggio giuridico, Milano: Giuffrè, 1990.

MacCormick, N. Legal Theory and Legal Reasoning, Oxford: Clarendon Press, 1978.

Manzin, M. Il petrarchismo giuridico. Filosofia e logica del diritto agli inizi dell'umanesimo giuridico. Padova: Cedam, 1994.

Manzin, M. "Ricordando Perelman: dopo e oltre la "nouvelle rhétorique"." Edited by G. Ferrari and M. Manzin. La retorica fra scienza e professione legale. Questioni di metodo, 17-22. Milano: Giuffrè, 2004.

Manzin, M. Ordo Iuris. La nascita del pensiero sistematico, Milano: Franco Angeli, 2008.

Manzin, M. 'L'ordine infranto. Ambiguità e limiti del sillogismo giudiziale nell'età postmoderna." Tigor: rivista di scienze della comunicazione, 1, no. 1 (2009): 31-41 [Accessed August 31, 2012 http://hdl.handle.net/10077/3188].

Manzin, M. "La verità retorica del diritto. Patterson.” D. Diritto e verità, 9-51. Milano: Giuffrè, 2010.

Manzin, M. "Rhetorical vs. Syllogistic Models of Legal Reasoning: the Italian Experience." Edited by F. H. van Eemeren, B. Garssen, D. Godden and G. Mitchell. Proceedings of the $7^{\text {th }}$ Conference of International Society for the Study of Argumentation, 1165-1174. Amsterdam: Rozenberg / Sic Sat, 2011.

Manzin, M. "Vérité et logos dans la perspective de la rhétorique judiciaire. Contributions perelmaniennes à la culture juridique du troisième millénaire.” Edited by B. Frydman and M. Meyer. Chaïm Perelman. De la nouvelle rhétorique à la logique juridique, 261288. Paris: P.U.F - Presses Universitaires de France, 2012a.

Manzin, M. "A Rhetorical Approach to Legal Reasoning. The Italian Experience of CERMEG.” Edited by F. H. van Eemeren and B. Garssen. Exploring argumentative contexts, 137-148. Amsterdam: John Benjamins, $2012 b$. 
Manzin, M. "Quale logica per il processo penale? Ragionamento giudiziale e forme di controllo argomentativo della sentenza." Edited by V. Comi and G. Dominici. L'argomentazione giudiziale e il suo controllo in Cassazione, 63-79. Roma: Aracne, 2012c.

Montesquieu, C.L. de Secondat (baron de la Brède et de) [1748] De l'esprit des lois, Paris: Nathan, 1994.

Paganini, E. Vaghezza, Roma: Carocci, 2008.

Patterson, D. Law and Truth, New York - Oxford: Oxford University Press, 1996.

Peczenik, A. On Law and Reason, Dordrecht: Kluwer, 1989.

Perelman, C. And L. Olbrechts-Tyteca. La nouvelle rhétorique. Traité de l'argumentation. Paris P.U.F - Presses Universitaires de France, 1958.

Plantin, C. Les bonnes raisons des émotions. Principes et méthode pour l'étude du discours émotionné, Bern: Peter Lang, 2011.

Prakken, H. Logical tools for modelling legal argument. A study of defeasible reasoning in law. Dordrecht: Kluwer, 1997.

Puppo, F. "Vagueness of Language and Judicial Rhetoric.” Edited by F. H. van Eemeren, B. Garssen, D. Godden and G. Mitchell. Proceedings of the $7^{\text {th }}$ Conference of International Society for the Study of Argumentation, 1583-1595. Amsterdam: Rozenberg / Sic Sat, 2011.

Puppo, F. Dalla vaghezza del linguaggio alla retorica forense. Saggio di logica giuridica, Padova: Cedam, 2012.

Rotolo, A. Identità e somiglianza. Saggio sul pensiero analogico del diritto, Bologna: Clueb, 2001.

Scarpelli, U. “Auctoritas non veritas facit legem.” Rivista di filosofia, 75, 1 (1984): 29-43. 
Snow, C.P. The Two Cultures and a Second Look, Cambridge: Cambridge University Press, 1959.

Tarski, A. [1946], Introduction to Logic and to Methodology of Deductive Sciences, New York - Oxford: Oxford University Press, 1994.

Taruffo, M. La semplice verità. Il giudice e la costruzione dei fatti, Bari: Laterza, 2009.

Varzi, A., Nolt, J. and S. Rohatyn. Logica, Milano: McGraw Hill, 2004.

Walton, D. Informal logic: a handbook for critical argumentation, Cambridge: Cambridge University Press, 1989.

Walton, D. The place of emotion in argument, University Park PA.: Penn State Press, 1992.

Walton, D. The New Dialectic, Toronto: University of Toronto Press, 1998.

Walton, D. Ethical argumentation. Lanham: Lexington Books, 2002.

Walton, D. Relevance in argumentation. Mahwah: Lawrence Erlbaum Associates, 2004. 
IV. EDUCATION 


\title{
Debate as an Educational Tool: Is Polarization a Debate side effect?
}

\author{
Manuele De Conti, University of Padua
}

Summary

Competitive debate is a challenging educational tool for argumentation. As the empirical research proves, debating improves learning, critical thinking and verbal and non-verbal communication skills, among others. Nonetheless, many scholars criticize it for one of its alleged and detrimental impacts: polarization. Indeed, listening to them, polarization would lead to bias assimilation, close-mindedness, dichotomization and disagreement and conflict escalating attitudes, polarization would appear as a debate "side effect" and debate itself as a detrimental educational tool. Therefore, the purposes of this survey will be (i) to show that polarization is neither a necessary nor a likely consequence of debating, (ii) to argue that even when polarization occurs bias assimilation, close-mindedness, dichotomization and disagreement and conflict escalating attitudes, do not necessarily follow, and (iii) to stress the mistakes these detractors commit. Finally, polarization will lose its "side effect" color and debating will be recognized as an effective and organic tool for argumentation education.

Keywords: competitive debate, polarization, argumentation education

1. Debate and competitive debate: framework and definition

Debate is a particular type of dialogue. Theoretically, dialogue means a process of communication between at least two people that occurs through a series of back and forth messages also considered as organized steps toward fulfilling a goal (Walton, 1992, 1998, 2006). A dialogue is genuinely communicative: the units of dialogue are primarily speech acts, and these communicative acts are sent out by participants in reply to other messages (Walton, 1992). Therefore, a dialogue can be more straightforwardly defined as a sequence of exchanges of messages or speech acts between two (or more) participants (Walton, 1998, 2006, 2008; $c f$. Fuentes \& Santibáñez, 2011). The most elementary illustration of a dialogue is when one party asks another party a question (Walton, 2007). 
Rules and goals are other important components of dialogue. Rules define the types of messages allowed at each move, the turn taking, and what counts as a successful sequence of messages in fulfilling the goal. The goal in contrast is the final state toward which the sequence of moves progresses. There are two types of goals: collective and individual. A collective goal refers to the goal pursued by a particular type of dialogue. Some examples of collective goals are the following: to resolve a difference of opinion, to reach an informed basis for action, to reveal a deeper conflict, or to transfer knowledge. Individual goals, on the other hand, are the goals individuals pursue in order to realize the collective goal of the type of dialogue they are engaged in. Some examples of individual goals are to persuade one party of the correctness of a particular proposition, to obtain or give advice on a problem, to verbally strike at and humiliate an opponent, or to obtain information (Walton, 1992, 2006).

Several identifiable types of dialogue exist based on this framework. A pedagogical type of dialogue stems from an initial situation where one party is ignorant and involves the collective goal of transferring knowledge. Diversely, negotiation occurs in the context of a conflict of interest with settlement as the collective goal. Lastly, persuasion dialogue or critical discussion emerges from a difference of opinion with the aim of resolving the disagreement as a collective goal (Walton, 1992, 1996).

Debate is a type of dialogue, too. Its context is adversarial, and both parties aim to persuade a third party, i.e., the audience or the judge, by making the strongest argument for their side. In addition, debate is strictly regulated by rules of procedure that determine when and how long each arguer may speak. When the debate ends, the audience, either one or more judges or another type of referee, determine by voting which side had the better argument (Snider, 2008; Walton, 2008).

Some scholars do not recognize these debate rules, also called debate format, to be the main features of this type of dialogue because a real debate means advancing, disputing and 
defending arguments relevant to the issue debated (Branham, 1991: 22). However, in this paper we consider both rules and advancing, disputing and defending arguments relevantly to the issue debated, the main features of the debate and elements of the definition of debate itself. Indeed, if we do not consider rules as a fundamental aspect of debate, debate would not differ from other types of dialogue. Furthermore, if we do not consider arguing relevantly to the issue as a fundamental aspect of debate, debate could be confused with the eristic dialogue as some scholars seems to do ( $C f$. Walton, 1992): when debaters, as well discussion partners, turn eristic, they violate the norm of the model, letting the interaction deteriorate in a different kind of exchange (Jørgensen, 1998: 439).

Therefore, in this paper, debate will be considered a strictly ruled type of competitive (Wood and Goodnight, 1994) dialogue where opposing parties try to win their opponents, by persuading the audience, the judges or the referees, i.e. the decision makers, through advancing, disputing and defending arguments relevant to the issue being debated (Branham, 1991: 22). The benefits of debate as a type of dialogue are, among others, to enable parties to make wise decisions (Ehninger and Brockriede, 1978), to facilitate spreading of information (Walton, 1992), to test different points of view (Brimble and Pritchard, 2003) and to determine how changes should occur (Snider, 2008).

Following this framework, the so-called academic debate (Freely, 1961), competitive debate (Hensley \& Carlin, 1994), and classroom debate (Snider \& Schnurer, 2002), among other designations (from now on, all known as competitive debate), differ from the general definition of debate. Unlike forensic, public, political, or parliamentary debate, competitive debate is rigorously conducted under the direction of an educational institution for the purpose of providing educational opportunities for its students (Freely, 1961).

\subsection{Debate's positive impacts}


Many positive impacts of competitive debate exist for students. For our purposes, we will focus just on three of them: learning (Combs and Bourne, 1994; Scott, 2008; Vo \& Morris, 1996), critical thinking and argumentation (Allen et al., 1999; Colbert, 1995; Korcok, 1997), and verbal and non-verbal communication (Inoue \& Nakano, 2004).

School or academic debate occurs on controversial issues. Performing research to find material to advocate pro or contra positions facilitates the ability to understand issues, as shown by the five-year study of Combs and Bourne (1994). According to their survey, students participating in their business administration courses considered competitive debate a better learning tool than standard lectures. Of those students, $88.9 \%$ declared competitive debate better than standard lectures for gaining an understanding of the various positions on issues, and furthermore, $77.5 \%$ of them thought that they learned more than if they had attended a normal class. These results were corroborated by Han Vo and Richard Morris's survey (1996). Three out of four students in Vo and Morris's economy course considered debate helpful in understanding the course material and in developing a more realistic idea of the economy. In addition, the same outcome was recently reported by Sophia Scott for a Science, Technology and Society course (2008).

Debating as a method for learning has been adopted in many disciplines, including economics (Vo \& Morris, 1996), business administration (Combs \& Bourne, 1994), psychology (Moeller, 1985; O'Kon \& Sutz, 2005), sociology (Scott, 2008), philosophy (Nicolli \& Cattani, 2008), geography (Estaville, 2001), chemistry (Streitberger, 1988), statistics (Shatz, 1985), and nutrition (Magnus, 2000), only to mention a few. However, few of the research studies mentioned involved statistical analysis, and even for those that did (Combs \& Bourne, 1994; Scott, 2008; Vo \& Morris, 1996), the investigation was limited to students' perceptions. In conclusion, without doubting these outcomes, it seems appropriate to ask whether the data needs to be confirmed through other evidence and research methods. 
Indeed, multiple choice testing, which was used in the survey of Green and Klug (1990), and mixed methods research, like that conducted by Duffin (2006), led to the conclusion that classrooms that make heavy use of debate have greater improvement with respect to students' understanding of the material than other classes, as well as the conclusion that competitive debate itself, adopted directly as an assessment tool in schools, might help the scientific community to strengthen its results.

Critical thinking and argumentation skills are the other benefits of debate that are often stressed. Semlak and Shields (1977), using judges' reports, revealed how students with debate training had significantly higher scores in analysis than students with only public speaking training. Furthermore, Colbert (1995), in considering the objections of Hill (1993) and indirectly those of Greenstreet (1993), proved with a meta-analysis that debaters score better than non-debaters in critical thinking. In addition, Colbert argued that the Watson-Glaser Critical Thinking Appraisal (WGCTA), the questionnaire adopted by the surveys he reviewed, was one of the best tools developed thus far for critical thinking, in spite of its flaws (Ennis, 1958, 2009). In conclusion, Colbert, as Korcok did (1997), tried to promote cooperation among scholars for methodologically more valid surveys.

Improvements in critical thinking and argumentation skills were also confirmed by another exhaustive meta-analysis. After having reviewed 17 empirical research studies on communication, Allen et al. (1999) concluded that "regardless of the specific measure used to assess critical thinking, the type of design employed, or the specific type of communication skills training taught, critical thinking improved as a result of training in communication skills. [...] Participation in forensic demonstrated the largest improvement in critical thinking score whether considering longitudinal or cross-sectional designs" (ibidem: 27).

Recently, an Italian pre- and post- text analysis study has been done (Turchi, et. al., 2008) and critical thinking improvement has continued to be investigated, even if considering 
the perception only of both teachers (Cf. Martens, 2007) and students (Scott, 2008), and in addition, critical thinking in the classroom setting is still actively promoted (Oros, 2007). Nonetheless, more empirical surveys on the relationship between debate and critical thinking are necessary to transcend the meta-analyses conducted by Colbert (1995), Korcok (1997), and Allen et al. (1999) (Cf. Bellon, 2000; Broda-Bahm, 2002).

In conclusion, improvement of verbal and non-verbal communication is the last impact of debate on students we consider in this brief review. The study of Semlak and Shields (1977), previously presented, explains the situation best: not only do debaters score better in analysis, but also they perform better than public speaking students in organization and communication of the message. Furthermore, according to the research by Williams, McGee, and Worth (2001), as well as by Littlefield (2001), students perceive the improved ability to speak and communicate as the most common benefit of debate. This same outcome also emerged from a broader survey (Inoue \& Nakano, 2004) that provided an intercultural point of view.

\section{Polarization as a debate "side effect"}

Among the several debate impacts on students some are considered highly negative. Polarization is one of them. Polarization means moving in the direction of the initial tendency or attitude (Petty and Wegener, 1998) strengthening the original position (Sears et al., 1964) or becoming more entrenched in it (Lord et al., 1979). Polarization seems to be linked to bias assimilation or confirmation bias (ibid.), i.e. the inclination to give weight only to evidence that is consistent with the hypothesis in question (Risen and Gilovich, 2007), and seems due to the cognitive engagement with the topic (Lao and Kuhn, 1996). Indeed, polarization may occur when a party believes in a particular opinion (Lao and Kuhn, 1996; Pomerantz et al., 1995; Raden, 1985), when this opinion is strongly advocated for or its advocacy is listened to 
(Budesheim and Lundquist, 1999; Lao and Kuhn, 1996; Sears et al., 1964), and with aging (Kuhn et al., 1997).

Polarization mostly occurs in the debate setting. Sears et al. (1964) recognized that the debate audience's confidence in previous opinions was strengthened after having watched a debate. Lao and Kuhn (1996) and Budesheim and Lundquist (1999) showed that debaters also polarize, and our exploratory survey on 63 debaters confirmed this result. The exception was when debaters advocated for a position opposite to their personal belief, in which case their confidence in their opinion weakened significantly (De Conti, in press; $c f$. Budesheim \& Lundquist, 1999; Green \& Klug, 1990).

The trouble with polarization is that it seems to trigger bias assimilation or confirmation bias (Lord et al., 1979; Nickerson, 1998; Sears et al., 1964), dichotomization i.e. "radicalizing a polarity by emphasizing the incompatibility of the poles and the inexistence of intermediate alternatives by stressing the obvious character of the dichotomy as well as of the pole that ought to be preferred" (Dascal, 2008: 34; $c f$. Dascal and Knoll, 2011) — and escalate conflict and disagreement attitudes, as Glasl (1997), Pruitt and Kim (2004) and Kennedy and Pronin (2008) attest.

These negative outcomes help us to make explicit the reasoning behind many scholars who discard debate. If debate leads to polarization and polarization leads to bias assimilation, dichotomization or disagreement and conflict escalating attitudes, then debate is a detrimental educational tool. Johnson and Johnson (1994) consider debate as a context where "competitors tend to avoid communicating with each other, misperceive each other's position and motivations, be suspicious of each other, deny the legitimacy of others' needs and feelings, and see the situation only from their own perspective" (ibidem: 118) concluding that debate promotes closed-mindedness or refusing to incorporate any opponent's arguments into one's own position as Felton et al. (2009) point out. In addition, Tannen (1999) argues that 
since debaters "want to win the argument [...] they must go for the most gross and dramatic statements they can muster. They will not concede an opponent's point, even if they can see its validity because that would weaken their position" (ibidem: 261). Furthermore, Westbrook (2002) although he conceded that some debaters in nineteenth-century colleges and debate societies could have reexamined their position on dominant values, concluded that debating did not influence debaters to resist hegemonic ideologies because they were arguing for victory, instead of inquiring for the truth.

In addition, Andrews (1995) considered the Hegelian dialectic structuring the debate as a simplification for the mind and of the mind and Tumposky (2004) argued that "Debate can oversimplify and misrepresent the nature of knowledge. By setting up issues as dichotomies, debate reinforces a Western bias toward dualism and ignores the multiplicity of perspectives inherent in many issues" (ibidem: 53-54). Moreover, Barnard (1937) considered debate as developing in an over-aggressive and combative manner that results in a bellicose attitude, and again, Tannen sees debate as agonistic in nature where agonism means "an automatic warlike stance" and "agonistic response" means "a kind of programmed contentiousness - a prepatterned, unthinking use of fighting to accomplish goals that do not necessarily require it" (Tannen, 1999: 10). Therefore, these conclusions, influenced these scholars to consider debate an unsuitable tool for education in a multilingual, multicultural, and economically diverse society (ibid.), as Hyde and Bineham (2000) also argue.

All these features played a significant role in making competitive debate appear like a disdained tool belonging to the so often rejected and considered harmful adversary paradigm (Cf. Menkel-Meadow, 1996; Moulton, 1983; Tannen, 1999, 2002).

3. Is polarization a "side effect"? 
The purpose of this paper is not to rebut the arguments against the adversary paradigm, which has been done by some scholars already, who effectively argued in favor of the adversary paradigm with a special focus on competitive debate (Cattani 2005; Foster, 2004). We simply wish to say that substituting debating with role playing so as to avoid antagonism, for example, will lead to too much focus on perspective taking at the expense of argumentation and its associated benefits.

Indeed, Mitchell (2000) himself, after praising role-playing over debating, recognized that "since arguments advanced in role-play simulations involve highly subjective identity interpretations, it would be difficult indeed for teachers to develop evalutative criteria that would judge radically different student performances fairly" (ibidem: 136). Otherwise, debate "adversaries present arguments in the voice of omniscient commentators, delivering [an] overarching assessment of issues that 'clash' directly with positions staked out by opponents" (ibidem: 148).

In addition, even if not directly, psychological and educational science research supports the benefits of the adversary paradigm too. For example, Sears (1966) proved that in a mock trial setting subjects familiar with neither side's arguments seek a nonpartisan twosided presentation. Although this choice was made as an economical way of comparing the virtues of the two alternatives and arriving at a reasonable preference, it was preferred over one-sided partisan argument. Furthermore, Turner et al., (2010) showed that people seek out counter-attitudinal information mostly when they are confident in their arguments and forewarned to interact with someone with opposite views. Therefore, on the contrary, the purpose of this paper is to show that polarization is not a debate "side effect", to reject the reasoning concluding that debate is a detrimental tool because it leads to polarization.

Nonetheless, it is of the most importance to stress that debating is neither necessarily nor likely to lead to polarization. As previously seen, when debaters advocate for an opposite 
position than their personal beliefs, the confidence in such opinions weakens significantly (De Conti, in press; $c f$. Budesheim and Lundquist, 1999; Green and Klug, 1990). This means that debaters de-polarize, implying that they move in the opposite direction rather than the initial view or attitude (Petty and Wegener, 1998). Therefore, after considering the above arguments it can be concluded that some debaters polarize. However this is neither necessary nor likely in a long period. Many debate formats, such as the Lincoln-Douglas and more generally all Switch-Side Debates require students to debate several times, both for and against, about the same issue (Lewis and Wiese, 2000; Muir, 1993). In such instances, a tendency to moderate radicalization occurs because people have to support positions opposite to their opinion (Huckfeldt et al., 2004). Moreover, it is always possible to adopt procedures specifically developed to prevent polarization. For example, the 5'R model (Williams, 2010) suggests Reading research articles representing different points of view on each issue, Rapping the articles with the debate group and with the instructor, wRiting an essay on the core disagreement across the two opposing arguments recognizing bias and persuasive strategies and evaluating the empirical merit of the data, Reporting or having a debate and finally, Repeating or having another debate on the same motion, some months later. In conclusion, as William proved, the 5'R model helped nearly $33 \%$ of the students to change their attitude, a greater outcome than that documented by other studies on debate (ibidem; $c f$. Landrum, 1991). Therefore, after having reviewed some research it can be concluded that debating is neither necessarily nor likely to leads to polarization.

The question arises whether, whenever polarization occurs, it is necessary that bias assimilation, close-mindedness, dichotomization and disagreement, and conflict escalating attitudes will follow. The answer to this question is negative: it is not necessary.

\subsection{Against bias assimilation as a debating consequence}


Walton (1992) and Blair (1988) argue that not all bias is harmful; there is nothing inherently wrong about partisan argumentation "which takes up only one side of an issue in contentious dialogue with an opposed advocate of a differing point of view" (Walton, 1992: 155). Indeed, having a position on an issue is different from having a censurable bias which means that the argument is never really open to the risk of loss. Censurable bias or "bad" bias, i.e. bias that is open to criticism (Blair, 1988), is a fault called hardened bias (Walton, 1992: 157). Therefore, advocating a position does not necessarily mean being biased in a harmful way. Even more relevant to this point is that, as Nickerson (1998) argues, there is a huge difference in building a case deliberately and consciously instead of engaging in case-building without being aware of doing so. The first type of case-building is illustrated by what attorneys and debaters do, namely to confirm a particular position. Otherwise, the second type of case-building is a less explicit and a less conscious process. This is what psychologists refer to as the confirmation bias (Nickerson, 1998: 175-176). What seems really important for education is that the difference between case-building and evidence-weighing must be explicit (Narveson, 1980).

Accordingly, even dogmatism if moderate can play an important role and not to be considered harmful. Popper himself regarded a little dogmatism, even a little obstinacy, to be useful in avoiding the premature rejection of a hypothesis (Popper, 1972): "a degree of conservatism plays a stabilizing role in science and guards the field against uncritical acceptance of so-called discoveries that fail to stand the test of time" (Nickerson, 1998: 207). For this reason and in the light of the rules (Wood and Goodnight, 1994) and game (Snider, 1983, 1984) features of competitive debate, that require for actively and consciously building a case (Nickerson, 1998), and in the light of the previous empirical research that attests to the improvements of debaters in critical thinking skills (Allen et al., 1999; Colbert, 1995, Korcok, 
1997) for example, leading students to avoid fallacies because judges can penalize them, it could be concluded that debate does not necessarily lead to hardened bias or confirmation bias.

Moreover, debate does not necessarily lead to hardened bias or confirmation bias because the debate format can be adapted to avoid such consequences. Fuentes and Santibáñez (2011) strongly suggest adding a third team in the debate match, so as to facilitate understanding between adversaries. Quite often competitors do not refer to what the opponents established as a reason for their point of view. Consequently, a third team appointed to introduce into the debate the omitted information or the motion's core arguments, can help mitigating bias assimilation and off topic debates.

\subsection{Rejecting close-mindedness as debating outcomes}

Close-mindedness and dichotomization do not necessarily result from debating. Authorities argued that considering the issues regardless of prejudices (Alden, 1900) and developing the attitude to examine and compare opinions before reaching a reasoned decision (Branham, 1991) are attributed to debate practice and the elements of open-mindedness, namely being receptive to new and different ideas (Johnson and Johnson, 2000). These benefits suggest that debate is an effective tool in preparing for a more thorough evaluation of the different points of view and their reasons. Even the philosophers, such as John Stuart Mill (1992) and Karl Popper (1962), recognized these benefits of debate practice; although, they were referring to less formalized debates than competitive ones. As we have already hinted, these benefits are also supported by previously presented empirical results as, for example learning and understanding issues (Duffin, 2006; Scott, 2008). Furthermore, competitive debate promotes understanding of counter-attitudinal points of view. Tjosvold and Johnson (1977) and Tjosvold et al. (1980) assert that the presence of controversy promotes a greater understanding of another person's cognitive perspective than when it is not present, and 
Bonomo et al. (2010) claim that debate promotes tolerancia critica, namely acceptance of others without devaluing one's own ideas and convictions. This last outcome was empirically proved by Rogers and Rennels (in press) in a 13-year-longitudinal survey. In their research Rogers and Rennels conclude that "debaters were significantly more likely to display understanding and cultural tolerance than those who were not trained in competitive debate". As an ultimate proof, Lord, Lepper and Preston (1984), after having taken into account the less than optimal evaluation of counter-attitudinal evidence, by people who hold strong opinions (Lord, et al., 1979), showed that either direct instruction or indirectly making opposing possibilities more salient actions that could be taken by coaches themselves, promotes impartiality (ibidem: 1239). Hence, close-mindedness does not necessary result from debate practice.

\subsection{Discounting dichotomization as a debating impact}

The outcomes previously mentioned favor the case against dichotomization too. Dedichotomization means "showing that the opposition between the poles can be constructed as less logically binding than a contradiction, thus allowing for intermediate alternatives; actually developing or exemplifying such alternatives" (Dascal, 2008: 35). Therefore, if competitive debate is considered also as a game (Snider, 1983, 1984) and not the way in which people should relate with one another all the time, and, as we noticed before, competitive debate leads to understanding issues and people significantly deeper (Combs and Bourne, 1994; Duffin, 2006; Rogers and Rennels, in press; Scott, 2008; Vo and Morris, 1996), de-dichotomization, rather dichotomization, is more likely to occur.

In addition, de-dichotomization is not only pointed out by reasoning and surveys. It can be also attained by specific guidelines. For example, multisided debates were born due to the realization that some issues are not clearly black and white. Indeed, most debate motions 
can be answered by a spectrum of answers (Snider and Schnurer, 2002). To clarify how this kind of debate works:

Consider a debate about what the United Nations stance should be concerning the nation of Iraq. One side of the debate might represent a hard-line stance that advocated strict sanctions and a vigorous bombing campaign to get the Iraqi people to rebel against Saddam Hussein. A second side might advocate humanitarian assistance to help rebuild the shattered infrastructure of Iraq and feed starving children. Yet, a third position might represent a decided "hands-off" approach, arguing that the best thing that the UN could do would be to leave Iraq alone (Snider and Schnurer, 2002: 75). Another example could be choosing a motion such as "Who has the most pride (or prejudice) in Austen's novel?" rather than "Elizabeth Bennett has more pride (or prejudice) than Darcy in Jane Austen's Pride and Prejudice". Rephrasing the motion following this suggestion will split up the classroom into more groups allowing a multisided debate (Mareli, 2011).

Furthermore, it is always possible to refrain from choosing and rewarding a "winning" team by leaving the debate open to structural alteration, such as open dialogue or to adopt debate formats that allow direct questioning among debaters, as the cross examination format allows. Undoubtedly, these debate formats can allow students to perceive, address and work with the contingency and relativity of their arguments (Mareli, 2011) avoiding dichotomization.

\subsection{Dismissing disagreement and conflict escalating attitudes as necessary debating results}

The cases against bias assimilation, close-mindedness and dichotomization lead us directly to our last point; escalating disagreement and conflict attitudes. To escalate means to increase rapidly or to make something more intense and serious; although, sometimes, this can be interpreted as using heavier tactics than before or putting more pressure on the 
participants (Pruitt and Kim, 2004). As Glasl (1982; 1997) declares, debate and polemic involve polarization in thinking, feelings and will, and they lead to the use of verbal violence and gain recognition by speaking to an audience, namely addressing a third party rather than the other party. Indeed, Kennedy and Pronin (2008) proved that the more we disagree with someone the more we tend to have the perception that those who disagree with us are biased. This undesirable outcome has, among its consequences, become more and more aggressive. However, competing activities are not necessarily linked to aggressiveness. As Pruitt and Kim (2004) pointed out, competing activities sometimes inhibit aggression. Moderate heat could provoke aggression, but severe heat could result in flight, if the situation allows it. Similarly, the best way to stop angry children from crying is to divert their attention to a pleasurable competing activity. Nonetheless, and most importantly, it is always possible to avoid using verbal aggression or not to allow the conflict to escalate to a more dangerous behavior.

Glasl gives some tested suggestions on avoiding harsh debate or conflict escalation, which are: concentrating on the disputed core issues, avoiding violence in communication, recognizing unfair debating tactics. Hence, as it clearly appears, these suggestions require fundamental skills in debating, as every complete debate book proves (Huber and Snider, 2005; Trapp et al., 2005; Wood and Goodnight, 1994). Moreover, Kennedy and Pronin (2008) argue that increasing efforts to achieve an accurate understanding of the world is a promising intervention to avoid disagreement and conflict escalation. But again, this is exactly what debate and debate preparation lead to, as the surveys on learning attest.

In conclusion, Infante et al. (1984) showed that argumentative people are less aggressive than non-argumentative ones. Swift and Vourvoulias (2006) also pointed out that argumentative people have more satisfying relationships and Mezuk (2009) proved that African American male high school debaters were $70 \%$ more likely to graduate and three 
times less likely to drop out of high school than those who did not participate in debates. Such an outcome implies that, since competitive debate leads to a diminishing school drop out rate, it diminishes criminal behavior because dropouts are more likely to engage in criminal activities than students and educated people (Blomberg et al., 2012; Kimberly et al. 2012; Moretti, 2005).

As a result, from what has been argued so far, it is only reasonable to conclude that bias assimilation, close-mindedness, dichotomization and conflict or disagreement escalating attitudes do not necessarily result from debate and polarization. Therefore, polarization is not a necessary "side effect" of debate even if some of the negative consequences mentioned so far are likely to occur in some debaters when training or judging are inadequate (Cox and Adam, 1993; Ehninger, 1952; Friedley, 1983; Hinck, 2003; Stepp, 1990; Thomas and Hart, 1983; Wood and Rowland-Morin, 1989).

\section{Detractors mistakes}

As previously shown, polarization is neither a necessary nor a likely consequence of competitive debating even if it sometimes occurs among debaters. Nonetheless, we have also seen that, even if polarization occurs, it does not necessarily lead to bias assimilation, closemindedness, dichotomization and disagreement and conflict escalating attitudes. Therefore, if the reasoning and proof brought in favor of these propositions are compelling, debate detractors must have made mistakes in determining that debate is detrimental.

One of these mistakes is hasty generalization. Hasty generalization happens when a conclusion is drawn before enough evidence is found (Groarke and Tindale, 2008: 282) or when we conclude too much on too little evidence (Tindale, 2007: 150). Quite often competitive debate is deemed detrimental just because other categories of debate have negative features. For example, public debates or TV debates' negative features are 
transferred to competitive debate (Tannen, 1988, 2002), negative features in debates influence the idea of competitive debate (Moulton, 1983, Tannen, 2002) and the negative features of a highly competitive debate ( $C f$. Ehninger, 1952; Ulrich, 1986b) are extended to competitive debate in toto (Johnson and Johnson, 1994; Tannen, 1988, 2002).

Actually, hasty generalization occurs regardless whether negative and positive types of debate are distinguished. For example, Tannen argues that neither debating nor all oppositions are evil. In her, The Argument Culture, she clearly states, "In a word, the type of opposition I am questioning is what I call 'agonism'”, namely an automatic warlike stance (Tannen, 1999: 10), and "The message of this book is not, 'Let's stop arguing and be nice to each other.' Quite the contrary, the message is, 'Let's look more closely at the effect of the ritualized opposition, so we can have the real arguments.' The opposite of argument culture is not being 'nice' and avoiding conflict; it is finding constructive ways of arguing, debating, and confronting conflict" (ibidem: 6). However, the whole book seems to be an invective against every kind of debate. Indeed, in The Argument Culture, as in her other papers on this topic $(C f$. Tannen, 2000, 2002), Tannen herself does not seem to talk about positive types of opposition, or even about positive aspects of debate, except in the conclusion where she states: "I'm moving away from a narrow view of debate, we need not give up conflict and criticism altogether. Quite the contrary, we can develop more varied - and more constructive - ways of expressing opposition and negotiating disagreement" (ibidem: 298). Thus, either debate is evil or debate and some types of opposition are positive. However, no examples of positive debates and types of opposition are advanced. Hence, from her framework, that debate is evil can be seen in many of her writings vehemently detracting from debating ${ }^{64}$. Indeed, it is difficult to understand how competitive debate should be distinguished from agonism and how, in her framework, debating could play a positive role. Consequently, even if some

\footnotetext{
${ }^{64}$ Actually, some types of opposition are presented in Tannen (1998). Nonetheless, when these types are relevant to our discussion, they are shown to be based just on authority or prejudiced evaluation of reasoning and evidence.
} 
prerequisites protecting premises from attack are presented (see Fogelin \& Sinott-Armstrong, 1997, p. 42), there is still room for hasty generation; unless further justifications/clarifications are given by the author.

Some other scholars seem to commit a different mistake than hasty generalization. The way debaters behave in a debating match is considered an impact of debate practice, namely a procedural effect with an educational impact. For example, Johnson and Johnson (1994) depict a debater as denying "the legitimacy of others' needs and feelings, and see the situation only from their own perspective" (ibidem: 118) or as "unwilling to make concession to the opponent's viewpoint, and close-mindedly refuse to incorporate any of it into their own position" (Johnson and Johnson, 2000: 3-22). However, what Johnson and Johnson point out in these quotations are not debate impacts. They are talking about the prescribed sets of behavior characterized by the debating match because of the rules of the match itself, i.e. debate role behavior. In fact, developing an issue from only one's own point of view, ignoring others' perspectives and avoiding making risky concessions for oneself are legitimate behaviors in debating matches. Nonetheless, this does not mean that a debater behaves in this manner, on all occasions. It would mean coming to the conclusion that a judoka usually fights people just because in competitions he or she struggles violently with an opponent.

Confusing procedural effects, i.e. role behavior, with educational impacts is mostly committed by cooperative learning supporters. These supporters sometimes seem to suggest that cooperative types of dialogue are better than competitive types on the basis that, at the end of the match, cooperative types of dialogue motivate students to agree instead of disagreeing. For example, Johnson and Johnson (2000) conclude that debaters refuse to incorporate any opponent's point of view into their own position, and Felton et. al. (2009) are of the opinion that, students in the deliberative condition are more likely to craft arguments 
that acknowledge opposing viewpoints. However, as pointed out before, these outcomes must be recognized as debate or deliberative roles rather than dwelling on their educational impact. Likewise, from an argumentative point of view, agreement cannot be considered as the criteria of distinguishing sound arguments from bad ones. It is always possible for two parties to reach an agreement using fallacious arguments because reaching an agreement could be a simple, or the expected way, of getting good marks in school.

A similar misinterpretation seems to be committed by Walton (1995) when he confuses debate's accidental features with the essence of debate or the ideal debate, i.e. debate hypothetical optimum. He declares that, "debaters can score good points and can win over a judge or audience successfully even while using bad or fallacious arguments". However, if debate exhibits some features of the eristic dialogue it does not mean that the debate $i s$ or should be performed as an eristic dialogue, as Walton seems to suggest (1994, 2008). Instead, in competitive debate the judge is in a position to reward effective argumentative techniques and to discourage the use of poor arguments (Ulrich, 1986a). In addition, the purposes often cited as overall goals of judging are to promote the educational aspects of academic debate, to promote fairness in the activity and to establish a favorable atmosphere for quality competition in debates (ibidem: 2). The achievement of these goals cannot be compared with allowing poor or fallacious arguments to flourish. Moreover, even if a debate team could win a match using fallacious arguments, reaching an agreement in a critical discussion type of dialogue does not avoid the same critique. It is always possible that, in a critical discussion, an agreement or persuasion is reached based on fallacious arguments if parties do not recognize such arguments as fallacious. Nonetheless, critical discussions are not considered eristic.

The last mistake emphasized seems to imply another conceptual confusion: debate format's theoretical implications are often confused with educational impact. Andrews (1995) 
and Tumposky (2004) suggest that considering the dialectic structure of debate a simplification seems to imply that debaters simplify issues. However, this is a mistake. As we have seen before, debaters understand issues better, and when they are preparing for debates, they acknowledge problematic issues. Therefore, it is likely that, this kind of mistake ensues from a recurrent misconception, which is considering competitive debate only as a strictly ruled type of competitive dialogue (Wood and Goodnight, 1994). Even if this definition is correct from a strictly theoretical point of view, from a pedagogical and practical perspective it is not exhaustive. In fact, debate also encompasses information seeking dialogue, where each debater looks for and shares information with teammates; critical discussion, where teammates explore issues together; negotiation, where teammates try to reach an agreement on organizational matters; and deliberation, where, for example, teammates have to decide which arguments to bring into the debate (Cf. Backer, 2010). Recognizing the need for a wider set of skills for debating than those strictly related to the match reveals how complete a tool debate is and how important cultivating all the skills associated with debate is for argumentation education. Additionally, promoting this idea of academic debate will help scholars to give a clearer idea of debate itself and its impacts. This will strengthen debate from oversimplification by those who consider debate just a way of making a prejudice more sound ( $C f$. Bono de, 1985). This is also a challenge that future researchers should face.

\section{Conclusion}

Debate is not detrimental. It is neither necessary nor likely that it leads to polarization. Debaters who advocate a counter-attitudinal side do not polarize but de-polarize, and debaters' de-polarization could be promoted by making debaters shift side many times, or by adopting appropriate procedures as the 5 ' $\mathrm{R}$ model describes. Also among those who polarize, debate does not necessarily lead to bias assimilation, close-mindedness, dichotomization or 
escalating conflict attitudes. Thus, polarization is not a necessary "side effect" of debate even if some of the negative consequences mentioned so far could occur in some debaters when training or judging is inadequate.

Nonetheless, important suggestions on unpleasant features or consequences such as eristic, exaggerate agonism, and issues simplification must be kept in mind. As educators, it is always important to make every effort to avoid such undesired consequences. Moreover, outcomes that stress other types of dialogue having greater positive impact than debate, as a more active search for information outside the class (Johnson and Johnson, 1985) or more evidence quotation (Felton et al. 2009), must be considered with open-mindedness and curiosity. They could suggest we consider debate from a wider and more complex perspective, and to develop the appropriate training. Indeed, team members preparing for competitive debate also engage in negotiation, when they organize for effective cooperation, in information-seeking dialogue, when they share information, in critical discussion, when they develop and test cases, in deliberation, when they choose strategy for the debate match, and finally in debate. From this perspective, debate could be seen as a complete tool for argumentation education because it provides a wide set of argumentative dialogues to work with and it assures, at the same time, the fundamental ingredient of argumentation itself: disagreement and confrontation (Jackson, 2002; Marttunen, 1992). As Willard (1988) suggests, disagreement is not a problem, but a value in itself; if we let it flourish, if we tolerate it and if we correctly manage it, we avoid conformity, we do not compromise democracy and we do not lose our liberty.

\section{References}

Alden R. MacD. The Art of Debate. New York: Henry Holt and Company, 1900. 
Allen M., Berkowitz S., Hunt S. and A. Louden. “A Meta-analysis of the Impact of Forensics and Communication Education on Critical Thinking." Communication Education, 48, no. 1 (1999): 18-30.

Andrews R. Teaching and Learning Argument. London: Casselli, 1995.

Backer T. Teaching Debate in Chile: "Age of Wisdom, Season of Light, Spring of Hope" 2010. Accessed August 9, 2012. http://www.scribd.com/doc/35530841/TeachingDebate-in-Chile-2010-Thomas-Baker.

Barnard R. H. "The Evils of High School Debating.” The Clearing House, 13 no. 4 (1937): 211-213.

Bellon J. “A Research-Based Justification for Debate Across the Curriculum.” Argumentation and Advocacy, 37, no. 3 (2000): 161-175.

Blair A. J. "What is Bias?" Edited by T. Govier. Selected Issues in Logic and Communication, 93-103. Belmont: Wadsworth, 1988.

Blomberg T. G., Bales W. D. and A. R. Piquero. "Is Educational Achievement a Turning Point for Incarcerated Delinquents Across Race and Sex?" Journal of Youth and Adolescence. 41, (2012): 202-216.

Bono de E. Six Thinking Hats. Boston: Little, Brown and Company, 1985.

Bonomo H., Mamberti J. M. And J. B. Miller. Tolerancia crítica y ciudadanía activa. Una introducción prática al debate educativo. New York: IDEA, 2010.

Branham R. Debate and Critical Analysis: the Harmony of Conflict. Hillsdale: Lawrence Erlbaum Associates, 1991.

Brimble J. and D .Pritchard. Guide to Debating: the Principles and Practice of Debate. Pontypridd: University of Glamorgan, 2003.

Broda-Bahm K., ed. Perspectives in Controversy: Select Essays From Contemporary Argumentation and Debate. New York: IDEA, 2002. 
Budesheim T. L. and A. R. Lundquist. “Consider the Opposite: Opening Minds Trough InClass Debates on Course-Related Controversies.” Teaching of Psychology, 27, no. 2 (1999): 106-110.

Cattani A. "Subjectivist and Objectivist Interpretations of Controversy-based Thought." Edited by P. Barrotta and M. Dascal. Controversies and Subjectivity, 185-200. Amsterdam: John Benjamins, 2005.

Chaiken S., Wood W. and A. H. Eagly. "Principles of persuasion.” Edited by E. T. Higgins and A. W. Kruglanski. Social psychology: Handbook of basic principles, 702742. New York: Guilford, 1996.

Colbert K. R. "Enhancing Critical Thinking Ability Through Academic Debate.” Comtemporary Argumentation and Debate. 16, (1995): 52-72

Combs H. W. and S. G. Bourne. "The Renaissance of Educational Debate: Results of a FiveYear Study of the Use of Debate in Business Education.” Journal on Excellence in College Teaching, 5, no. 1 (1994): 57-67.

Cox E. S. and W. C. Adams. "An answer to the Call for Experimentation by the CEDA Assessment Conference: A Descriptive Study of a Peer-Judged Round.” CEDA Yearbook, 14, (1993): 34-53.

Dascal M. "Dichotomies and Types of Debate." Edited by F. H. van Eemeren and B. Garssen. Controversy and Confrontation: Relating Controversy Analysis with Argumentation Theory, 21-34. Amsterdam: John Benjamins, 2008.

Dascal M. and A. Knoll. “'Cognitive Systemic Dichotomization’ in Public Argumentation and Controversies.” Edited by F. Zenker. Argumentation: Cognition and Community. Proceedings of the 9th International Conference of the Ontario Society for the Study of Argumentation (OSSA), 1-35. Windsor, 2011. CD ROM. 
De Conti M. “Dibattito regolamentato e sua influenza sull'atteggiamento dei partecipanti." Psicologia dell'educazione. (In press).

Duffin F. "Collaborative Discourse: Debate Across the Curriculum.” Research and Practice in Social Sciences, 2 , no. 1 (2006): 16-39.

Ehninger D. Six Earmarks of a Sound Forensics Program. The Speech Teacher. 1, no. 4 (1952): 237-241.

Ehninger D. and W. Brockriede. Decision by Debate. New York: Harper and Row, 1978.

Ennis R. "An appraisal of the Watson-Glaser critical thinking appraisal.” Journal of Educational Research, 52, no. 4 (1958): 155-158.

Ennis R. “Investigating and Assessing Multiple-Choice critical thinking tests.” Edited by J. Sobocan and L. Groarke. Critical Thinking Education and Assessment: Can Higher Order Thinking Be Tested?, 75-98. Ontario: Aymler Express Limited, 2009.

Estaville L. E. Jr. "Debate: A Teaching Strategy for Geography.” Journal of Geography, 86, no. 1 (2001): 2-5.

Felton M., Garcia-Mila M. and S. Gilabert. "Deliberation versus Dispute: The Impact of Argumentative Discourse Goals on Learning and Reasoning in the Science Classroom.” Informal Logic, 29, no. 4 (2009): 417-446.

Fogelin R. J. and W. Sinott-Armstrong. Understanding Arguments. An Introduction to Informal Logic. Troy: Harcourt Brace College Publishers, 1997.

Foster D. E. "In Defense of the Argument Culture: A Response to Recent Criticism Against the Use of Adversarial Debate as a Method of Societal Decision-Making." The Forensic of Phi Kappa Delta. 89, (2004) 13-29.

Freely A. J. Argumentation and Debate. Rational Decision Making. Belmont: Wadsworth, 1961. 
Friedley S. A. "Ethics and Evidence Usage: Current 'Codes' in Individual Events.” The National Forensic Journal, 1, no. 2 (1983): 109-117.

Fuentes B. C. and Y. C. Santibáñez. "Desegñando debates: preliminares para un enfoque dialógico y crítico.” Edited by A. Cattani. Argomentare le proprie ragioni. Organizzare, condurre e valutare un dibattito, 111-137. Casoria: Loffredo University Press, 2011.

Glasl F. Confronting Conflict. A First-Aid Kit for Handling Conflict. Gloucestershire: Hawthorn Press, 1997.

Glasl F. "The process of conflict escalation and roles of third parties.” Edited by G. B. J. Bomers and R. B. Peterson. Conflict management and industrial relations, 119-140. The Hague: Kluwer Nijhoff Publishing, 1982.

Green C. S. and H. G. Klug. "Teaching critical Thinking and Writing Through Debates: An Experimental Evaluation.” Teaching Sociology, 18, no. 4 (1990): 462-471.

Greenstreet R. “Academic Debate and Critical Thinking: A Look at the Evidence.” National Forensic Journal. 11, (1993): 13-28.

Groarke L. A. and C. W. Tindale. Good Reasoning Matters! A Constructive Approach to Critical Thinking. Canada: Oxford University Press, 2008.

Hensley D. and D. Carlin. Mastering Competitive Debate (4 ${ }^{\text {th }}$ ed.). Kansas: Carl Publishing, 1994.

Hill B. "The Value of Competitive Debate as a Vehicle for Promoting Development of Critical Thiking Ability." CEDA Yearbook. 14, (1993): 1-23.

Hinck E. A. "Managing the Dialectical Tension Between Competition and Education in Forensics: A Response to Burnett, Brand, \& Meister.” The National Forensic Journal, 21, no. 2 (2003): 60-76.

Huber R. B. and Snider C. A. Influencing through Argument. New York: IDEA, 2005. 
Hyde B. and Bineham J. L. "From Debate to Dialogue: Toward a Pedagogy of Nonpolarized Public Discourse." Southern Communication Journal, 65, no. 2-3 (2000): 208-223. Infante D. A., Trebing J. D., Shepherd P. E. and D. E. Seeds. "The Relationship of Argumentativeness to Verbal Aggression.” The Southern Speech Communication Journal, 50, no. 1 (1984): 67-77.

Inoue N. and M. Nakano. The Benefits and Costs of Participating in Competitive Debate Activities. Paper presented at the Wake Forest University/International Society for the Study of Argumentation “Venice Argumentation Conference”, June 27-30, 2004. Jackson S. "Designing Argumentation Protocols for the Classroom.” Edited by F. H. van Eemeren. Advances in Pragma-Dialectics, 105-119. Amsterdam: Sic Sat, 2002.

Johnson D. W. and R. Johnson. "Classroom Conflict: Controversy Versus Debate in Learning Groups." American Educational Research Journal, 22, no. 2 (1985): 237-256.

Johnson D. W. and R. T. Johnson. "Constructive Conflict in the Schools." Journal of Social Issues, 50, no. 1 (1994): 117-137.

Johnson D. W. and R. T. Johnson. Creative Controversy. Intellectual Challenge In The Classroom. Minnesota: Interaction Book Company, 2000.

Jørgensen C. "Public Debate - An Act of Hostility?” Argumentation, 12, (1998): 431-443.

Kennedy K. A. and E. Pronin. "When Disagreement Gets Ugly: Perceptions of Bias and the Escalation of Conflict.” Personality and Social Psychology Bullettin, 34, no. 6 (2008): 833-848.

Kimberly L. H., Knight K. E.and T. P. Thornberry. "School Disengagement as a Predictor of Dropout, Delinquency, and Problem Substance Use During Adolescence and Early Adulthood." Journal of Youth and Adolescence, 41, (2012): 156-166. 
Korcok, M. The Effects of Intercollegiate Debating on Critical Thinking Ability. Florida State University, 1997. Accessed August 9, 2012. http://mailer.fsu.edu/ ewotring/com5312/critical.html

Kuhn D., Shaw V. and M. Felton. "Effects of Dyadic Interaction on Argumentative Reasoning." Cognition and Instruction, 15, no. 3 (1997): 287-315.

Landrum R. E. "Student Evaluation of Classroom Debate.” College Student Journal, 25, no. 2 (1991): 163-165.

Lao J. e Kuhn D. "Effects of Evidence on Attitudes: Is Polarization the Norm?” Psychological Science, 52, no. 2 (1996): 115-120.

Lewis S. and Wiese J. Lincoln-Douglas Debate: Values in conflict. Topeka: Clark Pub, 2000.

Littlefield R. S. "High School Student Perception of the Efficacy of Debate Participation." Argumentation and Advocacy, 38, (2001): 83-97.

Lord G. C. Lepper R. M. and E. Preston. "Considering the Opposite: A Corrective Strategy for Social Judgment.” Journal of Personality and social Psychology, 46, no. 6 (1984): 1231-1243.

Lord G. C., Ross L. and R. M. Lepper. "Biased Assimilation and Attitude Polarization: the Effects of Prior Theories on Subsequently Considered Evidence.” Journal of Personality and Social Psychology, 37, no. 11 (1979): 2098-2109.

Magnus M. H. “Using a Debate to Teach Food Aid.” Journal of Nutrition Education, 32, no. 2 (2000): 119-120.

Mareli J. “The Classroom Debate as a Critical Thinking Strategy.” Queen's Pedagogy Commons. 1, no.2 (2011): 11-17.

Martens E. A. "The Instructional Use of Argument across the Curriculum.” Middle School Journal, 38, no. 5 (2007): 4-13.

Marttunen M. “Commenting on Written Arguments as a Part of Argumentation Skills - 
Comparison Between Students Engaged in Traditional vs On-line.” Scandinavian Journal of Educational Research, 36, no. 4 (1992): 289-302.

Menkel-Meadow C. "The Trouble With the Adversary in Postmodern, Multicultural World." William and Mary Law Review, 38, (1996): 5-44.

Mezuk B. "Urban Debate and High School Educational Outcomes for African American Males: The Case of the Chicago Debate League." The Journal of Negro Education, 78, no. 3 (2009): 290-304.

Mill S. J. On Liberty and Utilitarianism. London: David Campbell Publisher, 1992.

Mitchell G. R. "Simulated Public Argument as a Pedagogical Play on Worlds." Argumentation and Advocacy. 36, no. 3 (2000): 134-150.

Moeller T. G. "Using Classroom Debates in Teaching Developmental Psychology." Teaching of Psychology, 12, no. 4 (1985): 207-209.

Moretti E. "Does education reduce participation in criminal activities?" Paper presented at the Symposium on the social costs of inadequate education conducted at Teachers College. New York: Columbia University, 2005. Accessed August 9, 2012. http://devweb.tc.columbia.edu/manager/symposium/Files/74_Moretti_Symp.pdf Moulton J. "A Paradigm of Philosophy: The Adversary Method.” Edited by S. Harding and M. B. Hintikka. Discovering Reality, 149,164. Dordrecht: Reidel Publishing Company, 1983.

Muir S. A. "A Defense of the Ethics of Contemporary Debate." Philosophy \& Rhetoric, 26, 4 (1993): 277-295.

Narveson R. D. "Development and Learning: Complementary or Conflicting Aims in Humanities Education?” Edited by R. F. Fuller, R. F. Bergrstrom, E. T. Carpenter, H. J. Corzine, J. A. McShance, D. W. Miller, D. S. Moshman, R. D. Narveson, J. L. Petr, M. 
C. Thornton and Williams V. G. Piagetian Programs in Higher Education, 79-88. Lincoln: ADAPT Program, 1980.

Nickerson R. S. “Confirmation Bias: A Ubiquitous Phenomenon in Many Guises.” Review of General Psychology. 2, no. 2 (1998): 175-220.

Nicolli S. and A. Cattani. Palestra di botta e risposta. La disputa filosofica come formazione al dibattito nella scuola. Padova: CLEUP, 2008.

O’Kon J. and R. Sutz. "Using In-Class Debates to Teach Gender Issues in Psychology." Edited by B. K. Saville, T. E. Zinn and V. W. Hevern. Essays from e-xcellence in teaching. 2005. Accessed August 9, 2012. http://teachpsych.org/ebooks/eit2004/eit0408.html

Oros A. L. "Let's Debate: Active Learning Encourages Student Participation and Critical Thinking.” Journal of Political Science Education. 3, (2007): 239-311.

Petty R. E. and D. T. Wegener. Attitude change: Multiple roles for persuasion variables. Edited by D. Gilbert, S. Fiske and G. Lindzey. The Handbook of Social Psychology, 323-390. New York: McGraw-Hill, 1998.

Pomerantz E., Chaiken S. and R. Tordesillas. "Attitude Strength and Resistance Processes." Journal of Personality and Social Psychology, 69, no. 3 (1995): 408-419.

Popper K. R. Conjectures and Refutations: The Growth of Scientific Knowledge. New York: Basic Books, 1962.

Popper K. R. Objective Knowledge: an Evolutionary Approach. Oxford: Clarendon Press, 1972.

Pruitt D. G. and S. H. Kim. Social Conflict. Escalation, Stalemate, and Settlement. New York: McGraw-Hill, 2004.

Raden D. “Strenght-Related Attitude Dimensions.” Social Psychology Quarterly, 48, no. 4 (1985): 312-330. 
Risen J. and Gilovich T. “Informal Logical Fallacies.” Edited by R. J. Sternberg, H. L. Roediger III and D. F. Halpern. Critical Thinking in Psychology, 110-130. Cambridge: Cambridge University Press, 2007.

Rogers J. E. and A. Rennels. “Outcome Based Life Choices: An Outcome Assessment Confirmation Study Measuring Positive Social Outcomes Beyond Undergraduate Experiences in Competitive Intercollegiate Debate for Partecipants and Society," in Snider, A., Proceedings of the III Thinking and Speaking a Better World Conference. In press.

Scott S. 'Perceptions of Students' Learning Critical Thinking through Debate in a Technology Classroom: A Case Study.” The Journal of Technology Studies. 34, no. 1 (2008): 39-44.

Sears D. O., Freedman J. L. and E. F. O’Connor. "The Effects of Anticipated Debate and Commitment on the Polarization of Audience Opinion." Public Opinion Quarterly, 34, (1964): 615-627.

Sears D. O. "Opinion Formation and Information Preferences in an Adversary Situation.” Journal of Experimental Social Psychology. 2, (1966): 130-142.

Semlak W. D. and D. Shields. "The Effect of Debate Training on Students Participation in the Bicentennial Youth Debates.” Journal of the American Forensic Association. 13, (1977): 192-196

Shatz M. A. "The Greyhound Strike: Using a Labor Dispute to Teach Descriptive Statistics." Teaching of Psychology. 12, no. 2 (1985): 85-86.

Snider C. A. Gaming as a Paradigm for Academic Debate. Doctoral dissertation. Kansas: Lawrence, 1983.

Snider C. A. "Ethics in Academic Debate: A Gaming Perspective." The National Forensic Journal. 2, no. 2 (1984): 119-134. 
Snider C. A. Code of the Debater. Introduction to Policy Debating. New York: IDEA, 2008.

Snider A. and M. Schnurer. Many Sides: Debate Across the Curriculum. New York: IDEA, 2002.

Stepp. P. "Taking CEDA Debaters Out of the Normal Tournament Setting." Contemporary Argumentation and Debate. 11, (1990): 80-87.

Streitberger H. E. “A Method for Teaching Science, Technology, and Societal Issues in Introductory High School and College Chemistry Classes." Journal of Chemical Education, 65, no. 1 (1988): 60-61.

Swift L. C. and C. Vourvoulias. “Argumentativeness, Verbal Aggressiveness, and Relational Satisfaction in the Parlamentary Debate Dyad." Journal of the National Parliamentary Debate Association. 11, (2006): 1-25.

Tannen D. "Managing Confrontation: Lessons from Abroad." The Responsive Community. 8, no. 2 (1998): 33-40.

Tannen D. The Argument Culture. London: Virago, 1999.

Tannen D. "Agonism in the Academy.” The Chronicle of Higher Education. 31 March, B7B8. 2000.

Tannen D. “Agonism in Academic Discourse.” Journal of Pragmatics. 34, (2002): 1651-1669. Thomas D. A. and J. Hart. "Ethics in Speech Events: A Replication and Extension." The National Forensic Journal. 1, no. 2 (1983): 74-95.

Tindale C. W. Fallacies and Argument Appraisal. Cambridge: Cambridge University Press, 2007.

Tjosvold D. and D. W. Johnson. "Effects of Controversy on Cognitive Perspective Taking." Journal of Educational Psychology. 69, no. 6 (1977): 679-685.

Tjosvold D., Johnson D. W. and J. F. Lawrence. "Effects of Controversy and Defenseveness on Cognitive Perspective-Taking.” Psychological Reports. 47, (1980): 1043-1053. 
Trapp R., Zompetti J. P., Motiejunaite J. and W .Driscoll. Discovering the World Trough Debate. A Practical Guide to Educational Debate for Debaters, Coaches and Judges. New York: IDEA, 2005.

Tumposky N. R. “The Debate Debate.” The Clearing House. 78, no. 2 (2004): 52-55.

Turchi G. P., Barbanera D. and C. Monaco. "Valutazione dell'efficacia del percorso formativo.” Edited by S. Nicolli and A. Cattani. Palestra di Botta e Risposta. La disputa filosofica come formazione al dibattito nella scuola, 85-92. Padova: CLEUP, 2008.

Turner M. M., Yao S., Baker R., Goodman J. and Matarese S. A. "Do Lay People Prepare Both Sides of an Argument? The Effects of Confidence, Forewarning, and Expected Interaction on Seeking out Counter-Attitudinal Information." Argumentation and Advocacy. 46, no. 4 (2010): 226-239.

Ulrich W. Judging Academic Debate. Lincolnwood: National Textbook Company, 1986 a.

Ulrich W. "The Ethical Obligations of the Forensic Educator." Contemporary Argumentation and Debate. 7, (1986b): 76-88.

Vo. H. X. and R. L. Morris. "Debate as a Tool in Teaching Economics: Rationale, Tecnique, and Some Evidence.” Journal of Education for Business. 81, no. 6 (1996): 315-320.

Walton D. Plausible Argument in Everyday Conversation. Albany: State University of New York Press, 1992.

Walton D. A Pragmatic Theory of Fallacy. London: The University of Alabama Press, 1995.

Walton D. Arguments from Ignorance. University Park: The Pennsylvania State University Press, 1996.

Walton D. The New Dialectic: Conversational Contexts of Argument. Toronto: University of Toronto Press, 1998. 
Walton D. Fundamentals of Critical Argumentation. New York: Cambridge University Press, 2006.

Walton D. Dialog Theory for Critical Argumentation. Philadelphia: Jon Benjamins Publishing, 2007.

Walton D. Informal Logic. A Pragmatic Approach. New York: Cambridge University Press, 2008.

Westbrook B. E. "Debating Both Sides: What Nineteenth-Century College Literary Societies Can Teach Us about Critical Pedagogies.” Rhetoric Review. 21, no. 4 (2002): 339-356.

Willard C. A. A Theory of Argumentation. Tuscaloosa: University of Alabama Press, 1988.

Williams P. H. 'Using Debates on Family Issues with Undergraduate Students: The 5 R's Strategy for Promoting Skill Development and Attitude Change.” Michigan Family Review. 14, no. 1 (2010): 91-109.

Williams D. E., McGee B. R. and D. S. Worth. "University Student Perceptions of the Efficacy of Debate Participation: An Empirical Investigation.” Argumentation and Advocacy. 37, no. 4 (2001): 198-209.

Wood R. V. and L. Goodnight. Strategic Debate. Lincolnwood: NTC, 1994.

Wood S. and Rowland-Morin, P. A. "Motivational Tension: Winning vs Pedagogy in Academic Debate.” The National Forensic Journal. 7, (1989): 81-97. 
Teaching the writing of argumentative genre through imitatio: A solid basis for the 'beginner' writers

Fotini Egglezou, Athens

\section{Summary}

This paper concerns the contribution of imitatio to the argumentative writing of twenty three 11-years old students of an elementary school (case-study) in the context of a socially constructed classroom. Through the lecture, listening, analysis and explicit teaching of the argumentative topics and stylistic figures found in a hybrid literary-argumentative text, students were conduced to the mimesis and genesis of multiple persuasive arguments. Imitatio seemed to influence positively the student's argumentative writing. The qualitative analysis of the final written argumentative texts showed a better awareness of the argumentative genre. Also, the quantification of data revealed an increased use of the argumentative topics of relations (cause-effect, antithesis) and of the figure of rhetorical questions.

Key words: imitation, argumentative writing, genre, elementary school

1. Introduction

Diachronically and interdisciplinarilyy the act of mimeisthai [ $\mu 1 \mu \varepsilon \bar{\imath} \sigma \theta \alpha \mathrm{l} /$ mimisthe], the notion of imitation, consists of a pivotal but, also, diversified, disputed or 'elusive' term (Fanner and Arrington, 1993:13) in many cognitive fields. Either as the representation of the real world in art and literature or as the deliberate imitation of various social behaviors and even more as pedagogical practice, imitatio or mimesis obtained fervent theoretical supporters as well as bitter enemies who tried either to reveal or to underestimate its value.

2. Historic roots of imitatio in rhetorical pedagogy

2.1 The ancient theoretical pedigree

Sophistic rhetoric identifies imitation as a necessary factor of the development of successful orators. Besides, sophists are considered the first imitators of oral rhapsodies (Schiappa, 1999:6). 
As regards Plato and Aristotle, they both accept the contribution of imitation to learning even if they don't perceive it as an emulating practice (Corbett, 1971:243). For Plato, the positive or negative evaluation of imitation depends on its role in the acquisition of the ideal truth. Finally, he approves its use as a medium capable of educating the Republic's future, ideal citizens (Plato, 1937; Tate, 1932:161).

In Phaedrus Socrates presents an analogous bilateral attitude towards it. On the one hand, he applies the art of imitation by offering a more accurate version of Lysias' speech and he accepts, explicitly, the existence of ideal models of orators. On the other hand, he advises Phaedrus not to imitate entirely a speech which contains bad examples of what he considers as true rhetoric (Plato, 1993, 278b 4-5:201, 264e 5-7).

As with Aristotle, he recognizes that through imitation, as an inherent impulse, 'a kind'

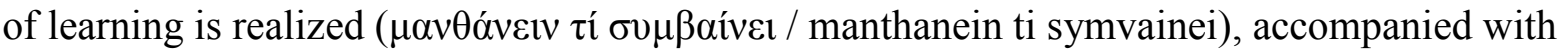
a certain feeling of pleasure which derives from the syllogism that the object of imitation is identified with the prototype (Aristotle, Rhetoric, I, x-xi, 1371b:176). McKeon holds the opinion that Aristotle doesn't invoke the imitation of prior orators (1936:27) despite Aristotle's lessons about arguments from example and about exemplar heros - both as models praiseworthy to be imitated.

The history of the vigorous support of imitation as a method of acquiring rhetorical excellence has begun. It is accepted that Isocrates first highlighted its guaranteed role in the successful practice of philosophy. In his Against the Sophists, he attributes to the teacher consequently to himself - the obligation to function as a model for his students in order to help them "... appear more florid and graceful” (Cagarin, 2000:65). Also, in the theoretical framework of Isocrates' paideia, imitation should be practiced, equally, at three levels; at the level of action, of thought and of speech (Haskins, 2000:18, 22). It is due to imitative 
exercises of various kinds of discourse that Isocrates inserted imitation in the field of writing because of its close relation to exercitatio (practice) (Fleming, 2003:109; Kinneavy, 1984:74).

\subsection{Greco-Roman conceptions of imitatio}

In the Rhetorica ad Herennium, imitatio is viewed as an independent training method and as an important aid for achieving rhetorical proficiency combined with ars (theory) and exercitatio (practice) (II, ii, 3). In his turn, Cicero shares the above ideas and he reinforces Isocrates' previous concepts about the immeasurable value of carefully selected models of creative imitation (Muckelbauer, 2003:69). As Antonius, he doesn't avoid proving his argument using the example of Sulpicius and the positive influence received by the imitation of his contemporary model, Crassus. All the same, Cicero highlights that the deliberate selection of a model - even an actor's model - must be strictly accompanied by the exclusive and exhaustive imitation of its 'marvelous characteristics'. Also, he emphasizes its pivotal role in the acquisition and transmission of a certain style (elocutio) (De Oratore, II, xxii, 92:159; xxiii:160).

Longinus, following Cicero, recognizes that the elevation of the poetic style is due to the imitation of major, prior models. Imitatio is conceived as an emulative practice which honors the imitators even if their talent is not comparable to the models (Longinus, 1999, XIII:71,73). Analogous ideas about style and imitation are also found in other treatises like Demetrius', On Style and Dionysius' of Halicarnassus, On Imitation. The author of the latter, fragmentally saved treatment, encourages the imitation of older attic authors in order to elevate the style of the writers of his era. Examining the nature, the models and the process of imitation, Dionysius credits it, equally, with procedural and psychological features subtly interwoven (Demetrius, 1902:22; McKeon, 1936:28; Clark, 1951:13).

2.3 Quintilian and the pedagogical use of imitatio 
Beyond any doubt, Quintilian inserts imitation as a crucial pedagogical practice in the educational history of Roman Provincial, Medieval and Renaissance schools. For Quintilian, the training of students in declamatio requires, first, the conscious imitation of excellent models, cautiously selected by the teacher of literature, the grammaticus. It is by imitating 'a stock of words, a variety of figures and the art of composition' that students will be led on the desirable route of the personal inventio and the intended facilitas (Institutes of Oratory, X, ii, 1:334-5, Murphy, 1996:584). On the other hand, Quintilian admits the finite power of imitative practice (X, ii, 8:335). Its educational energy becomes acceptable due to the possible generative and creative results which it may incur to students. Imitation is not considered to be a passive process but, rather, an agonistic one. The 'ideal' orator is challenged to reason and to emulate the offered models through the addition of personal elements and the substitution or deletion of existent features of the proposed discourse or style. In this sense, imitation acts as an incentive force which stimulates the cognitive, aesthetic, functional and linguistic choices of the imitator.

In the medieval period, Saint Augustine seems to draw upon Quintilian's teachings. He couples imitation, as a rhetorical method of cultivating the expression of discourse (modus preferendi), with Christian ideas. He explicitly suggests that for future preachers the imitation of prior models like the holy scriptures are a safe way of acquiring eloquence and wisdom (Saint Augustin, 1958:154-5).

Similar Greco-Roman ideas about imitation can be easily detected in the era of English Renaissance education. In the influential work of Wilson (1560), The Arte of Rhetorique, the author admits the necessity of 'following the waies of wifemen', by taking '...fome colour of them...' (p.5). Imitation is recognized as an undeniable method of learning to speak and write eloquently, since the model of the literate man represented the person 'who could speak spontaneously, copiously and persuasively on any subject' (Rhodes, 1992:43). 


\subsection{The period of the crisis}

The methodic and systematic commitment of Erasmus to copiousness is considered to be a representative example of Tudor's educational trend. For Erasmus, the passionate practice of imitative exercises for the achievement of various educational purposes focuses, especially, on students' moral training (Desiderius, 1978:682-3). Unfortunately, his effort can't be paralleled with Plutarch's example. By presenting both the Lives of honest and bad men - as mimetic poles or as models to avoid - Plutarch aimed at the formation of virtuous characters (Duff, 2002). On the contrary, Erasmus intended to students' ethical indoctrination according to current Christian demands influencing in a catalytic way the imitative pedagogy of his era. The semantic distortion of the term imitatio is a consequence of the alteration to classical principles of its practice by Erasmus. (Erdmann, 1993:3, 10)

This seems to start the ongoing crisis of imitatio in pedagogy and, especially, in the field of writing. The passage of the $18^{\text {th }}$ century may be characterized as a dark page in its history. Scholars ascribe the decline to two main reasons. First, imitation is interpreted as a sterile and passive act of copying stripped of all positive, assimilative characteristics. Especially, in the writing domain rhetorical pedagogy and, consequently, imitation, are considered to be responsible for a mechanistic, predetermined and skill-based mode of writing. Second, the Romantic movement, obsessed by the principle of personal genius, fights against the commonly shared characteristics of imitative elaboration and production (Welch, 1986:167; Knoblauch \& Brannon, 1984:80; Starkey, 1974). In addition, Sullivan (1989) accuses imitation of lacking the desirable scientism that should characterize every educational practice. In contrast with the process theories of writing, imitatio insults the teacher's scholarship. Fanner and Arrington (1993) point out the importance of the new, negative theoretical orientation towards imitation insofar as it results in its long-lasting marginalization (p. 24). 
Despite the downfall of imitatio in England, pedagogical practices in America in the beginning of the $19^{\text {th }}$ century still reflect its classical principles as a mean for developing students' knowledge and mental discipline. An interesting approach of the theoretical conversion towards imitation after the American Civil War is presented by Wilson (2003), who correlates it with racial politics. He supports the deliberate redefinition of the term in pedagogy to be a constraint on the threat of black imitation of the 'dominant systems of white power' (p. 89).

\subsection{The modern look at imitation}

During the $20^{\text {th }}$ century the value of imitation remains disputable. Perplexity may be the term that best describes the state of whoever seeks to research the issue. On the one hand, imitation finds theoretical refuge in structural and post-modern literary theories which seem to encourage the use of imitatio in the teaching of writing (Minock, 1995:492). Bakhtinian notions such as heteroglossia, polyphony and dialogism presuppose the incessant interaction, the uninterrupted dialogue with another's utterances (Bakhtin, 1986). Structuralists like Kristeva and Barthes (1981) invoke, implicitly, the act of imitation through the notion of intertextuality, since every text is paralleled with a 'mosaic' made by the 'absorption and transformation' of others (Kristeva, 1986:37). Genette (1997), also, admits its importance and talks, explicitly, about 'mimotexts' (pp. 75, 81). For post-moderns, such as Derrida (1988), a linguistic sign, oral or written, acquires its identity as such due to its capacity for being iterated, replicated.

On the other hand, the process theories of writing consist of the main theoretical adversary of imitation. For Berlin (1988) the development of cognitive rhetoric changed the whole picture of writing and, consequently, influenced the imitative practice. Apparently, the ascendant criticism of imitation in the 1980's is not incidental. It is, exactly, the date of birth of Flower and Hayes' (1981) three-fold cognitive model of writing, composed by such 
elements as the task environment, the writer's long-term memory and the writing processes. The three writing actions of the continuously expanded model, planning, translating and reviewing, consist of an onslaught on product theories that emphasize the role of 'assisted' imitation in learning and in writing development (Bereiter and Scardamalia, 1981; Flower et al., 1986; Gee, 1997:25; Pincas, 1982:24).

Notwithstanding their expansion, process theories didn't remain impervious to criticism (Horowitz, 1986). Since 1990 the development of genre-based approaches seem to dissent from viewing writing, only, as an 'unconscious process' between the writer and his unreachable inner world (Swales, 1990; Tribble, 1996; Badger and White, 2000:155). Teaching writing via genre-approaches serves not only for learning particular 'patterns of forms' but, mainly, as Miller (1984) points out, for participating 'in the actions of a community' (p. 165). In this theoretical framework, imitation is accepted, even partially, as a useful pedagogical means to the development of writing. Genre based models of writing propose strategies which include the modeling of the target-genre and the analysis of the organization of textual patterns for teaching literacy and writing (Cope and Kalantzis, 1993; Devitt et al., 2003; Beaufort, 2007:178). Such actions recall the classic activities of progymnasmata as the reading aloud of the text, textual analysis and transliteration. Similar techniques are used in modern workshops of creative writing, while the practice of imitation in writing is already inserted in the curriculum of teachers in Denmark (Fleming, 2003, Geist, 2004:170).

The long pedagogical tradition of imitation influenced the two-fold aim of this paper. First, the theoretical and diachronic review of its practice attempted to gain a deeper comprehension of the way that could, still, facilitate the modern rhetorical pedagogy. Second, it is examined whether its practice could still facilitate students' familiarity with argumentative writing. The research reveals an explicit commitment to classical rhetorical 
teachings as well as to modern instructive practices. Moreover, it challenges the repetition (or imitation!) of similar efforts in the future.

3. Purpose of the research

The purpose of the research was the examination of the influence of imitation on a random sample of beginner students in the field of argumentative writing in a Greek primary school. Emphasis was placed on its use in order to foster students' argumentative capacities in writing, and especially, in the inventio of arguments due to the development of topics.

4. Materials and methods

\subsection{Theory and methodology}

The following research describes a classroom intervention with 23 pupils, 11-years old, in the fifth $\left(5^{\text {th }}\right)$ grade of a public primary school in Alimos, an urban zone of Athens. The experimental group consisted of 14 boys and 9 girls who shared an homogeneous middle class social back-ground.

The experimental group had no previous training experience in argumentative writing. During the intervention the researcher acted as a participant observer trying to direct the instruction of the proposed text-model and to observe students' reactions.

The intervention was influenced by the socio-cultural theory of learning and by the principles of mediated and rhetorical pedagogy (Bazerman, 2009:283). According to Vygotsky imitation consists of a necessary process of 'stepping from something one knows to something new'. Coupled with instruction, imitation activates latent qualities in order to advance students' learning in the zone of proximal development and to transfer them to the potential level of their cognitive development (Vygotsky, 1962:103; Vygotsky, 1978:87).

Also, according to the socio-cultural theory, learning may be achieved due to the scaffolding method and the mediation of cultural tools as a text (Wood et al., 1976). For the text oriented 
approach of literacy the use of texts may contribute positively to students' development of written competence (Fterniati and Spinthourakis, 2005/2006).

Based on Pike's (1959) metaphor of particle, wave and field, we tried to find out which were the scaffolding effects of the analysis and explicit instruction of some common topics and stylistic patterns, found in an extract of a literary text (particle) through imitation, first, to a student's argumentative letter of the same content in order to create the necessary prior knowledge in written argumentation (wave) and, second, to a free written argumentative letter (field).

The corpus of data was composed: a) by transcripts from audio-taped instruction in the classroom and b) by students' individual pre- (Text A) and post-tests (Text B and Text C) in the form of informal argumentative letters. The writing of the texts was carried out before (Text A) and after (Text A, Text B) the lecture and the analysis of the text-model. The effects of imitation in students' writing were analysed in qualitative and quantitative terms (triangulation of data) in order to provide validity and reliability to the research. The qualitative analysis was based on Fairclough's three-dimensional model of critical discourse analysis which examines both features of grammar or vocabulary as well as features of the textual organization and the appearance of genres in the produced texts. (Fairclough, 1995:188-9; Blommaert and Bulcaen, 2000:448). The quantitative analysis used two statistical tests: a) the Friedman and b) the Wilcoxon test. The category system was identified as reliable because of the calculation of Cohen's Kappa coefficient for two raters (Cohen 1960). Alpha values of $0,907,0,832$ and 0,881 were obtained for the observations regarding the existence of arguments of cause and effect in the student's written texts A, B and C correspondingly. A high statistical significance of Kappa for the Text A was noticed (overall $\mathrm{k}=0,907 \mathrm{p}<0,001)$. Therefore, there was evidence that the observation system used by the researcher was valid. 
4.2 Materials development and teaching intervention

The intervention was carried out for a total of six didactic hours of 45 minutes in a period of 7 days. The steps followed were:

a) First, the free writing of an informal, exhortative letter (Text A) to the mayor of the town. By using arguments, students asked him not to permit the cutting of a tree for the construction of a new apartment building in the neighborhood (one didactic hour). The requested text form of a letter was considered the most appropriate, since ars dictaminis integrates elements of oral and written rhetoric, and also it can be an answer to an implicit, underlying controversy, well-hidden beneath its structure (East, 1968:242). The text A served as a basic criterion of students' initial writing and as a point of reference in comparison with the two following texts.

b) The next two days the reading and the analysis of an extract with analogous content $^{65}$ followed (three didactic hours). The extract, written in dialogic form, was taken from the novel My friend, the filbert tree ${ }^{66}(1982: 72-3)$.

The selection of the text satisfied the basic criteria of an exemplum for linguistic, stylistic, literary and active (ethical) imitation as proposed by Lausberg (1998:13; Papadopoulou, 1999:49). The comprehensible language, the vivacity of expression, the content explaining ecological and citizenship issues and the use of common topics and subtopics made it appropriate for the research. In short, the text provided the space for the connection of rhetorical and social features necessary for learning the argumentative genre.

At a first level, the lecture of the text-model offered an alternative approach to the examined issue and provoked in students an 'inner dialogue', relative to the post-hoc

\footnotetext{
${ }^{65}$ A little boy, Doros, saves Fundu (the tree) who is in danger, from the constructor, the bulldozer, the mechanic and the chopper.

${ }^{66}$ The book of Angeliki Varela was chosen to represent Greece at the international competition of books for children, and it was awarded one of the three "Honourable Mentions" from the International Award, JANUSZ KORCAC in 1985.
} 
performance of their writing and to the genre's learning (Stables, 2003:9-10; Spencer, 1982:43; Myers, 1983:15). According to Winterowd 'you learn to write by (usually) unconscious imitation of what you read' (1975:117-8).

The text was read twice: a) A read-aloud lecture was carried out by the researcher. Then, a genre analysis of the segment was made by following the lebovean model (Labov, 1972) of questions about: a) the abstract (what was the text about?), b) the orientation (who participated? where? for what?), c) the complicating action (what will happen after the interview?), d) the evaluation (why do you think this segment was interesting?), e) the result (what do you think that will be the result of the interview taken?). The segment, as a form of discursive interaction, was correlated with the social event that caused it, while the aims of the 'strategic action' of the heroes (f.e. justification of an opinion, persuasion) were emphasized (Fairclough, 2003:65, 70-1).

b) Then, in an independent reading level, students underlined the arguments presented in the text. The arguments provided, were characteristic examples of two main categories of common topics and sub-topics as presented in the taxonomy of Corbett and Connors (1999:87):

a) The common topic of comparison (similarity, difference of degree). For example:

- "We are attached to trees!" she told me. "We look alike. They live and respire like us". ( similarity / metaphor) and

b) the common topic of relationship (cause and effect, antecedent and con-sequence, antithesis/contraries). For example:

- "Standing by trees, men should make the sign of cross, because trees inspire carbon dioxide and breathe out oxygen". (cause and effect)

- If someone wanted to cut down your filbert-tree what would you do? I asked George. -I would try to prevent him. (antecedent and consequence) 
Students focused their attention on the above organizational patterns and the analysis of their structure, based on the assumption that knowledge of common topics may facilitate the production of arguments on any future given subject (Zompetti, 2006:22). Accepting the idea that topics may provide an argumentative classification, the above topics were modeled on the blackboard as petals of a flower. Each petal represented a different argumentative locus, a different kind of thought which could help students in generating more arguments to support their opinion.

Furthermore, during the text analysis students searched for the main stylistic features used by the author, such as metaphors and rhetorical questions. Scholars propose that such an effort improves students' personal linguistic and stylistic expression as well as their syntactic competence (D’ Angelo, 1973). For example:

- "A tree is a breathe of life". (metaphor)

- "Mister Mayor, I learnt that a Dutch airline offered to Athens forty thousands tulips. And you, can't you offer not even a tree to neighborhood's children?" (antithesis expressed in a form of rhetorical question)

c) The writing of a second letter (Text B) to the mayor with the same theme followed (one didactic hour). The change of the dialogic extract in a letter-form was an attempt to give a more dynamic character to the imitative practice similar to the classical rhetorical exercise of paraphrase or, in intertextuality terms, to the strategy of adaptation of the original text (Sanders, 2006:26; Clark, 1951:20).

d) Three days later, students carried out a similar writing task (Text C) (one didactic hour). This time, the theme of the argumentative letter was: You want desperately a pet. Write a letter to your mother trying to convince her with your arguments to buy it. The activity highlighted the effects of the prior imitative practice, mainly, of the topical invention of arguments and examined whether the results obtained could be dynamically transferred to a 
new writing attempt relative to a different content and context, to a 'new conceptual intention' (Kelly, 1987:375).

5. Results

\subsection{Qualitative analysis}

The students' first, free written argumentative letter (Text A) revealed the necessity of accurate instruction of argumentative writing. First, the prevalence of a written narrative schemata became obvious. Five students $(\mathrm{N}=5,21,7 \%$ in the total sample) didn't respond to the demand of writing a letter. On the contrary, they developed the subject in the only wellknown method, the narration. For example:

- "It was Friday, the day of the assembly for examining if my beloved tree should be cut down. The majority supported the opinion that it should, definitely, be cut down. I had to react quickly. The only solution was to send a letter to the mayor. ... (Yannis)"

Emphasis was placed on the chronological organization of personal experiences with the beloved tree:

- "Well, I and my friends we have grown up with that tree. We were 7 years old when we played over there. When we were 8 years old we played on the swing and now that we have turned 10 years old we have made a tree-house and you want to cut it down. (Konstantinos)"

Second, students' writing revealed their limited prior knowledge in developing arguments. The mean of the produced arguments was low. The initial letters were very short in length, while stylistic elements were scarcely present.

The majority of written arguments was presented either in the introduction or in the conclusion of the texts, while the rest of the letter was, mainly, dedicated to recalling personal memories. Even when arguments were given in an explicit form, they usually made part of the knowledge-telling model of writing (i). For example: 
(i) "I ask you not to cut down my neighbourhood's tree because I used to play over there, to climb and to sit on its branches." (Minas)

In the second text (Text B), students as sensible citizens developed a more accurate and extended argumentation in order to support their thesis based on a critical interaction with the problem emerged (Terrill, 2011:301). For example:

- "Resolving this problem is crucial for all the children of our neighborhood, because we are the habitants of the zone and you can't take decisions against our rights." (Thanos)

Two were the main persuasive strategies used: 1) First, the removal of personal experiences. Students approached the interests' of the receiver of their arguments invoking either personal motives (i), or personal experiences (ii), fears and bias (iii) as shown by the following examples:

(i)"All the mayors until now showed an increased interest for the trees of our neighbourhood. This is the reason why you should stop cutting the hazel. Do you imagine the consequences of your action if it will be repeated and repeated in the future? That's why we would propose you not to be the first mayor who will start this destructive action.” (John)

(ii) “To my opinion this tree shouldn't be cut down, because we used to play there since we were too young as, also, you did when you were a little boy." (Maria) (iii)“Also, if you permit it, the citizens won't vote for you” (Theodoris)

2) Second, students allowed the appearance of passion in their speech, mainly, due to the use of the stylistic element of rhetorical questions (iv) invoking further socio-economic parameters.

(ii) "What is more important for you...oxygen or money?" (Helen)

Also, in the third text (Text C) students used as evidence examples taken either from the mythology (i.e. the powerful relationship between Ulysses and his dog) or from the friendly 'milieu', while their lexical, syntactic and functional choices were more accurate. 


\subsection{Quantitative analysis}

The basic criteria of students' pre- (Text A) and post- tests (Text B and C) quantitative analysis with the S.P.S.S. (statistical package for the social sciences) were:

a) The number of all the written arguments of each text. The argumentative unit consisted of one or more sentences which guaranteed the basic structure of the argument (Caccamise, 1987; Kellogg, 1990).

b) The number of arguments based on the topics of: (i) cause and effect, (ii) antithesis, (iii) antecedent and consequent (expressed by conditional conjunctions), (iv) similarity and v) difference of degree.

c) The number of stylistic elements. More specifically, a rating scale from 0-2 was created. The existence of (i) metaphors (0-1) and of b) rhetorical questions (0-1) was marked. d) Text length: counting the words of a text provided a useful analytical device.

As an alternative test for the one-way repeated measures ANOVA, the Friedman analysis of variance by ranks was used because of the sample size of our research (23 students). The Friedman test consisted of a non-parametrical test which detected differences across multiple test attempts at a significant level of 5\%. In our case the attempts were represented by the texts A, B and C. Furthermore, the Wilcoxon's test was used in order to detect which texts contained statistical significant differences. The significance level of $0.05 / 3=0,017$ was calculated with the Bonferroni adjustment.

The practice of imitatio was considered as the independent variable of the research (YES/NO) (Verma and Mallick, 1999). The total number of the written arguments, the number of arguments based on the above mentioned topics, the number of stylistic elements and the text length constituted the dependent variables.

The experimental group produced a higher total mean of written arguments as attested by the statistical analysis. The initial mean of arguments $\mathrm{M}=1,09(\mathrm{SD}=0,900)$ in the Text $\mathrm{A}$ 
increased after the intervention. In the Text $\mathrm{B}$ the mean raised $(\mathrm{M}=3,65, \mathrm{SD}=1,849)$ as well as in the Text $\mathrm{C}(\mathrm{M}=3,70, \mathrm{SD}=1,329)$ (Figure 1). The analysis showed a significant difference among the mean of arguments of texts B and A $(p=0,000<0,017)$ and of texts $C$ and A $(p=0,000<0,017)$, while the difference among the texts B and C wasn't significant.

\begin{tabular}{lccc}
\hline & TEXT A & TEXT B & TEXT C \\
\hline Mean \pm SD & $1,09 \pm 0,900$ & $3,65 \pm 1,849^{*}$ & $3,70 \pm 1,329^{\wedge}$ \\
\hline
\end{tabular}

Significant difference among the mean of arguments of texts $B$ and A, $p=0,000<0,017$

Significant difference among the mean of arguments of texts $C$ and $A, p=0,000<0,017$

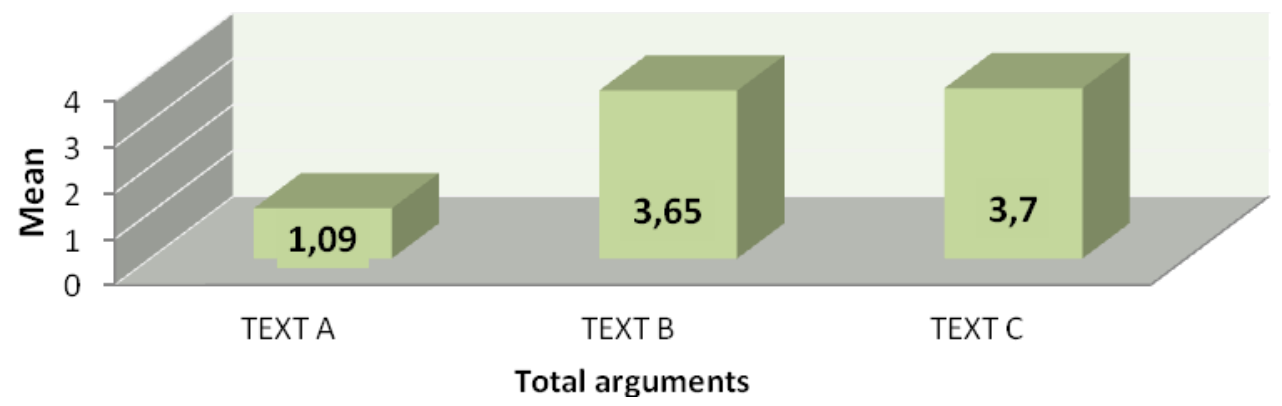

Fig. 1 Total mean of written arguments in texts A, B and C

The produced arguments were mainly based on the topic of relationship as expressed by the sub-topics of cause and effect $(\mathrm{M}=0,52, \mathrm{SD}=0,593:$ Text $\mathrm{A}, \mathrm{M}=1,70, \mathrm{SD}=1,222$ :Text $\mathrm{B}$ and $\mathrm{M}=2,04, \mathrm{SD}=1,022$ :Text C) (Figure 3), of antithesis $(\mathrm{M}=0,13, \mathrm{SD}=0,344$ :Text $\mathrm{A}, \mathrm{M}=0,78$, $\mathrm{SD}=0,736$ :Text $\mathrm{B}$ and $\mathrm{M}=0,78, \mathrm{SD}=0,671$ :Text $\mathrm{C}$ ) (Figure 2) and of antecedent and consequent ( $\mathrm{M}=0,13:$ Text $\mathrm{A}, \mathrm{M}=0,52:$ Text $\mathrm{B}$ and $\mathrm{M}=0,57$ :Text $\mathrm{C}$ ) (Fig. 4). 


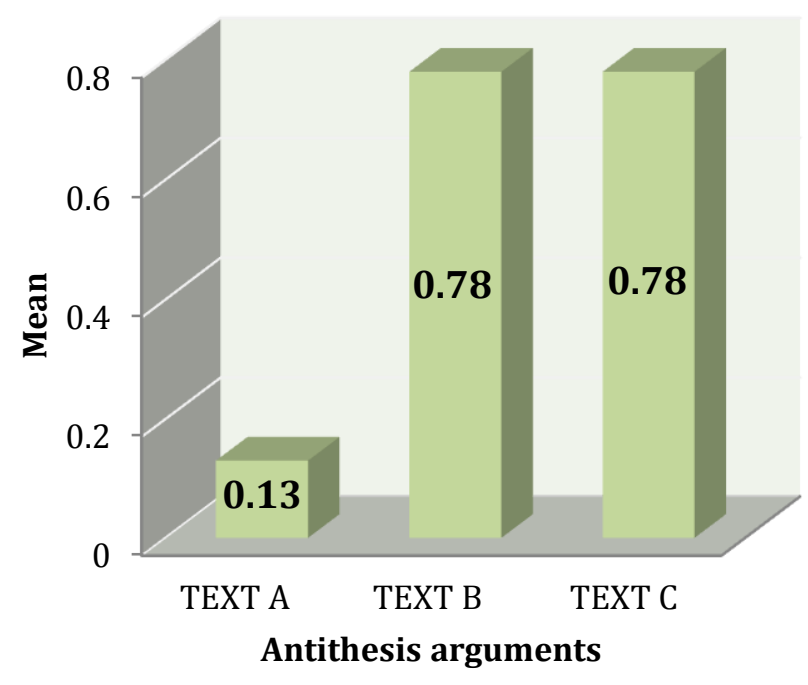

Fig. 2: Mean of arguments based on the topic of antithesis in texts A, B and C.

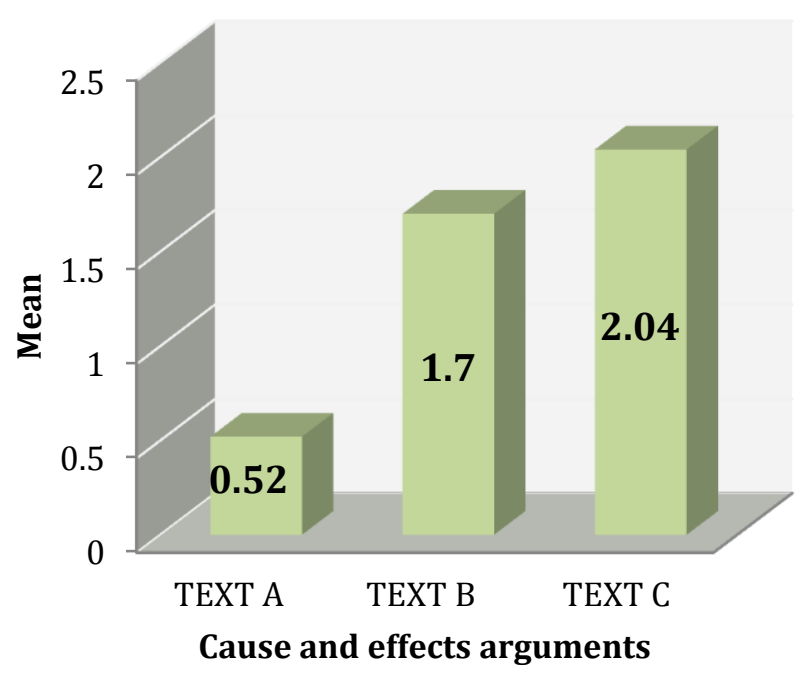

Fig. 3: Mean of arguments based on the topic of cause and effect in texts A, B and C.

\begin{tabular}{lccc}
\hline & TEXT A & TEXT B & TEXT C \\
\hline $\begin{array}{l}\text { Mean } \pm \text { SD } \\
\begin{array}{l}\text { Cause and effect } \\
\text { arguments }\end{array}\end{array}$ & $0,52 \pm 0,593$ & $1,70 \pm 1,222^{*}$ & $2,04 \pm 1,022^{\wedge}$
\end{tabular}




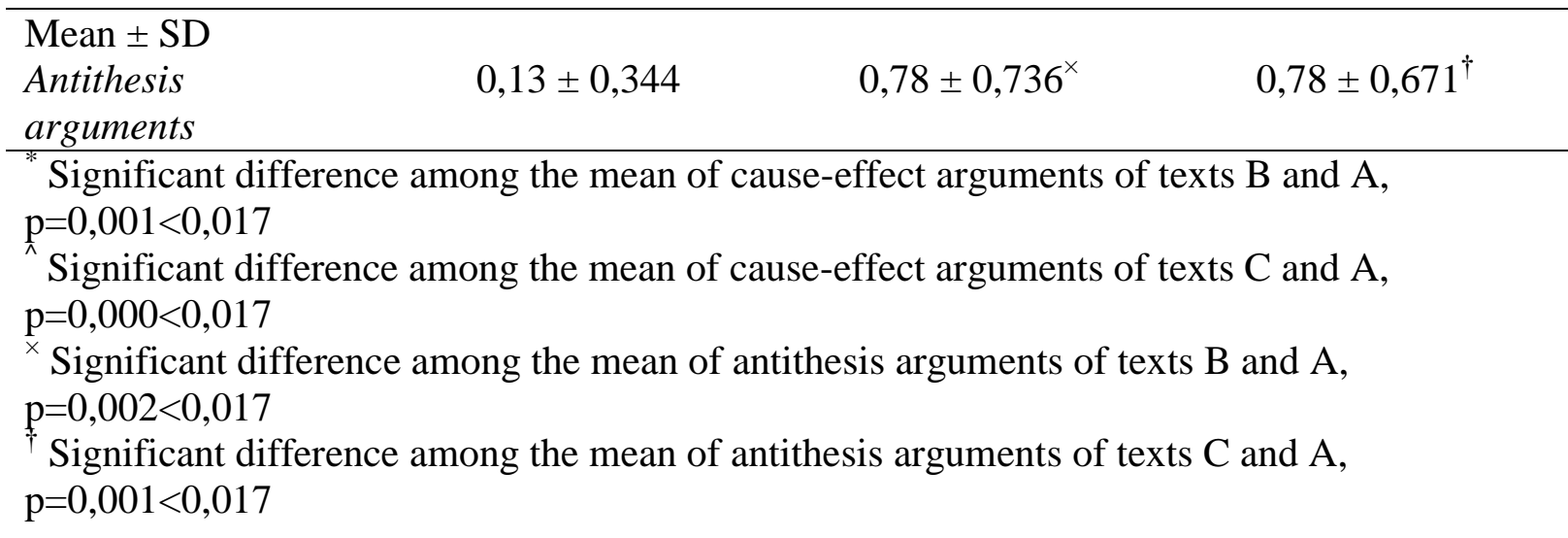

The difference of cause and effect arguments was significant among texts B and A $(\mathrm{p}=0,001<0,017)$ and among texts $\mathrm{C}$ and $\mathrm{A}(\mathrm{p}=0,000<0,017)$, while the difference among the texts B and C was not statistically significant ( $p=0,193>0,017)$. Also, the increase of antithesis arguments was statistically significant among texts $\mathrm{A}$ and $\mathrm{B}(\mathrm{p}=0,002<0,017)$ and among texts $A$ and $C(p=, 001<0,017)$, but not among the texts $B$ and $C(p=, 894>0,017)$. When it comes to the arguments based on the sub-topic of antecedent and consequent, a significant difference was noticed only between the initial Text $\mathrm{A}(\mathrm{M}=0,13)$ and the final Text $C(M=0,57)(p=0,013<0.017)$ in favor of the final text (Text $C)$. On the contrary, no significant difference concerning the production of arguments based on the sub-topic of similarity and the subtopic of difference was noticed.

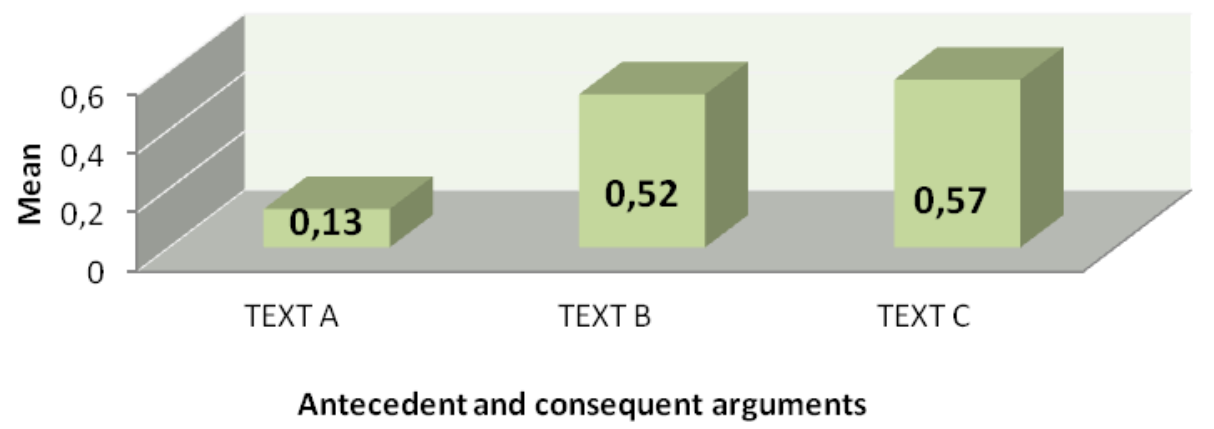

Fig. 4: Total mean of antecedent and consequent arguments in texts A, B and C 
Furthermore, the statistical analysis showed a significant increase of the mean of stylistic elements $(M=0,4783, S D=0,51075$ : Text $A, M=1,6087, S D=1,49967$ : Text $B$ and $\mathrm{M}=1,2609, \mathrm{SD}=1,05388$ : Text C). A statistically important difference was noticed among texts $\mathrm{A}$ and $\mathrm{B}(\mathrm{p}=0,003<0,017)$ and among texts $\mathrm{A}$ and $\mathrm{C}(\mathrm{p}=0,004<0,017)$, while there was no important difference among texts B and C.

The mean of rhetorical questions, to complete the one-way repeated-measures ANOVA, varied from $\mathrm{M}=0,13$ ( $\mathrm{SD}=0,344$ :Text $\mathrm{A})$, to $\mathrm{M}=1,17$ ( $\mathrm{SD}=1,154$ :Text $\mathrm{B}$ ) and to $\mathrm{M}=1,04$ ( $\mathrm{SD}=0,976:$ Text $\mathrm{C}$ ) (Figure 5). It was confirmed that the mean of rhetorical questions statistically increased for B and C Texts versus Text A ( $\mathrm{p}=0,000<0,017$ among Texts $\mathrm{A}$ and $\mathrm{B}, \mathrm{p}=0,001<0,017$ among Texts $\mathrm{A}$ and $\mathrm{C}$ ), while it was statistically equal between the texts B and C. On the contrary, no significant difference concerning the production of metaphors as stylistic elements of texts A, B and C was noticed $(M=0,35$, $\mathrm{SD}=0,49:$ Text A, $M=0,43, \mathrm{SD}=0,59:$ Text $\mathrm{B}$ and $\mathrm{M}=0,22, \mathrm{SD}=0,42$ :Text $\mathrm{C}$, Sig: 0,273>0,05).

\begin{tabular}{cccc}
\hline & TEXT A & TEXT B & TEXT C \\
\hline Mean \pm SD & $0,13 \pm 0,344$ & $1,17 \pm 1,154^{*}$ & $1,04 \pm 0,976^{\wedge}$
\end{tabular}

* Significant difference among the mean of rhetorical questions of texts B and A, $\mathrm{p}=0,000<0,017$

Significant difference among the mean of rhetorical questions of texts $\mathrm{C}$ and $\mathrm{A}$, $\mathrm{p}=0,001<0,017$ 


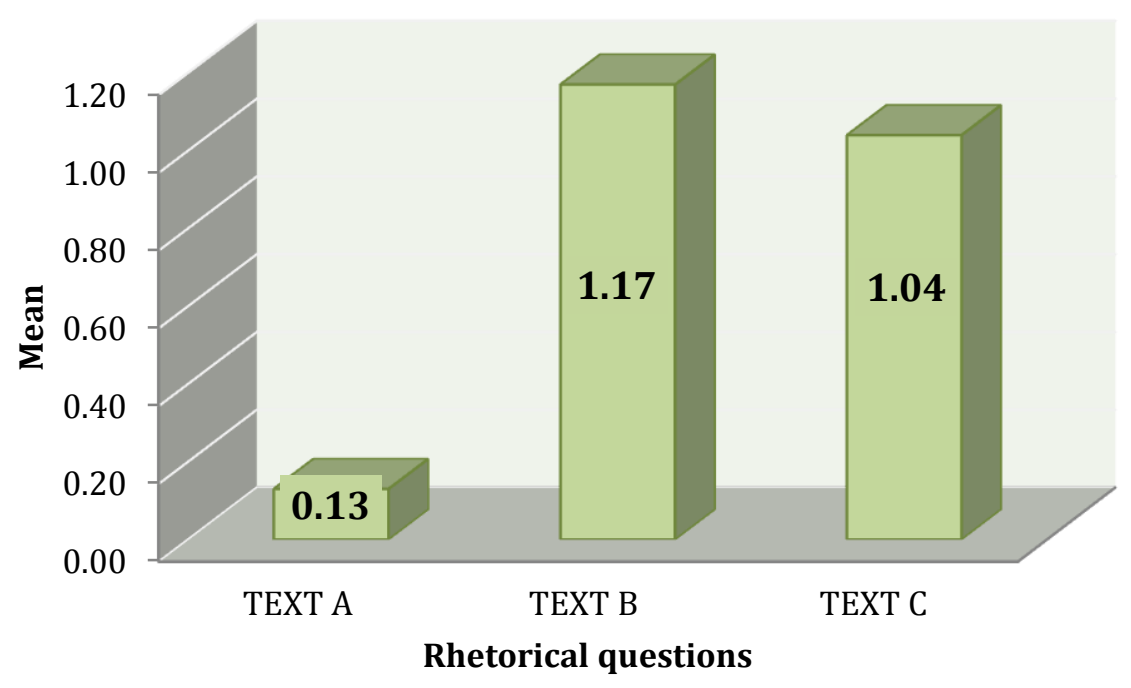

Fig. 5 Mean of rhetorical questions in the texts A, B, C

Finally, a significant increase in the text length relative to the invention of more arguments suitable to the situational context and to the communicative result of persuasion was noticed (Figure 6). The mean $\mathrm{M}=85,87$ words of the text $\mathrm{A}(\mathrm{SD}=42,939)$, increased to the mean $\mathrm{M}=140$, 17 words for the text $B(S D=55,998)$ and to the mean $M=136$ words for the Text $C(S D=47,944)$. It was confirmed that the text length statistically increased for B and C Texts against Text $\mathrm{A}$ $(\mathrm{p}=0,000<0,017$ among Texts $\mathrm{A}$ and $\mathrm{B}, \mathrm{p}=0,000<0,017$ among Texts $\mathrm{A}$ and $\mathrm{C}$ ) and that it was statistically equal between cases B and C.

\begin{tabular}{cccc}
\hline & TEXT A & TEXT B & TEXT C \\
\hline Mean \pm SD & $85,87 \pm 42,939$ & $140,17 \pm 55,998^{*}$ & $136 \pm 47,944^{\wedge}$ \\
\hline
\end{tabular}

* Significant difference of the text length among the texts B and A, $p=0,000<0,017$

^Significant difference of the text length among the texts $\mathrm{C}$ and $\mathrm{A}, \mathrm{p}=0,001<0,017$ 


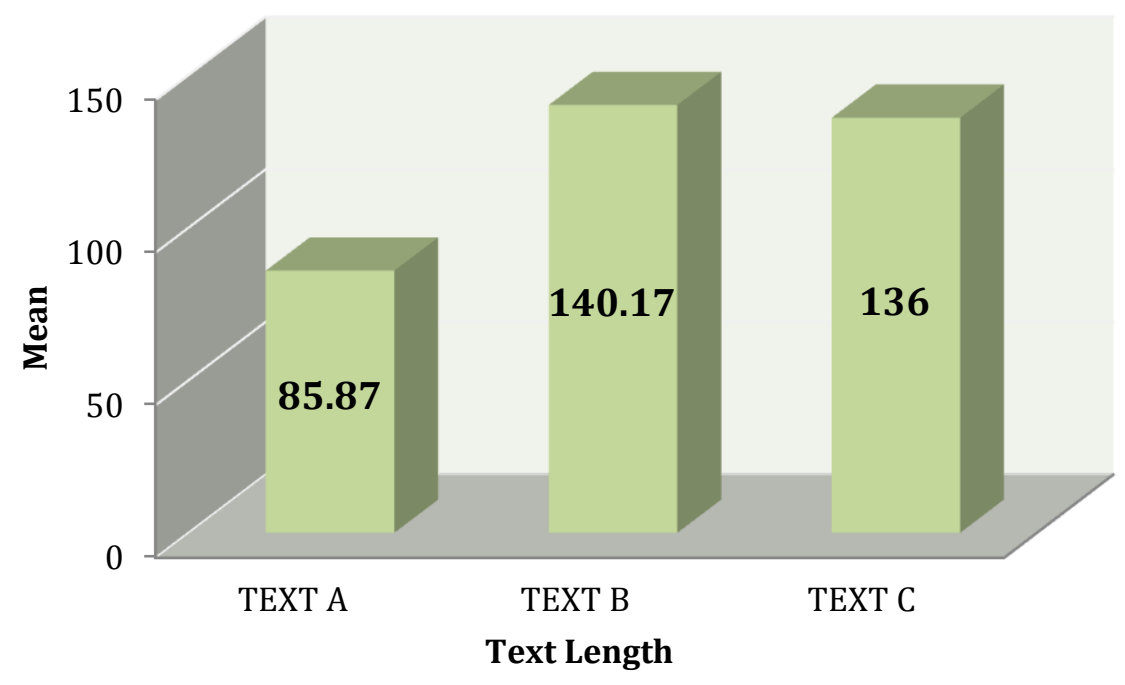

Fig. 6 Text length of texts A, B, C

\section{Discussion}

The statistical results affirmed that the practice of imitation stimulated, significantly the students' cognitive, aesthetic, functional and linguistic choices. More precisely, its use contributed to the students' better awareness of the argumentative genre as a bridge between familiar and unfamiliar textual genres (Prince, 1989:730).

The two texts-letters (Texts B and C) accomplished the necessary rhetorical interaction among reality, reader and writer according to the demands of the new genre. First, there was notice of critical restraint of the knowledge-telling model of writing and of its substitution by the model of knowledge-transforming, since students created more logical and organized argumentative patterns instead of narrative schemes (Grabe and Kaplan, 1996:125). Second, the re-appearance of analogous statistical results in the third text (Text C) revealed a successful transfer of the acquired knowledge in a new context reinforcing the view that learning through imitation is not a passive and static process.

Indeed, by imitating the presented argumentative topics and sub-topics, students constructed in a more organized way their thought and produced more, accurate and valid arguments, in contrast to the first text, independently of the subject matter (Freedman, 
1993:238; Nelson, 1970:121, 124; Infante, 1971:128). At the same time, they developed their critical thought by discovering supporting reasons for their claims. Instead of a 'stultifying and inhibiting' practice, imitation became a liberating and empowering tool for argumentative, persuasive writing (Eschholz, 1980:24, Grubber, 1977:491). The increased use of the subtopics of cause and effect consisted of a device for the improvement of students' inductive thinking. Multiple possible adequate causes related to potential effects were produced. Moreover, the increased use of arguments based on the topic of antecedent and consequent revealed a better performance of students' use of the hypothetical syllogism, while the increased use of antithesis arguments led them to a dialectical game with opposite terms and ideas in order to empower the validity of the proposed claims.

Furthermore, the increased use of rhetorical questions, as a stylistic element, may be related to the interpersonal relations that emerged among the authors and the message's receiver either as a mean of the author's imposition or as a tool facilitating the social contact of the participants. Finally, imitation activated features of the students' vocabulary which remained inert in the beginning of their writing efforts, since a significant increase to the textlength was noticed (Texts B and C).

But, according to the classical teachings of Quintilian, imitation isn't a panacea. Despite the more persuasive character of the produced texts, its practice didn't influence either the production of arguments based on the topic of comparison or the use of metaphors. More precisely, students showed weakness, especially in the final text (Text C), in the invention of arguments based on the sub-topic of difference. Their limited use may be ascribed to the subtle differentiation among the topics of difference and of antithesis as well as to the acknowledgement of the difficulty of their settling (Corbett and Connors, 1999:97, 105). Finally, as regards the limited use of metaphors and the relative underdeveloped sub- 
topic of similarity, it may be related to the need for more interactive activities and students' joint participation in classroom (Cameron, 1996).

7. Conclusion

To conclude, the statistical results of the research showed that imitation should still serve as a useful method of teaching and learning in the field of writing and the acquisition of literacy (Murphy, 1990; Mendelson, 2001:289). Its practice in a Greek primary school seemed to help the students who lack skills in argumentative writing. More specifically, the students improved the form, the style and the content of their texts by releasing latent abilities even from the beginning of their efforts (Gorrell, 1987:53; Butler, 2002:26). The successful imitation of the argumentative topics concerning cause and effect, antecedent and consequent, antithesis, and rhetorical questions led to a variety of results. In particular, students were helped towards the production of more elaborated texts, the development of argumentative genre awareness and the construction of a solid basis upon which they placed the social artifact of argumentation. However, imitation doesn't exclude the practice of more interactive argumentative activities in the classroom. On the contrary, such activities in combination with imitation, may extend the acquired argumentative "textual basis" facilitating students "to understand what they are doing more deeply, more purposefully and more rhetorically' (Devitt, 2004:202).

\section{References}

Aristotle. Rhetoric.Vol. 1, Athens: Kaktos, 1995.

Badger, R. and G. White. "A process genre approach to teaching writing.” ELT Journal, 54, no. 2 (2000): 153-160. 
Bakhtin, M.M. “The Problem of Speech Genres.” Edited by C. Emerson and M. Holquist. Speech Genres and Other Late Essays, 60-102. Austin:University of Texas Press, 1986.

Barthes, R. "Theory of the text." Edited by R. Young. Untying the Text, 31-47. London: Routledge, 1981.

Bazerman, Ch. "Genre and cognitive development: Beyond writing to learn." Edited by Ch. Bazerman et al. Genre in a Changing World, 279-294. West Lafayette, Indiana:The WAC Clearinghouse and Parlor Press,2009.

Beaufort, A. College Writing and Beyond: A New Framework for University Writing Instruction, Logan, Utah:Utah State University Press, 2007.

Berlin, J.A. "Rhetoric and Ideology in the Writing Class." College English. 50, no. 5 (1988): 477-494.

Blommaert, J. and Ch. Bulcaen. "Critical discourse analysis." Annual Review of Anthropology. 29, (2000): 447-466.

Butler, P. "Imitation as freedom: (Re)forming student writing." The Quarterly, 24, no. 2 (2002): 25-32.

Caccamise, D. J. "Idea generation in writing." Edited by A. Matsuhashi. Writing in Real Time, 224-253. Norwood:Ablex, 1987.

Cagarin, M., ed. Isocrates I. Austin, TX:University of Texas Press, 2000. 0

Cameron, L. "Discourse context and the development of metaphor in children." Current Issues in Language and Society. 3, no. 1 (1996): 49-64.

Cicero. De Oratore, Athens: Polis, 2008.

Cicero. Ad Herennium, Cambridge, Mass: Harvard University Press, 1954.

Clark, D. L. "Imitation:Theory and practice in Roman Rhetoric." Quarterly Journal of Speech, 37, no. 1 (1951): 11-22. 
Cohen, J. "A coefficient of agreement for nominal scales." Educational and Psychological Measurement. 20, no. 1 (1960): 37-46.

Cope, B. and M. Kalantzis. The Powers of Literacy: A Genre Approach to Teaching Writing, London:Falmer Press, 1993.

Corbett, Edward P. J. "The theory and practice of imitation in classical rhetoric." College Composition and Communication. 22, no. 3 (1971): 243-250.

Corbett, E. P. J. and R. J. Connors. Classical Rhetoric for the Modern Student, N.Y./Oxford:Oxford University Press, 1999.

D'Angelo, Fr. "Imitation and style." College Composition and Communication. 24, (1973): 283-90.

Demetrius. On Style, Cambridge:At the University Press, 1902.

Derrida, J. Limited Inc, Evanston, Illinois:Northwestern University Press, 1988.

Desiderius, E. De Ratione Studii. Vol. 24 of Collected Works of Erasmus: Literary and Educational Writings 2. Toronto:University of Toronto Press, 1978.

Devitt, A.J., Jo Reiff, M. and A. Bawarsshi. Scenes of Writing: Strategies for Composing with Genres, London: Longman, 2003.

Devitt, A.J. Writing Genres, Carbondale, IL: Southern Illinois University, 2004.

Duff, T. Plutarch's Lives: Exploring Virtue and Vice. Oxford: Oxford University Press, 2002.

East, J.R. "Brunetto Latini's rhetoric of letter rhetoric.” Rhetoric Society Quarterly, 54, no. 3 (1968): 241-246.

Erdmann, Ed. "Imitation pedagogy and ethical indoctrination.” Rhetoric Society Quarterly. 23, no. 1 (1993): 1-11.

Eschholz, P. "The prose models approach using products in the process." Edited by T.R Donovan and B. W. McClelland. Eight Approaches to Teaching Composition, 21-35. Urbana:Illinois National Council of Teachers of English, 1980. 
Fairclough, N. Critical Discourse Analysis: The Critical Study of Language, London:Longman, 1995.

Fairclough, N. Analysing Discourse: Textual Analysis for Social Research, London:Routlege, 2003.

Fanner, Fr.M. and Ph. K. Arrington. "Apologies and accommodations: Imi-tation and the writing process." Rhetoric Society Quarterly. 23, no. 1 (1993): 12-34.

Fleming, D.J. “The very idea of progymnasmata." Rhetoric Review. 22, no. 2 (2003): 105120.

Flower, L. and J. R. Hayes. “A cognitive process theory of writing.” College Composition and Communication. 32, (1981): 365-387.

Flower, L. et al. "Detection, diagnosis, and the strategies of revision." College Composition and Communication. 37, no. 1 (1986): 16-54.

Freedman, A. "Show and tell? The role of explicit teaching in the learning of new genres." Research in the Teaching of English. 27, (1993): 222-251.

Fterniati, A. and J. A. Spinthourakis. "Implementing a text oriented approach to effect students' textual competence." The International Journal. 12, no. 3 (2005/2006): 309316.

Gee, S. "Teaching writing a genre-based approach.” Review of English Language Teaching. 62, (1997): 24-40.

Geist, U. "Stylistic imitation as a tool in writing pedagogy." Edited by G. Rijlaarsdam, H. van den Bergh and M. Couzijn. Studies in Writing, 169-179. Dordrecht: Kluwer Academic Publishers, 2004.

Genette, G. Palimpsests: Literature in the Second Degree, Lincoln, NB: University of Nebraska Press, 1997.

Gorrell, D. "Freedom to write through imitation." Journal of Basic Writing. 6, (1987): 53-59. 
Grabe, W. and R. B. Kaplan. Theory and Practice of Writing, London: Longman, 1996.

Grubber, W.E. “"Servile copying' and the teaching of English composition.” College English. 39, no. 4 (1977): 491-497.

Haskins, E.V. "Mimesis between poetics and rhetoric: Performance culture and civic education in Plato, Isocrates and Aristotle." Rhetoric Society Quarterly. 30, no. 3 (2000): 7-33.

Horowitz, D.M. "Process, not product: Less than meets the eye." TESOL Quar-terly. 20, no. 1 (1986): 141-144.

Infante, D.A. "The influence of a topical system on the discovery of arguments." Speech Monographs. 38, no. 2 (1971): 125-128.

Kellogg, R.T. "Effectiveness of prewriting strategies as function of tasks demands." American Journal of Psychology. 103, no. 3 (1990): 327-342.

Kelly, D. "The imitation of models and the uses of argumenta in topical invention." Argumentation. 1, (1987): 365-377.

Kinneavy, J.L. "Translating theory into practice teaching composition: A historical view and a contemporary view.” Edited by R. S. Connors, S. E. Lisa and A. A. Lun-sford. Essays on Classical Rhetoric and Modern Discourse, 69-81. Carbon-dale:Southern Illinois University Press, 1984.

Knoblauch, C. H. and L. Brannon. Rhetorical Traditions and the Teaching of Writing. Upper Montclair, NJ:Boynton/Cook, 1984.

Kristeva, J. "Word, Dialogue, and Novel." Edited by T. Toril Moi. The Kristeva Reader, 3461. New York:Columbia University Press, 1986.

Lausberg, H. Handbook of Literary Rhetoric: A Foundation for Literary Study. New York: Brill, 1998. 
Labov, W. Language in the Inner City. University Park:University of Pennsylvania Press, 1972.

Longinus On the Sublime, Athens:Kaktos, 1999.

McKeon, R. "Literary criticism and the concept of imitation in antiquity." Modern Philology. 34, (1936): 1-35.

Mendelson, M. "Quintilian and the pedagogy of argument." Argumentation. 15, (2001): 277293.

Miller, C. R. “Genre as social action.” Quarterly Journal of Speech. 52, (1984): 151-167.

Minock, M. "Toward a post-modern pedagogy of imitation." JAC: A Journal of Composition Theory. 15, (1995): 489-509.

Muckelbauer, J. "Imitation and invention in antiquity: An historical-theoretical revision." Rhetorica. 21, no. 2 (2003): 61-88.

Murphy, J. J. "Roman Writing Instruction as Described by Quintilian." A Short History of Writing Instruction, 19-76. Davis, CA:Hermagoras Press. 1990.

Murphy, J. J. “Quintilian.” Edited by T. Enos. Encyclopedia of Rhetoric and Compo-sition: Communication from Ancient Times to the Information Age, 581-585. N.Y.:Gar-land, 1996.

Myers, M. "Modeling: Writing as the Approximation of Texts." Edited by M. Myers and J. Gray. Theory and Practice in the Teaching of Composition: Pro-cessing, Distancing, Modeling, 4-18.Urbana:NCTE, 1983.

Nelson, W. F. “Topoi:functional inhuman recall.” Speech Monographs. 37, no. 2 (1970): 121126.

Papadopoulou, Sm. The Whole Language. Thessaloniki: Kodikas, 1999.

Pike, K. "Language as particle, wave and field.” Texas Quarterly. 2, no. 2, (1959): 37-54.

Pincas, A. Teaching English Writing, London:Macmillan, 1982. 
Plato. The Republic, Cambridge, Mass:Harvard University Press, 1937.

Plato. Phaedrus, Athens:Kaktos, 1993.

Prince, M.B. "Literacy and genre: Toward a pedagogy of mediation." College English. 51, (1989): 730-749.

Quintilian. Edited by P. Bizzell and Br. Herzberg. Rhetorical Tradition: Readings from Classical Times to the Present. Boston:Bedford Books, 1990.

Rhodes, N. The Power of Eloquence and English Renaissance Literature. N.Y.:St Martin's Press, 1992.

Saint Augustin. On Christian Doctrine. New York: Liberal Art Press, 1958.

Sanders, J. Adaptation and Appropriation. London and New York: Routledge, 2006.

Scardamalia, M., Bereiter, C. and B. Fillion. Writing for Results: A Source-book of Consequential Composing Activities. Toronto: OISE Press, 1981.

Schiappa, E. The Beginnings of Rhetorical Theory in Classical Greece. New Haven, London:Yale University Press, 1999.

Spencer, J. Learning to write through imitation. English Quarterly. 15, (1982): 42-45.

Stables, A. "Learning, identity and classroom dialogue." Journal of Educational Inquiry. 4, no. 1 (2003): 1-18.

Starkey, P. "Imitatio Redux.” College Composition and Communication. 25, (1974): 435-437.

Sullivan, D. "Attitudes toward imitation: Classical culture and the modern temper." Rhetoric Review. 8, no.1 (1989): 5-21.

Swales, J. Genre Analysis. Cambridge: Cambridge University Press, 1990.

Tate, J. "Plato and imitation." The Classical Quarterly. 26, no. 3-4 (1932): 161-69.

Terrill, R. "Mimesis, duality and rhetorical education." Rhetoric Society Quarterly. 41, no. 4 (2011): 295-315.

Tribble, Ch. Writing. Oxford: Oxford University Press. 1996. 
Varella, A. My friend, the filbert tree. Athens: Patakis, 1982.

Verma, G.K. and K. Mallick. Researching Education: Perspectives and Techniques. Philadelphia: The Falmer Press, 1999.

Vygotsky, L. Thought and Language, Cambridge: The MIT Press, 1962.

Vygotsky, L. Mind in Society: The Development of Higher Psychological Processes. London: Harvard University Press, 1978.

Welch, K. E. “A manifesto: The art of rhetoric.” Rhetoric Society Quarterly. 16, no. 3 (1986): $167-179$

Wilson, K. H. "The racial politics of imitation in the $19^{\text {th }}$ century." Quarterly Journal of Speech. 89, no. 2 (2003): 89-108.

Wilson, Th. Arte of Rhetorique. Oxford:At the Clarendon Press, 1560.

Winterowd, R. W. The Contemporary Writer. N.Y.: Harcourt, Brace Jova-novich, 1975.

Wood, D., Bruner, J.S. and G. Ross. "The role of tutoring in problem solving." Journal of Child Psychology and Psychiatry. 17, (1976): 89-100.

Zompetti, J. P. “The value of topoi.” Argumentation. 20, (2006): 15-28. 


\section{MEDIA}




\title{
Challenges of Rhetoric in the Era of 'Bytes and Likes'
}

\author{
Petra Aczél, Corvinus University of Budapest
}

\begin{abstract}
"Rhetoric is no longer the title of a doctrine and a practice, nor a form of cultural memory; it becomes instead something like the condition of our existence." (Bender-Wellbery, 1990: 25)

"How will our rhetorical and media theories need to be reworked to account for the interactivity inherent in participatory entertainment?" (Urbanski 2010: 67-68)
\end{abstract}

\section{Summary}

Although defined, traditionally, as the art of persuasion, rhetoric has always tended to outgrow its original concern. Its twofold disciplinary nature, of theory and practice (utens-docens as Burke named them), has been calling constantly for redefinitions and scientific legitimization. Often, scholars augured or stated the death and recognized and announced the rebirth of rhetoric. Anti/Postmodernist theories were seeking new horizons to (re)interpret it in a more 'integrative' way, introducing it to function as a communicative framework of all societal and mediated functions.

In the era of digital literacy and new media, rhetoric is facing new challenges which urge theoreticians to rediscover the hidden capacities of the classical faculty. Contributing to e-rhetoric, netoric, digital and visual rhetoric, this paper intends to cast light upon the almost forgotten 'subdomains' of rhetoric and endeavours to prove its capability to be both the condition and the critical view of (new) media discourse.

Key words: rhetorical ideal, new media, visual rhetoric, procedural rhetoric, spatial rhetoric, aural rhetoric 


\section{Prologue}

In the second media age, the challenges to rhetoric concern mainly the faculty itself. The new, semi-virtual, participative publicity media maintains and makes rhetoric enact in the way, originally, to which it was entitled. Although the classical "toolbar" of rhetoric needs a bit of reconfiguring, rhetoric's main challenge is to discover its hidden fields and capacities which can offer more than the functionalist description of new media discourse. This chapter aims at outlining a theoretical framework to interpret classical rhetoric in a new way; to show the capaciousness of the ancient discipline; and to highlight those aspects and characteristics which relate rhetoric to new media in an organic way.

\section{Introduction}

Rhetoric is a great survivor. It has escaped decades - if not centuries - of moral resentment, scholarly rejection, and democratic suspicion and remains ready and invigorated to re-enter the scholarly landscape and to influence practices of social discourse. Undoubtedly, rhetoric has been able to resist the attacks of those who considered it vague; superfluous; manipulative; or outdated. With more than 2500 years of disciplinary history, it gained considerable stamina to answer new challenges be they social; political; technological; or scientific.

Classical rhetoric derives from the ancient Greek and Roman worlds where it served as the universal science of the public sphere in which right acting and right speaking were considered one. Although defined as the art of persuasion, it has tended, with persuasive public speaking, to outgrow always its original concern. Its genuine communicative, symbolic and strategic characteristics; its references to both the public and the personal; and its 
communicatively holistic nature have made rhetoric an interdisciplinary field of interpersonal, mediated and public discourse. In the classical tradition, a cultural ideal evolved, that of the "politically and socially active polymath" (Halloran, 1994: 332). This cultural ideal, regarded as the master of rhetoric, "was the man who had interiorized all that was best in his culture and applied this knowledge in public forums (...)" (1994: 331). The existence, of such a cultural ideal, suggested a worldview in which "values are coherent and the wisdom of public can be fully mastered by one man" (1994: 331). Classical rhetoric was informed by a world of the acting community which, clearly, was changed, mostly in the sense of coherence and eminence. As the original sociocultural-political context of rhetoric was being reconfigured, the discipline had to overcome several existentially critical phases. However, there were two eras of rejection which turned out to be almost fatal.

According to Bender and Wellbery's (1990) seminal article, both the Enlightenment and Romanticism caused this rejection of rhetoric. From the former's perspective, rhetoric seemed empty, blurred, and diffuse. Public discourse had to be freed of its individual interests; deprived of rhetorical ambiguity, and magniloquence and passion. For Romanticism, rhetoric had become a craft rather than the faculty of the genius, a way of producing rather than creating. These two sets of attacks resulted in the rejection of rhetoric's classical tradition for the following reasons: ascendant scientific objectivity with values of transparency and neutrality; a new emphasis on individual originality and authorship; liberalism's displacement of republicanism in political theory; the dominance of literacy over orality; and the rise of the vernacular language nation state. With the recession of this rejection, rhetoric managed to regain its significance. This shift was caused by those phenomena which characterized modern, postmodern scientific thinking, and global communicative culture. With the advent of new media technologies, a lingua franca, of influential communication, was reclaimed. 
New spaces of democratic debating called for a global language through which epistemological pluralism and individual voices were manifested.

Through the capacity to relieve scientific and moral paradoxes of postmodern societies, to perform playfulness in communication, and to fulfil global communicative exigencies and objectives, rhetoric managed to retrieve its practical and theoretical status amongst disciplines of discourse and returned (again) to the contemporary cultural and scientific landscape.

\section{Rhetoric}

As Aristotle put it, rhetoric, is "the faculty of observing in any given case the available means of persuasion" (1355b). Debated as a science, it was defined as being either a faculty or a virtue referred to mainly as art. However, its verbal persuasive function was accepted widely and, with a growing rational suspicion, it was labelled agonistic. In the meanwhile, its reduction, to the techniques of elocution, led to the pejorative use of the term rhetoric. In order to escape the inhibiting limitation of rhetoric to the study of persuasive speech and to lessen the democratic fears, towards its subjectivity and influential nature, modernist and postmodernist copings with rhetoric (see the works of Kenneth Duva Burke; Chäim Perelman; Ivor A. Richards; Henry Johnstone Jr.; and Colling G. Brooke) sought new horizons to interpret rhetoric in a more integrative way. Thereby, rhetoric was legitimized to function as a dimension of communication and its meta-representations.

Rhetoric's scope was widened to provide a framework of all symbolic, societal and mediated functions. Reboul (1991) pointed to the broadening of modern rhetoric by emphasizing its expansion from the verbal to the visual; and from the conscious to the nonconscious. In designating new directions for rhetoric in everyday life, Nystrand and Duffy (2003: ix), assumed that rhetoric ought not to refer to "the classical arts of persuasion, or the verbal ornamentation of elite discourse, but rather to the ways that individuals and groups use 
language to constitute their social realities (...). The discourses, of institutions and popular culture, are rhetorical in the sense that they situate us in our worlds: they shape our ideas about the 'way things are' who we are; where we belong; and guide what we talk about and what we say (and don't say).” Worldwide discussions, of rhetoric, (Burke, 1950, Grassi, 1980, Corder, 1985, Hauser 1999, Johnstone, 2007, Skarič, 2007, Mifsud, 2007, Aczél, 2012) rediscovered those capacities, of rhetoric, which proved that the classical discipline had more to offer than a set of persuasive techniques; a pack of discursive tricks; and disciplined genres of mono-logic discourse.

\section{Rhetoric and New Media}

From the turn of the 21 st century, rhetorical theory has been challenged strongly by the complex system and phenomena of new media. A communicative culture is being formulated whose currency is information and which is characterized by permanent connection, publicity, and participation. Information and information technologies have created - as theorists claim - the attention economy (Goldhaber, 1997, Davenport-Beck, 2001) in which "the wealth of information means a dearth of something else: a scarcity of whatever is that information consumes" (Simon 1971: 40). It is the human attention which communication and information strive to grasp and compete for. This attention economy operates through "cognitive capitalism" (Crogan and Kinsley, 2012: 3) and is the natural economy of mediaspace (Goldhaber, 1997). Although the attention economy paradigm is being debated with perspectives over a new vision of the location economy, whereby one's location is the scarce resource on which new media applications are built, it determines our everyday discursive practices when we produce, create, and consume ('cresume' or 'presume').

When consuming texts, we screen, scan, and browse and try to be energy-conscious with our attention (Johnson, 2012). Messages are produced to become noticed. Therefore, they 
endeavour to eliminate this consciousness and to catch and gain attention. The norms, of message formation, were changed in accordance with the challenges of the attention economy. Writing little, using micro-style, breaking the rules, and evoking conversation are those principles which seem to rule our communicative culture. Participating in new media spaces needs new competencies and literacies (Hoechsmann-Poyntz, 2012) in order to be conscious, creative, and communicative concerning convergent media usage.

Originally, European rhetoric was worked out for the discursive practices of the public spaces of the polis where people met, shared ideas, and influenced each other strategically in the traditional one-to-many relationships. The textual ideal of rhetoric used to be the 'finished and polished' speech, the formal act of discourse with which someone persuaded many others by means of structure, common places, figures of speech, and argumentation. Formal oratory was a conservative force preserving the moral and political values, of the past; its function was to preserve things as they were. Traditional rhetoric prepared the speaker for winning with words: winning the receiver's soul and will. Offering the canon, rhetoric enabled the speaker to invent topics, arrange them hierarchically into structural units, to express them in language, and remember texts and perform speeches. The rhetorical model, of this tradition, is that of the well-educated man who is trained to express, in one speech, the common wisdom of his society. Consequently, rhetoric is to be about the excellence of the speaker, and about the formality of the situation and the speech. However, new media widened and replaced real public spaces and fluidized texts. The operation and usage, of new media, blurs the border between the roles of the speaker and audience; remediates discourse (visual and verbal) constantly and accustoms users to the infiniteness of messages. New media should be considered to be the complex of new textual experiences; new ways of representation, new impressions and experiences of embodiment, new relations between user and technology, new ways of expression (verbal, visual, multimedia), new patterns of organizations, production 
and control, and new realizations of identity and social relations (Lister, 2003, Fuery, 2009,

Miller 2011). 'New media' is a convergent notion of convergent and digital media

technologies consisting of the computer, the internet, the mobile phone, social media, digital television, and so on. In media-lingo, new media's most frequently used characteristics are digital, interactive, hyper-textual, and virtual. Digital as it is, rhetoric, of the new media's discursive practice, was called, also, digital rhetoric.

Kathleen Welch argued (1999: 104) that electric rhetoric is "an emergent consciousness or mentalité within discourse communities, is the new merger of the written and the oral, both now newly empowered and reconstructed by electricity and both dependent on print literacy. Electronic technologies have led to electronic consciousness, an awareness or mentalité that now changes literacy but in no way diminishes it." Screen generations, with that consciousness, form new codes of interactions and interfaces mark new common ways of getting into contact. A new (virtual) subjectivity and inter-subjectivity ${ }^{67}$ emerges. Rhetoric is gaining new characteristics which feature mediated text production and non-linear consumption.

Firstly, there is no clear border between the speaker and the audience; the continuous exchanging of roles enables the person to be both speaker and listener, to be both writer and reader; and, in the same rhetorical situation, to be, concurrently, both communicator and receiver. In the public domain, texts are not objects; by representing, talking, and constituting relationships, they are themselves, public. This means not only that the speaker is acting constantly as an audience but, also, that the result, of that simultaneous, multi-identical communication, is the interaction within and with texts. Interactivity penetrated the rhetorical

\footnotetext{
67 "Computer screen and television screen coexist as centers of familial activity. In this kind of private space, the household member can delve into the computer screen by visiting websites, by associatively surfing locations , by shopping, by entering a synchronous chat room or MUD (a multi-user domain, in which the digitally literate person can assume various personae), by reading and/or posting to an asynchronous list serve (or by reading only, a move that has been named "lurking"), and by many other activities with CD-ROMs. Many people have reported the experience in their digital households and HUTs (or their offices or cyberhall cafes) of subjectively going elsewhere on the computer, of interacting subjectively with the machine in a way that increases and/or complicates human interaction with technology." (Welch, 1999: 156)
} 
situation, the role of the sender and the text which is open to modification, being un-finished, fluid, and trans-medial. New media discourse suggests informality, a characteristic which is unfamiliar with traditional rhetorical practices. As Judith T. Irvine (1979: 776-779) suggested, formality is due to increased code structuring, the consistency of choices, and the invocation, of the positional, rather than the personal identities and the emergence of a central situational focus. Formal speech and communication imposes special rules of style and delivery on the speaker and deals with important activities and central figures in them (Kennedy, 1997). However, the interactivity and permanence, of new media communication, stir up the situational borders of formality, lessen the importance of rules and positions, and boost the significance of personal identities and side involvements.

New media's basic characteristics changed, also, the way ethos, pathos and logos could operate. As Gurak (2009) claimed, speed - combined with reach - was a predominant feature which had a dramatic impact on the content and practice of communication. A significant shift, from invention to delivery (distribution), can be detected in digital practice. Speed enhances the need to distribute on the speaker's side and the desire to find on the consumer's side. The register has become blended, and communication is more repetitive and redundant. Now, the intention, to persuade specific audiences, is less important than the ability to reach many audiences. In connection with the changes, the traditional one-to-many configuration was modified into many-to-many relationships to enable users to have a democratic reach. Multiple identities, formed by the possibilities and spaces of the digital environment, de/reformed the digital speaker's ethos. Anonymity evokes not only tendencies like masking, flaming, and contingency but, also, altruism in communication. The logic (and arrangement), of texts, is different, also, from that of the traditional canon and of the culture of print. In hypermedia, the cause-effect logic was replaced by an associational one. In parallel, processing substitutes were serial processing, linear-indexical thinking, and changes to 
network-associational. In electrical rhetoric, the process replaces the product,,consequently, the speaker creates an information environment in which the user chooses the line or path.

Digital rhetoric testifies that, with the advent of new media, new modes of rhetorical operations have to be implemented. Nevertheless, it draws attention mainly to the changes with which rhetoric has to cope and does not focus on the very rhetorical nature of new media. With the rediscovery of the spatial, visual, procedural and aural nature of rhetoric, an original connection can be detected between rhetoric and new media and, therefore, the 'challenges of bytes and likes' are answered. Although they provide rhetoric with a (new) media perspective, the spatial, visual, procedural and aural dimensions, of the rhetorical discipline, have been shadowed for a long time. The following sections cast light on these domains in order to introduce an integrative redefinition of rhetoric.

\section{Visual Rhetoric}

Until the 1970's, rhetoric was conceived almost solely as the study of verbal discourse. The spirited inquiry, into the rhetorical study of images, started with scholars such as Kenneth Burke (1950) or Douglas Ehninger (1972) whose definitions, of rhetoric, did not privilege verbal symbols and which were sufficiently broad to include the visual. They considered rhetoric to be the use and study of symbols and addressed symbolically not as exclusively verbal. Through these approaches, a deeper understanding, of the influences and operations of the rhetorical object (product), could be developed. Had the natural affinity, between the visual image and rhetoric, not been discovered, the process of the expansion of rhetoric to encompass the visual, could have been disrupted easily and stopped by the "vociferous objections" (Foss, 2005: 142) of language-centred interpretations. Current definitions of the discipline tend to support the development of visual rhetoric; this suggests an easier fit between the visual and the rhetorical. 
Visual rhetoric, as a subdomain of the classical discipline, endeavoured to purport rhetorical literacy, for the visual, and to provide a framework to interpret and produce visual artefacts rhetorically. In rhetoric, the visual perspective indicated, also, the emerging recognition of the significance of images in human understanding, discursive practices, and media communication. On defining visual rhetoric, scholars distinguished between at least two meanings. One conceptualized visual rhetoric as a communicative artefact, a product, made of images and visual symbols (analogously to a speech), whilst the other understood it to be an analytical tool with which the creation and performing of communication, by visual symbols, could be examined (Foss, 2004). Although this dualistic view of visual rhetoric reflects rhetoric as a practice and rhetoric as a theory, it is not sensitive enough to the possible tripartite division of rhetoric. This assumes that rhetoric is either a product (a multimodal 'speech'), a procedure (mechanism), or a process (communication). Following the latter division, we conceive visual rhetoric either as a product to address public, a persuasive, visual representation, or a procedure, logic to experience and to see and form pictures, images, or a process with which we interpret the world around us (Ott-Dickinson, 2009).

As a product, visual rhetoric is the counterpart of verbal rhetoric, namely, the rhetoric of persuasive speeches. To put it simply, we replace the verbal with the visual and apply the strategies of rhetoric to produce and analyse persuasive, influential messages. Commercials, campaign spots, and billboard pictures are the kind of visual, or visual-verbal messages which address the public and are structured rhetorically in order to achieve the planned reaction. However, this functional refiguring of the classical discipline and its adaptation to the visual domain, is not without obstacles. Traditionally, rhetoric, used for verbal interactions, feels non-socialized within the field of images when it comes to the analysis of their persuasive power. Forcing the terminology once worked out for speech to function satisfactorily with the visual, scholars have to face the organic difference between the constitutive nature of words 
and pictures. Nevertheless, in the context of vigorous debates about visual argument and persuasion this functional view preserved its legitimacy to regard pictures and moving images as rhetorical products.

In the second view, visual rhetoric is a process and it facilitates the perspective of those 'non-traditional' theorists ${ }^{68}$ of rhetoric who state that there is a shift from rhetoric as product (and composition) to rhetoric as a process, and call it the rhetoric of everyday life. By this they primarily mean the "rhetorical character and dynamics of language in mundane contexts" (Nystrand-Duffy, 2003: viii); the realization, of which leads to the identification of the rhetorical character of literacy development, which shapes the location and meaning of everyday life. Albeit in terms of language, this view differentiates rhetoric as a process clearly from rhetoric as a product. However, we integrate images into this paradigm by stating that, as a process, visual rhetoric means the rhetorical character and dynamics of images in the contexts of everyday life. As a process, visual rhetoric is a vision of culture, a constitutive interaction between culture and subjectivity, and a continuous enactment of their multiple relationships. Here, visualizing is considered to be the grounding for reality, a container of memory, a dimension of everyday existence by which we refract continuously and rhetorically our understanding of the world and ourselves within it. In this sense, visualizing does not represent, but creates experience by relating, through images, the person to the concrete situation. It is more a constitutive part of subjectivity, identity, and culture than an effect of the eye. It is contextual, spatial, and material (Ott-Dickinson, 2009: 396398). Flickr and YouTube photos, shared on Facebook, are characteristic examples, of this visualizing, and of the visual rhetoric as the process of everyday life. As a process, visual rhetoric provides a perspective of media communication, which reflects both image-reading

\footnotetext{
${ }^{68}$ Non-traditional rhetoricians focus on those rhetorical practices which are not mainstream in the sense of social power and its rhetorical character. They are researchers investigating those capacities of rhetoric which have long been forgotten or re-declared as belonging to other faculties of discourse studies; please see, for example, Carolyn R. Miller's or John Ackerman's writings on genre or space.
} 
and reshaping, and which develops complex visual competencies within the constituted social world.

The approach of visual rhetoric as a procedure suggests that images are underlying forms of our thinking and that the pictures are created as a visual mode comprising visual logic and intelligence. As a procedure, visual rhetoric is about the logic of seeing and about visual thinking as a procedure of rhetorical practices. In this view, procedure is conceived as the logic of constitution and deconstruction. Visual logic is based on studies of perception and cognition to which Rudolf Arnheim's seminal contribution (1969) was determinative. Cognitive scientists agreed that seeing was creative; it was selective; spatial; and contextual. Creative means that seeing is a subjective way of reconstruction affected by personal beliefs and cultural contexts. Seeing is more of a production governed by aesthetic factors of images (e.g. light; form; texture) than consumption. Seeing is selective because of the zooming application of our glances; gazes; and looks. Therefore, we select image-parts and filter out others depending on inner needs and outer factors. Whilst linguistic signs are temporal, visual signs are arranged spatially; this allows the viewer to perceive several images simultaneously in a single place. Then, seeing is spatial and visual logic occupies space. Finally, seeing is contextual since it is connected to the cultural, historical context of observation entailing values and ideologies of the concrete situation. We add that seeing is, also, figurative since it is the resource and the reinforcement of conceptual metaphors and the regulator of the rhetorical figures and their envisioning. As a procedure, visual rhetoric provides rhetoric with the literacy of seeing and concurrent cognition: this is what the production or presumption of media-messages calls for. 


\section{Spatial Rhetoric}

In the shadows of the visual or iconic turn, a spatial turn occurs, also. This turn marks the fruitful weaving together of the concept of space, place, location, and milieu. Spaces, as produced interactively, places as lived inter-relatedly, and newly opened cultural spaces and places, are amongst those key ideas which determine scientific thinking about space practices and representations of space. These are the ones which reveal the communicative and rhetorical horizon of space and place.

Nevertheless, in rhetorical discussions, space emerges still as a partly enigmatic and often vague notion with malleable definitions. Although spatial rhetoric is an accepted term to name compositional practices which represent place-experiences, by using two basic presumptions, the present apprehension, of spatial rhetoric, introduces a broader interpretation. The first is that rhetoric is the creator of cultural space; the second is that rhetorical speeches are built on visual and spatial imagery. Following the idea of third space (Bhabha, 1994, Soja, 2009), namely, a place where culture is displaced from the interactions and, therefore, a hybrid, common identity is created to enter a dialogue and share place and space, the researcher proposes that rhetorical communication opens a psycho-geographical location for the interactions and offers a discursive place in the context of a spatial experience. Rhetoric forms the "constantly shifting and changing milieu of ideas, events, appearances, and meanings" (Soja, 1996: 2); a third space is a reflective space from which the actual and practical cultural place can be seen.

If we revisit its disciplinary history, rhetoric's spatial capacity is unquestionable. The main aim of the establishment of rhetoric was to form the building elements and rules which inhabit and govern an autonomous discursive sphere apart from - or authentically connected to reality. In oral communication rhetoric was also a container (Esposito, 2002) where traces of past experiences were stored and exposed on certain occasions. As the architect of culture, 
rhetoric provided communities and societies with spaces of discourse; this could not be done without spatial logic and intelligence in message construction.

Spatial intelligence, one of Howard Gardner's multiple intelligences (1993), concerns the ability of thinking in three dimensions: having mental imagery, graphic skills, and the capacity to reason spatially and imagine actively. From this, it is obvious that spatial intelligence is related closely to visual intelligence and visual, hyper-textual new media. However, the intelligence for space also includes abilities for less concrete impressions including skills for the abstract, for the schematic, and for the mapped. Although visualizing governs spatial practices, in order to be understood and answered, space has its specific requirements. Conceiving and analysing an argument is less a visual than a spatial experience even if exploited in pictures or images, as Venn-diagrams with the overlapping circles may prove. Spatial capacities add dimensions to the visual and develop structural hierarchy, reasoning, and hyper-textual consumption skills.

Ancient speakers used their spatial intelligence effectively in remembering their speeches. They were architects of their ideas, imagining them either in buildings or in streets, and they were landlords of that building to which the audience was invited to visit. The imaginative is memorable; in classical rhetoric, the art of memory highlights the way rhetoric performers recoded their speeches in pictures, in spaces, and in mental sites from where words and ideas could be recalled. With the urge to remember, they worked out the text's spatial experience, enriched by visual impressions. Hence, the rhetorical text was recomposed visually and spatially to convey, in a persuasive way, meanings, symbols, and ideas. The discursive sphere was created by a visual-spatial thinking about and of words and relationships. Therefore, the researcher claims that rhetorical "texts" are messages which have visual and spatial characteristics and they recreate images and spaces. Spatial rhetoric enriches media production and analysis with the awareness of space and the figures and practices of place- 
forming. In media, rhetorical penetration helps the realization of new media texts and messages as objects and events in the real and intellectual space and supports the development of spatially sensitive (multi)media literacy. Hyperlinked texts exploit spatial logic and operate with visual force - namely, what spatial rhetoric can contribute relevantly to in description and interpretation.

\section{Procedural Rhetoric}

In his work on persuasive (digital) games, Ian Bogost introduced a new term of rhetoric suggesting:

the name of procedural rhetoric for the new type of persuasive and expressive practice at work (...). Procedurality refers to a way of creating, explaining, or understanding processes. And processes define the way things work: the methods, techniques, and logics that drive the operation of systems, from mechanical systems like engines to organizational systems like high schools to conceptual systems like religious faith. (...) Procedural rhetoric, then, is a practice of using processes persuasively. More specifically, procedural rhetoric is the practice of persuading through processes in general and computational processes in particular. (...) Procedural rhetoric is a technique for making arguments with computational systems and for unpacking computational arguments others have created. (2010: 2-3)

Procedural rhetoric is built on procedural logic which has its roots in both graphical (depiction of movement, lighting, rhythm of change, collision, etc.) and textual (selection, combination, sequencing) operations. It is fed, also, by operational models and their common patterns of media usage and interaction (menu; toolbar). Hence, procedural rhetoric uses figures of operational, textual and graphic thinking in order to form ideas and draw conclusions out of processes. However, as Bogost emphasized, procedural representations 
differ from textual, visual and plastic representations. They depict how codes regulate through hardware and software systems.

Although these representations may lead us further from the complex communicative and rhetorical phenomena of new media, procedural rhetoric may reveal how media message programming and program coding is inherently rhetorical. Procedural rhetoric is an invigorating dimension of the classical discipline, in the sense that it connects interface strategies with systemic ones and highlights the argumentative capacity of rules and regulations. La Molleindustria's online games exemplify argumentative procedural rhetoric in a spectacular way. As it is announced on the homepage: "Our objective is to investigate the persuasive potentials of the medium by subverting mainstream video gaming clichè (and possibly have fun in the process)." ${ }^{99}$. Games, such as the Phone story, lead the player to the "dark side" of consumers' society, for example, the smart phones, forcing them to realize the consequences of only drawing on the process' rules and regulations. Consequently, procedural rhetoric helps to reveal the meaning of system operations and their cultural patterns. Then, in using toolbars and software and logic, there is the switching on and off rhetoric. Therefore, media rhetoric is supported by a capacity with which systemic, operational and graphical coding can be unveiled and elaborated.

Procedural rhetoric can function as the literacy of system-operations and argumentations, which expands visual literacy. More of a rediscovery than an innovation, it identifies predominant characteristics of new media technologies and, consequently, is to be taken into consideration in understanding, interpreting, and producing new media messages.

\footnotetext{
${ }^{69}$ www.molleindustria.org
} 


\section{Aural Rhetoric}

Whilst the branch of visual rhetoric was struggling with the 2500-years-long disciplinary determination and domination of the verbal, aural rhetoric was strangled into almost total silence and scholarly neglect. Aural discussions are omitted practically from contemporary rhetorical theory; rhetoric's aural dimension seems to be forgotten or unheard.

Nevertheless, sonority, as a symbolic activity, used to be an inherent part of the rhetorical speech. In the classical rhetorical tradition, voicing was discussed with the last rhetorical canon of speech (delivery). However, in the first place, there were some treatises which dealt with it and suggested that the aural was prior to the textual, determining structural;and aesthetic verbal features. In rhetorical performance, the oral/aural mingled with the visual: the speaker's appearance, body postures, and gestures. Aristotle (1403b) said that delivery was "a matter of the right management of the voice to express the various emotions-of speaking loudly, softly, or between the two; of high, low, or intermediate pitch; of the various rhythms that suit various subjects. These are the three things - volume of sound, modulation of pitch, and rhythm-that a speaker bears in mind." The rhetorical speech used to be considered as the orchestration of a text serving semantic and pragmatic aims, supporting the speaker's credibility. Even in later centuries, "accento rhetorico" was considered to be the highest virtue of the performer, placed above the "accento grammatico" which had no sensitivity to the totality of the rhetorical communication.

Although sound was considered to be of great importance, aural rhetoric has remained a less discussed aspect of understanding; interpreting and producing (new) media messages. Scott Halbritter (2004: 225) assumed that it was overlooked by media theorists for the following reasons: "1. our visually oriented terminology has screened out terminology for realizing the aural, 2. the information aural tools support appears, when successfully composed, to be subordinate to the visual information with which it is contextualized. 3 . We 
have not traditionally established, nor recognized legitimate aurally rhetorical ends for the conventional forms of academic compositions."

Neglected as it is, aural rhetoric does not cease to offer an enriched view of new media argumentation and persuasion. It highlights the aural dimension of a media-message as a rhetorical activity. Whilst audio branding (sonic branding; acoustic branding) has gained considerable significance in the field of marketing communication - recognizing and revealing the role of sound, melody, and noise in making the message persuasive and memorable - the need for aural literacy; 'auralacy' is only now awakening. Whilst, within new media, for a long time, the internet was considered to be silent or mute, we are also moving in the context of soundscapes. It is aural rhetoric which can provide consumers with literacy and competence to understand, interpret, and represent meaningful sound-constructs. Hence, aural rhetoric can be apprehended in three ways:

- As the strategic formation of sounding structures in the multi-media message. Here, we consider aural rhetoric as a product, the functions, of which, can be categorized as aural genres.

- As a critical tool to interpret how the aural is related to the visual and verbal. How it constitutes the context of drawing conclusions and what meanings it generates. It is the phenomenological apprehension, of aural rhetoric, to focus on the reality it creates and the signifying processes by which it operates.

- As an interpretive method to report on what are our culturally patterned soundscapes and how they are imposed on us by media (image) events.

Aural rhetoric, conceptualized as either a formation or a method, is best considered the special capacity of new media rhetoric, or integrates with the complex visual literacy which media requires. It 'vocalizes' procedural new media spaces in which sounds contextualize 
images and images imbricate aural experience, offering sound arguments to both rhetorical and new media theory.

Epilogue in Lieu of Conclusions

This theoretical essay pursued the unveiling of those perspectives of rhetoric which its most common definitions suppressed for a long time. It sought, also, new dimensions of new media understanding through the consideration of visual, spatial, procedural and aural rhetorics. Notwithstanding its age, the ancient faculty is invigorated and capable of being applied to new media events. This approach, comprising visual, spatial, procedural and aural subdomains beside the verbal, strove to prove that rhetoric was more complex than thought of generally. By these dimensions, rhetoric can be seen no longer as alienated from discursive practices of digital and interactive new media. On the contrary, a natural resonance is manifest. Therefore, rhetoric answers the challenge of bytes and likes with its readiness to be redefined as the condition of multi-media existence and as the theory and practice of new media discourse.

Although much remains to be considered, elaborating on the rhetoric of images, spaces, procedures and sounds deepens our general and specific understanding of both the classical discipline and new media phenomena.

\section{References}

Aczél, P. "Mediarhetoric: Complex Visual Literacy.” Edited by A. Benedek and K. Nyíri. The Iconic Turn in Education, 67-84. (series, Visual Learning, vol. 2.). Frankfurt: Peter Lang, 2012. 
Aristotle. On Rhetoric: A Theory of Civic Discourse. Translated by G. A. Kennedy. New York, NY: Oxford University Press, 1991.

Arnheim, R. Visual Thinking, London: University of California Press, 1969.

Bender, J. and D. E. Wellbery. "Rhetoricality: On the Modernist Return of Rhetoric." Edited by J. Bender and D. E. Wellbery. The Ends of Rhetoric. History, Theory, Practice. Stanford, C.A.: Stanford University Press, 1990.

Bhabha, H. K. The Location of Culture, London: Routledge, 1994.

Bogost, I. Persuasive Games. The Expressive Power of Videogames. Cambridge, MA: MIT Press, 2010.

Burke, K. D. A Rhetoric of Motives. Los Angeles: University of California Press, 1950.

Corder, J. “Argument as Emergence, Rhetoric as Love.” Rhetoric Review. 4, no. 16 (1985): 32. Crogan, P. and S. Kinsley. "Paying Attention: Towards a Critique of the Attention Economy." Culture Machine, vol. 13, 2012. Accessed October 10, 2012. http://www.culturemachine.net/index.php/cm/article/viewDownloadInterstitial/463/500

Davenport, T.H. and J. C. Beck. The Attention Economy. Understanding the New Currency of Business. Boston MA: Harvard Business School Press, 2001.

Ehninger, D. Contemporary Rhetoric: A Reader's Coursebook. Glenview, IL: Scott, Foresman and Co, 1972.

Esposito, E. Soziales Vergessen. Formen und Medien des Gedächtnisses der Gesellschaft. Translated by Alessandra Corti. Frankfurt am Main: Suhrkamp, 2002.

Foss, S.K. "Framing the Study of Visual Rhetoric: Toward a Transformation of Rhetorical Theory." Edited by Ch. A. Hill and M. Helmers. Defining Visual Rhetorics, 303-315. Mahwah, NJ: Lawrence Erlbaum Associates, 2004. 
Foss, S. K. “Theory of Visual Rhetoric.” Edited by K. Smith, S. Moriarty, G. Barbasits, and K. Kenney. Handbook of Visual Communication: Theory, Methods and Media, 141-153. Mahwah, NJ: Lawrence Erlbaum Associates, 2005.

Fuery, K. New Media. Culture and Image. Houndmills: Palgrave Macmillan, 2009.

Gardner, H. Multiple Intelligences: The Theory in Practice, New York: Basic Books, 1993.

Goldhaber, M. "The Attention Economy and the Net." First Monday, 2, no. 4 (1997). Accessed October 9, 2012. http://firstmonday.org/article/view/519/440

Grassi, E. Rhetoric as Philosophy. The Humanist Tradition. Translated by J. M. Krois and A. Azodi. University Park, PA: Pennsylvania State University Press, 1980.

Gurak, L. J. "Digital Rhetoric and Public Discourse." Edited by A. A. Lunsford. The Sage Handbook of Rhetorical Studies, 409-509. Los Angeles: Sage. 2009.

Halbritter, S. K. Sound Arguments: Aural Rhetoric in Multimedia Composition. PhD Diss., University of North Carolina at Chapel Hill, 2004.

Halloran, M. S. “On the End of Rhetoric, Classical and Modern.” Edited by Th. Enos and S. C. Brown. Professing the New Rhetorics, 331-343. Boston MA: Prentice Hall, 1994.

Hauser, G. A. Vernacular voices. The rhetoric of publics and public spheres. Columbia: University of South Carolina Press, 1999.

Hoechsmann, M. and S. Poyntz. Medialiteracies. A Critical Introduction. London: WileyBlackwell, 2012.

Irvine, J. T. "Formality and Informality in Communicative Events." American Anthropologist. 81, no.4 (1979): 773-790.

Johnson, C. Microstyle: The Art of Writing Little. New York: W.W. Norton and Co. Kindle Edition, 2012.

Johnstone, H. W. (2007). “The Philosophical Basis of Rhetoric.” Philosophy and Rhetoric. 40, no. 1 (2007): 15-26. 
Kennedy, G.A. Comparative Rhetoric: An Historical and Cross-Cultural Introduction. USA: Oxford University Press, 1997.

Krones, H. "Rhetorik und Stilistik in der Musikwissenchaft." Edited by U. Fix, A. Gardt and J. Knape. Rhetorik und Stilistik. Ein internationales Handbuch historischer und systematischer Forschung, Band 2., 1936.

Lister, M., Dovey, J., Giddings, S., Grant, I. and K. Kelly. New Media. A Critical Introduction. New York, NY: Routledge, 2003.

Mifsud, M. L. “On rhetoric as Gift/Giving.” Edited by G. A. Hauser. Philosophy and Rhetoric in Dialogue, 89-108. University Park, PA: Pennsylvania State University Press. 2007.

Miller, V. Understanding Digital Culture. London: Sage, 2011.

Newcombe, N. S. and A. Frick. "Early Education for Spatial Intelligence: Why, What and How." Mind, Brain and Education. 4, no. 3 (2010): 102-111.

Nystrand, M. and J. Duffy, J. "Rhetoric, Writing and the Everyday. Some Preliminary Remarks.” Edited by M. Nystrand and J. Duffy. Towards the Rhetoric of Everyday Life. New Directions in Research on Writing, Text and Discourse, 7-13. Madison: The University of Wisconsin Press, 2003.

Ott, B. L. and G. Dickinson. "Visual Rhetoric and/as Critical Pedagogy." Edited by A. A. Lunsford. The Sage Handbook of Rhetorical Studies, 391-405. Thousand Oaks, CA: Sage, 2009.

Reboul, O. Introduction à la rhétorique. Paris: PUF, 1991.

Simon, H. A. "Designing Organizations for an Information-Rich World." Edited by M. Greenberger. Computers, Communication, and the Public Interest, 37-72. Baltimore, MD: The Johns Hopkins University Press. 1971.

Škarić, I. and I. Ivas, eds. Razgovori o retorici. Zagreb: Hrvaško filološko društvo, Filozofski fakultet Sveučilišta u Zagrebu, Odsjek za fonetiku. 2007 
Soja, E. W. Thirdspace: Journeys to Los Angeles and other real-and-imagined places. Malden: Blackwell, 1996.

Soja, E.W. "Third space: Toward a New Consciousness of Space and Spatiality.” Edited by K. Ikas and G. Wagner. Communicating in the Third Space, 49-62. New York: Routledge, 2009.

Urbanski, H. "Introduction: Blurring Rhetorical Borders." Edited by H. Urbanski. Writing and the Digital Generation. Essays on New Media Rhetoric, 57-249. Jefferson, NC: Mc Farland and co. Kindle Edition, 2010.

Welch, K. Electric Rhetoric: Classical Rhetoric, Oralism, and a New Literacy. Cambridge. MA: MIT Press, 1999. 


\section{The Cowboys, the Poets, the Professor... - Antonomasia in Croatian Sports Discourse}

Ana Grgić \& Davor Nikolić, University of Zagreb

Summary

News style (or journalistic style) relies on the frequent use of tropes, especially metaphors and metonymies. Previous research concerning Croatian newspapers (Ivas, 2004; Runjić-Stoilova, 2012) showed that antonomasia is also a very frequent trope both in the headlines and in the body of journal articles. The aim of our research was to further explore types of antonomasia in the sports news sub-style. The corpus consisted of three groups of sports news: (1) sports news articles in daily newspapers; (2) articles in specialized sports newspapers and magazines; (3) the prime-time sports news in the daily news program of the three Croatian national networks (HRT, Nova TV and RTL).

Three conclusions can be drawn from the analysis: (1) sports antonomasias mostly substitute names of athletes, sports clubs and national selections; (2) metonymic-based antonomasias are most frequently used; (3) journalists tend to use antonomasia more frequently in written articles than in television news.

Key words: antonomasia, metaphor, metonymy, rhetoric, sports discourse

\section{Introduction}

There is no spoken or written discourse which is purely literal. Following this maxim, three equally mindful scholars - the rhetorician, the stylistician and the linguist - could look up figures of speech in any discourse. Upon close scrutiny, none of them would fail to find at least one figure of speech even in the simplest form of discourse. But from this point forward their research would go in different directions. The linguist would treat all figures equally (because they are all language products); the stylistician would be interested only in observing the intentionally produced figures (since only striking or "deviant" features of discourse are those which have stylistic "value"); the classical rhetorician, on the other hand, would be interested in analyzing which figures (regardless of their origin) had (or could have) the 
strongest effect on the target audience. All of those researchers could concentrate on one figure only, or they could analyze a whole group of figures.

The authors of this paper are rhetoricians and their research concentrated on one figure (more precisely, a trope) in one type of discourse. The trope is that of antonomasia which was tested on the "battlefield" of sports discourse. Aware of the specific problems of their "favorite", the authors tried to avail themselves of linguistics (especially onomastics and cognitive linguistics), stylistics as well as cultural theory.

\subsection{Between metaphor and metonymy}

Antonomasia is a trope which has two functions. The first one is a substitution of a proper name by an appellative, epithet or periphrasis (e.g. the Philosopher for Aristotle, Our Beautiful for Croatia or the Queen of Pop for Madonna). This type is called classical or proper antonomasia because it was defined in this sense in the classical handbooks of rhetoric (see Anderson, 2000; Quintilian, 1959). The second function is a substitution of a certain trait by a proper name which has become synonymous with a specific trait (Schumacher for "a fast driver", Penelope for "a faithful wife" or Mozart for "an exceptional one, a virtuoso"). This type is called Vossian antonomasia, after Gerardus Johannis Vossius, $17^{\text {th }}$ century Dutch rhetorician who first described the second function (Lausberg, 1990). ${ }^{70}$

Defined in the broader sense, antonomasia can be regarded as a trope that relies on the processes of appellativization and deappellativization, both common in everyday language (Van Langendonck, 2007). In the classical type of antonomasia, appellative words are treated as proper ones: they are usually written in capital letters and they are never used alongside the name which they substitute. In stark contrast to this, Vossian antonomasia treats proper names as if they were common nouns. This is the reason why sometimes the figurative use of a

\footnotetext{
${ }^{70}$ For those interested in more detailed discussion on different definitions of antonomasia and the distinction between two types, look in Grgić and Nikolić, 2011a, 2011 b.
} 
proper name becomes necessary in naming a certain object or process (e.g. the word "boycott" originates from the English Captain Charles Boycott, who was socially ostracized by his local community in Ireland; the word "pasteurization" is derived from the inventor of this chemical process, Louis Pasteur; the flower "dahlia" can be traced to the Swedish botanist Anders Dahl etc.). In all of these cases antonomasias transformed to catachreses which are classified as eponyms in linguistics.

There has been a strong tradition of reducing tropes to only four major ones metaphor, metonymy, synecdoche and irony (Burke, 1969). In this tradition antonomasia is seen as a part of metonymy or synecdoche (see Lausberg, 1990; Monson, 2003). ${ }^{71}$ The structuralist view on tropes is often simplified through Jakobson's discussion about metaphoric/paradigmatic and metonymic/syntagmatic relations (Nerlich, 2005), but the similar dichotomic principle can be traced through the works of cognitive linguists (who are often deemed opposed to linguistic structuralism). If they ever discuss antonomasia as an independent linguistic entity, they are mostly concerned with the classical form which can easily be interpreted as metonymy. The Vossian type is rejected as a special form of antonomasia and it is simply described as a metaphor (Brdar and Brdar-Szabó, 2001). Other authors close to the cognitive linguistic view describe the classical type as metonymic as opposed to the metaphoric Vossian type (Holmqvist \& Pluciennik, 2010).

Although this strict binary classification seems valid, there are many examples of antonomasia which can be described as a combination of metaphor and metonymy (e.g. the Swiss Wizard for Roger Federer, the Giant from Šalata for Ivo Karlović, the basketball Mozart for Dražen Petrović, the Croatian Ibiza for the Zrće beach on the island of Pag etc.). All of these examples are phrases, consisting of two parts: head and dependent. Head is in most cases a common or proper noun (e.g. wizard, giant, Mozart, Ibiza) and dependent is

\footnotetext{
${ }^{71}$ This view could be accepted if we disregard the existence of the second, Vossian type of antonomasia. Since the followers of this approach defined antonomasia only in its classical form, they could easily classify it simply either as metonymy or synecdoche.
} 
usually an adjective (e.g. Swiss, basketball, Croatian) or a prepositional phrase containing a noun (e.g. from $\check{S}$ alata). The head part is always some type of trope (usually a metaphor) which all by itself already constitutes antonomasia, but in order to be properly and unambiguously understood it requires a non-figurative dependent part. For example, naming Ivica Kostelić King or his sister Janica Queen could be easily confused with the same figurative substitution for Usain Bolt or Madonna, respectively. Therefore, if we want antonomasia to be specific and unambiguous, we must add some kind of dependent which will have a strict literal meaning such as snow, of athletics or of pop.

It is important to note that this combination is not some third possible type of antonomasia. All of these examples are classical antonomasias (they substitute proper names), but the head part of the phrase is not metonymic and this feature distinguishes them from typical examples of the classical type. Furthermore, this combined type often contains proper names which are again sometimes used metonymically and sometimes metaphorically. Examples like the Swiss Wizzard or the Giant from Šalata contain proper names in the dependent part which impart the metonymic "truth" to their metaphoric head parts.

Conversely, when the head part contains a proper name (the basketball Mozart, the Croatian Ibiza), things get even more complex because the head part already constitutes Vossian antonomasia. ${ }^{72}$ As it is the case with all other "simple" Vossian antonomasias, the proper name is reduced to one specific meaning while other connotations or alternate meanings are disregarded. An identical process occurs when common nouns are used metaphorically (Marković, 2010), so this could be taken as an additional argument for denying the recogniton of antonomasia. However, this argument only shows that the processes behind the creation of Vossian antonomasia are basically metaphoric. Antonomasia, nevertheless, must be treated as a separate trope because it always involves a proper name

\footnotetext{
${ }^{72}$ This subtype could be described as Vossian antonomasia inside the classical one. News style frequently uses this kind of antonomasia because the Vossian element has strong connotations for a specific audience (e. g. the Switzerland of Latin America for Uruguay or the Venice of the North for several European cities).
} 
which is always treated as a specific linguistic feature (Marković, 2010; Van Langendonck, 2007).

\subsection{Sports discourse and antonomasia}

In order to understand the use of antonomasia in sports discourse, it is necessary to point out its figurative characteristics. Sports discourse can be defined as the subtype of news (or journalistic) style. This general style frequently uses tropes (especially metaphor and metonymy), and the sports news sub-style sometimes seems to be nothing but tropical. One of the reasons for using figures and tropes in the type of discourse whose primary function is informing may be found in the need to have an emotional impact on the recipient (RunjićStoilova, 2012).

Antonomasia is used in sports discourse mostly in its first function - it substitutes the names of athletes, clubs, national teams, as well as coaches, sports arenas etc. The relatively frequent use of antonomasia in sports discourse can certainly be ascribed to the specific "problem" of sports news: the same names are very often repeated in the same text. To avoid monotony, journalists substitute them with contextual periphrases such as the Club from Split, Wenger's players, the world's best player or they rely on the established antonomasia or "nickname", as it is usually called in everyday language. On the other hand, there is some kind of general agreement that the high frequency of stereotypical expressions (so called "journalisms") is a negative characteristic of news style. Some authors, nevertheless, find it very functional because this automated use of expressions helps the recipients in better understanding the message (Runjić-Stoilova, 2012).

In the previous section we tried to establish the connection between antonomasia and both metonymy and metaphor (not strictly through the classical/Vossian antonomasia dichotomy) and in further analysis we will observe the sports antonomasias through the 
concepts of source and target domain. This methodology was adopted from cognitive linguistics, which approaches metaphor and metonymy in a different manner than classical rhetoric and stylistics. Cognitive linguistics treats metaphor and metonymy not as figures of speech (ornaments in language) but as cognitive models by which people make concepts of the world ${ }^{73}$.

Cognitive linguistics makes a distinction between a specific metaphorical expression in language (e.g. the modern gladiators for athletes) and the metaphorical concept in our mind (SPORT IS FIGHT). General mental concepts thus derive specific linguistic metaphors and through these concepts we can better understand certain discourse or even culture (Kövecses, 2005). As we can see, metaphors in sports discourse are mainly derived from the general concept SPORT IS WAR/BATTLE/FIGHT, and, consequently, we have examples like: They left their hearts in the arena or The Croatian cavalry swept the French musketeers.

Metonymies are also an important part of sports discourse and they are mostly derived from the following concepts: THE PART FOR THE WHOLE ( a fresh pair of legs), THE WHOLE FOR THE PART (Croatia scored just before half-time), and OBJECT USED FOR USER (The world's best racquet).

Traditional rhetoric defines metaphor as a trope which makes a substitution of one expression by another on the ground of similarity (using the analogies), whereas metonymies make substitutions by association (using causal relationships, spatial or temporal relations, part-whole relations ${ }^{74}$ etc.). In short, metonymy is a trope that relies on the contiguity, while metaphor relies on similarity. Cognitive linguistics adopted this generalized difference but tried to connect metonymy with the concept of "reference point" where one conceptual entity

\footnotetext{
${ }^{73}$ This concept was introduced in the well-known book Metaphors We Live By (Lakoff and Johnson, 1980). For further information on cognitive linguistic research concerning metaphor and metonymy see Kövecses, 2002.

${ }^{74}$ Although classical rhetoric connects part-whole relations with synecdoche, we decided to stay in concordance with the cognitive linguistic approach to metonymy.
} 
provides mental access to another conceptual entity (Krišković and Tominac, 2009; Radden and Kövecses, 1999).

When analyzing conceptual metaphors and metonymies it is important to distinguish the source domain (physical entity), from which the cognitive processes transfer the similarity/contiguity relations, and the target domain (abstract entity) to which these concepts are applied. In the concept SPORT IS FIGHT the targets like athletes or clubs (the conceptual target is SPORT) obtain their metaphorical expressions from the source domain concerning fights, especially using words with a historical meaning (gladiators, musketeers, cavalry etc.). A similar method is used for analyzing metonymies. For example, the target "substitute" uses the source/vehicle "reserve bench" because they are connected by the concept CONTAINER FOR THE CONTENT, and as a result we get the expression: A good coach is judged by the good bench.

Classical antonomasias created inside sports discourse are not strictly metonymic in their origin. Although the context establishes them as an unambiguous substitute for a particular proper name, the word or phrase used in substitution are often created through the same concepts as metaphors. ${ }^{75}$ Metaphoric antonomasias use the general concept SPORT IS WAR/BATTLE/FIGHT to derive particular substitutions for athletes, clubs or national teams. The sources, therefore, must belong to the physical reality which corresponds to the general concept of conflict. When we approach antonomasia in this manner then there is no surprise that most "nicknames" belong either to predators (the Eagles, the Barracudas, the Wolves), armed conflict "professions" (the Musketeers, the Cowboys, the Gunners) or entities connected with aggression and destruction (the Fiery Ones, the Red Devils, La Furia).

A similar classification can be done for metonymic antonomasias but the general concept which is used in their creation can be described as a modified THE PART FOR WHOLE

\footnotetext{
${ }^{75}$ It is obvious that the uncritical transfer of the metonymy/metaphor relation to the classical/Vossian antonomasia dichotomy can be more than just misleading. The origin of classical antonomasia can be found in both metonymic and metaphoric conceptualization.
} 
concept. As it will be shown in the research results, there are some typical source/vehicle domains which are used in the creation of metonymic sports antonomasias. The most important ones are the kit color, the name of the club, the sports emblem or the sponsor. It must be emphasized that these relations are easily understood by sports discourse participants in the know (authors and readers/spectators/listeners), but for the "outsiders" these relations are not so obvious and that is the reason why sometimes they can not recognize particular antonomasia.

\section{Aims of research and methods}

In order to better understand the role of antonomasia in sports discourse we conducted research through which we gathered instances of antonomasia from both written and spoken sports discourse. By analyzing the collected examples we tried to answer the three questions: 1. What is the main target domain of sports antonomasias? 2. Are classical sports antonomasias more metonymic or metaphoric in origin? 3. Is there a difference between the use of antonomasias in written and in spoken (televised) discourse?

The analyzed corpus consisted of three groups of sports news: sports news articles in the daily newspapers (24 sata, Jutarnji list, Večernji list and Vjesnik); articles in the specialized sports newspapers and magazines (Hrvatska košarka, Nogomet and Sportske novosti); and the prime-time sports news in the daily news program of the three Croatian national networks (HRT - Croatian Radio Television, Nova TV and RTL). All the newspapers were published and all the television news was broadcast in the same week: from Monday, January $23^{\text {rd }}$, until Sunday, January $29^{\text {th }} 2012$.

The research focused on the journalistic style and, therefore, we had to exclude quotes (made by athletes or coaches) which appeared in the interviews or news reports. All substitutions of proper names which were contextually dependent and non-figurative (e.g. 
Naši su dali gol = Our team (meaning the Croatian national handball team) scored a goal;

Brazilac $=$ Brazilian (used for Sammir, a football player from Brazil); nogometaši iz Zagreba = football players from Zagreb (meaning GNK Dinamo Zagreb players)) were not treated as antonomasias.

\section{Results and Discussion ${ }^{76}$}

Using the described methodological approach we gathered a total number of 640 instances of classical antonomasia and in the ensuing analysis we will refer to this number as tokens. Of course, many instances were repeated during the observed week so we needed to find out how many different antonomasias appeared in the analyzed corpus. After reducing tokens to a single headword (for example antonomasia Bijeli = The Whites (Hajduk F.C.) appeared 80 times), we came up with 154 different antonomasias. There were only 3 different Vossian antonomasias, which is not so extraordinary because antonomasia occurs primarily in its classical form in sports discourse. The instances of Vossian antonomasia were therefore not included in the further analysis.

After the tokens were reduced to headwords they could be classified according to their target domain (name of the athlete, club etc.), source domain (kit color, sponsor, emblem etc.), sport and type of antonomasia (metaphoric, metonymic or combined ${ }^{77}$ ). Secondary information was attached to each token concerning the position of the specific token in the text (headline or body text). This information was necessary to better understand the specific use of antonomasia in sports discourse as it was obvious that in written discourse antonomasia occurred frequently in the headlines (especially on the front covers).

\footnotetext{
${ }^{76}$ Since the examples were collected from the Croatian media, in this paper they will be always presented in Croatian with the English translation the first time when they appear. The target of the examples discussed or used for illustration will also be explained the first time (unless they were already explained in the Introduction). ${ }^{77}$ We needed to differentiate the combined type from the classical and Vossian since those examples could not be strictly classified as metaphoric or metonymic in origin.
} 


\subsection{Target domains of sports antonomasias}

The question about target domains of sports antonomasia was not difficult to answer. After classifying headwords by their target domain, we constructed the following chart with twelve categories.

Chart 1 Target domains by category

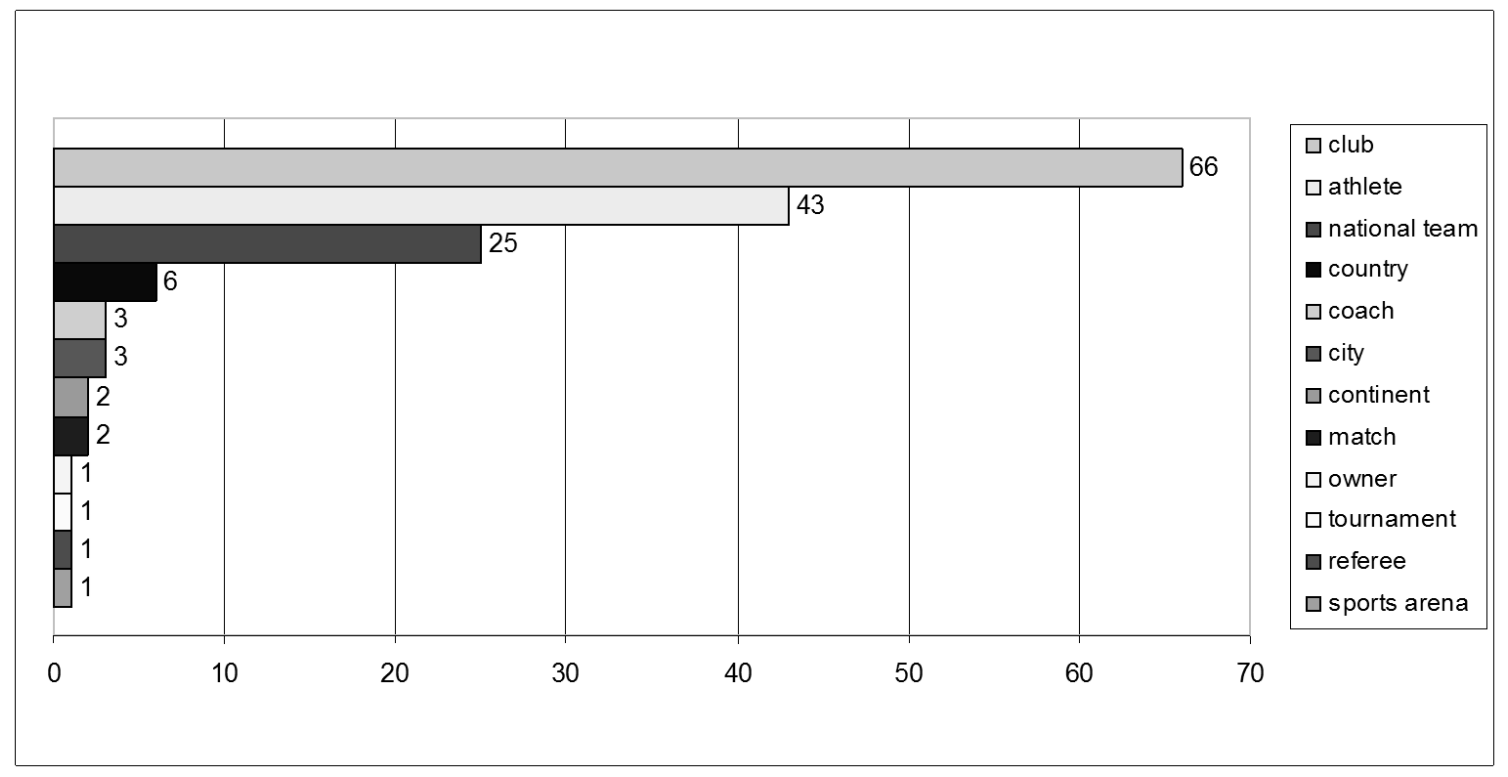


The categories with the largest number of different antonomasias were club, athlete and national team. Examples in these three categories constituted $87 \%$ of all the headwords. As it is evident from the chart, many categories were represented by only a single example. It is somewhat surprising that clubs and national teams are so frequently substituted by antonomasia in comparison to individual athletes. However, this is very logical: clubs and national teams are durable in contrast to a career of an individual athlete and, consequently, their figurative name remains present in the cultural memory. Moreover, absolute antonomasias like King of Athletics see their referents change in accordance with the constant breaking of records. Yesterday it was Carl Lewis, today it is Ussain Bolt, and tomorrow who knows (but there is only one club in Croatia that is always The Whites).

One might ask how nicknames like Kauboji = the Cowboys (for the Croatian national handball team), Vatreni $=$ The Fiery Ones (for the Croatian national football team) or Barakude $=$ the Barracudas (for the Croatian national water polo team) can be treated as classical antonomasia if the definition requires a substitution of a proper name. It is obvious that the Croatian national handball/football/water polo teams are not proper names but one has to remember that in sports discourse it is quite normal to substitute the phrase "Croatian national sports team" by the proper name Croatia using the metonymic concept THE PART FOR THE WHOLE. Therefore, Kauboji, Barakude or Vatreni are antonomasias that substitute the proper name Croatia which has already been metonymically used to refer to national sports teams representing the Republic of Croatia.

\subsection{Metonymic or metaphoric origin}

Although classical antonomasias are used as metonymies because they unambiguously refer to the substituted name, their origin is not always metonymic (as it was explained thoroughly in the Introduction). As is visible in Chart 2, one third of the headwords were not 
created through the metonymic process. The same proportion is kept in the tokens, but the other third of both the headwords and tokens differs in the ratio of metaphor-based and combined type antonomasias (Chart 3).

Chart 2 Proportion of antonomasias (headwords)

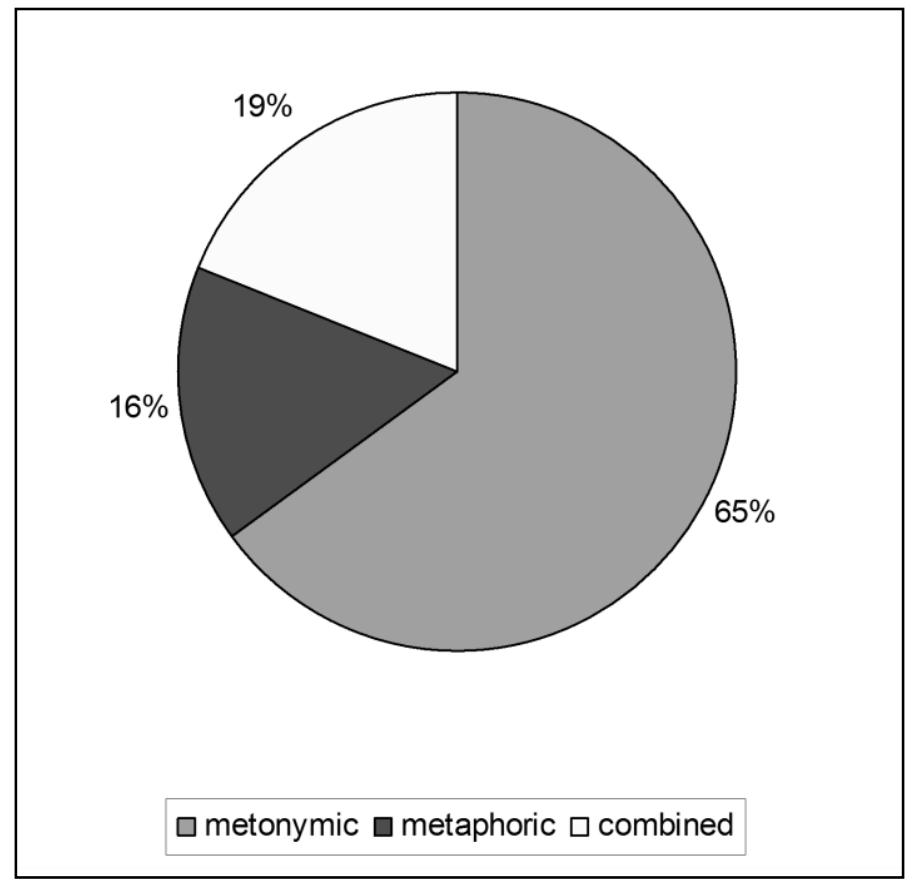

Chart 3 Proportion of antonomasias (tokens)

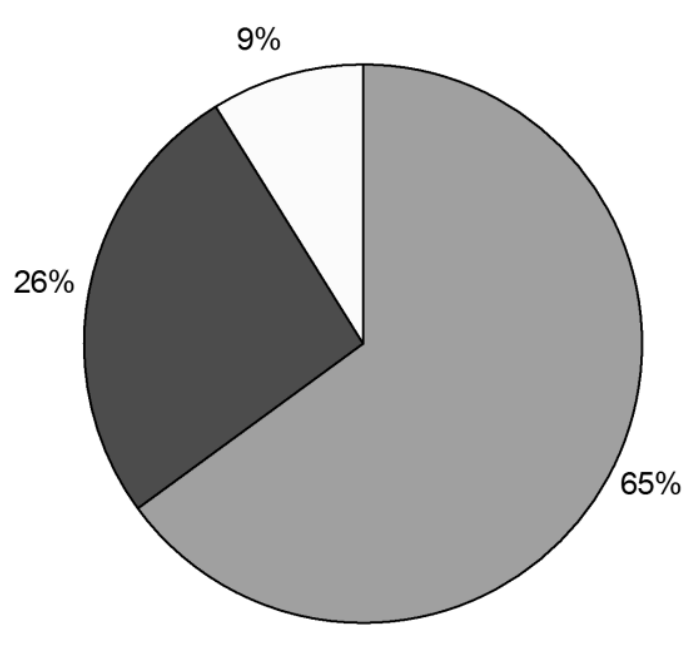

$\square$ metonymic $\square$ metaphoric $\square$ combined 
While there are $16 \%$ of metaphor-based headwords in the collected list, those antonomasias were used more often during the examined week $(26 \%)$ than those of the combined type. ${ }^{78}$ There are two possible explanations for this. The first one would be due to the economy of language which prevents frequent use of longer or complex expressions and favors shorter ones. Metaphorical antonomasias in most cases consist of a single word (e.g. Barakude, Furija $=$ Fury (the Spanish national team), Kauboji, Vukovi $=$ Wolves $($ BC Cibona $)$ etc.), whereas those of the combined type by their definition need to be phrases (e.g. Crveni vragovi $=$ the Red Devils (Manchester United F.C.), Argentinski čarobnjak $=$ the Argentinean Wizard (Lionel Messi), Rukometni Mozart = the Handball Mozart (Ivano Balić), Švicarski čarobnjak $=$ the Swiss Wizard (Roger Federer) etc.).

Second reason for this discrepancy could be found in Chart 4.

Chart 4 Top 10 antonomasias

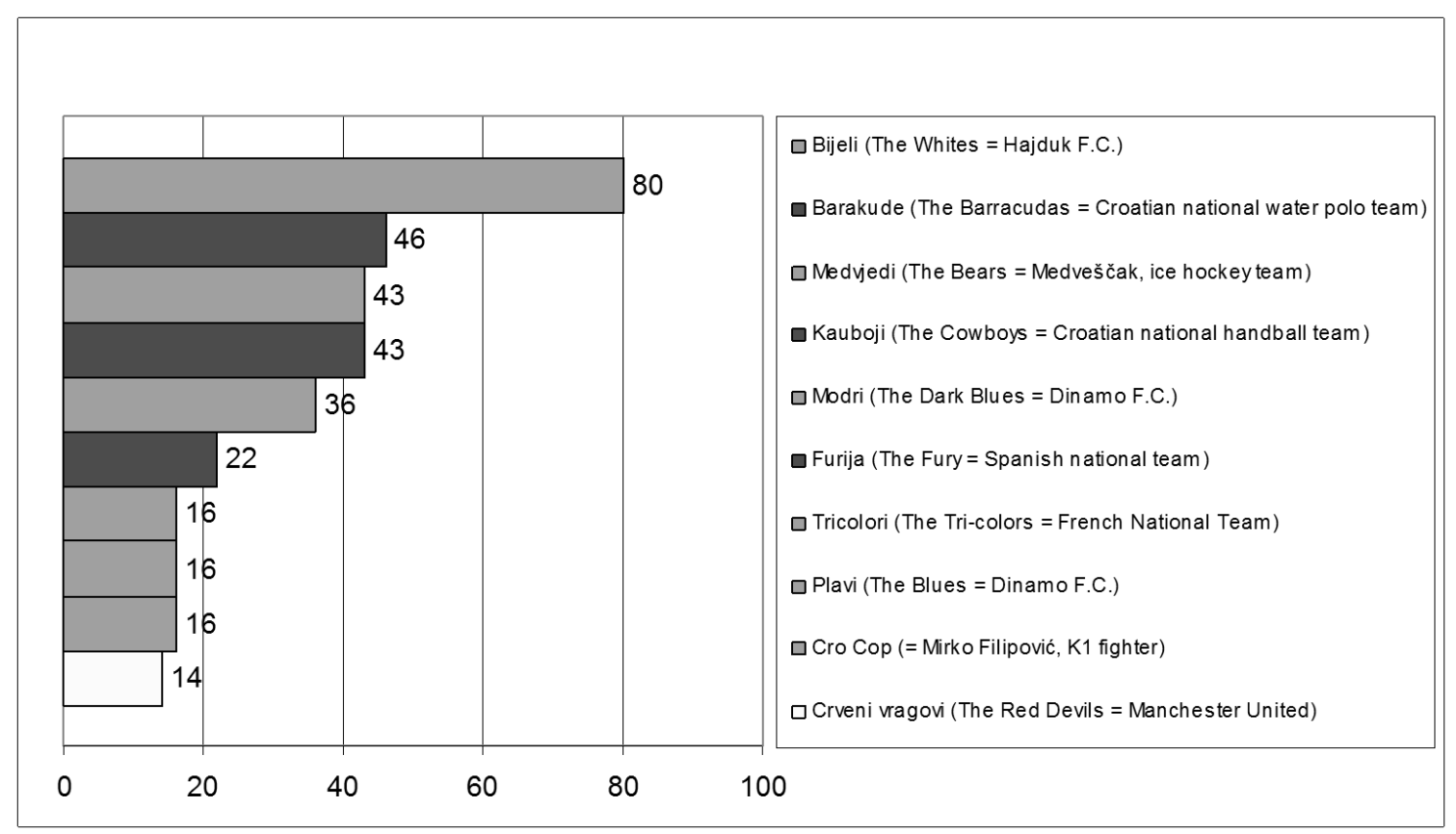

\footnotetext{
${ }^{78}$ Many combined-type instances of antonomasia appeared only once during the week (e.g. Majstori s mora = the Masters from the Sea (Hajduk F.C.), Rukometni Jordan = the Handball Jordan (Ivano Balić) or Briljant s istok $a=$ the Brilliant from the East (Victoria Azarenka)).
} 
Here are the top 10 antonomasias ${ }^{79}$ in regard to all the tokens. These 332 instances make one half of all the tokens, therefore, it is interesting to look closer at the metaphormetonymy ratio. As it was shown in Charts 2 and 3, the metonymically based antonomasias are in light gray, metaphor-based in dark gray and combined-type in white. The metaphorically created antonomasias (Barakude, Kauboji and Furija) make one third of the list, which again shows how a relatively small number of metaphor-based headwords is frequently used in sports discourse. These three examples confirm the dominance of the concept SPORT IS WAR/BATTLE/FIGHT in the creation of typical metaphorical antonomasias and this could be the second explanation of the discrepancy between the headwords and the tokens. An interesting coincidence is that these metaphoric antonomasias represent the three typical groups (predators, professions, aggressive entities) discussed earlier in the paper.

Only one individual athlete came into the top 10 and that was the ultimate fighter Mirko Filipović, worldwide known as Cro Cop. When we compare this example with the other top 10 example Crveni vragovi, it is easy to distinguish strict metonymically based antonomasia from that of the combined type. Although both examples are phrases, Cro Cop has both a metonymic head and a dependent (Mirko Filipović was indeed member of Croatia's Police Special Forces tactical unit), while Crveni vragovi has a metaphoric head (Devils) and a metonymic part (Red) corresponding to the kit color. All phrasal antonomasias require both parts in order to become unambiguous substitutions of a certain athlete, club or national team. The simple antonomasia Cop is uncertain without its dependent part Cro; on the other hand, the "simple" antonomasias Vragovi (Devils) or Crveni (The Reds) could be used as sports antonomasias because both parts use metaphorical or metonymical concepts typically used in the creation of sports antonomasias. A partial confirmation of this theoretical

\footnotetext{
${ }^{79} \mathrm{We}$ are aware that this is not the list of the most frequent or the most common sports antonomasias in the Croatian media. These results largely depend on the matches or tournaments played in the analyzed week. Nevertheless, they are all highly recognizable and generally used in the Croatian sports discourse.
} 
possibility is found in the metonymical "nickname" The Reds denoting Liverpool F.C., Benfica F.C., and Split F.C., as it is their typical kit color.

This chart is also suitable for pointing out the most common sources of metonymic antonomasias. It is the kit color (The Whites, The Blues), name of the club (Medvjedi $=$ the Bears from the name of the hockey club Medveščak ${ }^{80}$ ) or off-sport profession (Cro Cop). Beside these, there are metonymic antonomasias whose source is the club or national team emblem (The Hammers (West Ham F.C.), The Eagles (the Serbian national handball team)) or the sponsor (The Pharmacists (Bayer Leverkusen F.C. or Slaven Belupo F.C.)).

We have to mention that there were a few examples whose sources were very interesting, for instance Vučica = the She-Wolf (Roma F.C.) and Pjesnici = the Poets (Zagreb F.C.). In the first case, the antonomasia's source is a famous mythological story about Rome's founders Romulus and Remus and the she-wolf which nursed the abandoned twins. The reference point for this metonymic antonomasia was therefore directly connected to the home town and not to the football club itself. The source of the second antonomasia, Pjesnici, is much more complex. The Zagreb F.C. stadium is situated in Kranjčevićeva Street, Silvije Strahimir Kranjčević being a famous Croatian $19^{\text {th }}$ century poet. Therefore, Zagreb's players are the Poets. The reference point in this case could be described as double-shifted from the target domain.

\subsection{Antonomasia in written and in spoken sports discourse}

The third question, the difference in the use of antonomasia in written and in spoken sports discourse, was the most difficult to answer. In our corpus of 640 examples only 34 (around 5\%) were collected from TV news. There are several reasons for this disproportion, but we are aware that the basic one is the fact that written and spoken sports discourse was not

\footnotetext{
${ }^{80}$ Name of the club comes from the name of a historical district in the city of Zagreb, and its etymology is derived from the Croatian word medvjed (bear).
} 
equally represented in our research. There was no spoken counterpart for the written articles in the specialized newspapers and magazines and that is the reason why we had so many more examples from written sports discourse. Nevertheless, when we compared daily newspapers sports articles and TV sports news about the same topic (for instance, the outcome of a handball match), in most cases there was not a single example of antonomasia in the TV sports news. Quite the contrary, in almost every written article antonomasia was used at least once to substitute a particular name. We were compelled to make a qualitative comparison between the two media since there was no ground for quantitative analysis.

In our opinion, the most important reason for a low frequency of antonomasia in spoken articles is a general difference between the two media. The visual stimulus in TV news requires less linguistic material - we simply see what is/was happening. This makes the use of tropes redundant because sports subjects do not need to be verbalized as often as in written discourse (TV news also benefits from name captions which are, for instance, shown when an athlete is giving a press statement).

The other reason is the amount of text in written and in spoken discourse. The sports news program on Croatian TV channels usually lasts up to 5 minutes (including four reports at least) and it usually provides basic information (the time and place of the event, participants, score etc). On the other hand, written sports articles are obliged to provide more extensive commentaries beside basic information. This gives written discourse more opportunity to repeat the same names.

Before we conducted the research, we expected to find the same examples in written and in spoken discourse (at least the most frequent ones), but to our surprise spoken discourse was again antonomastically "poorer". Out of our top 10 most frequent tokens, only 3 appeared in both written and spoken discourse and 7 of them were found only in written discourse. This can be illustrated by the following chart. 
Chart 5 Top 10 antonomasias in the daily newspapers and TV news

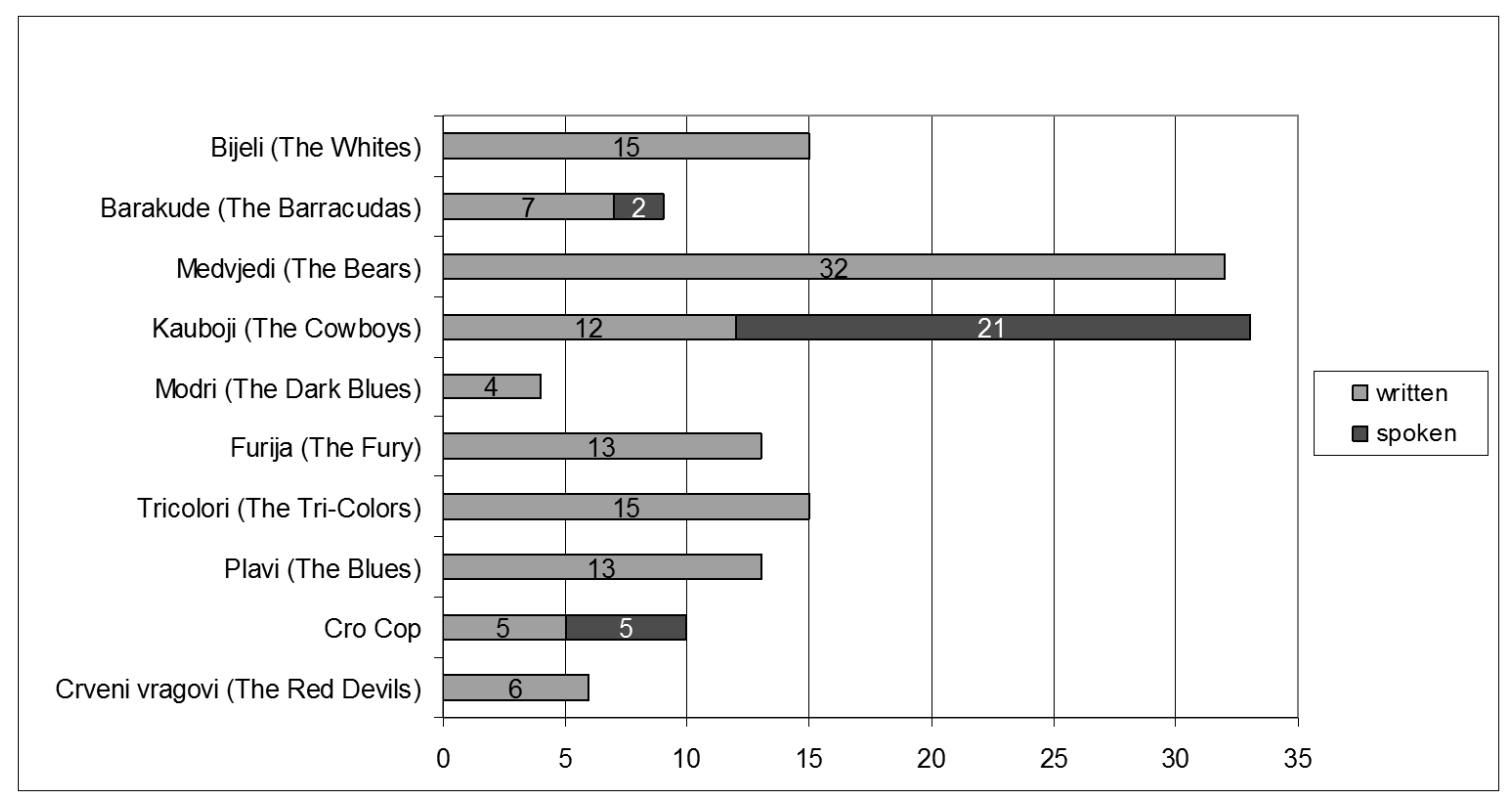


These numbers represent tokens in the daily newspapers and TV news. As mentioned earlier, we ignored specialized newspapers and magazines because we did not have the appropriate specialized sports program. Out of the original 304 top 10 tokens belonging to written discourse, only 122 tokens appeared in the daily newspapers. This "loss" is more evident when we compare Charts 4 and 5. That is the reason why we kept the same order of antonomasias.

The only instance of antonomasia that appeared more often in spoken than in written discourse (21:12) was Kauboji. This antonomasia was so frequently used in the TV news because that week (at the European Men's Handball Championship) the Croatian national team beat the French national team in the match that journalists named Rukometni El Classico $=$ Handball El Classico. In the semifinal match the Cowboys played against the Eagles and this event had wide press coverage not only in sports news.

The last reason for the disproportion of antonomasias in the two media could be found in the function of headlines in newspapers. The headline has a key role as an entrance to the text, its function is "to lure" a reader (Ivas 2004: 10). Owing to its position and graphic design, the headline will certainly attract attention; if it is figurative, this attraction is amplified. That is the main reason why journalists formulate headlines figuratively. Since antonomasia in sports discourse has an additional function of identification (journalists use them because their recipients will surely recognize the substituted target), it does not come as a surprise that exactly every fifth example of written antonomasias appeared in newspaper headlines. The cover pages of all the newspapers in our research profusely used antonomasia in the headlines and so we can conclude that antonomasia certainly has a big emotional impact on sports readers, especially in attracting them to buy and read newspaper. 


\section{Conculsion}

In our research we tried to answer three questions that concerned the role of antonomasia in Croatian sports discourse. The primary targets of classical antonomasias are shown to be clubs, athletes and national teams (in that exact order). Two out of three headword antonomasias were metonymic in origin, and the same ratio is kept in the tokens. Metaphor-based antonomasias are used more often than the combined type because the economy of language favors the use of shorter expressions and the combined type is necessarily a phrase. The other reason for the more frequent use of metaphorical antonomasias can be found in their realization of the general concept SPORT IS CONFLICT (using the names of predators, war professions or aggressive entities). The source of metonymic antonomasias was in most cases the kit color, the emblem, the name of the club or the name of the city the club comes from. The referential point is in most cases very obvious although there are some examples which require more sports or even cultural knowledge in detecting the connection between the target and the source/vehicle.

We could not give a straightforward answer whether antonomasias are used more in written or in spoken discourse - instead we tried to point out possible reasons why there were so many newspaper tokens when compared to those from TV. The general difference between the two media obviously generates difference in the use of antonomasia. Television reports require less linguistic material because they benefit from the visual stimulus and they usually provide their recipients with basic information about sports events. Written sports discourse uses the advantage of headlines as attractors and that is the reason why every fifth instance of antonomasia appeared there.

The most important contribution of this research is the affirmation of the role which antonomasia has inside sports discourse. It connects journalists and the recipients of sports news (reader, spectators and listeners) and identifies them as participants in sports discourse. 
Although many sports antonomasias have transcended their original discourse and have become known to the general audience, there are still many more of them which are known and used only by true connoisseurs.

\section{References}

Anderson, R. D. A Glossary of Greek Rhetorical Terms, Leuven: Peeters, 2000.

Brdar, M. and Brdar-Szabó, R. "Vlastita imena između metonimijske Scile i metaforičke Haribde.” Rasprave Instituta za hrvatski jezik i jezikoslovlje. 27, (2001): 31-48.

Burke, K. A Grammar of Motives. Berkeley/Los Angeles/London: University of California Press, 1969.

Grgić, A. and Nikolić, D. "Upotreba i prepoznavanje antonomazija - usporedba mlađih i starijih govornika." Govor. 28, no. 1 (2011a): 25-43.

Grgić, A. and Nikolić, D. “Antonomazija - figura kulturnoga pamćenja.” Fluminensia. 23, no. 2 (2011b): 129-142.

Holmqvist, K. i Płuciennik, J. "Princess Antonomasia and the Truth: Two Types of Metonymic Relations.” Edited by A. Burkhardt and B. Nerlich. Tropical Truth(s), 373381. Berlin/New York: De Gruyter, 2010.

Ivas, I. “Tropi u novinskim naslovima.” Medijska istraživanja. 10, no. 2 (2004): 9-34.

Kövecses, Z. Metaphor: A Practical Introduction. New York/Oxford: Oxford University Press, 2002.

Kövecses, Z. Metaphor in Culture - Universality and Variation, Cambridge: Cambridge University Press, 2005.

Krišković, A. and S. Tominac. "Metonymy Based on Cultural Background Knowledge and Pragmatic Inferencing: Evidence from Spoken Discourse.” Fluminensia, 21, no. 2 (2009): 49-72. 
Lakoff, G. and M. Johnson. Metaphors We Live by, Chicago/London: The University of Chicago Press, 1980.

Lausberg, H. Elemente der literarischen Rhetorik. Ismanig: Max Hueber Verlag, 1990.

Marković, I. “O uporabi i značenju imenâ u hrvatskome.” Folia onomastica Croatica. 19, (2010): 175-202.

Monson, D. A. “L’antonomase dans Le Chevalier au lion.” Poétique. 133, (2003): 35-43.

Nerlich, B. "Metonymy." Edited by K. Brown. Encyclopedia of Language and Linguistics, Vol. 8, Mel-N, Amsterdam: Elsevier, 2005.

Quintilian. The Institutio Oratoria III, (Books VII-IX). Cambridge: Harvard University Press, 1959.

Radden, G. and Z. Kövecses. "Towards a Theory of Metonymy.” Edited by K. U. Panther and G. Radden. Metonymy in Language and Thought,17-59. Amsterdam/Philadelphia: John Benjamins Publishing Company, 1999.

Runjić-Stoilova, A. "Retorički tropi u hrvatskim dnevnim novinama." Zbornik radova Filozofskoga fakulteta u Splitu. 4, (in print) 2012.

Van Langendonck, W. Theory and Typology of Proper Names, Berlin/New York: Mouton de Gruyter, 2007. 


\title{
Stakeholders in promotional genres. A rhetorical perspective on marketing communication
}

\author{
Sabrina Mazzali-Lurati \& Chiara Pollaroli, University of Lugano
}

Summary

This contribution aims at exploring the domain of business communication from a rhetorical perspective. A full comprehension of the rhetorical situation - especially of its participants - where a communicative event is ascribed, is fundamental in order to produce an effective text. Participants in a rhetorical situation are framed as stakeholders: they are interested and favour a successful communicative event in relation to its rhetorical situation

We will present our rhetorical approach through the example of four texts from the category of promotional genres in a commercial realm. Insights into similar analyses of texts belonging to different realms will be briefly provided. We will also mention how our rhetorical approach can be useful in educational contexts, such as Rhetoric and Composition courses.

Key words: stakeholder, rhetorical situation, business communication, discourse genre, promotional text

\section{Introduction}

This study explores the domain of business communication from a rhetorical viewpoint. At the core of our approach is the concept of rhetorical situation (henceforth RS), namely a context composed of persons, events, objects, relations, needs and expectations (cf. Bitzer, 1968) in respect to which a text aims at successfully achieving a given goal. The RS configuration has an influence on a text's contents, structure and style. Therefore, considering and understanding the RS is essential in order to produce an effective text.

Many studies have shown difficulties in defining the RS of promotional genres, especially in identifying and characterizing the actors taking part in an advertisement (Atkin and Richardson, 2005); some scholars have defined the addresser as a "corporate persona created by the ad agency" (Corbett and Connors, 1999: 3; see also Brierley, 1995: 57; 
Calabrese, 2008: 28). Our approach allows us to describe in detail the participants, their needs and influences on the text, thus moving beyond generic references to advertisers and consumers and proving a systematic perspective on the text RS.

The kernel notion to our approach is, together with the notion of genre (as a set of prefabricated communicative choices realizing a specific communicative task in a given context; cf. Bakhtin 1986 and the relationship he underlines between discourse genres and different spheres of human activity), that of stakeholders.

The notion of stakeholders stems from the domain of corporate communication and refers to those people who have a stake in the activity of an enterprise, thus wish that the enterprise would succeed and work in their favour. In a similar perspective, we claim that all texts written in an enterprise in order to carry out its activity and achieve its goal have stakeholders, i.e. persons who have an interest in the communicative success of those texts. By describing the stakeholders of a text, it is possible to gain an in-depth understanding of actors playing within a given communicative situation and their roles. This notion has been applied to the analysis and production of texts written to carry out various organization activities and has been successfully integrated in a course on Rhetoric and Composition at the University of Lugano.

In this paper we will show this especially through four promotional genres, which have a similar generic goal (i.e. to advertise a product or a service), but different structure and style: a press release, a brochure, a print ad and a TV commercial. By applying our model of stakeholders, we will be able to shed light on the diverse RSs generating texts.

Section 2 presents the research gap where this contribution fits in. When adopting a basic functional model of communication it is rather difficult to fully characterize a communicative event and its participants. The model of context proposed by Rigotti and Rocci (2006) seems to be adequate when conceiving communicative events as complex interactions where people 
wish to accomplish their goals. Rhetorical discourse is always bound to a context; its situated nature can be well described through Bitzer's concept of rhetorical situation, which will be outlined in section 3 . Section 4 is devoted to the introduction of the notion of stakeholder. This is a kernel notion to our approach since we believe that all texts (either written or spoken) are created in order to carry out an organization activity and achieve its goals. To better describe the notion of stakeholders and to relate it to those of genre and rhetorical situation, in section 5 we take as examples four promotional texts - a press release, a brochure, a print ad and a TV commercial. The stakeholders approach is a valuable tool for teaching how to produce effective texts which adhere to the exigence of a given rhetorical situation. In section 6 we show how it can be used to make students aware of the situated character of a text.

2. The research gap

As it has been noticed in different works on advertising discourse, in promotional genres a difficulty in identifying the participants to a communication (particularly, addressers and addressees) is often highlighted. The key question to be answered in order to understand advertising discourse appears to be "who is communicating with who?" (Atkin and Richardson, 2005: 165). The non-coincidence among those persons who "physically" and actually produce the ad, managers who require the ad, and the "voice which speaks in the ad" is usually pointed out as a demonstration of the difficulty in identifying an ad's addresser(s). As for instance Corbett and Connors (1999: 3) observe

In most ads, as in most forms of technical writing, the least prominent of the components is the speaker/writer. Who is addressing us in the ad? Most ads are composed by the staff of the ad agency that the company or the manufacturer hired. The speaker or writer in an ad - unlike the speaker or writer in a speech or an essay - 
is not a particular person; it is usually a corporate persona created by the ad agency $[\ldots]$.

The actors playing the role of addressers in an advertising text are defined as "a corpora persona", a blurred entity whose characteristics are hard to distinguish. Similarly, Corbett and Connors (1999: 3) point out difficulties in identifying an ad's addressee(s). The most straightforward answer to the question "whom is the ad addressing?" seems to be " "the reader of the ad', referred to frequently by the second-person pronoun you'. However it appears to be unclear who is you: is it an individual or a group of people? For instance, in relation to an ad for the Hewlett Packard printer they are commenting, Corbett and Connors observe that

One possible candidate as an antecedent for the pronoun you is the administrative officer of a company that is responsible for purchasing equipment, such as typewriters or computers or printers for the workers. In that case, the you stands for a group of people. On the other hand, the you may stand for an individual out there who is in the market for a color printer. The point is that the audience for most ads is not as easily definable as is the audience, for instance, for a nomination speech at a national political convention. We just sense that there is somebody out there - preferably thousands of people - that the ad-writer wants to persuade to buy something. (Corbett and Connors, 1999: 3)

These difficulties usually emerge when the communicative action of advertising is described according to basic functional models of communication, such as (as it is the case in Corbett and Connors, 1999) the communication triangle (Figure 1), derived from Kinneavy (1969: 302, 1971) and referring to Bühler's and Jakobson's models of communication: ${ }^{81}$

\footnotetext{
${ }^{81}$ Kinneavy (1969: 301) is mainly concerned with composition and the classification of aims of discourse and shows that a discourse can focus on either the encoder (expressive function), the decoder (persuasive function), the reality (referential function), or the signal (literary function). Jakobson's well-known model has a very similar perspective; he extends the number of functions a text may have distinguishing one function for each
} 


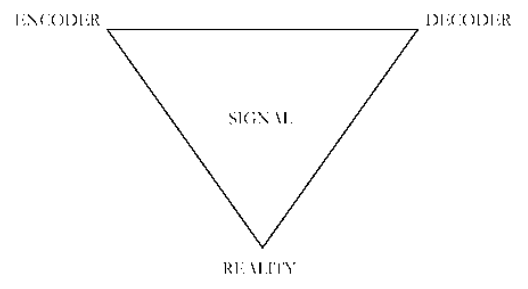

Figure 1 - Kinneavy's (1969: 302) communication triangle

These models are code-centered, focused on a process of coding and decoding (Rigotti and Greco, 2006; Rigotti and Rocci, 2006: 163), and do not adequately take into consideration the participants and the context in which communication processes are created and live. Rigotti and Cigada (2004: 23-56) point out that each communication act is an event, in other words it is something that happens and that "touches" us, "moves" us, changes us because we are interested in it. Meaning corresponds to this change. Thus, a communication event is not simply a relation between a signal and the participants, it is not a process of encoding and decoding a message, but it is a continuous process of interpretation of the meaning of the message in relation to the whole situation in which the communication event takes place.

In order to overcome the difficulties in understanding who are the participants in the communication process of advertising, a more refined model of the context of communication and the communicative situation is needed. Particularly, more refined conceptual tools for the description of the relationship between a text, its goal, and task (which, according to the tradition of Ancient rhetoric, we call officium - cf. Greco Morasso, 2009: 222 - and which 
relate to the notion of genre - cf. Askehave and Swales, 2001) and the participants in the communication are required.

Rigotti and Rocci's (2006) model of communicative context (stemming from pragmatic theories of verbal communication, particularly from speech act theory; see figure 2) provides an adequate conceptual framework. According to these scholars, communication context results from the combination of an institutionalized component and an interpersonal one:

Within the institutionalized component, activity types are seen as resulting from the mapping of culturally shared interaction schemes onto an actual interaction field (a social reality characterized by shared goals and mutual commitments). As a result of the mapping, communicative flows and roles are created. Within the interpersonal dimension, we distinguish between a relationship-based personal component and a communal component connected with cultural identities. (Rigotti and Rocci, 2006: 155)

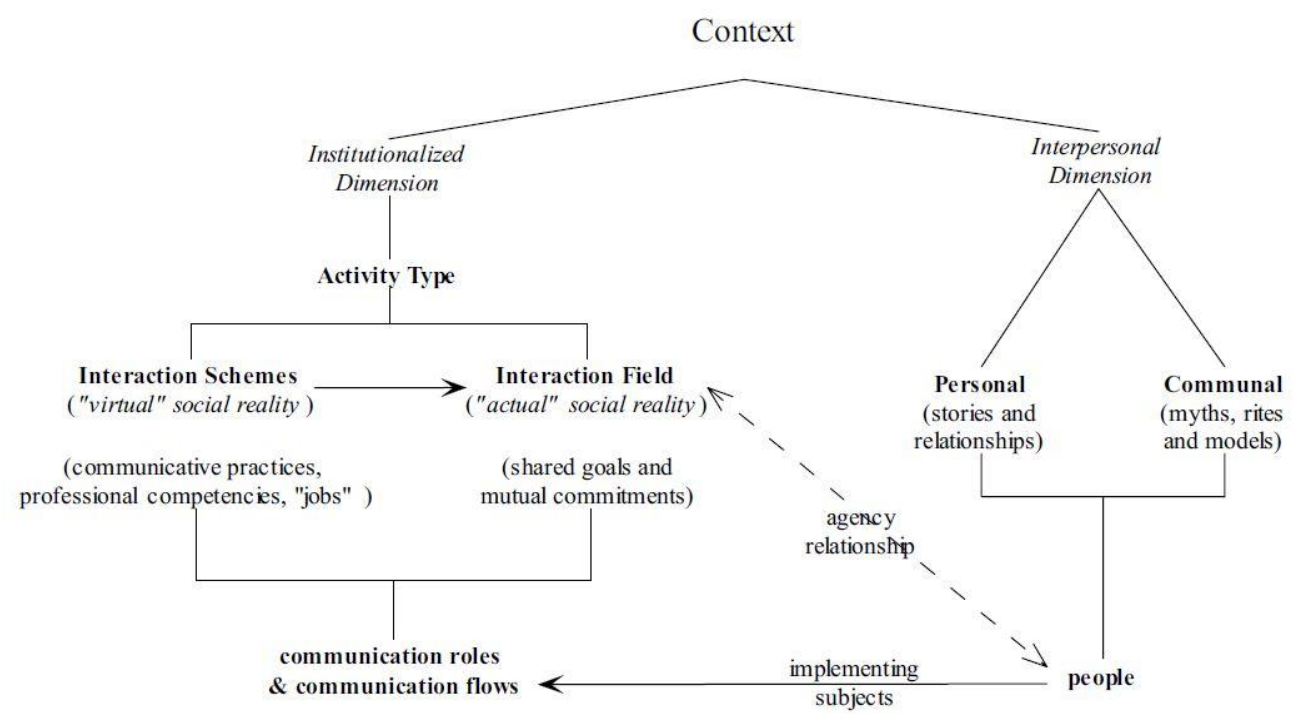

Figure 2 - Rigotti and Rocci's (2006: 171) model of context

A communicative event such as, for instance, a print ad for training shoes, is composed - in its institutional dimension - of an activity type of promoting a pair of training shoes. Within this activity type we can identify the market of shoes as the interaction field and advertising as 
the interaction scheme. The personal component of the interpersonal dimension is, in the case of a print ad, sterile since it is unusual that potential consumers have had previous personal communicative interactions with the company promoting the training shoes; on the contrary, the communal component is often strongly present since it hints at shared knowledge and experience of advertising within a culture.

Culturally shared interaction schemes encompass discourse genres, that is, standard rhetorical schemes used in order to achieve the goals of a given interaction scheme (Rigotti and Rocci, 2006: 173, cf. also Bakhtin 1986: $\left.60^{82}\right) .{ }^{83}$ In our example, the interaction scheme of advertising extracts the genre of print ad from the group of discourse genres (billboards, TV commercials, flyers, etc.) related to a similar communicative practice. Social roles of the interaction field and communicative roles deriving from the implementation of the interaction scheme onto the interaction field identify the participants to the communication. From Rigotti and Rocci's model of context it emerges that participants are identified and characterized within both the institutional and the interpersonal dimensions. In fact, they are characterized by the role and function they have in an organization, by the culture to which they belong, by previous interactions they had with other participants and by their personal characteristics and attitudes. From this perspective this model highlights that participant's act in a specific context with a specific goal. It is often the case that in order to achieve their goal(s) participants write texts. The context itself in which they act directs and constrains the production of the text. For instance, an organization which wants to sell its medical products, such as the example we are going to present later on in this paper, belongs to a specific interaction field (the market of medical products) and, in order to achieve its goal, it activates

\footnotetext{
${ }^{82}$ Here Bakthin highlights that "[...] each sphere in which language is used develops its own relatively stable types of these utterances. These we may call speech genres" and that "individual concrete utterances (oral and written) by participants in the various areas of human activity [...] reflect the specific conditions and goals of each such area".

${ }^{83}$ The concepts of purpose and task in the definition of genre are stated (and debated) to be fundamental in most major communicative approaches to genres since the beginning of the "new" genre movement of the early 1980s (Askehave and Swales, 2001: 195-196).
} 
a certain interaction scheme (that of promotional texts) and it produces a certain number of texts belonging to one or more discourse genres (a print ad, a billboard, a brochure, etc.) which can help the organization increase the sales of their medical products.

This model of communication context focuses on the goal to be accomplished and the activity to be performed in a specific social environment composed by people, their desires, their needs, their culturally shared knowledge, their view of the world, etc. This viewpoint on communication events, being then either routine-based or complex, allows us to look at texts as contextualized (situated) and subjected to the interpretation of the participants to the event.

\section{The rhetorical situation}

The contextualized and situated nature of text can be better described by referring to the concept of rhetorical situation developed by Lloyd Bitzer $(1968,1980)$. According to Bitzer "rhetoric is situational" (1968: 3), i.e. "a particular discourse comes into existence because of some specific condition or situation which invites utterance" (1968: 4) and "rhetorical discourse comes into existence as a response to situation" (1968: 5), a rhetorical situation, that is to "a natural context of persons, events, objects, relations, and an exigence which strongly invites utterance" (1968: 5). More precisely, the constituents of any rhetorical situation are "an exigence - a problem or defect, something other than it should be [...] an audience capable of being constrained in thought or action in order to effect positive modification of the exigence $[\ldots]$ a set of constraints capable of influencing the rhetor and an audience" (1980: 23). Among these constituents, exigence is crucial since we usually react to situations according to how we perceive things are and should be (1980: 25); exigence is the element which operates the engine of change in communication:

Exigence is the necessary condition of a rhetorical situation. If there were no exigence, there would be nothing to require or invite change in the audience or in the world - 
hence there would be nothing to require or invite the creation and presentation of pragmatic messages. (Bitzer, 1980: 26)

Human beings perceive defects, obstacles, and imperfections and urge for some change. This urgency is felt because of some interests and valuations toward the rhetorical situation. Bitzer specifies that the constituents of a rhetorical exigence are both a factual condition and an interest relation (1980: 28): factual condition is "any set of things, events, relations, ideas, meanings - anything physical or mental - whose existence is (or is thought to be) independent of one's personal subjectivity"; interest is "any appreciation, need, desire, aspiration which, when related to factual conditions, accounts for the emergence of motives and purposes" (1980: 28). The speaker/writer's decision to speak/write derives from the exigence (i.e., the perception of a factual condition and the existence of an interest related to it) and aims to positively modify the exigence through discourse that influence audience's thought or action. This happens quite easily when speaker/writer and audience have the same perception and evaluation of the factual condition and the interest composing the exigence.

It is likely that speaker and audience disagree on one of these two aspects or even on both. However, "to the extent that apprehension of factual conditions and the experience of interests can be shared" (1980: 30) an exigence can be communicated: "the rhetor, if he knows his audience is capable of experiencing the exigence, will awaken it to the reality of the exigence by providing a representation of the factual condition that evokes or engages the required interest." (Bitzer, 1980: 31)

This is what happens in advertising (1980: 31), where the speaker/writer sees a factual condition (he offers either a product or a service to clients), perceives an interest in relation to it (he wants to sell it), and decides to produce an utterance in order to awaken the addressees' interest for the same factual condition. Once the addressees' interest is awakened the next step is to produce an audience's action (to buy the product or service) that modifies the audience's 
exigence (the product or service satisfies a need or a desire) and, as a consequence, a positive modification of their exigence to sell the product.

This is the pivotal exigence at the basis of any promotional texts and it identifies the purpose of the text, what the text aims at. It identifies a basic task of promotional genres, their officium (i.e., the officium of a text consists in positively modifying the exigence for which the text comes into existence) and it is the central constituent of the related rhetorical situation.

The speaker/writer of the ad is the person who first perceives the exigence and decides to speak/write in order to positively change it. This provides us with a first indication for the identification of the addresser of advertising messages. The speaker/writer is the company that wants to sell the advertised product, independently of the fact that they produce the messages themselves or that they charge someone else with producing it. These latter are also actors in the production process of the message, but they participate in it with a different role, which we will more precisely identify in the following section. It is not even the "voice which speaks in the ad"; as Cook (2001: 4) observes, the sender of the advertising message can differ from the person who actually speaks it. The latter can correspond both to what the tradition of narrative studies (developed by Jameson, 2004a and 2004b within composition and business communication) defined as the implied author and the narrator; therefore, it has to be distinguished from the actual persons who, with different roles, intervene in the writing process of the ad.

The audience, as Bitzer points out, "must be distinguished from a body of mere hearers or readers [...] [it] consists only of those persons who are capable of being influenced by discourse and of being mediators of change" (1968: 8); "[s]ince the audience must be capable of modifying the exigence positively, it follows that listeners incapable of this modifying influence will not count as a rhetorical or functional audience" (1980: 23). In this perspective, the rhetorical audience for promotional texts is composed of all those who can 
remove the speaker/writer's exigence, i.e. all those who can buy or can be interested in buying the product. The rhetorical audience will therefore be different according to the kind of advertised product or service; it can be broader or narrower depending on the product. For instance, the rhetorical audience for car advertisements comprise all people who have a driving license or who need a car as a means of transport (therefore, in some countries, almost all adult people), while the rhetorical audience for the Hewlett Packard printer mentioned in Corbett and Connors 1999 is narrower and it comprises, for instance, organizations where many documents are printed. However, being the advertisement public, all people see it, all people can read the message, even if they are not interested and do not perceive the factual conditions of buying a Hewlett Packard printer. Even if they are not the target of the speaker/writer's exigence, even if they are not those who can positively modify the exigence of the speaker/writer, they are in some ways (with a role that we will more precisely describe below) entitled to take part in the communicative action of the advertisement. Cook (2001: 4) and, in his line, Atkin and Richardson (2005: 166) speak of addressees and receivers.

Whatever the terms and categories we can use, these first distinctions show that, besides the speaker/writer and the audience, other persons are involved in the rhetorical situation. These persons, from Bitzer's perspective, are sources of constraints that the speaker/writer takes into consideration when operating. We name them stakeholders.

\section{Stakeholders of a text}

The notion of stakeholders stems from the domain of corporate communication and refers to those people who have a stake in the activity of an organization or institution, thus wish that it would succeed and work in their favour. In a similar perspective, we maintain that all texts written in an enterprise in order to carry out its activity and achieve its goal have stakeholders, i.e. persons who have an interest in the communicative success of the text (Mazzali-Lurati 2011). Different stakeholders play different roles and have a different interest in respect to the 
text. Thanks to the concept of stakeholders it is possible to gain an in-depth understanding of actors playing within a given communicative situation and their different roles.

We drew the concept from the field of corporate management, where it has been used for the first time by Freeman (1984) in relationship to strategic management (Post et al., 2002: 18). The conventional model of corporate stakeholders includes, beside investors (who are traditionally considered the partner of the corporation management, the ones the management has to reward and care about - cf. the ownership view of corporation; Post et al., 2002: 12), customers and users, also employees, governments, regulatory authorities, unions, joint venture partners and alliances, local communities and citizens, private organizations and supply chain associates (Post et. al., 2002: 22).

From the field of corporate management the concept has then been drawn on in the field of web design and usability, in order to identify and refer to the "persons who have expectations, goals and interests connected to the implementation and success of the site" (Cantoni et al., 2003: 32; translated by the authors). In web design and usability stakeholders are users, clients, decision makers, opinion makers, project managers, product managers, domain and content experts, content providers, as well as the development team (Perrone et al., 2005).

Some of these categories of stakeholders appear to be relevant not only in relationship to the corporation, its activity and its website, but also in relationship to the texts that are daily and continuously written in the realm of the corporation's activity. For instance, texts produced in the written communication of organizations have clients (someone who asks to write the text in order to face a given exigence) and users or customers (the persons who are meant to read the texts and to react to it) and, sometimes, have regulatory authorities, that is, persons or institutions that elaborate rules (at the level of content and at the level of their presentation) the text has to follow and respect. Drawing on a concept from media sociology we see that texts in organizations sometimes also have gatekeepers, that is, individuals and 
groups that have the power to let information get through channels of communication or to block it (Lewin, 1947: 145). ${ }^{84}$

In line with fundamental pragmatic approaches to verbal communication (cf. Clark 1996: 14-15), the identification of the stakeholders of a text can be refined by taking into consideration the description of the roles of the participants to communication elaborated by Goffman (1979). In his work on footing, the Canadian sociologist observed that "[w]hen one uses the term 'speaker', one often implies that the individual who animates is formulating his own text and staking out his own position through it" (Goffman, 1979: 145). However, in communication, situations in which the individual who animates the text is different from the one who formulates it and from the one who stakes his own position through it are very frequent. "Plainly, reciting a fully memorized text or reading aloud from a prepared script allows us to animate words we had no hand in formulating, and to express opinions, beliefs, and sentiments we do not hold. We can openly speak for someone else and in someone else's words, as we do, say, in reading a deposition or providing a simultaneous translation of a speech - the latter an interesting example because so often the original speaker's words, although ones that person commits himself to, are ones that someone else wrote for him" (Goffman, 1979: 145-146). In other words, Goffman pointed out that behind the word "speaker" three different roles are hidden: the animator ("an individual active in the role of utterance production"; 1979: 144), the author ("someone who has selected the sentiments that are being expressed and the words in which they are encoded"; 1979: 144) and the principal ("Someone whose position is established by the words that are spoken, someone whose beliefs have been told, someone who is committed to what the words say"; 1979: 144). This is, as Atkin and Richardson (2005: 166) already noticed, precisely in respect to advertising, a very relevant distinction, that provides a deeper insight about the participants in the

\footnotetext{
${ }^{84}$ See for instance the role played by the journalist who screens news and press releases for deciding which news is worth being published in the newspaper (Wolf, 1996: 178-179).
} 
communication. Similarly, Goffman observed that behind the term "hearer" three different roles have to be distinguished: the addressee (the person/s to whom the utterance is addressed; McCawley, 1999: 596; cf. Goffman, 1979: 131-133), ${ }^{85}$ the ratified participant (the person/s who hold/s an "official status as a ratified participant in the encounter"; Goffman, 1979: 131; McCawley, 1999: 596) and the overhearer/bystander (the person/s who follow/s the talk unintentionally and inadvertently or surreptitiously; Goffmann, 1979: 131-132; McCawley, 1999: 596). Thus, "[t]he ratified hearer in two-person talk is necessarily also the 'addressed' one, that is, the one to whom the speaker addresses his visual attention and to whom, incidentally, he expects to turn over the speaking role" (Goffman, 1979: 132-133), while in encounters in which three or more official participants are found, "it will often be feasible for the current speaker to address his remarks to the circle as a whole, encompassing all his hearers in his glance, according them something like equal status. But, more likely, the speaker will, at least during periods of his talk, address his remarks to one listener, so that among official hearers one must distinguish the addressed recipient from 'unaddressed' ones" (Goffman, 1979: 133). And this is a very common situation in communication, as well as situations in which bystanders and overhearers are involved:

[...] much of talk takes place in the visual and aural range of persons who are not ratified participants and whose access to the encounter, however minimal, is itself perceivable by the official participants. These adventitious participants are 'bystanders'. Their presence should be considered the rule, not the exception. In some circumstances they can temporarily follow the talk, or catch bits and pieces of it, all without much effort or intent, becoming, thus, overhearers. In other circumstances they may surreptitiously exploit the accessibility they find they have, thus qualifying

\footnotetext{
${ }^{85}$ For the description of Goffman's roles we refer, besides Goffman's original text, to the same model recovered by McCawley 1999.
} 
as eavesdroppers, here not dissimilar to those who secretly listen in on conversations electronically (Goffman, 1979: 132).

Combining the original classification of stakeholders developed in the management field, the one elaborated from scholars dealing with a websites production, Goffman's roles of participants in communication, adding the category of gatekeeper highlighted by media sociology, and applying them to written communication in organizations, we obtain the classification of eight different stakeholder roles of a text: the principal, the author, the animator, the addressee, the ratified participant, the overhearer/bystander, the gatekeeper, and the regulator (table 1).

In the following, on the basis of an example, we will show that the description of the stakeholders of a text according to this classification can clarify and describe in a richer way the communicative situation of promotional texts.

\section{Table 1 - Stakeholders}

\begin{tabular}{|l|l|}
\hline Role & Description \\
\hline Animator & $\begin{array}{l}\text { Someone who materially writes a text } \\
\text { by activating a writing technology. }\end{array}$ \\
\hline Author & $\begin{array}{l}\text { Someone who produces a text } \\
\text { formulating the content and choosing } \\
\text { expressive strategies. The author is often } \\
\text { asked to write a text and to accomplish a } \\
\text { communicative purpose by a } \\
\text { commissioner. In an organization it is } \\
\text { likely to have many authors } \\
\text { (collaborative writing). }\end{array}$ \\
\hline Principal & $\begin{array}{l}\text { The principal is the source of the text } \\
\text { content, expressed opinion, and } \\
\text { communicative goal. The author must } \\
\text { realize the principal's communicative } \\
\text { goal when writing. The principal is } \\
\text { responsible, even in legal terms, for the } \\
\text { text. The principal's opinion is } \\
\text { expressed in the text. The principal can } \\
\text { also be an institution or an enterprise. }\end{array}$ \\
\hline
\end{tabular}




\begin{tabular}{|l|l|}
\hline Addressee & $\begin{array}{l}\text { The person to whom the text is directly } \\
\text { and explicitly addressed. }\end{array}$ \\
\hline Ratified participant & $\begin{array}{l}\text { Someone who the text is not directly } \\
\text { addressed to but is entitled to take part } \\
\text { in the communicative event as a right. }\end{array}$ \\
\hline Overhearer/Bystander & $\begin{array}{l}\text { Someone who can come in contact - } \\
\text { directly or indirectly - with a text } \\
\text { without either the principal or the } \\
\text { author's knowledge. He is not the } \\
\text { addressee to whom the principal directs } \\
\text { the text. Overhearers include opinion } \\
\text { leaders, who can be affected by the text } \\
\text { even if they are not addressees. The } \\
\text { importance of an overhearer varies } \\
\text { according to the text distribution. }\end{array}$ \\
\hline Gatekeeper & $\begin{array}{l}\text { Someone who, thanks to his/her role in a } \\
\text { specific social context, can decide } \\
\text { whether the text can reach its addressees } \\
\text { or not. }\end{array}$ \\
\hline Regulator & $\begin{array}{l}\text { A government or control authority who } \\
\text { gives norms and regulations for how } \\
\text { communication should be maintained } \\
\text { and how texts should be written. It can } \\
\text { be either a national or independent } \\
\text { institution. }\end{array}$ \\
\hline
\end{tabular}

\section{Rhetorical situation of three different promotional genres}

Let us take, as examples, a press release, a brochure, a print ad and a TV commercial promoting Xylo Mepha, ${ }^{86}$ a generic nasal spray for adults and children, marketed by Mepha Pharma AG (a Swiss leader manufacturer and wholesaler of generic pharmaceutical products). The press release titled "Xylo-Mepha - lo spray nasale senza conservanti" ${ }^{87}$ was published on pressportal.ch on October $31^{\text {st }} 2005$ to launch the nasal spray and give information about it; the press release was issued by Mepha Pharma AG and Martina Beranek is indicated as the person to contact in order to have more information about the launch of the product. The

\footnotetext{
${ }^{86}$ The authors asked Mepha Pharma AG for permission to publish images of the press release, the brochure, the print ad, and the TV commercial, but permission was denied.

${ }^{87}$ ["Xyo-Mepha - the nasal spray without preservatives"] Authors' translation.
} 
brochure is composed of 6 pages: the front page shows the picture of a woman and a little girl smiling at each other and the title "Meglio informati sul raffreddore" ${ }^{88}$, the back page gives details about who should use the product (a pack shot of the product is also depicted) and how, internal pages give information on what is a cold. The same image of a woman and a little girl is employed as the visual of the print ad published on SunStore; the headline reads "Raffreddore? Xylo-Mepha Libera il naso in pochi minuti - per ore" $" 89$ and it is matched with the pack shot of the nasal spray. The TV commercial has a problem-solution structure: the viewer sees a woman suffering from a cold and the product Xylo-Mepha, the same woman is then presented happily playing in the snow with her little girl. In the following sections, firstly we characterize the four texts from the point of view of genre, by highlighting the exigence they face and by describing the goal they pursue. Secondly, we identify their stakeholders.

\section{In terms of genre}

These four texts are responses to the producer's exigence of selling the product. The officium of all these four texts is to positively modify this exigence by making the rhetorical audience aware of the factual condition (the Xylo-Mepha nasal spray) and its interest (all the advantages it provides in respect to other nasal sprays), thus awakening in it an exigence (to benefit from Xylo-Mepha nasal spray) that pushes to an action (to buy Xylo-Mepha nasal spray) capable of modifying the producer's exigence of selling the product. This is an exigence that creates a complex rhetorical situation (Bitzer 1968: 12) and, as it is the case for most rhetorical situations in the realm of business communication, a highly structured one (Bitzer, 1968: 12), i.e. a rhetorical situation that employs usual and well-known communicative practices, for which in the course of time a structured rhetorical response has

\footnotetext{
${ }^{88}$ ["Better informed on cold"] Authors' translation.

89 ["Cold? Xylo-Mepha Unblock you nose in few minutes - for hours] Authors' translation.
} 
been elaborated. This structured rhetorical response corresponds to Bakhtinian discourse genres.

Indeed, the whole officium of meeting the exigence of selling the product in the activity type of advertising in the field of business is carried out through the activation of "culturally shared 'recipe[s]"” (Rigotti and Rocci, 2006: 173) of advertising a product, an interaction scheme that relies on the employment of different textual genres. Each of them accomplishes a sub-officium through a given combination of thematic content, style, and compositional structure (cf. Bakhtin, 1986: 60) that has proved to be the most adequate to reach a specific goal. In our case the sub-officia are to announce the launch of Xylo Mepha on the market (the press release), to inform people about how cold develops and Xylo Mepha's positive effects on it (the brochure), to call to the attention the existence and availability of Xylo Mepha (the print ad and the TV commercial).

The complex rhetorical situation described above is broken down into sub-rhetorical situations, which differ in respect to the specific officium and the participants involved in the communication event, that is in respect to the involved stakeholders.

\section{In terms of stakeholders}

The press release, on the one side, the brochure, the print ad and the TV commercial, on the other side, differ in respect to the addressed rhetorical audience. The addressee of the press release (published online on a news portal) ${ }^{90}$ can be identified with both the journalists using the portal and all other users of this website (people who plausibly are interested in recent news). On the one hand, journalists aim at bringing themselves up to date with recent news which they can write articles on, they are also concerned with understanding what kind of product Xylo Mepha is and which advantages it has over similar products. Web-users in

\footnotetext{
${ }^{90}$ The press release is published on presseportal.ch, a service offered by news aktuell (Schweiz) AG, a company of the group of the Swiss national news agency.
} 
general, not working as journalists, are also interested in knowing more about the product, but they may not have a specific goal concerning this product. ${ }^{91}$ The brochure can be both downloaded in pdf format from the organization website and taken in paper version from chemists' (when it is available on the counter), thus addressees are both website users and chemist's clients who need to understand what kind of product Xylo Mepha is and what are its advantages over other nasal sprays. ${ }^{92}$ The print ad is published on the magazine SunStore; therefore readers of SunStore magazine are the addressees of the print ad, the magazine is both sent by mail to Ticinese citizens and available in chemists'. The audience of the TV commercial encompasses all TV viewers: everyone watching TV receives the message and counts as someone being able to positively modifying the principal's exigence of selling Xylo Mepha.

In Bitzer's terms, the speaker/writer of the four texts is Mepha Pharma AG, particularly its managers. According to our framework of stakeholders we name this participant in the communicative event principal. However, at least in the cases of the print ad and of the TV commercial, it is likely that Mepha Pharma AG managers did not produce the text; it is likely that the principal commissioned the creation and production of these two texts to a specialized advertising agency, which holds the role of author. Besides, the print ad had to be "printed somewhere", namely in some specialized magazines devoted to informing pharmacies' clients on different topics and products related to health and wellness. This brings into play another actor, namely the publisher of the magazine, who holds the role of animator of the print ad:

\footnotetext{
${ }^{91}$ Organizations and corporations are getting used to publishing press releases on web portals or on their websites. In such cases, both the wide public and journalists are addressees. However, there still are organizations that do not publish their press releases online. Even in this case, though, it is becoming more and more usual to address the press release to a public wider than journalists. For instance, some organizations, when promoting an event, send their press releases by e-mail not only to journalists, but also to a mailing-list of potentially interested people who are likely to assure the public of the event (we can mention i2a istituto internazionale di architettura of Vico Morcote, Ticino, as an actual example we dealt with in the course of composition described in section 6). Also in this case, the addressees of the press release can be ascribed to different categories.

${ }^{92}$ There exist two groups of addressees because the text is released on two different channels. In business communication, however, addressees often entail different categories, even when the text is released on a unique channel. See as an example the analysis of the addressees of an institutional brochure described in section 6.
} 
by launching it on a communicative channel, he "gives voice" to the text. ${ }^{93}$ Equally, the animator of the press release is the news portal on which it has been published and the animator of the TV commercial is the TV channel which telecasts it.

People to whom the text is not directly addressed but are entitled to take part into the communicative event do not come into play in the press release, ${ }^{94}$ whereas they can be identified as participants of the TV commercial and of the brochure's rhetorical situation. In the case of the TV commercial, children count as ratified participants because, on the one side, as TV viewers, they take part in the communicative event (they can see and hear the message; besides, they are mentioned in the message, both because the text points out that Xylo Mepha is available in a specific dosage for children and because part of the visual stages a girl playing in the snow with her mother and their dog), but, on the other side, they are not directly in a position to positively modify the principal's exigence. In the case of the brochure, ratified participants are health professionals who look through the website for some information on health products and health professionals who subscribed to this website and received the brochure by mail; they wish to know the product and its advantages better. Again, since the brochure is provided on chemists' counters, it is plausible to think of chemists themselves as gatekeepers of the text: they must restock the counter with other brochures when all have been taken. No gatekeeper is identified in relation to the press release; in fact, journalists open and close gates not to press releases but rather to news and their content (cf.

\footnotetext{
${ }^{93}$ In Goffman's examples (which deal with oral discursive practices) the animator offers his voice to the text and activates the text by reading it. Accordingly, in the case of written communication, the actual animation of the text consists in its reading and therefore the recipient and the other receiving stakeholders play also the role of animators. However, in order to be read, the text must be published, visible; the text has to reach its recipients. Therefore, in a sense, in the case of written communication, animators are also those who offer the channel and who activate it on and through that channel, by publishing and printing it.

${ }^{94}$ However, there exist rhetorical situations of press releases in which this kind of participant is present. We can mention again as an example some press releases written by i2a for promoting their expositions. The press releases present both the main artist of the exposition and other artists intervening in various exhibitions usually held during vernissages and finissages. Since they are mentioned in the texts, the artists become ratified participants of the communicative event.
} 
note 4 above). Press releases always reach journalists as addressees, subsequently journalists can decide whether to write an article on that news or not. ${ }^{95}$

Apart from rules regulating the compositional structure and style of press releases as discourse genres, no regulators in terms of stakeholders are recognized. Interestingly, the brochure, the print ad and the TV commercial hint at national norms governing advertisements for medical products. According to the Swiss Ordinance on Advertising for Medical Products only medical products without doctor's prescription can be advertised to the general public. Ads must not be misleading and must not incite an inappropriate use of the product; in a print ad some indication like "This is a medicine. Read carefully the medical instructions" must be added, while at the end a TV commercial (which can be telecast only if it is approved by Swissmedic, the Swiss agency for authorisation and supervision of theraupetic products) must state "This is a medicine. Ask your specialist for advice and read the medical instructions".

In the rhetorical situations of these four texts no bystander can be identified. As we already noticed, the fact that the TV commercial is telecast on a TV channel implies that every TV viewer is an addressee or a ratified participant. Similarly, the fact that the press release is published on a public website implies that every Internet user is a ratified participant. The same can be said for the brochure, which is downloadable from the Mepha website. However, even if we consider the other channel of distribution of the brochure (the chemist), no bystander emerges: when a person enters the chemist, s/he becomes a chemist's customer and, accordingly, s/he assumes the role of addressee. Similarly, when a person picks up the Sunstore magazine at the chemists or takes it in her/his hand at home and browses through it, s/he becomes a Sunstore reader and therefore an addressee.

\footnotetext{
${ }^{95}$ Since more and more frequently organizations publish press releases online, the role of gatekeeper of the journalist is partially reduced (cf. Strobbe \& Jacobs 2005).
} 
On the base of the analysis of these four examples, we can provide a more precise description of the stakeholders of promotional texts (table 2).

Table 2 - Stakeholders of texts promoting Xylo Mepha

\begin{tabular}{|c|c|c|}
\hline Role & Description & $\begin{array}{l}\text { Example from texts } \\
\text { promoting Xylo Mepha }\end{array}$ \\
\hline Animator & $\begin{array}{l}\text { Someone who materially writes a text } \\
\text { by activating a writing technology. }\end{array}$ & $\begin{array}{l}\text { The webmaster of } \\
\text { pressportal.ch who is asked to } \\
\text { upload a press release on the } \\
\text { website. }\end{array}$ \\
\hline Author & $\begin{array}{l}\text { Someone who produces a text } \\
\text { formulating the content and choosing } \\
\text { expressive strategies. The author is often } \\
\text { asked to write a text and to accomplish a } \\
\text { communicative purpose by a } \\
\text { commissioner. In an organization it is } \\
\text { likely to have many authors } \\
\text { (collaborative writing). }\end{array}$ & $\begin{array}{l}\text { An assistant who is asked to } \\
\text { produce a brochure promoting } \\
\text { a new product from Mepha } \\
\text { Pharma AG. He or she is given } \\
\text { some details about the product } \\
\text { itself and about where the } \\
\text { brochure will be distributed. }\end{array}$ \\
\hline Principal & $\begin{array}{l}\text { The principal is the source of the text } \\
\text { content, expressed opinion, and } \\
\text { communicative goal. The author must } \\
\text { realize the principal's communicative } \\
\text { goal when writing. The principal is } \\
\text { responsible, even in legal terms, for the } \\
\text { text. The principal's opinion is } \\
\text { expressed in the text. The principal can } \\
\text { also be an institution or an enterprise. }\end{array}$ & $\begin{array}{l}\text { The director of Mepha Pharma } \\
\text { AG who asks an advertising } \\
\text { agency to produce a print ad } \\
\text { which will promote the new } \\
\text { Xylo Mepha the organization } \\
\text { has just made. }\end{array}$ \\
\hline Addressee & $\begin{array}{l}\text { The person to whom the text is directly } \\
\text { and explicitly addressed. }\end{array}$ & $\begin{array}{l}\text { Readers of Sunstore magazine } \\
\text { where a print ad for Xylo } \\
\text { Mepha is published. }\end{array}$ \\
\hline Ratified participant & $\begin{array}{l}\text { Someone who the text is not directly } \\
\text { addressed to but is entitled to take part } \\
\text { in the communicative event as a right. }\end{array}$ & $\begin{array}{l}\text { A health professional who } \\
\text { receives a paper copy of a } \\
\text { brochure which was mainly } \\
\text { created for chemists' clients. }\end{array}$ \\
\hline Overhearer/Bystander & $\begin{array}{l}\text { Someone who can come in contact - } \\
\text { directly or indirectly - with a text } \\
\text { without either the principal or the } \\
\text { author's knowledge. He is not the } \\
\text { addressee to whom the principal directs } \\
\text { the text. Overhearers include opinion } \\
\text { leaders, who can be affected by the text } \\
\text { even if they are not addressees. The } \\
\text { importance of an overhearer varies } \\
\text { according to the text distribution. }\end{array}$ & $\begin{array}{l}\text { A friend of the journalist who } \\
\text { receives the press release } \\
\text { promoting a new nasal spray } \\
\text { who is informed, by the } \\
\text { journalist himself, about the } \\
\text { product. }\end{array}$ \\
\hline
\end{tabular}




\begin{tabular}{|l|l|l|}
\hline Gatekeeper & $\begin{array}{l}\text { Someone who, thanks to his/her role in a } \\
\text { specific social context, can decide } \\
\text { whether the text can reach its addressees } \\
\text { or not. }\end{array}$ & $\begin{array}{l}\text { The chemist's assistant who is } \\
\text { in charge of restocking the } \\
\text { counter with brochures and } \\
\text { who does not do it. }\end{array}$ \\
\hline Regulator & $\begin{array}{l}\text { A government or control authority who } \\
\text { gives norms and regulations for how } \\
\text { communication should be maintained } \\
\text { and how texts should be written. It can } \\
\text { be either a national or independent } \\
\text { institution. }\end{array}$ & $\begin{array}{l}\text { The Swiss Federal Council } \\
\text { gives guidelines about how } \\
\text { medical products must be } \\
\text { advertised in the Ordinance on } \\
\text { Advertising for Medical } \\
\text { Products. For example, only } \\
\text { non-prescription drugs, such as } \\
\text { Xylo Mepha, can be advertised } \\
\text { to the general public. }\end{array}$ \\
\hline
\end{tabular}

\section{Educational application}

The notion of stakeholders and the classification presented above have been introduced in a bachelor course of composition at the Faculty of Communication Sciences of the University of Lugano. Concretely, students were asked to write texts of organizational genres (such as letters, press releases, reports, proposals, brochures, leaflets, interviews) in order to face actual communication needs of actual (local) organizations (which agreed to play the role of principals). For instance, some students had to write press releases and the related email cover letters for the promotion of expositions by $\mathrm{i} 2 \mathrm{a}$, as well as leaflets and letters for the promotion of some of i2a laboratories for kids; other students were asked to produce a sponsoring dossier, a magazine and the corresponding email cover letter for promoting Lugano LongLake Festival, a summer event organized by the Youths and Events Department of Lugano; other students were asked to conceive a new and more effective format for the annual report of the Federation of the non-governmental organizations of Italian Switzerland (FOSIT), as well as a new brochure for the institutional presentation of the federation and a press kit.

Before starting the writing of the committed texts, students were asked to identify the text's stakeholders according to the above exposed classification and to describe stakeholders in terms of role, attitudes, needs, aspirations, desires, 
knowledge, goals, relationship to other stakeholders. The stakeholder's description method was inspired by the methods of audience analysis exposed by Schriver (1997: 154-162), particularly by the classification-driven analysis and by the intuition-driven analysis. The description encompassed the two main dimensions of communication context according to Rigotti and Rocci's (2006) model: the institutional dimension and the interpersonal dimension.

Such a detailed description of stakeholders - and the in-depth understanding of the rhetorical situation of texts it allows us to reach - can be a valuable tool for the teaching of composition and it provides students with a conceptual tool that sustains them in achieving effectiveness in business functional communication. Starting from the assumption that a text is effective when it achieves its goal, that is, when it positively modifies the exigence from which it stemmed, and considering that one of the essential components of a text's effectiveness is its adequacy to the rhetorical situation, a precise and concrete identification of the stakeholders of a text makes students aware of the very situated character of each text and helps them in producing texts adherent and relevant to the exigence. For instance, a detailed description of the stakeholders of the institutional brochure for FOSIT shows that addressees belong to different categories with different needs and imposing different requirements on the text, which have an impact on the choice of the brochure contents. The addressees are Italian Swiss non-governmental organizations which are considering whether to join the federation, actual and potential sponsors as well as the media and all the Italian Swiss population. It is important for them all to know that the federation exists and what it does, which are the affiliated NGOs and which projects are being carried out. However, this is not sufficient information either for potential sponsors (who may want to know also how the federation is organized and managed and which is its 
actual financial situation) or for NGOs interested in becoming members of the federation (which also want to know who can join it, how and when, and which advantages this affiliation would have for them). Besides, the analysis of stakeholders outlines that affiliated NGOs are ratified participants of the brochure: they care that the image of the federation and of themselves that emerges out of the text corresponds to the set of values that leads them and that convinced them to join FOSIT.

In fact, such a conceptual tool can be useful in order to shape and build into the text the implied writer and the implied reader (Jameson 2004a, 2004b). As Jameson (2004a) points out, the implied writer and reader do not coincide with the live writer and reader, but they are a "subset of the whole, complex person" (392). "The whole, live human being who writes is never exactly the same as the writer's representation of self implied in the text" (Jameson, 2004b: 231). By becoming aware of the stakeholders of the texts and of the needs, exigencies and requirements of those stakeholders (which emerge in the stakeholders' description), students can be supported in eliciting the traits and aspects of concrete and real stakeholders that has to be coped with in order to build into the text an adequate implied writer and an adequate implied reader. In this perspective, composition exercises such as the following one can be developed: students are given the examples we have analyzed above as sources, that is, texts from which they can retrieve some useful information about the organization and its products. After describing the rhetorical situation for each text and its stakeholders, students are asked to produce, for instance, a letter by a chemist asking to be sent more brochures and some other promotional material together with more Xylo Mepha to sell (this letter will be sent together with the formal commercial order for more products). In such an exercise students will for instance realize that some participants in the communication event of the brochure and of the letter they have to write are the same (Mepha Pharma, chemist), but they play different roles, they are different stakeholders: in the communication event of the 
brochure Mepha Pharma is the principal (and maybe also the author) and the chemist is a ratified participant as well as a gatekeeper, while in the communication event of the letter Mepha Pharma is the addressee and the chemist is the principal (while students play the role of authors). The "situatedness" of each text will therefore emerge: even if the two texts refer roughly "to the same thing", the communication event they realize is different. Besides by describing these two stakeholders and, for instance, their usual relationship, students discover how to implement the characteristics of real stakeholders in the text, particularly in the implied writer and reader. As to our example, for instance, is the relationship between Mepha Pharma and the chemist a formal one or a confidential one? And is it usual for chemists to require additional brochures or not? Does it often happen that the number of brochures Mepha Pharma thought to be sufficient is in fact insufficient? Accordingly, has the letter's implied writer to be someone who is expressing a normal routine-based request to a colleague he is used to contacting for lots of big and small problems and questions or someone who is risking an unusual request to a corporation with which he usually does not interact?

\section{Conclusion}

In this contribution we have attempted to answer the question 'who is communicating to whom in promotional genres'. Taking examples - a press release, a brochure, a print ad and a TV commercial promoting a nasal spray - from the marketing communication domain, we have presented our rhetorical approach. Its application to texts belonging to different domains has been only briefly described; a wider illustration would be possible (and will be the theme of future works), but it is out of the scope of the present paper, which aims at providing an illustrative example of the interest of the model of stakeholders of a text.

The fundamental concepts of our approach are those of rhetorical situation, genre and stakeholders. 
All the participants in a communicative event are stakeholders since they are interested in the success of the communication taking place. Communication arises for an exigence, which is a kernel element in every rhetorical situation. Texts are communicative events arising within a specific context in order to adhere to this specific exigence. The contextbound goal is achieved using communicative tools known as discourse genres, which are shared flexible recipes for communication that stakeholders can interpret and produce according to their goals. Texts such as the examples we have presented here show that texts with similar goals - that of promoting a product - apply to different rhetorical situations where various stakeholders play specific roles.

Adherence to rhetorical situations and stakeholders is crucial for the communicative success of texts in business communication. Therefore, we believe that this approach, especially the model of stakeholders, is a valuable tool not only for understanding a text but also for teaching how to produce effective texts in organizational and business realms.

\section{References}

Askehave, I. and J. M. Swales. "Genre identification and communicative purpose: a problem and a possible solution.” Applied Linguistics. 22, no. 2 (2001): 195-212.

Atkin, A. and J. E. Richardson. "Constructing the (imagined) antagonist in advertising argumentation." Edited by F. H. van Eemeren and P. Houtlosser. Argumentation in Practice, 163-180. Amsterdam/Philadelphia: John Benjamins Publishing Company, 2005

Bakhtin, M. Speech Genres and Other Late Essays. Austin: University of Texas Press, 1986.

Bitzer, L. F. “The rhetorical situation.” Philosophy and Rhetoric. 1, (1968): 1-14.

Bitzer, L. F. "Functional communication: A situational perspective.” Edited by E. E. White. Rhetoric in transition: Studies in the nature and uses of rhetoric, 21-38. PA: Pensylvanian State University Press, 1980. 
Brierley, S. The Advertising Handbook. London/New York: Routledge, 1995.

Bühler, K. Sprachtheorie. Jena, 1934.

Calabrese, S. Retorica del linguaggio pubblicitario. Bologna: Archetipolibri, 2008.

Cantoni, L. et al. Comunicazione, qualità, usabilità. Milano: Apogeo, 2003.

Clark, H. Using language. Cambridge University Press, 1996.

Cook, G. The Discourse of Advertising. London and New York: Routledge, 2001.

Corbett, E. P. J. and R. J. Connors. [1965]. Classical rhetoric for the modern student, New York/Oxford: Oxford University Press 1999.

Freeman, R. E. Strategic management: a stakeholder approach. Boston: Pitman, 1984.

Goffman, E. Forms of talk. Philadelphia: University of Pennsylvania Press, 1981.

Greco-Morasso, S. “The Argumentum experience.” Edited by N. Muller Mirza and A. N. Perret-Clermont. Argumentation and Education. Theoretical foundations and practices, 215-235. Dordrecht: Springer, 2009.

Kinneavy, J. E. "The basic aims of discourse." College Composition and Communication. 20, no. 5 (1969): 297-304.

Kinneavy, J. E. A theory of discourse. The aims of discourse. NJ: Pretice Hall, 1971.

Jameson, D. A. "Implication versus inference. Analyzing writer and reader representations in business texts.” Business communication quarterly. 67, no. 4 (2004a): 387-411.

Jameson, D. A. “Conceptualizing the writer-readers relationship in business prose.” Journal of business communication. 41, no. 3 (2004b): 227-264.

Lewin, K. "Frontiers in group dynamics.” Human relations. 1, no. 2 (1947): 143-153.

Mazzali-Lurati, S. "Genere e portatori di interesse: due nozioni-chiave per la scrittura nelle organizzazioni." Cultura e Comunicazione. 3, (2011): 12-18.

McCawley, J.D. "Participant roles, frames, and speech acts." Linguistics and Philosophy. 22, (1999): 595-619. 
Perrone, V., Bolchini, D. and P. Paolini. “A Stakeholders Centered Approach for Conceptual Modelling of Communication-Intensive Applications." Proceedings of the $23^{\text {rd }}$ annual international on design of communication. Documenting and designing for pervasive information, 2005

Post, J. E. et al. Redefining the corporation: Stakeholders management and organizational wealth. Stanford: Stanford University Press, 2002.

Rigotti, E. and S. Cigada. La comunicazione verbale. Milano: Apogeo, 2004.

Rigotti, E. and S. Greco-Morasso. "Communication: Semiotic approaches.” Edited by K. Brown. Encyclopedia of Language and Linguistics, 658-666. Amsterdam: Elsevier, 2006.

Rigotti, E. and A. Rocci. "Towards a definition of communication context. Foundations of an interdisciplinary approach to communication." Studies in Communication Sciences. 6, no. 2 (2006): 155-180.

Schriver, K. Dynamics in document design. New York: John Wiley \& Sons, 1997.

Wolf, M. Teorie della comunicazione di massa. Milano: Bompiani, 1996. 


\title{
The Representation and Reception of Paraphrase in Newspaper Headlines
}

\author{
Anita Runjić-Stoilova \& Josip Galić, University of Split
}

\section{Summary}

Newspaper headlines are specific types of texts in which one or more words announce the following article. The basic functions of the headline are to inform the reader and attract his/her attention. In order to successfully inform, the headline has to provide answers to one or more basic questions (who, what, where, when, why). The headline also has to attract the attention of the reader by the means of figurativeness which arises not only from the positional prominence and the graphic features of the headline, but also as a result of specific linguistic combination and arrangement of various parts of the message within the whole.

The paraphrase is a common figure in newspaper headlines. This term signifies a basic rhetorical process of statement development, as well as a macro-structural stylistic figure. With regard to discursive basis, we differentiate between four types of paraphrase: linguistic, commentary, literary and ludic.

The purpose of this study was to identify the frequency of ludic paraphrases in daily (Slobodna Dalmacija and Vjesnik) and weekly newspapers (Nacional and Globus) as well as to test the knowledge and understanding of modified phrases used in the headlines on two groups of selected examinees. The initial hypothesis about the differences in the usage of paraphrases between daily and weekly newspapers was confirmed. The analysis of percentages of paraphrased headlines recognized by examinees revealed different levels of understanding.

Key words: journalistic discourse, figurativeness, newspaper headlines, paraphrase

\section{Introduction}

\subsection{Headline, figurativeness, journalistic discourse}

Newspaper headlines are specific types of texts in which one or more words announce the following article. The headline takes the central place in the text: it is graphically separated from the text body and often classified in the group of small texts (phrases, proverbs, catchwords, aphorisms, jokes, graffiti etc.) (Halliday, 1994: 392-397, in Ivas, 2004). 
The basic function of the headline is defined in its positional prominence, the purpose of which is to attract the reader's attention and inform the reader about the basic content of the text body. The above mentioned functions represent the pragmatic and semantic roles of the headline (Iarovici and Amel, 1989) and they form the basic requirements of the journalistic style. The semantic role is evident in the text body and the pragmatic role is evident in the effect it exerts on the reader. In order to successfully inform, the headline has to provide answers to one or more basic questions (who, what, where, when, why). The headline also has to attract the attention of the reader through a figurativeness which arises not only from the positional prominence and the graphic features of the headlines, but also as a result of distinct linguistic choice and specific arrangement of parts of the message within the whole (Tošović, 2002; Silić, 2006).

The journalistic style is also known as the hybrid style (Pranjić, 1968: 17) because it includes features of other functional styles such as literary, scientific, administrative and conversational, according to the type of the newspaper text (news, report, paper, review, interview, chronicle...) (Tošović 2002: 242, 250).

The headline strongly relies on figurativeness - it must adhere to principles of language economy and transfer a meaningful message to another person. That message has to arouse the interest of the reader (Veselica-Majhut 2006: 753). The construction of newspaper headlines changes depending on the type of audience targeted, the historical context, generation, gender, age of the reader, etc. The pragmatic and semantic function of the headline is to point to an extra-textual reality, thus other texts to which a headline also refers become an inter-textual junction or the reader's connection with the author of the text (Ivas 2004: 14). The headline's compact format enables its function as a paraphrase.

Figurativeness is very important in newspaper headlines. A figurative device is created through a special arrangement of language and it serves to fulfill most of the headline's 
functions (Ivas, 2004). Recognition of figurativeness reveals the reader's level of education and cultural awareness, as well as a capacity for abstract thinking. In addition, headlining is challenging for the reporter because he/she has to keep in mind the audience addressed, presume their level of cultural experience and also successfully attract attention, entertain or disturb the audience. Even when it is not clearly figurative, the headline takes on this function because of its positional prominence in regard to the addressed text. Figurative devices in the headline additionally assert its independence from the text body. The headline or newspaper article does not necessarily have to employ figurativeness: the frequency or lack of figurative language use depends on the type of news and also on the journalist's style and skill. These characteristics generate differences between newspapers.

The most common type of figurative speech in a headline in addition to metaphor and metonymy is paraphrase.

\subsection{Paraphrase - the history of the term}

The term paraphrase derives from the Greek word paráphrasis meaning description, loose translation. It signifies the fundamental rhetorical process of statement development, and functions as a macro-structural stylistic figure. In both cases paraphrase refers to rewriting, retelling, reworking of a sentence or statement (Bagić, 2007).

In the $20^{\text {th }}$ century the term paraphrase became obsolete in language and literature. Aestheticians, literary theorists and linguists today often discuss paraphrase with negative connotations, defining it as a simplification of serious discourse. A pejorative meaning can frequently be found in everyday communication, as we think about paraphrase as chaotic, bulky and imprecise commentary (Bagić, 2007). Many linguists have adopted a broader definition of paraphrase. They define it as a restatement of a text in another form or in other words, often to simplify or clarify meaning. For example Crystal (2003) says that it is a term 
used in linguistics for the result or process of producing alternative versions of a sentence or text without changing the meaning. One sentence may have several paraphrases, e. g. The dog is eating a bone, A bone is being eaten by the dog, It's the dog who is eating a bone, and so on (Crystal, 2003: 336). Most semantic theories would treat all these sentences as having a single semantic representation. Linguists use syntactic paraphrase as a major procedure for establishing certain types of transformational relations (Crystal, 2003: 336).

In spite of the neglect of paraphrase in the $20^{\text {th }}$ century, this has not always been the case: in ancient Greece and Rome paraphrase was the most important exercise in the education of orators, writers and intellectuals. Pupils were asked to reformulate or paraphrase a text or a phrase. It was also recommended by the great rhetoricians Quintilian and Hermogen. Quintilian described it as the best method for a basic understanding of the text. However, he warned against using a paraphrase as a literal translation of the original, but rather advised that it should compete with the original in expression of thought (Quintilian, 1986). Ancient Romans recommended three types of periphrastic reformulation: (1) Latin translation of Greek orators, (2) prose paraphrase of Latin poetry and (3) rewriting their own texts (Bagić, 2007). Therefore, Greeks and Romans defined paraphrase more as a process of statement development than as a macro-structural stylistic figure.

Quintilian's definition of paraphrase is also confirmed by some modern-day linguists: "telling, describing, formulating thoughts and names with different or clearer words" (Anić, 2006: 996); it could be said that paraphrase is "modifying the known phrase in a way that it remains recognizable but with a new meaning" (Škarić, 2000: 127). Paraphrase can therefore appear: (1) as a fundamental rhetorical process of statement development and (2) also as a macro-structural stylistic figure. In the first case the meaning of the original is preserved, while in the second case the original phrase is usually used as a suitable framework for semantic changes (Bagić, 2007: 38). With regard to the discursive basis we differentiate 
between four types of paraphrase: linguistic, commentary, literary and ludic (Bagić, 2007).

This paper focuses on the fourth type of paraphrase. The term ludic paraphrase implies the intervention into structurally and semantically canonized statements such as proverbs, clichés, collocations, titles of books, titles of songs, titles of films, etc.

\section{Purpose and hypothesis}

Because this research was divided in two parts, there are also several goals and hypotheses. In the first part of the research the goals were (1a) to determine the representation of paraphrase in daily and weekly newspapers' headlines and (1b) to determine the frequency in the use of paraphrase between daily and weekly newspapers. In the second part of the research the goal was (2) to analyze the reception of newspaper headlines between two different groups of examinees.

The hypotheses were divided in two groups, those relating to representation and those relating to reception. The hypotheses related to the representation were the following: (1a) the analysis of the corpus will show certain differences in the usage of paraphrase in daily and weekly newspapers; (1b) more frequent usage of paraphrases is expected in weekly paper headlines due to the dominance of a pragmatic over a semantic function of the headlines; (1c) the daily newspaper Slobodna Dalmacija will contain more paraphrases than Vjesnik. These two daily papers target very different readerships, which is why there are certain differences in the structure of their headlines. Despite its low circulation, Vjesnik ${ }^{96}$ was among the best daily papers on the market, singled out in its serious approach to journalism and professional treatment of information ${ }^{97}$. However, this research will not focus on an analysis of the

\footnotetext{
${ }^{96}$ The daily newspaper Vjesnik stopped being published in 2012 after 72 years.

${ }^{97}$ This is the opinion held by many eminent Croatian experts such as judges of the Supreme court, directors of different institutions, union leaders, and cultural and scientific staff. http://www.vjesnik.hr/Article.aspx?ID=221DA256-F05C-4D98-8585-5F349DCE7BBF).
} 
difference between these newspapers on the content level, but rather on the difference between quality and popular newspapers - a differentiation common in Anglophone societies (Veselica, Majhut, 2006: 455). Therefore, it is presumed that Slobodna Dalmacija, as a popular newspaper, will contain more inter-textual games (paraphrases) than a quality paper such as Vjesnik. Finally, (1d) the presumption is that, unlike the daily newspapers, weekly papers will contain equal frequency of paraphrasing.

The presumptions of the second part of the research were the following. (2a) There will be certain differences between two groups of examinees in the reception of paraphrases. The largest differences were expected for buzz words and phrases, which are limited just to one generation or social group. Along with this basic assumption, additional differences in the reception of paraphrases in relation to gender, level of education and cultural awareness were examined. (2b) It is expected that educated examinees, regardless of age and gender, will recognize historical, mythological and literary paraphrases more frequently.

\section{Research methodology}

Research was conducted in two parts. The representation of paraphrase in newspaper headlines was examined in the first part. For this purpose headlines from Croatian daily papers (Slobodna Dalmacija and Vjesnik) and weekly newspapers (Nacional and Globus) were collected and analyzed. Data were not collected systematically because the goal was not to compare the frequency of paraphrases in various papers during the same period. Thirty-one 
copies of each daily paper from August till December 2011, and thirty-one copies of each weekly paper from October 2009 till December 2011 were analyzed.

In the second part of research the reception of paraphrases within two groups of examinees was analyzed. There were 80 examinees, 40 younger and 40 older ones.

Respondents were given a questionnaire with 57 paraphrased headlines from the first part of the research. In the first part of the questionnaire basic demographic data were collected (age, gender, level of education, profession). Also data about examinees' cultural awareness (reading books and magazines, going to the theatre, doing quizzes) were gathered. For the last two questions (general and cultural awareness) respondents were offered scaled answers: rare (less than 5), periodically (from 5 to 10), regularly (more than 10). In the second part of the questionnaire, the respondents had to suggest the original form of the modified headline, eg. for the proverb Through the mud to the stars ${ }^{98} /$ Preko blata do zvijezda $a^{99}$ they had to write Through the thorns to the stars / Preko trnja do zvijezda. The authors of this paper wanted to ascertain the recognition of the original form of the paraphrase which would enable readers to have a better reception of the headlines.

In order to ascertain the degree of the recipients' recognition and understanding of paraphrases in headlines, the questionnaire was given to 80 examinees. The first group consisted of 40 undergraduate and graduate students of Croatian Language and Literature at the Faculty of Philosophy in Split and their average age was 22. The second group consisted of 40 examinees and their average age was 56. In the first group, most of the examinees enrolled in undergraduate and graduate programs after completing gymnasium high schools (78\%). In the second group, examinees with completed high school education were

\footnotetext{
${ }^{98}$ Per aspera ad astra or Ad astra per aspera is a Latin phrase which means any of the following: "Through hardships to the stars", "A rough road leads to the stars" or "To the stars through difficulties". The phrase is one of many Latin sayings which use the expression $\underline{\text { Ad astra. }}$

${ }^{99}$ Since the examples were collected from Croatian newspaper, they will be always presented both in Croatian and English. The meaning of the examples discussed or used for illustration will also be explained the first time they appear.
} 
predominant (63\%), while only $37 \%$ of examinees only completed a high school education.

In the first group the women to men ratio was $80: 20 \%$ and in the second group it was $25: 75 \%$.

\section{Results and Discussion}

4.1. Representation of paraphrase in daily and weekly newspapers

In the overall corpus of nine thousand eight hundred sixty-six headlines fifty-seven headlines with some paraphrastic conversion were found. In the headlines extracted from the corpus, journalists arranged known lexical groups - phrases, movie titles, songs, books, lyrics, classical proverbs - into new combinations. They modified them to produce an allusion, a game between the original and its transformations.

As it has been expected, the analysis of the representation of paraphrases in daily and weekly papers revealed some differences. In the ratio of paraphrased and non-paraphrased headlines the results are the following: in daily papers twenty paraphrases were extracted from the total number of seven thousand ninety-five headlines, which makes up "only" $0.28 \%$ of the corpus, while in weekly papers thirty-seven paraphrases were extracted from the total number of two thousand seven hundred seventy-one, which makes up $1.34 \%$ of the corpus. This difference is also confirmed with the measure of frequency defined in the absolute number of paraphrased headlines. 


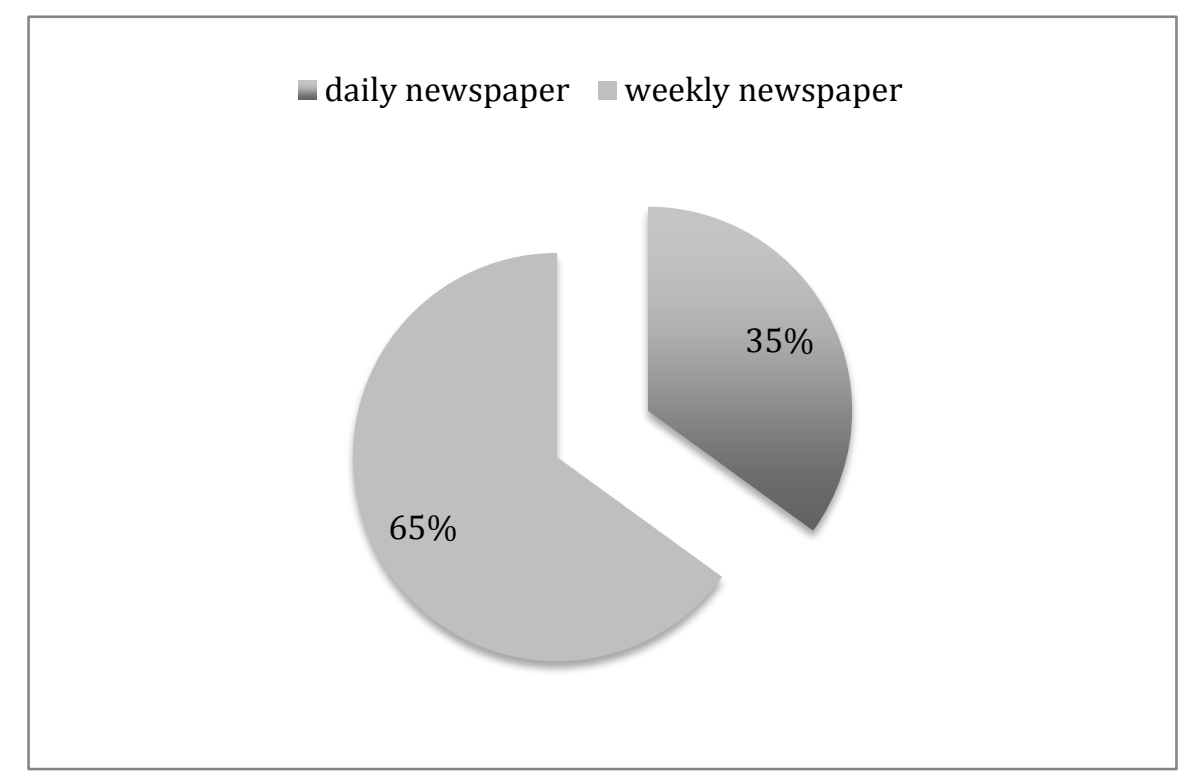

Figure1 Percentage of paraphrases in daily and weekly newspapers

In daily papers twenty paraphrases were found, which amounts to $35 \%$ of the total number of selected headlines, while thirty-seven paraphrases were found in weekly papers, which amounts to $65 \%$ of the total number of selected headlines. The results (both in the ratio of paraphrased and non-paraphrased headlines and in the absolute number of paraphrased headlines) confirmed the hypothesis that weekly papers contain more paraphrases than daily papers. The first reason lies in their requirements. The first requirement of daily newspapers Slobodna Dalmacija and Vjesnik is to inform the readers. In the headlines this could be explained through the dominance of their semantic over pragmatic function and consequently the reduced number of paraphrases. On the other hand, weekly newspapers form more casual discourse the function of which is to entertain the readers in addition to being of an informative character.

The analysis revealed differences in representation of paraphrase not only in daily papers, but also in weekly papers. The measure of frequency in the ratio of paraphrased and non-paraphrased headlines showed the following results: twelve paraphrased headlines out of a total number of four thousand one hundred eighty-four headlines were found in Slobodna Dalmacija, which makes up $0.29 \%$ of the corpus and eight paraphrased headlines out of two 
thousand nine hundred and eleven headlines were found in Vjesnik, which makes up $0.27 \%$ of the corpus. Furthermore, twenty-eight paraphrased headlines out of one thousand one hundred forty-seven headlines were found in weekly paper Nacional (2.4\%), and only nine paraphrased headlines out of total number of one thousand six hundred twenty-four headlines were found in Globus $(0.55 \%)$.

These results are also confirmed by the measure of frequency defined in the absolute number of paraphrased headlines. Twelve out of twenty paraphrases in daily papers were found in Slobodna Dalmacija (60\%), and eight paraphrases were found in Vjesnik (40\%), which confirms our previous hypothesis about the difference in addressing readership between popular and quality newspapers. A greater difference was found in the usage of paraphrase in each weekly newspaper. Twenty-eight out of thirty-seven paraphrases in weekly papers were found in Nacional (76\%), and nine paraphrases were found in Globus (24\%). These relations are presented in Figure 2 and Figure 3.

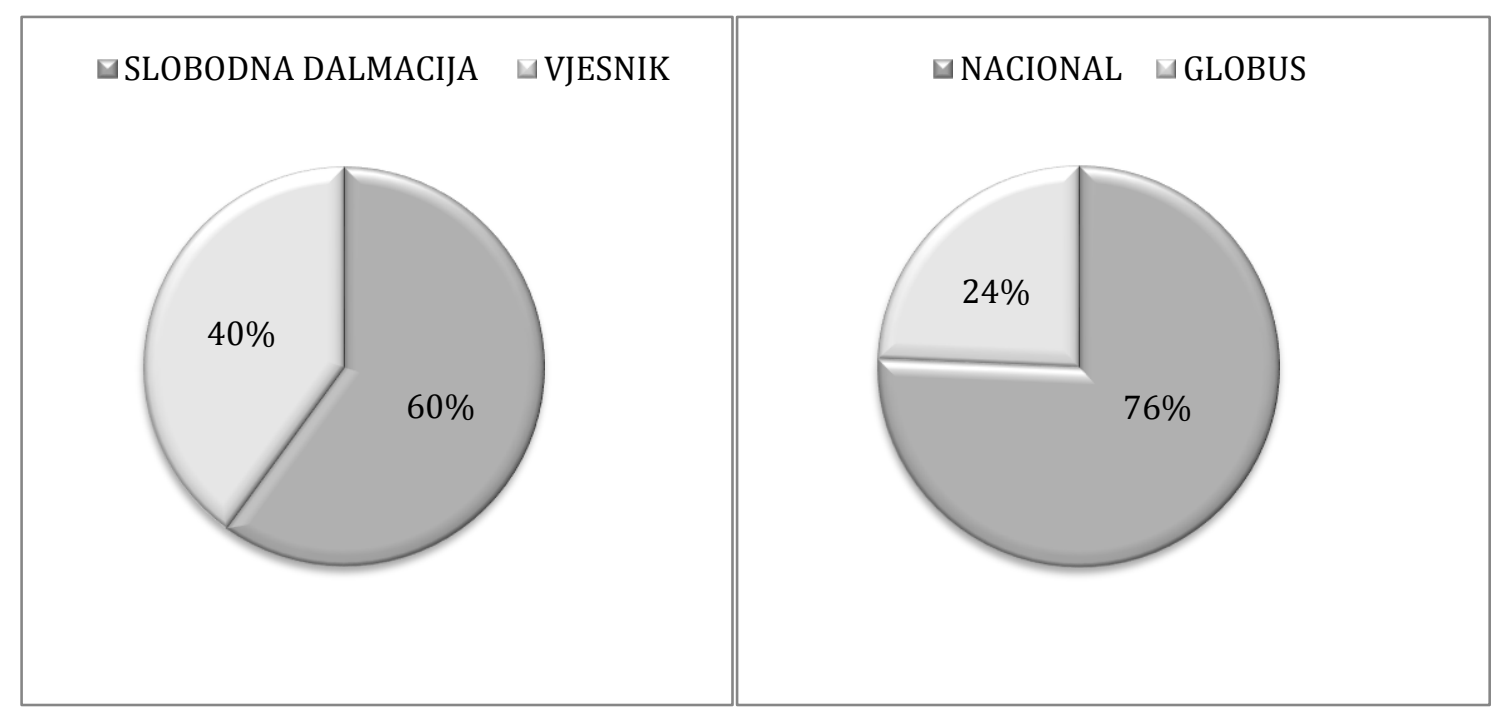


Figure 2. Representation of paraphrase in daily newspapers
Figure 3. Representation of paraphrase in weekly newspapers

4.2. Reception or recognition of paraphrase in daily and weekly newspapers

In the second part of the research, slight differences in the understanding of modified phrases were revealed between the two groups of examinees. The results represented show differences between examinees only on the basis of their age not on their level of education or cultural awareness. The older examinees have $45.8 \%$ correct answers in relation to attempting to answer $68 \%$ of the time, while younger examinees have $49.8 \%$ of correct answers in relation to attempting to answer $62 \%$ of the time. See Chart 4.

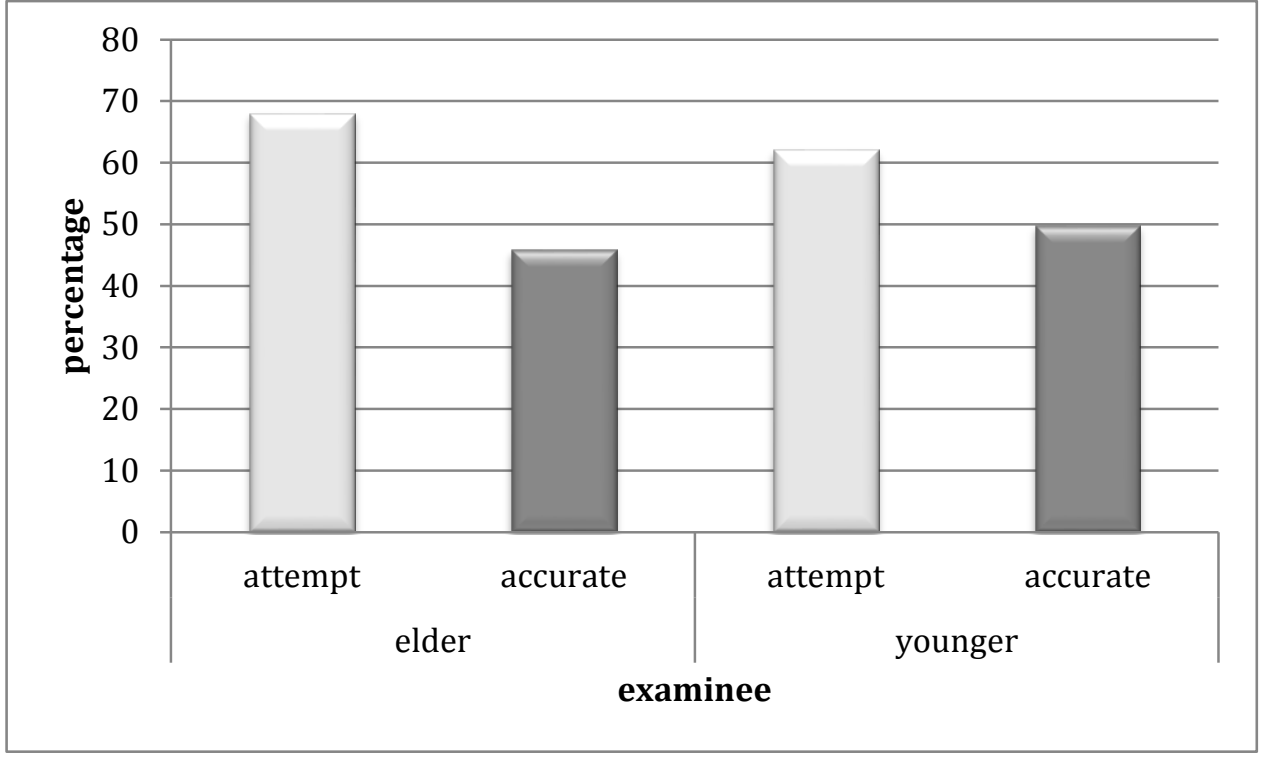


Figure 4 Attempted and accurate reconstructions of headlines by both groups of examinees

More detailed analysis or individual results showed differences in recognizing paraphrases due to the respondents' general and cultural awareness (literacy, general culturedness, cultural immersion). The questionnaires revealed that $23 \%$ of the student population regularly follows cultural events, ${ }^{100}$ and that $57 \%$ of them do so occasionally. This was not the case with the older population, because they attend cultural events to a much lesser degree (or perhaps they were simply more sincere in their answers). Only $7.5 \%$ of older examinees are regular readers and $58 \%$ are occasional readers. The results concerning global awareness ${ }^{101}$ of the examinees are somewhat different: both groups of examinees are equally well informed by the media (48\%).

Therefore, there were obviously significant individual differences in the degree of recognition of the paraphrased original. Just attempting to reconstruct the model informed us of the examinee's ability to recognize the origin of the paraphrased headline: the number of recognized sources of headline paraphrases ranged from $26 \%$ to $88 \%$.

\subsubsection{Different degrees of reception of headlines by younger examinees}

Younger examinees showed different stages of recognition of headlines from the corpus. According to the percentage of successful original form reconstruction, results can be divided in four groups:

A. Maximum degree of recognition in which 75-100\% of examinees recognized a group of 15 paraphrases. This is $26 \%$ of the corpus. Here are some examples. ${ }^{102}$ The Dalmatian folk song title Šime is back / Vratija se Šime is recognized by $100 \%$ of examinees in the headline Drago is back / Vratija se Drago. The famous movie title Lassie come home / Lassie se vraća kući

\footnotetext{
${ }^{100}$ Cultural events include visiting theatre, cinema, museums and so on.

${ }^{101}$ General awareness refers to internet usage, reading a newspaper, listening to the radio, watching television...

102 All examples are in Appendix 1.
} 
was recognized by $98 \%$ of examinees in the headline Kobe Bryant come home / Kobe Bryant se vraća kući. The old proverbs Pay so you can mock / Plati pa se rugaj and Through the thorns to the stars / Preko trnja do zvijezda are recognized by $90 \%$ of the examinees in the headlines Pay so you can swim / Plati pa se kupaj and Through the mud to the stars / Kroz blato do zvijezda. $75 \%$ of examinees knew that the headline Spices against humanity / Začini protiv čovječnosti comes from the phrase Crimes against Humanity / Zločini protiv čovječnosti.

B. Second degree of recognition in which 50-74\% of examinees recognized a group of 16 paraphrases which makes up $28 \%$ of the corpus. For example ${ }^{103}$, examinees recognized the movie title Lost in translation / Izgubljeni u prijevodu in the headline Lost in the institution / Izgubljeni u zavodu (73\%) and the Czech movie My Sweet Little Village / Selo moje malo in the headline My sweet nuclear village / Selo moje nuklearno (63\%). "Only" 58\% of examinees recognized Croatian National Tourist Board / Hrvatska turistička zajednica in the phrase Croatian National Tourist Deception / Hrvatska turistička obmana. The Latin phrase Man is wolf to another man ${ }^{104} /$ Čovjek je čovjeku vuk is identified by $55 \%$ of the examinees in the headline Croat is a Serb to another Croat / Hrvat je Hrvatu Srbin.

C. Third degree of recognition in which $25-49 \%$ of examinees recognized a group of 12 paraphrases, which is $21 \%$ of the corpus. E.g. in the headline Mulder without Scully / Mulder bez Scully, $43 \%$ of examinees recognized the characters Mulder and Scully from TV series The X-Files. One of the most famous rallying cries of communism Workers of the world, unite! / Proleteri svih zemalja, ujedinite se! was identified by $33 \%$ of the respondents in the exclamation Croatists and Slavists, unite! / Kroatisti i slavisti, ujedinite se! The James Bond movie From Russia with love / Iz Rusije s ljubavlju was also identified by $33 \%$ of the examinees in the headline To Russia with love / Rusiji s ljubavlju.

\footnotetext{
${ }^{103}$ For other examples see Appendix 1.

${ }^{104}$ Homo homini lupus est is a Latin phrase meaning "man is wolf to (his fellow man)." First attested in Plautis' Asinaria.
} 
D. Minimum degree of recognition in which 0-24\% of examinees recognized a group of 14 paraphrases which makes up $25 \%$ of the corpus. For example, the TV commercial slogan for the Croatian National Tourist Board The Mediterranean as it once was / Mediteran kakav je nekad bio was recognized by only $15 \%$ of the examinees in the headline Istria as it once was / Istra kakva je nekad bila. No one recognized the movie title Closely watched trains ${ }^{105}$ / Strogo kontrolirani vlakovi in the headline Closely watched bulls of arts / Strogo kontrolirani bikovi umjetnosti.

The younger examinees who were unable to identify the original phrase stated their own modification of headlines or they connected them to a similar one. We will quote several examples. The headline was Sanader ${ }^{106}$ stole my Christmas / Sanader mi je ukrao Božić. Examinees recognized the movie How the Grinch Stole Christmas ${ }^{107} /$ Kako je Grinč ukrao Božić but mostly suggested a modified version of it - The Grinch Stole my Christmas / Grinč je ukrao moj Božić. The second example is the headline Grandma and her Credits are Gone / Prošla baba s kreditima, which the examinees identified as Grandma and her candies/cookies/eggs are gone / Prošla baba s bombonima/kolačima/jajima. The original phrase is Grandma and her cookies are gone 108 / Prošla baba s kolačima.

\subsubsection{Different degrees of reception of newspaper headlines by older examinees}

Older examinees also showed different degrees of the recognition of headlines. The corpus can be divided into several groups according to the percentage of successful original form reconstruction.

A. Maximum degree of recognition in which $75-100 \%$ of examinees recognized a group of 11 paraphrases, which makes up $19 \%$ of the corpus.

\footnotetext{
${ }^{105}$ A Czech movie from 1966. Director Jiri Menzel was the recipient of the Academy Award for Best Foreign Language Film that year.

${ }^{106}$ Ivo Sanader, former Croatian Prime Minister, now under investigation for embezzlement.

${ }^{107}$ It is a children's story by Dr. Seuss, adapted as an animated special in 1966.

${ }^{108}$ Croatian proverb meaning "somebody missed his chance", "when it's over it's over".
} 
B. Second degree of recognition in which 50-74\% of examinees recognized a group of 15 paraphrases which makes up $26 \%$ of the corpus.

C. Third degree of recognition in which $25-49 \%$ of examinees recognized a group of 11 paraphrases which makes up $19 \%$ of the corpus.

D. Minimum degree of recognition in which $0-24 \%$ of examinees recognized a group of 14 paraphrases which makes up $25 \%$ of the corpus ${ }^{109}$.

Some individuals from the older group of examinees who were also unable to identify the original form of a paraphrase developed their own modifications. For example the headline was Through the mud to the stars / Preko blata do zvijezda and the examinees identified it as Through the mud to freedom / Preko blata do slobode instead of the proverb Through the thorns to the stars / Preko trnja do zvijezda. Another interesting modification was for the headline In search of lost innocence / U potrazi za izgubljenom nevinošću. Examinees stated the phrase In search of a lost suitcase / U potrazi za izgubljenim kovčegom instead of the original book title In Search of lost time $e^{110} /$ U potrazi za izgubljenim vremenom. For many examples the examinees had broader associations, e.g. the headline The curse of Prime Minister Sanader / Sanaderova kletva which is a paraphrased old Croatian curse The curse of King Zvonimir ${ }^{111}$ / Zvonimirova kletva. However, the examinees identified the headline as Remetinec ${ }^{112}$ or Whoever digs a pit (for another man's feet) shall fall into it himself. / Tko pod drugim jamu kopa ${ }^{113}$ or To have and have not ${ }^{114}$ / Dabogda, imao pa nemao.

It has already been said that two groups of examinees can hardly be differentiated on the bases of overall results in the understanding of paraphrases. Therefore, our previous

\footnotetext{
${ }^{109}$ Complete list of paraphrases see in Appendix 2.

${ }^{110}$ A novel by Marcel Proust.

111900 hundred year-old Croatian legend. The legend says that King Dmitar Zvonimir cursed Croats after they killed him such that they would never again have a ruler of their own blood.

112 The Croatian jail where the ex-Prime Minister was imprisoned.

113 Old Croatian proverb.

${ }^{114}$ Old Croatian folk proverb.
} 
hypothesis based on the assumption that age and different cultural backgrounds have no influence on paraphrase recognition should be discarded. For example, the younger and older groups of examinees displayed very different, and occasionally significantly opposite, levels of knowledge and paraphrase recognition, especially when asked to identify movie and song titles. The degree of the examinees' familiarity with the modified headline depends on several circumstances. It is known that phraseological in general and paraphrastic groups in particular are very dynamic and many paraphrases are short-lived and are quickly replaced by new ones. The headlines that were most frequently recognized by examinees were modifications of common proverbs, pragmatic formulas, fairytale titles, commercials, famous movies, collocation and so on. The headlines that were less frequently identified are actually unmodified titles of old movies which the younger generations were unfamiliar with, titles of old songs, ancient phrases, international phrases, proverbs... The following examples show the great level of difference between the two groups of examinees in recognizing paraphrase originals: $98 \%$ of the older examinees recognized the title of the song Blue eyes shed tears ${ }^{115}$ / Suze liju plave oči in the form Suze Lyon plave oči, while the younger examinees recognized it only $50 \%$ of the time; the paraphrase Tower neither in socialism nor in capitalism / Čardak ni и socijalizmu ni u kapitalizm was identified by $95 \%$ of the older examinees as the Serbian folk tale Tower neither in heaven nor on earth / Čardak ni na nebu ni na zemlji. Nowadays, due to the fact this story is no longer a part of the school curriculum, its recognition was significantly lower among the younger examinees, meaning only $25 \%$. A similar result is also found in the socialist slogan Proletarians of all countries, unite! / Proleteri svih zemalja, ujedinite se! The older examinees recognize it from the paraphrase Kroatisti i slavisti, ujedinite se! / Croatists and slavists, unite! 58\% of the time, while the younger examinees only $33 \%$.

\footnotetext{
${ }^{115}$ Song by Croatian songwriter and singer Ivica Šerfezi from 1966.
} 
There is one example where the results of recognition are higher in the younger examinee group: the title of the movie Pirates of the Caribbean / Pirati s Kariba which appears in the form Pirates of the river Danube / Pirati s Dunava was recognized by as many as $95 \%$ of the younger examinees, and by only $70 \%$ of the older examinees. Another interesting example is the paraphrase Lost in the institute / Izgubljeni u zavodu. The younger examinees identified it mostly as Lost in translation / Izgubljeni u prijevodu and the older examinees identified it as the proverb Lost in time/space/universe / Izgubljeni $u$ vremenu/prostoru/svemiru.

\section{Conclusion}

The usage of paraphrases in headlines is a very efficient way of drawing the reader's attention to the content of an article. In addition to hinting at the theme of the article, headlines encourage the reader to be an active participant in the interpretation of the text. Manipulation of phraseological meaning usually provokes surprise, humor or irony in readers and that is why headlines are strong stylistic tools.

The purpose of this study was to verify the frequency of ludic paraphrases in daily (Slobodna Dalmacija and Vjesnik) and weekly newspapers (Nacional and Globus) as well as to verify the knowledge and understanding of modified phrases used in headlines.

The research has confirmed the authors' presumption that paraphrases appear more frequently in weekly than in daily newspapers because of specific rules in discourse formation related to the style of a certain author and a weekly or daily newspaper. Daily newspapers are focused on informing the reader about everyday events, and in addition weekly newspapers have entertainment features as well, manifested in the use of figurative headlines. In general, serious sections and subjects covered in Croatian newspapers automatically exclude the 
possibility of the use of intentional paraphrase. However, the use of paraphrase does not have to undermine the seriousness of the subject. On the contrary, it could reveal the journalist's enormous creativity.

As it was assumed, there are certain differences between the two daily and two weekly papers. The higher frequency of paraphrases in the headlines in Slobodna Dalmacija should be observed in the broader context of the existing differences between popular and quality newspapers that are addressing different audiences. Unexpected differences appeared in the structure of headlines in the political weekly newspapers Globus and Nacional. The higher frequency of paraphrases in Nacional could be explained by different ways of addressing the same audience.

It is clear from the research that journalists use all kinds of established groups of words (phrases, movie titles, book titles, verses, classical proverbs) which they modify to create allusions, games between the speaker and his/her transformation.

The research also showed that there is only a slight difference in paraphrase reception between young and older examinees. The same could be said for the relevance of asymmetrical cultural backgrounds, culturedness and the education of the journalists and readers as well. As was already presumed, a difference in reception between two generations arose from different social circumstances and asymmetrical knowledge.

In conclusion, the results of the reception of modified phrases showed that the examinees displayed different degrees of understanding.

The number of modified phrases and diversities in readers' associations are instructive not only for linguists who describe and theoretically interpret them but also for the journalists who produce them.

\section{References}


Anić, V. Rječnik hrvatskoga jezika. Zagreb: Novi Liber, 2006.

Bagić, K. "Postoji li jezik fikcije." Edited by K. Bagić. Jezik književnosti i književni ideologemi: zbornik radova 35. seminara Zagrebačke slavističke škole, 37-49. Zagreb: Zagrebačka slavistička škola, Hrvatski seminar za strane slaviste, 2007.

Crystal, D. A Dictionary of Linguistics and Phonetics, Oxford: Blackwell Publishing, 2003.

Iarovici, E. and R. Amel. "The strategy oft he headline." Semitoica. 77, no. 4 (1989): 441459.

Ivas, I. “Tropi u novinskim naslovima.” Medijska istraživanja. 10, no. 2 (2004): 9-34.

Kvintilijan, M. F. Obrazovanje govornika: odabrane strane. Sarajevo: Veselin Masleša, 1985.

Pranjić, K. Jezik i književno djelo. Zagreb: Školska knjiga, 1968.

Silić, J. Funkcionalni stilovi hrvatskoga jezika. Zagreb: Disput, 2006.

Škarić, I. Temeljci suvremenog govorništva. Zagreb: Školska knjiga, 2000.

Tošović, B. Funkcionalni stilovi. Graz: Institut für Slawistik der Karl-Franzens-Universität Graz, 2002.

Veselica-Majhut, S. “Intertekstualnost u novinskim naslovima.” Edited by J. Granić. Jezik $i$ mediji - jedan jezik: više svjetova, 753-760. Zagreb-Split: Hrvatsko društvo za primijenjenu lingvistiku, 2006.

Vjesnik Tiskara. Accessed April 2, 2012. www.vjesnik.hr 
Appendix 1 List of all paraphrased headlines and the percentage of their understanding by young examinees ${ }^{116}$

100\%: Drago is back/Šime is back;

The Mandarin tree isn't picked / The olive tree isn't picked;

98\%: Kobe Bryant come home / Lassie come home;

95\%: Pirates of the river Danube / Pirates of the Caribbean;

93\%: Boredom at two pm / Sunday at two pm;

90\%: Pay so you can swim / Pay so you can mock;

Through the mud to the stars / Through the thorns to the stars;

Ante is alone in the world / Pale is alone in the world;

85\%: End of the elephants / End of the world;

Nobel Hope Prize, Nobel Prize in Hope / Nobel Peace Prize/in Physics/in chemistry/in medicine etc;

Šeks scandal / Sex scandal;

80\%: All the president's dribbling / All the president's men;

Grain by grain - pleasure is here / Grain by grain - bread is here;

78\% Spices against humanity / Crimes against Humanity;

Love is in the Balkans / Love is in the countryside;

73\%: Serbian theorem / Pythagorean/Thales' theorem;

I rape you in the name of the Father and of the Son and of the Holy Ghost / I baptize thee in the name of the Father and of the Son and of the Holy Ghost;

Lost in the institute / Lost in translation;

68\%: Grandma credits are gone / Grandma and her cookies are gone;

Good spirit of skyscrapers / Good spirit of Zagreb;

\footnotetext{
${ }^{116}$ Original phrases are not italicized.
} 
63\%: My sweet nuclear village / My Sweet Little Village;

60\%: In search of lost innocence / In search of lost time/for lost treasure;

58\%: Sanader's curse /Zvonimir's curse;

Crying and screaming, which means life / Boards that make you live;

Ready for all! / Ready for the country!;

Croatian National Tourist deception / Croatian National Tourist Board;

55\%: Shower of the absurd/Theatre of the absurd;

Croat is a Serb to another Croat / Man is wolf to another man;

50\%: The good old corruption / For good old times;

45\%: A German doesn't believe a Greek / A well-fed man doesn't believe a hungry one;

43\%: Sanader stole my Christmas / How the Grinch Stole Christmas;

Mulder without Scully / Mulder and Scully;

Kosor didn't like them / Hawk didn't like him;

35\%: To die for the new recession / To die for your country;

33\%: Croatists and slavists, unite! / Proletarians of all countries, unite!;

The slaughter of innocent pigs / The slaughter of the innocents;

To Russia with love / From Russia with love;

My gunfight with Sanader / Gunfight at the OK corral;

25\%: Tower neither in socialism nor in capitalism / Tower neither in heaven nor on earth;

Major railway robbery / The Great Train Robbery;

18\%: Potemkin farmer / Potemkin villages;

15\%: The working class doesn't go to heaven / The working class goes to heaven;

Istria as it as it once was / The Mediterranean as it once was;

10\%: It's time for sun to shine on Hajduk / It's time for me to be at peace with the world; The false hope traders / The fake goods traders; 
When the spies go marching in / When the saints go marching in;

8\%: Worm in the Big Apple / Worm in the apple;

0\%: Closely watched bulls of arts / Closely Watched Trains;

Mausoleum of Croatian heritage / Mausoleum of Croatian kings;

Olympic screams and silence / Cries and Whispers;

Going to black / Back in Black;

Hitler from our beach / Hitler from our street;

Collective suicide / Lovely collective murder.

Appendix 2. List of all paraphrased headlines and the percentage of their understanding by older examinees.

98\%: The Mandarin tree isn't picked / The olive tree isn't picked;

All the president's dribbling / All the president's men;

Grain by grain - pleasure is here / Grain by grain - bread is here;

95\%: Tower neither in socialism or in capitalism / Tower neither in heaven nor on earth; My sweet nuclear village / My Sweet Little Village;

Nobel Hope Prize, Nobel Prize in Hope / Nobel Peace Prize/in Physics/in chemistry/in medicine;

93\%: Pay so you can swim / Pay so you can mock;

90\%: Drago is back/Šime is back;

88\%: Ante is alone in the world / Pale is alone in the world;

83\%: The good old corruption / For good old times;

70\%: Pirates of the river Danube / Pirates of the Caribbean;

68\%: Kobe Bryant come home / Lassie come home; 
Šeks scandal / Sex scandal;

65\%: Boredom at two pm / Sunday at two pm;

Croatian National Tourist deception / Croatian National Tourist Board;

63\%: Spices against humanity / Crimes against Humanity;

Ready for all! / Ready for the country!;

60\%: Love is in the Balkans / Love is in the countryside;

End of the elephants / End of the world;

58\%: Croatists and slavists, unite! / Proletarians of all countries, unite!;

55\%: Through the mud to the stars / Through the thorns to the stars;

53\%: Major railway robbery / The Great Train Robbery;

50\%: German doesn't believe Greek / Well-fed man doesn't believe a hungry one;

48\%: I rape you in the name of the Father and of the Son and of the Holy Ghost / I baptize thee in the name of the Father and of the Son and of the Holy Ghost;

Grandma credits are gone / Grandma and her cookies are gone;

45\%: Serbian theorem / Pythagorean/Thales' theorem;

Kosor didn't like them / Hawk didn't like him;

38\%: When the spies go marching in / When the saints go marching in;

Potemkin farmer / Potemkin villages;

My gunfight with Sanader / Gunfight at the OK corral;

Closely watched bulls of arts / Closely Watched Trains;

35\%: In search of lost innocence / In search of lost time/for lost treasure;

30\%: Croat is a Serb to another Croat / Man is wolf to another man;

23\%: Lost in the institute / Lost in translation;

20\%: Good spirit of skyscrapers / Good spirit of Zagreb;

To Russia with love / From Russia with love; 
18\%: The working class doesn't go to heaven / The working class goes to heaven;

The slaughter of innocent pigs / The slaughter of the innocents;

Hitler from our beach / Hitler from our street;

15\%: To die for the new recession / To die for your country;

13\%: Sanader stole my Christmas / How the Grinch Stole Christmas;

10\%: Istria as it as it once was / The Mediterranean as it once was;

Olympic screams and silence / Cries and Whispers;

8\%: Sanader's curse / Zvonimir's curse;

5\%: $\quad$ Mulder without Scully / Mulder and Scully;

Shower of the absurd / Theatre of the absurd;

The false hope traders / The fake goods traders;

Collective suicide / Lovely collective murder;

0\%: Mausoleum of Croatian heritage / Mausoleum of Croatian kings;

Going to black / Back in Black;

Worm in the Big Apple / Worm in the apple;

It's time for sun to shine on Hajduk / It's time for me to be at peace with the world. 


\section{ABOUT THE AUTHORS}

Petra ACZÉL is associate professor at Corvinus University of Budapest, and head of the Institute of Behavioral Science and Communication Theory. She earned her PhD degree in rhetoric in 2003 at ELTE Budapest, and gave her habilitation lecture for a university professorship in 2011. Her research interests are focused on the theory and practice of rhetoric. She is author and co-author of four books and numerous essays on verbal and visual argumentation, persuasive speech and media communication. Her recent publications contribute to the discussion on (new) media rhetoric. She holds memberships in Hungarian and international communication associations and editorial boards.

Ana DIMIŠKOVSKA is an Associate Professor at the Institute of Philosophy within the Faculty of Philosophy, University Ss. Cyril and Methodius in Skopje, Republic of Macedonia, where she obtained her M.A. and Ph.D degrees.

Dr. Dimiskovska currently teaches courses in History of Logic, Philosophy of Language and Philosophy of Law. Her main areas of interest are history of logic, argumentation theory and legal reasoning.

Paul DANLER studied Romance philology and political science at various universities in Europe and in North- and South-America. Currently he is professor of Romance linguistics (French, Italian, Portuguese, Spanish) at the University of Innsbruck, Austria. He has done research and published mainly in the fields of cognitive linguistics, semantics and discourse analysis.

Manuele DE CONTI, graduated in philosophy, and is currently a $\mathrm{Ph}$. D. student in Educational Science at theUniversity of Padua with a dissertation on the role of competitive debate for disagreement and conflict management education. Since 2004 he has been running debate projects in Italy and he is a debate trainer recognized by the World Debate Institute, University of Vermont (U.S.A).

Fotini EGGLEZOU has a B.A. degree in Philosophical-Pedagogical-Psychological Studies and a Master's degree in Language Arts from the National and Kapodistrian University of Athens. She is Doctor of Philosophy in Language Arts Education at the University of Ioannina. She speaks Greek, French, English, Italian. She is a teacher-researcher and director of an elementary school in Athens. She is the vice-president of education to the Greek Toastmasters rhetorical club. She is, also, the General Secretary of the Union for the Promotion of Rhetoric in Greek Education.

Josip GALIĆ is a Graduate student of Croatian Language and Literature and Italian Language and Literature at the University of Split. Winner of Rector's Award for 2011. The specific area of his scientific interests is figurative speech in Croatian media.

Ana GRGIĆ was born in 1983 in Bjelovar, Croatia. In 2008 she majored both in Croatian language and literature and in phonetics at the Faculty of Humanities and Social Sciences, 
University of Zagreb, after which she enrolled in the postgraduate course in Croatian culture. Since 2007 she has worked as a lecturer and phonetician at the Croaticum - The Center for Croatian as a Second and Foreign Language (Department of Croatian Language and Literature, Faculty of Humanities and Social Sciences). The additional areas of her professional and scientific interest are rhetoric and stylistics. Since 2004 she has appeared 15 times as teaching mentor at the School of Rhetoric "Ivo Škarić". This paper is the fourth in collaboration with Davor Nikolić on the subject of antonomasia.

Leo GROARKE studied at the University of Calgary, Simon Fraser University, the University of Helsinki, and the University of Western Ontario. He is currently Professor of Philosophy and Vice-President Academic at the University of Windsor. Prof. Groarke`s areas of research and scholarly interest include ancient philosophy, the history of ideas, social and political philosophy, informal logic and argumentation theory and visual argumentation. He has published many articles and books.

Hans V. HANSEN received his $\mathrm{PhD}$ in philosophy from Wayne State University.

He now teaches in the Philosophy Department at the University of Windsor where he is also a fellow of the Centre for Research in Reasoning, Argumentation and Rhetoric (CRRAR).

Hansen's research interests centre on the history of informal argumentation. He is one of the editors of Informal Logic.

Agnieszka KAMPKA, PhD in Sociology and MA in Philology and History of Art, is Assistant Professor at the Faculty of Social Sciences at the Warsaw University of Life Sciences (SGGW) and a member of the Polish Rhetorical Society. Her research interest include the sociology of politics, the political rhetoric and semiotic. She has written numerous articles on these subjects. She has also authored a book Perswazja w języku polityki (2009).

Gabrijela KIŠIČEK, PhD works as a senior research assistant at the Faculty of Humanities and Social Sciences, University of Zagreb. She teaches Argumentation and History of Rhetoric for graduate students of Rhetoric at the Department of Phonetics and Communication skills for the students of Landscape design at the Faculty of Agriculture. Her research interests are focused on rhetorical analysis of political discourse and Critical Discourse Analysis. She published several papers which discuss argumentation in political speeches and rhetorical strategies in public discourse. She presented her research at several international conferences. Periodically she teaches public speaking and communication skills to interested politicians, teachers, priests, journalists and television presenters.

Fabrizio MACAGNO (Ph.D. Università Cattolica del Sacro Cuore, Milan, 2003) works as a researcher and auxiliary professor at the Universidade Nova de Lisboa, where he teaches. His current research, between the fields of Linguistics and Philosophy of language, is focused on the persuasive use of emotive language and on the dialectical dimension of discourse implicitness, which he analyzes within the contexts of legal and political discourse. He is author of several papers on definition, informal fallacies, argumentation schemes, and dialogue theory. His publications include the book Argumentation Schemes and several papers 
published in international peer-review journals, such as Journal of Pragmatics, Pragmatics \& Cognition, Argumentation, Philosophy \& Rhetoric and Informal Logic.

Maurizio MANZIN (Philosophy of Law, PhD) is full professor of Legal Philosophy at the Faculty of Law of the University of Trento, Italy. He is at present Chairman of the Research Centre on Legal Methodology (CERMEG) and scientific director of the Series Acta Methodologica (Giuffrè: Milan). He has worked in the field of legal argumentation and rhetoric since 1986, having been responsible for many research projects financed by Italian Ministry of Education, University of Trento, Autonomous Province of Trento and others. He is author or editor of about 80 publications in Italian, English, French and Spanish.

Sabrina MAZZALI-LURATI is Lecturer of Rhetoric and Composition at the University of Lugano, Switzerland. She gained her PhD in 2003 on the multimedia application of literary texts from a semiotic approach. Her research interests are literature and hypermedia, semiotics, metaphor and multimodality, document design and composition, rhetoric and written communication. She is author of several papers on these topics.

Davor NIKOLIĆ was born in 1981 in Zenica, Bosnia and Herzegovina. In 2006 he majored both in Croatian language and literature and in phonetics at the Faculty of Humanities and Social Sciences, University of Zagreb, after which he enrolled in the postgraduate course in Croatian culture. Since 2007 he has worked as a junior researcher and teaching assistant at the Chair of Croatian Oral Literature, University of Zagreb. The additional areas of his professional and scientific interest are rhetoric, stylistics and argumentation theory. Since 2003 he has appeared 18 times as teaching mentor at the School of Rhetoric "Ivo Śkarić". This paper is the fourth in collaboration with Ana Grgic on the subject of antonomasia.

Chiara POLLAROLI is a PhD candidate for a doctorate in Communication sciences at the University of Lugano, Switzerland. Her research deals with tropes and argumentative topoi in advertising. She is interested in rhetoric and argumentation, advertising, semiotics and multimodality. She works as a Teaching Assistant at the Institute of Argumentation, Linguistics and Semiotics.

Anita RUNJIĆ-STOILOVA is currently working as an assistant professor at the Department of Croatian Language and Literature at the University of Split. She is lecturing on phonetics, phonology, rhetoric and stylistics, and doing research especially on media discourse. She is also working as a speech coach on Croatian National Television and as a language advisor at the Croatian National Theatre in Split.

Joanna SZCZEPAŃSKA-WLOCH - an academic teacher and a doctoral candidate in the Institute of English Studies at the Jagiellonian University. Her PhD dissertation touches upon the political discourse from the perspective of game-theoretical semantics by Jaakko Hintikka ("Contemporary political interview in Poland and Great Britain- a contrastive analysis of the genre with respect to the theory of discourse games"). In her thesis she concentrates on the political discourse in Poland and Great Britain, specifically linguistic strategies politicians 
deploy to attain their goals. Her research interests are focused on the theory of discourse, particularly media and political discourse, rhetorics, eristics and pragmalinguistics.

Diana TOMIĆ is a teaching and research assistant at the Department of Phonetics, Faculty of Humanities and Social Sciences, University of Zagreb. Among other more specialized phonetics courses she is teaching introductory public speaking courses for teachers and also for athletes at the Faculty of Kinesiology. Her research interests include speech acquisition and child phonology, some aspects of public speaking (teaching public speaking, public speaking anxiety, development of listening skills) and political discourse.

Alma VANČURA, $\mathrm{PhD}$ is a Senior Teaching Assistant at the Department of English, Faculty of Humanities and Social Sciences, University of J. J. Strossmayer in Osijek (Croatia). She teaches courses in Phonetics, English Language Practice, and introductory Public Speaking. Her research interests lie in the field of of applied linguistics and phonetics, especially conference interpreting with special interest in simultaneus interpreting, various aspects of public speaking, rhetorics, media and political discourse.

Gordana VAROŠANEC-ŠKARIĆ is a full time professor at the Department of Phoneticis, Faculty of Humanities and Social Sciences, University of Zagreb. She teaches Rhetoric, Stage Speaking, Orthophony, Speech and voice exercises, Croatian language orthoepy, and Forensic phonetics. During her career she has been a lecturer at other Faculties at the University (Theatre, Film and Television Academy, Faculty of Political Studies, Music Academy....). She has published two books and numerus scientific papers.

Sheldon WEIN is Professor of Philosophy and of International Development Studies at Saint Mary's University in Halifax, Canada. He has published widely in several areas of analytic philosophy. His current research explores the various devices and institutions (such as moralities, religions, legal systems, traditions, and manners) which groups use to organize their behavior and overcome collective action problems.

Igor Ž. ŽAGAR studied philosophy, sociology, and linguistics in Ljubljana, Paris, and Antwerp. He received his doctoral degree in Sociology of Culture from the University of Ljubljana. He is Professor of Rhetoric and Argumentation (University of Primorska), and a Senior Research Fellow (Head of the Centre for Discourse Studies) at the Educational Research Institute, Ljubljana, Slovenia. He has lectured in Belgium, United States, Italy, China, United Kingdom, The Netherlands, Spain, Russia, Romania, Poland, and France. Žagar's interests lie in pragmatics (speech act theory, (critical) discourse analysis), philosophy of language, argumentation, and rhetoric. He is (co)author and (co)editor of twelve books, and more than a hundred articles.

Address: Educational Research Institute, Gerbičeva 62, 1000 Ljubljana, Slovenia. E-mail: igor.zzagar@gmail.com, WWW: www.igorzagar.net. 


\section{INDEX}

\section{A}

antonomasia..... 283, 414, 415, 416, 417, 418, 419, 420, $421,422,423,424,425,426,428,429,430,432$, 433

argumentation education. 346,347 argumentation in the language-system.... 30, 44, 45, 46 argumentation profile......167, 168, 169, 170, 171, 174, $178,179,180$

argumentation profile 179

argumentation theory ....6, 8, 15, 20, 22, 24, 25, 70, 229 argumentation worker..........................167, 174, 178, 179 argumentative discourse .........................23, 67, 72, 91, 92 argumentative orientation..... $30,32,35,36,37,40,42$, $44,46,51,52$

argumentative strategies.

74,184 argumentative writing ........................360, 367, 372, 382 Aristotle..... 9, 12, 24, 66, 68, 69, 70, 72, 73, 75, 95, 117, $123,126,148,149,153,172,239,240,241,242$, $243,250,253,254,256,262,290,303,361,386$, $394,407,415$

aural rhetoric. $. .407,408,409$

\section{B}

Bakhtin, M. M. $30,54,55,365,437,442,453$

Blair, J. A. ...17, 336

Burke, K. D. $188,391,394,395,399,416$

business communication. ... $436,453,454,462$

\section{C}

Cicero..................... 73, 190, 191, 193, 204, 242, 251, 362 competitive debate..326, 328, 329, 330, 334, 337, 338, $341,342,343,344,345,346$

crisis $\quad . . . . .183,184,185,186,187,188,193,195,196$, $198,199,202,203,205,260,364$,

critical thinking ..........148, 149, 151, 152, 162, 330, 331 Croatian Parliament........... 267, 268, 270, 272, 273, 294

\section{D}

definition.109, 117, 118, 119, 120, 121, 122, 123, 124, $127,128,129,130,131,132,133,134,135,136$, $137,138,139,140,141,142,150,169,183,185$, $187,188,189,190,191,192,193,201,205,442$ dialectical role $173,174,176,179,180$ dialogical position 174,176 dialogical role.................................................142, 174, 176 dialogue....... 14, 15, 16, 17, 54, 118, 241, 309, 318, 326, $327,328,344,345,346$

Ducrot, $0 . . .30,31,37,38,40,41,42,44,45,47,48,51$, $53,54,55,56,60,61,62,68,69,75$

\section{$\mathbf{E}$}

ethos.. 66, 67, 68, 70, 71, 72, 73, 74, 75, 76, 78, 79, 173, $212,235,239,242,243,244,245,246,249,274$, $275,276,282,310$

Europhiles 214

Europhobes 214

\section{F}

Fairclough, N. ........ 197, 214, 218, 221, 244, 247, 251, 368,370

fallacies. $.148,149,150,151,152,153,275$

fallacy $150,151,152$

figurativeness $465,466,467$

\section{G}

genre $366,368,380,437,442,462$

Govier, $\mathrm{T}$ $.22,150$

Groarke, L. $6,17,20,22,72,229,342$

imitation....360, 361, 362, 363, 364, 365, 366, 367, 381 implicit definition. 138,141 insult $267,268,269,271,272,273$ insulting practices............................................................... 269 inventio 242

Johnson, R. H. $13,14,17,212$

journalistic discourse 465

\section{L}

language of politicians $239,240,255$ legal argumentation ................................................... 313 logos .......4, 9, 68, 72, 119, 172, 176, 212, 239, 242, 253, $254,302,310$

\section{M}

metaphor.184, 185, 190, 192, 193, 194, 196, 200, 204, $205,217,218,415,416,417,419,420$

metonymy ……..................................... 415, 416, 419, 420 mitigating strategies ........................................................... 267

\section{$\mathbf{N}$}

new media 392, 394, 395, 396, 397, 398, 399, 404, 408 newspaper headlines 465

\section{$\mathbf{P}$}

paraphrase. $371,465,467,468$ parliamentary debate ............................................204, 329 parody...... 88, 89, 96, 97, 103, 104, 105, 106, 108, 109, $110,111,112$

pathos.......173, 212, 213, 239, 242, 250, 251, 252, 253, 275, 310

Perelman, C. ..........70, 75, 125, 126, 282, 287, 288, 291, $303,315,317,394$

persuasion....... $66,71,72,146,172,176,191,213,222$, $240,242,243,244,250,252,254,261,391,392$, 394

Plato ….....................13, 74, 185, 240, 249, 262, 303, 361 
polarization...... 277, 293, 326, 331, 332, 334, 336, 340, 341,346

political discourse.....211, 235, 249, 259, 261, 273, 280 polyphony ………........................................... $30,45,54,55$ procedural rhetoric .........................................405, 406, 407 promotional text .................................. 445, 446, 450, 457

\section{Q}

Quintilian ...73, 190, 204, 244, 249, 251, 261, 363, 381, 468

\section{$\mathbf{R}$}

rhetoric.... $6,11,12,13,23,66,67,68,70,74,147,148$, $186,187,188,212,239,240,241,256,261,262$, $310,361,391,392,393,394,395,396,397,399$, $400,401,404,409$

rhetorical situation...183, 186, 187, 191, 192, 205, 398, $436,443,444,445,451$

\section{S}

science wars $86,87,112$

Sokal affair. $86,88,105,111,113$ sophists $23,24,74,361$

spatial rhetoric. ... 403,405

speech act $71,72,117,119,130$ sports discourse $418,419,420$ stakeholder $437,446,447,448,459,460,462$ subversion in argumentative discourse 86,89

\section{$\mathbf{T}$}

thick theory ....................................... $7,8,10,12,14,17,23$ Tindale, C. W. ...17, 20, 22, 23, 73, 212, 229, 272, 278, $279,292,342$

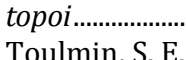
$30,45,47,48,53,75,255$ truth ................ 9, 10, 109, 146, 195, 314, 316, 317, 318

\section{V}

van Dijk, T. A. …………………….........................211, 251 van Eemeren, F. H. 14,172 visual rhetoric $399,400,401,402,403$

\section{W}

Walton, D. N. .............15, 69, 92, 119, 122, 123, 125, 126, $127,135,170,171,173,179,190,191,222,225$, $226,227,232,279,326,327,328,336,344$

Woods, J. 229

\section{$\mathbf{Z}$}

zero tolerance $146,147,154,155,156,158$ 


\section{What Do We Know About the World consists of selected}

papers delivered at "First International Conference on Rhetoric in Croatia: the Days of Ivo Škarić" in May, 2012, and subsequently revised for publication. Through a variety of different routes, the papers explore the role of rhetoric and argumentation in various types of public discourse and present interdisciplinary work connecting linguists, phoneticians, philosophers, law experts and communication scientists in the common ground of rhetoric and argumentation.

\section{WSIA Editorial Board}

\section{Editors-in-Chief}

Leo Groarke (University of Windsor)

Christopher Tindale (University of Windsor

\section{Board}

Mark Battersby (Capilano University)

Camille Cameron (University of Windsor)

Emmanuelle Danblon (Université libre de Bruxelles) Ian Dove (University of Nevada Las Vegas)

Bart Garssen (University of Amsterdam)

Michael Gilbert (York University)

David Godden (Old Dominion University) Jean Goodwin (Iowa State University) Hans Hansen (University of Windsor)
Marcin Koszowy (University of Białystok)

Marcin Lewinski (New University of Lisbon)

Catherine H. Palczewski (University of Northern lowa)

Steven Patterson (Marygrove College)

Chris Reed (University of Dundee)

Andrea Rocci (University of Lugano)

Paul van den Hoven (Tilburg University)

Cristián Santibánez Yánez (Diego Portales University)

Igor Z. Zagar (University of Maribor \& University of Primorska) Frank Zenker (Lund University)

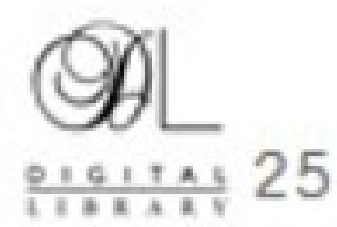

$978-0-920233-70-2$ 